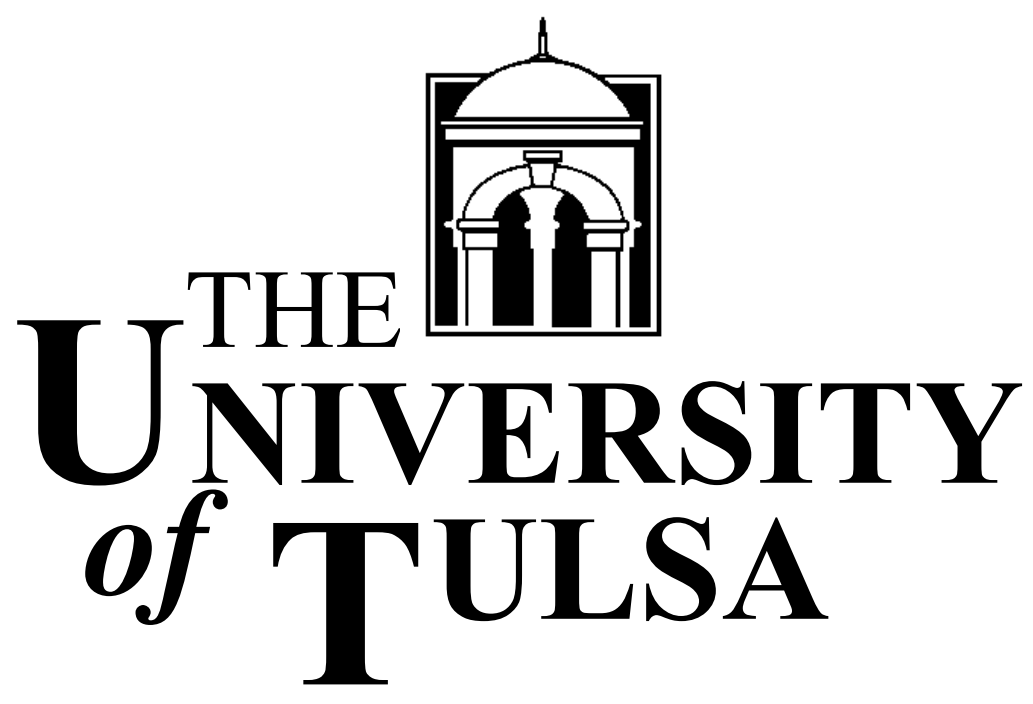

Department of Chemical Engineering

\title{
Fundamentals of Delayed Coking Joint Industry Project
}

FINAL REPORT

September 2005

Principal Investigators

Dr. Michael Volk, Jr. \& Dr. Keith Wisecarver

600 S. College Tulsa, OK 74104

October, 2005

DOE Award DE-FC26-02NT15381 
The University of Tulsa 


\section{Table of Contents DOE Final Report}

1. Disclaimer 17

2. Public Abstract 18

3. Executive Summary 20

4. Experimental Methods 26

A. Scope of Problem

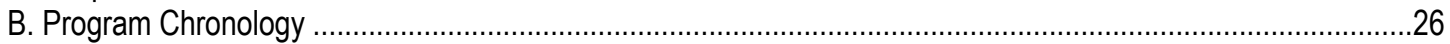

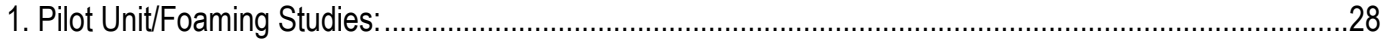

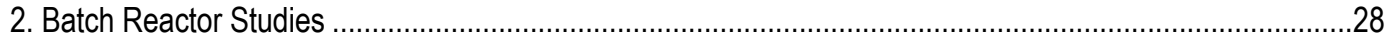

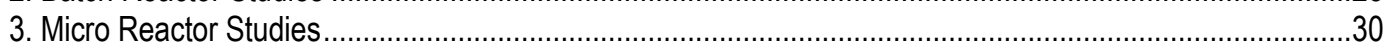

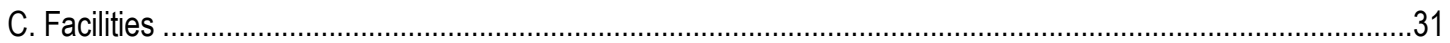

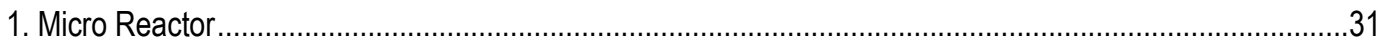

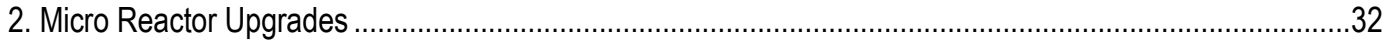

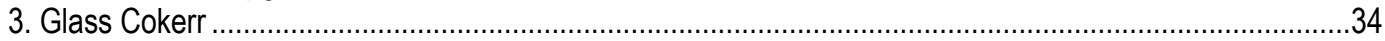

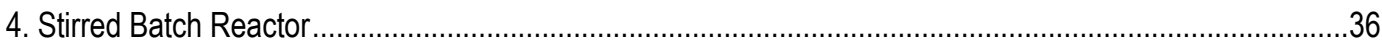

5. Stirred Batch Reactor Upgrades - Quarter 4, 2002 \& Quarter 1, 2003 ..................................................37

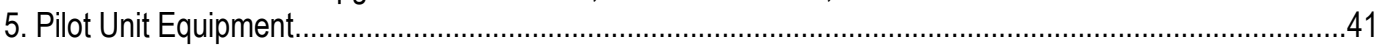

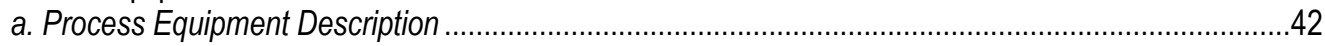

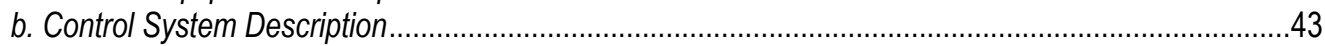

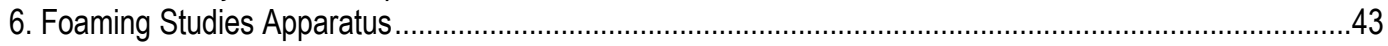

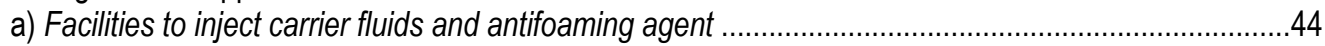

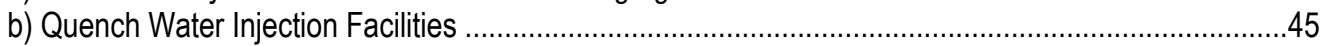

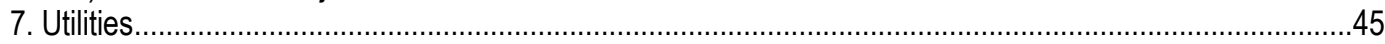

5. Micro Reactor Studies $\quad 46$

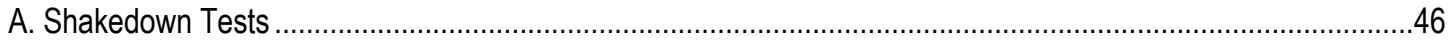

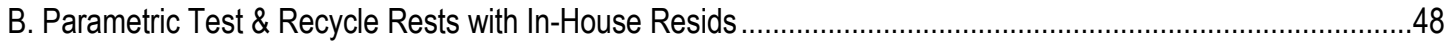

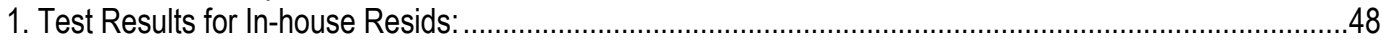

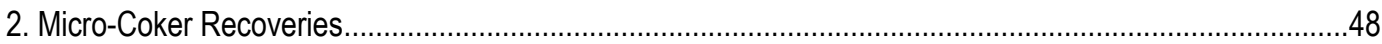

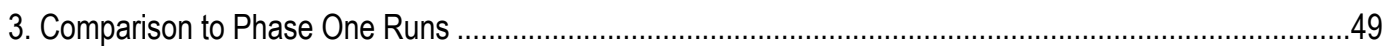

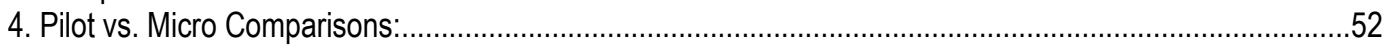

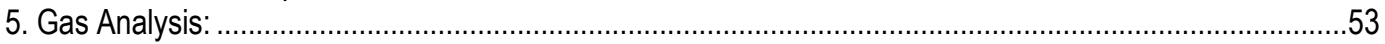

a) Effect of Temperature on Gas Composition:.............................................................................

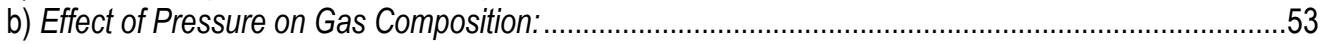

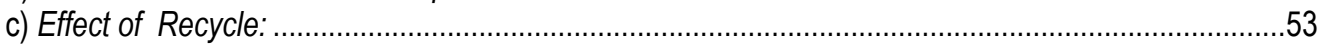

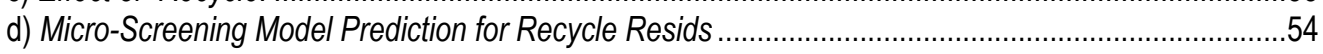

e) Pilot vs. Micro Unit Comparisons for Marathon and Suncor Resids ...................................................55

f) Effect of temperature and pressure on main and liquid sub-product yields .......................................56

g) Effect of Temperature and Pressure on Average Molecular Weight of Gas Composition ...................56

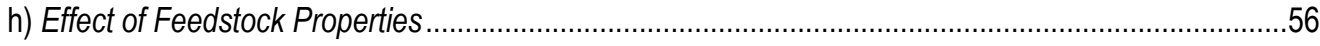

C. Conclusions:

6. Glass Coker Studies $\quad 61$

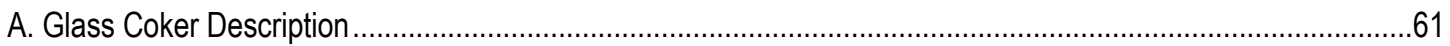

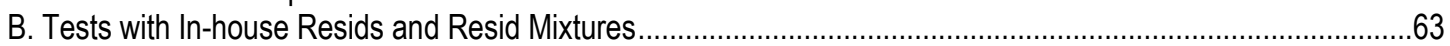

C. Results from preliminary shakedown runs with In-house Resids and resid mixtures......................................64

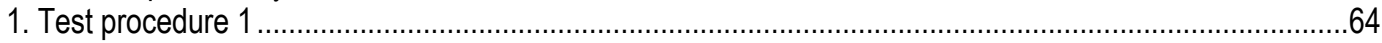

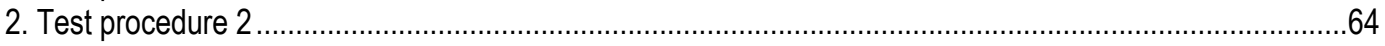

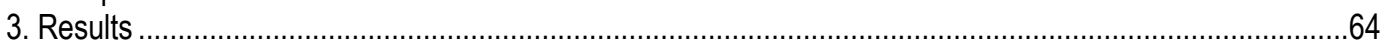

D. Analysis of Temperature profile for the partially insulated glass coker runs: .................................................68

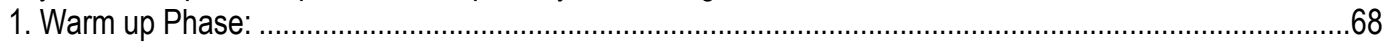

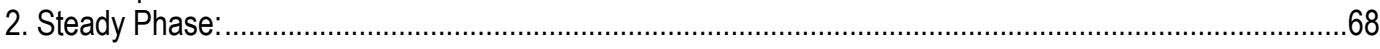

3. Foam over Phase:

E. Ranking of resids:

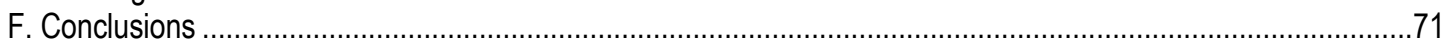


The University of Tulsa

7. Batch Reactor Studies $\quad 72$

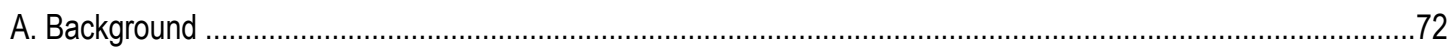

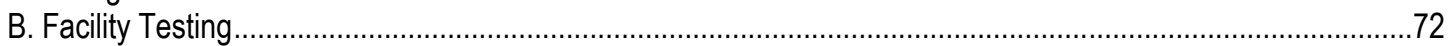

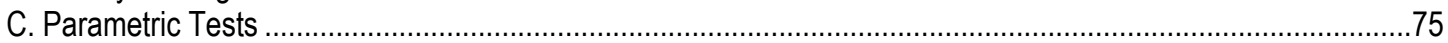

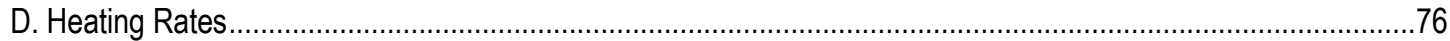

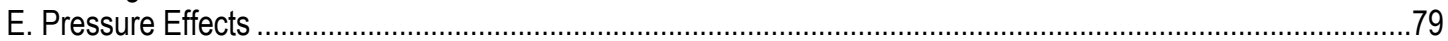

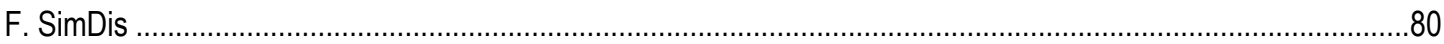

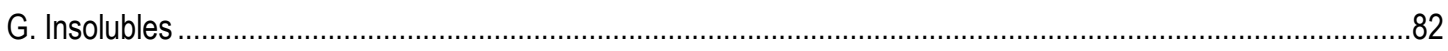

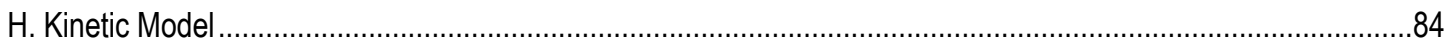

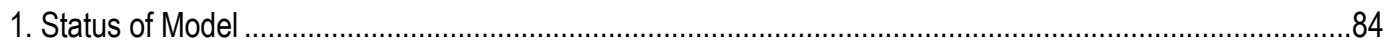

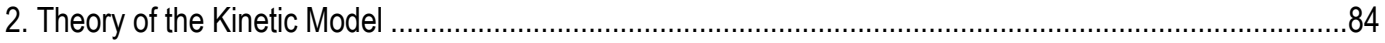

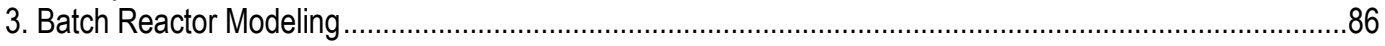

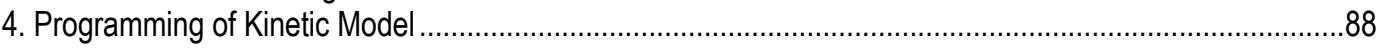

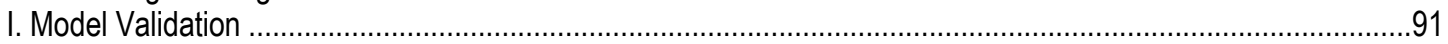

8. Pilot Unit Studies $\quad 94$

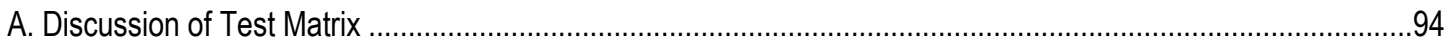

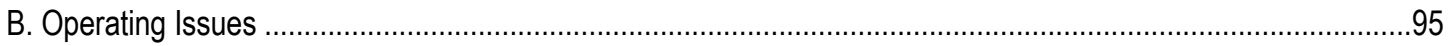

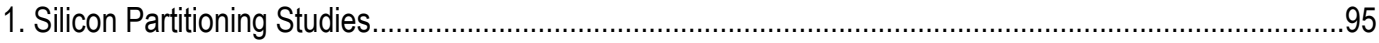

a) Overhead Antifoam Injection - Silicon Carry Over Study .........................................................95

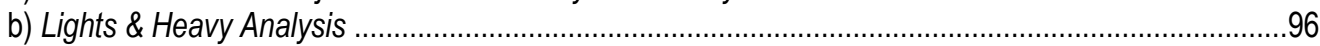

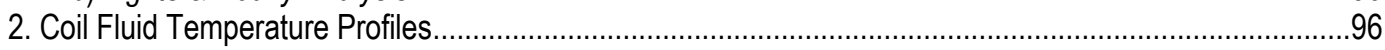

3. Drum/Coil Velocity Calculations ......................................................................................................101

4. Impact of Antifoam on Coil \& Overhead Temperature ……..............................................................103

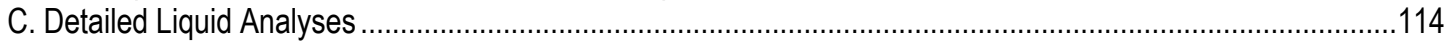

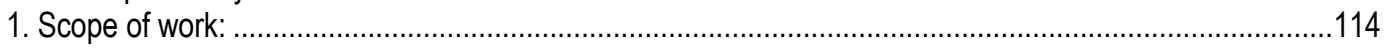

2. Distillation:

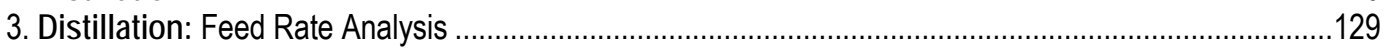

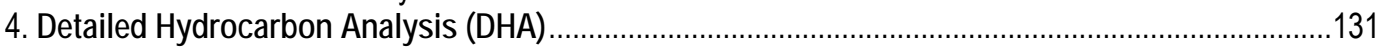

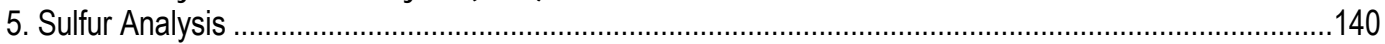

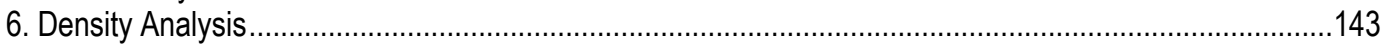

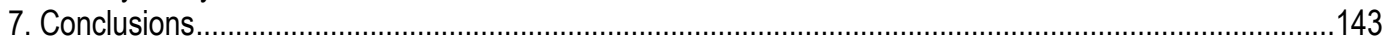

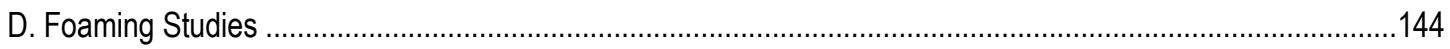

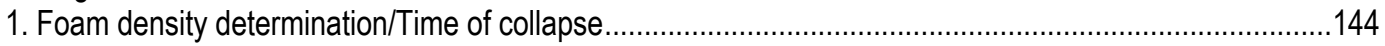

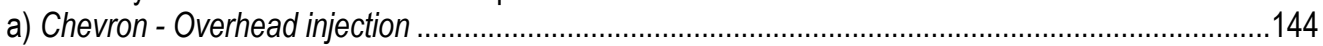

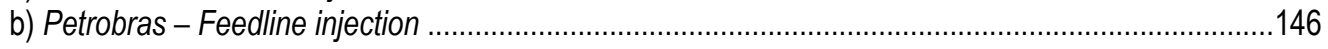

2. Comparison of Antifoam Injection Techniques............................................................................149

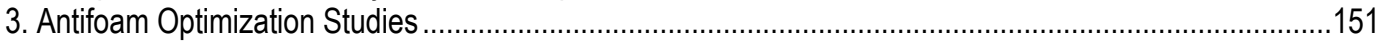

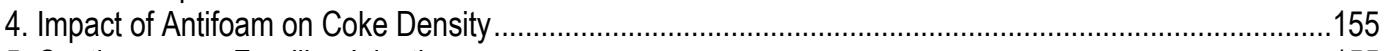

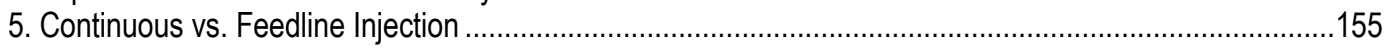

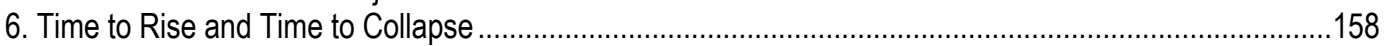

7. Quantification of Bubbly Liquid and Foam Layers.........................................................................163

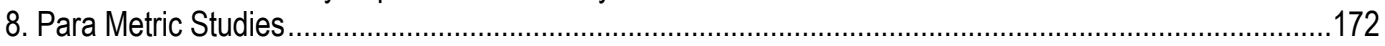

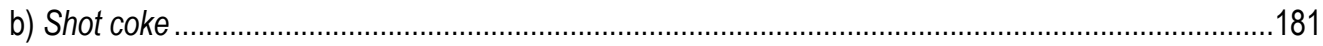

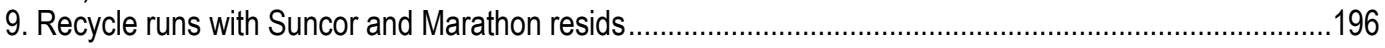

10. Foaming Tendencies for Suncor Recycle Runs ............................................................................199

11. Foaming Tendencies for Marathon Recycle Runs ........................................................................199

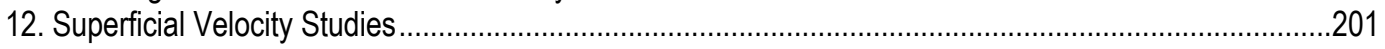

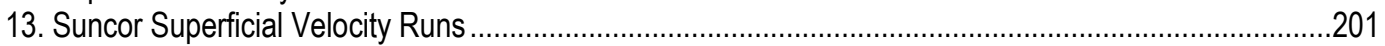

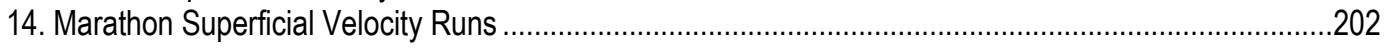

15. Yields comparison for Suncor and Marathon Superficial runs .........................................................20

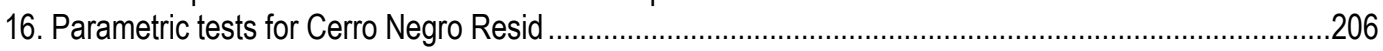

17. Foaming tendencies for EMCN parametric tests ......................................................................20

18. Parametric tests of Exxon Mobil Medium Heavy Canadian (EMHC) …...............................................208

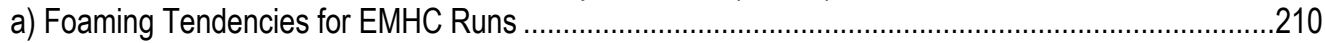

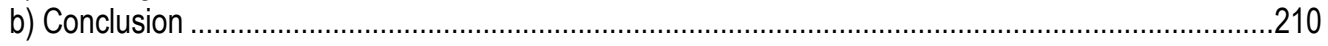

19. Parametric tests of Marathon Rose Pitch (MRP) ………............................................................211 


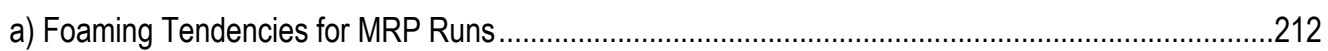

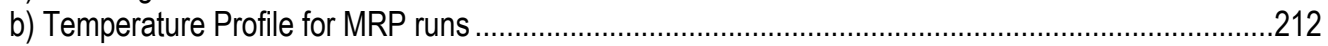

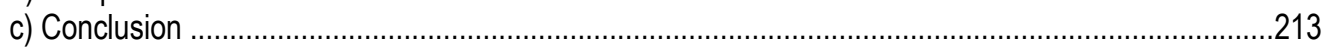

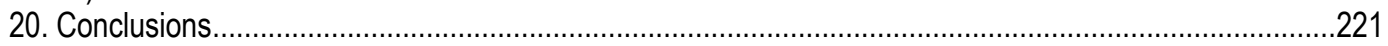

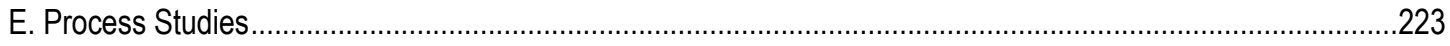

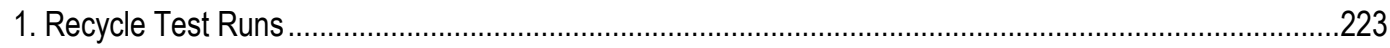

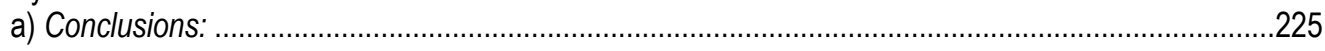

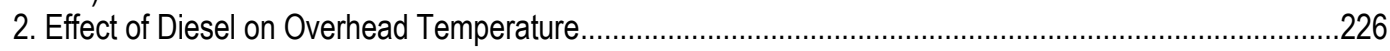

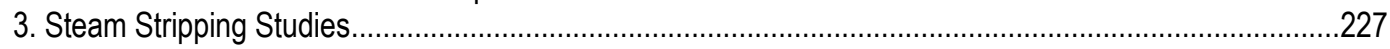

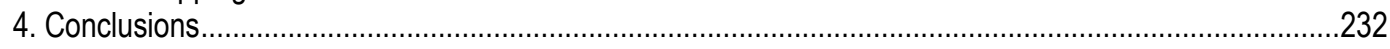

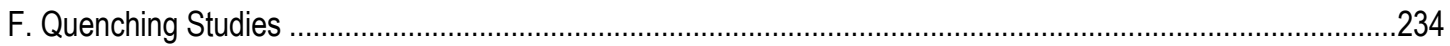

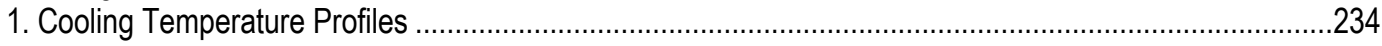

a) Open Furnace Door ……...............................................................................................234

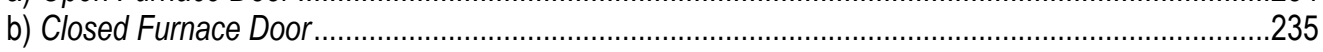

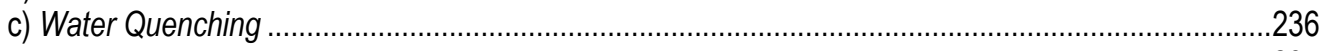

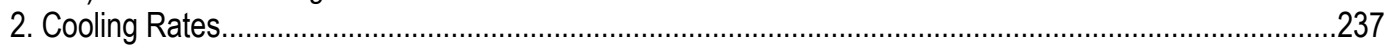

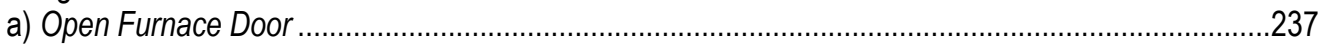

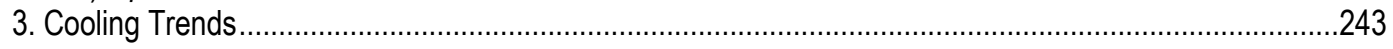

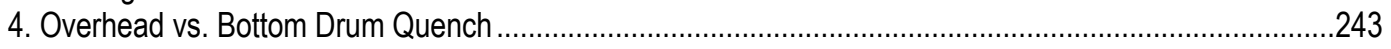

5. Conclusions

9. Modeling Studies 246

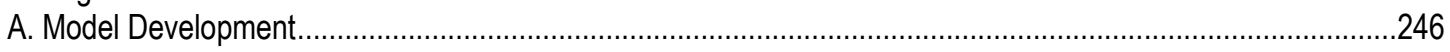

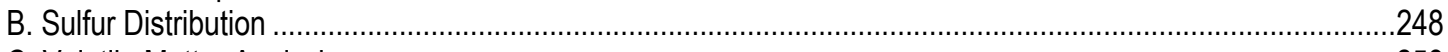

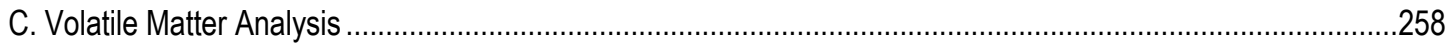

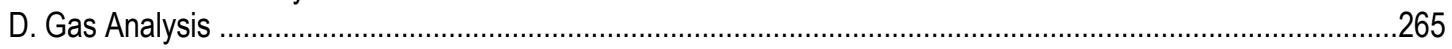

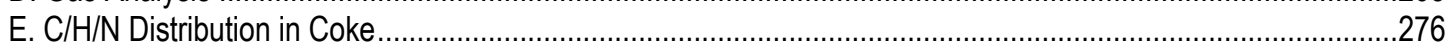

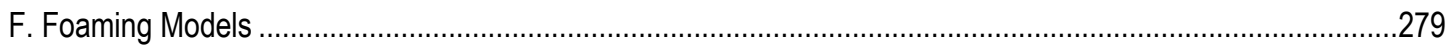

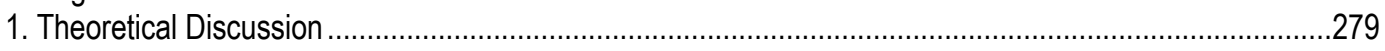

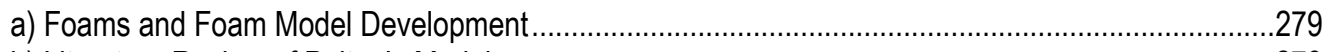

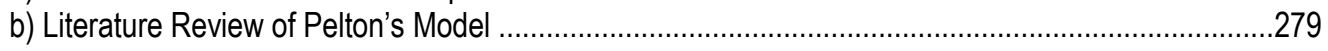

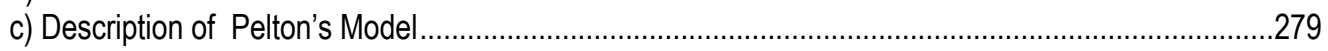

2. Application of Pelton's Model to the Delayed Coking Project ..............................................................28

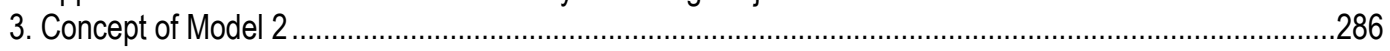

4. Results Attained Using Model 2 and Comparison with Pelton's Model and Gamma Densitometer Findings ......288

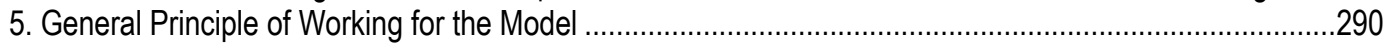

6. Important Updates in Calculation of Foam Heights with the Model ................................................290

7. Foam Height Results and Comparison for the Pilot Unit................................................................29

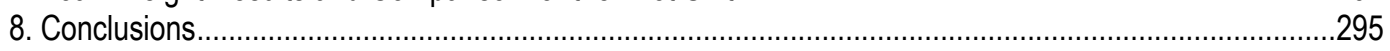

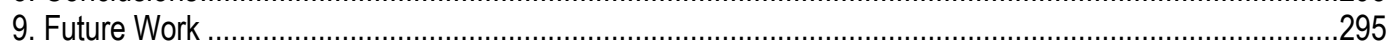

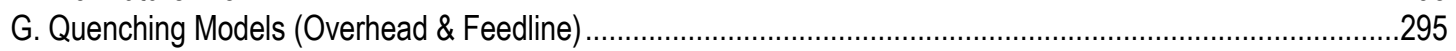

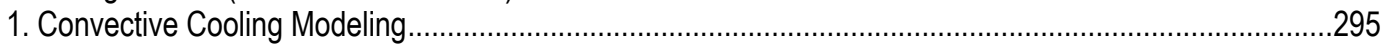

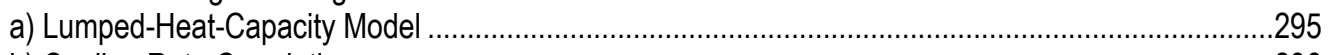

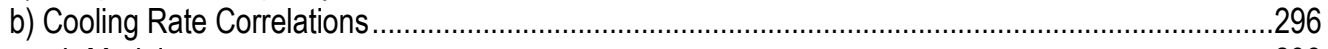

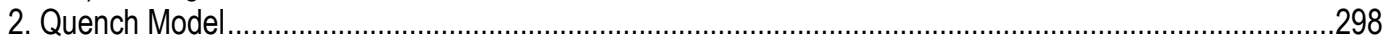

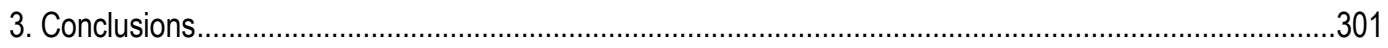

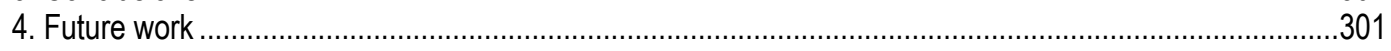

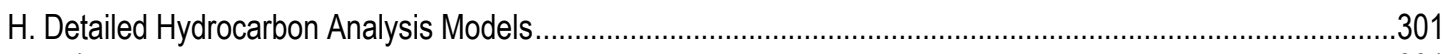

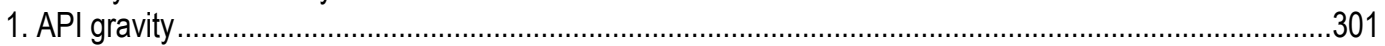

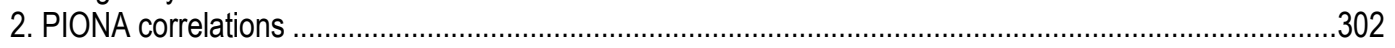

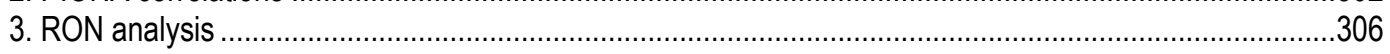

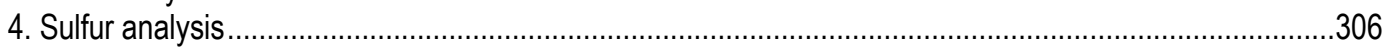

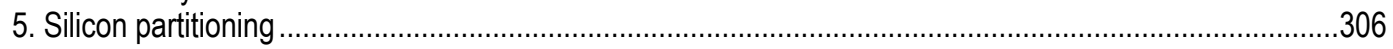

I. Density Correlation for Coke ...........................................................................................................

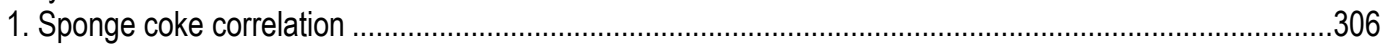

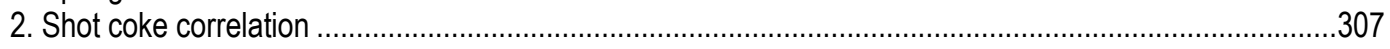

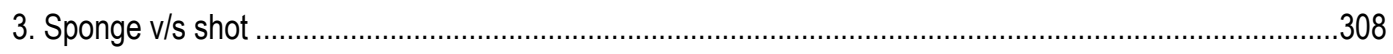




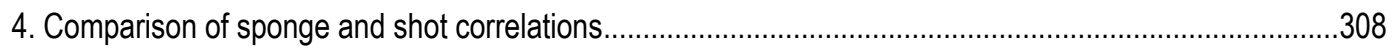

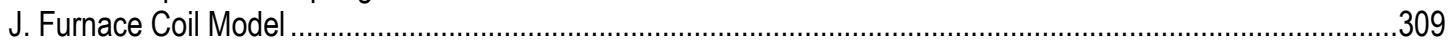

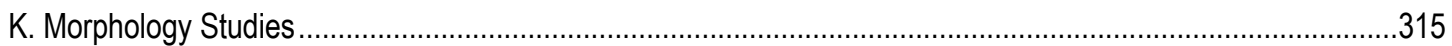

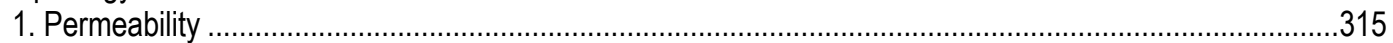

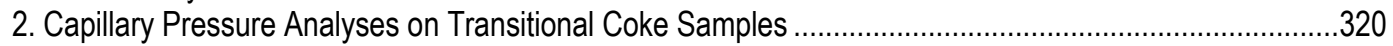

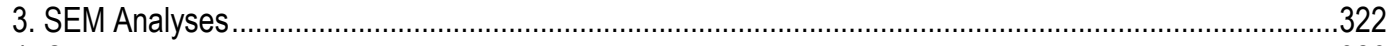

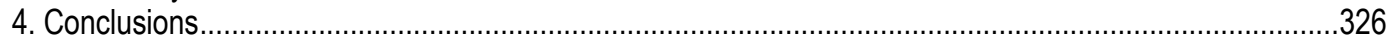

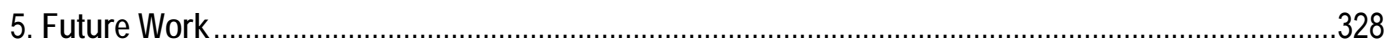




\section{Table of Figures}

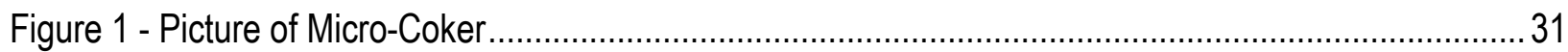

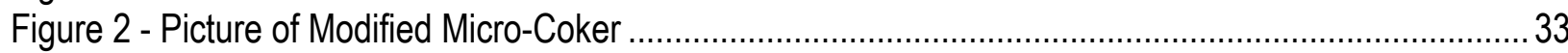

Figure 3 - Temperature profiles inside the drum ........................................................................... 34

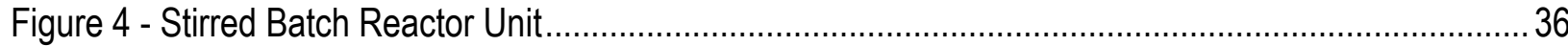

Figure 5 - Liquid collection system with Hoke cylinders and quick disconnect valves ...............................37

Figure 6 - Batch Reactor Furnace.............................................................................................. 39

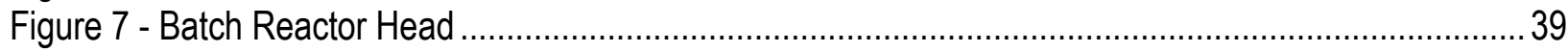

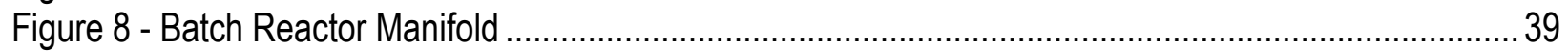

Figure 9 - Batch Reactor Tanks and Bypass S Switching System ......................................................39

Figure 10 - Batch Reactor Wet Test Meter ............................................................................... 39

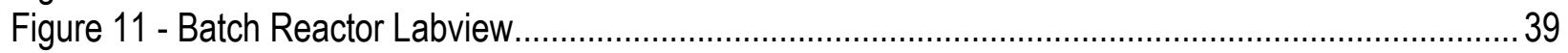

Figure 12 - Batch Reactor Labview.......................................................................................... 40

Figure 13 - Batch Reactor Back Side View................................................................................... 40

Figure 14 - Old Batch Sample Tube Assembly ……..................................................................... 40

Figure 15 - New Batch Sample Tube Assembly ............................................................................. 41

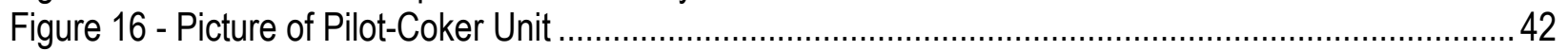

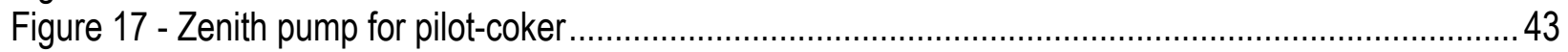

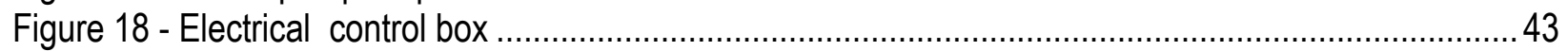

Figure 19 - Foxboro field bus module cabinet and a Foxboro -IA controller mounted on the bottom .......... 43

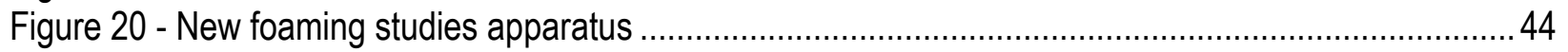

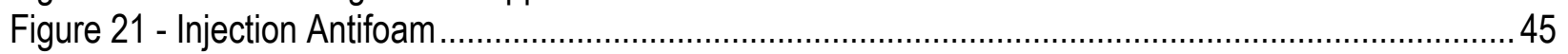

Figure 22 - Water Injection Facilities...................................................................................... 45

Figure 23 Product Yields at constant Temp. and Pressure for Marathon ..............................................48

Figure 24 Product Yields at constant Temp. and Pressure for Marathon ...............................................48

Figure 25 Experimental Yields - Old vs. New runs for Equilon...........................................................50

Figure 26 Experimental Yields - Old vs. New runs for Marathon...........................................................50

Figure 27 Experimental Yields - Old vs. New runs for Petrobras ..........................................................51

Figure 28 - Pilot vs. Micro .................................................................................................... 52

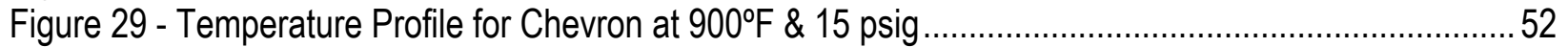

Figure 30 Predicted vs. Experimental yields for Pilot Unit after Correction.............................................59

Figure 31 Predicted vs. Experimental yields for Pilot Unit after Correction ...............................................60

Figure 32: Schematic of Glass Coker Experimental Apparatus ..........................................................61

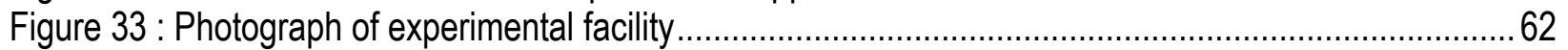

Figure 34 : Bottom and Middle temperature comparison data for runs 6-16 .........................................65

Figure 35: Bottom and Middle temperature comparison data for runs 17-19........................................66

Figure 36: Bottom and Middle temperature comparison data for runs $6,19,20,21 \ldots \ldots \ldots \ldots \ldots \ldots \ldots \ldots \ldots \ldots . . . . . . . . . . . . . . .67$

Figure 37: Patches on the walls created by Figure 38: Patches on the walls created by....................68

Figure 39: Temperature profile with time for partial insulation glass coker runs......................................6 69

Figure 40 - Bottom Temperature of first recorded black splashing vs time of black splashing for partially

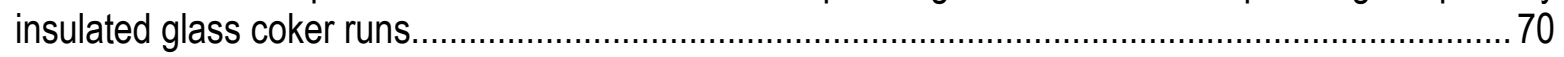

Figure 41 - Batch Element Warm-up Temperature Profile $(\mathrm{H} 2 \mathrm{O}$ \#4) ………………………................. 73

Figure 42 - Batch Element Run Temperature Profile(H2O \#4) ..........................................................73

Figure 43 - Batch Internal Run Temperature Profile(H2O \#4) ............................................................... 74

Figure 44 - Batch Vacuum Oil BP Curve(Manufacturer Supplied) …………..........................................74 
Figure 45 - Batch Element Warm-up Temperature Profile(Oil \#1) ……………………............................

Figure 46 - Batch Element Run Temperature Profile(Oil \#1) ………................................................... 74

Figure 47 - Batch Facility Testing Recoveries - 100\% Recycle Runs ..................................................75

Figure 48 - Batch Facility Testing Recoveries - 100\% Recycle Runs - MARBR-FT-2 …………............... 75

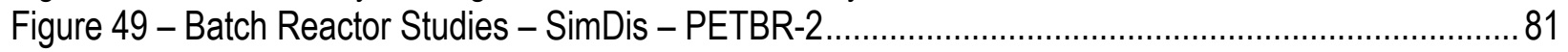

Figure 50 - Batch Reactor Studies - SimDis - PETBR-2 …....................................................... 81

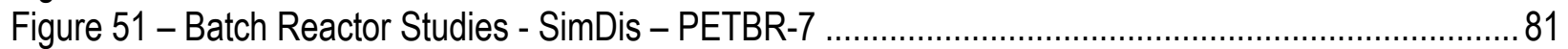

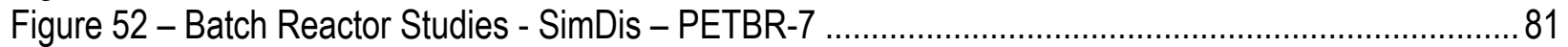

Figure 53 - Batch Reactor Studies - SimDis - PETBR-10 ……................................................... 82

Figure 54 - Batch Reactor Studies - SimDis - PETBR-10 …........................................................ 82

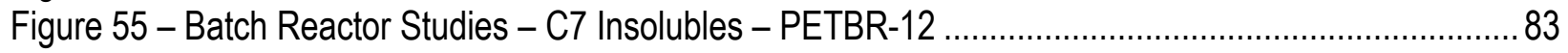

Figure 56 - Batch Reactor Studies - Tol Insolubles - PETBR-12 ……............................................... 83

Figure 57 - Batch Reactor Studies - C7 Insolubles - RPBR-5 ….................................................... 83

Figure 58 - Batch Reactor Studies - Tol Insolubles - RPBR-5 …................................................. 83

Figure 59 - Reaction rate for the heaviest pseudo component (CHVBR-20) ……................................. 87

Figure 60 - Flowchart for the Levenberg-Marquardt algorithm built by LAN .......................................... 89

Figure 61 - Flow Diagram for the Kinetic Model Programmed in FORTRAN .........................................90

Figure 62 - Connection of the Levenberg-Marquardt Algorithm and the Kinetic Model..............................90

Figure 63 - Batch Reactor Studies - \% Off vs. Temperature - CHVBR-2 ……….................................. 92

Figure 64 - Batch Reactor Studies - \% Off vs. Temperature - CHVBR-2 ………............................... 92

Figure 65 - Batch Reactor Studies - \% Off vs. Temperature - Gasoline - CHVBR-2 ……......................... 92

Figure 66 - Batch Reactor Studies - \% Off vs. Temperature - Diesel - CHVBR-2 ………….................. 92

Figure 67 - Batch Reactor Studies - \% Off vs. Temperature - Gas Oil - CHVBR-2 …….......................... 92

Figure 68 - Furnace Coil Heating - Loop 2 ……......................................................................... 98

Figure 69 - Furnace Coil Heating - Loop 4 …........................................................................ 98

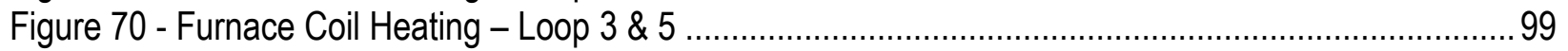

Figure 71 - Furnace Coil Temperature Profiles - Loop 3 \& 5 ............................................................ 99

Figure 72 - Furnace Coil Temperature Profiles - Loop 4 ………......................................................... 100

Figure 73 - Temperature profiles for CHEV 13 PUAFC and CHEV 14 PUAFC runs ...............................103

Figure 74 - Temperature profiles for CHEV 12 PUAFI and CHEV 14 PUAFC runs ..................................104

Figure 75 - Temperature profiles for CHEV 12 PUAFI and CHEV 16 PUAFI runs...................................105

Figure 76 - Temperature profiles for CHEV 14 PUAFC and CHEV 16 PUAFI runs .................................106

Figure 77 - Temperature profiles for CHEV 8 PUAFI and CHEV 12 PUAFI runs.....................................107

Figure 78 - Temperature profiles for CHEV 8 PUAFI and CHEV 13 PUAFC runs ......................................107

Figure 79 - Temperature profiles for CHEV 8 PUAFI and CHEV 14 PUAFC runs ....................................108

Figure 80 - Temperature profiles for EQU 5 PUAFI and EQU 6 PUAFI runs .........................................109

Figure 81 - Temperature profiles for EQU 7 PUAFI and EQU 8 PUAFC runs ......................................110

Figure 82 - Temperature profiles for EQU 8 PUAFC and EQU 9 PUAFI runs ......................................111

Figure 83 - Temperature profiles for PETR 3 PUAFI and PETR 13 PUAFC runs ...................................112

Figure 84 - Temperature profiles for PETR 14 PUAFC and PETR 15 PUAFC runs ...............................113

Figure 85: PU Distillation at 15psig with bottom temperatures of 900F and 930F ................................. 121

Figure 86: PU Distillation at 40psig with bottom temperatures of 900F and 930F ................................121

Figure 87: PU Distillation at 15psig with average overhead temperatures.............................................122

Figure 88: PU Distillation at 40psig with average overhead temperatures............................................122

Figure 89: PU Sim. Distillation at 15psig with bottom temperatures of 900F and 930F .........................123

Figure 90: PU Sim. Distillation at 40psig with bottom temperatures of 900F and 930F ...........................123

Figure 91: PU Sim. Distillation at 15psig with average overhead temperatures.....................................124 
Figure 92: PU Sim. Distillation at 40psig with average overhead temperatures.....................................124

Figure 93: Flow rate analysis of Chevron PUAF samples at 15psig ..................................................129

Figure 94: Flow rate analysis of Chevron PUAF samples at 40psig ................................................130

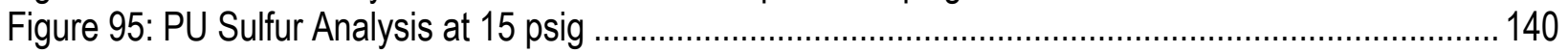

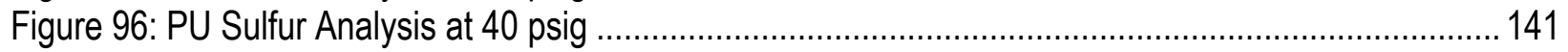

Figure 97: PU Chevron Density Analysis at 15 psig ...................................................................... 143

Figure 98 - Chevron Anti-Foaming Runs - Height vs. Density (Temperature and Pressure Effects on

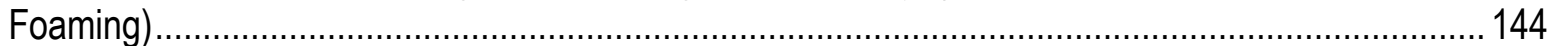

Figure 99 - Chevron Anti-Foaming Runs - Height vs. Density (Temperature and Pressure Effects on

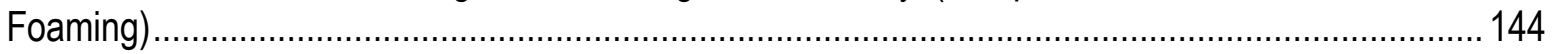

Figure 100 - Chevron Anti-Foaming Runs - Height vs. Density (Temperature and Pressure Effects on

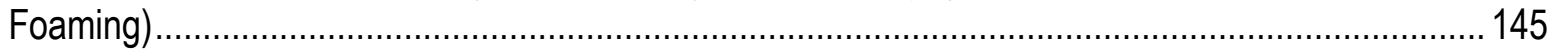

Figure 101 - Chevron Anti-Foaming Runs - Density vs. Time (Foam Suppression)............................... 145

Figure 102 - Chevron Anti-Foaming Runs - Density vs. Time (Foam Suppression)................................ 145

Figure 103 - Chevron Anti-Foaming Runs - Density vs. Time (Foam Suppression)............................... 146

Figure 104 - Chevron Anti-Foaming Runs - Density vs. Time (Foam Suppression)................................. 146

Figure 105 - Chevron Anti-Foaming Runs - Density vs. Time (Foam Suppression)................................ 146

Figure 106 - Chevron Anti-Foaming Runs - Density vs. Time (Foam Suppression)................................ 146

Figure 107 - Petrobras Anti-Foaming Runs - Height vs. Density (Temperature and Pressure Effects on

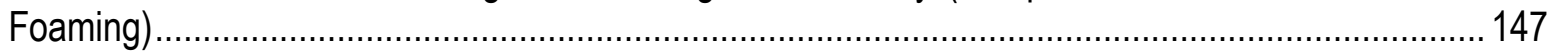

Figure 108 - Petrobras Anti-Foaming Runs - Density vs. Time (Foam Suppression).............................. 147

Figure 109 - Petrobras Anti-Foaming Runs - Density vs. Time (Foam Suppression).............................. 148

Figure 110 - Petrobras Anti-Foaming Runs - Density vs. Time (Foam Suppression)............................... 148

Figure 111 - Petrobras Anti-Foaming Runs - Density vs. Time (Foam Suppression)............................... 148

Figure 112 - Petrobras Anti-Foaming Runs - Density vs. Time (Foam Suppression)............................... 148

Figure 113 - Petrobras Anti-Foaming Runs - Density vs. Time (Foam Suppression).............................. 148

Figure 114 - Petrobras Anti-Foaming Runs - Density vs. Time (Foam Suppression)............................... 148

Figure 115 - Suncor Anti-Foaming Runs - Density vs. Time (Overhead Injected Antifoam) ..................... 149

Figure 116 - Suncor Anti-Foaming Runs - Density vs. Time (Feed Injected Antifoam)............................149

Figure 117 - Comparison of Density traces for all 5 runs after 60 minutes of coking ............................... 150

Figure 118 - PETR 9 - Antifoam Injection Response \#1 After 15 Minutes of Coking ............................... 151

Figure 119 - PETR 9 - Antifoam Injection Response \#2 After 50 Minutes of Coking ............................... 151

Figure 120 - PETR 9 - Antifoam Injection Response \#3 After 90 Minutes of Coking ................................ 152

Figure 121 - PETR 9 - Antifoam Injection Response \#4 After 148 Minutes of Coking ..............................152

Figure 122 - PETR 10 - Antifoam Injection Response \#1 After 10 Minutes of Coking .............................. 152

Figure 123 - PETR 10 - Antifoam Injection Response \#2 After 20 Minutes of Coking .............................152

Figure 124 - PETR 11 - Antifoam Injection Response \#1 After 16 Minutes of Coking ............................153

Figure 125 - PETR 11 - Antifoam Injection Response \#2 After 24 Minutes of Coking ..............................153

Figure 126 - PETR 11 - Antifoam Injection Response \#3 After 112 Minutes of Coking ............................ 153

Figure 127 - PETR 11 - Antifoam Injection Response \#4 After 126 Minutes of Coking ............................. 153

Figure 128 - PETRO 11 Antifoam Injection \#5 Response After 139 Minutes of Coking............................ 154

Figure 129 - Continuous Overhead Antifoam Injection For PETR 13 Run............................................155

Figure 130 - Continuous Feedline Antifoam Injection for PETR 14 Run ................................................ 156

Figure 131 - PETR 15 - 600,000 cSt Antifoam Injection Response \#1 After 18 Minutes of Coking .......... 157

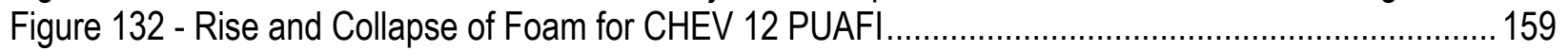

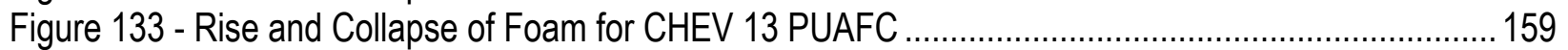

Figure 134 - Rise and Collapse of Foam for CHEV 14 PUAFC .........................................................160 
Figure 135 - Rise and Collapse of Foam for CHEV 15 PUAFC ...........................................................160

Figure 136 - Rise and Collapse of Foam for CHEV 16 PUAFI.........................................................161

Figure 137 - Rise and Collapse of Foam for EQU 7 PUAFI............................................................ 161

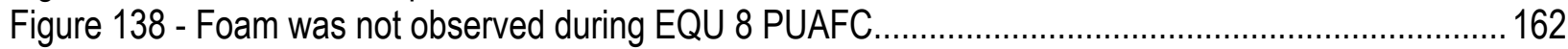

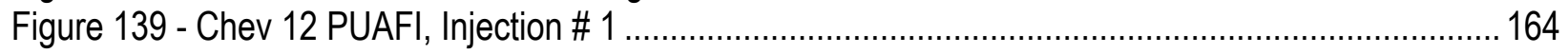

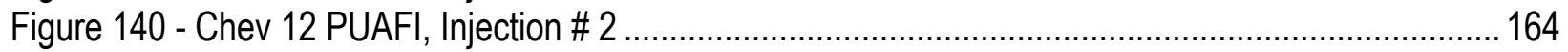

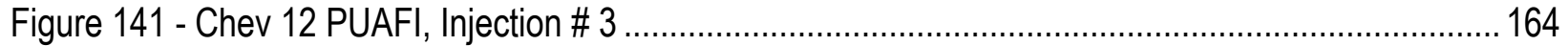

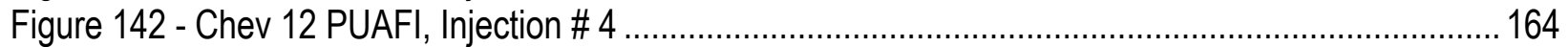

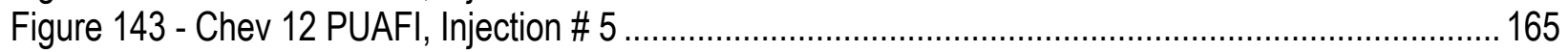

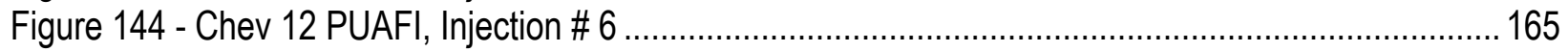

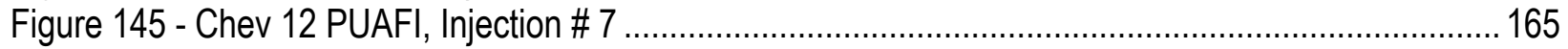

Figure 146 - Chev 12 PUAFI, Injection \# 8 ............................................................................... 165

Figure 147 - Build-up of coke, bubbly liquid and foam layer with coking time for CHEV 13 PUAFC .......... 166

Figure 148 - Build-up of coke, bubbly liquid and foam layer with coking time for CHEV 14 PUAFC .......... 166

Figure 149 - Build-up of coke, bubbly liquid and foam layer with coking time for CHEV 12 PUAFI ........... 167

Figure 150 - Build-up of coke, bubbly liquid and foam layer with coking time for EQU 5 PUAFI................ 168

Figure 151 - Build-up of coke, bubbly liquid and foam layer with coking time for EQU 8 PUAFC .............. 169

Figure 152 - Build-up of coke, bubbly liquid and foam layer with coking time for PETR 13 PUAFC .......... 170

Figure 153 - Build-up of coke, bubbly liquid and foam layer with coking time for PETR 14 PUAFC .......... 170

Figure 154 - Build-up of coke, bubbly liquid and foam layer with coking time for PETR 11 PUAFI............ 171

Figure 155 - Build-up of coke, bubbly liquid and foam layer with coking time for PETR 16 PUAFI............ 171

Figure 156 - Marathon Anti-Foaming runs - Height vs. Time (Sponge coke from Mar 2 PUAF) ................ 173

Figure 157 - Citgo Anti-Foaming Runs - Height vs. Time (shot coke from Cit 10 PUAF) .......................... 173

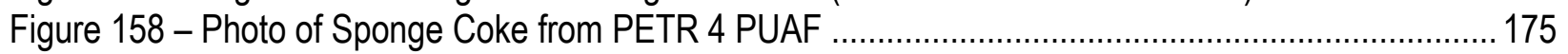

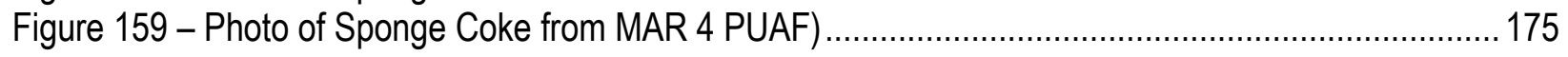

Figure 160 - CT scan of sponge coke made by Petrobras resid...................................................... 175

Figure 161 - Petrobras Anti-Foaming - Height vs. Time - (Sponge Coke for PETR 4 PUAF) .................. 176

Figure 162 - Marathon Anti-Foaming - Height vs. Time - (Sponge Coke for MAR 2 PUAF) ................... 176

Figure 163 - Petrobras Anti-Foaming -Density vs. Time - (Sponge Coke for PETR 4 PUAF................... 176

Figure 164 - Marathon Anti-Foaming - Density vs. Time - (Sponge Coke for MAR 2 PUAF) ................... 176

Figure 165 - Petrobras Anti-Foaming Runs - Height vs. Time (Sponge Coke from PET 5 PUAF) ........... 177

Figure 166 - Petrobras Anti-Foaming Runs - Height vs. Time (Sponge Coke from PET 6 PUAF) ............ 177

Figure 167 - Petrobras Anti-Foaming Runs - Temperature Profile (High density Sponge Coke from PET 2 PUAF)

Figure 168 - Petraobras Anti-Foaming Runs - Temperature Profile (Lower Density Sponge Coke from PET

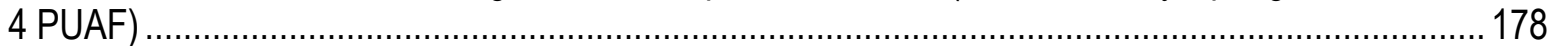

Figure 169 - Marathon Anti-Foaming runs - Height vs. Time (Sponge Coke from MAR 5 PUAF) ............ 179

Figure 170 - Marathon Anti-Foaming Runs - Height vs. Time (Sponge Coke from MAR 3 PUAF).......... 179

Figure 171 - Marathon Anti-Foaming runs - Height vs. Time (Sponge coke from MAR 3 PUAF)............... 180

Figure 172 - Marathon Anti-Foaming runs - Height vs. Time (Sponge coke from MAR 2 PUAF).............. 180

Figure 173 - Marathon Anti-Foaming runs - Height vs. Time (Sponge coke from MAR 4 PUAF).............. 181

Figure 174 - Marathon Anti-Foaming runs - Height vs. Time (Sponge coke) .......................................181

Figure 175 - Photo of Sponge Coke from MAR 4 PUAF ................................................................. 182

Figure 176 - Photo of Shot coke from SUN 5 PUAF Bottom ............................................................ 182

Figure 177 - Suncor Anti-Foaming Runs - Coke Picture (SUN 5 PUAF Bottom).................................. 184

Figure 178 - Suncor Anti-Foaming Runs - Coke Picture (SUN 5 PUAF Bottom)...................................... 184

Figure 179 - Suncor Anti-Foaming Runs - CT Scan (Sun 5 PUAF Bottom) ........................................ 184 
Figure 180 - Suncor Anti-Foaming Runs - CT Scan (Sun 5 PUAF Bottom) ..........................................184

Figure 181 - Marathon Anti-Foaming runs - Height vs. Time (Sponge coke from MAR 3 PUAF)............. 185

Figure 182 - Equilon Anti-Foaming Runs - Height vs. Time (Shot coke from EQ 1 PUAF) .................... 185

Figure 183 - Suncor Anti-Foaming Runs - Height vs. Time (Aggl Shot Coke from SUN 2 PUAF)............ 186

Figure 184 - Suncor Anti-Foaming Runs - Height vs. Time (BB Shot Coke from SUN 3 PUAF) ............. 186

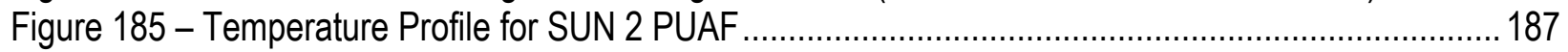

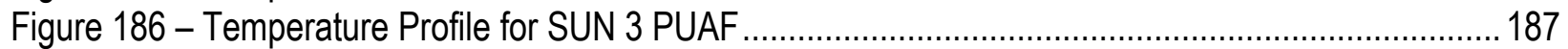

Figure 187 - Tl-214 Bottom Temperature Comparison for Suncor Runs ............................................ 187

Figure 188 - Tl-107 Fluid Temperature Comparison for Suncor Runs ................................................. 187

Figure 189 - Equilon Anti-Foaming Runs - Height vs. Time (EQ 5 PUAF) ..........................................190

Figure 190 - Equilon Anti-Foaming Runs - Height vs. Time (EQ 6 PUAF) ..........................................190

Figure 191 - Chevron Anti-Foaming Runs - Height vs. Time (Sponge Coke from CHEV 6 PUAF) .......... 191

Figure 192 - Chevron Anti-Foaming Runs - Height vs. Time (Aggl Coke from CHEV 8 PUAF) ............... 191

Figure 193 - Chevron Anti-Foaming runs - Height vs. Time (CHEV 8 PUAF) ....................................... 193

Figure 194 - Chevron Anti-Foaming Runs - Height vs. Time (CHEV 10 PUAF) ...................................... 193

Figure 195 - Citgo Anti-Foaming runs - Height vs. Time (Sponge Coke from CIT 8 PUAF) ...................... 194

Figure 196 - Citgo Anti-Foaming runs - Height vs. Time (Aggl Coke from CIT 11 PUAF) ........................ 194

Figure 197 - Citgo Anti-Foaming runs - Height vs. Time (Cit 9 PUAF) .................................................... 196

Figure 198 - Citgo Anti-Foaming Runs - Height vs. Time (Cit 11 PUAF) .............................................. 196

Figure 199 - Furnace Skin temperature comparisons for Suncor runs..............................................197

Figure 200 - Temperature Profile for Marathon 8, 9 (5\%RC) and $10(10 \% R C)$ runs.............................. 198

Figure 201 - Steam strip plots for Suncor runs 14 and 22 ............................................................204

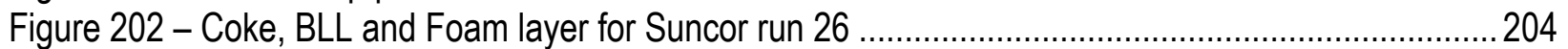

Figure 203 - Coke, BLL and Foam layer for Suncor run 27 .............................................................2.

Figure 204 - Furnace skin temperature profile for Marathon runs ....................................................2.20

Figure 205 - Drum height of foam, bubbly liquid and coke layers with time for EMCN runs 1 to $4 \ldots \ldots \ldots . . .208$

Figure 206: Drum height of foam, liquid and the coke layer during EMHC run 8. ...............................2.214

Figure 207: Drum height of foam, liquid and the coke layer during EMHC run 9................................215

Figure 208: Drum temperature profile for MRP run 1 ……................................................................ 216

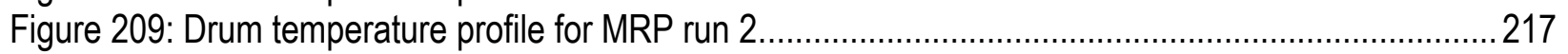

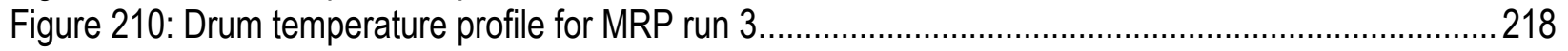

Figure 211: Drum temperature profile for MRP run 4................................................................ 219

Figure 212: Temperature profiles for SUNC 14 PUAFI and SUNC 15 (5\% RC) PUAFI runs......................224

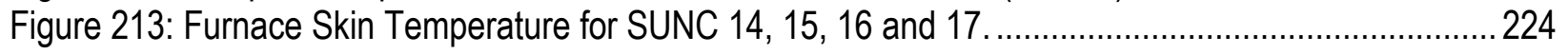

Figure 214 - Temperature vs. time at drum top, run EQ4 PUAF......................................................226

Figure 215 - Temperature vs. time at drum top, run EQ7 PUAF .........................................................226

Figure 216 - Temperature vs. time at drum top, run EQ8 PUAF ........................................................226

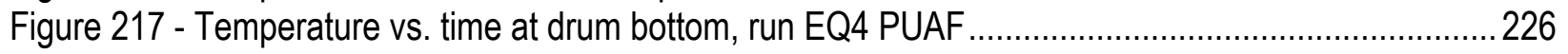

Figure 218 - Temperature vs. time at drum bottom, run EQ7 PUAF ....................................................226

Figure 219 - Temperature vs. time at drum bottom, run EQ8 PUAF ................................................226

Figure 220 - Gamma densitometer traces for run SUN 6 PUAF before and after steam stripping............. 228

Figure 221 - Gamma densitometer traces for run PETR 5 PUAF before and after steam stripping........... 229

Figure 222 - Gamma densitometer traces for run PETR 9 PUAF before and after steam stripping........... 230

Figure 223 - Gamma densitometer traces for run PETR 9 PUAF before and after steam stripping............ 231

Figure 224 - Gamma densitometer traces for run PETR 10 PUAF before and after steam stripping......... 231

Figure 225 - Gamma densitometer traces for run EQU 7 PUAF before and after steam stripping ............ 231 
Figure 226 - Cooling Temperature Profiles as a Function of Thermocouple Heights for a Chevron Run Allowed to Cool for 17 Hours .............................................................................................24

Figure 227 - Cooling Temperature Profiles as a Function of Thermocouple Heights for a Chevron Run Allowed to Cool for 17 Hours ........................................................................................ 235

Figure 228 - Cooling Temperature Profiles as a Function of Thermocouple Heights for a Citgo Run Allowed to Cool for 16 Hours ................................................................................................... 236

Figure 229 - Cooling Temperature Profiles as a Function of Thermocouple Heights for a Marathon Run

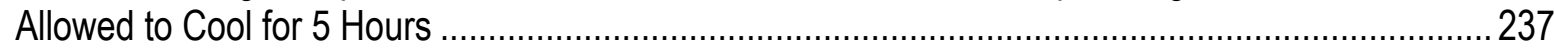

Figure 230 - Typical Cooling Rate Curves of Coke Cooled with Nitrogen and with Furnace Door Opened 238

Figure 231 - Effect of Coke Morphology on Cooling Rates for Chevron .............................................2238

Figure 232 - Effect of Coke Density on Cooling Rates for Equilon.......................................................2239

Figure 233 - Effect of Coke Particle Size on Cooling Rates for Equilon ..................................................2 240

Figure 234 - Photo of a Microscopic View of a Large BB Pellet.......................................................2 240

Figure 235 - Effect of Pressure on Cooling Rates of Sponge Coke for Citgo Resid................................ 241

Figure 236 - Effect of Pressure on Cooling Rates of Sponge Coke for Petrobras Resid ......................... 241

Figure 237 - Comparison of Cooling Rates between a Run with Furnace Door Opened After Steam

Stripping and a Run with Furnace Door Opened After Water Quenching .....................................2243

Figure 238 - Delayed Coking Optimization Simulator Structure ..............................................................246

Figure 239 - Delayed Coking Optimization Simulator Spreadsheet .....................................................247

Figure 240 - Chevron- Experimental vs Predicted Sulfur Model Yields.................................................25

Figure 241 - Citgo- Experimental vs Predicted Sulfur Model Yields ....................................................251

Figure 242 - Equilon- Experimental vs Predicted Sulfur Model Yields ...................................................252

Figure 243 - Marathon- Experimental vs Predicted Sulfur Model Yields ..................................................253

Figure 244 - Petrobras- Experimental vs Predicted Sulfur Model Yields...............................................2. 254

Figure 245 - Suncor- Experimental vs Predicted Sulfur Model Yields....................................................25

Figure 246 - EMCN- Experimental vs Predicted Sulfur Model Yields.....................................................25

Figure 247 - EMHC- Experimental vs Predicted Sulfur Model Yields......................................................256

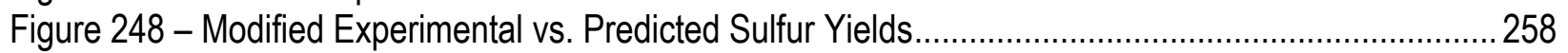

Figure 249 - Modified Experimental vs. Predicted Sulfur Yields ............................................................2. 258

Figure 250 - Predicted vs Experimental Bottom VM Based on Run Temperature \& Pressure.................. 261

Figure 251 - Predicted vs Experimental Bottom VM Based on Run Temperature \& Pressure................... 261

Figure 252 - Predicted vs Experimental Top VM Based on Run Temperature \& Pressure ........................ 262

Figure 253 - Predicted vs Experimental Top VM Based on Run Temperature \& Pressure ........................ 262

Figure 254 - Predicted vs Experimental Bottom VM Based on Overhead Temperature \& Pressure......... 263

Figure 255 - Predicted vs Experimental Bottom VM Based on Overhead Temperature \& Pressure......... 263

Figure 256 - Predicted vs Experimental Top VM Based on Overhead Temperature \& Pressure ............... 264

Figure 257 - Predicted vs Experimental Top VM Based on Overhead Temperature \& Pressure ............... 264

Figure 258 - Model Predicted vs. Excperimental Yields for Gas Composition (Chevron) .........................267

Figure 259 - Model Predicted vs. Excperimental Yields for Gas Composition (Citgo)............................... 268

Figure 260 - Model Predicted vs. Excperimental Yields for Gas Composition (Equilon) ............................269

Figure 261 - Model Predicted vs. Excperimental Yields for Gas Composition (Marathon) ........................2270

Figure 262 - Model Predicted vs. Excperimental Yields for Gas Composition (Petrobras)........................ 271

Figure 263 - Model Predicted vs. Excperimental Yields for Gas Composition (Suncor)............................ 272

Figure 264 - Model Predicted vs. Excperimental Yields for Gas Composition (EMCN) ……...................2273

Figure 265 - Model Predicted vs. Excperimental Yields for Gas Composition (EMHC) ............................224

Figure 266 - Model Predicted vs. Excperimental Yields for Gas Composition (MRP) .............................. 275 
Figure 267 - Predicted vs. Experimental Yields for $\mathrm{C} / \mathrm{H} / \mathrm{N}$ in coke for all the resids ...............................2278

Figure 268 - Predicted vs. Experimental Yields for $\mathrm{C} / \mathrm{H} / \mathrm{N}$ in coke for all the resids ...............................22

Figure 269 - Schematic Diagram showing the different elements of the

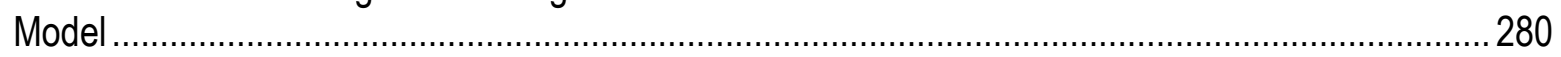

Figure 270 - Flowchart showing the sequence of the model calculations ..............................................283

Figure 271 - Constant volume of liquid layer after 150 mins for PET 2 ................................................ 285

Figure 272 - Foam height comparisons done with the Models and Gamma Densitometer findings for CHEV 3 run(here the y axis represents foam heights and the x-axis, time during the run foam heights are

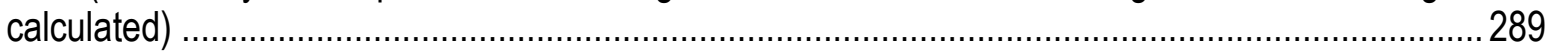

Figure 273 - Foam height comparisons done with the Model 2 Adjusted and Non adjusted for CHEV 3 run (here the $y$ axis represents foam heights and the $x$-axis, time during the run foam heights are

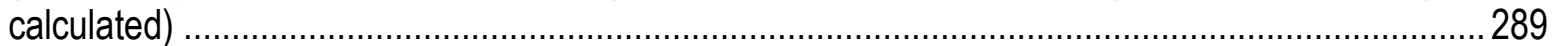

Figure 274 - Foam Height comparisons for different Chevron pilot unit runs ..........................................294

Figure 275 - Comparison between Measured and Predicted Temperature by Using the Lumped-HeatCapacity Model (MARA 7 PUAF - Sponge Coke) ……….....................................................296

Figure 276 - Individual Resid Cooling Rate Correlation for Sponge Coke .............................................298

Figure 277 - Individual Resid Cooling Rate Correlation for Shot Coke ........................................................

Figure 278 - Actual vs. Predicted API Gravity of Liquid Sub-Products ....................................................302

Figure 279 - Suncor PIONA Distribution Correlation (Un-normalized) ..................................................303

Figure 280 - Marathon PIONA Distribution Correlation (Un-normalized) ............................................... 303

Figure 281 - Petrobras PIONA Distribution Correlation (Un-normalized) …….......................................304

Figure 282 - Chevron PIONA Distribution Correlation (Un-normalized) ………………………..............304

Figure 283 - Citgo PIONA Distribution Correlation (Un-normalized) ….................................................305

Figure 284 - Equilon PIONA Distribution Correlation (Un-normalized)...................................................305

Figure 285 - Process of phase equilibrium and thermal cracking in tube furnace ...................................310

Figure 286 - Physical model for slug flow .............................................................................. 312

Figure 287 -Flow chart of slug flow model for the tube furnace.........................................................314

Figure 288 Permeability vs Porosity, calculated using different methods .............................................317

Figure 289 Estimation of permeability using the Swanson approach.....................................................318

Figure 290 Permeability vs porosity, using TU Swanson approach.....................................................319

Figure 291 Capillary Pressure Air-Water-Coke system (Transitional coke) ............................................320

Figure 292 Pore Size Distribution (Transitional coke) ..................................................................... 321

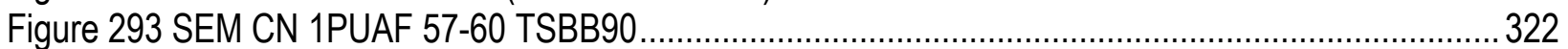

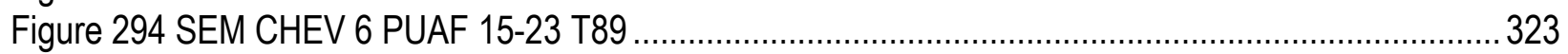

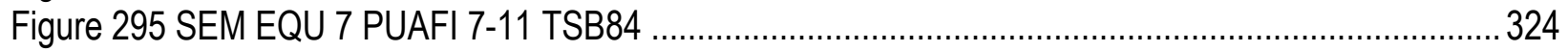

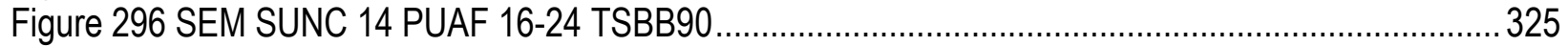

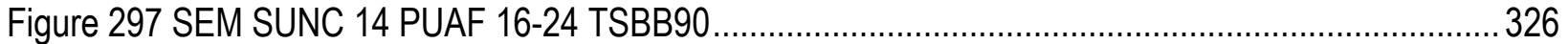

Figure 298 Purcell permeability comparison with measured values .......................................................327 


\section{Table of Tables}

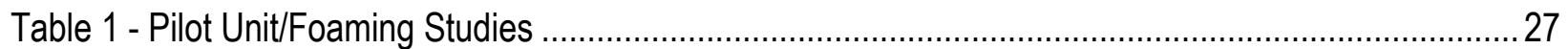

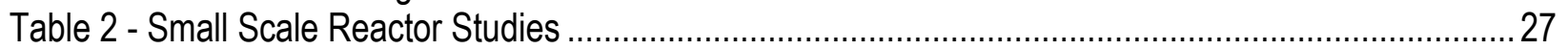

Table 3 - Test to be Conducted for Foaming Studies ......................................................................... 28

Table 4 - Batch reactor tests to be conducted with in-house resids.........................................................29

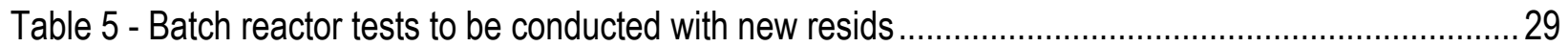

Table 6 - Micro reactor test conducted with in-house resid............................................................... 30

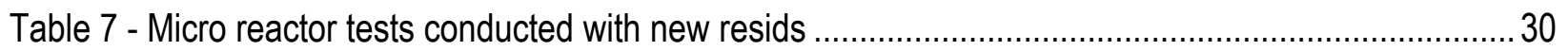

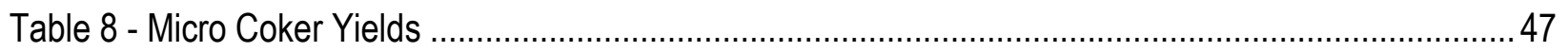

Table 9: Micro Reactor test completed with In-house Resid .............................................................. 48

Table 10: Micro-Coker yields for all six resids: Unnormalized and normalized yields: ...............................49

Table 11: Micro Reactor Yields - Old vs. New Runs Comparison ..........................................................50

Table 12 Micro Old vs. New Liquid Sub-product Comparisons for Marathon.............................................51

Table 13 Tomas Model Prediction vs. Experimental Yields for Straight Recycles ...................................54

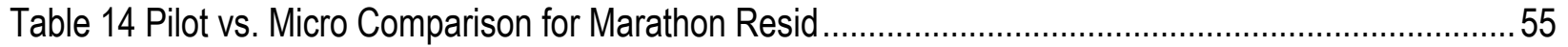

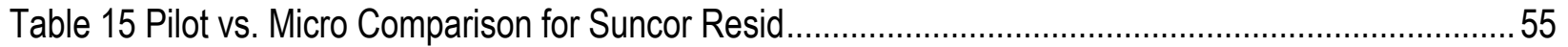

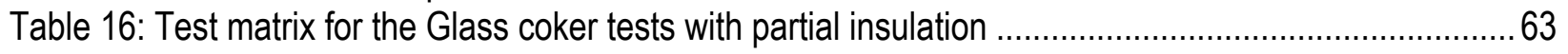

Table 17: Test matrix for the Glass coker tests with complete insulation............................................. 63

Table 18 - Batch Reactor Facility Testing Data - 100\% Recycle Runs................................................75

Table 19 - Batch Reactor - Un-normalized Yields with Internal Sample Weights....................................... 76

Table 20 - Batch Reactor - Yield Fluctuations Due to Heating Rate.......................................................... 77

Table 21 - Batch Reactor Testing - Heating Rate Effects(All \& 15 psig) .................................................78

Table 22 - Batch Reactor Testing - Heating Rate Effects(40 \& 60 psig) ................................................79

Table 23 - Yield Fluctuations Due to Pressure ...................................................................................... 80

Table 24 - Activation energy and frequency factor for the heaviest pseudo component (CHVBR-20)........ 88

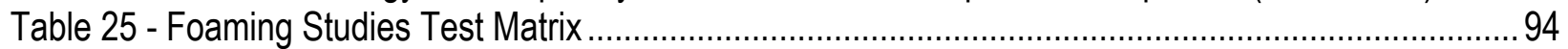

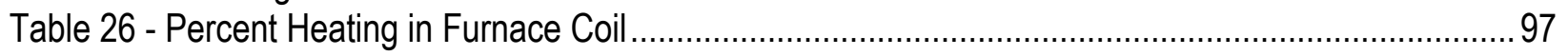

Table 27 - Effect of feed flow rate and drum diameter on superficial velocity at drum outlet ....................101

Table 28 - Effect of feed flow rate and drum diameter on superficial velocity in coil and at drum inlet ...... 102

Table 29 - Estimated coke level for 1", 2" and 3" drums (inches of coke formed in 5 hrs) ...................... 102

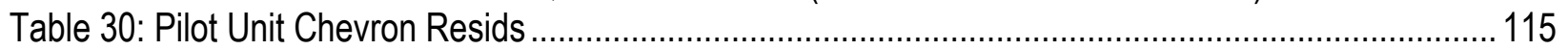

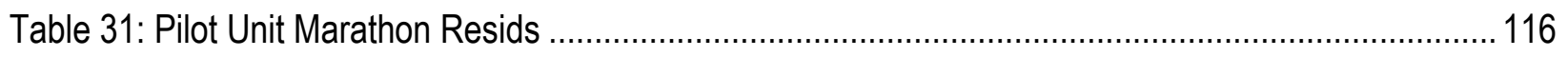

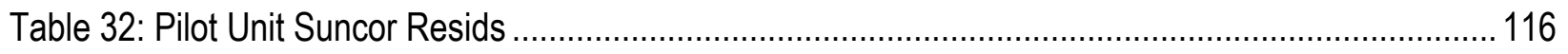

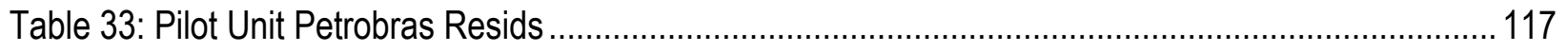

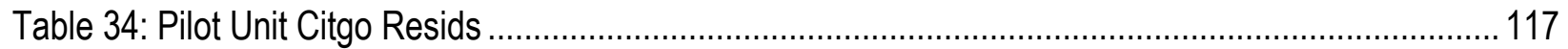

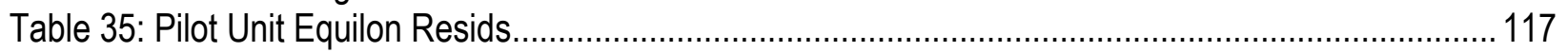

Table 36: PUAF Chevron Resids $\quad$ *No Normalized wt\% (overhead) temperatures ............................118

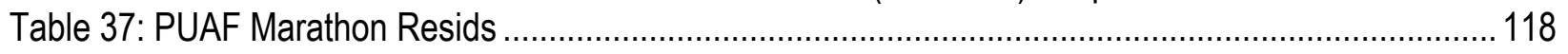

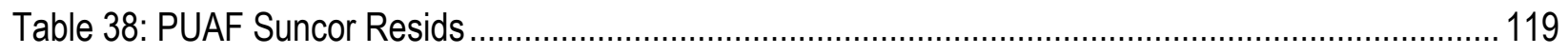

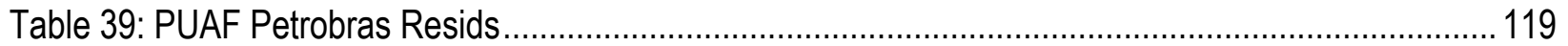

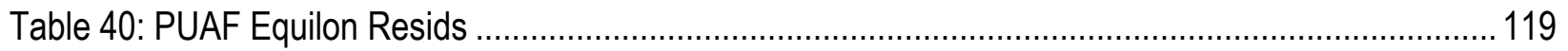

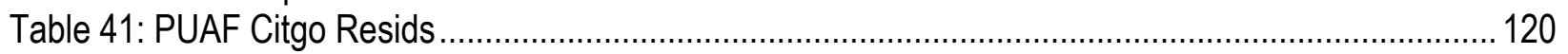

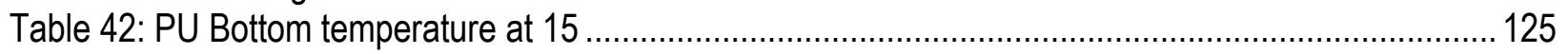

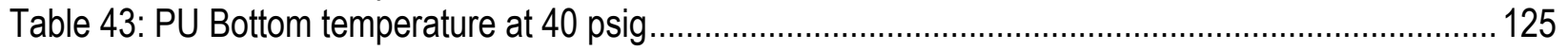

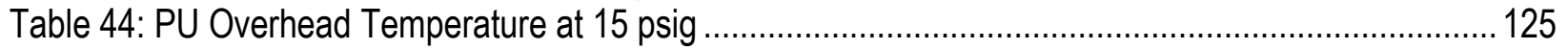




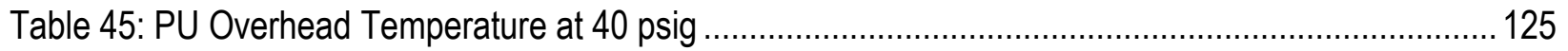

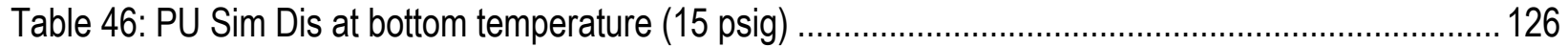

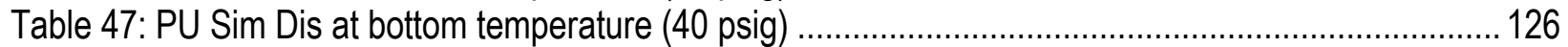

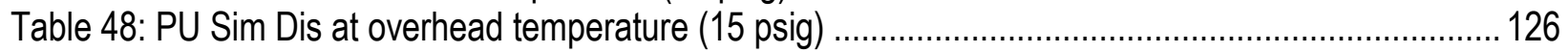

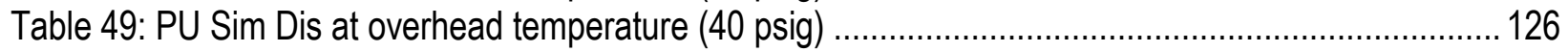

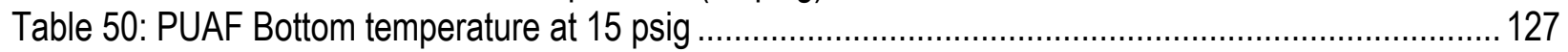

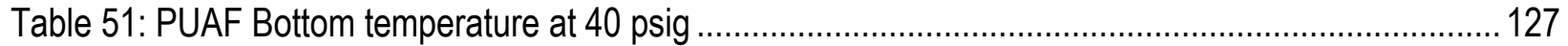

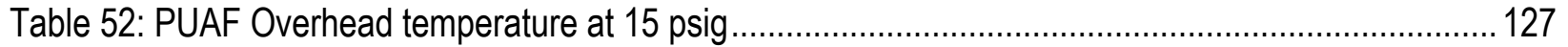

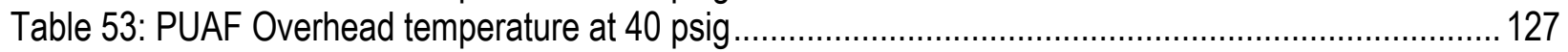

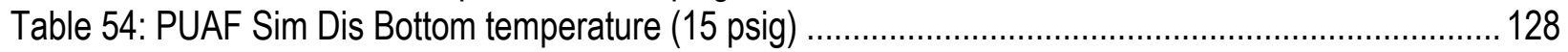

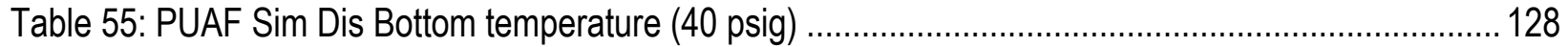

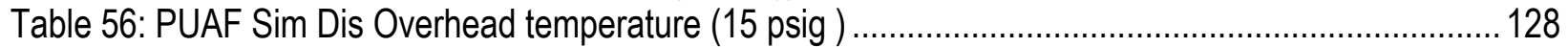

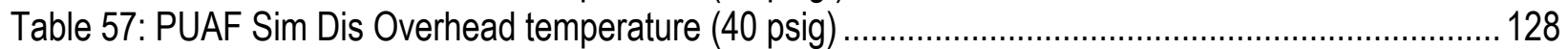

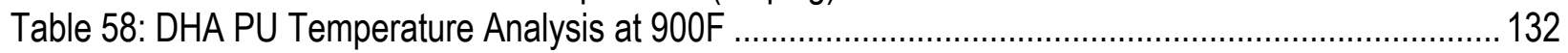

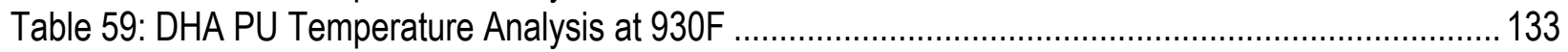

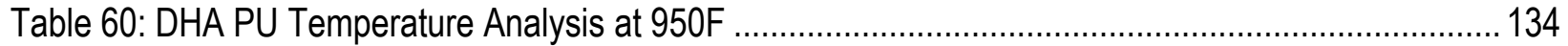

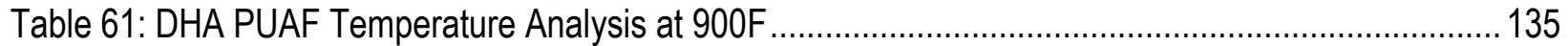

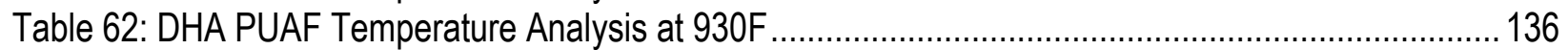

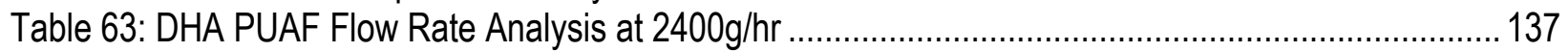

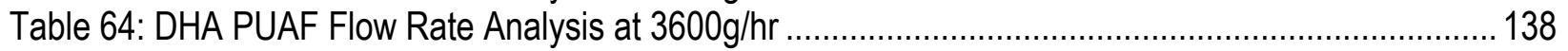

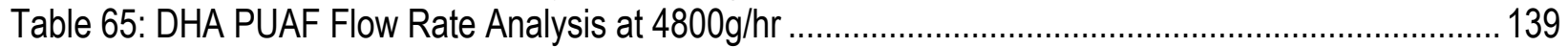

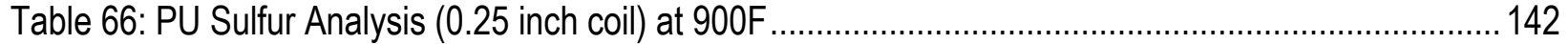

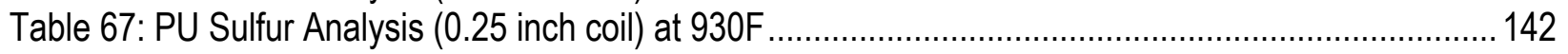

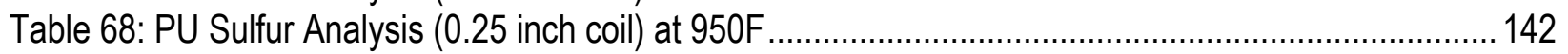

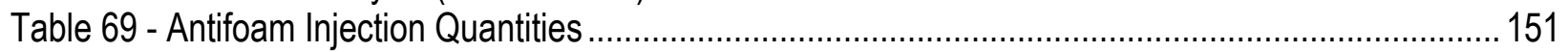

Table 70 - Pilot Unit Antifoam Runs Considered by Resid ................................................................. 172

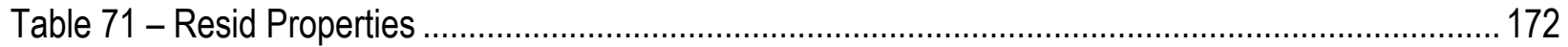

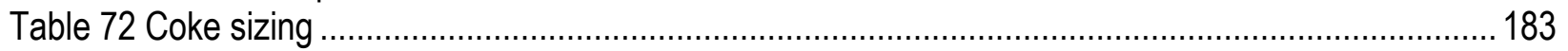

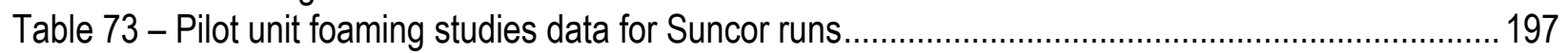

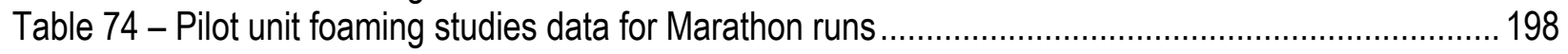

Table 75 - Foaming tendencies data for Marathon runs .................................................................200

Table 76 - Summary of recycle runs for Marathon and Suncor resids ..................................................20

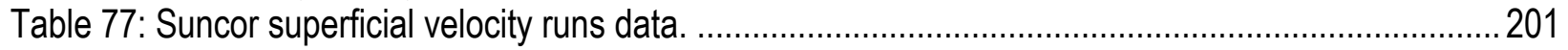

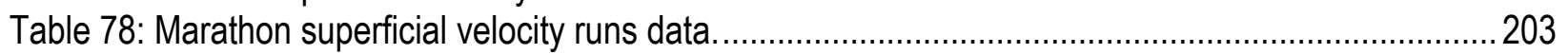

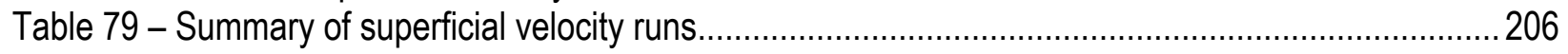

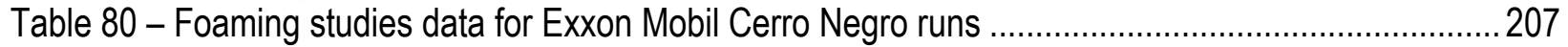

Table 81: Foaming studies data for Exxon Mobil Heavy Canadian runs..................................................209

Table 82: Pilot Unit foaming studies data for Marathon Rose Pitch runs. ...............................................211

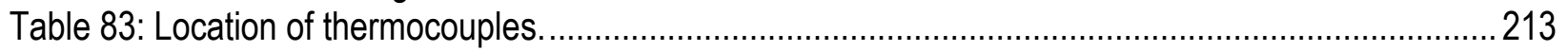

Table 84: Thermocouple locations along the coke drum height...........................................................22

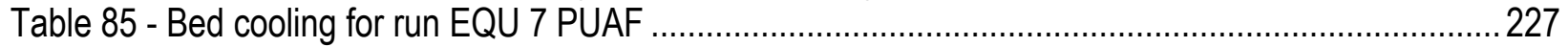

Table 86 - Status of Delayed Coking Product Correlations ...................................................................248

Table 87 - 6 foot Drum Cooling Rate Correlations - Temperature ......................................................297

Table 88 - Correlation coefficients of Predicted Bulk and Gamma densities for Petrobras and Marathon

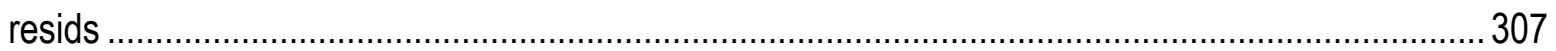

Table 89 - Correlation coefficients of Predicted Bulk and Gamma densities...........................................307

Table 90 - Correlation coefficients of Predicted BB density for Suncor resid ..........................................308 
Table 91 - Correlation coefficients of Predicted Bulk and Gamma densities. 308

Table 92 - Correlation coefficients of Predicted Gamma densities for overall sponge and shot coke ....... 309 


\section{Disclaimer}

This report was prepared as an account of work sponsored by an agency of the United States Government. Neither the United States Government nor any agency thereof, nor any of their employees, makes any warranty, express or implied, or assumes any legal liability or responsibility for the accuracy, completeness, or usefulness of any information, apparatus, product, or process disclosed, or represents that its use would not infringe privately owned rights. Reference herein to any specific commercial product, process, or service by trade name, trademark, manufacturer, or otherwise does not necessarily constitute or imply its endorsement, recommendation, or favoring by the United States Government or any agency thereof. The views and opinions of authors expressed herein do not necessarily state or reflect those of the United States Government or any agency thereof. 


\section{Public Abstract}

Delayed coking evolved steadily over the early to mid 1900s to enable refiners to convert high boiling, residual petroleum fractions to light products such as gasoline. Pound for pound, coking is the most energy intensive of any operation in a modern refinery. Large amounts of energy are required to heat the thick, poor-quality petroleum residuum to the 900 to 950 degrees $F$ required to crack the heavy hydrocarbon molecules into lighter, more valuable products. One common misconception of delayed coking is that the product coke is a disadvantage. Although coke is a low valued (near zero economic value) byproduct, compared to transportation fuels, there is a significant worldwide trade and demand for coke as it is an economical fuel. Coke production has increased steadily over the last ten years, with further increases forecast for the foreseeable future. Current domestic production is near 111,000 tons per day. A major driving force behind this increase is the steady decline in crude quality available to refiners. Crude slates are expected to grow heavier with higher sulfur contents while environmental restrictions are expected to significantly reduce the demand for high-sulfur residual fuel oil. Light sweet crudes will continue to be available and in even greater demand than they are today. Refiners will be faced with the choice of purchasing light sweet crudes at a premium price, or adding bottom of the barrel upgrading capability, through additional new investments, to reduce the production of high-sulfur residual fuel oil and increase the production of low-sulfur distillate fuels. A second disadvantage is that liquid products from cokers frequently are unstable, i.e., they rapidly form gum and sediments. Because of intermediate investment and operating costs, delayed coking has increased in popularity among refiners worldwide. Based on the 2000 Worldwide Refining Survey published in the Oil and Gas, the delayed coking capacity for 101 refineries around the world is 2,937,439 barrels/calendar day. These cokers produce 154,607 tons of coke per day and delayed coking accounts for $88 \%$ of the world capacity. The delayed coking charge capacity in the United States is $1,787,860 \mathrm{~b} / \mathrm{cd}$.

Despite its wide commercial use, only relatively few contractors and refiners are truly knowledgeable in delayed-coking design, so that this process carries with it a "black art" connotation. Until recently, the expected yield from cokers was determined by a simple laboratory test on the feedstock. As a result of Tulsa University's prior related research, a process model was developed that with additional work could be used to optimize existing delayed cokers over a wide range of potential feedstocks and operating conditions.

The objectives of this research program are to: utilize the current micro, batch and pilot unit facilities at The University of Tulsa to enhance the understanding of the coking process; conduct additional micro and pilot unit tests with new and in-house resids and recycles to make current optimization models more robust; conduct focused kinetic experiments to enhance the furnace tube model and to enhance liquid production while minimizing sulfur in the products; conduct detailed foaming studies to optimize the process and minimize process upsets; quantify the parameters that affect coke morphology; and to utilize the knowledge gained from the experimental and modeling studies to enhance the computer programs developed in the previous JIP for optimization of the coking process. These refined computer models will then be tested against refinery data provided by the member companies. Novel concepts will also be explored for hydrogen sulfide removal of furnace gases as well as gas injection studies to reduce over- cracking. 
The following deliverables are scheduled from the two projects of the three-year JIP:

1. A novel method for enhancing liquid yields from delayed cokers and data that provide insight as to the optimum temperature to remove hydrogen sulfide from furnace gases.

2. An understanding of what causes foaming in coker drums and ways to minimize sulfur in the produced liquids.

3. An understanding of the HES impacts resulting from hot spots, poor drainage, and settling.

4. A screening model to quantify how other feedstocks and/or a combination of feedstocks will behave in a refinery, and kinetic/optimization models that can represent virtually any delayed coking unit across a wide range of process conditions and feedstocks.

Primarily graduate students, post-Doctoral Research Associates and faculty members, will conduct the research in this project.

This research project should find ways to reduce the amount of contaminants in coke, making it better suited for commercial use in the metals or chemistry industry, as well as ways to reduce the amount of sulfur in the gasoline and diesel fractions. Reducing foaming in the coke drum will also be studied in this project. Reducing the amount of antifoamant used in the coke drum by $\$ 0.10$ per ton will save the refiners $\$ 5$ million per year. During 2001, both production and consumption of petroleum coke has increased, and this trend is set to continue. Since 1992 world petroleum coke production capacity has increased by more than $40 \%$ to reach a peak of 154,607 tpd in 2001. This expansion is expected to continue with at least fifteen new coking units coming into production by 2003 providing new jobs and markets for the coke, such as a fuel source for kilns in the cement industry and for boilers in electric power plants or in the manufacture of electrodes to be consumed in carbon anodes for aluminum smelting and graphite electrodes of steel making.

Knowledge from this project will be transferred to the industry through semiannual advisory board meetings, graduate education of two Ph.D. students and two MS students and through the coordination of annual workshops for hands on experience of using computer programs that come out of the research. 


\section{Executive Summary}

The Coking test facilities include three reactors (or cokers) and ten utilities. Experiments are being conducted using the micro coker, pilot unit and stirred batch reactor. Gas products are analyzed in-house using simulated distillation (HP 5880a), high temperature gas chromatography (6890), detailed hydrocarbon analysis, and ASTM distillation.

Facility Improvements were made to the micro reactor, batch reactor and the pilot unit to improve/enhance the quality of data obtained. For the micro reactor, the major improvements include Eurotherm temperature controls, pressure transducer to vapor line, thermocouples for reactor T's and Vapor T's, pulse meter for continuous gas volume readings, and Labview control and data acquisition system. These upgrades improved the assembly/disassembly time as well as increased the amount of data acquired and the process in which it was acquired. Increasing the amount of data acquired has improved the understanding of each run and improved the comparison of the micro reactor data to pilot unit data. The improvements to the batch reactor were made to remove operator error in system functions and data acquisition and to improve system functionality. Limiting operator error has improved data reproducibility as well as increased the time available for liquid sampling. The changes made were including higher wattage heaters, increasing the liquid sample receivers from 4 to 12, installing a larger sampling system to allow for SARA analyses, and a Labview control and data acquisition system. For the pilot unit, overhead and feedline injection capabilities were added for antifoams and a pump system that provided the ability to quench with large water volumes through the feedline and overhead.

The 5880 GC was replaced with the refurbished 5890 GC. Chemstation software was added and this instrument will be used for both DHA and sim dis analysis. The Foxboro operating system for the pilot unit (version 6.0) was replaced with the latest software package (version 7.1) and a new workstation computer.

The pilot unit was expanded to include a second coker that utilizes a larger coke drum to study wall effects. The second coke drum has its own gamma densitomer allowing us to operate as they do in the refinery, that is, as one drum is being filled the other is being decoked. A remote dialup system was installed that would notify the coking staff wherever they are at in case of any emergency situation. The air handlers in the building were modified to accommodate increased air flow when the vent fans are utilized during transfers. This ventilating system can be triggered manually or automatically should the $\mathrm{H} 2 \mathrm{~S}$ level rise above $10 \mathrm{ppm}$. The H2S monitors were also hooked up to the Foxboro system to record levels continuously. With the changes, recordings over the past month showed H2S levels of only 14 ppb which means no detectable odor.

In the second phase of study, 126 micro reactor tests have been conducted. 27 shakedown tests showed that the gas recoveries were excessively high when compared to the pilot unit. These runs resulted in the addition of a new pressure gauge on the vapor line, the addition of a carrier gas to remove the stagnant vapors and controlling the test using an internal thermocouple.

87 parametric tests were then conducted with the in-house resid samples at three temperatures and three pressures. Individual resid product and liquid sub-product yields were predicted fairly well using linear regression. Overhead temperature and pressure were the parameters used. A slight variation in 
experimental data was seen in the coke $(0.93 \%)$, liquid $(1.27 \%)$ and gas $(0.92 \%)$ yields when the data was compared to the data predicted with the micro-screening model. The individual liquid sub-product yield predictions improved for the new runs when compared to the previous runs when the liquid sub-products were estimated in terms of total weight percent of feed instead of total weight percent of liquids. Liquid content was seen to increase with temperature for the paraffinic resids while the aromatic, napthenic, and intermediate resids showed and optimum at $930^{\circ} \mathrm{F}$.

Thirteen runs were made with 5 and $10 \%$ recycle, five runs made with $100 \%$ recycle, and 13 tests conducted with the three new resids: four using the heavy Canadian, two with Cerro Negro and seven with the Rose Pitch. The Suncor resid showed an increase in coke yield with increasing recycle (0 to 100\%) at low temperature and high pressure whereas for Marathon, little change was observed. However, at a high temperature and low pressure, runs using Marathon recycle showed a decrease in coke yield with an increase in recycle. The effect of feedstock composition and operating conditions on product yields were successfully correlated for the nine resids used. When the new resids were added, a better correlation was found when asphaltenes were included. When the experimental data was compared to available correlations found in the literature, differences in the yield predictions varied by as much as $11 \%$. Microreactor results were documented and a user friendly GUI was added to the microcoker model for member utilization.

The Batch reactor was upgraded to generate high quality data. Forty-three batch reactor tests have been completed to date. Tests were run at pressures of 15,40 and $60 \mathrm{psig}$. The higher pressure runs are producing significantly different data than the 15 or 40 psig runs. The components for building the apparatus for conducting the SARA analysis were assembled and testing begun.

A batch reactor model was developed based on the model used in the literatures by different researchers (Raychaudhuri, Banerjee, \& Ghar, 1994; Stangeland, 1974). This model uses the boiling points of the feed that is produced by the HTGC and the operating conditions of the batch reactor to predict the product distributions. A program has been built and compiled using FORTRAN to predict the kinetic parameters using a nonlinear least square method. The method used in the program was the known Levenberg-Marquardt method developed separately by Levenberg (Levenberg, 1944) and Donald Marquardt (Marquardt, 1963). The subroutines and functions were programmed using FORTRAN. There were two distinctive sections in the program. One section calculates the model and then passes it to the other to calculate the model parameters. The kinetic model program was developed and compiled. The program was run using literature data and it worked very well.

HTGC data, which is essential to the development of the kinetic model, was completed. These data along with SimDis and GC data were used in our model to produce the kinetic parameters. The kinetic model was released for beta testing.

68 tests were conducted with the pilot unit using the six in-house resids from phase 2 studies. Studies were first conducted to determine the extent of antifoam carrying over during overhead injection using water. These studies indicated that some of the antifoam was carried over into the liquids when injected from overhead. However, the very low recovery of silicon indicates that most of the injected antifoam remained in the drum. More antifoam would be carried over during the coking process because the superficial velocity of the $\mathrm{HC}$ vapor is larger. Studies were also conducted to establish what was causing the fluctuations in the fluid in the furnace tube. By recording temperatures as a function of distance from coil inlet to outlet, it was hypothesized that an increase in vaporization of the fluid causes more 
irregularities in the flow pattern and temperature profile. When both recycle and antifoam were injected, it was noticed that the furnace had to be fired harder to achieve the desired operating temperature as compared to when only resid is injected.

Antifoam injection studies were run using both a low viscosity 100,000 cSt ( $0.3 \mathrm{ml} \mathrm{AF/} 70 \mathrm{ml}$ diesel) and a high viscosity $600,000 \mathrm{cSt}(0.75 \mathrm{ml} \mathrm{AF/} 70 \mathrm{ml}$ diesel) antifoam. In some of the tests, antifoam was injected continuously ( 2 min ON and 8 min OFF) while in others it was injected on as-needed basis (observation of foam determines the injection time). Antifoams were injected in the drum overhead, through the feedline, and mixed with the resid in the feed bucket. During the experiments, temperatures at the inlet to furnace coil, the fluid temperature, the furnace skin temperature, the overhead temperature and the temperature inside the coke drum near the bottom were measured. From test to test, variations were seen in the overhead temperature and the furnace coil temperatures. In general, injecting antifoam on a continuous basis reduces the overhead temperature, while injecting antifoam in the feedline requires the furnace to be fired harder to get the fluid to the desired temperature.

A partitioning study was conducted on the samples taken during the pilot unit tests in which oil and water samples were collected from the lights and heavies tank. More analytical results are needed for silicon in the liquid products but the tentative conclusion is that silicon from the antifoam injected overhead tends to carry over to the hydrocarbon liquids, while the silicon injected from the feedline tends to break down and end up in the decant water.

A detailed liquid analyses study was conducted. This study looked at 160 liquid samples generated in the first phase of study and those generated in the continuation phase. The samples were distilled and simulated distillation, detailed hydrocarbon analyses and sulfur analyses are run on each cut. The overall outcome of the study is a model that predicts what type of PiONA component, sulfur, etc. would be dominant at a certain temperature and pressure, and how a change in the temperature and pressure affects its production.

Foaming runs were also conducted. The first series of foaming tests were conducted using the Suncor resid to establish the differences between overhead, feed and feed line injection. The second series of tests were run using six in-house resids to gain an understanding of how pressure and temperature affect foaming as well as the impact of feed rate. This data was integrated with the results obtained during the first phase of study.

The parametric studies with the six in-house resids were completed. These tests show that paraffinic structured resids made Sponge coke, Aromatic resids made Shot coke, Napthenic resids made a mixture of shot and sponge coke while Intermediate structured resids made a mixture of agglomerated and large BB's. Petrobras and Marathon resids made an entire drum of sponge coke, irrespective of the operating conditions, while the Suncor resid made shot coke irrespective of operating conditions, Equilon made a mix of sponge, agglomerated shot and different sized BB's while Chevron and Citgo made either sponge coke or shot coke depending on operating conditions.

For the resids which produce sponge coke, the thickness of the liquid layer decreased with an increase in temperature; the coke density increased with an increase in either temperature or pressure and decrease in feed rate, unless it was affected by excess antifoam injection which also increased the density of the coke. Sponge coke has a linear bed growth, where as in the case of agglomerated shot, the coke bed attains a certain height at which point the lower layers grow denser until break through occurs or the 
test was terminated due to pressure buildup. Increasing the temperature and feedrate made more shot coke and also more BB's whereas an increase in pressure decreased shot coke formation. Samples have been selected for permeability, porosity and CT scans.

In general, the lower the temperature and pressure, and the higher the feedrate, the worse the foaming. This was especially true for the Marathon, Petrobras, and Chevron resid. However, Equilon \& Citgo foamed worse at higher pressure.

Nine antifoam optimization tests using the resid from Petrobras showed that injection of higher concentrations of antifoam/unit of carrier uses more antifoam than is required to effectively control foaming; however, the time between injection is longer and a denser coke is made. When large quantities of diesel are injected as the carrier, foaming appeared to be enhanced. Foaming resulted in uniform temperature profiles in the drum and when the temperatures in the drum were fairly uniform throughout, pure shot or a uniform sponge was made.

Continuous overhead and feed line injection are effective at controlling foaming throughout the run. Feed line injection with an antifoam/carrier concentration of $0.3 / 70$ was only effective at controlling foaming on a continuous basis for the first 80 minutes whereas the $30 / 70$ concentration was effective throughout the run. The 0.3/70 mixture was also the optimum AF concentration for controlling foaming overhead. It was also found that when $100,000 \mathrm{cSt}$ and $600,000 \mathrm{cSt}$ antifoams are used at equivalent concentrations, foam control is comparabl; however, the time to rise was longer for the $600,000 \mathrm{cSt}$ antifoam.

Parametric and superficial velocity tests were carried out using the Heavy Canadian and the Rose Pitch resids. A transition in morphology from agglomerated shot to transitional sponge was seen with an increase in superficial velocity for the Heavy Canadian resid. Foaming tendencies observed for the Rose Pitch runs were different than those observed for all the other runs. For the Rose Pitch resid, a shift in morphology from shot coke at $900 \mathrm{OF} / 15$ psig to sponge coke at 930 OF/40 psig was observed.

Coke morphology was seen to have an important effect on quenching. Hard dense sponge or agglomerated shot coke cooled very slowly, whereas the presence of loose shot or void spaces within the coke rum correspond to very fast cooling. This data was used to modify the quench model to account for varying porosity/permeability within the coke bed.

Testing with the $250 \mathrm{ml}$ glass coker was conducted to visually observe and measure foam formation under carefully controlled coking conditions. A camera was added to record the foaming process. A total of 20 tests were conducted with the 9 in-house resids. These tests showed two different trends with respect to kinetics and foaming. Even though additional processing is required, the trends seem to be related to the coke morphology produced in the pilot unit. These preliminary studies provided justification that valuable data could be obtained and the experimentation should be carried to the next level.

Progress continues has begun on developing an Integrated Delayed Coker Simulator, incorporating delveloped models and correlations to predict delayed coker performance basesd on feedstock and parametric conditions. Modeling and correlation work has been conducted on sulfur distrubition, volatile matter analysis, gas analysis, $\mathrm{C} / \mathrm{H} / \mathrm{N}$ distribution in the coke, coke density, API gravity of the liquid products, and detailed hydrocarbon analysis of the light liquids. In addition, a preliminary foaming model has been developed, a quench model has been developed and valideated, work has begun on a comprehensive furnace tube model, and modeling of coke morphology has commenced. 
A complete material balance was done for sulfur from the data obtained from analytical tests of product samples. The effect of feed temperature, pressure, average overhead temperature and quenching on sulfur distribution was determined. Individual correlations were developed for each resid considering the overhead temperature and pressure. The resids showed around 10\% (maximum) variation when checked for reproducibility in the sulfur distribution. The individual correlations between the sulfur weight percent in the coker products indicate that sulfur distribution is dependent on various parameters and also it is resid dependent.

The volatile matter distribution in the coke was analyzed for each individual resid. Preliminary studies of the volatile matter distribution in the bed indicate that coke taken from different levels of the coking chambers was not identical in quality. The top section of the coke bed had more volatile matter than middle section. The lower section of the coke bed had the least amount of volatile matter when compared to other sections. It was found from the preliminary studies that the lower section of the coke had almost same amount of VM whereas the top section had variations due to the experimental constraints such as shut down of run either due to pressure build up or due to the height of the coke in the drum. The effect of feed temperature, pressure and the overhead temperature on the VM of the coke was determined. Pressure had a varying effect on the amount of volatile matter in coke for individual resides, while coke morphology was found to have little effect on the volatile matter.

Gas analysis was conducted on the GC datat for components from methane (C1) to pentane (C5) single and double bonds in addition to hydrogen and hydrogen sulfide. The effects of temperature and pressure on these gas compositions were determined and gas composition correlations were developed selecting the overhead temperature and pressure as the parameters. The pilot unit gas composition data was compared with the available micro coker gas composition data to determine the similarity between the two units. The effect of temperature at constant pressure and effect of pressure at constant temperature on the average molecular weight of the gas composition for all the nine resids were also determined.

The weight percent of carbon, hydrogen and nitrogen data for the coke was used in the $\mathrm{C} / \mathrm{H} / \mathrm{N}$ analysis to develop correlations selecting feed temperature, pressure and run length as the independent variables. Preliminary conclusions which came out from this analysis are that the weight percent of carbon, hydrogen and nitrogen are uniformly distributed all along the coke structure or coke bed formed inside the drum. The adjusted $R^{2}$ values for most of the resids were reasonably good.

Analysis and correlation of liquid properties included API gravity correlations, PiONA correlations and RON analysis of the light liquids, and silicon partitioning in the hydrocarbon liquids due to antifoam addition. Density correlations were developed and compared for different coke morphologies.

A "first pass" model was developed that is capable of predicting foaming trends for the individual pilot unit runs as well as for resids investigated at refinery conditions. This model interrelates the major variables that contribute to foam heights through a physical understanding of upward gas bubble movement in the coke drum and factors that can impede the upward movement when using the model to make predictions.

A lumped heat capacity model was developed for the cooling of the coke drum by free convection to the surrounding air with the furnace door open. The heat capacities estimated for the coke were around $0.5 \mathrm{Btu} /{ }^{\circ} \mathrm{F}-\mathrm{hr}$ for sponge coke and $0.6 \mathrm{Btu} /{ }^{\circ} \mathrm{F}-\mathrm{hr}$ for shot coke. These values are in agreement with a few 
literature values of approximately $0.45 \mathrm{Btu} / \mathrm{hr}-{ }^{\circ} \mathrm{F}$. Plotting the predicted temperatures against the measured or real values showed that the method was satisfactory in roughly predicting how a certain coke morphology would cool as a function of time. Convective cooling rates were also correlated by averaging the cooling rates of different runs that were operated under very similar conditions and that produced similar coke morphologies and then using a curve fit to model the experimental data. Using this procedure it was found that an exponential curve fit predicts the cooling of the coke bed well.

A quench model was developed to predict temperature profiles when the coke bed is cooled by flowing water from the bottom. The model divides the coke bed into one-inch segments of coke and performs energy balances over the coke and steam or water on each segment. The model uses literature values of heat capacity and thermal conductivity of the coke and adjusts the heat transfer coefficient and coke porosity to best fit the given data. The model works very well in predicting the temperatures as a function of injection time for each zone. Some slight differences between the model and experimental data are probably due to assuming the same coke properties (porosity, heat capacity, and thermal conductivity) throughout the coke bed.

Work has begun on developing a comprehensive model for the furnace tube, based on reaction kinetics, two-phase flow patterns, and vapor-liquid equilibrium. The model is based on the feedstock properties and initial conditions in the furnace tube, and calculations are made of the reaction rate and the vapor-liquid equilibrium.

Coke morphology studies showed that agglomerated and transitional morphologies have the lowest permeabilities; this fact is in accord with the observations using SEM. Comparisons were made between different methodologies (Swanson and Purcell) for estimating permeabilities. 


\section{Experimental Methods}

\section{A. SCOPE OF PROBLEM}

Three state-of-the-art test facilities were developed for use in the previous JIP. The facilities were used to generate high-quality data. These facilities, with some minor modifications to improve them, are now being utilized to gather large quantities of coking related data to enhance the capabilities of the predictive models developed during the first three years of the Fundamentals of Delayed Coking Joint Industry Project (JIP). The work plans for this Joint Industry Project show the work being conducted with two major projects:

Project 1 - Small Scale Reactor Studies - conducts studies with the micro and batch reactors to generate sufficient data to enhance the robustness of the screening model and to better understand the reaction kinetics in the furnace tube and coke drum. Methods for removing sulfur, for enhancing liquid production, as well as ways to reduce sulfur in the liquids to help refiners meet the upcoming stringent sulfur requirements will also be studied.

Project 2 - Pilot Unit Studies - conducts detailed studies to enhance the robustness of the process optimization model and to better understand the foaming process thereby minimizing or eliminating process upsets as well as optimizing the use of antifoams thereby increasing refinery margins. Concurrent studies on the produced coke will provide a better understanding as to what parameters affect coke morphology as well as provide insight as to why settling, poor drainage and hotspots occur in coke drums minimizing health and safety hazards.

Results from these Projects will be used to further develop correlations for product yields and properties, as well as to develop mechanistic models for the furnace tube and coke drum that account for reaction kinetics and energy effects (i.e., heats of reaction, heats of vaporization, and heat transfer effects).

\section{B. Program Chronology}

The schedule for completing the complex and interrelated tasks over a three year period is shown in Table 1 and Table 2. Table 1 and Table 2 also show when significant deliverables in the form of report, models, and data will be provided to the participants. Those items colored blue are complete while those in red show when the task is scheduled for completion. 
The University of Tulsa

Table 1 - Pilot Unit/Foaming Studies

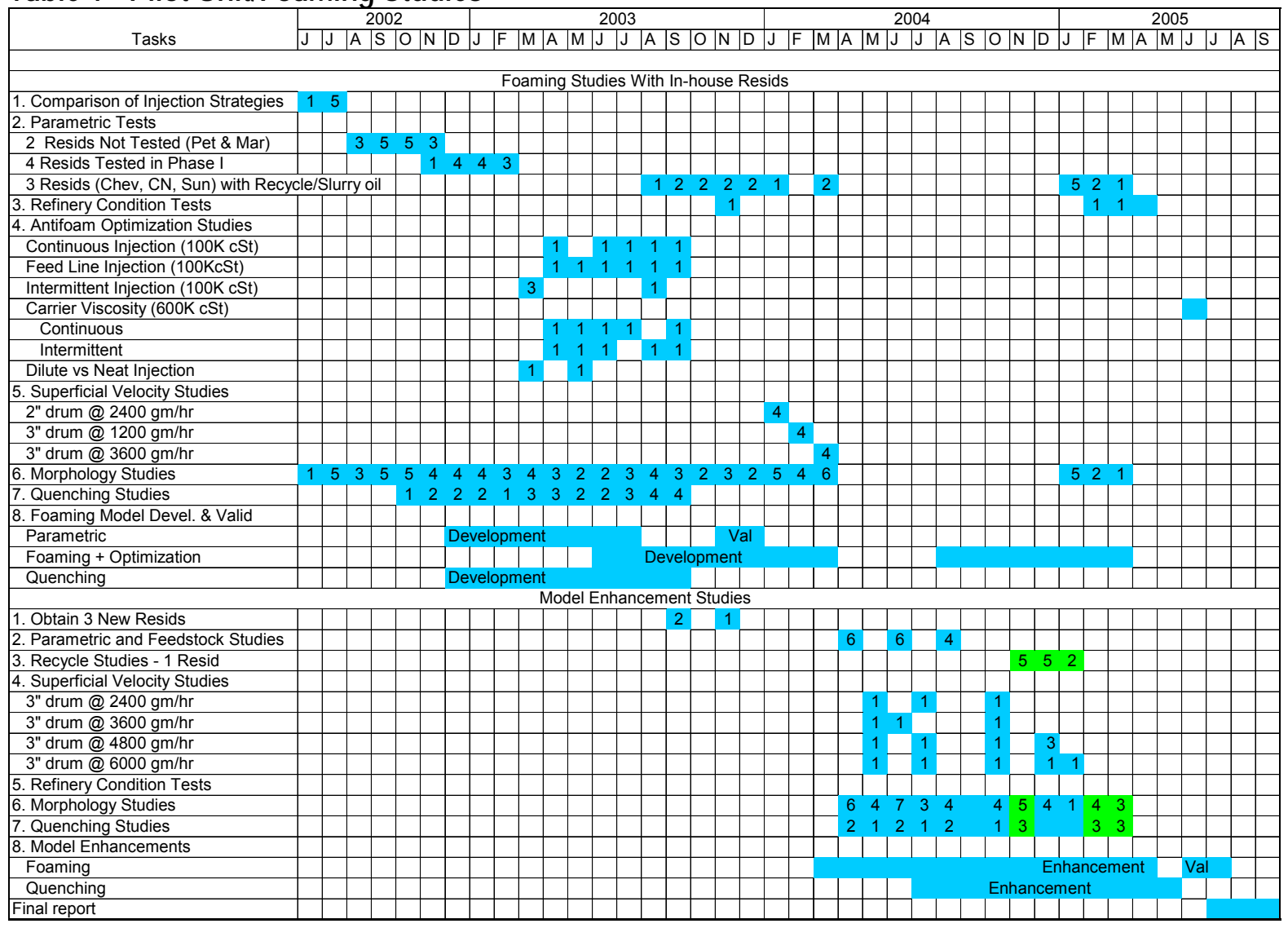

Table 2 - Small Scale Reactor Studies

\begin{tabular}{|c|c|c|c|c|c|c|c|c|c|c|c|c|c|c|c|c|c|c|c|c|c|c|c|c|c|c|c|c|c|c|c|c|c|c|c|c|c|c|}
\hline \multirow[b]{2}{*}{ Tasks } & \multicolumn{7}{|c|}{2002} & \multicolumn{11}{|c|}{2003} & \multicolumn{11}{|c|}{2004} & \multicolumn{9}{|c|}{2005} \\
\hline & $\mathbf{J}$ & $\mathbf{J}$ & $\mathbf{A}$ & 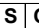 & 0 & $\mathbf{N}$ & D & $\mathbf{J}$ & $\mathbf{F}$ & $\mathbf{M}$ & \begin{tabular}{l|l}
$\mathbf{A}$ & $\mathbf{N}$ \\
\end{tabular} & \begin{tabular}{l|l}
$\mathbf{M}$ & $\mathbf{J}$
\end{tabular} & \begin{tabular}{|l|l|l|l} 
& $\mathbf{J}$ \\
\end{tabular} & A & $\mathbf{S}$ & 0 & $\mathbf{N}$ & D & $\mathbf{J}$ & $\mathbf{F}$ & $\mathbf{M}$ & \begin{tabular}{|l|l|l|l|l}
$\mathbf{A}$ & $\mathbf{N}$ \\
\end{tabular} & 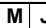 & \begin{tabular}{l|l|}
$\mathbf{J}$ & $\mathbf{J}$ \\
\end{tabular} & $\mathbf{A}$ & $\mathbf{S}$ & $\mathbf{O}$ & $\mathbf{N}$ & D & $\mathbf{J}$ & $\mathbf{F}$ & $\mathbf{M}$ & A & $\mathbf{M}$ & $\mathbf{J}$ & $\mathbf{J}$ & A & $\mathbf{S}$ \\
\hline & & & & & & & & & & & & & & & & & & & & & & & & & & & & & & & & & & & & & & \\
\hline \multicolumn{39}{|c|}{ Project 1a - Batch Reactor Studies to Improve Kinetic Model } \\
\hline & & & & & & & & & & & & & & & & & & & & & & & & & & & & & & & & & & & & & & \\
\hline \multicolumn{39}{|l|}{ 1. Equipment Design/Modification/Automation } \\
\hline 2. Shake Down Tests & & & & & & & & & & & & & & & & & & & & & & & & & & & & & & & & & & & & & & \\
\hline \multicolumn{39}{|l|}{ 3. Parametric and Feedstock Studies } \\
\hline - Using In-house Resids & & & & & & & & & & & & & & & 4 & 6 & 6 & 6 & 2 & & & & & & & & & & & & & & & & & & & \\
\hline - Using Three New Resids & & & & & & & & & & & & & & & & & & & 4 & 6 & 5 & & & & & & & & & & & & & & & & & \\
\hline - Recycle & & & & & & & & & & & & & & & & & & & & & & 5 & 5 & & & & & & & & & & & & & & & \\
\hline 4. Enhanced Kinetic Model Development & & & & & & & & & & & & & & & & & & & & & & & & & & & & & & & & & & & & & & \\
\hline \multicolumn{39}{|l|}{ 5. Final Report } \\
\hline & & & & & & & & & & & & & & & & & & & & & & & & & & & & & & & & & & & & & & \\
\hline \multicolumn{39}{|c|}{ Project 1b - Process Optimization Studies } \\
\hline \multicolumn{39}{|c|}{ 1. Gas Injection Studies to Reduce Cracking $\left(\mathrm{H}_{2}\right)$} \\
\hline 2. Sulfur Removal Studies & & & & & & & & & & & & & & & & & & & & & & & & & & & & & & & & 4 & & & & & & \\
\hline 3. Kinetic Model Enhancements & & & & & & & & & & & & & & & & & & & & & & & & & & & & & & & & & & & & & & \\
\hline 4. Final Report & & & & & & & & & & & & & & & & & & & & & & & & & & & & & & & & & & & & & & \\
\hline & & & & & & & & & & & & & & & & & & & & & & & & & & & & & & & & & & & & & & \\
\hline \multicolumn{39}{|c|}{ Project 1c - Micro Coker Studies to Improve Screening Model } \\
\hline 1. Equipment Modification/Automation & & & & & & & & & & & & & & & & & & & & & & & & & & & & & & & & & & & & & & \\
\hline 2. Shade Down Tests & & & & 7 & 8 & 8 & 4 & & & & & & & & & & & & & & & & & & & & & & & & & & & & & & & \\
\hline \multicolumn{39}{|l|}{ 3. Parametric \& Feedstock Studies } \\
\hline - Using In-house Resids & & & & & & & & 12 & 10 & 12 & 171 & 1111 & 18 & 3 & & & & & & & & & & & & & & & & & & & & & & & & \\
\hline - Using Three New Resids & & & & & & & & & & & & & & & & & & & 5 & 8 & 8 & 8 & & & & & & & & & & & & & & & & \\
\hline - Recycle & & & & & & & & & & & & & & 5 & 8 & 8 & 8 & 8 & 3 & & & & & & & & & & & & & & & & & & & \\
\hline 4. Enhanced Screening Model Development & & & & & & & & & & & & & & & & & & & & & & & & & & & & & & & & & & & & & & \\
\hline 5. Final Report & & & & & & & & & & & & & & 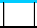 & & & & & & & & & & & & & & & & & & & & & & & & \\
\hline
\end{tabular}




\section{Pilot Unit/Foaming Studies:}

While conducting parametric studies in the previous JIP, runs were made with and without antifoams. Contrary to refinery experience, antifoams were successfully injected with the feed. Runs were made with and without foaming; however no technique was available to measure foam height. In the continuation study, a gamma densitometer is utilized for this purpose. The tests shown below are being conducted to gain a better understanding of the foaming process to minimize or eliminate process upsets as well as optimize the use of antifoams to increase refinery margins. In all studies, analyses will be conducted to quantify the amount of Silicon going into the quench water and hydrocarbon liquids. The test conditions for the pilot unit will include temperatures of 900,930 and $950^{\circ} \mathrm{F}$; pressures of 15, 30, 40 and $50 \mathrm{psig}$, carrier viscosities of 100,000 and $600,000 \mathrm{cSt}$; feed rates of 2400 and $3600 \mathrm{gm} / \mathrm{hr}$; and recycle rates of 5 and $10 \%$. The proposed test matrix includes 179 tests as shown in Table 3.

Table 3 - Test to be Conducted for Foaming Studies

\begin{tabular}{|c|c|c|c|c|c|c|c|c|c|}
\hline Type of Test & Temperature & Pressure & Resids & $\begin{array}{l}\text { Feed } \\
\text { Rates }\end{array}$ & $\begin{array}{c}\text { Recycle } \\
\text { Rates }\end{array}$ & Viscosity & $\begin{array}{l}\text { Drum } \\
\text { Sizes } \\
\end{array}$ & $\begin{array}{l}\text { Injection } \\
\text { Points }\end{array}$ & Total \\
\hline \multicolumn{10}{|c|}{ General Tests } \\
\hline $\begin{array}{l}\text { 1. Parametric and Feedstock } \\
3 \text { New Resids }\end{array}$ & 3 & 3 & 3 & 1 & & & & & 27 \\
\hline Old Resids Not Tested & 2 & 2 & 2 & 2 & & & & & 16 \\
\hline Resids Tested in Foaming & 2 & 2 & 4 & 1 & & & & & 16 \\
\hline Recycles & 3 & 2 & 3 & 1 & 2 & & & & 36 \\
\hline 2. At Refinery Conditions & 1 & 1 & 9 & 1 & ? & & & & 9 \\
\hline 3. Superficial Velocity & 3 & 3 & 1 & 1 & & & 3 & & 27 \\
\hline & & & & & & & & & \\
\hline 1. Continuous vs Feed Injection & \multicolumn{8}{|c|}{ Focused Tests } & \\
\hline & & & & & & & & & \\
\hline 2. Continuous vs Intermittent & 1 & 1 & 6 & 1 & & 1 & & 1 & 6 \\
\hline 3. Carrier Viscosity & 1 & 1 & 9 & 1 & & 2 & 1 & 1 & 18 \\
\hline 4. Dilute vs Neat Injection & 1 & 1 & 3 & 1 & & 2 & & 1 & 12 \\
\hline & & & & & & & & & \\
\hline Total & & & & & & & & & 179 \\
\hline
\end{tabular}

\section{Batch Reactor Studies}

In the prior JIP, 30 tests were run with six resids. All of these tests, except for the three that were run at $15 \mathrm{psig}$, were run at a pressure of $40 \mathrm{psig}$. These tests were not sufficient to adequately define the wide range ( 15 to $50 \mathrm{psig}$ ) of pressures that refinery furnaces and coke drums operate at. The batch reactor tests using the old and the new resid samples will generate the additional data needed to establish a robust kinetic model, especially over the wide range of pressures that commercial furnaces and coke drums operate at. Parametric studies will be conducted using the six resids that were utilized in the parametric studies in the prior JIP. Additional runs will be made with recycle. In addition, three new resids will also be run. These tests will be conducted at pressures of 15 and $40 \mathrm{psig}$. The analytical program will be enhanced to include other tests on the reactor resid samples that were not conducted in the previous JIP. An experimental program will be established, possibly using the visbreaking column, to quantify the amount of vaporization taking place in the furnace tube. The Delayed Coking Model that was developed in the previous Joint Industry Project was a lumping model based on boiling point distributions. It assumed that any material that is cracked into components light enough to become vapor will leave the drum without further cracking, while any cracked material that is heavy enough to stay in the drum will become heavier 
(through condensation or polymerization reactions) to eventually form coke. With additional data obtained from the continuation study, we will have a larger database of kinetic studies, so we will be able to better determine how feedstock properties affect the kinetics. We will also expand the analytical measurements for the batch reactor experiments to include SARA analyses on the reactor samples and PiONA analyses on the product liquids, which will allow us to enhance our kinetic model to include olefin-producing reactions, naphthene ring-opening and dehydrogenation reactions, and aromatic condensation reactions. These principles will expand modeling beyond correlated data available from this Joint Industry Project. The model should be able to represent virtually any delayed coking unit, commercial or pilot scale, across a wide range of process conditions and feedstocks. Thirty tests are planned with the six resids used in the prior JIP and thirty tests with three new resids as shown in Table 4 and Table 5.

Table 4 - Batch reactor tests to be conducted with in-house resids

\begin{tabular}{|c|c|c|c|c|c|c|c|}
\hline \multirow[b]{2}{*}{ Resid } & \multicolumn{3}{|c|}{ Pressure } & \multirow[b]{2}{*}{ Total } & \multicolumn{2}{|c|}{ Heating Rate } & \\
\hline & 15 & 30 & 40 & & Low & Medium High & Total \\
\hline Chevron & 2 & 1 & 2 & 5 & 3 & 2 & 5 \\
\hline Citgo & 2 & 1 & 2 & 5 & 3 & 2 & 5 \\
\hline Equilon & 2 & 1 & 2 & 5 & 3 & 2 & 5 \\
\hline Suncor & 2 & 1 & 2 & 5 & 3 & 2 & 5 \\
\hline Marathon & 2 & 1 & 2 & 5 & 3 & 2 & 5 \\
\hline Petrobras & 2 & 1 & 2 & 5 & 3 & 2 & 5 \\
\hline Total & 12 & 6 & 12 & 30 & 18 & 12 & 30 \\
\hline
\end{tabular}

Table 5 - Batch reactor tests to be conducted with new resids

\begin{tabular}{|c|c|c|c|c|c|c|c|}
\hline \multirow[b]{2}{*}{ Resid } & \multicolumn{3}{|c|}{ Pressure } & \multirow[b]{2}{*}{ Tota } & \multicolumn{2}{|c|}{ Heating Rate } & \multirow[b]{2}{*}{ Total } \\
\hline & 15 & 30 & 40 & & Low & Medium High & \\
\hline Resid 7 & 2 & 1 & 2 & 5 & 3 & 2 & 5 \\
\hline Resid 8 & 2 & 1 & 2 & 5 & 3 & 2 & 5 \\
\hline Resid 9 & 2 & 1 & 2 & 5 & 3 & 2 & 5 \\
\hline Recycle 1 & 2 & 1 & 2 & 5 & 3 & 2 & 5 \\
\hline Recycle 2 & 2 & 1 & 2 & 5 & 3 & 2 & 5 \\
\hline Recycle 3 & 2 & 1 & 2 & 5 & 3 & 2 & 5 \\
\hline Total & 12 & 6 & 12 & 30 & 18 & 12 & 30 \\
\hline
\end{tabular}




\section{Micro Reactor Studies}

A screening model is a useful tool to quantify how other feedstocks and or combination of feedstocks will behave in a refinery. Results from the prior JIP show the micro reactor produced results that were scaleable to industry. However, this model was built using only three feedstocks and the range of several key parameters such as asphaltene content, MCR, recycle and metals $(\mathrm{Ni}, \mathrm{V})$ were not broad enough for a robust model. The micro reactor tests using the old and the new resid samples will generate new data for making enhancements to the existing screening model. They will provide a better understanding of the effects of metals, MCR, recycle and asphaltene content on the coking process. Parametric studies will be conducted using the three resids (Citgo, Chevron and Petrobras) that were not utilized in the parametric studies in the prior JIP. In addition, three new resids will also be run. These tests will be conducted at three temperatures $\left(900,910,930\right.$ and $\left.950{ }^{\circ} \mathrm{F}\right)$ and at pressures of 6,15 and 40 psig. The analytical program will be the same as in the previous JIP. The tests to be conducted are shown in Table 6 and Table 7 below.

Table 6 - Micro reactor test conducted with in-house resid

\begin{tabular}{|l|c|c|c|c|c|c|c|c|c|c|}
\hline \multirow{2}{*}{ Resid } & \multicolumn{3}{|c|}{6 PSIG } & \multicolumn{3}{c|}{15 PSIG } & \multicolumn{3}{c|}{40 PSIG } & \\
\cline { 2 - 13 } & $910^{\circ} \mathrm{F}$ & $930^{\circ} \mathrm{F}$ & $950^{\circ} \mathrm{F}$ & $900^{\circ} \mathrm{F}$ & $930^{\circ} \mathrm{F}$ & $950{ }^{\circ} \mathrm{F}$ & $900^{\circ} \mathrm{F}$ & $930^{\circ} \mathrm{F}$ & $950^{\circ} \mathrm{F}$ & Total \\
\hline Chevron & 1 & 1 & 1 & 1 & & 1 & 1 & 1 & 1 & 8 \\
\hline Citgo & 1 & 1 & 1 & & 1 & 1 & 1 & 1 & 1 & 8 \\
\hline Equilon & & & & 1 & & 1 & 1 & & 1 & 4 \\
\hline Suncor & 1 & & 1 & & & & 1 & & 1 & 4 \\
\hline Marathon & 1 & & 1 & & & & 1 & & 1 & 4 \\
\hline Petrobras & 1 & & 1 & 1 & & 1 & 1 & & 1 & 6 \\
\hline & & & & & & & & & & \\
\hline Total & 5 & 2 & 5 & 3 & 1 & 4 & 6 & 2 & 6 & 34 \\
\hline
\end{tabular}

Table 7 - Micro reactor tests conducted with new resids

\begin{tabular}{|l|c|c|c|c|c|c|c|c|c|c|c|}
\hline \multirow{2}{*}{ Resid } & \multicolumn{3}{|c|}{6 PSIG } & \multicolumn{3}{c|}{15 PSIG } & \multicolumn{3}{c|}{40 PSIG } & \\
\cline { 2 - 11 } & $910^{\circ} \mathrm{F}$ & $930^{\circ} \mathrm{F}$ & $950{ }^{\circ} \mathrm{F}$ & $900{ }^{\circ} \mathrm{F}$ & $930^{\circ} \mathrm{F}$ & $950^{\circ} \mathrm{F}$ & $900{ }^{\circ} \mathrm{F}$ & $930^{\circ} \mathrm{F}$ & $9500^{\circ} \mathrm{F}$ & Total \\
\hline & & & & & & & & & & & \\
\hline Resid 7 & 1 & 1 & 1 & 1 & 1 & 1 & 1 & 1 & 1 & 9 \\
\hline Resid 8 & 1 & 1 & 1 & 1 & 1 & 1 & 1 & 1 & 1 & 9 \\
\hline Resid 9 & 1 & 1 & 1 & 1 & 1 & 1 & 1 & 1 & 1 & 9 \\
\hline & & & & & & & & & & \\
\hline Recycle 1 & 1 & 1 & 1 & 1 & 1 & 1 & 1 & 1 & 1 & 9 \\
\hline Recycle 2 & 1 & 1 & 1 & 1 & 1 & 1 & 1 & 1 & 1 & 9 \\
\hline Recycle 3 & 1 & 1 & 1 & 1 & 1 & 1 & 1 & 1 & 1 & 9 \\
\hline & & & & & & & & & & \\
\hline
\end{tabular}




\section{FACILITIES}

The coking test facilities consist of 3 reactors or cokers and eleven utilities. The microcoker was supplied by the U.S. Department of Energy (U.S. DOE). The batch-coker reactor, also supplied by U.S. DOE, required construction of the heating, control, and product gathering systems. The operational pilot-coker, that utilizes a 3 foot drum, was obtained from Equilon in exchange for membership. The University expanded this facility to a six foot drum with a gamma densitometer to study foaming. The utilities include an on-line gas chromatograph and caustic scrubber from Equilon; house air and nitrogen; a University of Tulsa glycol chiller, purchased steam generator, hydrogen sulfide monitors and sample storage refrigerators; and donated vent hood and oven. The three cokers and associated utilities are described below.

\section{Micro Reactor}

The micro-reactor is shown in Figure 1 . It consists of a syringe pump with stirrer, preheater, (corresponding to the commercial furnace), a coke drum with liner, three cooled liquid traps, a wet-gas test meter, and an on-line GC. The first cooled liquid trap is metal and the following two are glass. The first trap collects the majority of the liquid. Potential leaking between the glass joints limited the operating pressure of the micro-reactor as described and shown. Higher pressure is desirable to match refinery-operating conditions. Also foaming occurred in the pilotcoker coke drum when processing Equilon feed at the low pressure. For these two reasons and since the majority of the liquid was captured in the metal trap, a modified micro-coker set-up was developed. In this modified set-up the glass traps were removed and replaced by a single piece of metal tubing.

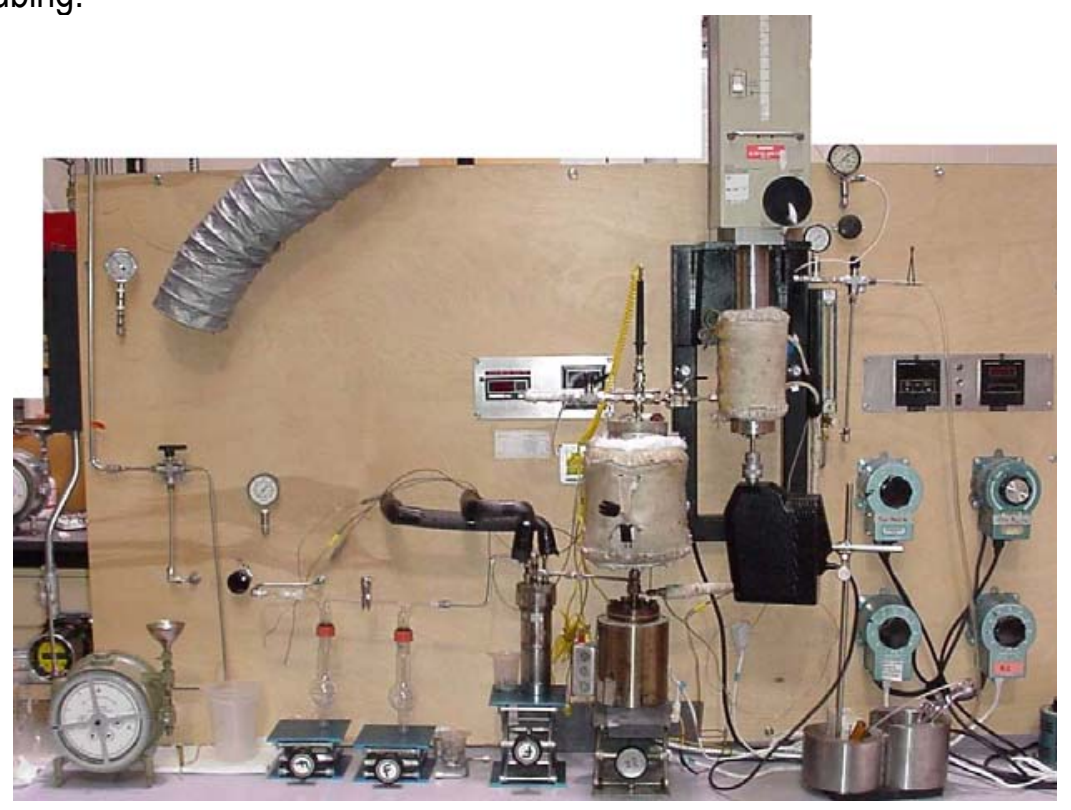

Figure 1 - Picture of Micro-Coker 
The main objectives for utilizing this reactor are to:

1. Reproducibly mimic commercial operation for a very short time, producing small quantities of coke, liquids and gases for testing,

2. Investigate and correlate the effect of feedstock composition and to a lesser extent pressure, temperature and residence time on product rates and compositions and on coke morphology,

3. Develop and validate a model(s), and

4. Investigate scale-up issues.

\section{Micro Reactor Upgrades}

To better monitor the micro-reactor and improve its functionality, upgrades to the system were made. These upgrades improved the assembly/disassembly time as well as the amount of data acquired and the process in which it is gathered. A picture of the modified micro-coker is shown in Figure 2.

During the first facility-testing phase of the micro-reactor, it was found that the gas recoveries were excessively high compared to pilot runs. The cause is considered in three phases. The vapor line pressure gauge was giving false (high) readings; this resulted in a highstandardized volume of gas. The absence of a carrier gas caused the vapors to become virtually stagnant at the beginning and end of each run, resulting in over cracking. The micro-reactor operating temperature was the furnace temperature, instead of an internal liquid temperature used in the pilot unit. This meant that the internal liquid temperature was lower. The lower internal temperature allows the liquids that are produced to sit in the reactor longer, extending cracking time. In response to these problems, a pressure transducer and digital pressure gauge was installed to measure the gas pressure more precisely, carrier gas flow is maintained even during the run to push off the stagnant vapors out of the reactor, and the run temperature is now controlled by an internal thermocouple at the bottom of the reactor. All the upgrades implemented are listed below:

1. New syringe pump housing is used to eliminate the stirrer. There were no apparent benefits to keeping the stirrer while its presence extends clean-up time and adds error to the mass balance due to the feed leaking around the seals-multiple housings has improved turn around time,

2. Temperature control- Four new Eurotherm temperature controllers were installed to control the reactor heater, pre-heater, mantle and the heat tape before the pre-heater-this upgrade eliminated the fluctuations in the temperature profiles from run to run,

3. A pressure transducer and digital pressure gauge was installed to measure the gas pressure more precisely. Helium is being injected into the top of the reactor to increase the flow rate of the hydrocarbon vapors out of the reactor. Pre-run helium flow data is recorded and an average flow rate is backed out of the final wet test meter reading. It has since been determined that the helium carrier which was left running over night was causing the evaporation of some of the liquids in the primary trap. The helium is now turned off at the end of each run and the system is being isolated to prohibit this evaporation. As a result the gas yields made a sizable decrease and were more consistent and comparable to the gas yields seen in the pilot unit.

4. Thermocouples- to improve correlations and comparisons to pilot unit data. 
a) Thermocouple well was installed in reactor head to hold thermocouple that reads top, middle and bottom reactor temperature,

b) Thermocouple was installed to read temperature of the vapors leaving the reactor,

c) Thermocouple was installed to read temperature of the vapors leaving the primary liquid trap,

A typical temperature profile inside the drum for the new runs using modified micro-coker equipment is shown in Figure 3.

5. Pulse meter installed on wet test meter for computer data acquisition, and

6. Labview software for system controls and data acquisition (T's, P's and flows).

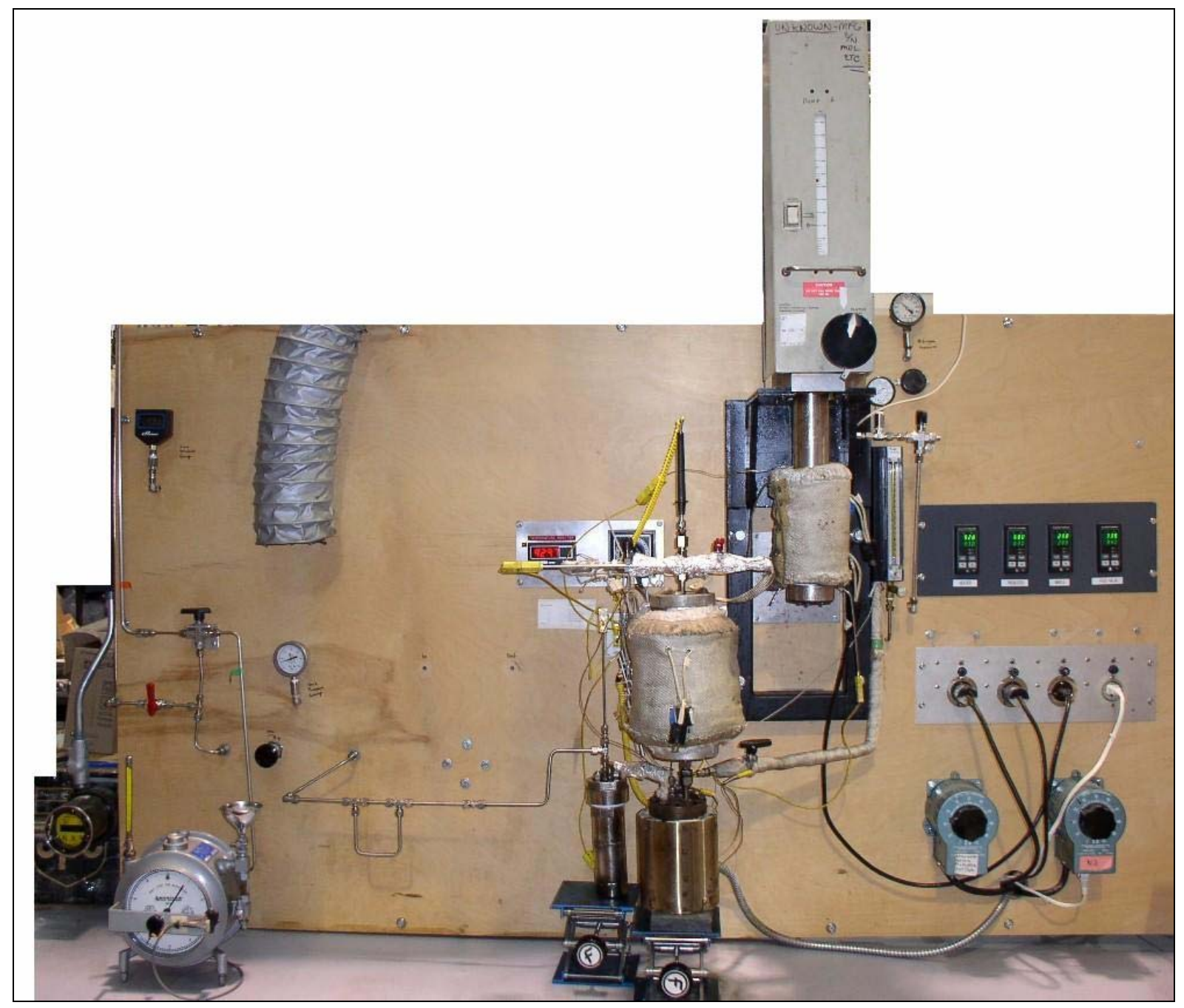

Figure 2 - Picture of Modified Micro-Coker 


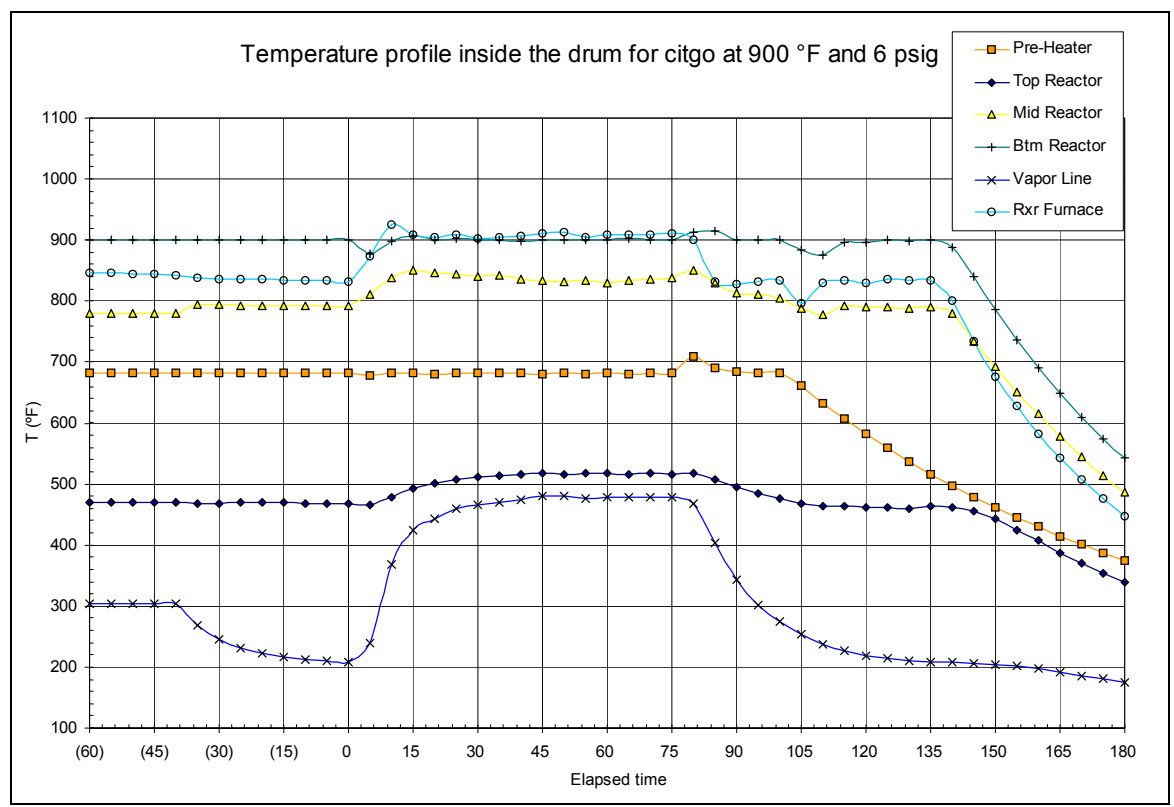

Figure 3 - Temperature profiles inside the drum

\section{Glass Cokerr}

Glass coker feasibility studies were conducted during the first quarter of 2005 using a $250 \mathrm{ml}$ glass flask. The results of the tests were presented during the May 2005 advisory board meeting. The following is a summary of the results presented:

1) Warm-up Phase: At a constant power output, the resid is heated until it reaches $600 \mathrm{oF}$ and is allowed to stabilize.

2) Steady State Phase: During this period of the run, with a constant increment in power, we see a uniform heating of the different resids. As the bottom temperature reaches $800 \mathrm{oF}$ and remains there for the next 30-40 minutes. A certain lag is observed in the middle temperature compared to the bottom temperature, as the middle temperature reaches the steady state approximately 10 minutes later into the run.

3) Black Splashing: A phenomenon of black splashing is observed during the steady state phase; the time of occurrence varies with different resids. It is observed that with shot producing resids, the black splashing is more prominent as compared to sponge producing resids. Also, the black splashing associated with shot producing resids; tend to coat the walls of the flask with black material, whereas with sponge coke producing resids, the flask remains clear until the foam over point.

4) Foam Over Phase: During this phase foam over occurs with different colors of fumes observed with different resids. When the foam over occurs, the bottom temperature rises from $800 \mathrm{oF}$ and crosses the 1000 of point within a couple of minutes. The flask along with the side arm is filled with foam over material. It is observed that the pure sponge making resids take longer to foam over compared to shot making resids. Marathon and Petrobras resids both produced pure sponge coke; it took them an additional 15 to 20 minutes to foam over compared to other resids. 
Based on the above results, a decision was made to enhance and continue the glass coker testing by using a larger glass flask and incorporating it into the existing micro coker system. The specifications of the new glass coker system are shown below. The purpose is to observe the foaming phenomenon with different resids and capture the foam bubble size to be used in the foaming model. The new system will enable us to operate the system with batch, semi-batch and continuous feed injection. The heating mantle has four viewing windows that will be used to observe and capture the foaming phenomenon via high speed cameras. The system is capable of generating ancillary gas data via the wet test meter and the online gas chromatograph. The liquid collection system consists of a primary trap and a secondary trap.

\section{Specifications of the new glass coker system:}

1) Customized Glass Flask:

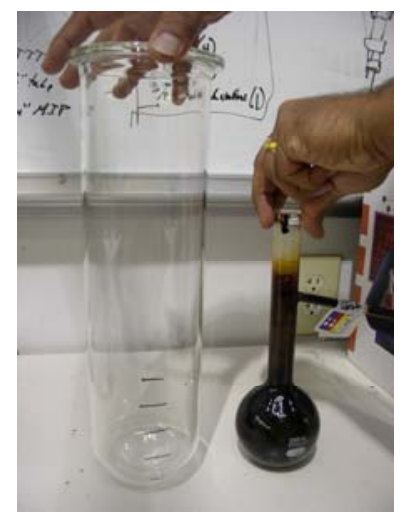

Outside diameter: 3.93 inch;

Thickness: 0.1377 inch;

Inside diameter: 3.66 inch;

Outside height: $14.5 \mathrm{inch}$;

Inside height: 14.36 inch;

Figure shows the old $250 \mathrm{ml}$ glass flask and the new customized glass flask.

2) Customized Heating Mantle:

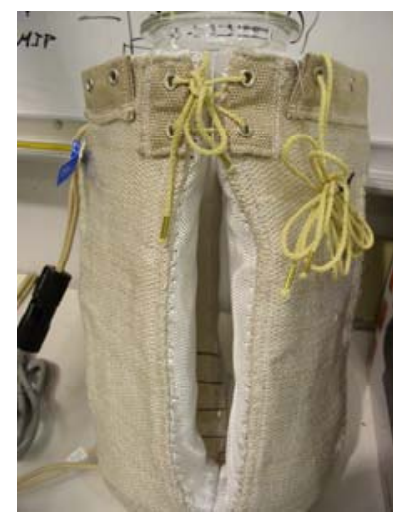

Mantle dimensions: 3.9375 inch inside diameter x 13.5 inch deep with rounded bottom;

Thickness: 2 inch;

Watts: 2 circuits with a total of 1500 watts;

Viewing windows: Four viewing windows, three at 1 inch $\times 8.5$ inch and one at 1.5 inch $\times 8.5$ inch;

Figure shows the new customized heating mantle with viewing windows to observe the foaming phenomenon.

3)Thermocouple:

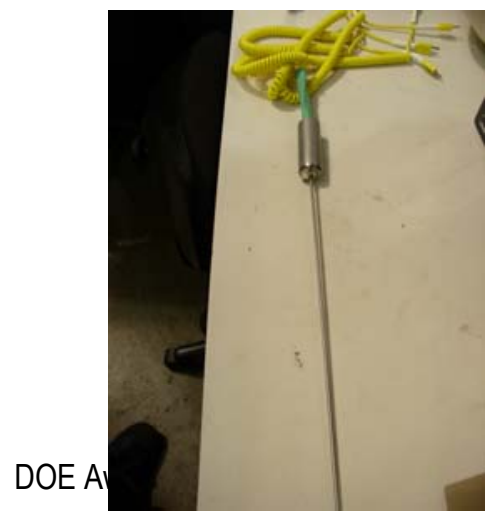

5 point type "K" thermocouple with point 1 at the bottom (tip) and the rest every 3 inches from bottom towards the top of the flask will be used to measure temperature along the height of the flask. Figure shows the 5 point thermocouple to be used with the new glass coker system. 


\section{Stirred Batch Reactor}

The stirred batch reactor unit is shown in Figure 4. It consists of a stainless steel cylinder, 13 inches tall and 11 inches outside diameter, with flanged lid. An 8"x 9.5" stainless steel liner that holds the feed and the coke product is placed inside the reactor. In addition, an impeller, for mixing and better heat transfer, is mounted on an overhung shaft and is situated two inches from the bottom. The shaft is driven by a 3-phase motor, which is controlled by an AC inverter for variable speed. The reactor is heated from the outside by two Mica band heaters. Other auxiliary equipment include: two gas-liquid separators, a blowdown tank, a cooler, a gas flowmeter, temperature controllers, and a back-pressure regulator.

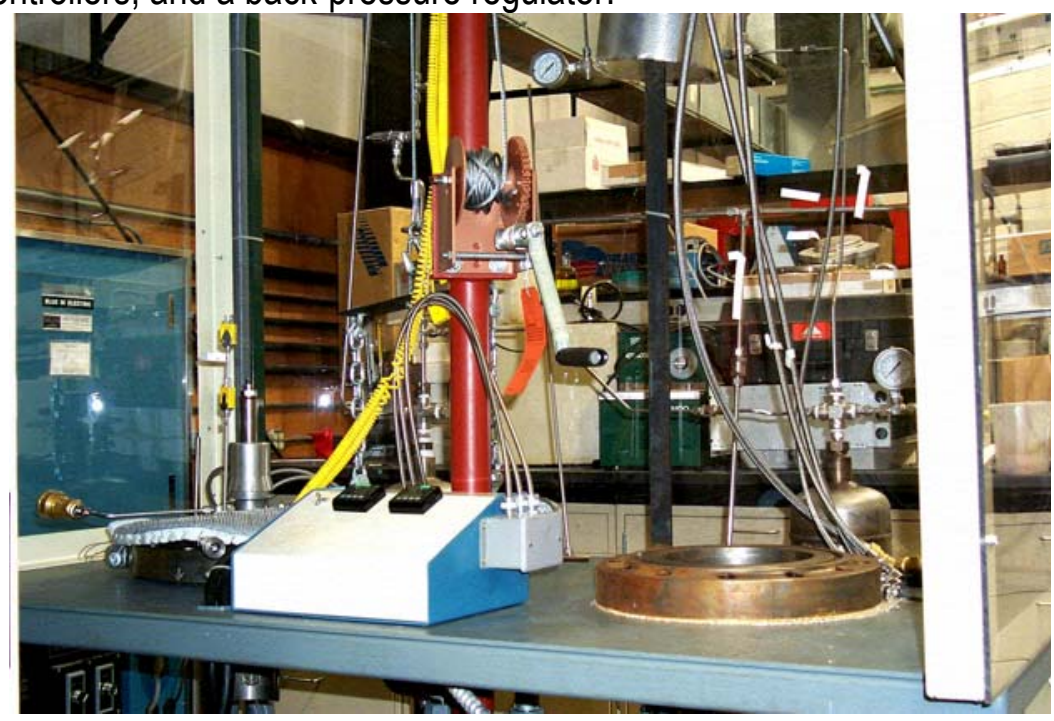

Figure 4 - Stirred Batch Reactor Unit

The main objectives for utilizing this reactor are to:

1. Identify the coke precursors,

2. Study heat rate effect on yields (simulate furnace tube), and

3. Study the kinetics of the thermal cracking reactions.

A hot resid sample is placed inside the liner. The band heaters heat this reactor and liner. To homogeneously heat the feed, the stirrer is rotated at a predetermined shaft speed. Unless there are two phases that cannot be mixed, the mixing effect also helps obtain a homogeneous composition of the contents of the reactor. The system is purged and pressurized with nitrogen to the desired test pressure. Also, the nitrogen displaces the vapor and gases remaining in the system at the end of the run.

During the test, processed resid samples are drawn from the reactor to identify the coke precursors. Since the samples are viscous or solid at room temperature or at a temperature lower than their sampling temperatures, they have to be set in the oven overnight and collected in a 20 $\mathrm{ml}$ sample jar. These samples then are analyzed using the high temperature gas chromatograph (HTGC) that can cover up to n-C100-n-C110 ( 1330 $\left.{ }^{\circ} \mathrm{F}\right)$. 
The vapor from the reactor flows to the gas-liquid separator that is wrapped with a steam coil. Approximately 80 \# steam, $250^{\circ} \mathrm{F}$, is used to cool the hot vapor. Gas that is not condensed flows to a cooler, which uses $37^{\circ} \mathrm{F}$ water as a coolant. Liquid from this cooling process is collected in a second gas-liquid separator. The liquid samples are collected using eight receivers (4 for the lights and 4 for the heavies) with quick disconnect fittings. Using the quick disconnect fittings eliminated the need to close the valves during the test. The receivers are connected and disconnected during the test to collect the different condensate batches. The gas trapped with the

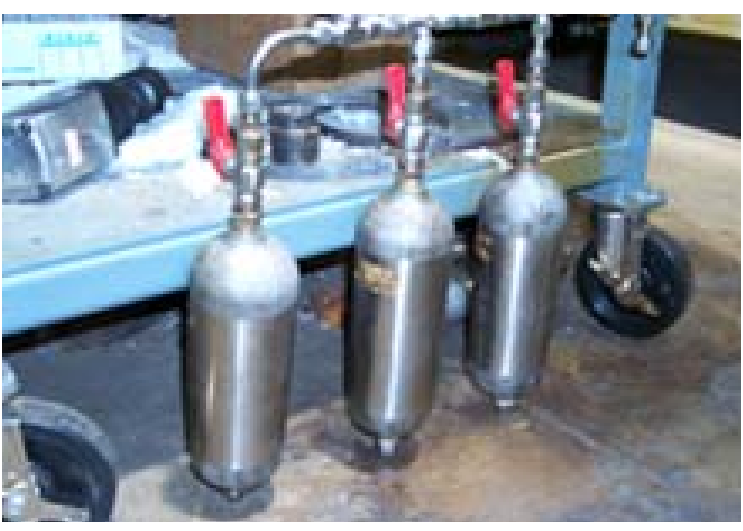

Figure 5 - Liquid collection system with Hoke cylinders and quick disconnect valves liquid is taken into account. The liquid and the gas are weighed in the receiver, then the liquid is weighed alone and the differences in weights, i.e. receiver, liquid, and gas, give the mass of the gas. This gas is assumed to have the same composition as the gas analyzed in the GC during the liquid collection period. This system is shown in Figure 5.

The remaining gas flows to a gas flowmeter and then to the online GC. A back- pressure regulator before the flowmeter maintains the system at the desired pressure.

\section{Stirred Batch Reactor Upgrades - Quarter 4, 2002 \& Quarter 1, 2003}

Upgrades to the batch reactor were made. The upgrades were focused on removing operator error in system functions and data acquisition and improving the system functionality. Limiting operator involvement will improve data reproducibility as well as increase time available for liquid sampling. The revised list of upgrades and the status of each upgrade is listed below.

1. The band heaters used in the old runs were run at the upper limits of voltage input causing early failure and limiting control. A new $11 \mathrm{~kW}$ ceramic heater was installed to eliminate this problem, see Figure 6 ,

2. The reactor was machined down from a 1.2 inch wall thickness to a 0.6 inch wall thickness to improve temperature control,

3. Thermocouples - see Figure 7

a. A thermocouple was installed to read temperature of vapors leaving reactor,

b. Thermocouples were installed to monitor reactor process temperature,

c. Thermocouples were installed to monitor furnace element temperature for the purpose of a high temperature shutoff,

d. Four thermocouples were installed in the reactor head at various heights from the bottom of the reactor. This gives a temperature profile inside the drum.

4. The hydrocarbon liquid collections system was automated, see Figure 8

a. The light and heavy hydrocarbon liquids are split into 12 tanks each (increased from 4 each)

b. The heavy tanks were fitted with dip tubes that allow a pressure differential indicator to measure the height of the liquid in the drums. 
c. Labview software is used to control two separate solenoid/pilot actuated manifold systems that step through the series of tanks as they fill. The tank stepping is controlled by the height of the liquids in the heavies tanks, the temperature of the resid in the reactor and time elapsed,

5. A computer bypass switching system was installed for emergency and cleaning purposes, see Figure 9,

6. A pressure transducer was installed to measure the vapor line pressure for improving gas yield calculations,

7. A pulse meter was installed on the wet test meter for acquisition of gas volume, see Figure 10 ,

8. Labview software that is used for system controls and data acquisition(T's, P's and flows), see Figure 11 and Figure 12

The Labview tank switching controls and data acquisition functions are in working order. The three variables for switching - time, temperature and liquid level - have all been tested. Each variable was tested individually by adjusting the set points for each tank and visually verifying that the next tank in sequence was activated. All three variables were then turned on simultaneously to verify that any of the three variables reaching its set point would cause a tank switch. For the case where an inadvertent switch occurs during operation, a tank increment and decrement switch was installed on the tank switching page in Labview, see Figure 12. For emergency and cleaning purposes a computer bypass switching system was installed. This switching system allows the operator to manually step through the series of tanks, see Figure 9 and Figure 13. 

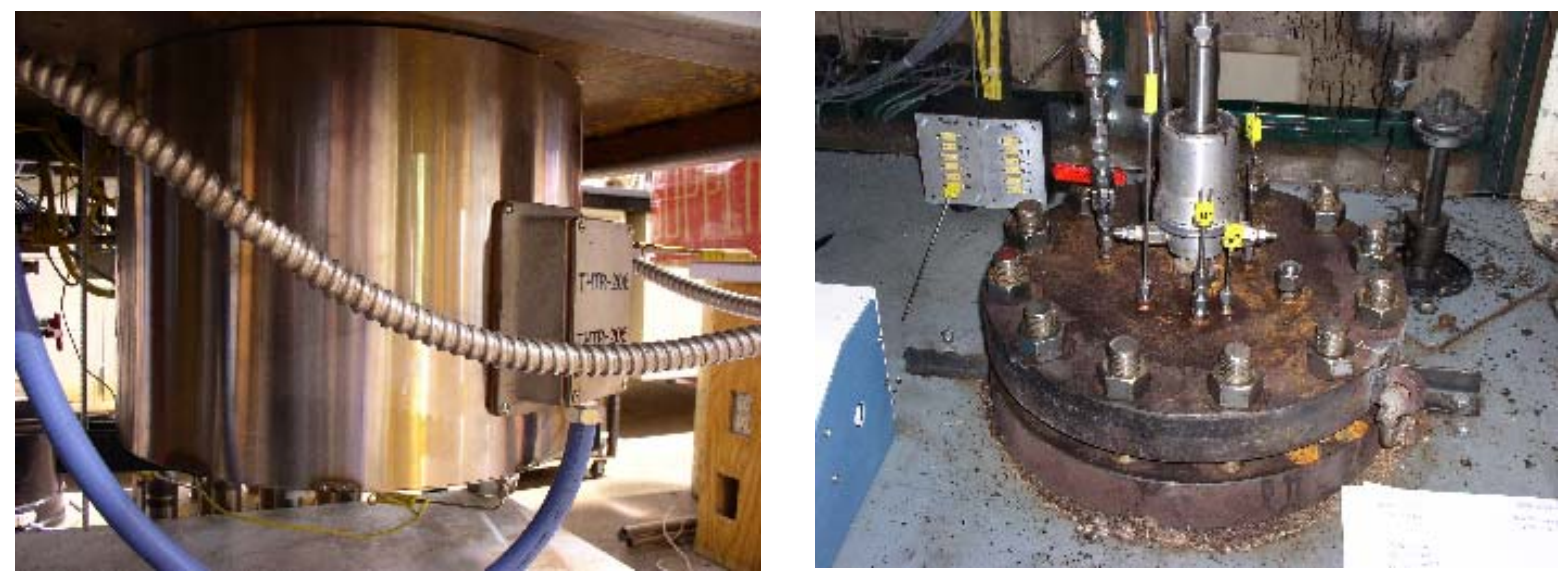

Figure 6 - Batch Reactor Furnace

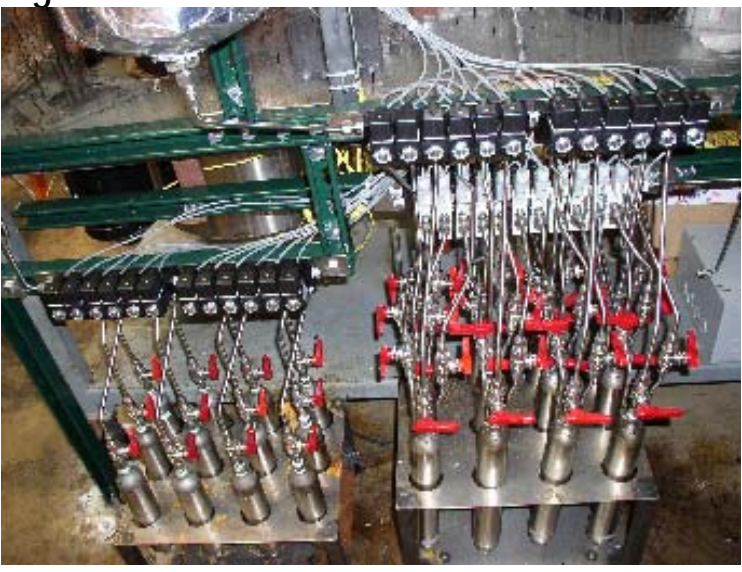

\section{Figure 7 - Batch Reactor Head}

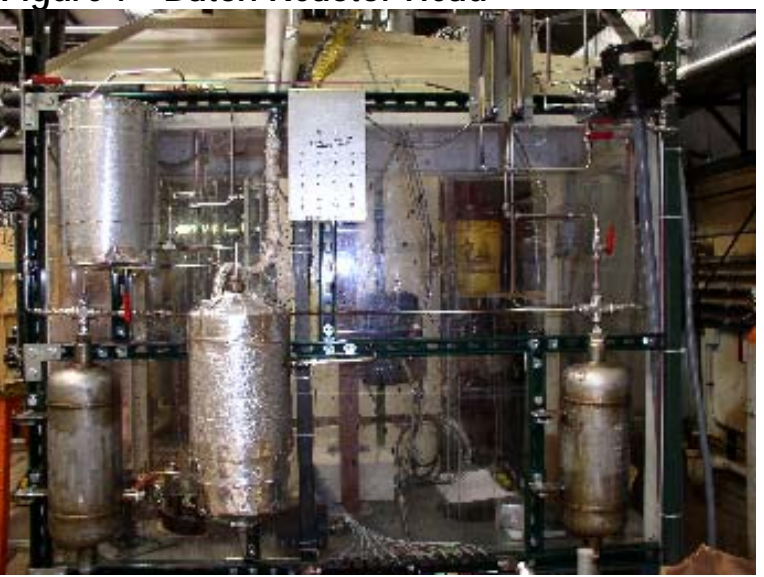

Figure 8 - Batch Reactor Manifold

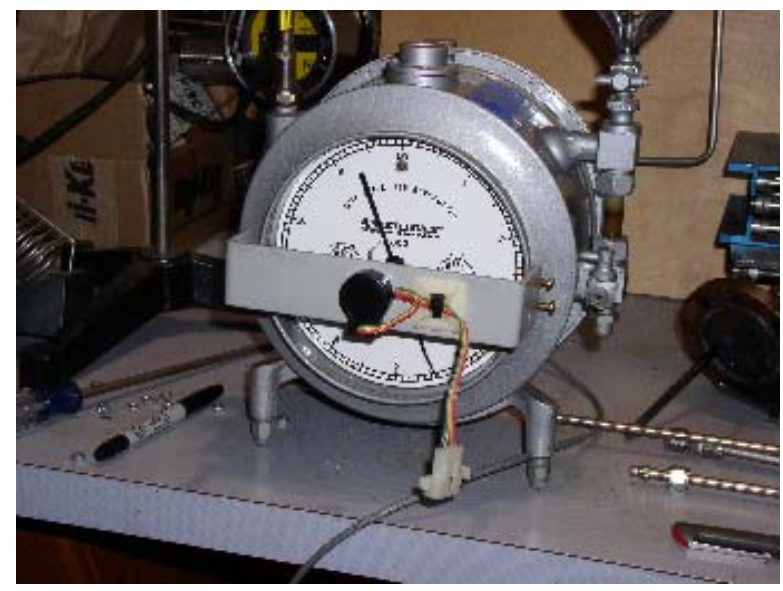

Figure 9 - Batch Reactor Tanks and Bypass Switching System

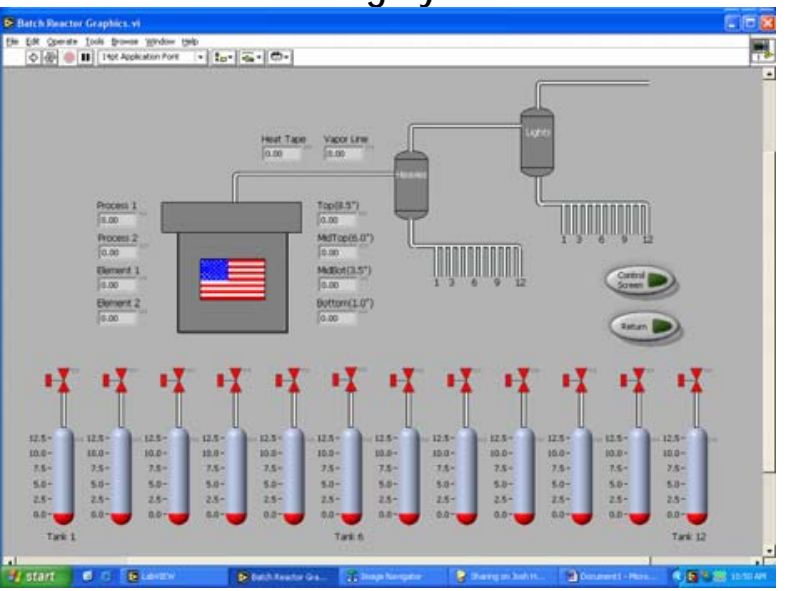

Figure 10 - Batch Reactor Wet Test Meter

Figure 11 - Batch Reactor Labview 


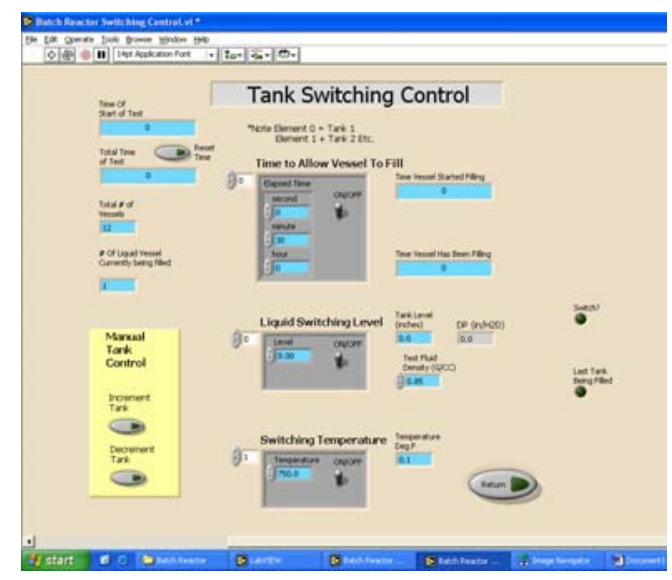

Figure 12 - Batch Reactor Labview

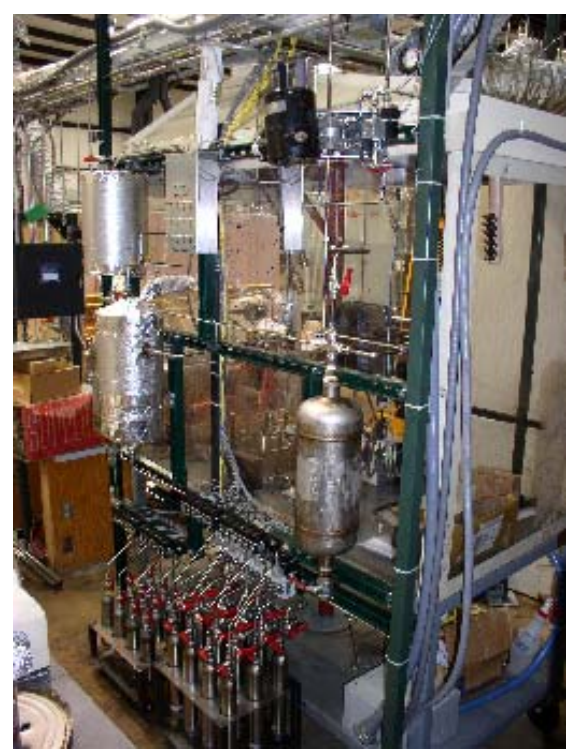

Figure 13 - Batch Reactor Back Side View

\section{Sample Tube Upgrades}

The old sampling tube was very cumbersome. It required many valves, attached nitrogen lines to purge resid from inserted tube and time to take each sample. The old sample tube can be seen in Figure 14. The new sample tube consists of a $1 / 2$ " diameter compression chamber between two valves and a collection tube that is inserted into the reactor, see Figure 15. The sample tube uses the pressure in the system to force the feed into the sample tube, compressing the gases above. The size of the compression chamber was calculated using a desired sample size of 30 $\mathrm{mL}$. The pressure of most of the batch runs will be approximately 3.72 atmospheres (40 psig). The gases in the compression chamber before the bottom valve on the sample tube is opened are assumed to be one atmosphere. Thus, the compression chamber volume must be approximately 1.27 times the desired sample volume.

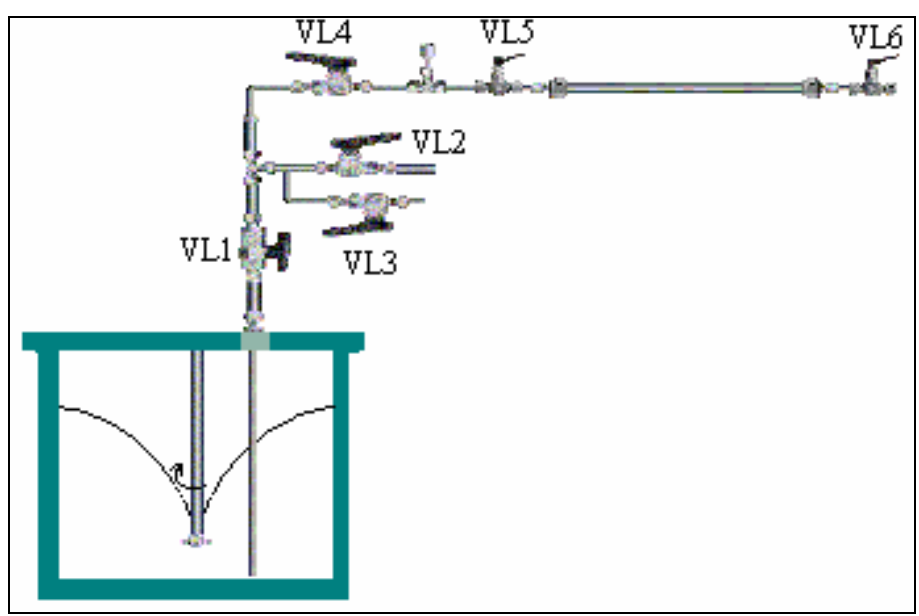

Figure 14 - Old Batch Sample Tube Assembly 
The collection tube was designed in two pieces. The bottom portion is $1 / 4$ " tubing and the top portion is $3 / 8$ " tubing. The two piece design was used because the $3 / 8$ " tubing holds more sample, minimizing the length of the assembly. The collection tube was oversized to allow a small head space between the sample and the bottom valve. Thus, the losses from each tube are limited to approximately $\$ 10$ worth of tubing and ferrules.

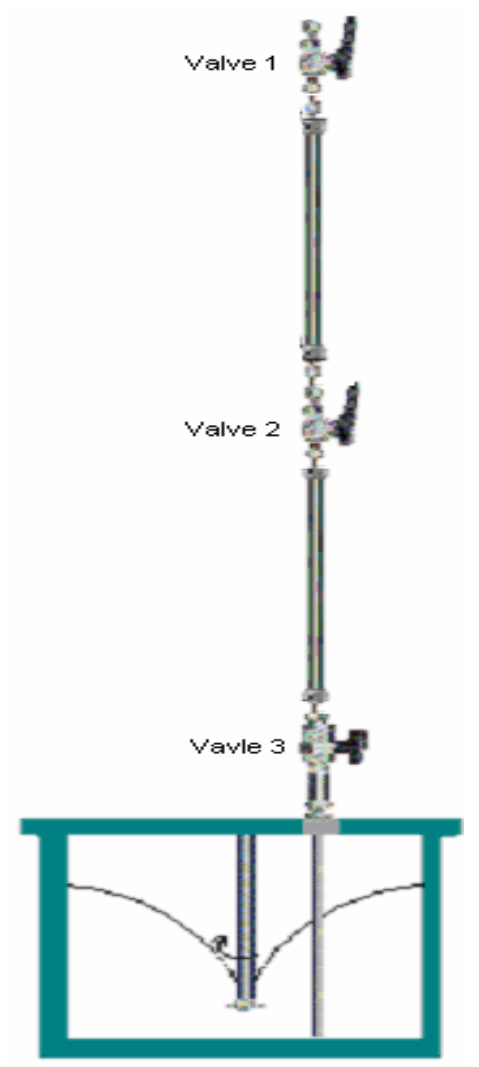

Figure 15 - New Batch Sample Tube Assembly

The new sample tube assembly was first tested with ambient water and hot oil. The tubes consistently drew $25-30 \mathrm{ml}$ of sample, over a series of eight attempts. A vent line has since been added to the new sample tube assembly above the valve at the bottom of the compression chamber. It was added to prevent any compressed gases above the sample from forcing the sample out of the tube after it is removed from the reactor. The new sample assembly has since been tested in the Marathon recycle facility testing runs. In a series of three facility testing runs, $20+$ grams of sample was taken in each attempt.

\section{Pilot Unit Equipment}

The pilot coker can be viewed as two main pieces: the process equipment and the control system. In the section below each piece is described. 


\section{a. Process Equipment Description}

The pilot-coker obtained from Equilon Enterprises, LLC is shown in Figure 16. It consists of a feed tank and circulation system, and a furnace with both the preheater and the coke drum. The feed drum holds approximately 15 gallons and is mounted on a scale. Feed passes from the outlet of the drum, goes to a Zenith pump (see Figure 17) with some return flow back to the feed drum. All the lines are steam traced. From the pump, the resid can flow back to the feed tank, to a slop tank or to the furnace. Initially the flow is back to the feed tank to circulate feed and stabilize the temperature. Once the unit is lined out the feed can be switched to a slop tank to check the flow rate (based upon the loss of weight measured by the scale).

When the rate is correct, flow is sent to the furnace. In the furnace are first a preheater coil (mimicking the commercial furnace) followed by a coke drum. The coke drum, with dimensions of 3" x 40" and a volume of $\sim 4,750 \mathrm{cc}$, is located in the furnace to prevent heat loss. Commercial coke drums are well insulated and have a high volume-to-surface area ratio, making them adiabatic. To simulate commercial steam injection water is injected upstream of the preheater coil. Operating variables include temperature, pressure, steam injection rate, and charge flow rate. The latter two variables affect residence time and Reynolds number.

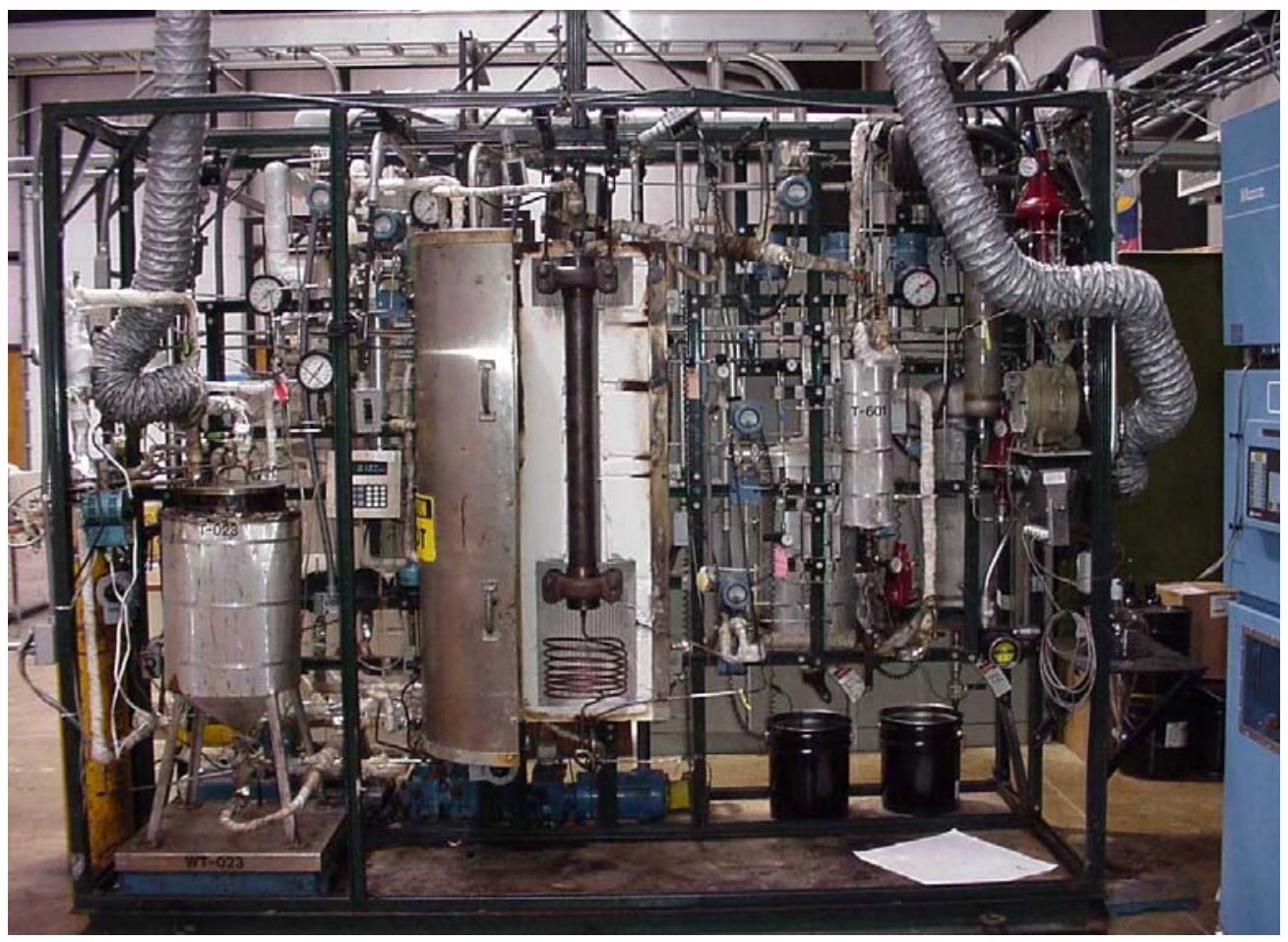

Figure 16 - Picture of Pilot-Coker Unit

The main objectives for utilizing this reactor are to:

1. Reproducibly mimic commercial operation producing sufficient quantities of coke, liquids and gases for testing, 
2. Investigate and correlate the effect of feedstock composition and reactor conditions on product rates \& compositions and coke morphology,

3. Maximize distillate product production and minimize coke and gas production,

4. Find ways to reduce tube fouling,

5. Develop and validate a model(s), and

6. Investigate scale-up issues.

This reactor is the workhorse in this Joint Industry Project (JIP) experimental investigation.

\section{b. Control System Description}

The control system includes an electrical control box, a cabinet that houses the Foxboro field bus modules (FBM's), a Foxboro $\mu$-IA controller, and Foxboro's Softpack 6.1 control software for NT installed on a $450 \mathrm{MHz}$ Pentium 2 computer (see Figure 18 \& Figure 19). The control logic is built on top of the Softpack utilities. The University bought the $\mu$-IA from Foxboro and Foxboro donated the Softpack 6.1 software.

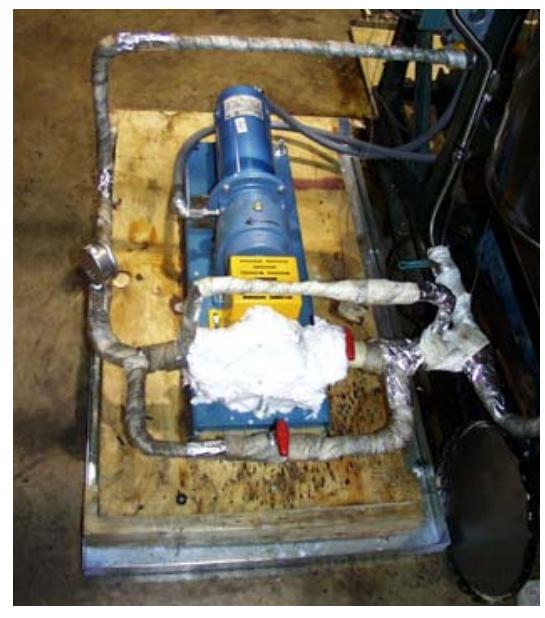

Figure 17 - Zenith pump for pilot-coker

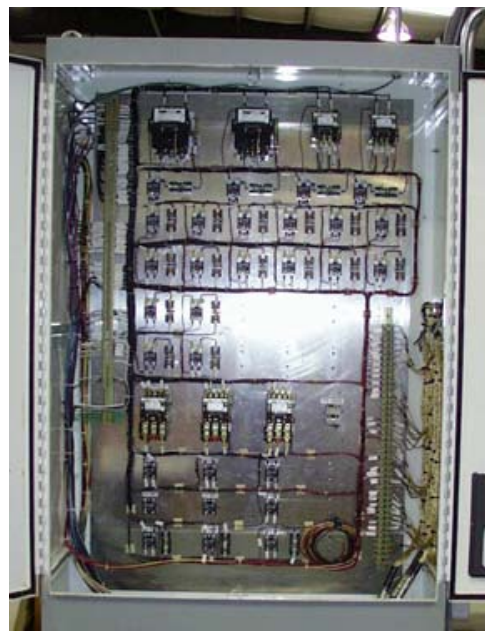

Figure 18 - Electrical control box

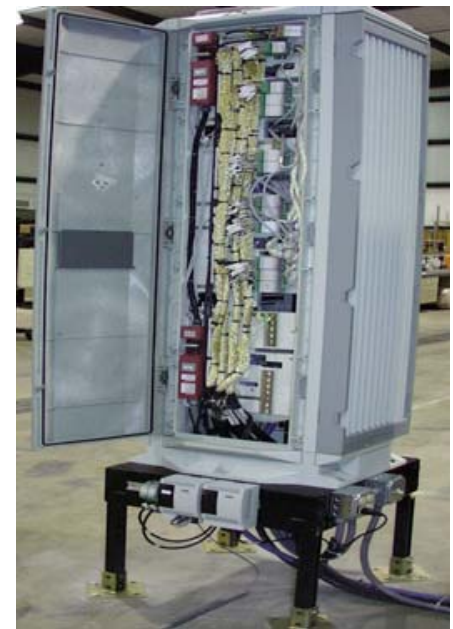

Figure 19 - Foxboro field bus module cabinet and a Foxboro -IA controller mounted on the bottom

\section{Foaming Studies Apparatus}


As shown in Figure 20, the pilot unit was modified to study foaming by adding two larger furnaces, two gamma densitometers and two lifts. The gamma densitometers are used to measure the density of the gas, foam, liquid layer, and coke columns in the drum. The data, as a function of height is displayed on the control monitor for each scan. Time, drum location and the corresponding density are recorded in an Excel spreadsheet. A Macro was built that plots the data as height vs. density as a function of time and density as a function of time vs. height in the drum. This set up allows the researchers to establish and track, via the forklift, the interfaces and densities as a function of time. The system was automated with a Labview control system.

To obtain a continuous flow of steam, the pulsating pump used in the parametric study was replaced with the HPLC pump that injects continuously. The antifoam is injected using an Eldex Metering Piston pump.

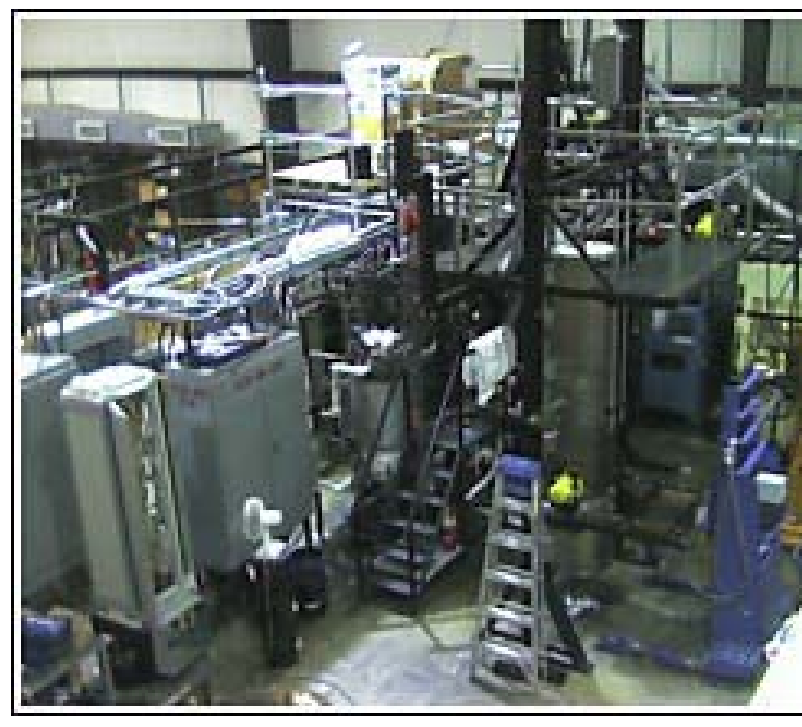

Figure 20 - New foaming studies apparatus

\section{a) Facilities to inject carrier fluids and} antifoaming agent

As shown in Figure 21, the carrier fluid and antifoam are stored in a calibrated burette to measure the amount of fluid being feed to the antifoam pump. The system is manifolded with a valving system such that the antifoam can be injected overhead or into the feed line. The pump can inject the antifoam/carrier mixture from very low rates to a rate of $600 \mathrm{cc} / \mathrm{hr}$.

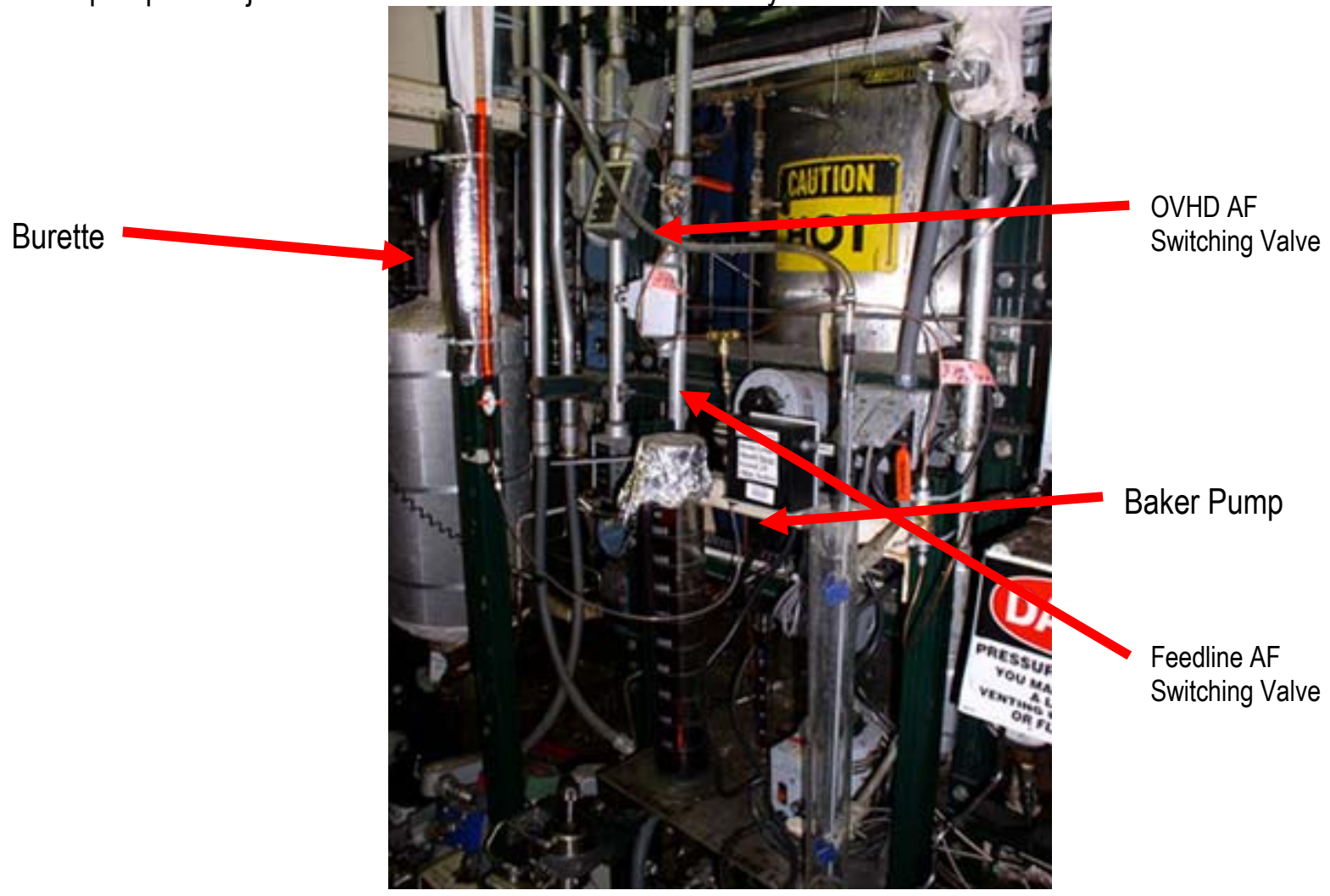




\section{Figure 21 - Injection Antifoam}

The objectives of this system are:

1. Quantify foam heights for model development,

2. Compare overhead injection of antifoam versus injection with feed,

3. Determine how antifoam partitions in the products,

4. Establish whether injection of antifoam in the feed alters the coke density, and

5. Longer coking runs (10 to 15 hours at feed rates used in the prior JIP).

b) Quench Water Injection Facilities

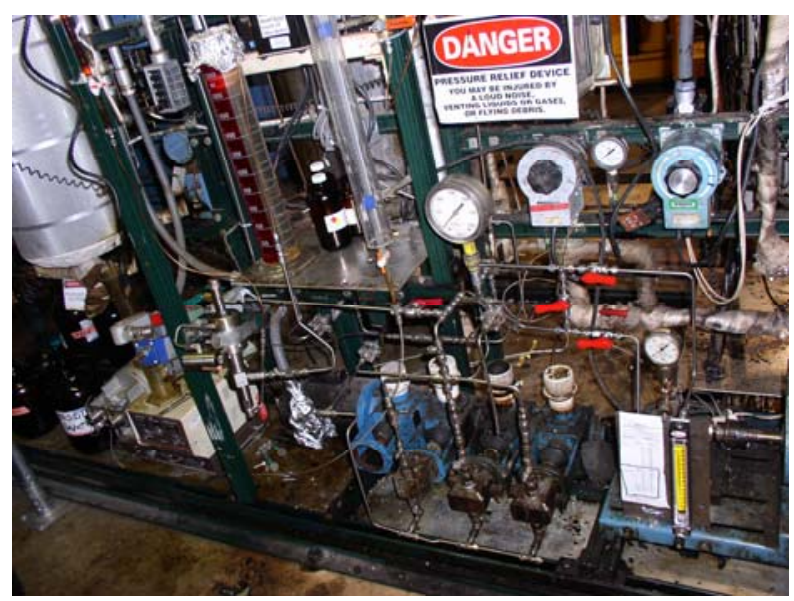

Figure 22 - Water Injection Facilities

\section{Utilities}

The utilities include an on-line gas chromatograph and caustic scrubber from Equilon, plus an ASTM distillation unit, a HP 5890, HP 6890 HTGC, house air and nitrogen; a University of Tulsa glycol chiller, purchased steam generator, hydrogen sulfide monitors, two freezer; and donated vent hood and oven. 
The University of Tulsa

\section{Micro Reactor Studies}

\section{A. SHAKEDOWN TESTS}

During the first facility testing phase of the micro coker, it was found that the gas recoveries were excessively high compared to pilot runs. The cause is considered three phase.

1. The vapor line pressure gauge was giving false (high) readings; this resulted in a high standardized volume of gas.

2. The absence of a carrier gas caused the vapors to become virtually stagnant at the beginning and end of each run, resulting in over cracking.

3. The micro-coker operating temperature was the furnace temperature, instead of an internal liquid temperature used in the pilot unit. This meant that the internal liquid temperature was much lower. The lower internal temperature allows the liquids that are produced to sit in the reactor longer, extending cracking time.

In response to these problems, the run temperature is now controlled by an internal thermocouple at the bottom of the reactor. A pressure transducer was installed to measure the gas pressure more precisely and helium was injected into the top of the reactor to increase the flow rate of the hydrocarbon vapors out of the reactor. Pre-run helium flow data was recorded and an average flow rate was backed out of the final wet test meter reading. It was then determined that the helium carrier which was left running over night was causing the evaporation of some of the liquids in the primary trap. The helium is now being turned off at the end of each run and the system is being isolated to prohibit this evaporation. The gas yields have since made a sizable decrease and are more consistent and comparable to the gas yields seen in the pilot unit. The shakedown runs are listed in Table 8.

The majority of these runs were completed with the old temperature control system and no helium carrier. These runs were rerun with the internal thermocouple as the run temperature controller. The results are presented in the next section. 
Table 8 - Micro Coker Yields

\begin{tabular}{|c|c|c|c|c|c|c|c|c|}
\hline Test & & $T$ & $\mathbf{P}$ & & Feed rate & & & \\
\hline Number & Date & $\mathbf{T}(\mathbf{F})$ & $P(p s i g)$ & CCR values & (g/min) & liquid $\%$ & coke $\%$ & gas $\%$ \\
\hline PETMR-4 & 9/19/2002 & 910 & 6 & 20.7 & 1.82 & $60.92 \%$ & $26.39 \%$ & $12.69 \%$ \\
\hline PETMR-5 & $9 / 24 / 2002$ & 950 & 6 & 20.7 & 2.01 & $61.41 \%$ & $25.00 \%$ & $13.59 \%$ \\
\hline PETMR-6 & $9 / 26 / 2002$ & 900 & 15 & 20.7 & 2.18 & $58.10 \%$ & $29.54 \%$ & $12.36 \%$ \\
\hline PETMR-10 & $10 / 31 / 2002$ & 930 & 6 & 20.7 & 2.16 & $64.01 \%$ & $23.98 \%$ & $12.01 \%$ \\
\hline PETMR-11 & $11 / 5 / 2002$ & 930 & 6 & 20.7 & 2.06 & $64.51 \%$ & $24.59 \%$ & $10.90 \%$ \\
\hline PETMR-12 & $11 / 7 / 2002$ & 930 & 6 & 20.7 & 2.13 & $64.20 \%$ & $24.71 \%$ & $11.10 \%$ \\
\hline PETMR-14 & $11 / 14 / 2002$ & 930 & 6 & 20.7 & 2.17 & $61.33 \%$ & $25.54 \%$ & $13.13 \%$ \\
\hline PETMR-18 & $12 / 4 / 2002$ & 930 & 6 & 20.7 & 1.96 & $60.67 \%$ & $26.16 \%$ & $13.16 \%$ \\
\hline PETMR-21 & $12 / 16 / 2002$ & 900 & 40 & 20.7 & 2.04 & $57.07 \%$ & $29.55 \%$ & $12.98 \%$ \\
\hline PETMR-22 & $12 / 18 / 2002$ & 900 & 15 & 20.7 & 2.07 & $61.09 \%$ & $27.13 \%$ & $11.78 \%$ \\
\hline PETMR-23 & $12 / 19 / 2002$ & 900 & 6 & 20.7 & 2.10 & $62.51 \%$ & $25.62 \%$ & $11.87 \%$ \\
\hline PETMR-26 & $1 / 7 / 2003$ & 900 & 15 & 20.7 & 2.17 & $61.99 \%$ & $27.85 \%$ & $10.16 \%$ \\
\hline SUNMR-15 & $9 / 4 / 2002$ & 910 & 6 & 20.2 & 2.14 & $54.40 \%$ & $31.60 \%$ & $14.00 \%$ \\
\hline SUNMR-16 & $9 / 10 / 2002$ & 950 & 6 & 20.2 & 1.77 & $55.63 \%$ & $27.59 \%$ & $16.79 \%$ \\
\hline SUNMR-17 & 9/12/2002 & 910 & 40 & 20.2 & 2.07 & $49.62 \%$ & $33.79 \%$ & $16.59 \%$ \\
\hline SUNMR-18 & 9/17/2002 & 950 & 40 & 20.2 & 1.70 & $48.95 \%$ & $33.61 \%$ & $17.43 \%$ \\
\hline SUNMR-19 & $10 / 10 / 2002$ & 910 & 40 & 20.2 & 1.75 & $51.68 \%$ & $32.93 \%$ & $15.40 \%$ \\
\hline SUNMR-20 & $10 / 15 / 2002$ & 930 & 40 & 20.2 & 2.27 & $48.42 \%$ & $34.07 \%$ & $17.51 \%$ \\
\hline SUNMR-21 & $10 / 17 / 2002$ & 930 & 40 & 20.2 & 1.92 & $48.12 \%$ & $33.38 \%$ & $18.50 \%$ \\
\hline SUNMR-22 & $10 / 22 / 2002$ & 930 & 40 & 20.2 & 1.79 & $47.42 \%$ & $33.38 \%$ & $19.20 \%$ \\
\hline SUNMR-23 & $10 / 29 / 2002$ & 930 & 6 & 20.2 & 1.93 & $53.31 \%$ & $29.29 \%$ & $17.40 \%$ \\
\hline
\end{tabular}




\section{B. Parametric TeSt \& Recycle ReStS WITH IN-House ResidS}

\section{Test Results for In-house Resids:}

Tests were conducted at two temperatures $\left(900^{\circ} \mathrm{F}\right.$ and $\left.930^{\circ} \mathrm{F}\right)$ and at pressures of 6,15 and 40 psig. A summary of the tests to be conducted with the In-house Resids is shown in Table 9 below.

Table 9: Micro Reactor test completed with In-house Resid

\begin{tabular}{|c|c|c|c|c|c|c|c|c|c|}
\hline \multirow[b]{2}{*}{ Resid } & \multicolumn{3}{|c|}{$900^{\circ} \mathrm{F}$} & \multicolumn{3}{|c|}{$930^{\circ} \mathrm{F}$} & \multicolumn{2}{|c|}{$950^{\circ} \mathrm{F}$} & \multirow[b]{2}{*}{ Total } \\
\hline & 6 psig & 15 psig & 40 psig & 6 psig & 15 psig & 40 psig & 15 psig & 40 psig & \\
\hline & & & & & & & & & \\
\hline Chevron & 1 & 1 & 1 & 1 & 1 & 1 & 1 & 1 & 8 \\
\hline Citgo & 1 & 1 & 1 & 1 & 1 & 1 & 1 & 1 & 8 \\
\hline Equilon & 1 & 1 & 1 & 1 & 1 & 1 & 1 & 1 & 8 \\
\hline Marathon & 1 & 3 & 1 & 1 & 1 & 1 & 1 & 1 & 10 \\
\hline Petrobras & 1 & 1 & 1 & 1 & 1 & 1 & 1 & 1 & 8 \\
\hline Suncor & 1 & 1 & 1 & 1 & 1 & 1 & 1 & 1 & 8 \\
\hline Total & 6 & 8 & 6 & 6 & 6 & 6 & 6 & 6 & 50 \\
\hline
\end{tabular}

Due to the minimum effects that residence time had on the product distributions in past runs, it was eliminated as a variable in the test matrix. In order to improve the comparison of micro unit data to pilot unit data, all runs will be made at medium residence times.

\section{Micro-Coker Recoveries}

The reproducibility of the micro-coker data was established by using the Marathon resid at $15 \mathrm{psig}$ and 40 psig at a constant temperature of $900^{\circ} \mathrm{F}$. The results are shown in and Figure 24. Good reproducibility was obtained for both the 15 and 40 psig runs.

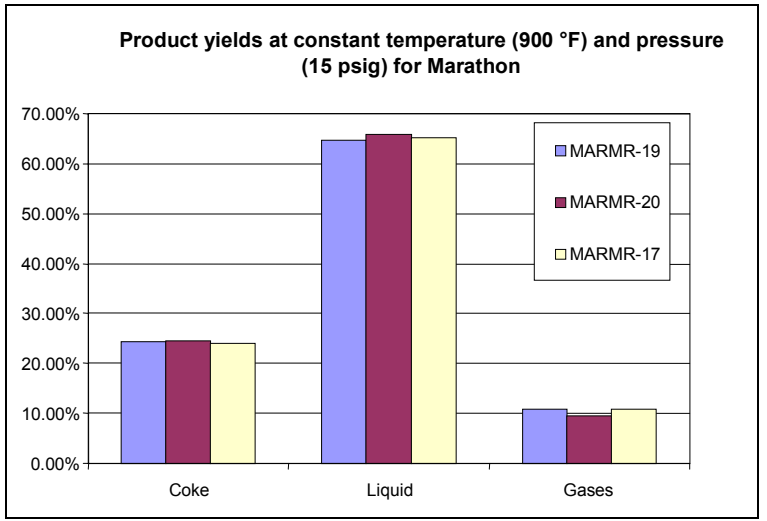

Figure 23 Product Yields at constant Temp. and Pressure for Marathon

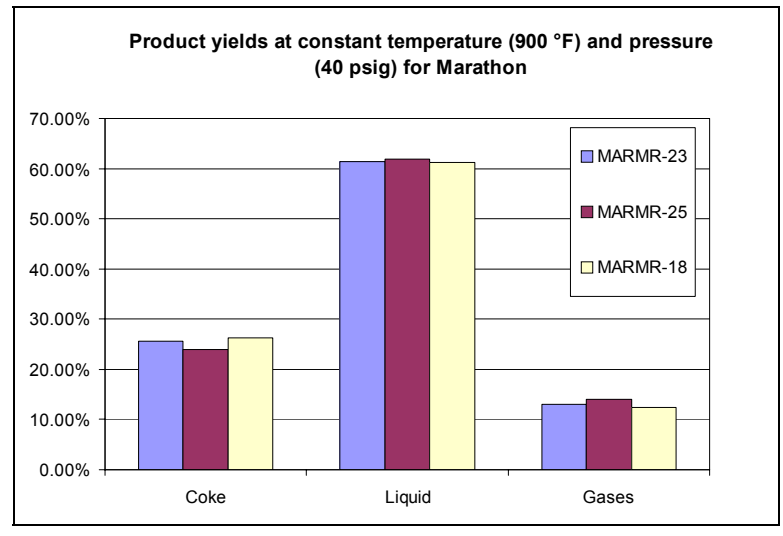

Figure 24 Product Yields at constant Temp. and Pressure for Marathon 
Summary of unnormalized product recoveries for all the runs completed in the modified microcoker is provided in Table 10.

Table 10: Micro-Coker yields for all six resids: Unnormalized and normalized yields:

\begin{tabular}{|c|c|c|c|c|c|}
\hline & & \multicolumn{3}{|c|}{ CONDTIONS } & \\
\hline Teit & & $T$ & $\mathbf{P}$ & Fand rate & 駡 \\
\hline Mumber & Eats & TPי & 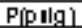 & 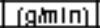 & Total \\
\hline CHW MR-A & $352 \mathrm{Wm}$ & 930 & 6 & 231 & $96.12 \%$ \\
\hline CHN' MR-1D & $3 / 252$ पु & 900 & 出 & 2.15 & $9.21 \%$ \\
\hline CHU' MR-11 & अ/262:03 & 930 & 15 & 121 & $96.85 \%$ \\
\hline CHU' MR-15 & 692003 & 930 & 吅 & 204 & $97.12 \%$ \\
\hline CHu' MR-17 & ?/102س0 & 950 & 15 & $2 \pi 9$ & $96.36 \%$ \\
\hline CHV' MR-18 & $7 / 152$ Ш & 950 & 虹 & $2 \pi$ & $96.96 \%$ \\
\hline CHu'MR-19 & $7 \sqrt{302 \mathrm{WU}}$ & SOD & 6 & $2 \pi$ & $9.2 \pi x$ \\
\hline $\mathrm{CH}$ 'MR-A & 7/31/2W0 & SOD & 15 & 2.13 & $99.15 \%$ \\
\hline CInUR-2 & अ282त्ण & SOD & 5 & 2.13 & $96.92 \%$ \\
\hline CחMR3 & अ31/2W & SOD & 15 & 2.18 & 1四.0内\% \\
\hline CIMUR-4 & W22प0ज & SOD & 40 & 2.19 & 1四.36\% \\
\hline CाTMR-6 & 132प⿴囗十丁 & 930 & 6 & 2.19 & $96.92 \%$ \\
\hline CTMR8 & Wह2प⿴囗十丁 & 930 & 15 & 223 & $96.95 \%$ \\
\hline CMUR-10 & $6 / 102 \mathrm{WU}$ & 930 & 㞹 & 125 & $99.11 \%$ \\
\hline CMUR-11 & $6 / 192 \square 0$ & 950 & 15 & 193 & $97.02 \%$ \\
\hline CMUR-12 & $6 / 242 \mathrm{WJ}$ & 950 & 吅 & 199 & $99.32 \%$ \\
\hline BQMR-14 & $2 / 32$ का & 900 & 6 & 2.18 & $99.5 \%$ \\
\hline EOMR-16 & $2 / 82$ पा & $\mathrm{gOO}$ & 15 & 201 & $\$ 6.91 \%$ \\
\hline BQMR-17 & $2 / 92$ प्यु & 900 & 吅 & 194 & $96.12 \%$ \\
\hline EQMR-18 & $2 / \pi 2 \omega 0$ & 930 & 6 & 125 & $96.73 \%$ \\
\hline BODR-22 & Wयू2प0 & 930 & 40 & 2.16 & $9.51 \%$ \\
\hline EQMR-Z3 & 5132 प्य & 930 & 15 & $2 \sqrt{25}$ & $95.75 \%$ \\
\hline EOMR-24 & $7 / 162$ س3 & 950 & 15 & $2 \mathrm{~m}$ & $96.13 \%$ \\
\hline BQMR-25 & 7/22200 & 950 & स⿴囗十 & 191 & 1向.25\% \\
\hline MQR RIRि-16 & $1 / 132$ 山ु & g00 & 5 & $2 \Pi 2$ & 9.04\% \\
\hline MQ́.RMR-17 & 1/16200 & SOD & 15 & 2.18 & $96.59 \%$ \\
\hline MQ́RाMR-19 & $1 / 23 / 2 \mathrm{Wm}$ & SOD & 15 & 19 & $96.17 \%$ \\
\hline MG RMR:D & $1 / 242 \mathrm{WU}$ & 900 & 15 & 199 & $1 \mathbf{m} .8$ ts \\
\hline MG RMR:-21 & 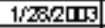 & 930 & 6 & 135 & $96.11 \%$ \\
\hline MQ RMR R-22 & $1 / \sqrt{3} 2 \mathrm{~m}$ & 930 & 15 & 2.15 & $9.47 \%$ \\
\hline MG RMR-31 & 6/2क्सु & 900 & 吅 & 2.17 & $97.39 \%$ \\
\hline MG RMR 32 & $6 / 22$ प3 & 930 & 忚 & 2.1 & $9.71 \%$ \\
\hline MQRMPR3 & $6132 \mathrm{WU}$ & 950 & 15 & $2 \pi 9$ & $96.61 \%$ \\
\hline MA. RMR 3 & 85 2س0 & 950 & 虹 & 228 & $96 . \mathrm{s} x$ \\
\hline MS RMR36 F\% RC & $8132 \mathrm{~W}$ & SOD & 5 & 224 & $95.96 \%$ \\
\hline MQ RMR 39 \&\% RC & $8 / 21 / 2$ W & 930 & 5 & 221 & $96.2 \mathrm{~d} \%$ \\
\hline MQRMR-A口 ER RC & $8 / 252$ 山ु & SOD & 15 & 1.56 & $9.13 \%$ \\
\hline MQ RMR-A1 S\% RO & $8 / 262$ प्य & 930 & 15 & 222 & 9.55\% \\
\hline MQRMR-42 S\% RC & 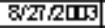 & SOD & 出 & $2 \pi$ & $94.37 \%$ \\
\hline MS RMR-A3 S\% RC & 922W0 & 930 & स⿴囗十 & 222 & $96.71 \%$ \\
\hline MQRMRAA S\% RC & 932ш0 & 950 & 15 & 2.19 & $9.78 \%$ \\
\hline MS RMR-4S (10\% RC) & $g / 162$ पू & 900 & 6 & 2.1 & $99.25 \%$ \\
\hline MS RMR-19 (10\% RO) & وi182س3 & 900 & 15 & $2 \mathrm{D5}$ & $97.25 \%$ \\
\hline 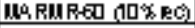 & $9222 \pi 0$ & 900 & 吅 & 2.15 & $96.09 \%$ \\
\hline MS RMR61 (10\%RC) & $9242 \mathrm{Wu}$ & 930 & 5 & $2 \pi 9$ & $95.15 \%$ \\
\hline PETMR-25 & 1/7/2س & SOD & 15 & 2.17 & $9.8 \%$ \\
\hline PETMR-2T & 1/102प0 & 930 & 15 & $2 D 5$ & $96.13 \%$ \\
\hline PETMR-Z6 & $2 / 32$ सु & SOD & 5 & 2.13 & 9.84 \\
\hline PETMR ज1 & 2/112س0 & 930 & 出 & $2 \sqrt{3}$ & $96.31 \%$ \\
\hline PETMRত⿹ & W172س0 & SOD & स⿴囗十 & 2.1 & $103.68 \%$ \\
\hline PETMR W5 & W2W & 990 & 5 & 2.17 & 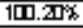 \\
\hline PETMR & $6 / 172 \mathrm{WU}$ & 960 & 15 & $2 D 5$ & $96.12 \%$ \\
\hline PETMR-JT & $6 / 182 \mathrm{WJ}$ & 950 & 㞹 & 135 & $9.64 \%$ \\
\hline & & & & & \\
\hline SUNMR-25 & 430200 & 900 & 15 & 2.19 & $96.61 \%$ \\
\hline SUN MR-25 & $51 / 2 \mathrm{WW}$ & 900 & 吅 & $2 \mathcal{2} 3$ & $9.45 \%$ \\
\hline SUN MR-T & $5 / 52 \mathrm{WO}$ & 930 & 6 & 2.16 & $96.93 \%$ \\
\hline SUN MR-29 & $582 \mathrm{WW}$ & 930 & 吅 & 2 D5 & $99.85 \%$ \\
\hline SUN MRZT & 5122 पु & 930 & 15 & 222 & $99.18 \%$ \\
\hline SUN MR-31 & 5152 Ш3 & 930 & 15 & 2.19 & $101.62 \%$ \\
\hline
\end{tabular}

\section{Comparison to Phase One Runs}

In order to compare old data to new data, the old data was adjusted using a new correction and normalization procedure. The Old vs. New runs comparisons are listed in Table 11. The lower interior temperature and the absence of carrier gas caused higher coke and lower liquid yields in the old runs. High 
gas readings for the old runs were due to overcracking of stagnant vapors inside the reactor. A comparison of the yields was done for three resids; Marathon, Equilon and Petrobras at the same temperature and pressure. The comparisons for coke, liquid and gas yields are shown in Figure 25 through Figure 27.

Table 11: Micro Reactor Yields - Old vs. New Runs Comparison

\begin{tabular}{|l|c|c|c|c|c|c|c|}
\hline RUN & Test Number & Date & $\mathbf{T}\left({ }^{\circ} \mathbf{F}\right)$ & $\mathbf{P}$ (psig) & Coke $\%$ & Liquids\% & Gases\% \\
\hline OLD RUN & EQMR-7b-PM & $10 / 13 / 1999$ & 930 & 6 & $33.60 \%$ & $52.54 \%$ & $13.87 \%$ \\
\hline NEW RUN & EQMR-18 & $2 / 20 / 2003$ & 930 & 6 & $32.81 \%$ & $55.17 \%$ & $12.02 \%$ \\
\hline & & & & & & & \\
\hline OLD RUN & EQMR-13 & $12 / 8 / 1999$ & 930 & 40 & $39.78 \%$ & $43.30 \%$ & $16.92 \%$ \\
\hline NEW RUN & EQMR-22 & $4 / 23 / 2003$ & 930 & 40 & $37.89 \%$ & $48.86 \%$ & $13.25 \%$ \\
\hline & & & & & & \\
\hline OLD RUN & MARMR-2-BT & $12 / 13 / 1999$ & 930 & 40 & $26.8 \%$ & $55.8 \%$ & $17.4 \%$ \\
\hline NEW RUN & MARMR-24 & $4 / 11 / 2003$ & 930 & 40 & $23.47 \%$ & $63.00 \%$ & $13.53 \%$ \\
\hline & & & & & & \\
\hline OLD RUN & MARMR-7 & $1 / 14 / 2000$ & 900 & 15 & $27.1 \%$ & $58.9 \%$ & $14.0 \%$ \\
\hline NEW RUN & MARMR-19 & $1 / 23 / 2003$ & 900 & 15 & $24.39 \%$ & $64.77 \%$ & $10.84 \%$ \\
\hline & & & & & & \\
\hline OLD RUN & MARMR-9 & $1 / 21 / 2000$ & 930 & 15 & $24.1 \%$ & $58.2 \%$ & $17.7 \%$ \\
\hline NEW RUN & MARMR-22 & $1 / 30 / 2003$ & 930 & 15 & $22.57 \%$ & $66.18 \%$ & $11.25 \%$ \\
\hline & & & & & & \\
\hline OLD RUN & MARMR-13 & $2 / 8 / 2000$ & 930 & 6 & $22.5 \%$ & $64.9 \%$ & $12.6 \%$ \\
\hline NEW RUN & MARMR-21 & $1 / 28 / 2003$ & 930 & 6 & $21.51 \%$ & $67.70 \%$ & $10.79 \%$ \\
\hline & & & & & & & \\
\hline OLD RUN & PETMR-2B-FS & $6 / 5 / 2000$ & 930 & 15 & $26.88 \%$ & $61.26 \%$ & $11.86 \%$ \\
\hline NEW RUN & PETMR-27 & $1 / 10 / 2003$ & 930 & 15 & $26.93 \%$ & $61.35 \%$ & $11.73 \%$ \\
\hline & & & & & & & \\
\hline OLD RUN & PETMR-3 & $2 / 21 / 2000$ & 930 & 40 & $29.83 \%$ & $53.98 \%$ & $16.19 \%$ \\
\hline NEW RUN & PETMR-31 & $2 / 11 / 2003$ & 930 & 40 & $29.63 \%$ & $57.70 \%$ & $12.66 \%$ \\
\hline
\end{tabular}

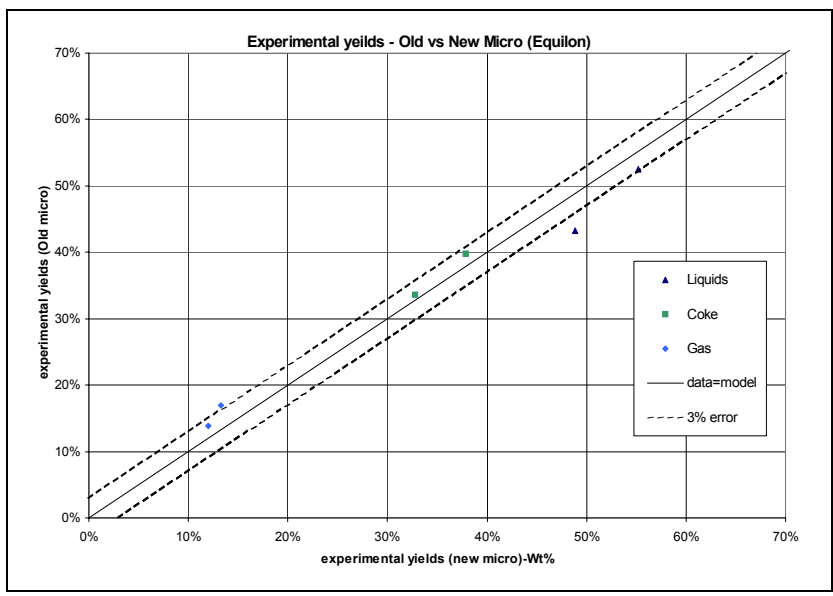

Figure 25 Experimental Yields - Old vs. New runs for Equilon

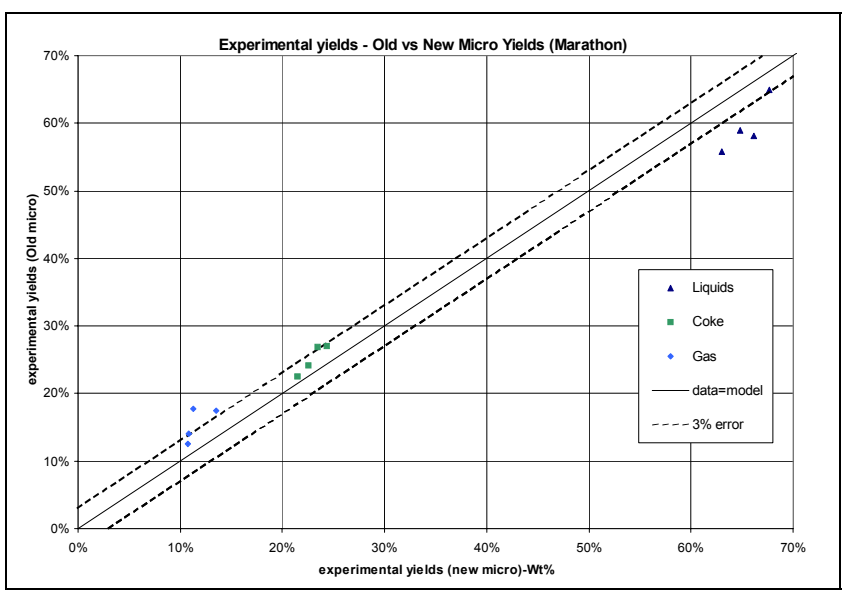

Figure 26 Experimental Yields - Old vs. New runs for Marathon 


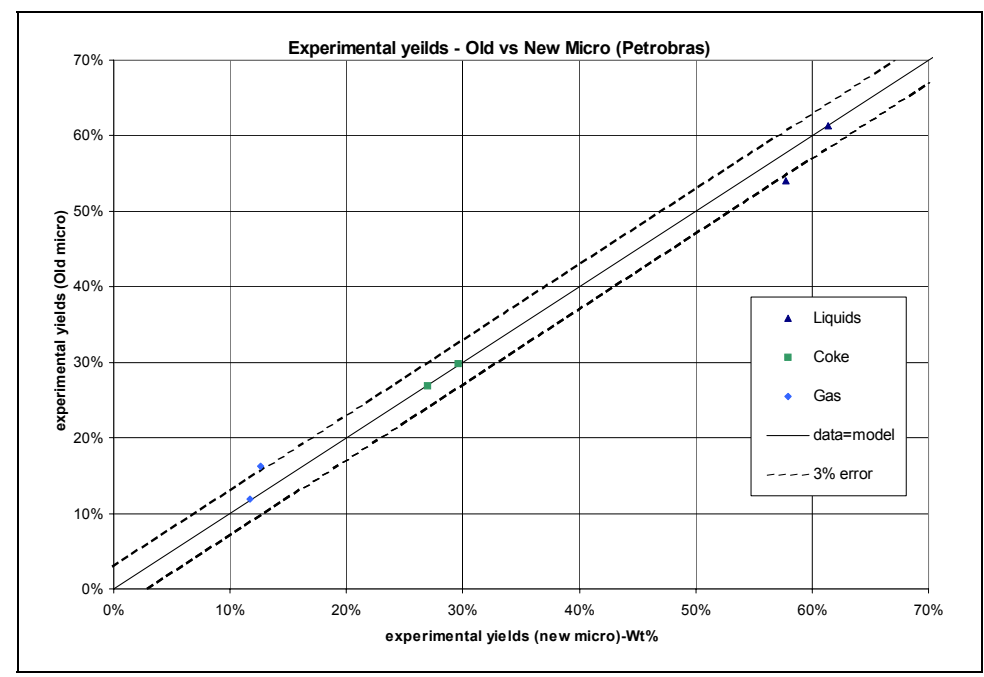

\section{Figure 27 Experimental Yields - Old vs. New runs for Petrobras}

Comparison of Liquid sub-product yields for the Marathon resid was done because more test runs were available to compare between old and new micro test runs. Old vs. New liquid sub-product yields are listed in Table 12. The gasoline yields were high for the old runs when compared with new runs because of the overcracking of heavy diesels and gas oils at low interior temperature.

Table 12 Micro Old vs. New Liquid Sub-product Comparisons for Marathon

\begin{tabular}{|l|c|c|c|c|c|c|c|c|}
\hline & & & & & & \multicolumn{3}{c|}{ Liquid Sub-Products } \\
\hline \multicolumn{1}{|c|}{ RUN } & Test Number & Date & $\mathbf{T}\left({ }^{\circ} \mathbf{F}\right)$ & $\mathbf{P}$ (psig) & $\%$ Gas & \multicolumn{2}{|c|}{ In terms of wt $\%$ of feed } \\
\hline & & & & & & Gasoline $\%$ & Diese $\%$ & Gas Oils $\%$ \\
\hline OLD RUN & MARMR-2-BT & $12 / 13 / 1999$ & 930 & 40 & $3.00 \%$ & $27.32 \%$ & $18.40 \%$ & $8.92 \%$ \\
\hline NEW RUN & MARMR-24 & $4 / 11 / 2003$ & 930 & 40 & $2.00 \%$ & $24.57 \%$ & $19.53 \%$ & $17.64 \%$ \\
\hline & & & & & & & & \\
\hline OLD RUN & MARMR-7 & $1 / 14 / 2000$ & 900 & 15 & $2.00 \%$ & $23.56 \%$ & $20.62 \%$ & $14.14 \%$ \\
\hline NEW RUN & MARMR-19 & $1 / 23 / 2003$ & 900 & 15 & $1.00 \%$ & $18.78 \%$ & $25.26 \%$ & $20.08 \%$ \\
\hline & & & & & & & & \\
\hline OLD RUN & MARMR-9 & $1 / 21 / 2000$ & 930 & 15 & $3.00 \%$ & $23.27 \%$ & $18.03 \%$ & $15.71 \%$ \\
\hline NEW RUN & MARMR-22 & $1 / 30 / 2003$ & 930 & 15 & $2.00 \%$ & $19.19 \%$ & $23.16 \%$ & $22.50 \%$ \\
\hline & & & & & & & & \\
\hline OLD RUN & MARMR-13 & $2 / 8 / 2000$ & 930 & 6 & $2.00 \%$ & $18.18 \%$ & $20.77 \%$ & $25.32 \%$ \\
\hline NEW RUN & MARMR-21 & $1 / 28 / 2003$ & 930 & 6 & $0.00 \%$ & $16.25 \%$ & $23.02 \%$ & $28.44 \%$ \\
\hline
\end{tabular}

Comparison of the Gas Compositions for the old and new runs for Marathon MARMR-7 \& MARMR19 test runs were made. The gas recoveries were high for the old runs when compared to the new runs because of the overcracking of stagnant vapors inside the reactor. The Gases for new runs are collected in less time due to the presence of carrier gas during the run. In all the comparisons, the gas recoveries for the old runs were higher when compared to the new runs except Hydrogen, which showed an opposite trend. 


\section{Pilot vs. Micro Comparisons:}

Comparisons of the Pilot unit to the Micro unit were completed for six resids at the same temperature and pressure. The comparisons in overall and liquid sub-product yields along with temperature profiles inside the drum are shown in Figure 28.

The major difference in the coker tests was that the Pilot unit had liquid temperature controlling and Micro unit had bottom reactor temperature controlling. Micro-Coker test runs showed high coke and low liquid yields when compared to Pilot unit test runs. When the temperature profiles inside the drum were compared, the top reactor temperature for Pilot unit was higher when compared to Micro unit. This resulted in high liquid yields for Pilot unit. The gas yields for the Micro unit were higher when compared to Pilot unit because the vapors overcrack in the Micro unit due to the lower top reactor temperature.

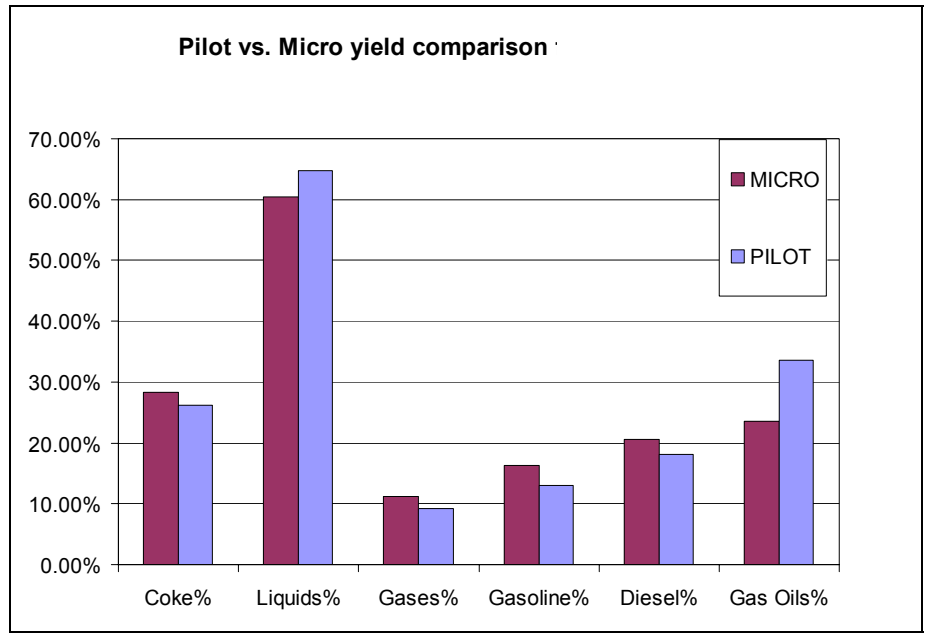

Figure 28 - Pilot vs. Micro

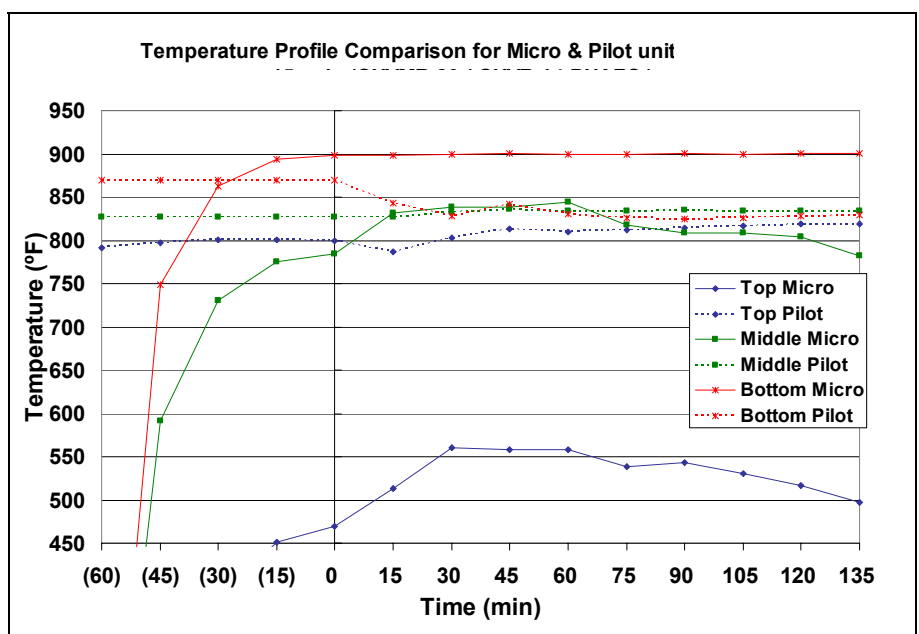

Figure 29 - Temperature Profile for Chevron at $900^{\circ} \mathrm{F} \& 15 \mathrm{psig}$

When the liquid sub-product yields are compared between the Micro unit and the Pilot unit runs, the Micro unit had high gasoline and high diesels. The heavy hydrocarbon vapors are staying inside the reactor for longer times in the Micro unit, which causes the vapors to overcrack and result in high gasoline and diesels. The gas oil yields were lower for the micro unit when compared to Pilot unit because of low vaporization resulting in more cracking. 


\section{Gas Analysis:}

The gas analyses for the Equilon resid to show the effect operating conditions have on gas composition.

\section{a) Effect of Temperature on Gas Composition:}

Effects of temperature on gas composition were studied at a constant pressure of 15 psig. Hydrogen increased when the temperature was increased from $900^{\circ} \mathrm{F}$ to $930^{\circ} \mathrm{F}$ but decreased when the temperature was raised to $950^{\circ} \mathrm{F} . \mathrm{H}_{2} \mathrm{~S}$, Methane, Ethane, $\mathrm{C} 4$ 's and $\mathrm{C} 5$ 's showed a decrease when temperature was increased from $900^{\circ} \mathrm{F}$ to $930^{\circ} \mathrm{F}$ but increased when temperature was increased from $930^{\circ} \mathrm{F}$ to $950^{\circ} \mathrm{F}$. Propane, Hexane and olefins showed an increase in composition with temperature. It was also observed that toward the end of the run (after the feed is complete) the gas composition for hydrogen increases.

\section{b) Effect of Pressure on Gas Composition:}

Hydrogen, ethane and propane increased with an increase in pressure. Methane, $\mathrm{H}_{2} \mathrm{~S}$, Hexane, C4's and C5's showed a decrease when the pressure was increased from 6 to 15 psig but showed an increase with pressure from 15 to $40 \mathrm{psig}$. Olefins increased from 6 to $15 \mathrm{psig}$ and decreased on further increase in pressure to $40 \mathrm{psig}$.

\section{c) Effect of Recycle:}

The effects of recycle on gas composition were determined for Marathon and Suncor resids. The gas composition was analyzed using the number of moles per gram of amount fed of each component that is passed through the Gas Chromatograph (GC). To simplify the gas composition comparisons, n-butane and isobutane are grouped as C4's; n-pentane and iso-pentane are grouped as C5's; and ethylene, propylene, isobutylene, trans 2-butene, cis 2-butene, 3-methyl 1-butene, 2-methyl 1-butene, 2-methyl 2butene, 1-pentene, trans 2-pentene, cis 2-pentene are grouped as olefins. Hydrogen, methane and olefins occupy eighty percent of the total gas composition and the remaining twenty percent gas composition contains hydrogen sulfide, ethane, propane, C4's, C5's and hexanes.

The hydrogen yields were high for $5 \%$ Marathon recycles due to overcracking caused by low temperatures at the top and middle reactor as discussed earlier. There was an overall decrease in hydrogen and methane yields with increase in recycles for the Marathon resid. Coming to the effect of recycle on the gas composition for the Suncor resid, the variation was within the error bars for the $0 \%, 5 \%$ and $10 \%$ recycle tests. At $900^{\circ} \mathrm{F}$ and $40 \mathrm{psig}$ the $100 \%$ recycle gas composition decreased significantly but at $930^{\circ} \mathrm{F}$ and $15 \mathrm{psig}$ there was no change in the gas composition. The variation in gas composition was not consistent with the increase in recycle for the Suncor resid. More test runs at $100 \%$ recycle would be helpful in drawing definite conclusions on the effect of recycle on gas composition. 


\section{d) Micro-Screening Model Prediction for Recycle Resids}

A material balance was done using $100 \%$ recycle and $0 \%$ recycle test runs to predict the yields at $5 \%$ recycle and $10 \%$ recycle. The fresh feed and the recycle resid were assumed to not interact with each other during cracking. A comparison was made of the predicted yields to the experimental yields. The differences in predicted and experimental yields are small for Marathon 5 and 10 percent recycles at $930^{\circ} \mathrm{F}$ and $15 \mathrm{psig}$. At $900^{\circ} \mathrm{F}$ and $40 \mathrm{psig}$, the $5 \%$ recycle for Marathon resid showed $2 \%$ low coke and $2 \%$ high liquid yields for the predicted yields. In the liquid sub-products, $4 \%$ low gasoline and diesels, and $9 \%$ high gas oils were predicted. The $10 \%$ recycle for Marathon resid showed little variation in coke and liquid yields. When the liquid sub-products were compared, 3 to $4 \%$ low gasoline and diesels and $5 \%$ high gas oils have been observed. The yields predicted using the non-recycle test runs and 100\% recycle test runs for Marathon resid worked fairly well for the main product yields.

The model prediction for Suncor recycle worked well for $930^{\circ} \mathrm{F}$ test runs when compared to $900^{\circ} \mathrm{F}$ test runs. The coke yields were 3 to $4 \%$ high and the liquid yields were $3 \%$ low when the experimental yields are compared with the predicted yields. There was a large variation for the Suncor resid when the recycle ratio was increased to five and ten percent at $900^{\circ} \mathrm{F}$ as shown previously. This resulted in large differences in the predicted and experimental yields for the Suncor resid at $900^{\circ} \mathrm{F}$.

The comparison between the Micro-Screening Model developed by Tomas Zambrano and the experimental yields for Marathon and Suncor straight recycles are shown in Table 13. The parameters used in the Zambrano Micro-Screening model were CCR, temperature and pressure. At $930^{\circ} \mathrm{F}$ and $15 \mathrm{psig}$, the model predicted $0.5 \%$ low coke yields and $2 \%$ high liquid yields for Marathon recycle. Coming to the liquid sub-products, the model predicted $16 \%$ high gasoline yields, 3\% high diesels and $16 \%$ low gas oils. At $900^{\circ} \mathrm{F}$ and $40 \mathrm{psig}$, the deviation from the experimental yields further increased. Large differences in predicted vs. experimental yields have been observed for Suncor recycles. The model gives high coke yields with high CCR\% but the Suncor recycle which has $9 \%$ CCR produced more coke than the Suncor resid which has $20.2 \%$ CCR. This shows that CCR does not work well as a parameter to predict the yields when recycle is used. Other feedstock properties like asphaltenes, asphaltic resins and \%Sat/Aromatics might be helpful in predicting the yields more accurately.

Table 13 Tomas Model Prediction vs. Experimental Yields for Straight Recycles

\begin{tabular}{|c|c|c|c|c|c|c|c|c|c|c|c|}
\hline \begin{tabular}{|l} 
Test Number \\
\end{tabular} & Date & $\mathrm{T}\left({ }^{\circ} \mathrm{F}\right)$ & $\mathrm{P}(\mathrm{psig})$ & $\mathrm{F}(\mathrm{g} / \mathrm{min})$ & CCR & Coke $\%$ & Liquids $\%$ & Gases\% & Gasoline $\%$ & Diesel\% & Gas Oils $\%$ \\
\hline \multicolumn{6}{|c|}{ Tomas Model P } & $8.73 \%$ & $84.75 \%$ & $6.51 \%$ & $24.35 \%$ & $25.70 \%$ & $34.70 \%$ \\
\hline MARMR-67 & $12 / 2 / 2003$ & 930 & 15 & 2.11 & 0.8 & $9.25 \%$ & $82.79 \%$ & $7.96 \%$ & $9.11 \%$ & $22.35 \%$ & $51.33 \%$ \\
\hline & & & & & & & & & & & \\
\hline \multicolumn{6}{|c|}{ Tomas Model Prediction } & $14.38 \%$ & $76.25 \%$ & $9.34 \%$ & $27.87 \%$ & $25.51 \%$ & $22.87 \%$ \\
\hline \begin{tabular}{|l|} 
MARMR-68 \\
\end{tabular} & $12 / 3 / 2003$ & 900 & 40 & 1.87 & 0.8 & $22.21 \%$ & $67.09 \%$ & $10.70 \%$ & $13.42 \%$ & $44.28 \%$ & $9.39 \%$ \\
\hline & & & & & & & & & & & \\
\hline \multicolumn{6}{|c|}{ Tomas Model Prediction } & $22.09 \%$ & $67.12 \%$ & $10.76 \%$ & $25.34 \%$ & $22.77 \%$ & $19.01 \%$ \\
\hline SUNMR-38 & 12/11/2003 & 900 & 40 & 1.98 & 9 & $47.27 \%$ & $39.72 \%$ & $13.01 \%$ & $14.30 \%$ & $18.67 \%$ & $6.75 \%$ \\
\hline \multicolumn{6}{|c|}{ Tomas Model Prediction } & $16.44 \%$ & $75.62 \%$ & $7.92 \%$ & $21.82 \%$ & $22.96 \%$ & $30.84 \%$ \\
\hline SUNMR-37 & $12 / 4 / 2003$ & 930 & 15 & 2.02 & 9 & $40.25 \%$ & $48.65 \%$ & $11.10 \%$ & $20.43 \%$ & $11.19 \%$ & $17.03 \%$ \\
\hline
\end{tabular}




\section{e) Pilot vs. Micro Unit Comparisons for Marathon and Suncor Resids}

Pilot vs. Micro data comparisons were made for Marathon and Suncor resids at the same temperature and pressure. The test run data compared for the Marathon and Suncor resids are shown in Table 14 and Table 15 respectively. The major difference in the coker tests was that the pilot unit had liquid temperature controlling and the Micro unit had bottom reactor temperature controlling. The Micro-Coker test runs showed 1 to $3 \%$ more coke and 2 to $5 \%$ less liquid when compared to the Pilot unit test runs for the Marathon resid. When the temperature profiles inside the drum were compared, the top reactor temperature for the Pilot unit was higher when compared to the Micro unit. This resulted in higher liquid yields for the Pilot unit. The gas yields for the Micro unit were higher when compared to the Pilot unit because the vapors overcrack in the Micro unit due to the longer residence times. The $930^{\circ} \mathrm{F}-40 \mathrm{psig}$ nonrecycle test run for the Marathon resid was the one exception where an opposite trend was observed.

When the Pilot vs. Micro test run data were compared for the Suncor resid, the non-recycle test runs showed high coke yields (2\%) and low liquid yields (2 to $4 \%$ ) for the Micro unit. When the recycle test runs were compared, higher coke yields (8 to 10\%) and lower liquid yields (6 to 10\%) were observed for the Micro unit. There was a large difference in product yields between the Micro and Pilot unit when the Suncor recycles were compared. When the liquid sub-product yields are compared between the Micro unit and Pilot unit runs, the Micro unit made more gasoline and more diesel. The heavy hydrocarbon vapors are staying inside the reactor for longer time in Micro unit, which caused the vapors to overcrack resulted in more gasoline and diesel product. The gas oil yields were lower for the micro unit when compared to the Pilot unit because of low vaporization resulting in more cracking.

The $100 \%$ recycle runs for the Pilot unit and the Micro unit were run at different temperatures and pressures. There were no common grounds to compare the yields for the Micro and Pilot unit test runs.

Table 14 Pilot vs. Micro Comparison for Marathon Resid

\begin{tabular}{|c|c|c|c|c|c|c|c|c|c|c|c|c|}
\hline \multirow[b]{3}{*}{ RUN } & \multirow[b]{3}{*}{ RECYCLE } & \multirow{3}{*}{$\begin{array}{l}\text { Test } \\
\text { Number }\end{array}$} & \multirow[b]{3}{*}{ Date } & \multicolumn{2}{|c|}{ CONDITIONS } & \multirow[b]{2}{*}{ Feed rate } & \multirow[b]{3}{*}{ Coke \% } & \multirow[b]{3}{*}{ Liquids\% } & \multirow[b]{3}{*}{ Gases\% } & \multirow{2}{*}{\multicolumn{3}{|c|}{$\begin{array}{l}\text { Liquid Sub-Products } \\
\text { In terms of } w \text { t } \% \text { of feed }\end{array}$}} \\
\hline & & & & & & & & & & & & \\
\hline & & & & $T\left({ }^{\circ} \mathrm{F}\right)$ & $P$ (psig) & & & & & Gasoline ${ }^{\circ}$ & Diesel\% & Gas Oils $\%$ \\
\hline MICRO & NO-REC & MARMR-22 & $1 / 30 / 2003$ & 930 & 15 & 2.15 & $22.57 \%$ & $64.87 \%$ & $12.56 \%$ & $18.81 \%$ & $2271 \%$ & $2206 \%$ \\
\hline PILOT & NO-REC & MARA 4 PUAF & $10 / 18 / 2002$ & 930 & 15 & 4800 & $20.16 \%$ & $71.35 \%$ & $8.49 \%$ & $13.56 \%$ & $17.84 \%$ & $39.95 \%$ \\
\hline
\end{tabular}

Table 15 Pilot vs. Micro Comparison for Suncor Resid

\begin{tabular}{|c|c|c|c|c|c|c|c|c|c|c|c|c|}
\hline & & & & \multicolumn{2}{|c|}{ CONDITIONS } & \multirow[b]{2}{*}{ Feed rate } & \multirow{3}{*}{$\begin{array}{c}\% \\
\text { Coke } \% \\
\end{array}$} & \multirow{3}{*}{\begin{tabular}{|c|}
$\%$ \\
Liquids $\%$ \\
\end{tabular}} & \multirow{3}{*}{$\begin{array}{c}\% \\
\text { Gases } \% \\
\end{array}$} & \multicolumn{3}{|c|}{ Liquid Sub-Products } \\
\hline & & Test & & & & & & & & In terms of & wt $\%$ of fee & \\
\hline RUN & RECYCLE & Number & Date & $T\left({ }^{\circ} \mathrm{F}\right)$ & $\mathrm{P}$ (psig) & $(g / \mathrm{min})$ & & & & Gasoline $\%$ & Diesel\% & Gas Oils\% \\
\hline & & & & & & & & & & & & \\
\hline ICRO & NO-REC & SUN & & 900 & & & & & & & & $14.73 \%$ \\
\hline PILOT & NO-REC & SUN 7 PUAF & $5 / 23 / 2002$ & 900 & 40 & 2400 & $28.53 \%$ & $59.97 \%$ & $11.50 \%$ & $16.19 \%$ & $17.39 \%$ & $26.39 \%$ \\
\hline
\end{tabular}

\section{Effect of Recycle on Pilot Unit for Marathon and Suncor resids:}

The effect of recycle on the product yields for Marathon and Suncor resids were determined in the Pilot Unit. The coke yield decreased by $2 \%$ when the recycle was increased from 0 to $10 \%$ for the Marathon resid at test conditions of $900^{\circ} \mathrm{F}$ and $15 \mathrm{psig}$. The same trend was seen for the Micro-Unit where the coke yields decreased with an increase in the recycle from 0 to $100 \%$. At $900^{\circ} \mathrm{F}-15 \mathrm{psig}$ and $940^{\circ} \mathrm{F}$ 40psig, the coke yields for the Suncor resid showed an increase with increase in recycle to $100 \%$. A similar trend was observed for Suncor recycle test runs in the Micro Unit. 


\section{f) Effect of temperature and pressure on main and liquid sub-product yields}

The effect of temperature were determined on product yields at constant pressures of 6,15 and 40 psig for Marathon with recycle and without recycle. The coke yields showed an overall decrease and the liquid yields showed an increase with an increase in temperature. The gas yields do not follow a definite trend. For the liquid sub-products, only a slight variation in gasoline yields was observed with an increase in temperature. The diesels and gas oils do not follow a definite trend with temperature.

The effect of pressure on product yields for the Marathon resid at $900^{\circ} \mathrm{F}, 930^{\circ} \mathrm{F}$ and $950^{\circ} \mathrm{F}$ were also determined. At constant temperature, the coke yields decreased consistently with an increase in pressure from 6 psig to $40 \mathrm{psig}$ and the liquid yields decreased with an increase in pressure following the expected trend. An increase in gas yields was observed when the pressure was increased. When the liquid sub-product yields were compared, the gasoline yields increased and the gas oil yields decreased with pressure. There was no definite trend for diesel.

Similar trends were observed for the product yields for the effect of temperature and pressure on the main and liquid sub-product yields for the Suncor recycles and the Cerro Negro resid.

\section{g) Effect of Temperature and Pressure on Average Molecular Weight of Gas Composition}

The effects of temperature and pressure on the average molecular weight of gas composition were determined for the six resids. Only a slight variation in average molecular weight was observed with a change in temperature. The variation in mole percent of the gas composition was not significant with temperature and hence the average molecular weight was not affected by an increase in temperature.

The trends in mole percent of hydrogen, methane and olefins with temperature and pressure for the six resids were established. With an increase in pressure, the average molecular weight showed a significant decrease. This is due to the decrease in mole percent of methane, ethane and olefins with an increase in pressure. The average molecular weight is contributed largely by this group in the gas composition. Even though there was a large increase in mole percent of hydrogen at higher pressures, this had little effect on the average molecular weight of the gas composition.

\section{h) Effect of Feedstock Properties}

The feedstock properties were analyzed to see the effect on product yields. Since asphaltic resins convert to ashpaltenes during the coking process, the combined effects of asphaltenes and asphaltic resins on the product yields were analyzed.

The trend line along with the $R^{2}$ value was calculated for each data series to reveal how closely the estimated values correspond to the actual data. The coke yields are predicted well using the MCR having $R^{2}$ values of $0.94,0.99$ and 0.98 for 6,15 and 40 psig pressures respectively. The coke yields showed a linear relationship with MCR. The liquids are predicted as good as the coke using MCR for 15 and 40 psig pressures having $R^{2}$ values 0.98 and 0.96 respectively. The trend line showed a negative slope for liquids. The gas yields did not show a definite trend with MCR and the $R^{2}$ values are worse. The liquid sub-product 
yield predictions using MCR is not as good as the predictions for the combined liquids. The trend line showed a negative slope for the liquid sub product yields similar to the trend observed in liquid yields.

The effect of asphaltenes on the main and liquid sub-product yields were analyzed at a temperature $930^{\circ} \mathrm{F}$ and pressures of 6,15 and 40 psig. The coke and liquid yields are predicted reasonably well using asphaltenes. The change in asphaltene percent from one resid to another resid stay close to trend followed by the MCR percent. This resulted in similar patterns of trend lines for MCR and asphaltenes in the prediction of product yields. When the product yield predictions for MCR and asphaltenes were compared, the MCR showed better predictions than the asphaltenes.

The combined effects of asphaltenes and asphaltic resins on coke and liquid yields were analyzed at $930^{\circ} \mathrm{F}$ for six resids (Chevron, Citgo, Equilon, Marathon, Petrobras and Suncor). The R ${ }^{2}$ values are 0.5 to 0.6 for coke and liquid yield predictions. The Equilon resid showed exceptionally high coke and low liquid yields when compared to the remaining five resids. When the Equilon resid was removed from the data series, the $\mathrm{R}^{2}$ values for coke and liquid yields significantly improved.

The percent of asphaltic resins stayed higher than the asphaltenes by twenty to thirty-five percent for the five resids where as for the Equilon resid there was only a two percent difference. Equilon resid has high coke yields when compared to the remaining five resids. The prediction worked well using MCR and asphaltenes because the increase in these feedstock properties showed a consistent increase in coke yields. The increase in the percent of asphaltic resins did not show a consistent increase in coke yields. For the Equilon resid, the other feedstock properties like MCR and asphaltenes might have affected the coke yields dominating the effect incurred by asphaltic resins.

The combined effect of asphaltenes and asphaltic resins on product yields at $930^{\circ} \mathrm{F}-15 \mathrm{psig}$ and $900^{\circ} \mathrm{F}-40 \mathrm{psig}$ for six resids and two recycles (Chevron, Citgo, Equilon, Marathon, Marathon Recycle, Petrobras, Suncor and Suncor Recycle) were determined. The predictions are good at $930^{\circ} \mathrm{F}-15 \mathrm{psig}$ test conditions having $R^{2}$ values of 0.9 and 0.92 for coke and liquids respectively. Whereas at $900^{\circ} \mathrm{F}-40 \mathrm{psig}$ the $\mathrm{R}^{2}$ values for the coke and liquid yields are 0.6 and 0.65 . At $900^{\circ} \mathrm{F}-40 \mathrm{psig}$, the prediction was not good because the data points of Marathon recycle, Equilon and Suncor recycle were high when compared to the remaining five resids. More straight recycles will be helpful to see the combined effect of asphaltenes and asphaltic resins on product yields.

\section{(i) $\underline{\underline{\text { Micro-coker correlations }}}$}

Correlations were developed for the micro-coker product yields for the six in-houe resids (Chevron, Citgo, Equilon, Marathon, Petrobras, and Suncor) including mixed (Marathon + Marathon Recycle, Suncor + Suncor Recycle), pure recycle as feed (Marathon and Suncor Recycles) and three new resids (Cerro Negro, Heavy Canadian and Rose Pitch). The three new resids along with the recycle resids did not correlate well with the feedstock Micro Carbon Residue (MCR), as previous studies with the micro-coker had indicated. Moreover, Asphaltenes did not show good correlation for the recycle resids. An overall model could not be developed using MCR or Asphaltenes as a feedstock parameter. Therefore, the overall model was developed using Asphaltenes plus Asphaltic Resins which showed good correlation for the three new resids and recycle resids when compared with MCR and Asphaltenes alone. These correlations were developed for all the six resids including mixed, recycle and three new resids. Good adjusted $\mathrm{R}^{2}$ values (about 0.82 ) were seen for the coke and liquid yields when compared to the liquid sub-product 
yields. The sign of the coefficients showed the expected trends for the operating conditions: temperature and pressure.

\section{(ii) Relation between micro-coker model and pilot unit/refinery results}

The purpose of the micro-coker experimental program is to develop a screening tool that can predict coker yields for industry-scale conditions with a short, simple test. In order to do this, the microcoker results need to be scaled up or correlated with the pilot unit results, which already have been shown in our previous work to match well with refinery conditions.

The micro-coker results correlated best with the middle reactor temperature. For refinery applications, however, a correlation with overhead temperature would be most practical, since this temperature is frequently the only coke drum temperature that is accurately known. Unfortunately, the micro-coker overhead temperature does not correspond to the overhead temperature seen in the pilot unit or the refinery. It reads much lower, for the same feed temperature, than the pilot overhead temperature does due to the purge stream of helium that was introduced at the top of the micro-coker.

To match the model prediction to the pilot yields, correction factors were introduced as previously discusseed in the thesis by Tomas Zambrano. The coke and liquid yields were adjusted by multiplying the results by constant factors and the gas yields by remaining percent left in overall material balance.

The constant factors multiplied to the results of the correlations were calculated by using the slope of trend line with zero intercept for predicted vs. experimental data. Figure 30 shows a comparison between predicted yields by adjusted correlations and experimental yields for the pilot unit.

A similar method was used to adjust the predicted yields of the micro correlations for predicting pilot unit yields. The equations were corrected such that the summation of liquid sub-products gives the adjusted liquid yields.

The comparison between predicted yields by adjusted correlations and experimental yields for pilot unit are shown in Figure 31. The data points for the model prediction using corrected new screening model for the pilot unit were more close to the model=data line when compared to the prediction used by the Zambrano model.

The micro-correlations now predict product yields that are more meaningful to the pilot unit and hence to the industrial yields. The experimental yields for the pilot unit were run at the feed temperatures of $900^{\circ} \mathrm{F}$ and $930^{\circ} \mathrm{F}$. The adjusted correlations should therefore be used between these feed temperatures. 


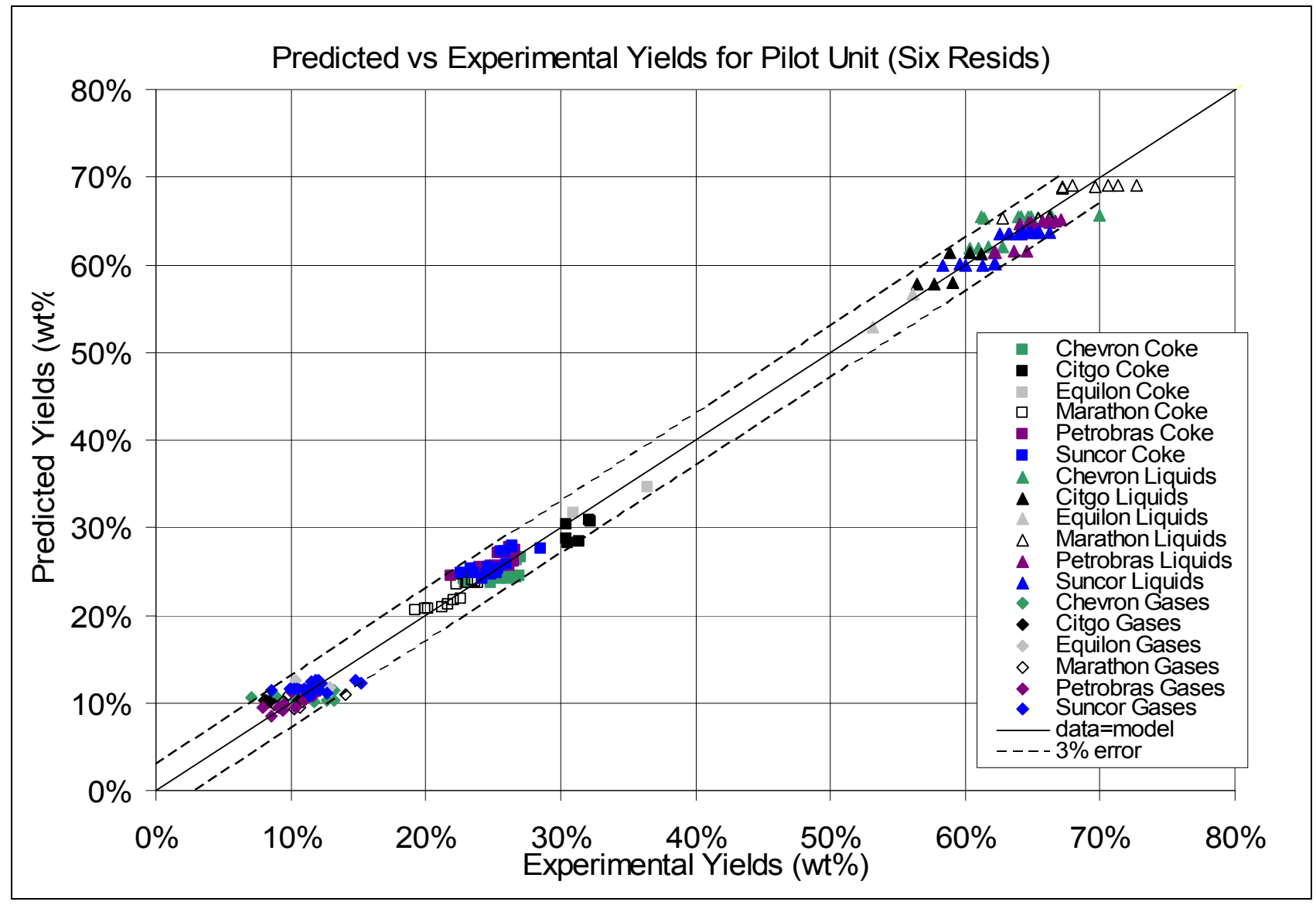

Figure 30 Predicted vs. Experimental yields for Pilot Unit after Correction 


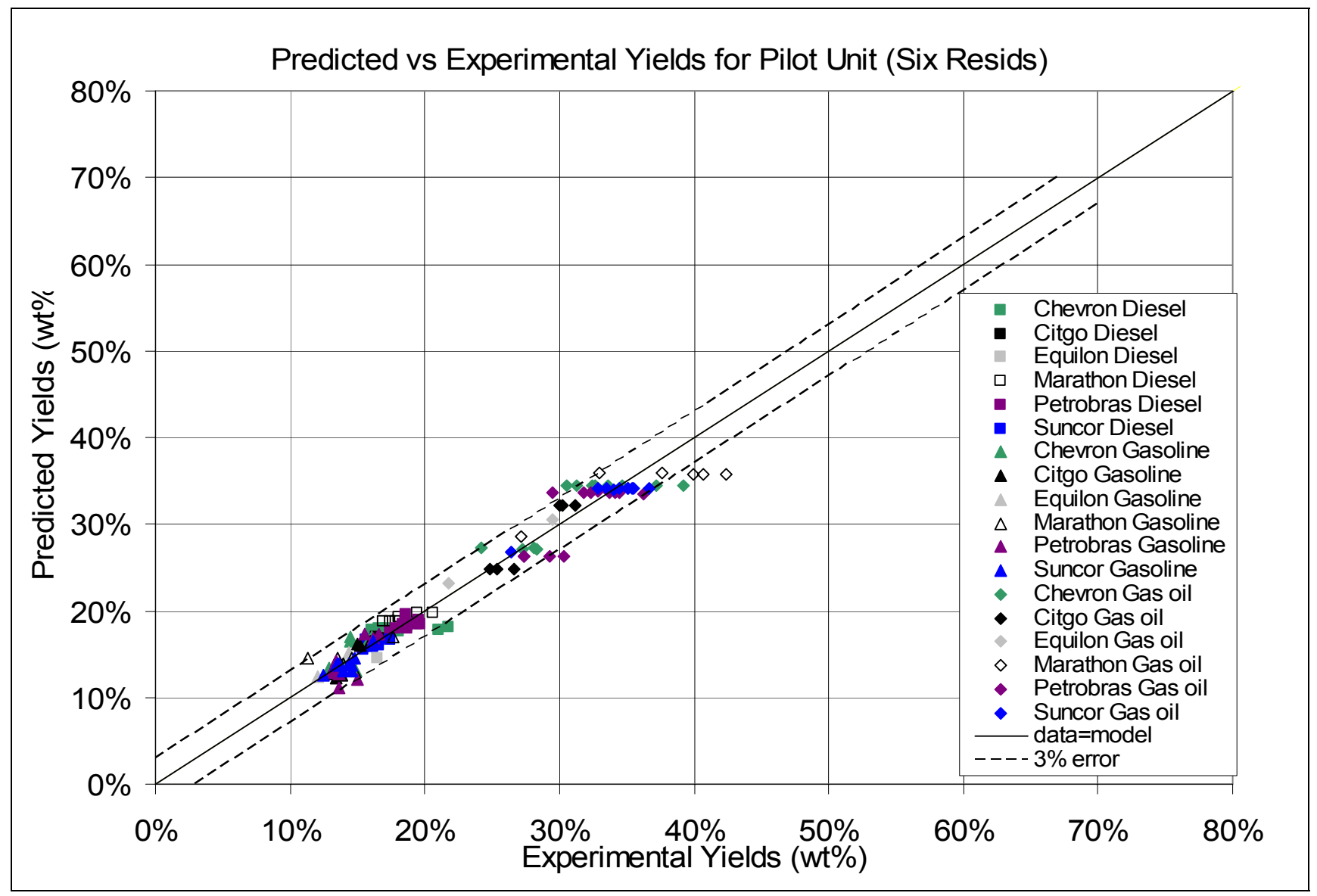

Figure 31 Predicted vs. Experimental yields for Pilot Unit after Correction

\section{CONCLUSIONS:}

New thermocouples installed in the micro-coker proved helpful in explaining the discrepancies in product yields with variation in parameters: overhead temperature and pressure.

Individual resid product and liquid sub-product yields were predicted fairly well using linear regression. Overhead temperature and pressure were the parameters used. A slight variation in experimental data was seen in the coke $(0.93 \%)$, liquid $(1.27 \%)$ and gas $(0.92 \%)$ yields when the data was compared to the data predicted with the new micro-screening model. The Micro-Coker tests give high coke and low liquid yields when compared to Pilot unit tests because of low top reactor temperature inside the drum.

Liquid content increased with temperature for the paraffinic resids while the aromatic, Napthenic and intermediate resids showed an optimum at $930^{\circ} \mathrm{F}$. The individual liquid sub-product yield predictions improved for the new runs when compared to the previous runs when the liquid sub-product yields are estimated in terms of total weight percent of feed instead of total weight percent of liquids. 


\section{Glass Coker Studies}

A glass coker was constructed and testing with it was begun for the purpose of visually observing and measuring foam formation under carefully controlled coking conditions. The tests are also helping to study the impact of different feedstocks on foam behavior. The following is a description of the work done to date with the glass coker.

\section{A. GLASS COKER DESCRIPTION}

The

experimental setup for

the glass

coker

is shown in

Figure 32. A photograph of the system currently constructed is shown in Figure 33.

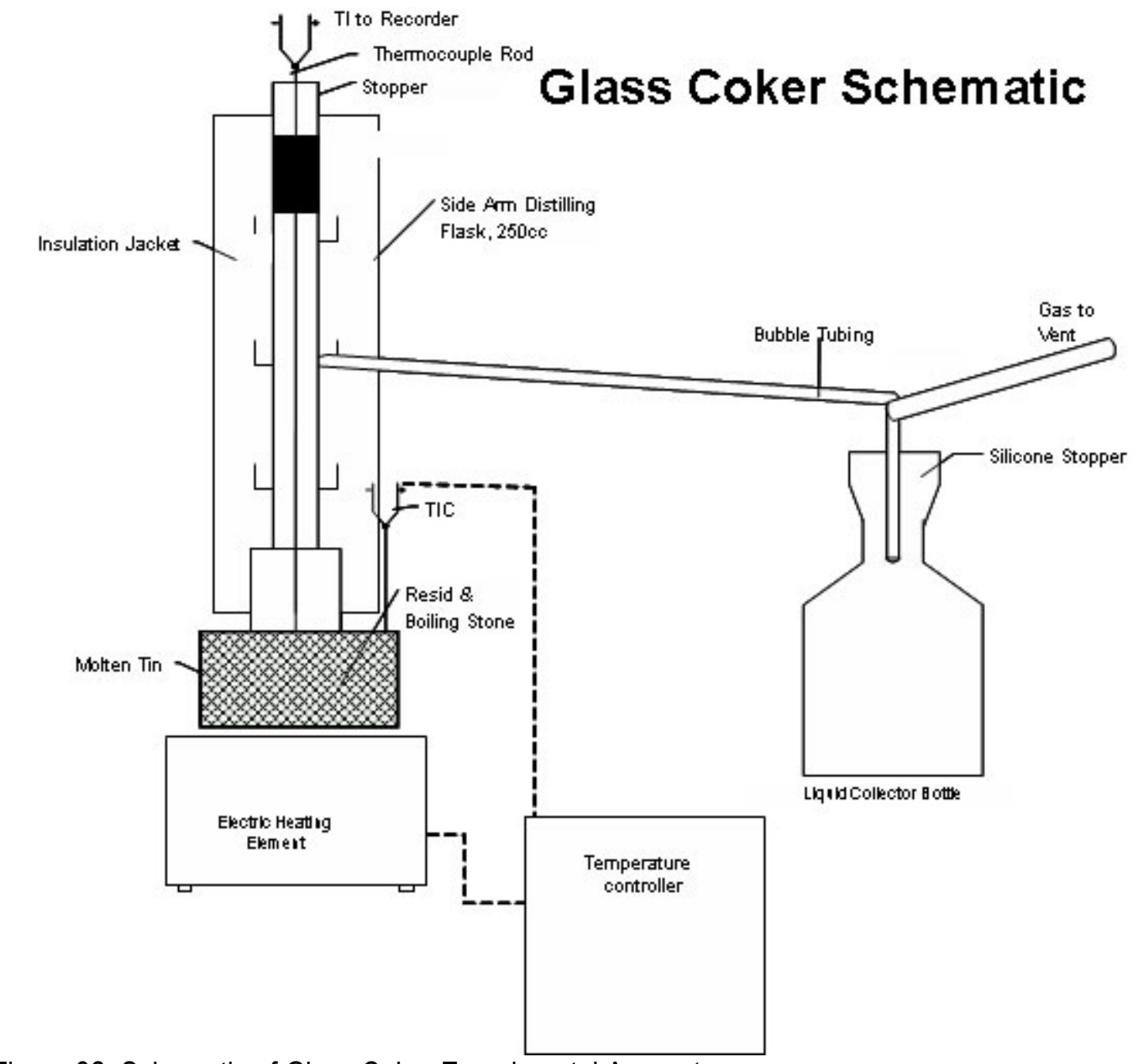

Figure 32: Schematic of Glass Coker Experimental Apparatus 


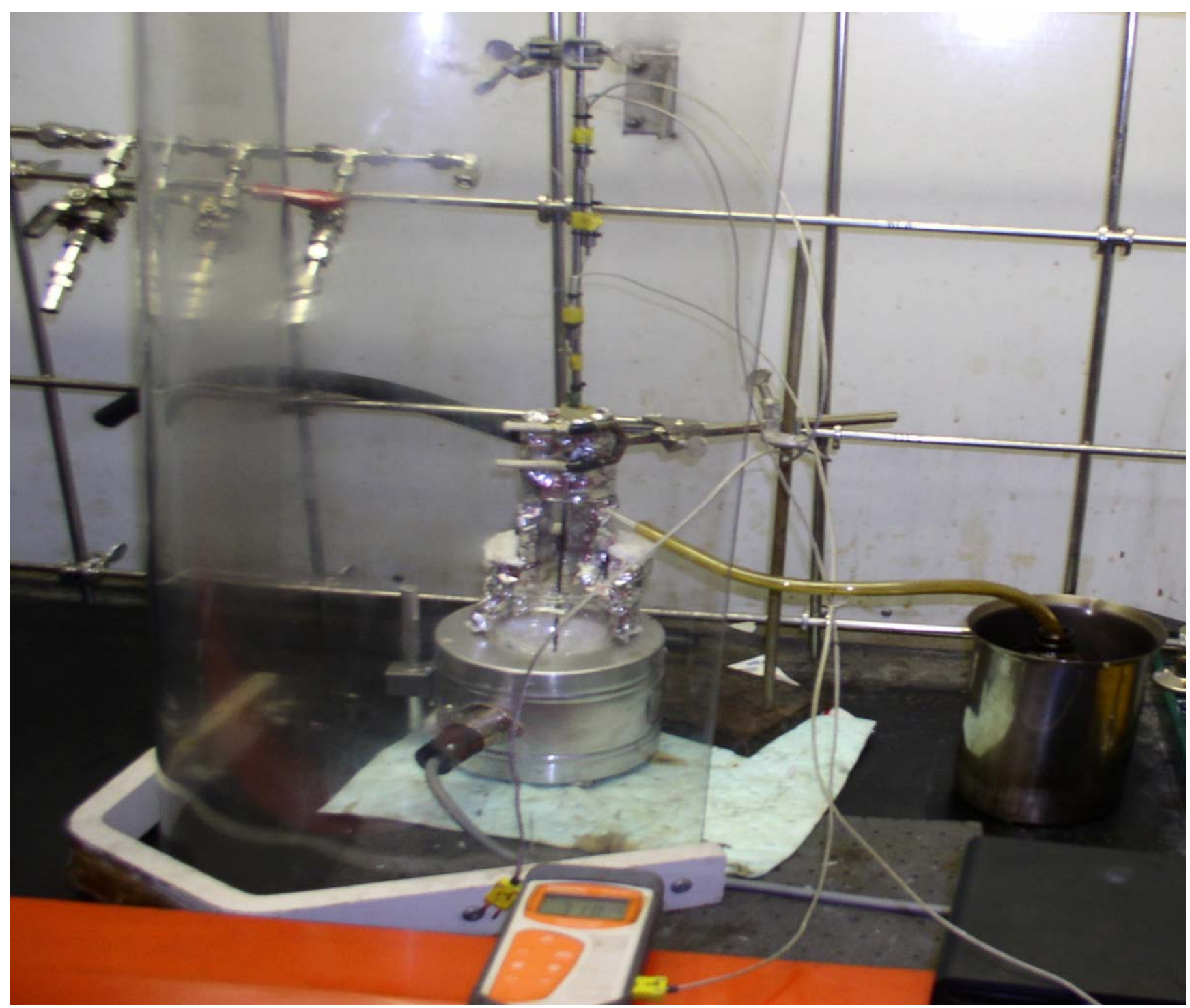

Figure 33 : Photograph of experimental facility

The setup of the runs being conducted consists of three main components: the distilling flask, the temperature control system and the heavy liquid collection system. A Pyrex brand $250 \mathrm{ml}$ distilling flask with side arm is used as the reactor. The heating mantle is a Glass-Col series STM heating mantle that has an operating temperature range from ambient to $650^{\circ} \mathrm{C}$. The temperature is monitored using a Digitrol $\Pi$ temperature controller that has an operating range of $0-750^{\circ} \mathrm{C}\left(32-1382^{\circ} \mathrm{F}\right)$. It is used to monitor temperatures at different locations in the flask(0.5, 3.5, 6.5 inches from the bottom) using a type $\mathrm{K}$ thermocouple. The vapors are condensed in a flask that is submerged in a water bath. Should antifoam be needed to collapse the foam, a $1 \mathrm{cc}$ syringe is used. The device is wrapped in a molded insulating blanket. The test device is surrounded by a blast shield and tests are conducted in a vent hood. 


\section{B. TESTS WITH IN-HOUSE RESIDS AND RESID MIXTURES}

The glass coker was used for the dual purpose of visual observation of foam and also testing the impact of feedstock properties on foam behavior under carefully controlled conditions. A detailed testing program was developed with each of the 9 in-house resids and strategic mixtures of resids were also tested. Duplicate tests were conducted as necessary. The first 16 tests were conducted where a window was left in the insulation to observe and photograph the phenomenon taking place. A second series of tests were conducted where the reactor was totally insulated to determine if excessive reflux was taking place in the reactor. With each test, our operational capabilities and understanding of resid foaming behavior improved.

Table 16: Test matrix for the Glass coker tests with partial insulation

\begin{tabular}{|c|c|c|}
\hline Run ID & Resid /Resid mixture tested & Date tested \\
\hline CIT 1 & Citgo & $01 / 06 / 2005$ \\
\hline CIT 2 & Citgo & $01 / 11 / 2005$ \\
\hline EMCN 3 & Cerro Negro & $01 / 17 / 2005$ \\
\hline EMCN 4 & Cerro Negro & $01 / 21 / 2005$ \\
\hline EMCN 5 & Cerro Negro & $01 / 26 / 2005$ \\
\hline MARA 6 & Marathon & $01 / 31 / 2005$ \\
\hline PETR 7 & Petrobras & $02 / 03 / 2005$ \\
\hline EMCN 8 & Cerro Negro & $02 / 28 / 2005$ \\
\hline CIT 9 & Citgo & $03 / 02 / 2005$ \\
\hline EMHC 10 & Heavy Canadian & $03 / 08 / 2005$ \\
\hline SUNC 11 & Suncor & $03 / 11 / 2005$ \\
\hline CHV12 & Chevron & $03 / 17 / 2005$ \\
\hline MRP 13 & Rose Pitch & $03 / 18 / 2005$ \\
\hline CHVESO 14 & Chevron+ Equilon slurry oil(75- & $03 / 22 / 2005$ \\
\hline 25 wt\% mix) & \\
\hline CHV 15 & Chevron & $03 / 25 / 2005$ \\
\hline EQU 16 & Equilon & $03 / 29 / 2005$ \\
\hline SUNC 21 & Suncor & $04 / 21 / 2005$ \\
\hline
\end{tabular}

Table 17: Test matrix for the Glass coker tests with complete insulation

\begin{tabular}{|c|c|c|}
\hline Run ID & Resid /Resid mixture tested & Date tested \\
\hline EMCN 17 & Cerro Negro & $04 / 01 / 2005$ \\
\hline MARA 18 & Marathon & $04 / 05 / 2005$ \\
\hline MARA 19 & Marathon & $04 / 08 / 2005$ \\
\hline SUNC 20 & Suncor & $04 / 15 / 2005$ \\
\hline \multicolumn{2}{|c|}{} \\
\hline
\end{tabular}




\section{RESULTS FROM PRELIMINARY SHAKEDOWN RUNS WITH IN-HOUSE RESIDS AND RESID MIXTURES}

\section{Test procedure 1}

The operating procedure outlined below was followed for MARA 6, MARA 19, SUNC 20, SUNC 21 runs. Before the resid is poured, $1 \mathrm{gm}$ of boiling stones is added to the flask and then the resid to be tested is poured into the flask (61 gms). The flask is placed into a heating mantle, is wrapped with insulation on the sides and the thermocouples are inserted into it after closing the top with the stopper. The stopper has two holes for insertion of the thermocouple rod and the antifoam syringe. The heating mantle is connected with the temperature controller which is connected to a power source. The tubing is connected with the side arm and is sent to a liquid collecting receiver placed inside a stainless steel beaker containing cold water. The area around the flask and the mantle is covered with the insulation jacket. The blast shield is then put in front of the distillation flask.

Heating of the resid is achieved by setting the controller to $600^{\circ} \mathrm{F}$ with the output clamped at $25 \%$. At 42 mins into the run, ramping is started by gradually increasing the power settings $3 \%$ every 5 mins. A run is complete when the bottom resid temperature reads $1030^{\circ} \mathrm{F}$. The temperatures of the middle $(3.5$ inches from bottom) and bottom thermocouples( 0.5 inch from bottom of flask) were consistently recorded at various times during the run and the coke and liquid yields are computed at the end of the run from the recorded weights of the collection bottle and by breaking the flask open after the run to remove the coke.

\section{Test procedure 2}

The operating procedure outlined below was followed for runs from CIT 1 to MARA 18 with the exception of the MARA 6 run for which test procedure 1 was followed. The same $1 \mathrm{gm}$ of boiling stones is added to the flask and then the resid to be tested is poured into the flask (61 gms). The same apparatus as in procedure 1 was used. The first stage of heating was achieved by heating the resids to $600^{\circ} \mathrm{F}$ with the output clamped at $25 \%$. The ramping during the second stage of heating from $600^{\circ}$ to $850^{\circ} \mathrm{F}$ was started after the bottom temperatures stabilized for each resid(became almost steady at $600^{\circ} \mathrm{F}$ ). Also the ramping was done non-uniformly on an as needed basis in order to reach $850^{\circ} \mathrm{F}$ as efficiently as possible. At the end of the run, the ramping was stopped and the power settings were kept constant so that large increases in resid temperatures with time could be minimized.

\section{Results}

Twenty-one runs were made using nine In-house resids and one run for a Chevron-Equilon slurry oil mixture( $75-25 \%$ wt mix). $T_{b}$ denotes temperature of the resid at the bottom thermocouple location, and $T_{m}$ at the middle location. The time factor during the runs from runs 6 through 18 with the exception of the MARA 6 run were adjusted by calculating the time factor from the time at which the second stage of steady ramping(as described in procedure 1)from 600 to $850^{\circ} \mathrm{F}$ starts. Runs $1-5$ were utilized to decide on best operating procedure. MARA 6, MARA 19, SUNC 20, SUNC 21, were not adjusted as they were run with 
steady ramping throughout the heating of the resid from 600 to $1030^{\circ} \mathrm{F}$. Since only one stage of cooling is used, some of the lights are lost with the gas that is vented. Gas yields are obtained by difference. Also the bottom temperature and the middle temperature data comparison is presented in Figure 34 for runs 6-16 and Figure 35 for runs 17-19 versus time(mins). The runs EMCN 17, MARA 18 and MARA 19, SUNC 20 were run with the insulation completely wrapped around the reactor in order to minimize heat loss and to determine refluxing in the reactor. Tests 1 through 16 were run with partial insulation. Also the images of runs from test 10 onwards were captured with a video camera.

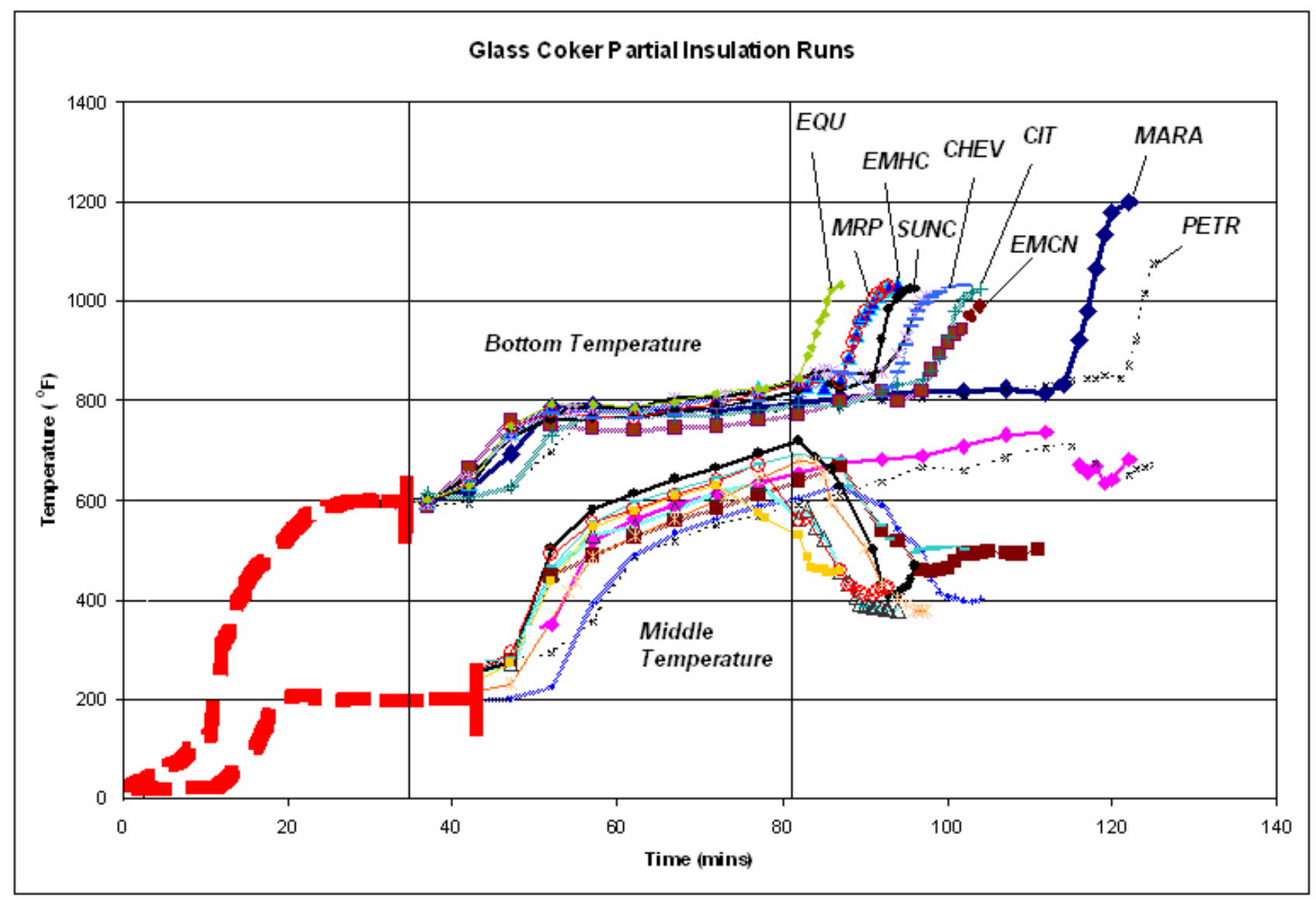

Figure 34 : Bottom and Middle temperature comparison data for runs 6-16. 


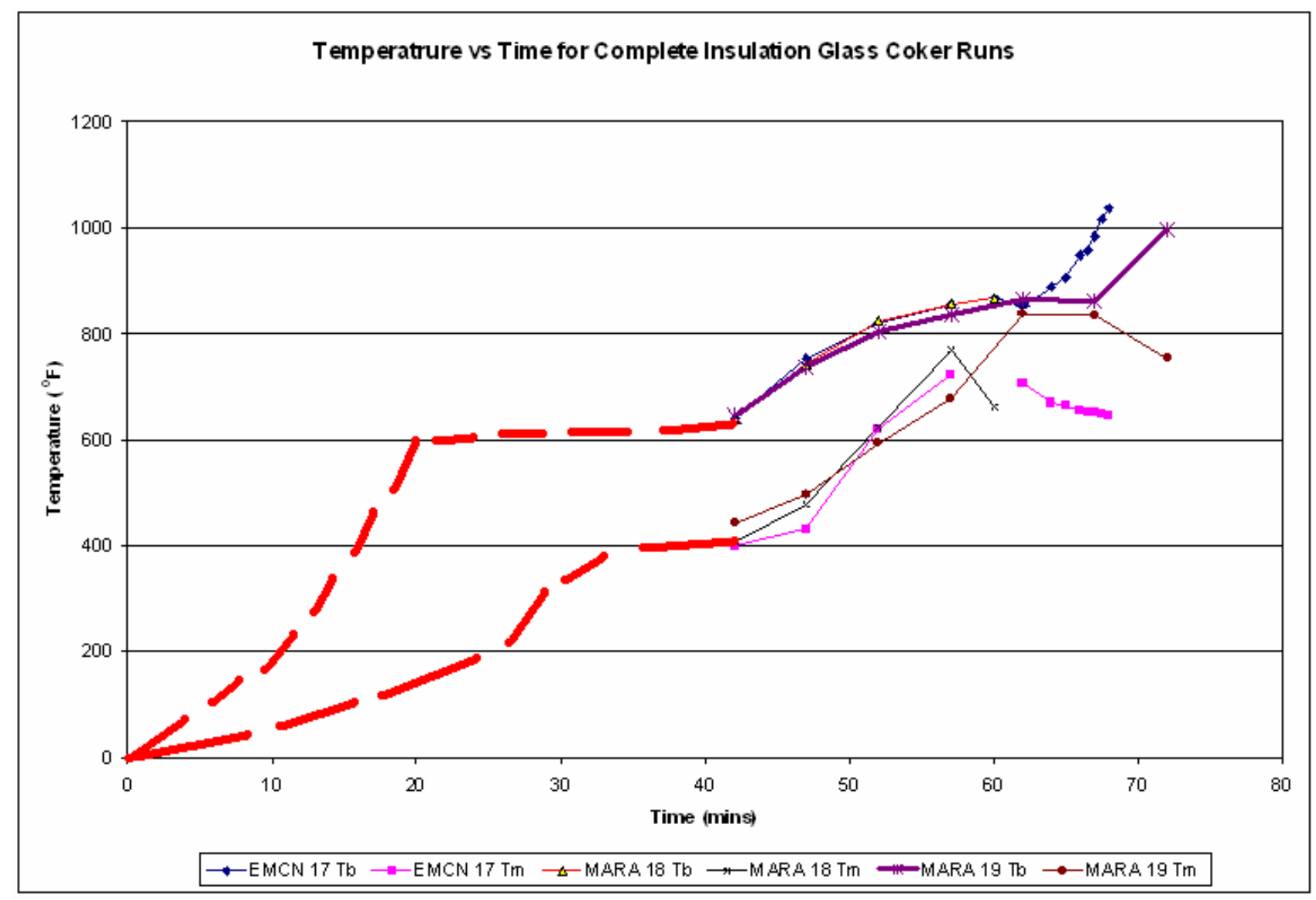

Figure 35: Bottom and Middle temperature comparison data for runs 17-19. 
As can be seen from Figure 35, less refluxing was seen for both the shot and sponge making resids when the reactor was completely insulated.

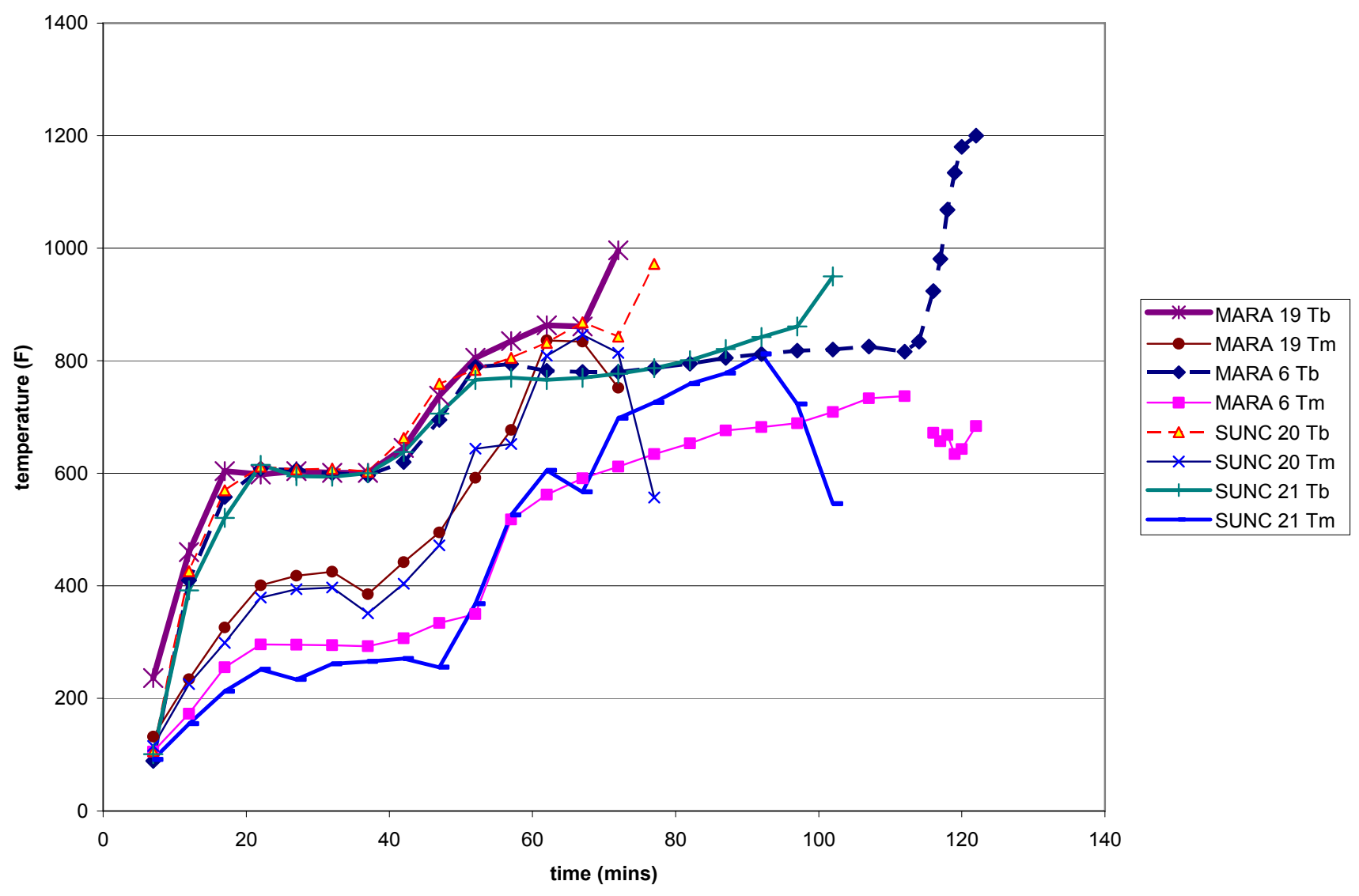

Figure 36: Bottom and Middle temperature comparison data for runs 6, 19, 20, 21

As can be seen from Figure 36, there is much more refluxing for the partially insulated runs than completely insulated runs. In the partially insulated runs, shot making resids went to coke sooner than the sponge making resid; however, this trend was reversed when the reactor was totally insulated.

In general, the sponge making resids tend to remain clear in the flask with no coating of sides of the reactor until the final phase of foam over and subsequent production of coke starts. The incidence of black splashing is much more for shot making resids and the sides of the reactor are coated black much more readily. The PETR 7 run also produced small patches on the walls created by gas bubble formation as seen in Figures 6 and 7 . These patches provide a first estimate of gas bubble radius for the resid. It was also observed that shot making resids go to coke sooner then sponge making resids, i.e., the sponge making resids are "plastic" for a longer period of time. The same observation was made for the pilot unit runs. 

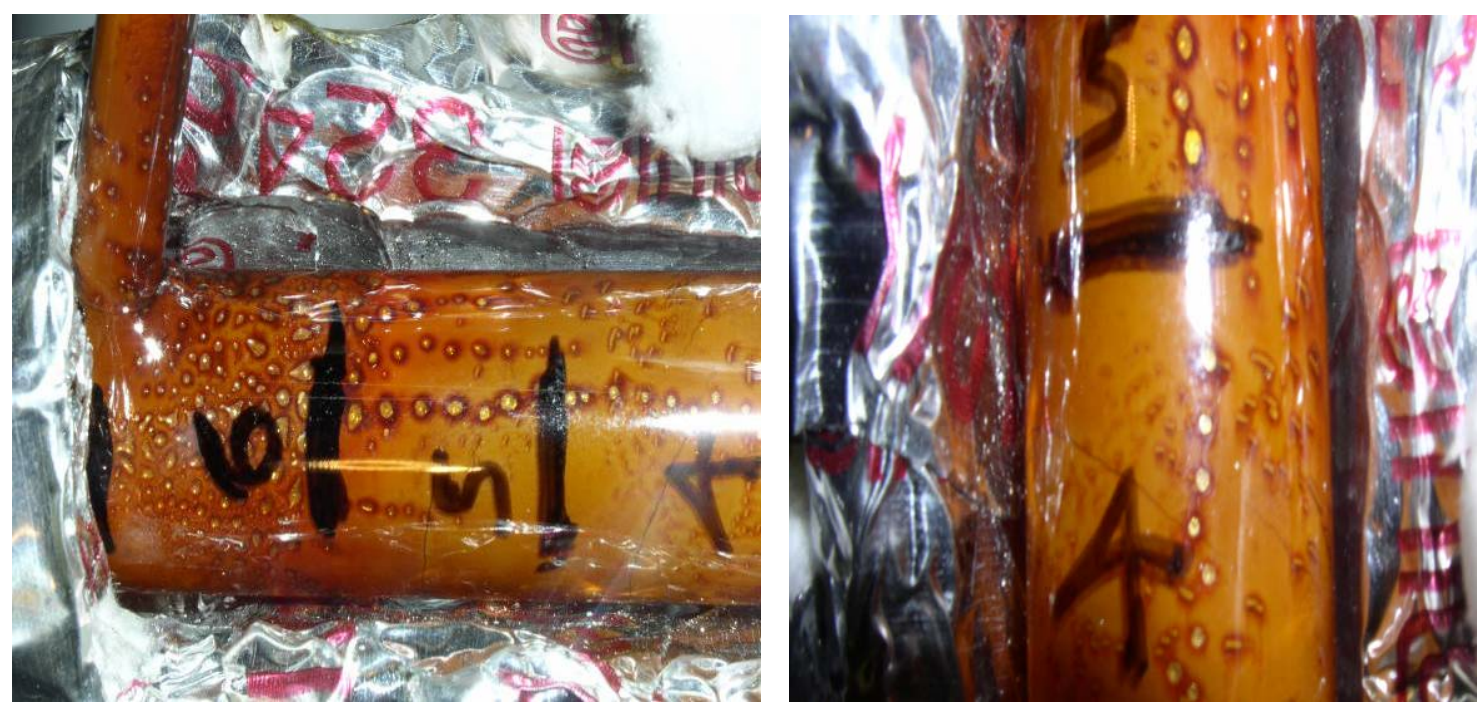

Figure 37: Patches on the walls created by gas bubble formation for PETR 7 run
Figure 38: Patches on the walls created by gas bubble formation for PETR 7 run

\section{ANALYSIS OF TEMPERATURE PROFILE FOR THE PARTIALLY INSULATED GLASS COKER RUNS:}

Figure 39 shows the plot of bottom temperature versus time for the partially insulated glass coker runs. It depicts the three phases observed during these runs.

\section{Warm up Phase:}

At a constant power output, the resid is heated until it reaches 600 o $\mathrm{F}$ and is allowed to stabilize. Since some runs were not heated at a uniform power, the time of those runs are normalized to compare with other runs. Runs are now conducted on a constant power output during the warm up and steady phase.

\section{Steady Phase:}

During this period of the run, with a constant increment in power, we see a uniform heating of different resids. As the bottom temperature reaches 800 oF and remains there for the next $30-40$ minutes. A certain lag is observed in the middle temperature compared to the bottom temperature, as the middle temperature reaches the steady state around 10 minutes later into the run.

A phenomenon of black splashing is observed during this phase, the time of occurrence varies with different resids. It is observed that with shot producing resids, the black splashing is more prominent as compared to sponge producing resids. Also, the black splashing, associated with shot producing resids, tends to coat the walls of the flask with black material, whereas with sponge coke producing resids, the flask remains clear until the foam over point. Based on the asphaltene content, this observation can be also related to the formation of the mesophase. The mesophase is formed earlier in the run with shot producing 
resids which form spheres and thereby produce shot coke (BB's, buck and bonded). Whereas, for sponge producing resids, the mesophase is formed later into the run when the liquid is inside the drum and has reached a quiescent state.

\section{Foam over Phase:}

During this phase, the foam over occurs with different colors of fumes observed with different resids. As seen in Figure 39, when the foam over occurs, the bottom temperature rises from 800 of and crosses the 1000 of within couple of minutes. The flask along with the side arm is filled with foam over material.

It is observed that the pure sponge making resids take longer to foam over compared to shot making resids. Marathon and Petrobras resid produce pure sponge coke, it took them an additional 15 to 20 minutes to foam over compared to other resids. Further testing with glass coker should give us better insight.

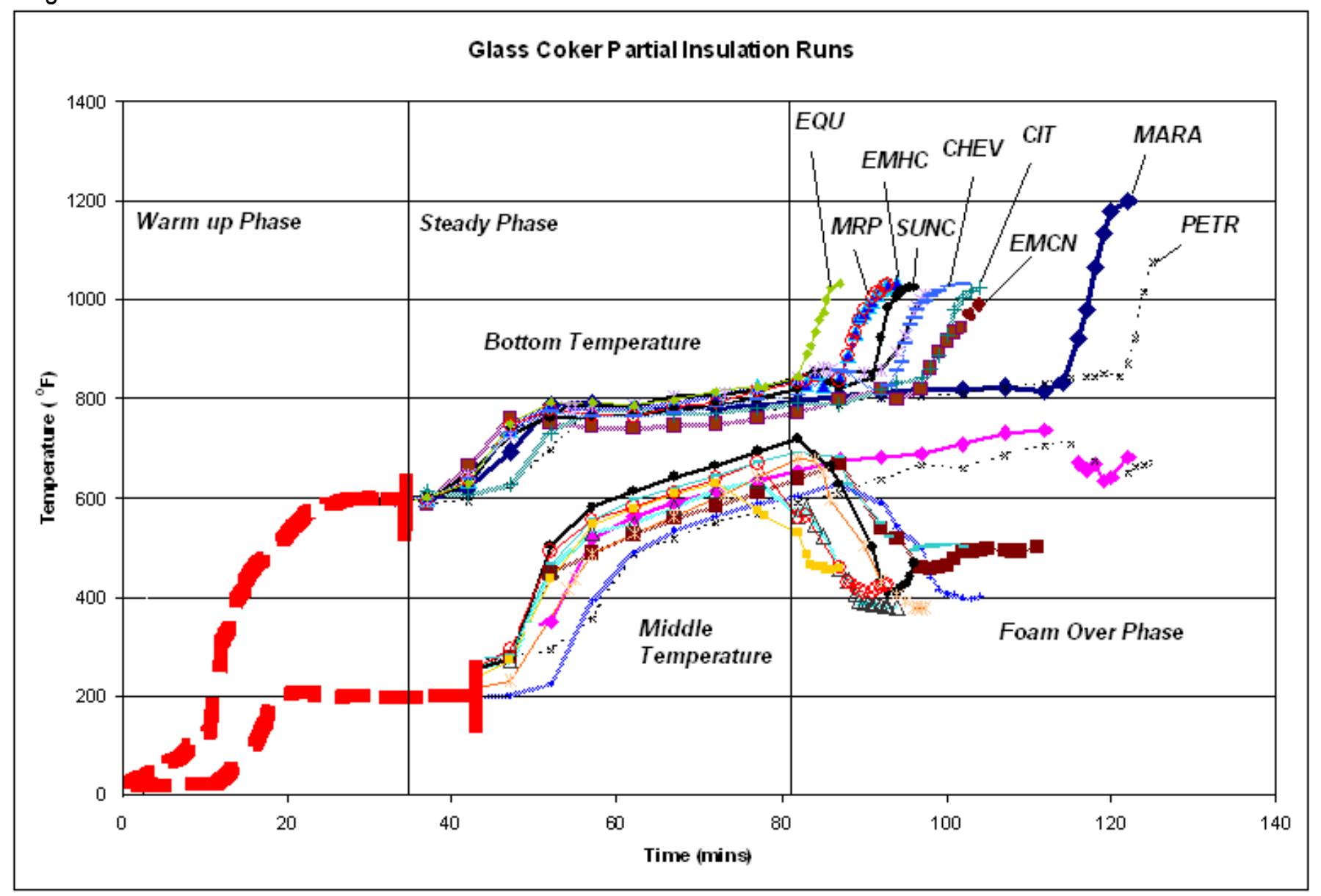

Figure 39: Temperature profile with time for partial insulation glass coker runs. 


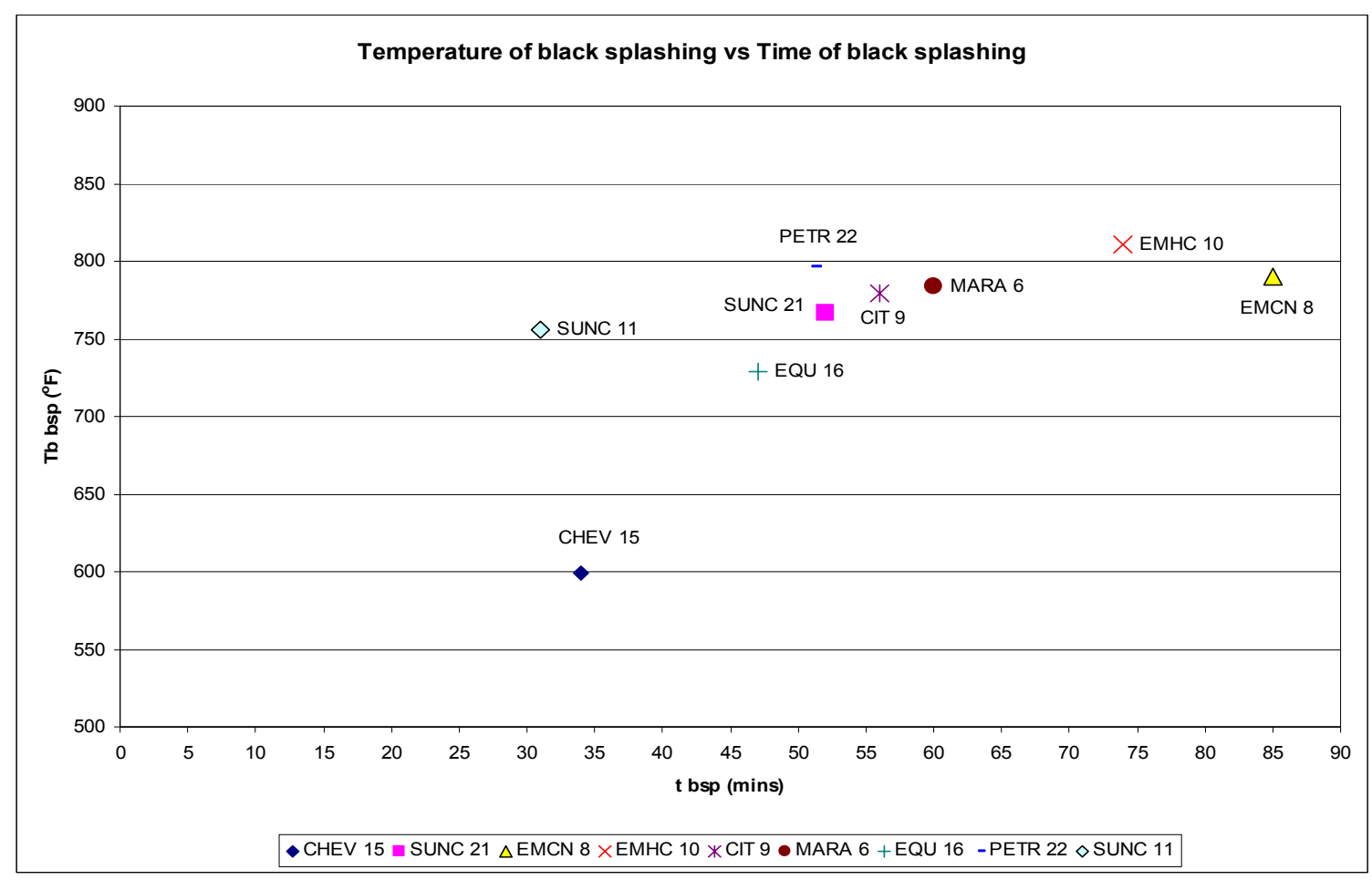

Figure 40 - Bottom Temperature of first recorded black splashing vs time of black splashing for partially insulated glass coker runs

\section{E. RANKING OF RESIDS:}

Based on the time it took for a particular resid to foam over, a preliminary ranking of resids in terms of worst to least foamer is determined. With a constant power output, a resid first warms up to $600^{\circ} \mathrm{F}$ then it stabilizes and the phenomenon of black splashing accompanied by white color smoke occurs. The black splashing increases with time for the shot making resids compared to the sponge making resids. The wall of the flask gets partially coated with black material due to the splashing. After reaching a temperature of around $800^{\circ} \mathrm{F}$, vigorous boiling accompanied by different color vapors (can due to the presence of sulfur and its compounds) starts to occur which eventually leads to foam over.

The visual observation of the spontaneity of boiling along with white color vapors and also the time required to reach the foam over point determines the rank of a particular resid. Based on these above criteria a preliminary ranking of resids on their foaming consistency was developed.

With the current dynamics of the glass coker flask, it is difficult to inject antifoam and collapse the foam and maintain the foaming tendencies of a particular resid. Future modifications to the glass coker should allow us to inject antifoam and thereby maintain the persistency of foaming observed with different resids. 


\section{F. CONCLUSIONS}

The temperatures of the resid data obtained through the tests provide vital insight to foam behavior. The tests also provided a comparison of the foaming characteristics of the nine in-house resids and strategic resid mixtures.

In general, the classification is close to what we see in the pilot unit. The only major difference is that Cerro Negro was the worst foamer in the pilot whereas in the glass coker it was $4^{\text {th }}$. In future work it is proposed to carry on with resid testing and obtain relevant working data for the model along with further improvement of procedures for testing resids. Also it is proposed to improve the existing testing equipment by bringing in a constant diameter reaction vessel as a possible future complement to the side arm flask for performing the resid testing.

These preliminary studies provided justification that valuable data could be obtained and that experimentation should be carried up to the next level. 
The University of Tulsa

\section{Batch Reactor Studies}

\section{A. BACKGROUND}

Previous work in the Fundamentals of Delayed Coking Joint Industry Project has resulted in the successful development of a kinetic model for describing the rate of production of gas and liquid products from the delayed coker. This model was shown to be successful at matching product formation data from the batch reactor for each feedstock tested. The model uses a lumping approach with three parallel reactions that produce gasoline, diesel, gas oil, gas, and an intermediate that forms coke. The model uses one activation energy and three frequency factors for the three reactions to successfully predict the production of liquid and its sub-products within $\pm 2.8 \%$ error of the experimental data.

Although this model has been quite successful, three particular shortcomings were noted: (1) experimental data from the batch reactor for which the model was developed lacked a sufficient number of product samples over time to allow the model to accurately distinguish activation energies; (2) there were no experimental data on coke formation, so the coke-formation kinetic expression in the model could not be experimentally confirmed; and (3) only the original six in-house resids were tested, which meant there was not enough feedstock variation to ascertain the particular feedstock properties that account for kinetic variations. As a consequence, we have undertaken continued batch reactor studies, with the aim of expanding the feedstock base, collecting more data at different reactor pressures, collecting product liquid data more frequently to allow more accurate model fitting, and conducting insolubles analysis on reactor samples over time to experimentally measure coke precursor and coke formation over time.

\section{B. FACILITY TESTING}

The first runs in the batch reactor were used to test the heating capabilities and the heat loss of the system. The first four runs were made with water. The first run was a system check. It proved the proper function of the data acquisition and controls systems and the new furnace. The three remaining $\mathrm{H}_{2} \mathrm{O}$ runs were all operated at similar conditions. Due to the lag time of the heat entering the system, the system cannot be controlled directly by the internal liquid temperature. A high temperature cutoff system was integrated into the controls system. If either of the elements of the split furnace surpasses the set temperature, the power to the furnace is cut. The output to the furnace is set at $100 \%$ for each run. The computer records the times when the limit switch is tripped. This allows for an exact measurement of the percentage of time the furnace is on and the wattage that is supplied to the system. This will allow for future calculations of the heat losses of the system.

The system was preheated to an element temperature of $400^{\circ} \mathrm{F}$, see Figure 41 . At the start of the run, the element cutoff temperature is set to $1400^{\circ} \mathrm{F}$. The element temperature cycles between $1375^{\circ} \mathrm{F}$ and $1425^{\circ} \mathrm{F}$ throughout the run, see Figure 42 . The furnace continues to cycle until all of the water is vaporized. This can be seen when there is a significant increase in the temperatures throughout the reactor, see Figure 43.

One oil run has been made to date. This run was the first run used to test the liquid separations system. The water runs would have only tested the separation of the lights because the heavy liquids tank is maintained at $300+^{\circ} \mathrm{F}$. The oil used was a vacuum pump oil. The boiling point curve for this oil was 
made available via the internet. Its IBP was approximately $720^{\circ} \mathrm{F}$ and $100 \%$ boiling was around $1004^{\circ} \mathrm{F}$, see Figure 44. For the oil run, the warm up and run element temperatures were set at $600^{\circ} \mathrm{F}$ and $1400^{\circ} \mathrm{F}$, see Figure 45 and Figure 46 . The separations system successfully stepped through each of the tanks using level and temperature limits.

Three runs have been completed using 100\% Marathon recycle. The data obtained from these runs is shown in Table 18. The data includes recoveries and cut weights for each of the liquid tanks. The three runs showed very comparable recoveries, see Figure 47 . The simulated distillation for each of the liquid fractions has not been completed. The completion of the SimDis could result in an increase in the gas recoveries and a decrease in the liquid recoveries. This is due to the normalization procedure; the masses of all $\mathrm{C}_{3}$ and $\mathrm{C}_{4}$ compounds are subtracted from the liquids and added to the gases. The mass of the $\mathrm{C}_{5}$ and $\mathrm{C}_{6}$ compounds in the gases have been added to the liquid cut.

The operating procedure used in the old batch reactor runs was used as a guide for the operation of the new batch reactor recycle runs. For warm-up, the furnace element cutoff temperature was set to $700^{\circ} \mathrm{F}$. This correlated to an internal temperature, $1^{\prime \prime}$ from the bottom of the drum, between $300^{\circ} \mathrm{F}$ and $400^{\circ} \mathrm{F}$. Figure 48 shows the last 60 minutes of the warm-up and the internal temperature profile during the run of MARBR-FT-2.

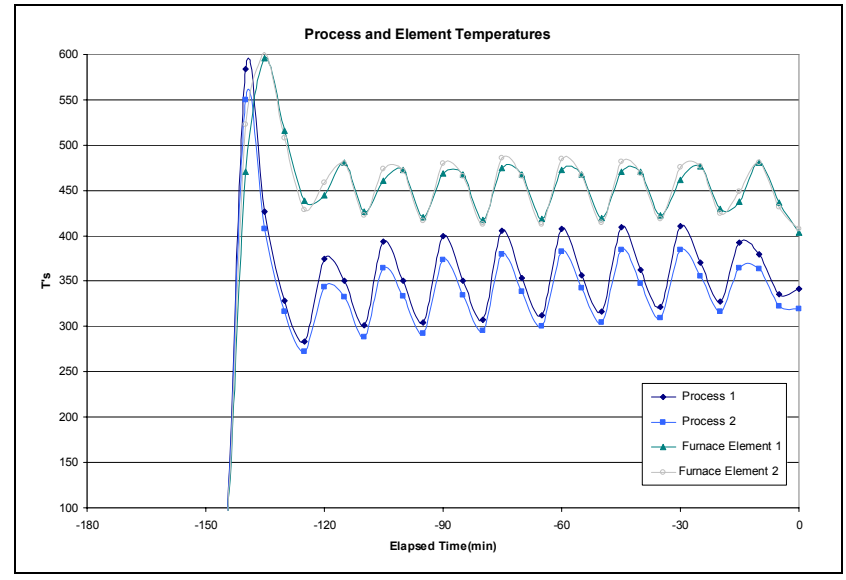

Figure 41 - Batch Element Warm-up Temperature Profile(H2O \#4)

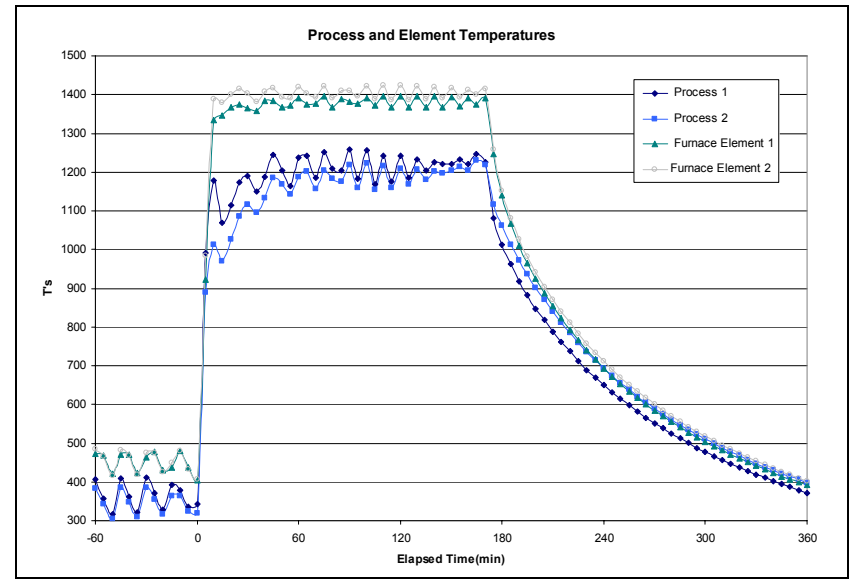

Figure 42 - Batch Element Run Temperature Profile(H2O \#4) 


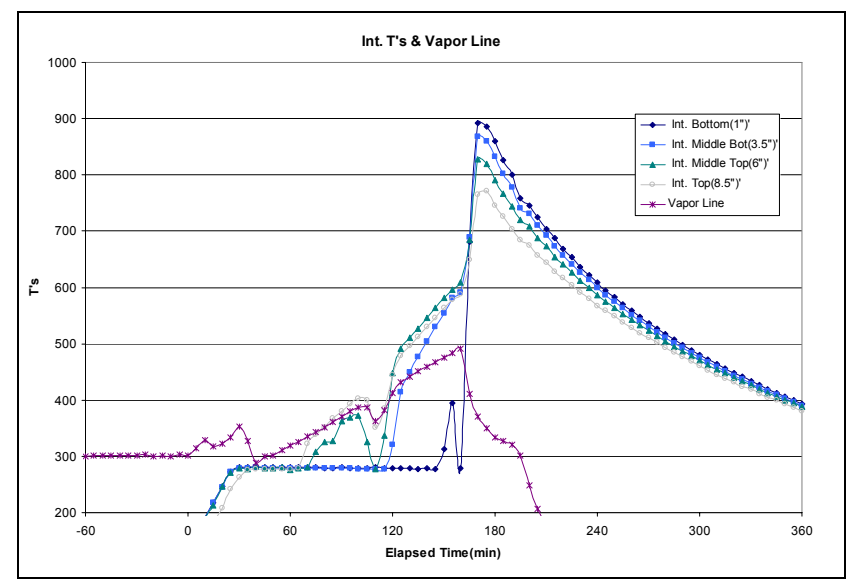

Figure 43 - Batch Internal Run Temperature Profile(H2O \#4)

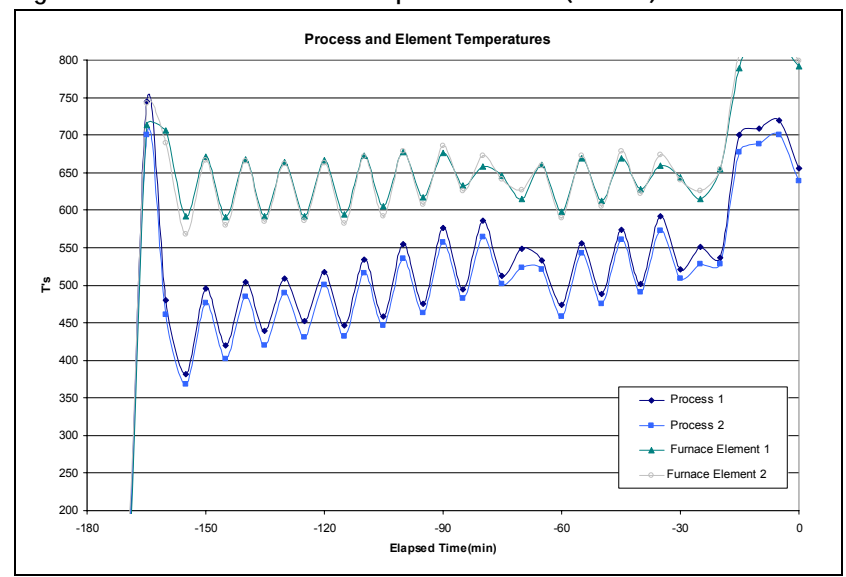

Figure 45 - Batch Element Warm-up Temperature Profile(Oil \#1)

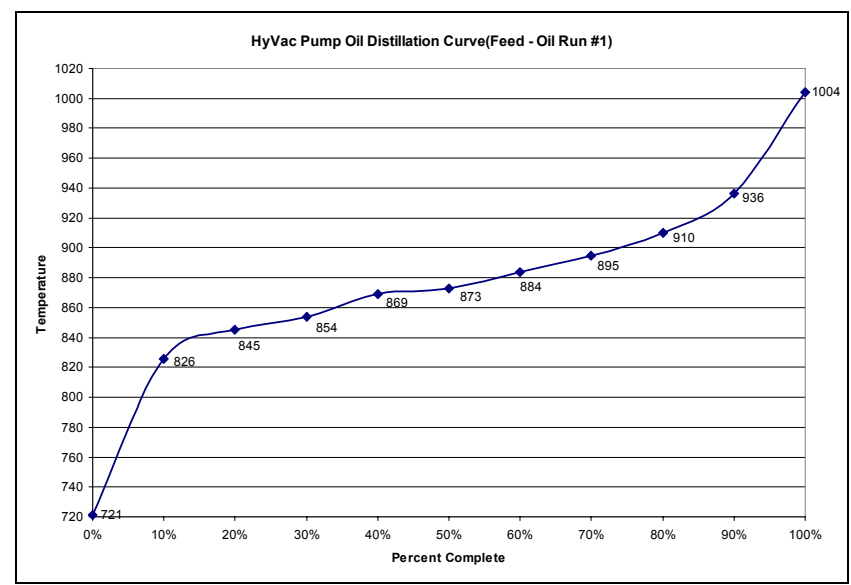

Figure 44 - Batch Vacuum Oil BP Curve(Manufacturer Supplied)

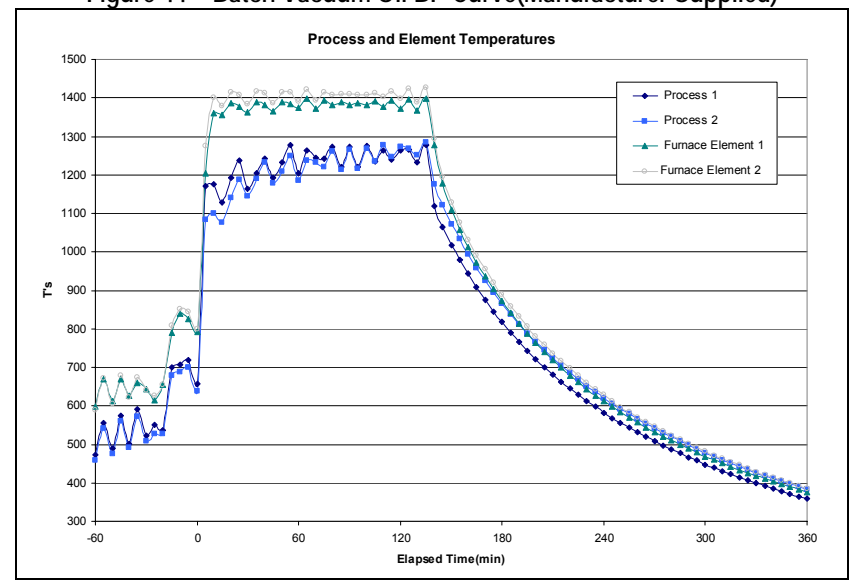

Figure 46 - Batch Element Run Temperature Profile(Oil \#1)

During the run the furnace element temperature was set at $1400^{\circ} \mathrm{F}$ until the internal temperature 1" from the bottom reached approximately $950^{\circ} \mathrm{F}$. The element limit was then set to $100^{\circ} \mathrm{F}$ and the power cut to the elements. The internal temperatures continue to rise during the end of these runs; this will have an affect on the liquid composition and the overall product yields. The temperature profile inside the drum for MARBR-FT-2 can be seen in Figure 48. The next stage of testing will be the shakedown tests. In the shakedown tests, there will be attempts to maintain the internal temperatures at the bottom of the reactor near $930^{\circ} \mathrm{F}$ until the resid has had ample time to react. 
Table 18 - Batch Reactor Facility Testing Data - 100\% Recycle Runs

\begin{tabular}{|c|c|c|c|c|c|c|c|}
\hline & & & \multicolumn{5}{|c|}{ Normalized Recoveries - No C5/C6 Adjustment } \\
\hline & \multicolumn{2}{|c|}{ Run ID } & Coke $\%$ & Liquids $\%$ & Gases\% & Samples & Total\% \\
\hline & \multicolumn{2}{|c|}{ MARBR-FT-1 } & $16.95 \%$ & $73.66 \%$ & $8.17 \%$ & $1.23 \%$ & $100.00 \%$ \\
\hline & \multicolumn{2}{|c|}{ MARBR-FT-2 } & $17.18 \%$ & $73.75 \%$ & $9.07 \%$ & $0.00 \%$ & $100.00 \%$ \\
\hline & \multicolumn{2}{|c|}{ MARBR-FT-3 } & $15.56 \%$ & $74.01 \%$ & $9.01 \%$ & $1.42 \%$ & $100.00 \%$ \\
\hline RunID & \multicolumn{2}{|c|}{ MARBR-FT-1 } & \multicolumn{2}{|c|}{ MARBR-FT-2 } & \multicolumn{2}{|c|}{ MARBR-FT-3 } & Int Temp(1") \\
\hline Tank & Lights & Heavies & Lights & Heavies & Lights & Heavies & Temp. Cutoff \\
\hline Tank 1 & 2.1 & 1.7 & 4.1 & 6.9 & 2.0 & 6.8 & 750 \\
\hline Tank 2 & 0.7 & 7.0 & 2.6 & 7.7 & 0.0 & 7.6 & 775 \\
\hline Tank 3 & 1.3 & 50.8 & 2.0 & 111.6 & 1.1 & 123.7 & 800 \\
\hline Tank 4 & 0.8 & 275.4 & 1.9 & 208.8 & 1.3 & 308.3 & 825 \\
\hline Tank 5 & 8.9 & 327.2 & 4.5 & 249.9 & $\overline{4.4}$ & 291.1 & 850 \\
\hline Tank 6 & 5.0 & 332.9 & 5.7 & 249.4 & 9.6 & 282.9 & 862.5 \\
\hline Tank 7 & 4.2 & 334.5 & 13.1 & 273.0 & 7.3 & 304.6 & 875 \\
\hline Tank 8 & 15.8 & 114.5 & 18.8 & 252.5 & 16.9 & 302.5 & 887.5 \\
\hline Tank 9 & 10.0 & 51.0 & 20.3 & 181.4 & 20.8 & 206.8 & 900 \\
\hline Tank 10 & 15.3 & 63.2 & 12.4 & 48.0 & 14.7 & 53.3 & 915 \\
\hline Tank 11 & 12.6 & 57.0 & 12.9 & 14.9 & 12.1 & 38.1 & 930 \\
\hline Tank 12 & 86.1 & 307.1 & 60.0 & 310.9 & 38.6 & 126.9 & 1000 \\
\hline Main & 131.0 & 5.0 & 10.3 & 124.2 & 21.7 & 33.9 & \\
\hline Total & 293.8 & 1927.3 & 168.6 & 2039.2 & 150.5 & 2086.5 & \\
\hline
\end{tabular}

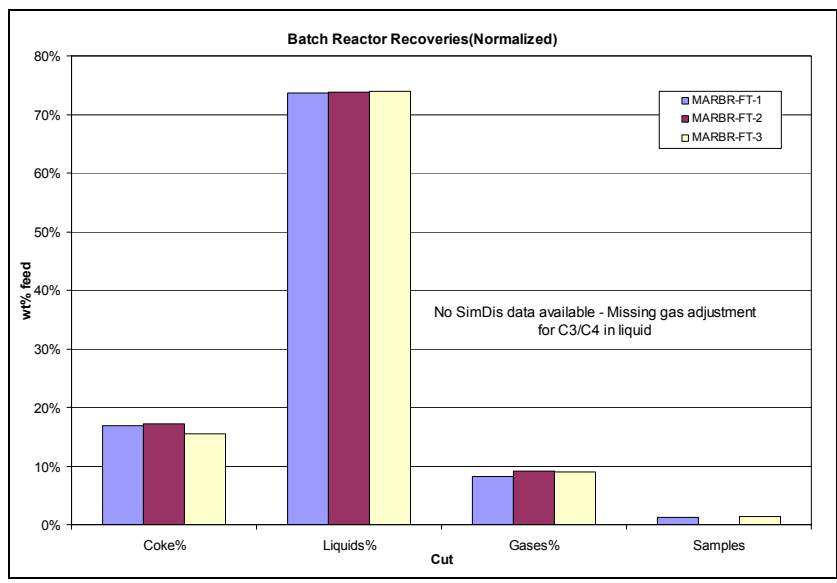

Figure 47 - Batch Facility Testing Recoveries - 100\% Recycle Runs

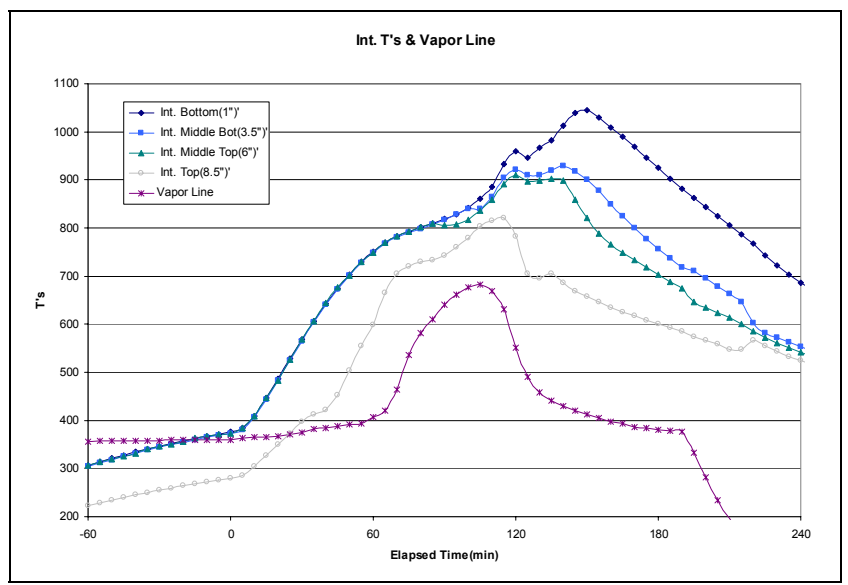

Figure 48 - Batch Facility Testing Recoveries - 100\% Recycle Runs - MARBR-FT-2

\section{PARAMETRIC TESTS}

Forty-eight batch reactor tests were conducted in the new facility using all resids. Operating conditions include $1400^{\circ} \mathrm{F}$ (medium heating) and $1700^{\circ} \mathrm{F}$ (high heating) element temperatures and 15,40 and $60 \mathrm{psig}$ reactor pressures. Runs operated with an element temperature of $1400^{\circ} \mathrm{F}$ generally have a 2$4^{\circ} \mathrm{F} / \mathrm{min}$ increase in the internal temperature at one-inch from the bottom. Runs operated with an element temperature of $1700^{\circ} \mathrm{F}$ generally have a $4+^{\circ} \mathrm{F} / \mathrm{min}$ increase. The un-normalized yields for the batch reactor tests are listed in Table 19. The operating conditions and heating rates can also be found in both tables. The heating rate is calculated as the time it takes to increase the one-inch internal temperature from $775^{\circ} \mathrm{F}$ to $930^{\circ} \mathrm{F}$. 
Table 19 - Batch Reactor - Un-normalized Yields with Internal Sample Weights

\begin{tabular}{|c|c|c|c|c|c|}
\hline & & \multicolumn{3}{|c|}{ CONDITIONS } & \\
\hline Test & & Element & $\mathbf{P}$ & $\begin{array}{l}\text { Heat } \\
\text { Rate }\end{array}$ & $\%$ \\
\hline Number & Date & $\left({ }^{\circ} \mathrm{F}\right)$ & (psig) & ( $\left.{ }^{\circ} \mathrm{F} / \mathrm{min}\right)$ & Total\% \\
\hline CHVBR-1 & $4 / 5 / 2004$ & 1700 & 40 & 7.0 & $96.36 \%$ \\
\hline CHVBR-2 & $4 / 12 / 2004$ & 1700 & 40 & 6.0 & $99.73 \%$ \\
\hline CHVBR-3 & $6 / 14 / 2004$ & 1700 & 15 & 7.8 & $96.39 \%$ \\
\hline CITBR-1 & 9/17/2004 & 1700 & 60 & 5.5 & $97.03 \%$ \\
\hline CITBR-2 & 9/20/2004 & 1700 & 40 & 3.4 & $94.93 \%$ \\
\hline EQBR-2 & $6 / 16 / 2004$ & 1700 & 15 & 5.5 & $102.74 \%$ \\
\hline EQBR-3 & $6 / 21 / 2004$ & 1700 & 40 & 5.7 & $99.25 \%$ \\
\hline PETBR-1-SD & $10 / 15 / 2003$ & 1400 & 40 & 2.3 & $99.48 \%$ \\
\hline PETBR-2-SD & $10 / 17 / 2003$ & 1400 & 40 & 3.1 & $101.97 \%$ \\
\hline PETBR-3-SD & $11 / 3 / 2003$ & 1400 & 40 & 1.6 & $101.59 \%$ \\
\hline PETBR-6-SD & $12 / 17 / 2003$ & 1700 & 40 & 4.7 & $100.47 \%$ \\
\hline PETBR-7-SD & $12 / 22 / 2003$ & 1700 & 40 & 5.5 & $101.24 \%$ \\
\hline PETBR-8-SD & $1 / 7 / 2004$ & 1700 & 40 & 4.6 & $100.68 \%$ \\
\hline PETBR-9 & $2 / 19 / 2004$ & 1400 & 15 & 3.3 & $98.60 \%$ \\
\hline PETBR-10 & $2 / 27 / 2004$ & 1700 & 15 & 5.5 & $98.34 \%$ \\
\hline SUNBR-1 & $3 / 3 / 2004$ & 1400 & 15 & 2.5 & $97.07 \%$ \\
\hline SUNBR-2 & $3 / 8 / 2004$ & 1700 & 15 & 6.5 & $97.91 \%$ \\
\hline SUNBR-3 & $3 / 10 / 2004$ & 1400 & 40 & 3.2 & $102.23 \%$ \\
\hline SUNBR-4 & $3 / 15 / 2004$ & 1700 & 40 & 6.2 & $102.63 \%$ \\
\hline EMHCBR-1 & $8 / 4 / 2004$ & 1700 & 15 & 9.7 & $97.11 \%$ \\
\hline EMHCBR-2 & $8 / 6 / 2004$ & 1400 & 15 & 4.2 & $98.92 \%$ \\
\hline EMHCBR-3 & $8 / 9 / 2004$ & 1400 & 40 & 5.0 & $99.10 \%$ \\
\hline EMHCBR-4 & $8 / 11 / 2004$ & 1700 & 40 & 7.4 & $100.40 \%$ \\
\hline EMHCBR-5 & $8 / 23 / 2004$ & 1400 & 60 & 3.4 & $99.59 \%$ \\
\hline EMHCBR-6 & $8 / 25 / 2004$ & 1700 & 60 & 7.8 & $95.84 \%$ \\
\hline RPBR-1 & $8 / 13 / 2004$ & 1400 & 40 & 2.7 & $100.04 \%$ \\
\hline RPBR-2 & $8 / 16 / 2004$ & 1700 & 40 & 6.5 & $97.40 \%$ \\
\hline RPBR-3 & $8 / 18 / 2004$ & 1400 & 15 & 3.7 & $99.41 \%$ \\
\hline RPBR-4 & $8 / 19 / 2004$ & 1700 & 15 & 7.4 & $95.62 \%$ \\
\hline RPBR-5 & 9/1/2004 & 1700 & 60 & 5.2 & $98.94 \%$ \\
\hline RPBR-6 & $9 / 3 / 2004$ & 1400 & 60 & 3.2 & $100.59 \%$ \\
\hline
\end{tabular}

\section{HeAting RATES}

All runs are classified by operating pressure and heating rate. The three classifications of runs by heating rate are low, medium and high. The heating rates are calculated by determining the time it takes for the internal temperature at one-inch from the bottom of the liner to increase from $775^{\circ} \mathrm{F}$ to $930^{\circ} \mathrm{F}$. The low heating rate runs are those run in the old facility. They generally saw an increase of the internal temperature at a rate of less than $2^{\circ} \mathrm{F} / \mathrm{min}$. The new facility runs are classified by the element temperature set point. The two setting used are $1400^{\circ} \mathrm{F}$ and $1700^{\circ} \mathrm{F}$. The $1400^{\circ} \mathrm{F}$ element temperature runs, depending on the resid, normally saw an increase in the temperature at a rate of $2-4^{\circ} \mathrm{F} / \mathrm{min}$. The number of runs outside this range are limited but one case saw the temperature rise at a rate as fast as $5^{\circ} \mathrm{F} / \mathrm{min}$ (EMHCBR- 
3). The $1700^{\circ} \mathrm{F}$ element runs had heating rates in excess of $4^{\circ} \mathrm{F} / \mathrm{min}$. The maximum heating rate for a high heating rate run was a 15 psig, Heavy Canadian run(EMHCBR-1).

The fluctuations in yields have been calculated in Table 20. The values have been separated by operating pressure for each resid and show the direction of the fluctuation as the temperature of the heating elements was changed from $1400^{\circ} \mathrm{F}$ to $1700^{\circ} \mathrm{F}$. In most cases, as the temperature was increased, the coke yields decreased and the liquid yields increased. The gas yield fluctuations were resid dependent.

Table 20 - Batch Reactor - Yield Fluctuations Due to Heating Rate

\begin{tabular}{|c|c|c|c|c|c|c|c|c|c|c|}
\hline & Pressure & \multicolumn{3}{|c|}{15 psig } & \multicolumn{3}{|c|}{40 psig } & \multicolumn{3}{|c|}{60 psig } \\
\hline & & Coke & Liq & Gas & Coke & Liq & Gas & Coke & Liq & Gas \\
\hline $\begin{array}{l}\text { Chevron } \\
\text { (No 1400's) }\end{array}$ & $\begin{array}{c}1400 \text { to } \\
1700\end{array}$ & 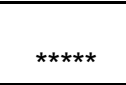 & 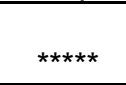 & 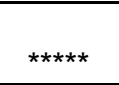 & 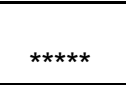 & $\star * \star * \star *$ & 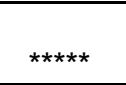 & 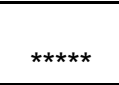 & 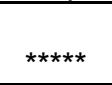 & 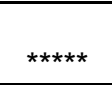 \\
\hline $\begin{array}{c}\text { Citgo } \\
\text { (No 1400's) }\end{array}$ & $\begin{array}{c}1400 \text { to } \\
1700\end{array}$ & $\star \star * * * *$ & $\star * * \star * *$ & 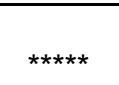 & 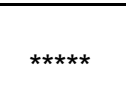 & 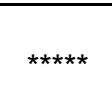 & 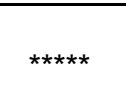 & 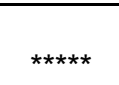 & 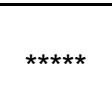 & 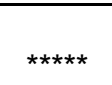 \\
\hline $\begin{array}{l}\text { Equilon } \\
\text { (No 1400's) }\end{array}$ & $\begin{array}{c}1400 \text { to } \\
1700\end{array}$ & $* * * * *$ & $* * * * *$ & $* * * * *$ & $\star * \star \star \star \star *$ & 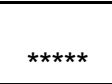 & $* * * * *$ & $* * \star \star *$ & $* * * * *$ & 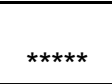 \\
\hline Petrobras & $\begin{array}{c}1400 \text { to } \\
1700\end{array}$ & $-1.90 \%$ & $-0.73 \%$ & $2.63 \%$ & $-3.57 \%$ & $3.89 \%$ & $-0.32 \%$ & 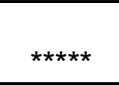 & 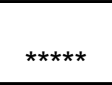 & 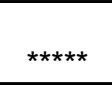 \\
\hline Suncor & $\begin{array}{c}1400 \text { to } \\
1700\end{array}$ & $-1.53 \%$ & $-0.16 \%$ & $1.69 \%$ & $-3.20 \%$ & $0.83 \%$ & $2.37 \%$ & $* * * * *$ & $* * * * *$ & 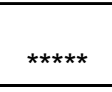 \\
\hline $\begin{array}{l}\text { Heavy } \\
\text { Can. }\end{array}$ & $\begin{array}{c}1400 \text { to } \\
1700\end{array}$ & $-2.69 \%$ & $1.51 \%$ & $1.18 \%$ & $-3.67 \%$ & $2.61 \%$ & $1.06 \%$ & $-0.62 \%$ & $0.13 \%$ & $0.50 \%$ \\
\hline Rose & 1400 to & $-385 \%$ & $624 \%$ & $-238 \%$ & $-378 \%$ & $577 \%$ & $-199 \%$ & $-1.96 \%$ & $2.60 \%$ & $-0.64 \%$ \\
\hline & & & $0.24 \%$ & $-2.38 \%$ & $-3.18 \%$ & $5.11 \%$ & $-1.99 \%$ & $-1.96 \%$ & $2.00 \%$ & $-0.04 \%$ \\
\hline
\end{tabular}

The minimum, maximum and average heating rates have been calculated for each resid at each of the two element set points and are listed in Table 21 and Table 22. Table 21 includes all resids by combining all operating pressures and for the 15 psig runs. Table 22 includes all resid runs at 40 and 60 psig. Under all operating pressures and heater element settings, Heavy Canadian was the fastest heating resid. 
Table 21 - Batch Reactor Testing - Heating Rate Effects(All \& 15 psig)

\begin{tabular}{|c|c|c|c|c|c|c|c|c|c|}
\hline All Runs & & & $\begin{array}{c}\text { Low Rate } \\
\left(1400^{\circ} \mathrm{F}\right)\end{array}$ & $\begin{array}{l}\text { High Rate } \\
\left(1700^{\circ} \mathrm{F}\right)\end{array}$ & 15 psig & & & $\begin{array}{l}\text { Low Rate } \\
\left(1400^{\circ} \mathrm{F}\right)\end{array}$ & \begin{tabular}{|l} 
High Rate \\
$\left(1700^{\circ} \mathrm{F}\right)$
\end{tabular} \\
\hline & \multirow{3}{*}{$\begin{array}{l}\text { Chevron } \\
\text { (3 runs) }\end{array}$} & $\max$ & 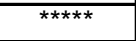 & 7.8 & & \multirow{3}{*}{$\begin{array}{c}\text { Chevron } \\
\text { (1 run) }\end{array}$} & $\max$ & $\star \star \star \star \star \star *$ & 7.8 \\
\hline & & $\min$ & 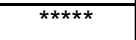 & 6.0 & & & $\min$ & 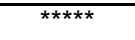 & 7.8 \\
\hline & & avg & $\star \star \star * \star \star *$ & 6.9 & & & avg & 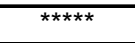 & 7.8 \\
\hline & & & & & & & & & \\
\hline & \multirow{3}{*}{$\begin{array}{c}\text { Citgo } \\
\text { (3 runs) }\end{array}$} & max & 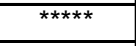 & 5.7 & & \multirow{3}{*}{$\begin{array}{c}\text { Citgo } \\
\text { (1 run) }\end{array}$} & max & 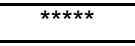 & 5.7 \\
\hline & & $\min$ & 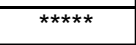 & 3.4 & & & $\min$ & 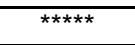 & 5.7 \\
\hline & & avg & $* * * * *$ & 4.9 & & & avg & $\star * * \star * *$ & 5.7 \\
\hline & & & & & & & & & \\
\hline & \multirow{3}{*}{$\begin{array}{l}\text { Equilon } \\
\text { ( } 2 \text { runs) }\end{array}$} & $\max$ & 3.2 & 5.7 & & \multirow{3}{*}{$\begin{array}{l}\text { Equilon } \\
\text { (1 run) }\end{array}$} & $\max$ & 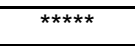 & 5.5 \\
\hline & & $\min$ & 3.2 & 5.5 & & & $\min$ & $\star * * * * *$ & 5.5 \\
\hline & & avg & 3.2 & 5.6 & & & avg & 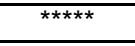 & 5.5 \\
\hline & & & & & & & & & \\
\hline & \multirow{3}{*}{$\begin{array}{l}\text { Petrobras } \\
\text { (8 runs) }\end{array}$} & max & 3.3 & 5.5 & & \multirow{3}{*}{$\begin{array}{c}\text { Petrobras } \\
\text { (2 runs) }\end{array}$} & $\max$ & 3.3 & 5.5 \\
\hline & & $\min$ & 1.6 & 4.6 & & & min & 3.3 & 5.5 \\
\hline & & avg & 2.6 & 5.1 & & & avg & 3.3 & 5.5 \\
\hline & & & & & & & & & \\
\hline & \multirow{3}{*}{$\begin{array}{l}\text { Suncor } \\
\text { (4 runs) }\end{array}$} & max & 3.2 & 6.5 & & \multirow{3}{*}{$\begin{array}{l}\text { Suncor } \\
\text { (2 runs) }\end{array}$} & max & 2.5 & 6.5 \\
\hline & & $\min$ & 2.5 & 6.2 & & & $\min$ & 2.5 & 6.5 \\
\hline & & avg & 2.8 & 6.3 & & & avg & 2.5 & 6.5 \\
\hline & & & & & & & & & \\
\hline & \multirow{3}{*}{$\begin{array}{c}\text { Heavy Can. } \\
\text { (6 runs) }\end{array}$} & max & 5.0 & 9.7 & & \multirow{3}{*}{$\begin{array}{c}\text { Heavy Can. } \\
\text { (2 runs) }\end{array}$} & max & 4.2 & 9.7 \\
\hline & & $\min$ & 3.4 & 7.4 & & & min & 4.2 & 9.7 \\
\hline & & avg & 4.2 & 8.3 & & & avg & 4.2 & 9.7 \\
\hline & & & & & & & & & \\
\hline & \multirow{3}{*}{$\begin{array}{c}\text { Rose Pitch } \\
\text { (6 runs) }\end{array}$} & max & 3.7 & 7.4 & & \multirow{3}{*}{$\begin{array}{c}\text { Rose Pitch } \\
\text { (2 runs) }\end{array}$} & $\max$ & 3.7 & 7.4 \\
\hline & & $\min$ & 2.7 & 5.2 & & & min & 3.7 & 7.4 \\
\hline & & avg & 3.2 & 6.3 & & & avg & 3.7 & 7.4 \\
\hline & \multicolumn{4}{|c|}{${ }^{*}$ No runs made } & & \multicolumn{4}{|c|}{${ }^{\star}$ No runs made } \\
\hline
\end{tabular}


Table 22 - Batch Reactor Testing - Heating Rate Effects(40 \& 60 psig)

\begin{tabular}{|c|c|c|c|c|c|c|c|c|c|}
\hline 40 psig & & & \begin{tabular}{|l} 
Low Rate \\
$\left(1400^{\circ} \mathrm{F}\right)$
\end{tabular} & $\begin{array}{l}\text { High Rate } \\
\left(1700^{\circ} \mathrm{F}\right)\end{array}$ & 60 psig & & & \begin{tabular}{|l} 
Low Rate \\
$\left(1400^{\circ} \mathrm{F}\right)$
\end{tabular} & $\begin{array}{l}\text { High Rate } \\
\left(1700^{\circ} \mathrm{F}\right)\end{array}$ \\
\hline & \multirow{3}{*}{$\begin{array}{c}\text { Chevron } \\
\text { (1 run) }\end{array}$} & $\max$ & 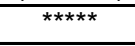 & 7.0 & & \multirow{3}{*}{$\begin{array}{l}\text { Chevron } \\
\text { (0 runs) }\end{array}$} & $\max$ & $\star * * * * *$ & $* * * * *$ \\
\hline & & $\min$ & $* * * * *$ & 6.0 & & & $\min$ & $* * * * *$ & $* * * * *$ \\
\hline & & avg & 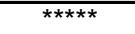 & 6.5 & & & avg & 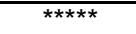 & 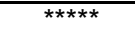 \\
\hline & & & & & & & & & \\
\hline & \multirow{3}{*}{$\begin{array}{c}\text { Citgo } \\
\text { (1 run) }\end{array}$} & $\max$ & $* * * \star *$ & 3.4 & & \multirow{3}{*}{$\begin{array}{c}\text { Citgo } \\
\text { (1 run) }\end{array}$} & $\max$ & $* * * * *$ & 5.5 \\
\hline & & $\min$ & $* * * \star \star$ & 3.4 & & & $\min$ & $\star * \star * \star *$ & 5.5 \\
\hline & & avg & $* * * * *$ & 3.4 & & & avg & $* * * * *$ & 5.5 \\
\hline & & & & & & & & & \\
\hline & \multirow{3}{*}{$\begin{array}{c}\text { Equilon } \\
\text { (1 run) }\end{array}$} & $\max$ & $* * * * *$ & 5.7 & & \multirow{3}{*}{$\begin{array}{l}\text { Equilon } \\
\text { (0 runs) }\end{array}$} & $\max$ & $* * * * *$ & $* * * * *$ \\
\hline & & $\min$ & $* * * \star *$ & 5.7 & & & $\min$ & $* * * * *$ & $* \star * * * *$ \\
\hline & & avg & $* * * * *$ & 5.7 & & & avg & $\star * \star * \star *$ & $\star * * * *$ \\
\hline & & & & & & & & & \\
\hline & \multirow{3}{*}{$\begin{array}{c}\text { Petrobras } \\
\text { (2 runs) }\end{array}$} & $\max$ & 3.1 & 5.5 & & \multirow{3}{*}{$\begin{array}{c}\text { Petrobras } \\
\text { (0 runs) }\end{array}$} & $\max$ & $\star \star \star \star \star \star *$ & $\star \star * \star * \star$ \\
\hline & & $\min$ & 1.6 & 4.6 & & & $\min$ & $* * * * *$ & $* * * * *$ \\
\hline & & avg & 2.3 & 4.9 & & & avg & $* * * * *$ & $* * * * *$ \\
\hline & & & & & & & & & \\
\hline & \multirow{3}{*}{$\begin{array}{l}\text { Suncor } \\
\text { (2 runs) }\end{array}$} & $\max$ & 3.2 & 6.2 & & \multirow{3}{*}{$\begin{array}{l}\text { Suncor } \\
\text { (0 runs) }\end{array}$} & $\max$ & $\star \star * \star * *$ & $* * * * *$ \\
\hline & & $\min$ & 3.2 & 6.2 & & & $\min$ & $\star \star \star * \star *$ & $\star * \star * \star *$ \\
\hline & & avg & 3.2 & 6.2 & & & avg & $\star * * * *$ & $* * * * *$ \\
\hline & \multirow{4}{*}{$\begin{array}{c}\text { Heavy Can. } \\
\text { (2 runs) }\end{array}$} & & & & & \multirow{4}{*}{$\begin{array}{c}\text { Heavy Can. } \\
\text { (2 runs) }\end{array}$} & & & \\
\hline & & $\max$ & 5.0 & 7.4 & & & $\max$ & 3.4 & 7.8 \\
\hline & & $\min$ & 5.0 & 7.4 & & & $\min$ & 3.4 & 7.8 \\
\hline & & avg & 5.0 & 7.4 & & & avg & 3.4 & 7.8 \\
\hline & \multirow{3}{*}{$\begin{array}{c}\text { Rose Pitch } \\
\text { (2 runs) }\end{array}$} & Imax & 27 & 65 & & \multirow{3}{*}{$\begin{array}{c}\text { Rose Pitch } \\
\text { (2 runs) }\end{array}$} & Imay & 32 & $5 ?$ \\
\hline & & \begin{tabular}{|l}
$\min$ \\
\end{tabular} & 2.7 & 6.5 & & & \begin{tabular}{|l|l} 
min \\
\end{tabular} & 0.2 & 0.2 \\
\hline & & \begin{tabular}{|l} 
avg \\
\end{tabular} & 2.7 & 6.5 & & & 足 & 32 & 52 \\
\hline & \multicolumn{4}{|c|}{ * No runs made } & & \multicolumn{4}{|c|}{ * No runs made } \\
\hline
\end{tabular}

\section{E. Pressure Effects}

Three operating pressures were used $-15,40$ and 60 psig. The fluctuations due to pressure of each of the yields are organized by resid and heating rate in Table 23 . In nearly every case, as the pressure in increased from 15 to $40 \mathrm{psig}$ or 40 to $60 \mathrm{psig}$ for a set element temperature set point, the coke yields increased, the liquid yields decreased and the gas yields increased. In the cases where these trends were not followed, the changes can be explained by analyzing the temperature profiles differences between the runs. The most dramatic changes in yields were when the pressure was increased from 15 to $40 \mathrm{psig}$. In the majority of the resids, the coke yields increased from 2 to 4 percent and the liquids decreased from 3 to 5 percent. The fluctuations as the pressure was increased from 40 to 60 psig were not as dramatic. This is not the trend for all resids, the Heavy Canadian resid saw an increase in the coke yields of 3.5 percent and a decrease in the liquid yields of 3.2 percent for the 40 to 60 psig increase. 
Table 23 - Yield Fluctuations Due to Pressure

\begin{tabular}{|c|c|c|c|c|c|c|c|}
\hline & Pressure & \multicolumn{3}{|c|}{1400} & \multicolumn{3}{|c|}{1700} \\
\hline & & Coke & Liq & Gas & Coke & Liq & Gas \\
\hline Chevron & 15 to 40 & 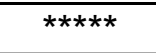 & $\overline{\star \star \star \star \star \star \star ~}$ & 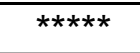 & $3.73 \%$ & $-6.55 \%$ & $2.82 \%$ \\
\hline Citgo & 15 to 40 & 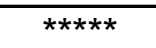 & $\star * * \star * *$ & 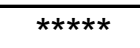 & 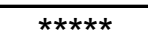 & 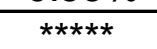 & $\star \star * \star \star * *$ \\
\hline & 40 to 60 & $\overline{\star \star \star \star \star \star \star}$ & 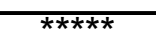 & 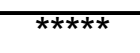 & $-0.31 \%$ & $-2.91 \%$ & $3.22 \%$ \\
\hline Equilon & 15 to 40 & $\star \star * \star * *$ & ***** & ***** & $3.82 \%$ & $-5.88 \%$ & $2.07 \%$ \\
\hline Petrobras & 15 to 40 & $4.01 \%$ & $-5.09 \%$ & $1.08 \%$ & $2.35 \%$ & $-0.47 \%$ & $-1.87 \%$ \\
\hline Suncor & 15 to 40 & $2.44 \%$ & $-5.60 \%$ & $3.16 \%$ & $0.76 \%$ & $-4.61 \%$ & $3.84 \%$ \\
\hline $\begin{array}{l}\text { Heavy } \\
\text { Can. }\end{array}$ & 15 to 40 & $2.37 \%$ & $-2.91 \%$ & $0.54 \%$ & $1.40 \%$ & $-1.81 \%$ & $0.41 \%$ \\
\hline & 40 to 60 & $0.52 \%$ & $-0.73 \%$ & $0.21 \%$ & $3.56 \%$ & $-3.21 \%$ & $-0.35 \%$ \\
\hline Rose & & & & & & & \\
\hline Pitch & 15 to 40 & $3.20 \%$ & $-3.37 \%$ & $0.16 \%$ & $3.28 \%$ & $-3.83 \%$ & $0.56 \%$ \\
\hline & 40 to 60 & $-0.48 \%$ & $-0.40 \%$ & $0.88 \%$ & $1.33 \%$ & $-3.56 \%$ & $2.23 \%$ \\
\hline
\end{tabular}

\section{F. SIMDIS}

Forty-seven runs were successfully completed with the batch reactor. These runs have a capability of producing liquids in twenty-seven separate tanks. Thirteen of these tanks are lights liquid tanks and the remaining fourteen are heavy liquid tanks. Thus, the maximum number of samples that could have been produced by these 47 runs was approximately 1290 samples. Any cut that did not produce more than 5 grams was collected but not utilized in the analysis. The justification for not analyzing this small of a sample is that 5 grams constitutes 0.1 percent of the total feed. Any analysis on a sample less than 5 grams would have very little effect on the overall analysis of the liquid sub-product data set. It was very common for many of the heavy and light samples at the beginning of each run to not produce enough liquids to be collected. In total there are approximately 890 samples that are to be analyzed. Of these 890 samples, 360 samples are light liquid samples and the remaining 530 are heavy liquid samples.

The thirteen light liquid samples for each run are referred to as samples L1 trough L12 and LM; M indicating the main light liquid tank. The heavy liquid tanks are referred to as $\mathrm{H} 1$ through $\mathrm{H} 12, \mathrm{HM}$ and Flash. The flash tank is the first tank that the vaporized liquids and gases flow through after leaving the reactor. The purpose of this flask is to protect the separation manifold on the main heavy tank from plugging due to displaced coke fines leaving the reactor.

For plotting purposes, each of the samples was associated with its sample cutoff temperature. The sample cutoff temperature is the internal temperature 1" from the bottom at the time that the system switches to the next tank. The control system was designed with three switching set points. The first is a temperature set point, the second is a tank level set point and the third is an elapsed time set point. At any point, if any of the three set points of each respective tank is exceeded, the system advances to the next tank in the series. The primary switching mode is based on the internal temperature. The secondary and 
tertiary modes are back-ups to protect the liquid collection system. The $\mathrm{L} 1$ and $\mathrm{H} 1$ samples for each run contain all of the light and heavy liquids that were collected until the internal temperature reached $775^{\circ} \mathrm{F}$. Likewise the $\mathrm{L} 2$ and $\mathrm{H} 2$ samples are the light and heavy liquids collected from the time the internal temperature reached $775^{\circ} \mathrm{F}$ and the time it reached $800^{\circ} \mathrm{F}$. This system continues in this manner until the internal temperature reaches $1000^{\circ} \mathrm{F}$. In the case that one of the collection tanks reaches a level that is greater than $80 \%$ of the maximum capacity of that tank, the control system proceeds with the secondary switching mode.

As a preliminary check of data quality, all liquid product production, total and sub-products, were plotted as a function of temperature for each run. The purpose of this was to verify that the data sets followed all expected trends. Figure 49 through Figure 54 are plots showing the rate of production of diesel and gas oil versus the internal

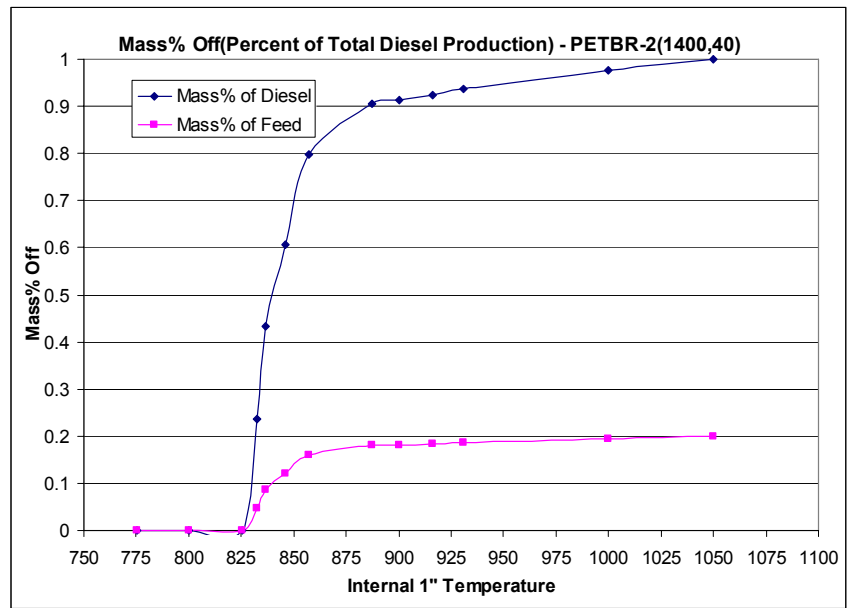

Figure 49 - Batch Reactor Studies - SimDis - PETBR-2

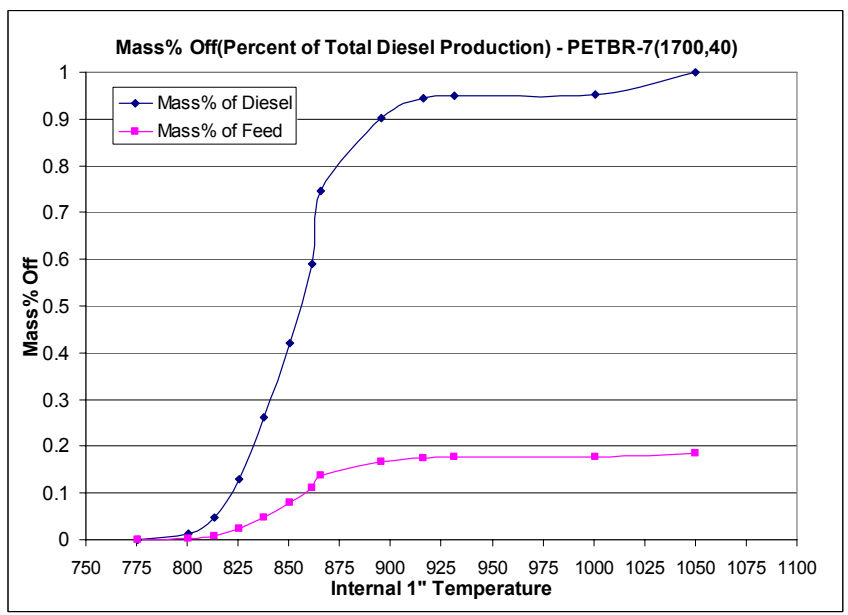

Figure 51 - Batch Reactor Studies - SimDis - PETBR-7

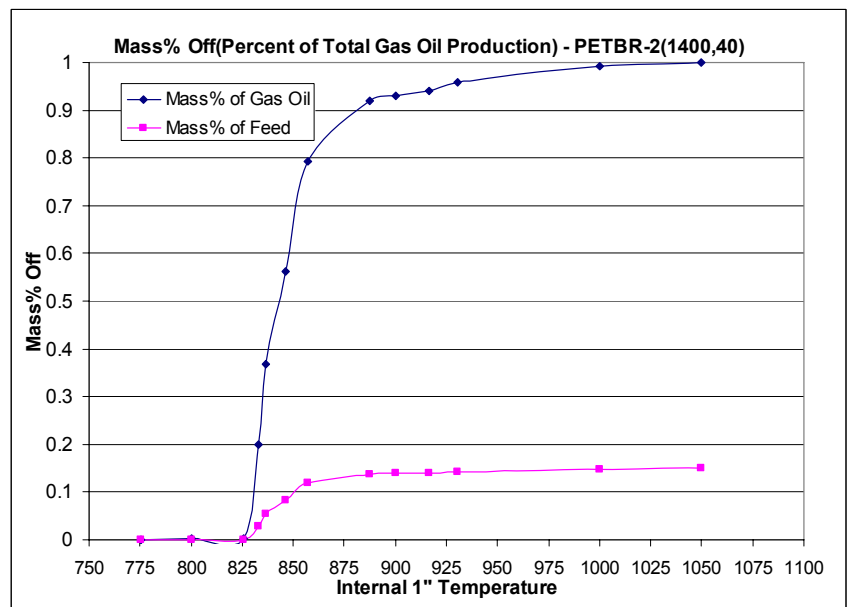

Figure 50 - Batch Reactor Studies - SimDis - PETBR-2

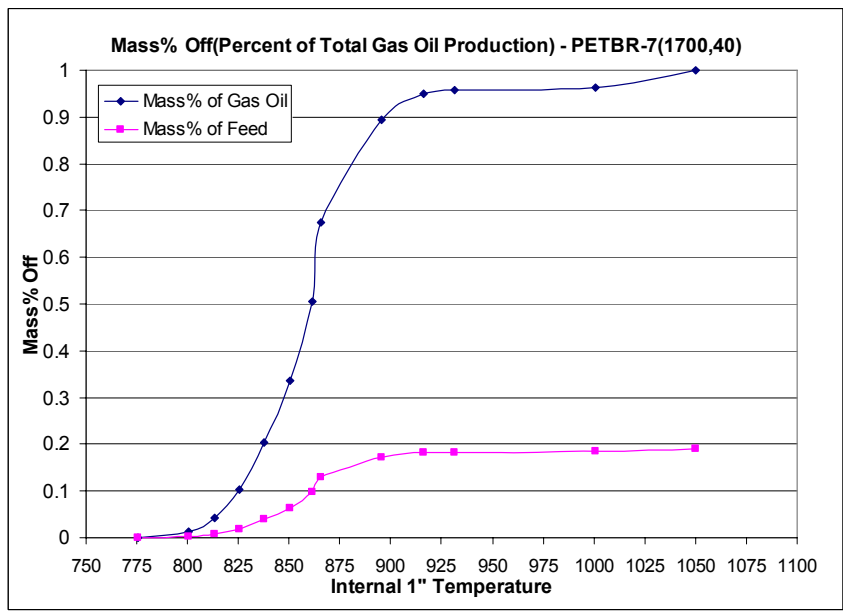

Figure 52 - Batch Reactor Studies - SimDis - PETBR-7 


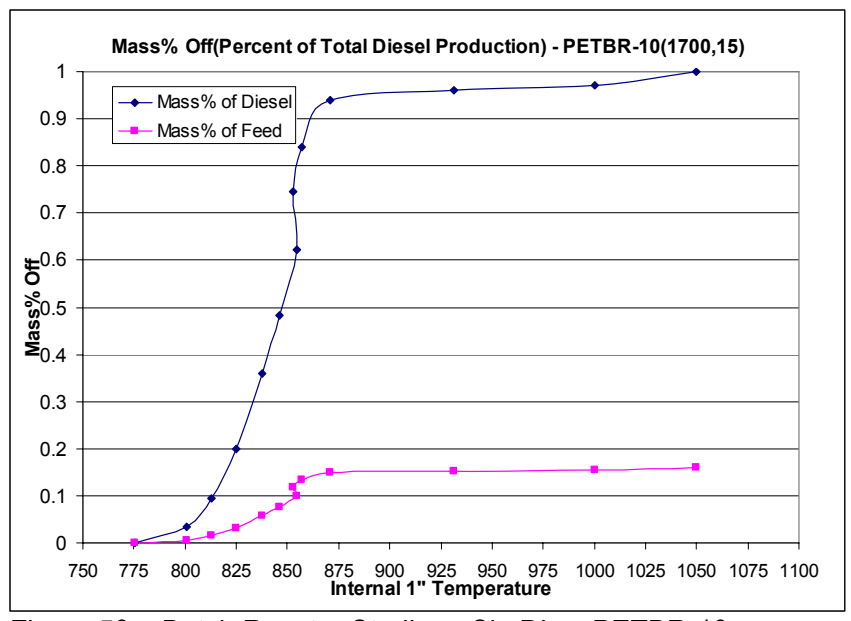

Figure 53 - Batch Reactor Studies - SimDis - PETBR-10

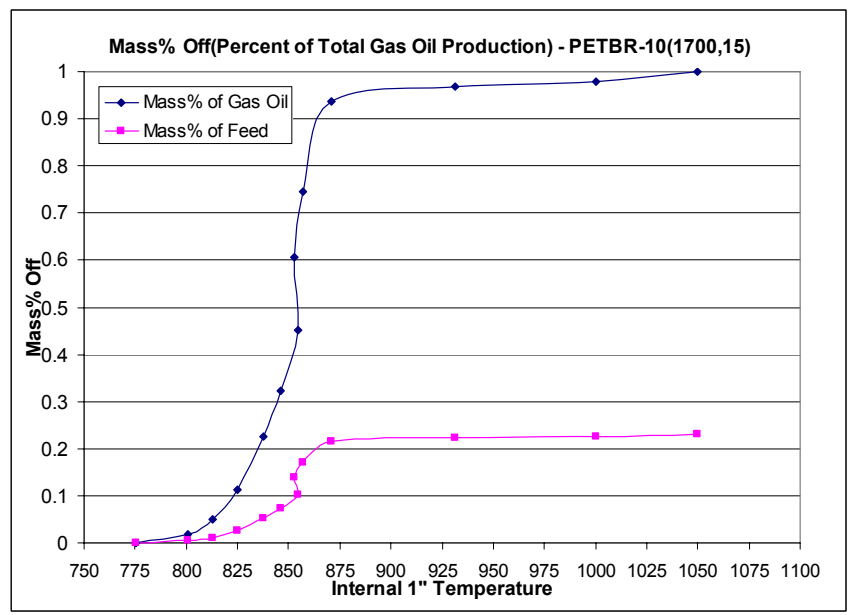

Figure 54 - Batch Reactor Studies - SimDis - PETBR-10

temperature, 1" from the bottom, for three sets of operating conditions. Figure 49 shows the diesel production as a percentage of the total diesel produced and as a percentage of the feed for PETBR-2. This run was operated at $1400^{\circ} \mathrm{F}$ element temperature and $40 \mathrm{psig}$. Figure 50 shows the gas oil production for the same run. Both plots show that $90+\%$ of the respective liquid sub-products come off of the reactor around $885^{\circ} \mathrm{F}$. Figure 51 and Figure 52 show the diesel and gas oil production rates for PETBR-7 which was operated at the same pressure as PETBR-2, $40 \mathrm{psig}$, but at a higher element temperature of $1700^{\circ} \mathrm{F}$. The higher element temperature run rate of production was very close to that of the low temperature run. Even though the rates of production were very similar, the increase in heating rate caused a $+10^{\circ} \mathrm{F}$ shift in the percent off versus temperature profile. Figure 53 and Figure 54 show the sub-product production for PETBR-10 which was operated at $1700^{\circ} \mathrm{F}$ and 15 psig. This is the same element temperature as the PETBR-7 run but at a lower operating pressure. The reduction in pressure caused a $-10^{\circ} \mathrm{F}$ shift in the percent off versus temperature profile. The majority of all of the resids with full sets of operating conditions saw the same trends. This gave confidence in the quality of the data set and showed promise that the data set is capable of being modeled.

\section{G. INSOLUBLES}

All of the internal reactor samples were analyzed for $\mathrm{C}$, Toluene and Quinoline insolubles. All of the solvents were vacuum filtered using a Whatman \#4 fast cellulose filter paper. Concerns were brought up that the size of the pores in this type of paper, $20-25 \mu \mathrm{m}$, were too big. A small set of samples were chosen from four different resids to be analyzed a second time using a Whatman cellulose filter paper with $2.5 \mu \mathrm{m}$ pores. Very little change was seen between the data acquired using the two different filters. Again concerns with the size of filter pores and the filter material were brought up. For this reason, the second set of samples that were analyzed with the $2.5 \mu \mathrm{m}$ filter were analyzed a third time using a nylon filter disk with a $0.45 \mu \mathrm{m}$ pore size. The data again fluctuated very little.

Figure 55 through Figure 58 show the fluctuations in the insolubles analysis for two runs, PETBR12 and RPBR-5. These runs were conducted at $1700^{\circ} \mathrm{F}$ element temperatures and $60 \mathrm{psig}$. Figure 55 
shows the heptane insolubles for the six internal samples taken during PETBR-12 for each of the three filters. Figure 56 shows the toluene insolubles for the same PETBR-12 samples. Figure 57 and Figure 58 show the heptane and toluene insolubles for RPBR-5. It can be seen in each of these plots that the fluctuation in data due to the filter paper was not great enough to warrant the time and monetary investment required to analyze all 247 samples with one of the two new filter disks. Therefore, all coke deposition predictions were based on the full database that is available from the $20-25 \mu \mathrm{m}$ cellulose filter paper.

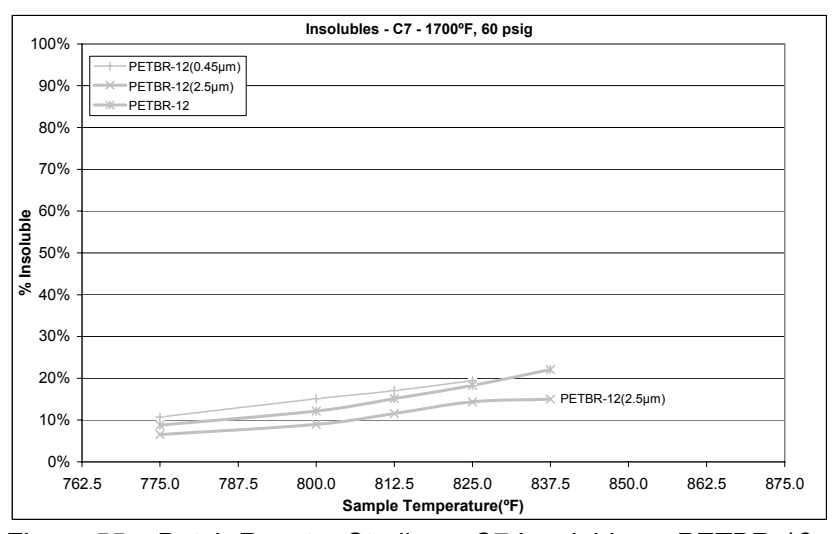

Figure 55 - Batch Reactor Studies - C7 Insolubles - PETBR-12

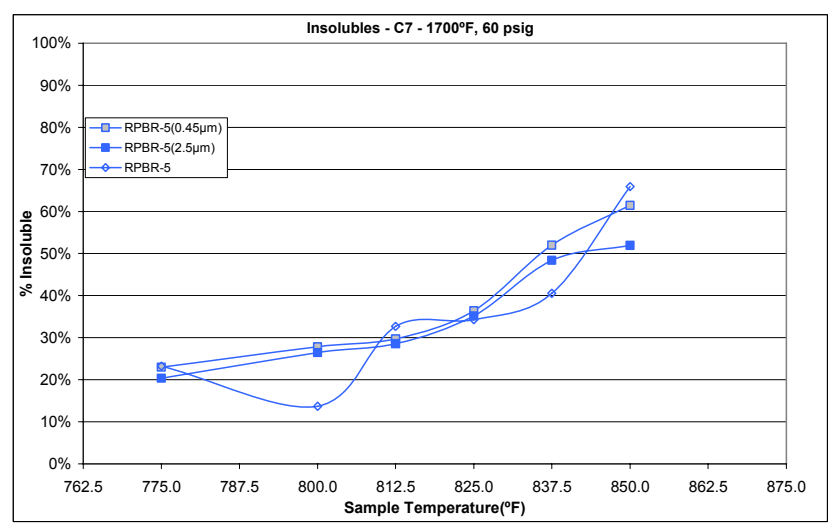

Figure 57 - Batch Reactor Studies - C7 Insolubles - RPBR-5

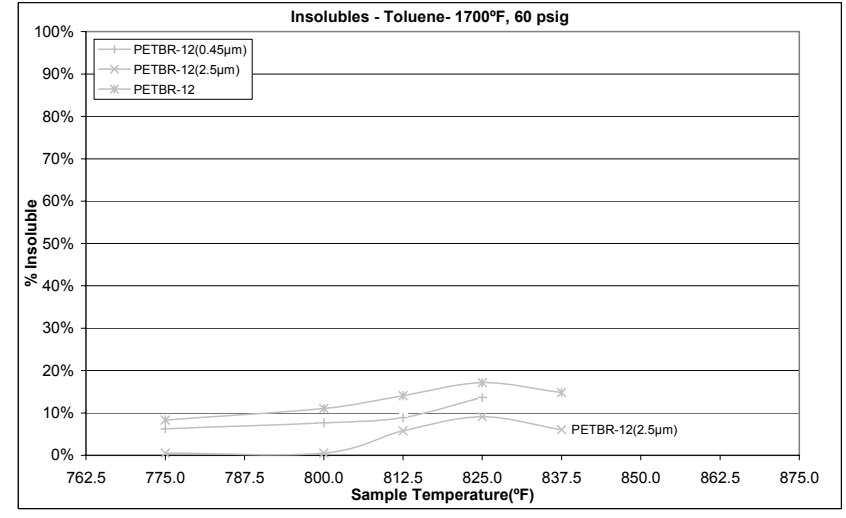

Figure 56 - Batch Reactor Studies - Tol Insolubles - PETBR-12

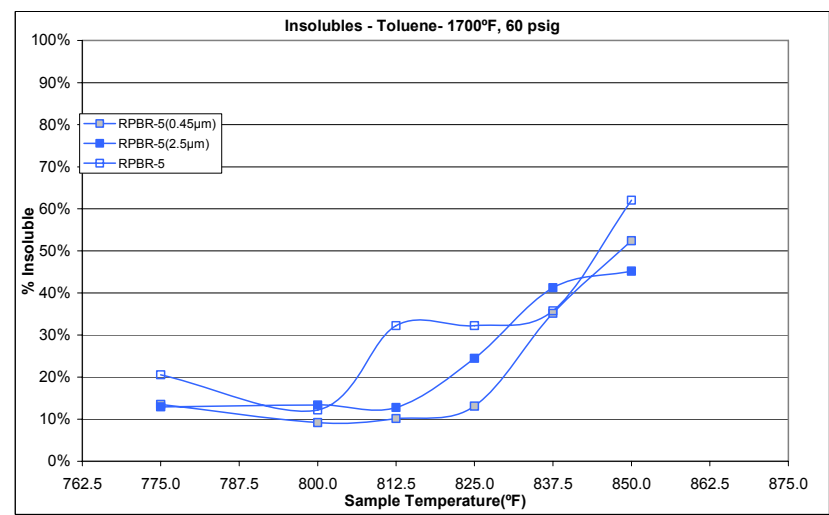

Figure 58 - Batch Reactor Studies - Tol Insolubles - RPBR-5 


\section{H. KINETIC MODEL}

\section{Status of Model}

A batch reactor model was developed based on the model used in the literatures by different researchers (Raychaudhuri, Banerjee, \& Ghar, 1994; Stangeland, 1974). This model uses the boiling points of the feed that is produced by the HTGC and the operating conditions of the batch reactor to predict the product distributions. A program was written and compiled using FORTRAN to predict the kinetic parameters using a nonlinear least square method. The method used in the program was the known Levenberg-Marquardt method developed separately by Levenberg (Levenberg, 1944) and Donald Marquardt (Marquardt, 1963). The program is still in the testing stage to check its ability to produce the kinetic parameters for the batch reactor.

HTGC data, which is essential to the development of the kinetic model, is completed. These data along with SimDis and GC data will be used in our model to produce the kinetic parameters.

\section{Theory of the Kinetic Model}

A study of comminution in batch ball milling done by Herbst and Fuerstenau (1968) has led to the development of a phenomenological model. Two primary functions were used to characterize and predict the grinding particle sizes. These two functions are, as called in the comminution field, the selection and breakage functions (Herbst and Fuerstenau, 1968; Reid, 1965). Herbst and Fuerstenau (1968) developed equations ( 1 ) through ( 6 ) which are the basic equations of their model. These equations were the starting point for other authors (Stangeland, 1974; and Raychaudhuri, Banerjee, and Ghar, 1994) to develop their models for hydrocracking reactions.

Equation ( 1 ) is the mass balance equation which describes the behavior of the material of a system. This differential equation can be written in a matrix form as given in equation ( 2 ). If the reaction rate, $\mathrm{K}$, is time-independent, an analytical solution can be obtained (Herbst and Fuerstenau, 1968).

$$
\begin{aligned}
& \frac{d M_{i}(t)}{d t}=-k_{i}(t) M_{i}(t)+\sum_{j=1}^{i-1} v_{i j} k_{j} M_{j}(t) \\
& \frac{d \underline{M}(t)}{d t}=-[\underline{\underline{I}}-\underline{\underline{V}} \underline{\underline{K}}(t) \underline{M}(t)
\end{aligned}
$$

For the case where no two cracking rates are equal, a solution (Herbst and Fuerstenau, 1968) for the above equation can be obtained as the following, 


$$
\left[\begin{array}{c}
M_{1}(t) \\
M_{2}(t) \\
\cdot \\
\cdot \\
\cdot \\
M_{n}(t)
\end{array}\right]=\left[\begin{array}{ccccc}
D_{11} & 0 & 0 & \cdot & 0 \\
D_{21} & D_{22} & 0 & \cdot & 0 \\
\cdot & \cdot & \cdot & \cdot & \cdot \\
\cdot & \cdot & \cdot & \cdot & \cdot \\
\cdot & \cdot & \cdot & \cdot & 0 \\
D_{n 1} & \cdot & \cdot & \cdot & D_{n n}
\end{array}\right]\left[\begin{array}{c}
e^{-k_{1} t} \\
e^{-k_{2} t} \\
\cdot \\
\cdot \\
e^{-k_{n-1} t} \\
1
\end{array}\right]
$$

where the elements of the $j$ th eigenvector, $D_{i j}$, are given as follow.

$$
\begin{array}{ll}
D_{i j}=\sum_{h=j}^{i-1} \frac{v_{i h} k_{h}}{k_{i}-k_{j}} D_{h j} & i>j \\
D_{i j}=M_{i}(0)-\sum_{h=1}^{i-1} D_{i h} & i=j \\
D_{i j}=0 & i<j
\end{array}
$$

To solve the above equations, one has to determine $v_{i j}$ and $k_{i}$. Stangeland (1974) and Raychaudhuri et al. (1994a, 1994b) used three adjustable parameters to determine these values. It is worthwhile to mention that these authors used the same equations, equations ( 10 ) through ( 14 ); originally developed by Stangeland (1974), to determine the model parameters with only different units for the temperature and, subsequently, adjusting the constants. However, Raychaudhuri et al. (1994b) correlated the parameters with temperature in three simple equations as the following.

$$
\begin{aligned}
& A=\frac{887.4}{(T+459.67)}-\frac{194656}{(T+459.67)^{2}} \\
& B=\frac{(T-32)}{240}-4.0 \\
& C=7.50486 \times 10^{-24}(T+459.67)^{7.5}
\end{aligned}
$$

Equations ( 7 ), ( 8 ), and ( 9 ) when combined with equations ( 10 ) through ( 14 ) form the complete model for hydrocracking cracking reactions.

$$
\begin{aligned}
& k_{i}=\frac{T B P_{i}}{T B P_{f}}+A\left[\left(\frac{T B P_{i}}{T B P_{f}}\right)^{3}-\frac{T B P_{i}}{T B P_{f}}\right] \\
& {\left[C_{4}\right]=C \times \exp \left[-0.00693\left(T B P_{j}-250\right)\right]}
\end{aligned}
$$




$$
\begin{aligned}
& x=\frac{T B P_{i}-50}{T B P_{j}-150} \\
& V_{i j}=x^{2}[1+B(x-1)]\left(1-\left[C_{4}\right]\right) \\
& y_{i j}=V_{i j}-V_{i-1 j}
\end{aligned}
$$

Stangeland (1974) suggests that an extension of his model could describe the yield from thermal cracking and coking reactions. In our research, we are interested in both reactions especially what is happening in the furnace tube of the delayed coker. To achieve this, the stirred batch reactor is being modeled using the above equations, mainly the one developed by Herbst and Fuerstenau (1968).

Although the theoretical model is complete, it still needs an algorithm to find the model parameters, equations ( 7 ), ( 8 ), and ( 9 ), for hydrocracking applications. A nonlinear least-squares method was developed by Marquardt (1963) and Levenberg (1944) which we are utilizing in our model to find the model parameters.

The problem to be solved is as the one given by Marquardt (1963) as in equation ( 15).

$$
y=f\left(x_{1}, x_{2}, \ldots, x_{m} ; \alpha_{1}, \alpha_{2}, \ldots, \alpha_{k}\right)
$$

In the above equation, the dependent variable $y_{i}$ is produced by the independent variable $x_{i}$ and the model parameters $\alpha$. A solution of the problem is reached when we find the parameters that will minimize the squared difference between the observed and the predicted variable as given in equation ( 16 ).

$\Phi=\sum_{i=1}^{n}\left[Y_{i}-\hat{Y}_{i}\right]^{2}$

Because of the nonlinearity of the model, other methods such as the Gauss method or the GaussNewton method will not work. This led Marquardt (1968) to develop an algorithm which benefits from the speed of the Newton-Raphson method and the power of convergence found in the gradient methods.

\section{Batch Reactor Modeling}

The proceeding section describes the kinetic model that was originally developed for comminution ball milling and then modified for hydrotreating and hydrocracking processes. The assumptions that were used in developing this model, i.e. reaction rates are independent of time, facilitated the integration of the mathematical equations; however, it limited the models usefulness to constant reaction rates with respect 
to time. To work around this assumption, Stangeland (1974) used relative reaction rates which are based on the heaviest pseudo component in the feed. Again, the relative reaction rates are time-independent.

The batch reactor data were obtained under nonisothermal conditions; thus, the model should account for changes of the reaction rates with time. For example, in Figure 59 the weight fraction of the heaviest pseudo component is decreasing exponentially with time. If we use equation (1) with a subscript 1 we get equation ( 17 ).

$\frac{d M_{1}(t)}{d t}=-k_{1}(t) M_{1}(t)$

Equation ( 17 ) cannot be integrated unless $k_{1}$ is constant or it has a known form that can be integrated. If we integrate equation ( 17 ) assuming a constant $k_{1}$, this will give an average $k_{1}$ which is not representative of each reaction rate.

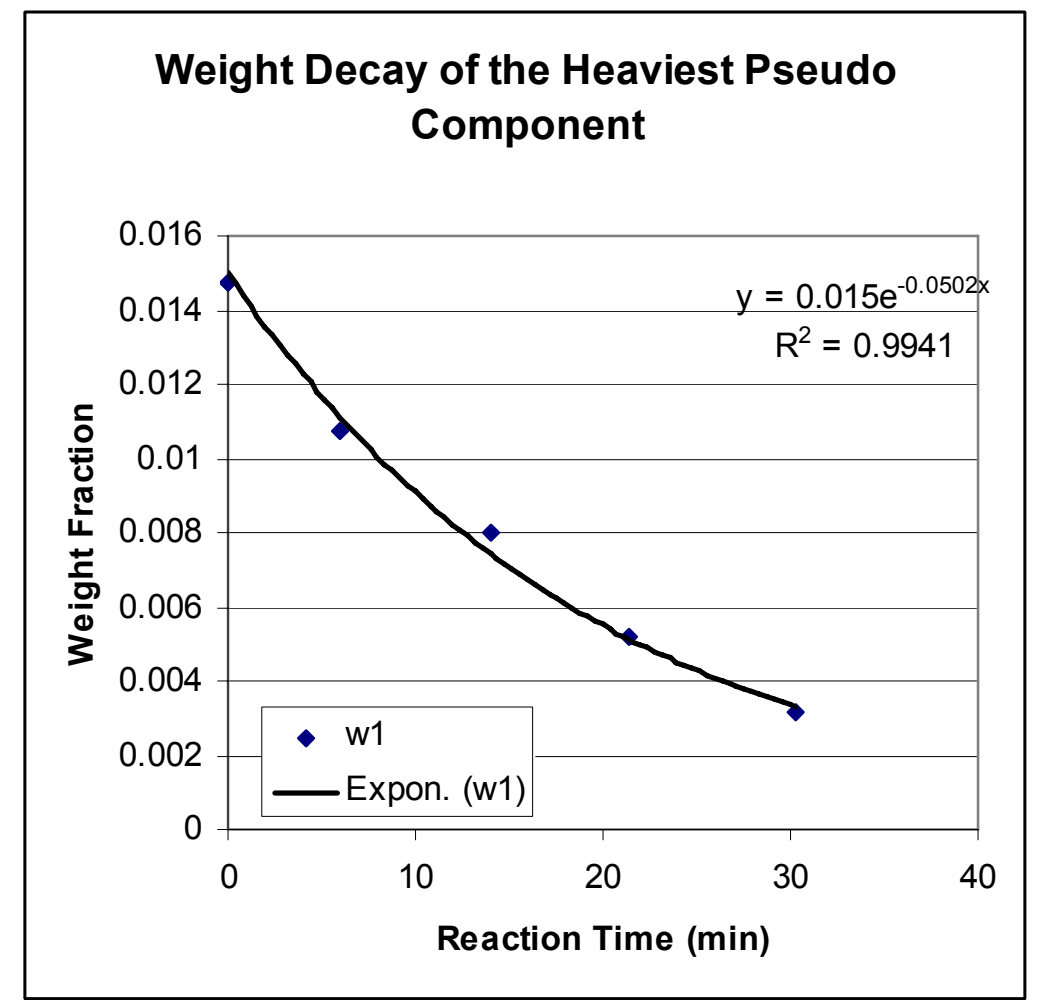

Figure 59 - Reaction rate for the heaviest pseudo component (CHVBR-20)

To overcome this problem we introduce the reaction rate equation we derived before, namely the CoatsRedfern equation.

$\ln \left(-\frac{\ln \left[\left(M_{i}\right)\right]}{T^{2}}\right)=\ln \left[\left(\frac{A_{i 0} R}{E_{i}}\right)\left(1-2 \frac{R T}{E_{i}}\right)\right]-\frac{E_{i}}{R T}$

Differentiating equation ( 18 ) with respect to time leads to the following equation; 
$\frac{d M_{i}(t)}{d t}=-\left[A_{i}\left(1-6\left(\frac{R T}{E_{i}}\right)^{2}\right) e^{\left(-\frac{E_{i}}{R T}\right)}\right] M_{i}(t)$

By comparing equation ( 17 ) and equation ( 19 ) we reach to equation ( 20 ) which is the form of $k_{1}$ as a function of time since temperature is a function of time.

$k_{1}(t)=A_{1}\left(1-6\left(\frac{R T}{E_{1}}\right)^{2}\right) e^{\left(-\frac{E_{1}}{R T}\right)}$

Application of equation ( 18 ) gives us the values for the activation energy and frequency factor as given in Table 24.

Table 24 - Activation energy and frequency factor for the heaviest pseudo component (CHVBR-20)

\begin{tabular}{|c|c|c|c|}
\hline$E=$ & 17474 & $\mathrm{~A} 0=$ & $1.57 \mathrm{E}+09$ \\
\hline$t(\min )$ & $T(K)$ & $\mathrm{k}$ by Arrhenius & k by equ. (20) \\
\hline 0.0 & 674.8 & $8.92 \mathrm{E}-03$ & $8.84 \mathrm{E}-03$ \\
\hline 6.0 & 685.9 & 1.36E-02 & $1.34 \mathrm{E}-02$ \\
\hline 14.0 & 699.8 & $2.25 \mathrm{E}-02$ & $2.23 \mathrm{E}-02$ \\
\hline 21.3 & 713.7 & $3.66 \mathrm{E}-02$ & 3.62E-02 \\
\hline 30.3 & 727.6 & $5.84 \mathrm{E}-02$ & $5.78 \mathrm{E}-02$ \\
\hline
\end{tabular}

\section{Programming of Kinetic Model}

A FORTRAN program for the Levenberg-Marquardt algorithm was obtained from the website of Argonne National Laboratory (ANL) to use in our model. As shown in Figure 1, the program is divided into separate sections. Each block in the flow diagram represents a subroutine or a function that is essential for the algorithm to be successful. Fortunately, this program is well documented which makes it easy to be read and understand. The subroutine LMDIF is the main subroutine in ANL's program. Its purpose is to minimize the squares of $m$ nonlinear equations in $n$ parameters using the Levenberg-Marquardt algorithm. A brief description is given at the end of the modeling section for each subroutine and function in this flow diagram. 


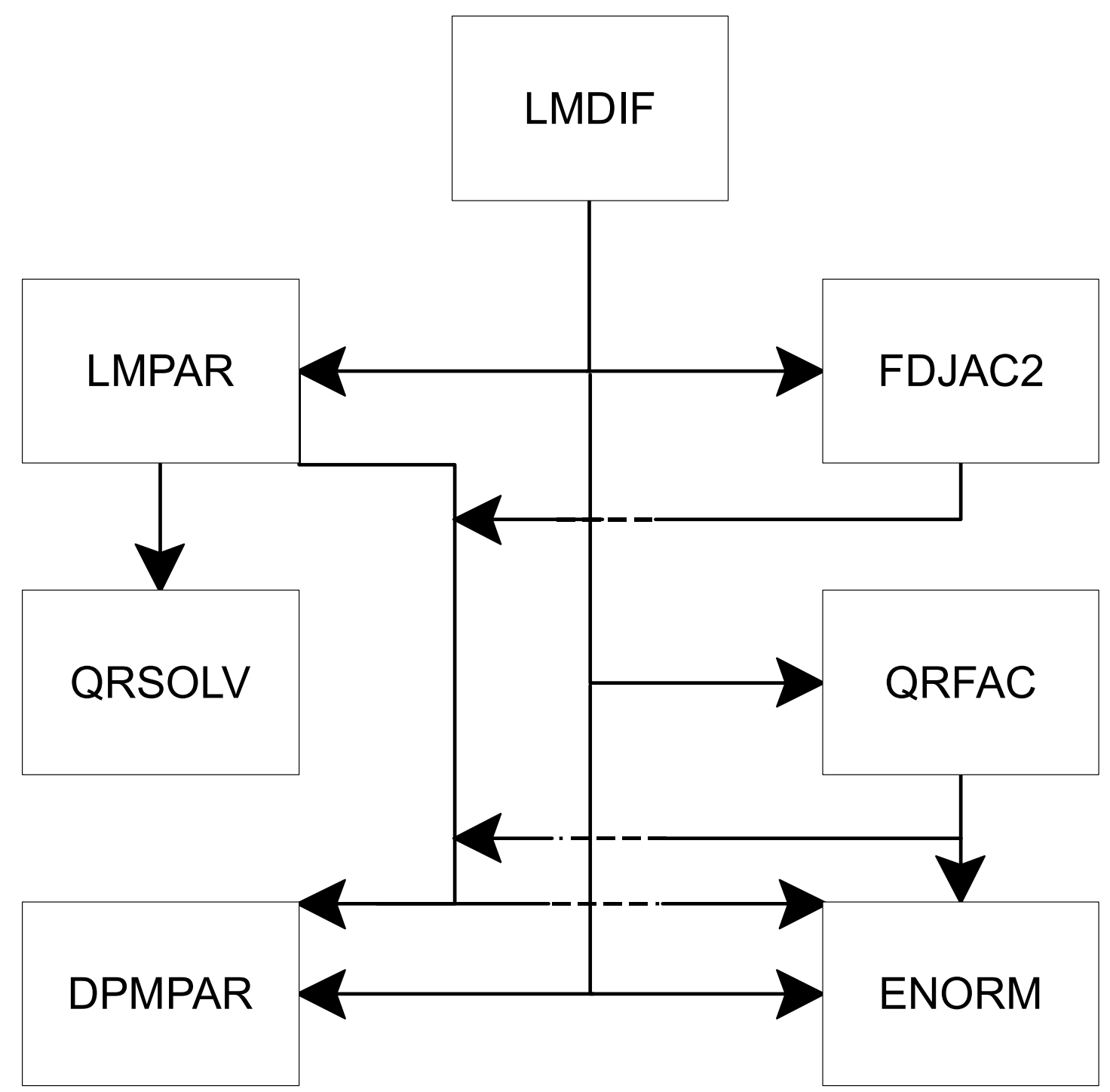

Figure 60 - Flowchart for the Levenberg-Marquardt algorithm built by LAN

The Levenberg-Marquardt algorithm given in Figure 60 is connected with the kinetic model in Figure 61 that we are developing at TU. Each block in Figure 61 represents a subroutine or a function written in FORTRAN. The connection between the program in Figure 60 and the program in Figure 61 is shown in Figure 62. The program was tested and verified to work properly. 


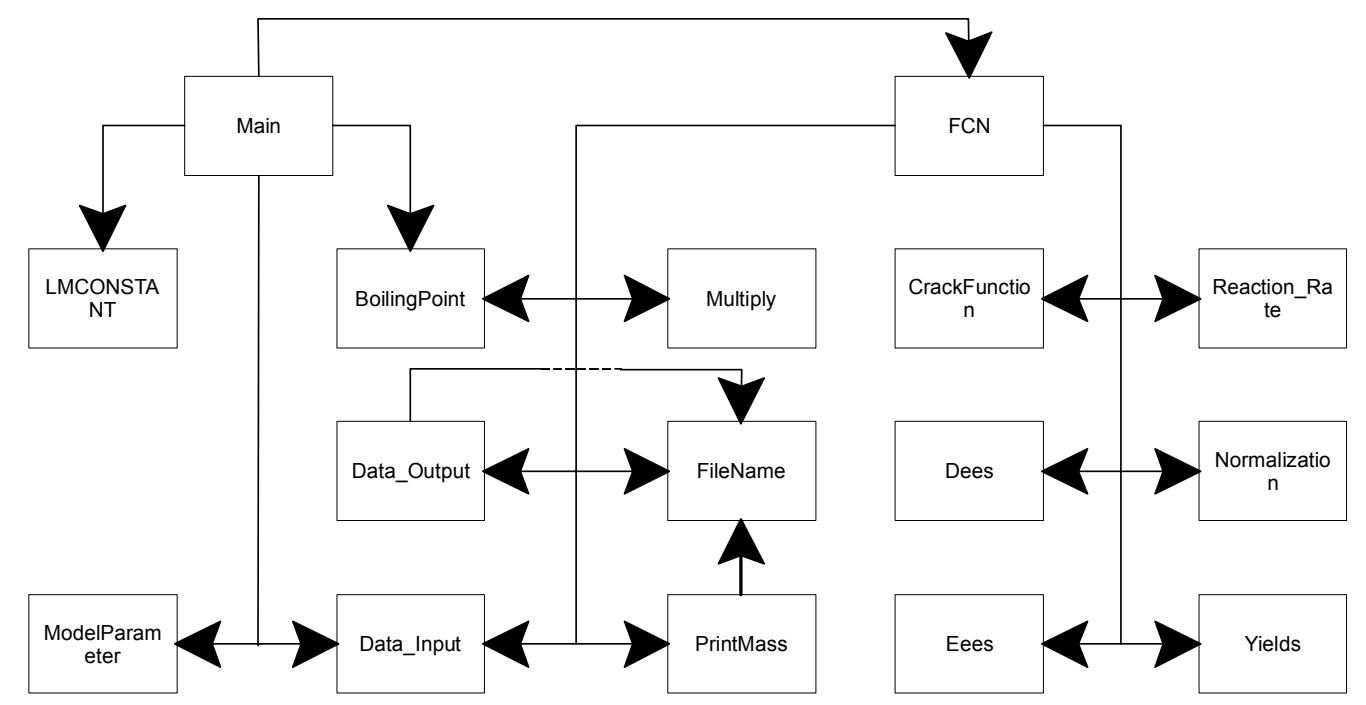

Figure 61 - Flow Diagram for the Kinetic Model Programmed in FORTRAN

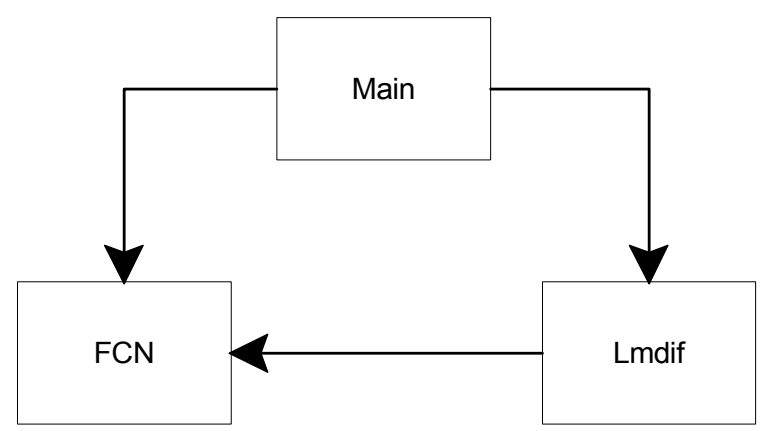

Figure 62 - Connection of the Levenberg-Marquardt Algorithm and the Kinetic Model

The subroutine and function names used in Figure 60 are described below.

o DPMPAR: A function that specifies the double precision machine parameters.

o ENORM: A function that calculates the Euclidean norm of $x$.

o FDJAC2: A subroutine that calculates the forward difference approximation for the $m$ by $n$ jacobian matrix.

o LMDIF: A subroutine that minimizes the sum of the squares of $m$ nonlinear functions in $n$ variables by a modification of the Levenberg-Marquardt algorithm. It calculates the jacobian of the functions by the forward-difference estimation.

o LMPAR: A subroutine that determines the parameters of the model.

- QRFAC: A subroutine that uses householder transformation to determine an orthogonal matrix $q$ and an upper trapezoidal matrix $r$.

o QRSOLV: A subroutine that solves for the matrices provided by QRFAC. 
The subroutine and function names used in Figure 61 are listed below alphabetically with a brief description.

o BoilingPoint: A subroutine that produces the pseudo components using the TBP curve.

o CrackFunction: A subroutine to calculate the stoichiometric coefficients of the pseudo components.

o Data_Input: A subroutine that gets the data from a text file.

o Data_Output: A subroutine that prints the output into a text file.

- Dees: A subroutine to calculate the matrix elements in equation ( 3 ) using equations ( 4 ), ( 5 ), and ( 6$)$.

o Eees: A subroutine to calculate the elements of the column matrix on the right side of equation ( 3 ).

- FCN: A subroutine that calculates the matrices and provides them to other subroutines to calculate the model parameters.

o FileName: A subroutine that chooses the names of the output files.

- LMCONSTANT: A subroutine that reads the constants used in LMDIF from a text file, otherwise it will give a preset values if there is no text file.

o Main: The main driver of the FORTRAN program used for the kinetic model.

o ModelParameter: a subroutine that initializes the model parameter to start the calculation.

o Multiply: A subroutine that multiplies two matrices together and find a column matrix.

o Normalization: A subroutine to normalize the pseudo components to the heaviest feed component.

o PrintMass: A subroutine to print the masses to an output file.

o Reaction_Rate: A subroutine to calculate the reaction rate coefficients of the pseudo components.

o Yields: A subroutine to calculate the weights for the pseudo components.

\section{MODEL VALIDATION}

In an effort to validate the current model using the new data acquired in the Phase II testing, the base equations from the model were inserted into an Excel spreadsheet. The spreadsheet uses the following inputs to calculate the percentage of the feed mass that vaporizes and leaves the reactor as a function of time: temperature profile versus time, an activation energy for the liquid reactions, frequency factors for each of the three liquid sub-products, the product yield percentages and the percentage gasoline, diesel and gas oils in the liquid product. All of the inputs listed are acquired from each individual run except the activation energy and the frequency factors. These terms were taken from an optimized fit to a run made with the same resid in Phase I testing - CHVBR-20. The run from Phase II testing that the data was taken from is CHVBR-2. Figure 63 shows the mass of the liquid products that are leaving the reactor as a function of temperature. The graph shows the production in terms of mass percent of feed and total liquids produced. Figure 64 shows the model prediction of the liquid produced for each of the data sets in Figure 63. Figure 65 through Figure 67 show comparisons of the model predictions and the experimental data for the three liquid sub-products. As the plots show, the model predictions, while following the general trend of the data, are not as strong as desired. 


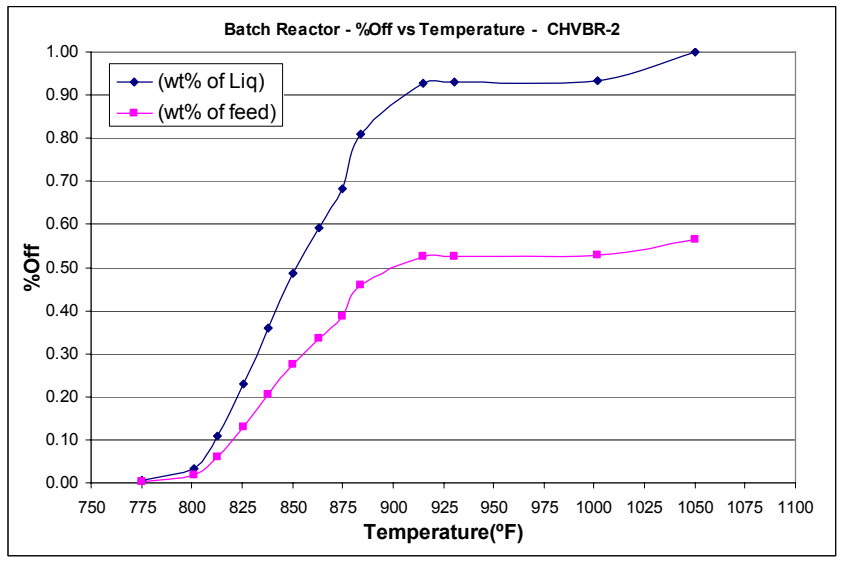

Figure 63 - Batch Reactor Studies - \% Off vs. Temperature CHVBR-2

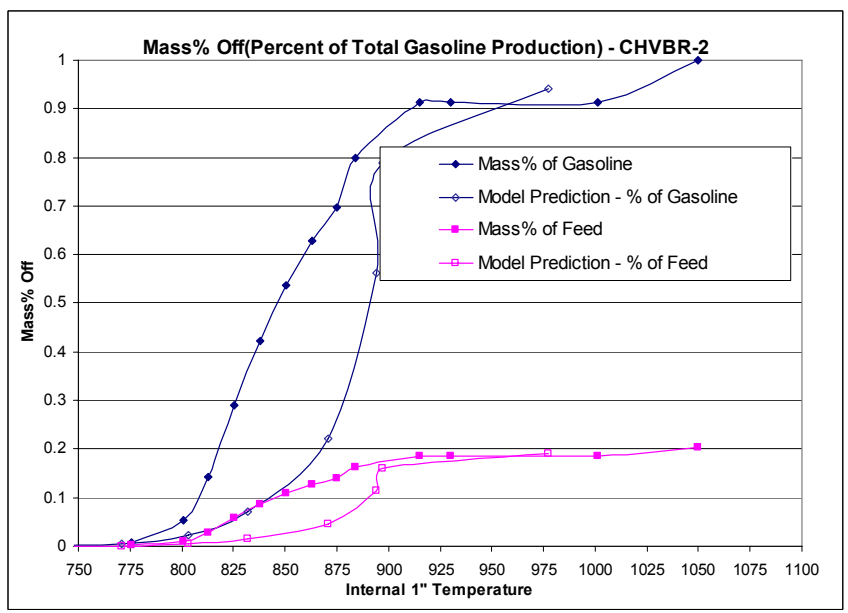

Figure 65 - Batch Reactor Studies - \% Off vs. Temperature Gasoline - CHVBR-2

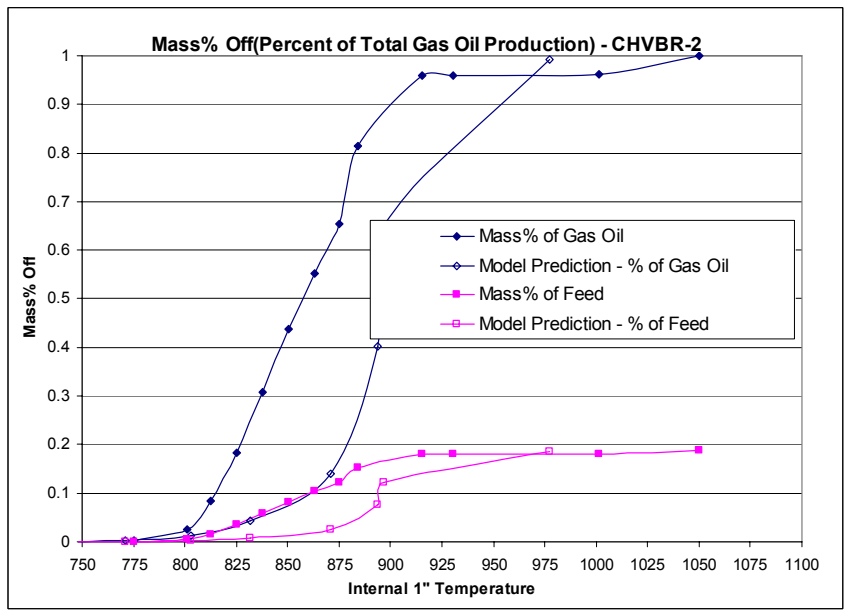

Figure 67 - Batch Reactor Studies - \% Off vs. Temperature - Gas Oil - CHVBR-2

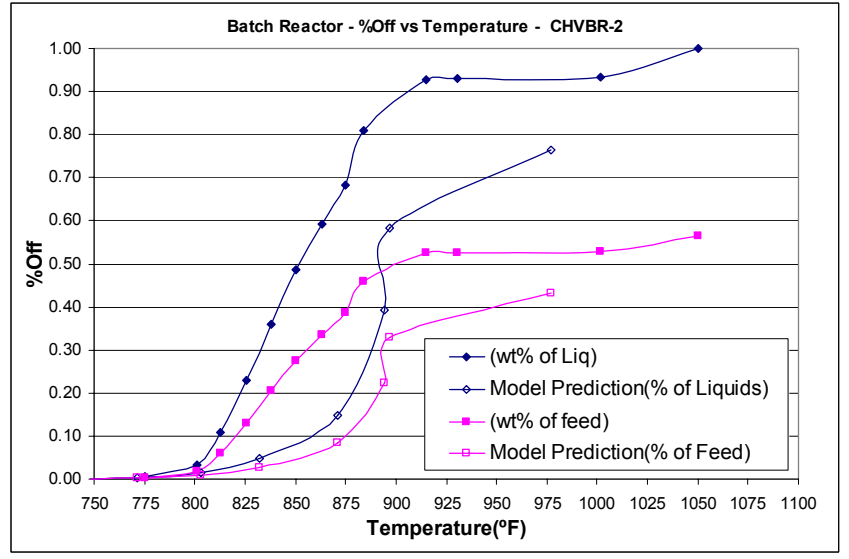

Figure 64 - Batch Reactor Studies - \% Off vs. Temperature CHVBR-2

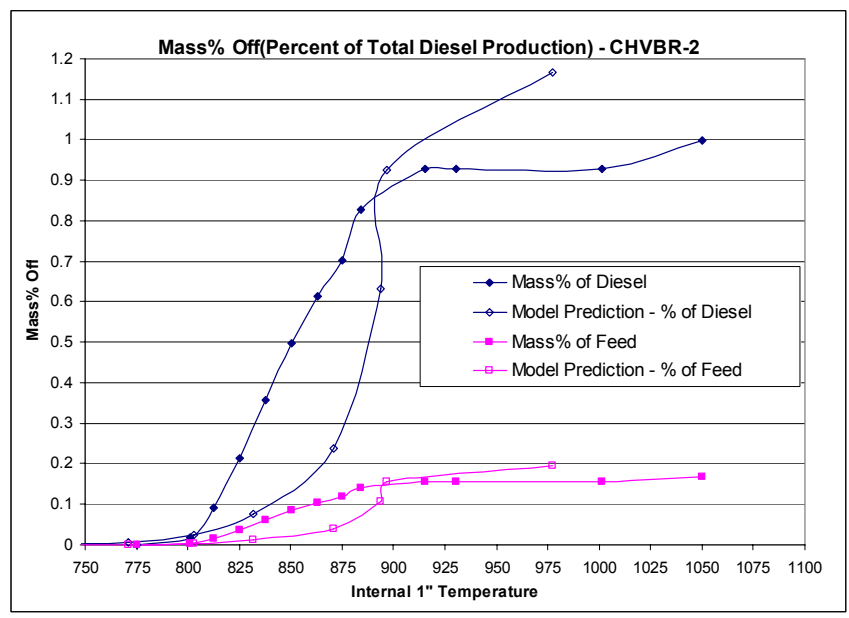

Figure 66 - Batch Reactor Studies - \% Off vs. Temperature Diesel - CHVBR-2 
There are a few reasons for this. First, there are samples that are removed from the reactor during the run. The mass of the samples that are being removed are not accounted for in the model calculations. Second, the activation energies and frequency factors that were chosen were optimized numbers from the Phase I run. The predictions in the previous plots, thought not perfect fits, give confidence that once the internal sample masses have been accounted for and the model can be used to optimize the activation energy and frequency factors, the model predictions will be very good.

After optimizing the model to each run, the next step will be to find one activation energy and one set of frequency or Arrhenius pre-exponential factors for each resid. Then efforts will be made to include the coke deposition function to the model using the insolubles and TGA data. This will require finding the rate constants for the conversion of intermittent coke compounds into coke for each of the three lumped reactions. The final stage will be to put the model into a user-friendly GUI so that all members will have easy access to the model. 


\section{Pilot Unit Studies}

\section{A. Discussion of Test Matrix}

The pilot unit was modified in the fall of 2001 and then utilized to study foaming. The objectives of the continuation study are:

- To make additional runs to quantify foam heights for model development. Runs will also be made at refinery conditions for scale-up comparisons,

- To quantify the effects of operating variables, such as, pressure, temperature, feed rate, steam velocity over a broader range of feedstocks,

- To compare different antifoam injection schemes such as in the feed, the feed line and overhead using different carriers and dilution rates,

- To determine how the anti-foam partitions in products, and

- To establish whether injecting anti-foam in the feed alters the coke density.

The test matrix for these studies is shown in Table 25. It consists of general tests that are designed to gather as much data as possible from each test on foaming tendencies, the impact of superficial velocity, the impact of parametric and feedstock properties and coke morphology studies and focused tests to gain an understanding of how different injection procedures behave.

\section{Table 25 - Foaming Studies Test Matrix}

\begin{tabular}{|c|c|c|c|c|c|c|c|c|c|}
\hline Type of Test & Temperature & Pressure & Resids & $\begin{array}{l}\text { Feed } \\
\text { Rates }\end{array}$ & $\begin{array}{c}\text { Recycle } \\
\text { Rates }\end{array}$ & Viscosity & \begin{tabular}{|l|} 
Drum \\
Sizes
\end{tabular} & $\begin{array}{c}\text { Injection } \\
\text { Points }\end{array}$ & Total \\
\hline \multicolumn{10}{|c|}{ General Tests } \\
\hline \multicolumn{10}{|l|}{ 1. Parametric and Feedstock } \\
\hline 3 New Resids & 3 & 3 & 3 & 1 & & & & & 27 \\
\hline Old Resids Not Tested & 2 & 2 & 2 & 2 & & & & & 16 \\
\hline Resids Tested in Foaming & 2 & 2 & 4 & 1 & & & & & 16 \\
\hline Recycles & 3 & 2 & 3 & 1 & 2 & & & & 36 \\
\hline 2. At Refinery Conditions & 1 & 1 & 9 & 1 & $?$ & & & & 9 \\
\hline 3. Superficial Velocity & 3 & 3 & 1 & 1 & & & 3 & & 27 \\
\hline & & & & & & & & & \\
\hline \multicolumn{10}{|c|}{ Focused Tests } \\
\hline 1. Continuous vs Feed Injectio & 1 & 1 & 6 & 1 & & 1 & & 2 & 12 \\
\hline & & & & & & & & & 6 \\
\hline 2. Continuous vs Intermittent & 1 & 1 & 6 & 1 & & 1 & & 1 & 6 \\
\hline 3. Carrier Viscosity & 1 & 1 & 9 & 1 & & 2 & 1 & 1 & 18 \\
\hline 4. Dilute vs Neat Injection & 1 & 1 & 3 & 1 & & 2 & & 1 & 12 \\
\hline Total & & & & & & & & & 179 \\
\hline
\end{tabular}




\section{B. OPERATING ISSUES}

\section{Silicon Partitioning Studies}

\section{a) Overhead Antifoam Injection - Silicon Carry Over Study}

A study was conducted to determine the extent of the antifoam blowing over during overhead injection due to the vaporization of the carrier (diesel) and the high vapor velocity in the drum. The system was purged overnight with $20 \mathrm{ml} / \mathrm{hr}$ distilled $\mathrm{H}_{2} \mathrm{O}$ and $0.25 \mathrm{SCFH}$ nitrogen with no antifoam injected. The water was collected at the end of this period. Analyses showed it contained $86.8 \mathrm{ppm} \mathrm{Si}$. Previous analysis of Tulsa tap water indicated a silicon content of $4.2 \mathrm{ppm}$. It seems likely that the purging process stripped out silicon that may have previously deposited in the drums or tubing.

The system was then run for the next two hours at the same steam and nitrogen flow rate with 0.2 $\mathrm{ml} / \mathrm{min} 100,000 \mathrm{cSt}$ antifoam injected; a total of $24.5 \mathrm{ml}$ was injected. The antifoam was diluted in diesel: $70 \mathrm{ml}$ diesel to $30 \mathrm{ml}$ antifoam. The water and antifoam were then turned off for one hour to allow for the system to be purged of the previous antifoam and water injections. All of the water was removed at the end of each of the sampling periods. The drum vapor flow rates were then increased to mimic run conditions. The nitrogen was increased to $4.50 \mathrm{SCFH}$, the steam was increased to $60 \mathrm{ml} / \mathrm{hr}$ and the antifoam remained at $0.2 \mathrm{~m} / \mathrm{min}$ for one hour. The water was removed from the liquid tanks and the system was purged with steam and nitrogen overnight to remove all remaining silicon. Only about $5 \%$ of the silicon was accounted for. When comparing the blank $\left(\mathrm{H}_{2} \mathrm{O}\right)$ silicon levels to the silicon levels in all the other samples, a noticeable increase in the silicon level can be noticed. If samples 2 and 3 were combined, the silicon levels would be $102 \mathrm{ppm}$ (a $20 \%$ increase). If samples 3 and 4 were combined, the silicon levels would be 108 ppm (a $25 \%$ increase). These calculations indicate that some of the antifoam is carried over into the liquids when injected from overhead. However, the very low recovery of silicon indicates that most of the injected antifoam remained in the drum. More may be carried over during the coking process because the superficial velocity of the $\mathrm{HC}$ vapor is the largest. 


\section{b) Lights \& Heavy Analysis}

During the pilot unit tests, oil and water are collected in the lights and heavies tank. The oil and water in these samples are separated and samples taken for partitioning analyses. Silicon enters the drum from three possible sources: antifoam, feedstock, and feed water injected (both process steam and stripping steam). Silicon is recovered in the coke, the hydrocarbon liquids, and the decant water. Estimates of the silicon input from the feed water were made using a value of $4.2 \mathrm{ppm}$ silicon in Tulsa tap water (measured in 2001). It should be noted that the silicon numbers in the coke tended to vary wildly between the top and bottom of the drum; some runs had nearly the same amount of silicon throughout the drum, while other runs showed up to forty times more silicon at the bottom of the drum than the top.

Several results are notable. First, note that the silicon entering the drum is dominated by the feedstock rather than the antifoam for most of the runs. This is especially true for the Suncor runs, since the Suncor feedstock has a very high silicon content.

The silicon content of the hydrocarbon liquids can be expected to increase if there is a foamover, as the liquids will be contaminated with resid and/or heavy gas oils containing the feed silicon. This appears to be the case for run SUNC 8 PUAF, for example, which has a very high silicon content in the hydrocarbon liquids but no antifoam was used.

It is assumed that silicon in the antifoam is insoluble in the water, but that the antifoam breakdown products may be water soluble and thus may show up in the decant water. This is illustrated by runs SUN 3 PUAF and SUN 4 PUAF, in which the antifoam was injected overhead and in the feed stream, respectively. SUN 3 PUAF has a higher concentration of silicon in the hydrocarbon liquid than does SUN 4 PUAF, perhaps due to carry-over of the antifoam, but SUN 4 PUAF has considerably more silicon in the water, apparently due to the breakdown of the antifoam. More analytical results are needed for silicon in the liquid products to form a firm conclusion (since SUN 4 PUAF is the only anti-foaming run with antifoam added to the feedline for which we have received the water analysis back), but the tentative conclusion is that silicon from antifoam injected overhead tends to carry over to the hydrocarbon liquids, while silicon from antifoam injected in the feedline tends to break down and end up in the decant water.

\section{Coil Fluid Temperature Profiles}

For the foaming tests conducted in the previous JIP, it was noted that the fluid temperature in the coil was fluctuating. To ascertain why, thermocouples were inserted in the coil at different locations. The results from these studies are discussed below.

Thermocouples were inserted into the furnace coil at various positions in order to study the rate at which the feed temperature changes. The data was collected from three consecutive runs. All the runs had a thermocouple at the inlet of the feed into the furnace (TI_131) and at the drum inlet/coil outlet (TI_107). The first run had a third thermocouple in the second loop of the coil - approximately 7 feet from the inlet, see Figure 68 . The second run had a thermocouple approximately 13 feet from the inlet (4th loop), see Figure 69. The third run had a thermocouple in the $3^{\text {rd }}$ and $5^{\text {th }}$ loop - approximately 10 and 16 feet from the inlet, see Figure 70 . The equation, $\left(T_{-}-T_{0}\right) /\left(T_{f}-T_{0}\right)$, was used to calculate the percentage of the heating accomplished by that point of the coil. Table 26 shows the results of these calculations. Looking at the steady state portion of the runs, approximately $41 \%$ of the total heating is accomplished in the first 7 
feet of the coil and $23 \%$ of the heating is done in the last 4 feet of the coil. Only $36 \%$ of the heating is accomplished in the middle 9 feet of the coil.

Table 26 - Percent Heating in Furnace Coil

\begin{tabular}{|c|c|c|c|c|}
\hline Loop 2(7') & Loop 3(10') & Loop 4(13') & Loop 5(16') & Time \\
\hline$\left(\mathrm{T}^{-} \mathrm{T}_{0}\right) /\left(\mathrm{T}_{\mathrm{f}}-\mathrm{T}_{0}\right)$ & $\left(\mathrm{T}-\mathrm{T}_{0}\right) /\left(\mathrm{T}_{\mathrm{f}}-\mathrm{T}_{0}\right)$ & $\left(\mathrm{T}-\mathrm{T}_{0}\right) /\left(\mathrm{T}_{\mathrm{f}}-\mathrm{T}_{0}\right)$ & $\left(\mathrm{T}-\mathrm{T}_{0}\right) /\left(\mathrm{T}_{\mathrm{f}}-\mathrm{T}_{0}\right)$ & (min) \\
\hline $58.41 \%$ & $67.30 \%$ & $76.00 \%$ & $77.97 \%$ & Prerun to 15 \\
\hline $39.58 \%$ & $53.45 \%$ & $63.53 \%$ & $75.07 \%$ & 16 to 90 \\
\hline $40.19 \%$ & $54.96 \%$ & $64.38 \%$ & $75.89 \%$ & 91 to 165 \\
\hline $39.96 \%$ & $54.90 \%$ & $63.93 \%$ & $76.24 \%$ & 166 to 240 \\
\hline $43.27 \%$ & $67.32 \%$ & $64.43 \%$ & $81.15 \%$ & 241 to 315 \\
\hline $64.22 \%$ & $67.57 \%$ & $64.43 \%$ & $79.54 \%$ & 316 to 390 \\
\hline $40.75 \%$ & $57.66 \%$ & $64.07 \%$ & $77.09 \%$ & Steady-state \\
\hline${ }^{*} \mathrm{~T}_{0}=\mathrm{TI} 131$ (Coil Inlet) & & & \\
\hline${ }^{* *} \mathrm{~T}_{\mathrm{f}}=\mathrm{TI}$ T107(Drum Inlet) & & & \\
\hline
\end{tabular}

Large fluctuations in the thermocouple readings have caused problems in controlling the fluid/furnace temperature. Figure 71 and Figure 72 show the fluctuations seen in the thermocouple readings during this study. It can be seen that the fluctuations increase as the fluid flows through the tube. As seen in Figure 72, the average fluctuation in the temperature of the fluid at the entrance of the coil is only $+/ 3^{\circ} \mathrm{F}$ while the average fluctuation at the exit of the coil is $+/-7^{\circ} \mathrm{F}$. It is believed that increase in vaporization of the fluid causes more irregularities in the flow pattern and the temperature profile. 


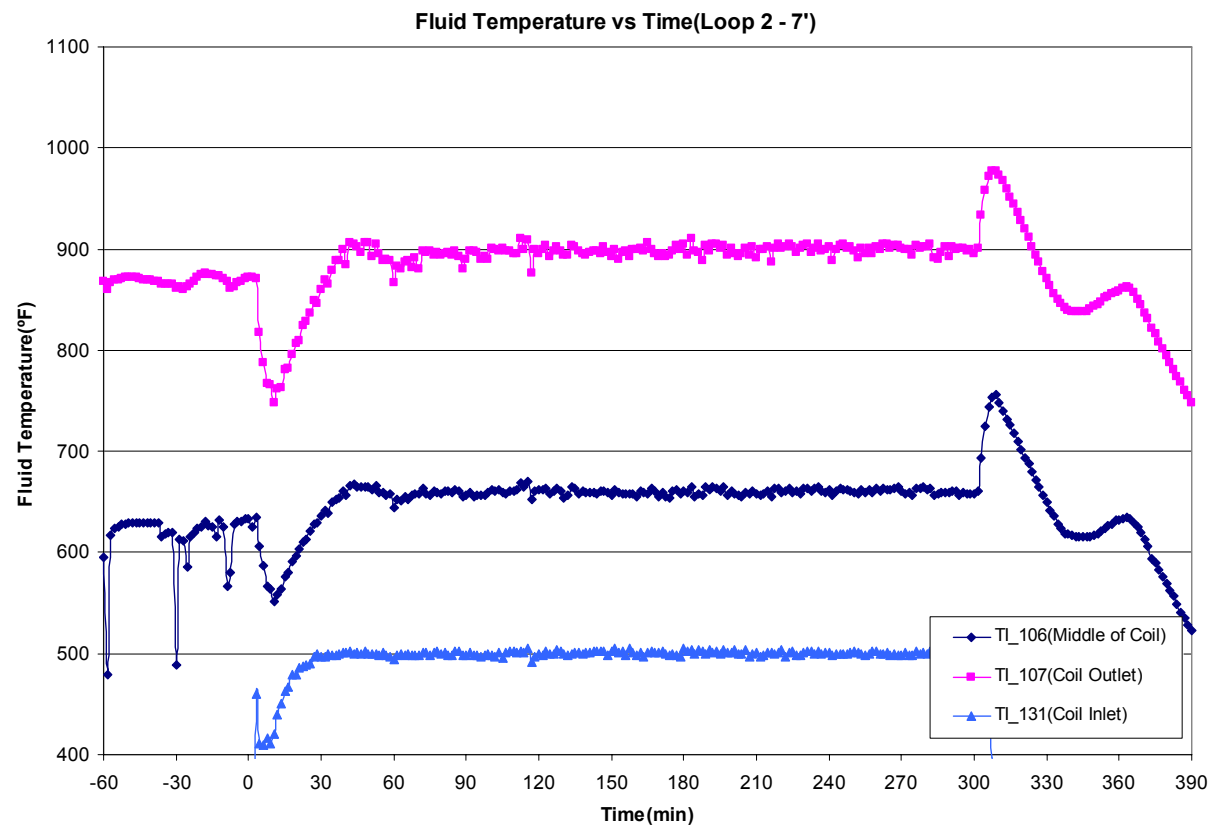

Figure 68 - Furnace Coil Heating - Loop 2

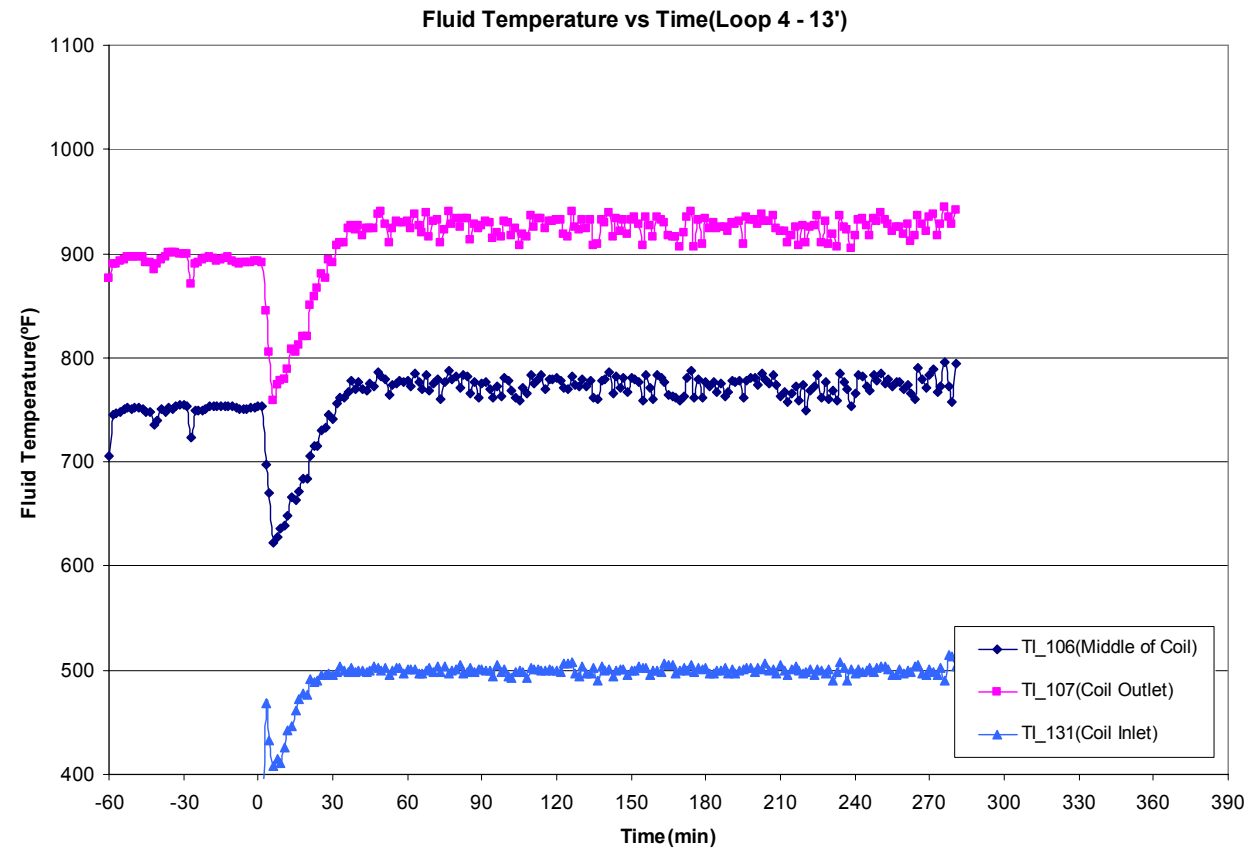

Figure 69 - Furnace Coil Heating - Loop 4 


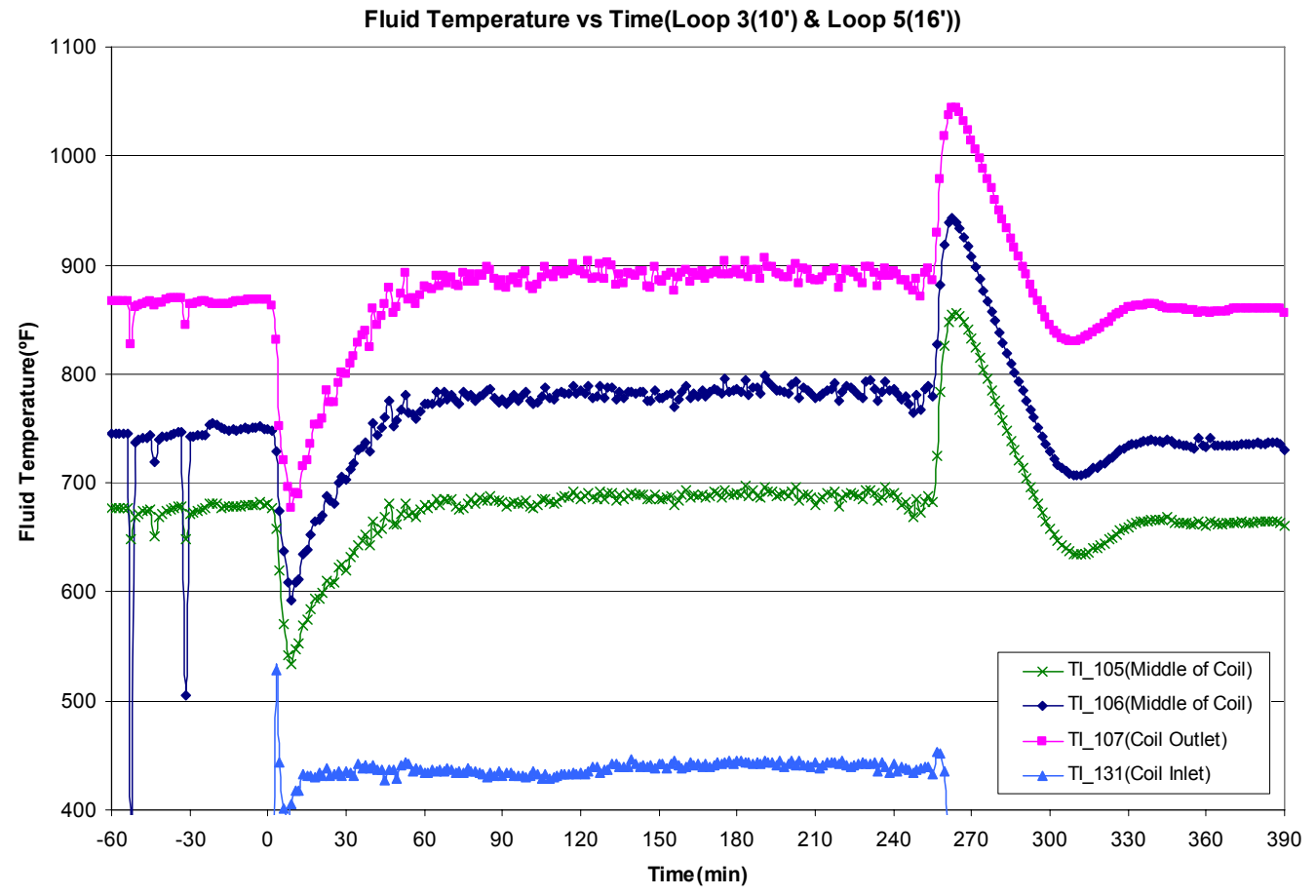

Figure 70 - Furnace Coil Heating - Loop 3 \& 5

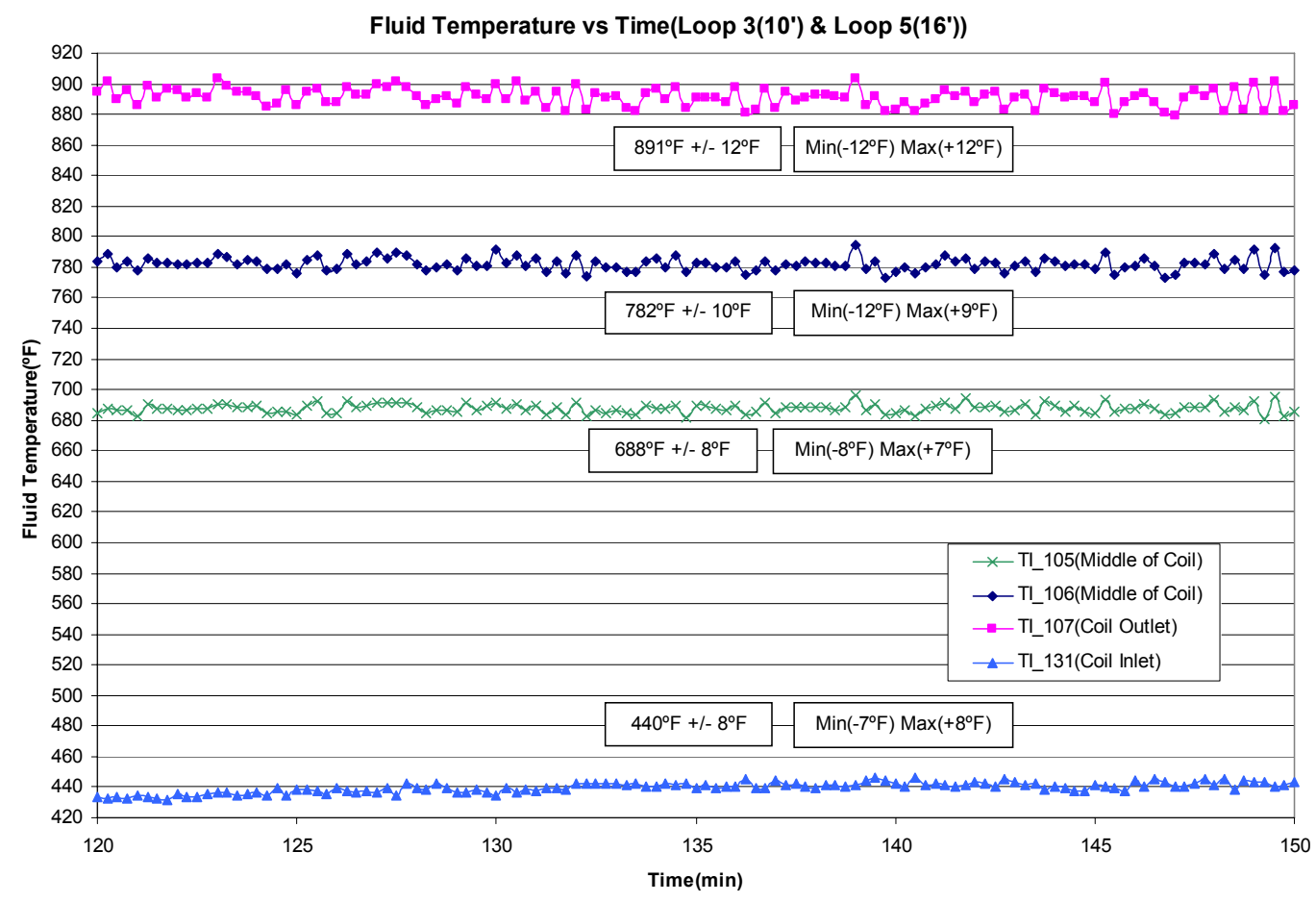

Figure 71 - Furnace Coil Temperature Profiles - Loop 3 \& 5 
Fluid Temperature vs Time(Loop 4 - 13')

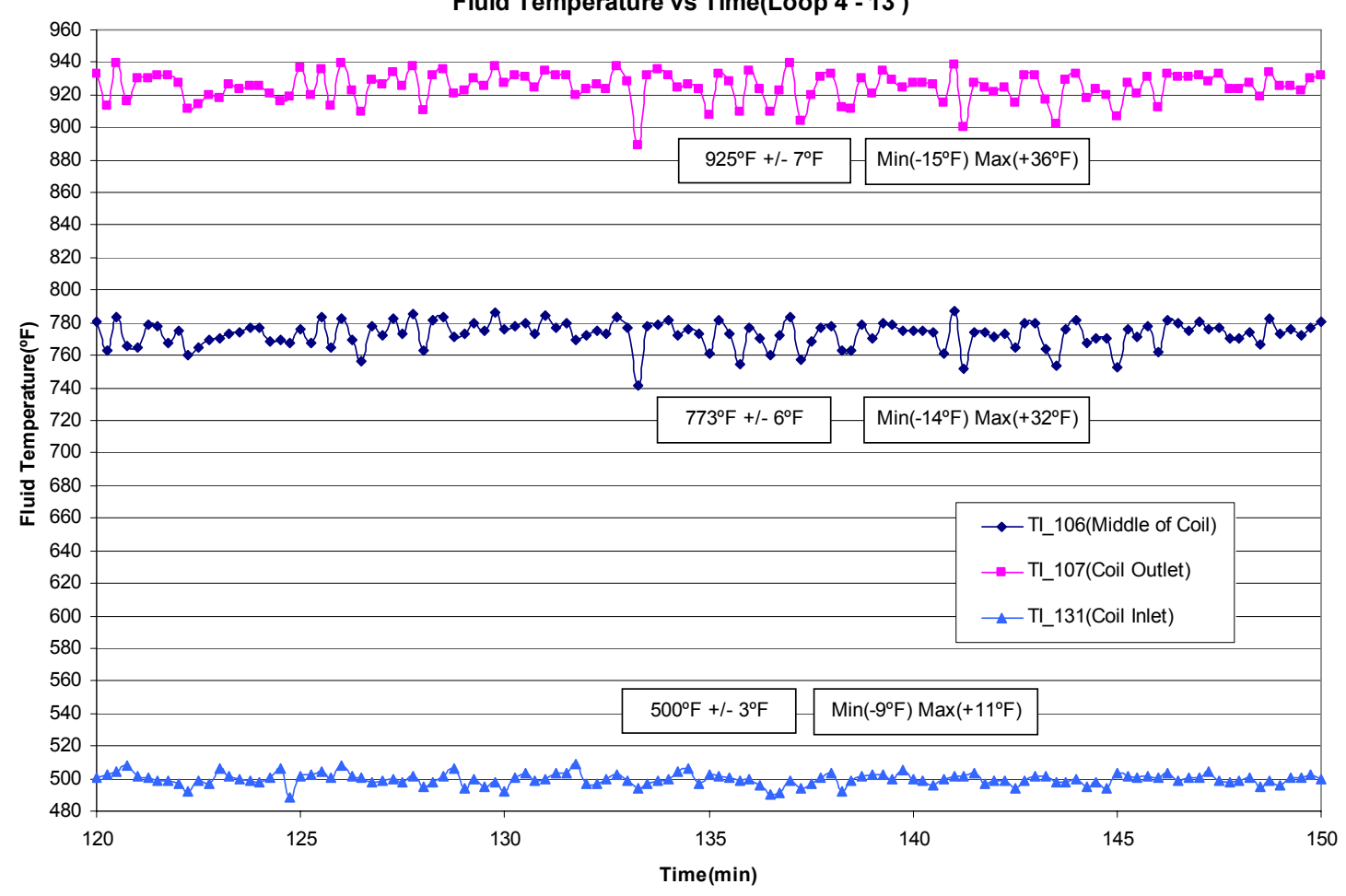

Figure 72 - Furnace Coil Temperature Profiles - Loop 4 


\section{Drum/Coil Velocity Calculations}

Table 27 shows the effects of feed flow rates and drum diameter on superficial velocities at the drum outlet. These values were estimated assuming $72 \mathrm{wt} \%$ of the feed exits the drum as vapor (an approximate average from our experimental results) and assuming a vapor molecular weight of 108 . Values of 0.3 to $0.7 \mathrm{ft} / \mathrm{s}$, which would approximate commercial units, can be attained using a 1 inch or 2 inch drum, but cannot be attained with the 3 inch drum using reasonable feed rates.

The effects of feed flow rates and drum diameter on the superficial velocities in the coil and at the drum inlet are shown in Table 28 . These values assume that $17 \mathrm{wt} \%$ the feed is vaporized in the furnace. The steam flow rate is seen to have little effect on overall vapor velocities for the ranges we are considering.

Table 27 - Effect of feed flow rate and drum diameter on superficial velocity at drum outlet

\begin{tabular}{|c|c|c|c|c|c|c|c|c|c|}
\hline \multirow[b]{3}{*}{ Feed rate (gems/hr) } & \multicolumn{9}{|c|}{ Drum Diameter } \\
\hline & \multicolumn{3}{|c|}{ 1" } & \multicolumn{3}{|c|}{ 2" } & \multicolumn{3}{|c|}{ 3" } \\
\hline & 1200 & 3000 & 4800 & 1200 & 3000 & 4800 & 1200 & 3000 & 4800 \\
\hline Steam flow $=10 \mathrm{~g} / \mathrm{hr}, \mathrm{N} 2=0.25 \mathrm{SCFH}$ & & & & & & & & & \\
\hline $\begin{array}{l}\text { Superficial Velocity of Vapor at } \\
\text { Drum Outlet (ft/s) }\end{array}$ & 0.46 & 1.08 & 1.71 & 0.12 & 0.27 & 0.43 & 0.05 & 0.12 & 0.19 \\
\hline Steam flow $=20 \mathrm{~g} / \mathrm{hr}, \mathrm{N} 2=0.25 \mathrm{SCFH}$ & & & & & & & & & \\
\hline $\begin{array}{l}\text { Superficial Velocity of Vapor at } \\
\text { Drum Outlet (ft/s) }\end{array}$ & 0.49 & 1.11 & 1.74 & 0.12 & 0.28 & 0.43 & 0.05 & 0.12 & 0.19 \\
\hline Steam flow $=40 \mathrm{~g} / \mathrm{hr}, \underline{\mathrm{N} 2}=0.25 \mathrm{SCFH}$ & & & & & & & & & \\
\hline $\begin{array}{l}\text { Superficial Velocity of Vapor at } \\
\text { Drum Outlet (ft/s) }\end{array}$ & 0.55 & 1.17 & 1.79 & 0.14 & 0.29 & 0.45 & 0.06 & 0.13 & 0.20 \\
\hline Steam flow $=40 \mathrm{~g} / \mathrm{hr}, \mathrm{N} 2=0.5 \mathrm{SCFH}$ & & & & & & & & & \\
\hline $\begin{array}{l}\text { Superficial Velocity of Vapor at } \\
\text { Drum Outlet (ft/s) }\end{array}$ & 0.56 & 1.19 & 1.81 & 0.14 & 0.30 & 0.45 & 0.06 & 0.13 & 0.20 \\
\hline Steam flow $=100 \mathrm{~g} / \mathrm{hr}, \underline{\mathrm{N} 2}=0.25 \mathrm{SCFH}$ & & & & & & & & & \\
\hline $\begin{array}{l}\text { Superficial Velocity of Vapor at } \\
\text { Drum Outlet (ft/s) }\end{array}$ & 0.72 & 1.34 & 1.97 & 0.18 & 0.34 & 0.49 & 0.08 & 0.15 & 0.22 \\
\hline Steam flow $=200 \mathrm{~g} / \mathrm{hr}, \quad \mathrm{N} 2=0.25 \mathrm{SCFH}$ & & & & & & & & & \\
\hline $\begin{array}{l}\text { Superficial Velocity of Vapor at } \\
\text { Drum Outlet (ft/s) }\end{array}$ & 1.01 & 1.63 & 2.25 & 0.25 & 0.41 & 0.56 & 0.11 & 0.18 & 0.25 \\
\hline
\end{tabular}


Table 28 - Effect of feed flow rate and drum diameter on superficial velocity in coil and at drum inlet

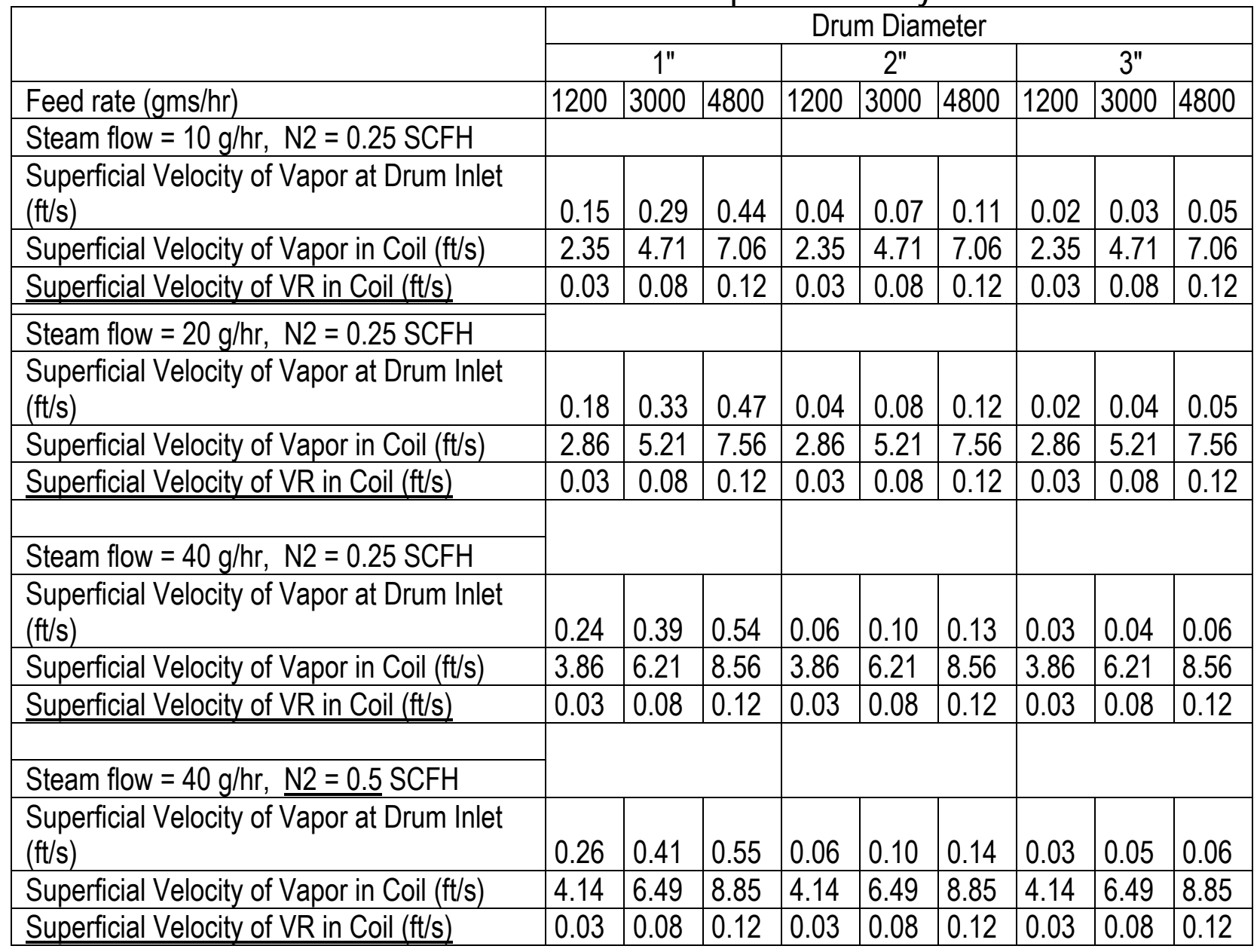

Table 29 shows the inches of coke that would deposit in the drum in a 5 hour run for various drum diameters and feed rates. This table shows that we cannot use the 1 inch drum, due to the extremely large drum height that would be required. Comparison of Table 27 with Table 29 shows that a 2 inch drum would allow us to achieve velocities approaching commercial values while maintaining a reasonable drum height. A 2 inch drum with a feed rate of $2400 \mathrm{~g} / \mathrm{hr}$, for example, would fill up about 65 inches of coke in a 4 hour run. If a steam flow rate of $60 \mathrm{~g} / \mathrm{hr}$ and a N2 flow rate of $0.5 \mathrm{SCFH}$ are used, the outlet drum velocity would be approximately $0.26 \mathrm{ft} / \mathrm{s}$, which is on the low end of commercial values. Other runs can be carried out with the 3 inch drum and $1200 \mathrm{~g} / \mathrm{hr}$ feed, $40 \mathrm{~g} / \mathrm{hr}$ steam, and $0.25 \mathrm{SCFH} \mathrm{N2}$, for an overhead velocity of 0.06 $\mathrm{ft} / \mathrm{s}$, and $3600 \mathrm{~g} / \mathrm{hr}$ feed, $40 \mathrm{~g} / \mathrm{hr}$ steam, and 0.25 SCFH N2, for an overhead velocity of $0.15 \mathrm{ft} / \mathrm{s}$.

Table 29 - Estimated coke level for 1", 2" and 3" drums (inches of coke formed in $5 \mathrm{hrs)}$

\begin{tabular}{|c|c|c|c|c|c|c|c|c|c|c|}
\hline \multirow{2}{*}{\multicolumn{2}{|c|}{$\begin{array}{l}\text { Drum Diameter } \\
\text { Feed rate (gms } / \mathrm{hr})\end{array}$}} & \multicolumn{3}{|c|}{ 1" } & \multicolumn{3}{|c|}{$2^{\prime \prime}$} & \multicolumn{3}{|c|}{$3^{\prime \prime}$} \\
\hline & & 1200 & 2400 & 3600 & 1200 & 2400 & 3600 & 1200 & 2400 & 3600 \\
\hline $\begin{array}{l}\% \text { of feed assumed } \\
\text { deposited as coke }\end{array}$ & $\begin{array}{l}\text { Density } \\
\text { of coke }\end{array}$ & & & & & & & & & \\
\hline 22.5 & 0.65 & 161.3 & 322.6 & 4883.9 & 40.3 & 80.76 & 121.0 & 17.9 & 35.8 & 53.8 \\
\hline 22.5 & 0.70 & 149.8 & 299.6 & 449.4 & 37.4 & 74.9 & 112.3 & 16.6 & 33.3 & 49.9 \\
\hline 25 & 0.65 & 1179.2 & 358.5 & 53.7 & 44.8 & 90.0 & 134.4 & 19.9 & 39.8 & 59.7 \\
\hline 25 & 0.70 & 166.4 & 332.9 & 499.3 & 41.6 & 83.2 & 124.8 & 18.54 & 37.09 & 5.5 \\
\hline
\end{tabular}




\section{Impact of Antifoam on Coil \& Overhead Temperature}

Antifoam injection studies were run using both a low viscosity $100,000 \mathrm{cSt}(0.3 \mathrm{ml} \mathrm{AF/} 70 \mathrm{ml}$ diesel) and a high viscosity $600,000 \mathrm{cSt}(0.75 \mathrm{ml} \mathrm{AF/} 70 \mathrm{ml}$ diesel) antifoam. In some of the tests, antifoam was injected continuously ( 2 min ON and 8 min OFF) while in others it was injected on as-needed basis (observation of foam determines the injection time). Antifoams were injected in the drum overhead, through the feedline, and mixed with the resid in the feed bucket. During the experiments, temperatures at the inlet to furnace coil (TIC131), the fluid temperature (TI107), the furnace skin temperature (TI200), the overhead temperature (TI208) and the temperature inside the coke drum near the bottom (TI214) are measured. From test to test, variations were seen in the overhead temperature and the furnace coil temperatures. In general, injecting antifoam on a continuous basis reduces the overhead temperature, while injecting antifoam in the feedline requires the furnace to be fired harder to get the fluid to the desired temperature. Discussed in the following section are the observations for the tests run using the Chevron and Equilon resids.

The CHEV 13 and CHEV 14 runs were carried out at a temperature of $900^{\circ} \mathrm{F}$, a pressure of 15 psig and a feed rate of $3600 \mathrm{gm} / \mathrm{hr}$. CHEV 13 used continuous overhead injection of 100,000 cSt (0.3/70) antifoam, whereas CHEV 14 used continuous feedline injection of 100,000 cSt (0.3/70) antifoam. As can be seen from the plot in Figure 73 the CHEV 13 run required less heat input to the feedline, had better control of fluid temperature and a cooler overhead. CHEV 14 required more heat input to the feedline, was harder to maintain the fluid temperature and had a comparatively warmer overhead.

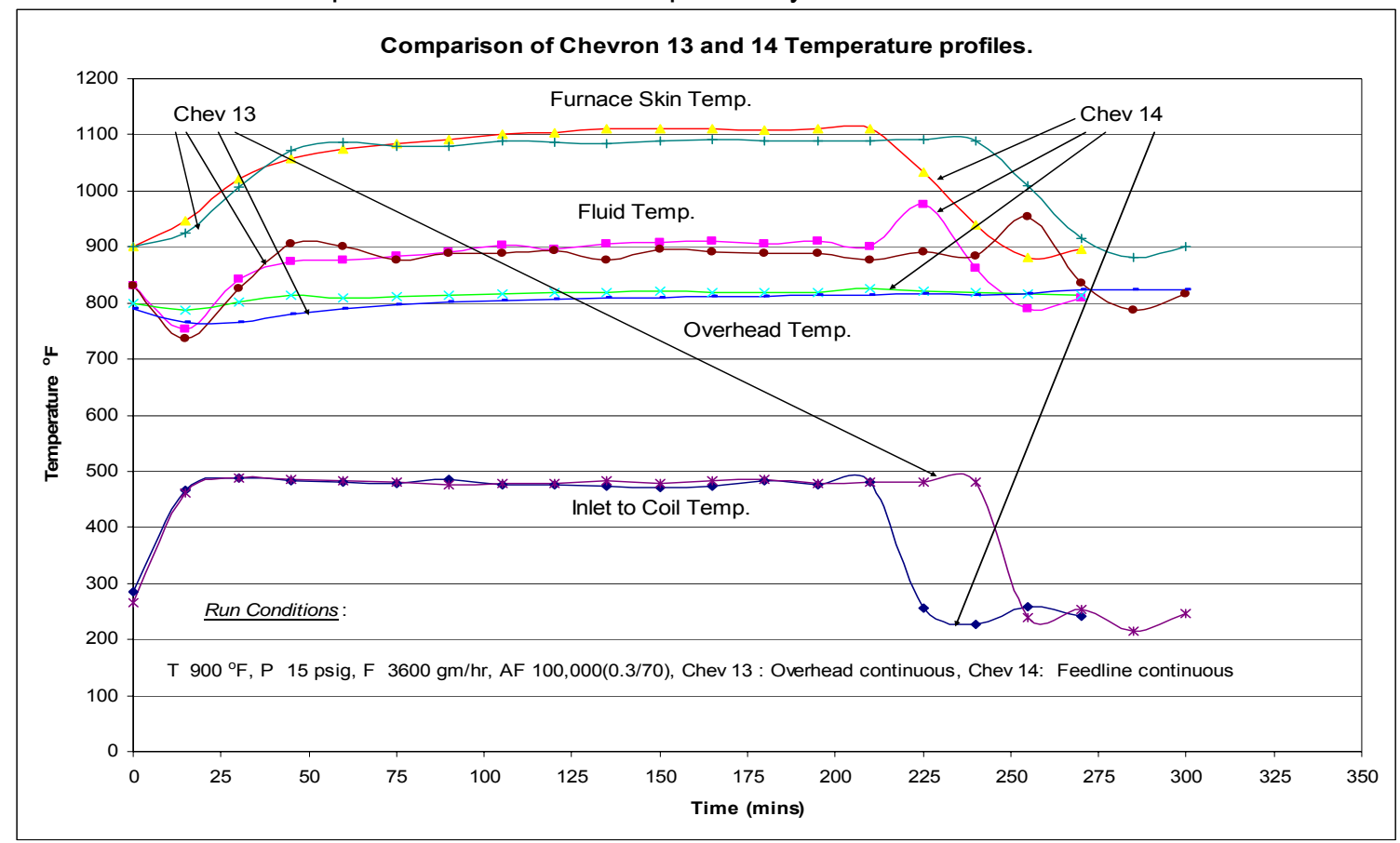

Figure 73 - Temperature profiles for CHEV 13 PUAFC and CHEV 14 PUAFC runs

The CHEV 12 and CHEV 14 runs were carried out at a temperature of $900^{\circ} \mathrm{F}$, a pressure of 15 psig and a feed rate of $3600 \mathrm{gm} / \mathrm{hr}$. CHEV 12 was an as-needed overhead injection of 100,000 cSt (0.3/70) antifoam, whereas CHEV 14 was a continuous feedline injection of 100,000 cSt (0.3/70) antifoam. As can be seen in Figure 74, CHEV 12 required less heat in feedline, was harder to maintain fluid temperature and the overhead was warmer. CHEV 14 required more heat in the feedline, had better control of fluid temperature and the overhead was comparatively cooler. 


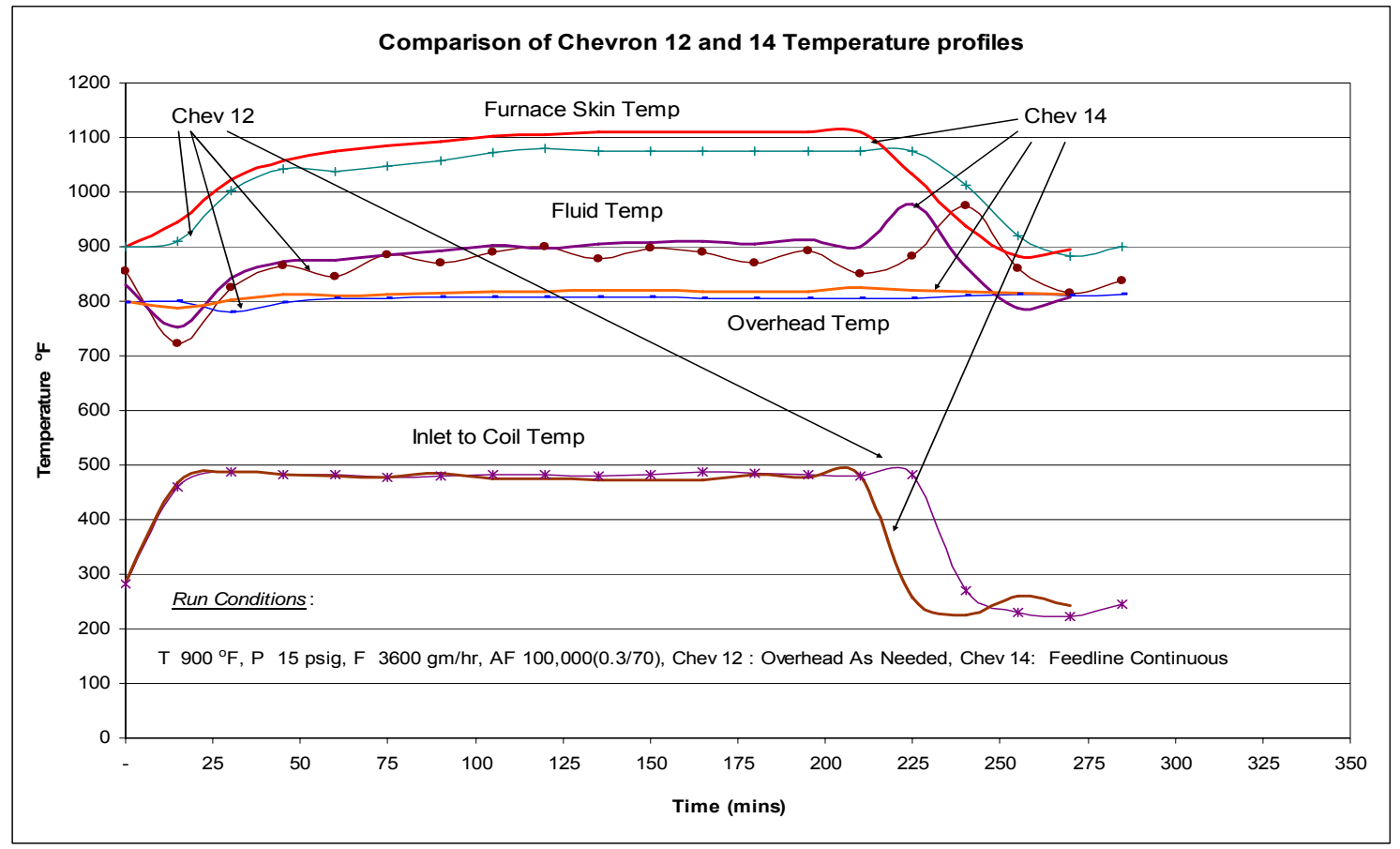

Figure 74 - Temperature profiles for CHEV 12 PUAFI and CHEV 14 PUAFC runs

The CHEV 12 and CHEV 16 runs were carried out at a temperature of $900^{\circ} \mathrm{F}$, a pressure of 15 psig and a feed rate of $3600 \mathrm{gm} / \mathrm{hr}$. CHEV 12 was an as-needed overhead injection of 100,000 cSt (0.3/70) antifoam, whereas CHEV 16 was an as-needed feedline+overhead injection of 600,000 cSt $(0.75 / 70)$ antifoam. As can be seen in Figure 75 CHEV 12 required less heat in the feedline, was harder to maintain the fluid temperature, and had a cooler overhead. CHEV 16 required more heat input to the feedline, had average control of fluid temperature and a comparatively warmer overhead. 


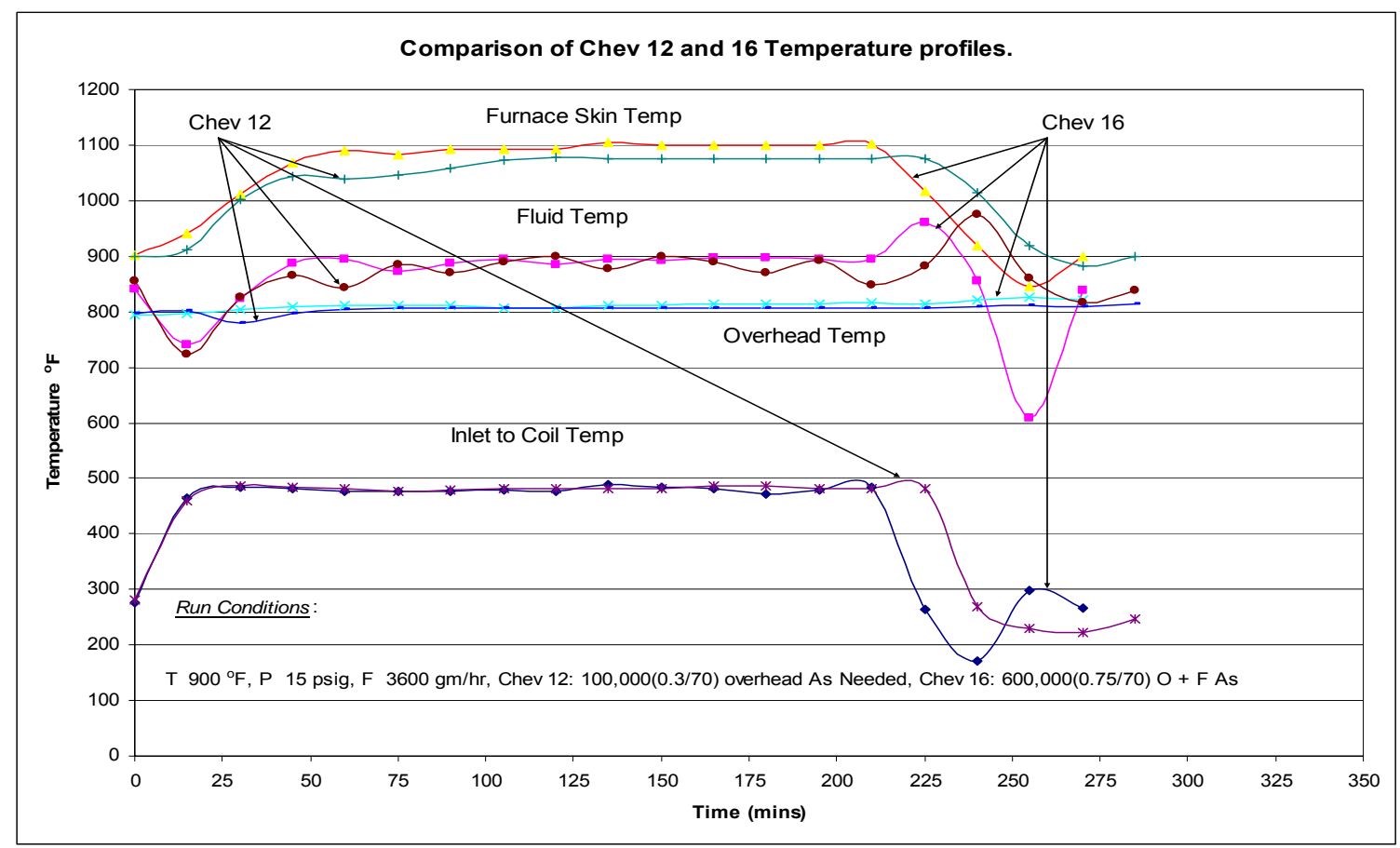

Figure 75 - Temperature profiles for CHEV 12 PUAFI and CHEV 16 PUAFI runs

The CHEV 14 and CHEV 16 runs were carried out at a temperature of $900^{\circ} \mathrm{F}$, a pressure of 15 psig and a feed rate of $3600 \mathrm{gm} / \mathrm{hr}$. CHEV 14 was a continuous feedline injection of $100,000 \mathrm{cSt}(0.3 / 70)$ antifoam, whereas CHEV 16 was an as-needed feedline+overhead injection of $600,000 \mathrm{cSt}(0.75 / 70)$ antifoam. As can be seen in Figure 76, CHEV 14 required more heat input to the feedline and the overhead was warmer. CHEV 16 on the other hand required less heat input to the feedline, had average control of fluid temperature and the overhead was comparatively cooler. 


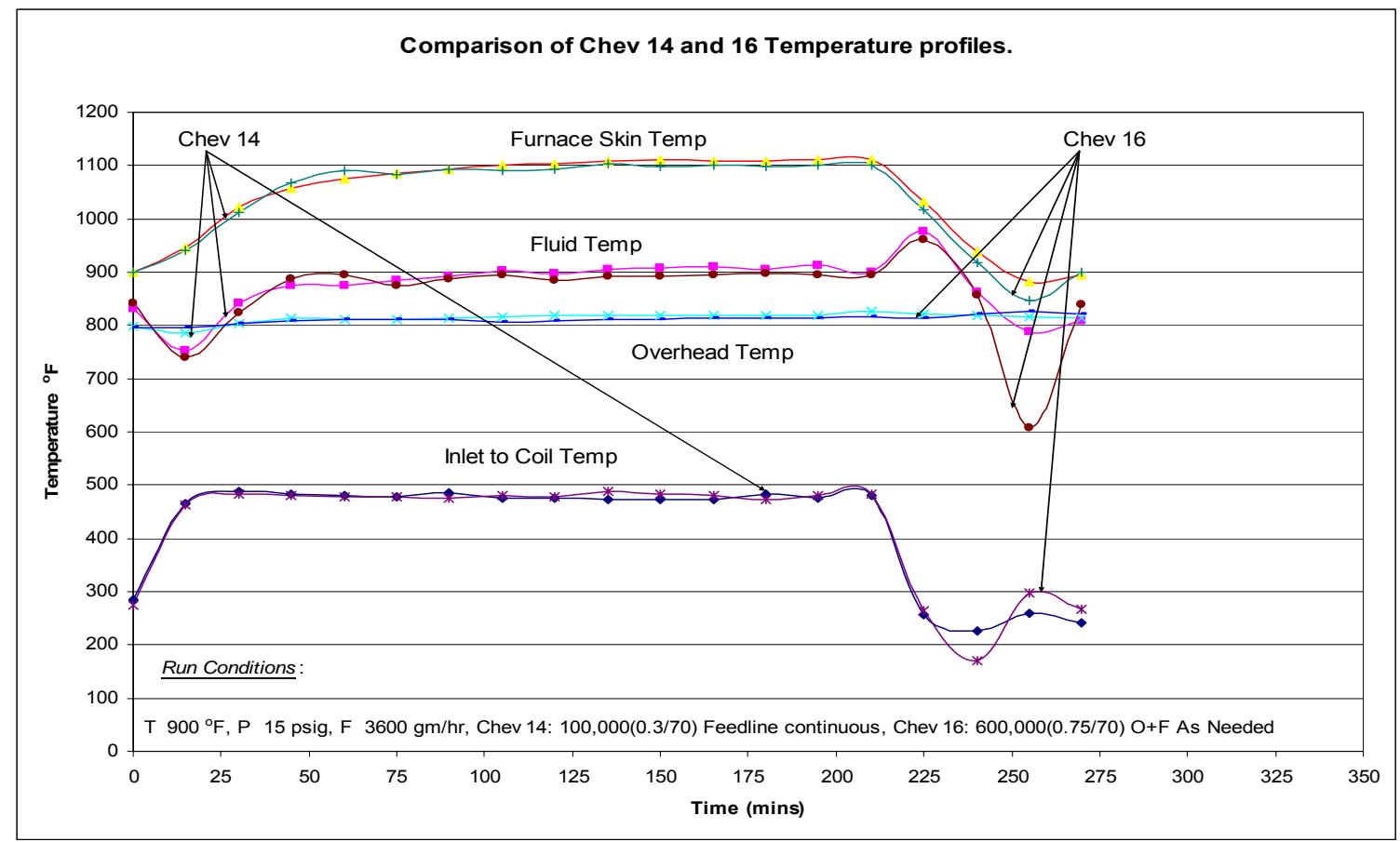

Figure 76 - Temperature profiles for CHEV 14 PUAFC and CHEV 16 PUAFI runs

The CHEV 8 and CHEV 12 runs were carried out at a temperature of $900^{\circ} \mathrm{F}$, a pressure of $15 \mathrm{psig}$ and a feed rate of $3600 \mathrm{gm} / \mathrm{hr}$. CHEV 12 was an as-needed overhead injection of 100,000 cSt (0.3/70) antifoam, whereas CHEV 8 was an as-needed overhead injection of $100,000 \mathrm{cSt}$ (30/70) antifoam. As can be seen in Figure 77, CHEV 8 required less heat input to the feedline, had higher fluid temperature and a warmer overhead temperature. CHEV 12 had a better control of the feedline temperature and substantially cooler overhead temperature.

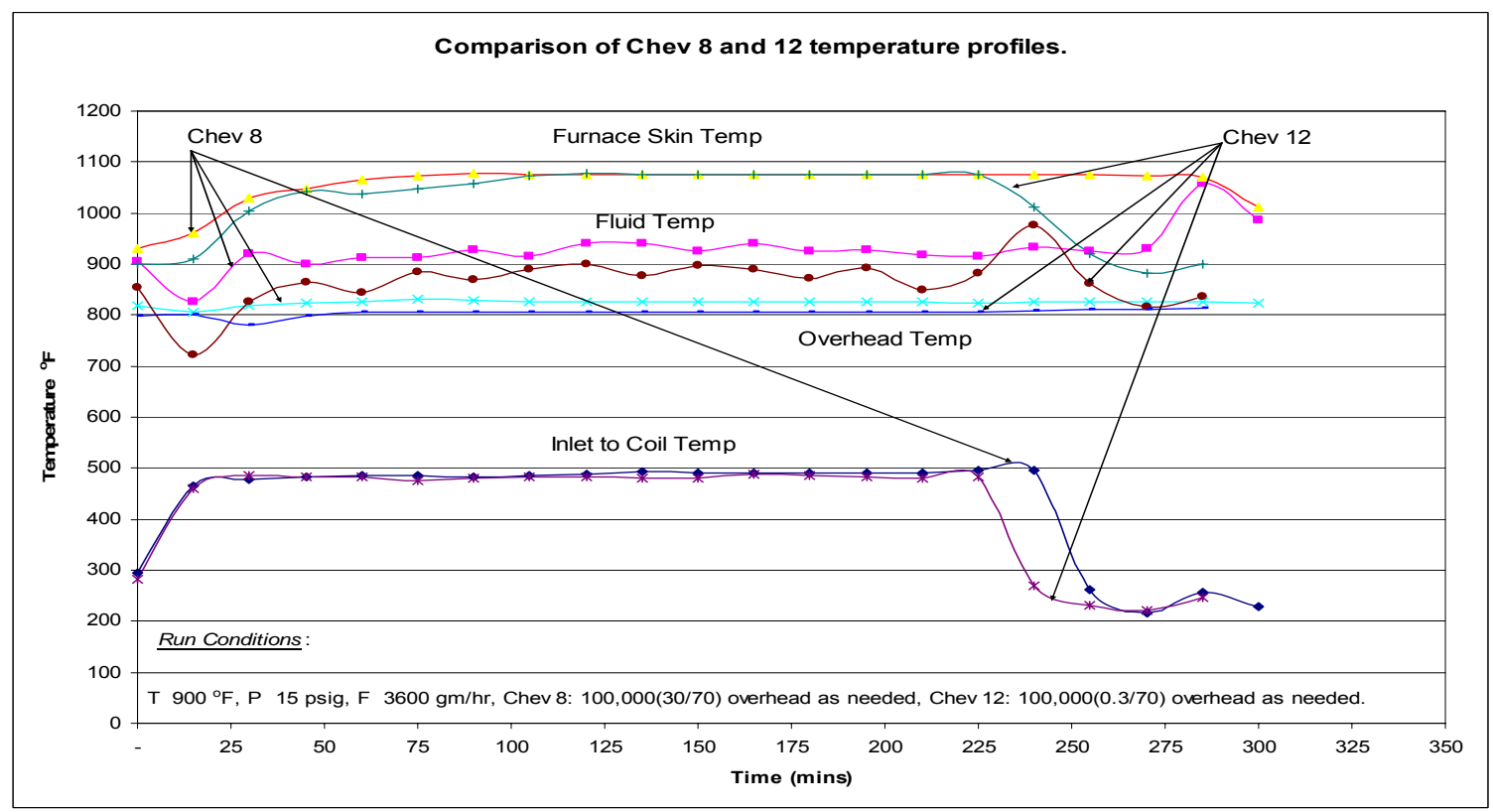




\section{Figure 77 - Temperature profiles for CHEV 8 PUAFI and CHEV 12 PUAFI runs}

The CHEV 8 and CHEV 13 runs were carried out at a temperature of $900^{\circ} \mathrm{F}$, a pressure of $15 \mathrm{psig}$ and a feed rate of $3600 \mathrm{gm} / \mathrm{hr}$. CHEV 13 was a continuous overhead injection of $100,000 \mathrm{cSt}(0.3 / 70)$ antifoam, whereas CHEV 8 was an as-needed overhead injection of 100,000 cSt (30/70) antifoam. As can be seen in Figure 78 that CHEV 8 required less heat input to the feedline, was harder to maintain fluid temperature and had a higher overhead temperature. CHEV 13 required more heat input to the feedline, had better control of fluid temperature and had a cooler overhead temperature.

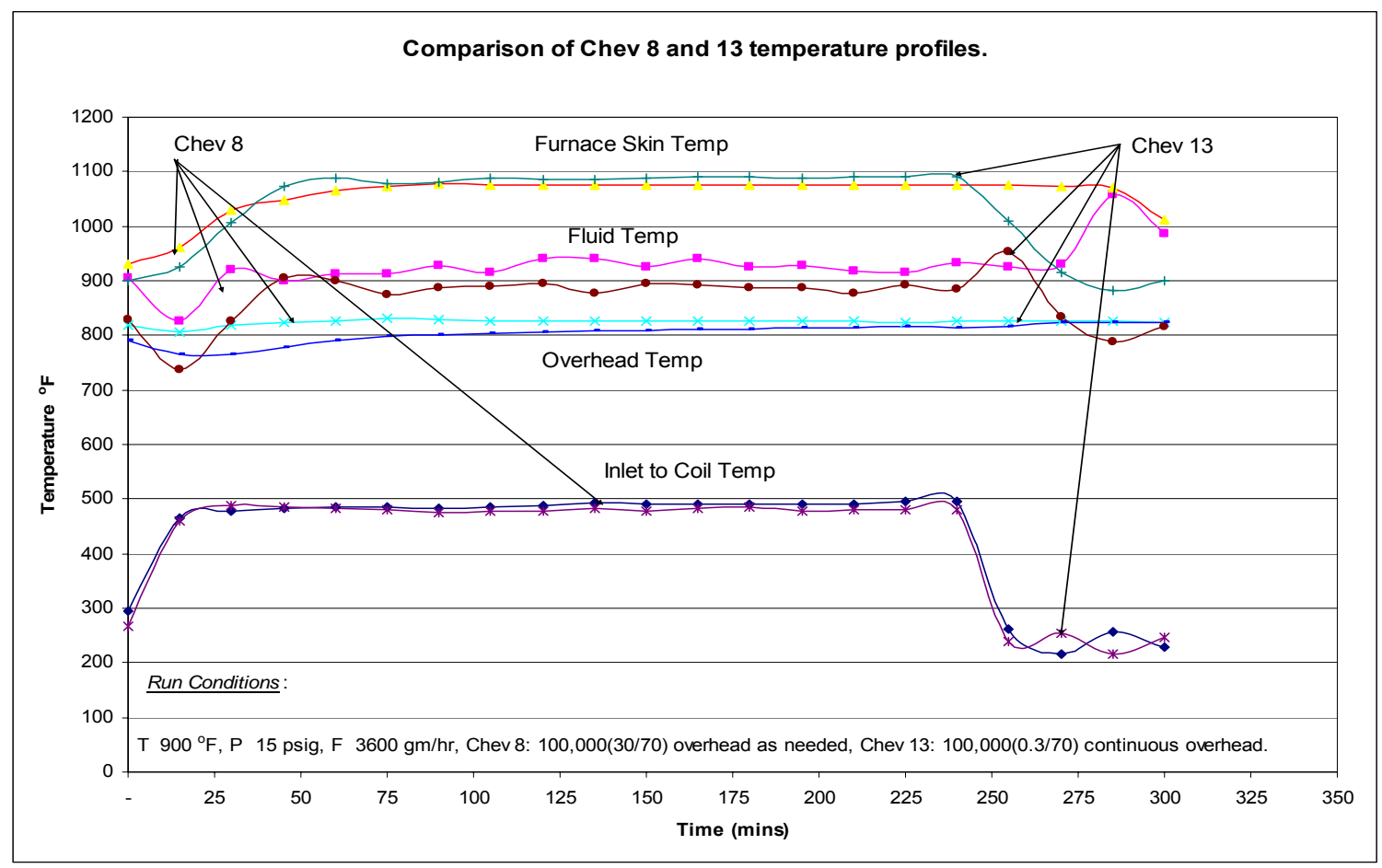

Figure 78 - Temperature profiles for CHEV 8 PUAFI and CHEV 13 PUAFC runs

The CHEV 8 and CHEV 14 runs were carried out at a temperature of $900^{\circ} \mathrm{F}$, a pressure of $15 \mathrm{psig}$ and a feed rate of $3600 \mathrm{gm} / \mathrm{hr}$. CHEV 14 was a continuous feedline injection of 100,000 cSt (0.3/70) antifoam, whereas CHEV 8 was an as-needed overhead injection of 100,000 cSt (30/70) antifoam. As can be seen in Figure 79, CHEV 8 required less heat input to the feedline, was harder to maintain the fluid temperature and had a warmer overhead temperature. CHEV 14 on the other hand required more heat input to the feedline, had better control of fluid temperature and a comparatively cooler overhead temperature. 


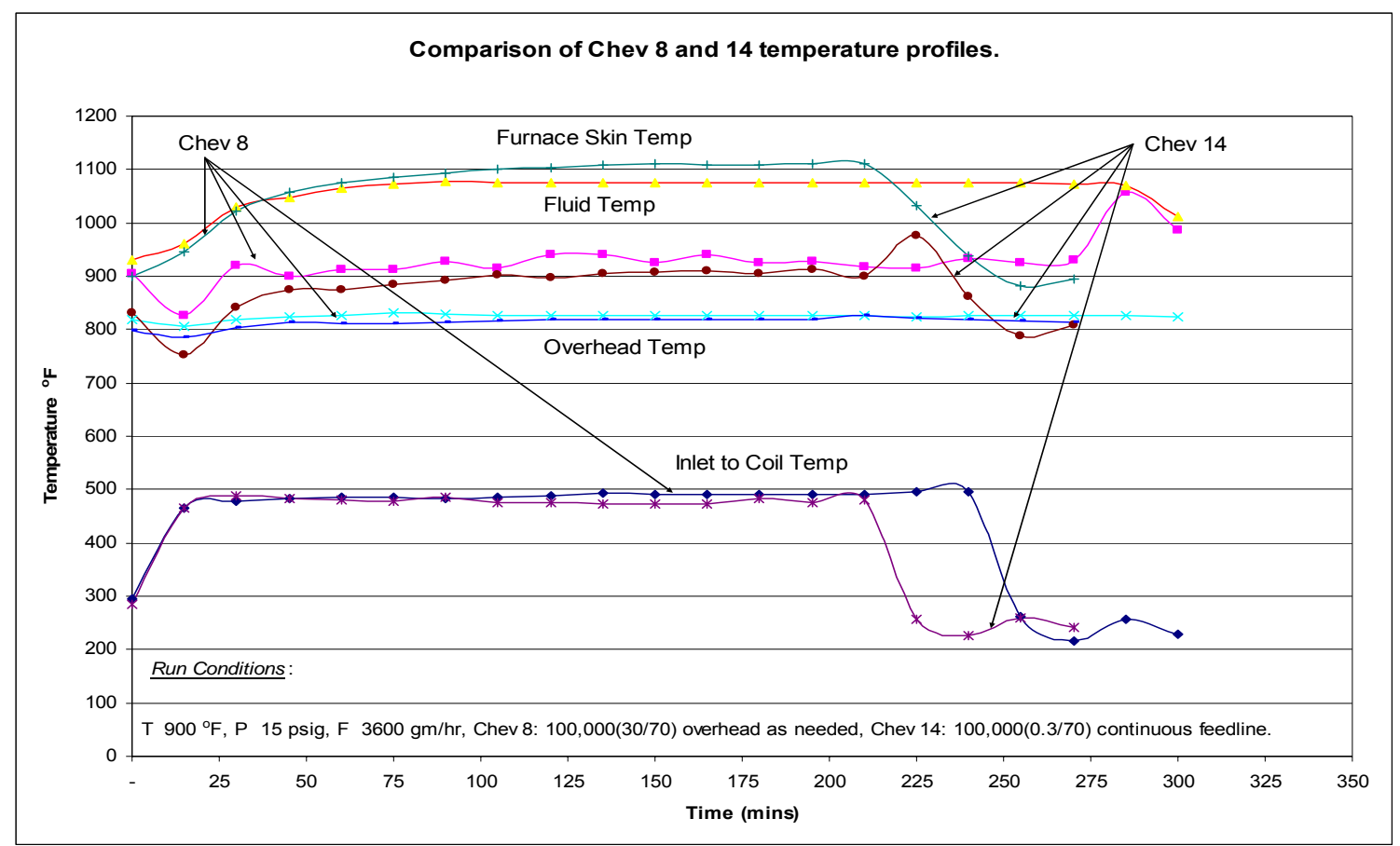

Figure 79 - Temperature profiles for CHEV 8 PUAFI and CHEV 14 PUAFC runs

EQU 5 run was carried out at a temperature of $930^{\circ} \mathrm{F}$, a pressure of 40 psig and a feed rate of $3600 \mathrm{gm} / \mathrm{hr}$, whereas EQU 6 run was carried out at a temperature of $900^{\circ} \mathrm{F}$, a pressure of $40 \mathrm{psig}$ and a feed rate of $3600 \mathrm{gm} / \mathrm{hr}$. EQU 5 was an as-needed overhead injection of 100,000 cSt (30/70) antifoam and EQU 6 was an as-needed feedline injection of 100,000 cSt (30/70) antifoam. As can be seen in Figure 80, Equilon required more heat input to the feedline to attain the higher temperature and the overhead temperature was very high compared to EQU 6. EQU 6 required less heat input to the feedline but the overhead temperature dropped remarkably. 


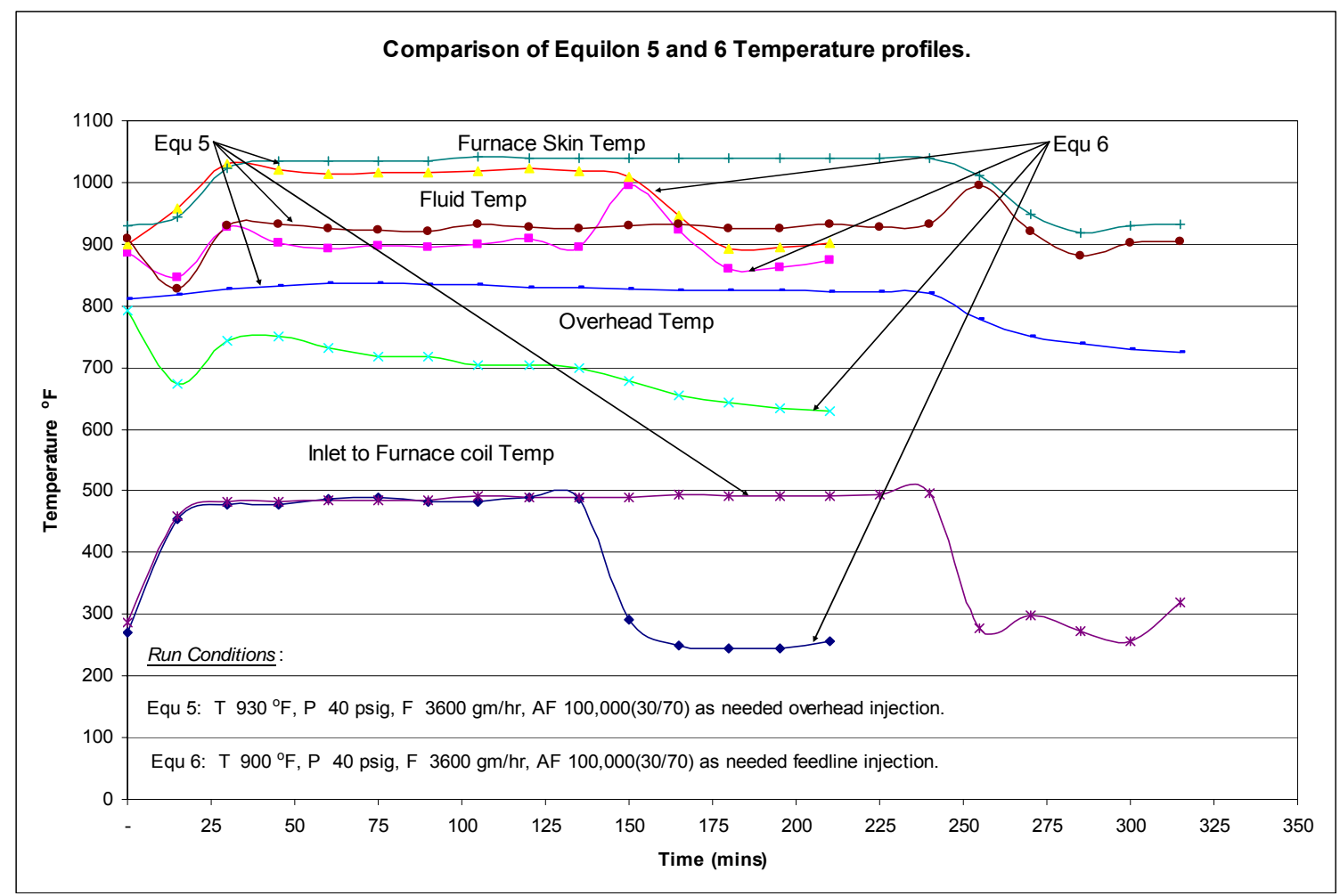

\section{Figure 80 - Temperature profiles for EQU 5 PUAFI and EQU 6 PUAFI runs}

The EQU 7 and EQU 8 runs were carried out at a temperature of $900^{\circ} \mathrm{F}$, a pressure of 15 psig and a feed rate of $3600 \mathrm{gm} / \mathrm{hr}$. EQU 7 used as-needed overhead injection of 100,000 cSt (0.3/70) antifoam, whereas EQU 8 used continuous feedline injection of 100,000 cSt $(0.3 / 70)$ antifoam. As can be seen in Figure 81, EQU 7 required more heat input to the feedline, was difficult to control the fluid temperature and had a cooler overhead temperature. EQU 8 had better control of feedline temperatures. 


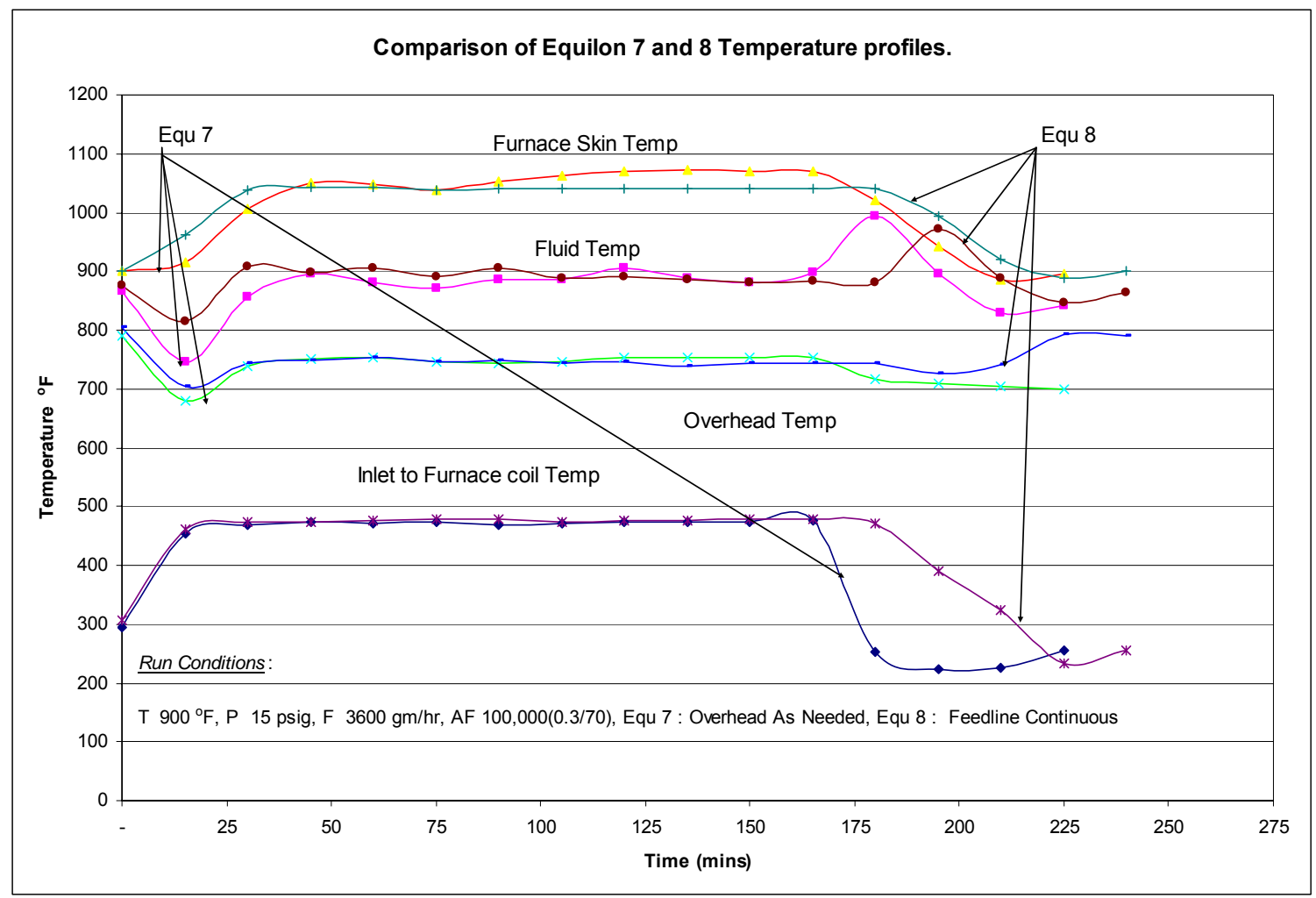

Figure 81 - Temperature profiles for EQU 7 PUAFI and EQU 8 PUAFC runs

The EQU 8 and EQU 9 runs were carried out at a temperature of $900^{\circ} \mathrm{F}$, a pressure of 15 psig and a feed rate of $3600 \mathrm{gm} / \mathrm{hr}$. EQU 8 was a continuous feedline injection of $100,000 \mathrm{cSt}(0.3 / 70)$ antifoam, whereas EQU 9 was an as-needed feedline injection of 100,000 cSt (0.3/70) antifoam. For EQU 9, observations during the run showed no foam and hence antifoam was not injected. As can be seen in Figure 82, EQU 9 required more heat input to the feedline, was difficult to maintain fluid temperature and the overhead temperature was much higher than EQU 8 was. EQU 8 required less heat input to the feedline, had a better control of the fluid temperature and the overhead temperature was remarkably lower. 


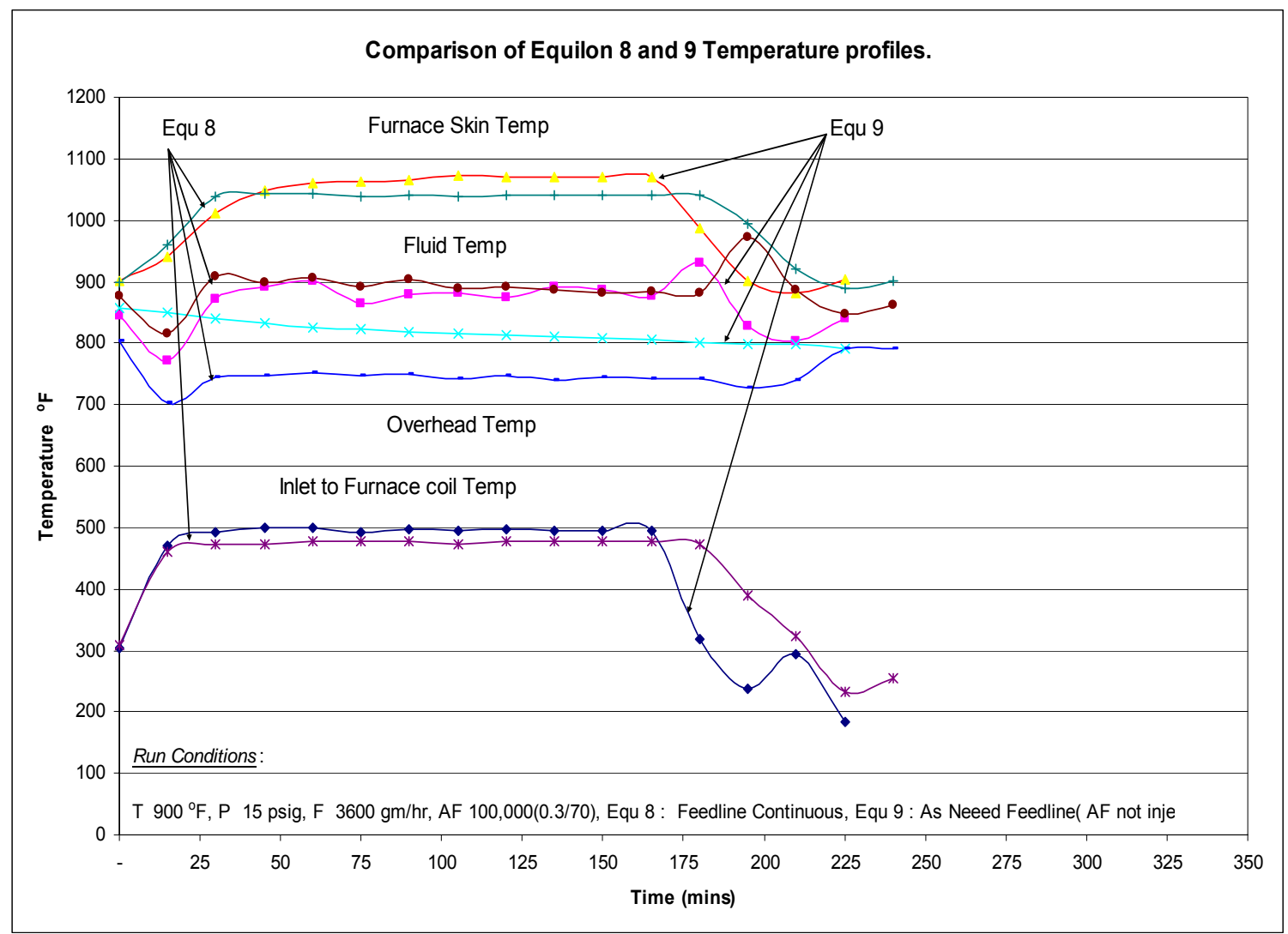

\section{Figure 82 - Temperature profiles for EQU 8 PUAFC and EQU 9 PUAFI runs}

The PETR 3 and PETR 13 runs were carried out at a temperature of $900^{\circ} \mathrm{F}$, a pressure of $15 \mathrm{psig}$ and a feed rate of $3600 \mathrm{gm} / \mathrm{hr}$. PETR 3 was an as-needed overhead+feedline injection of 100,000 cSt (30/70) antifoam, whereas PETR 3 was a continuous overhead injection of 100,000 cSt (0.3/70) antifoam. As can be seen in Figure 83, PETR 3 required less heat input to the inlet coil, and had a warmer overhead temperature. PETR 13 on the other hand required more heat input to the inlet coil and had a comparatively cooler overhead temperature. The fluid and the furnace skin temperature were the same for both the runs. 


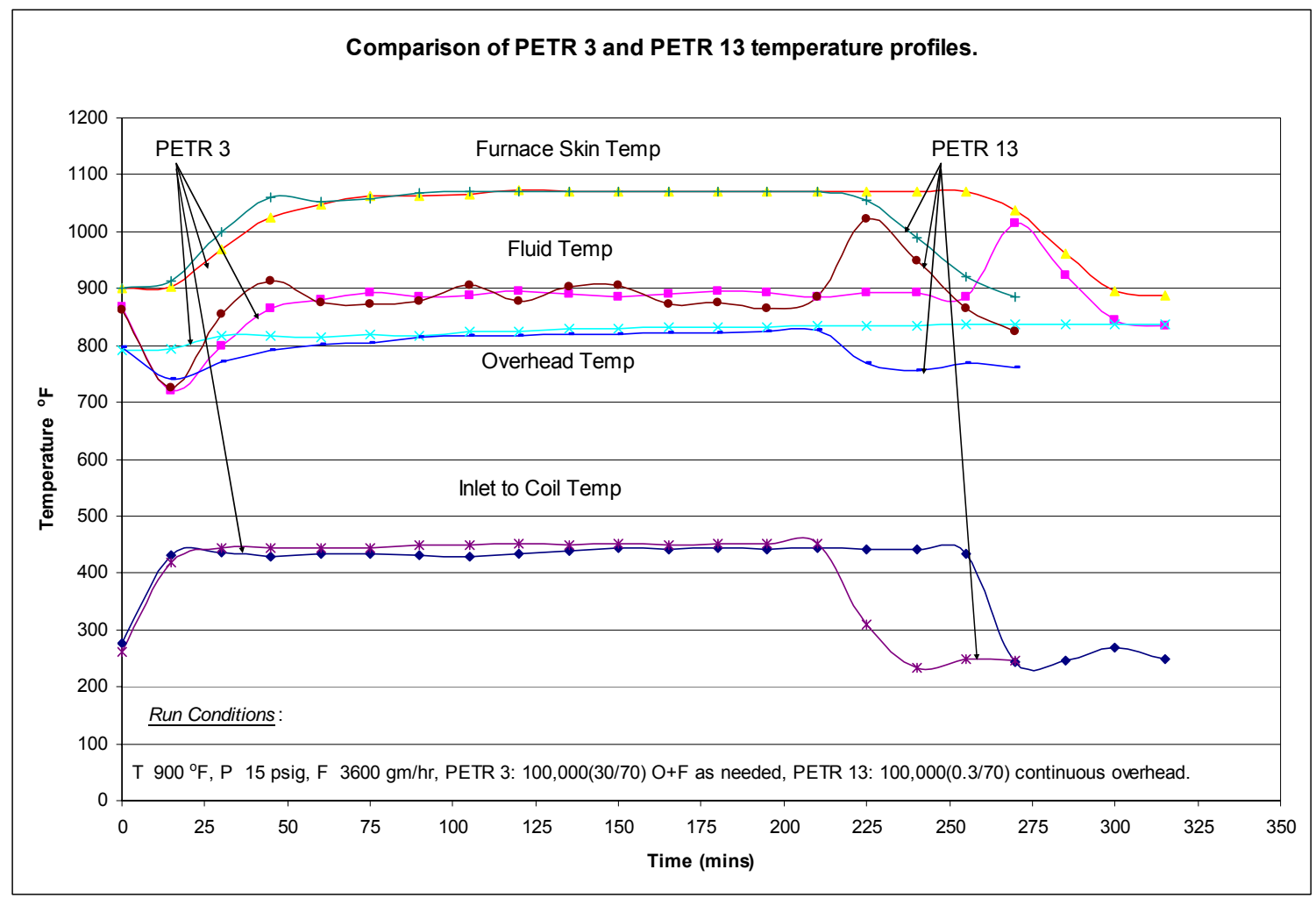

Figure 83 - Temperature profiles for PETR 3 PUAFI and PETR 13 PUAFC runs

The PETR 14 and PETR 15 runs were carried out at a temperature of $900^{\circ} \mathrm{F}$, a pressure of $15 \mathrm{psig}$ and a feed rate of $3600 \mathrm{gm} / \mathrm{hr}$. PETR 14 used continuous overhead+feedline injection of 100,000 cSt $(0.3 / 70)$ antifoam, whereas PETR 15 used continuous overhead+feedline injection of 100,000 cSt (0.3/70), 100,000 cSt (3/70), 600,000 cSt (0.12/70) and 600,000 cSt (0.75/70) antifoam. As can be seen in Figure 84, PETR 15 had a higher fluid and overhead temperature, whereas PETR 14 had a lower fluid and overhead temperature. 


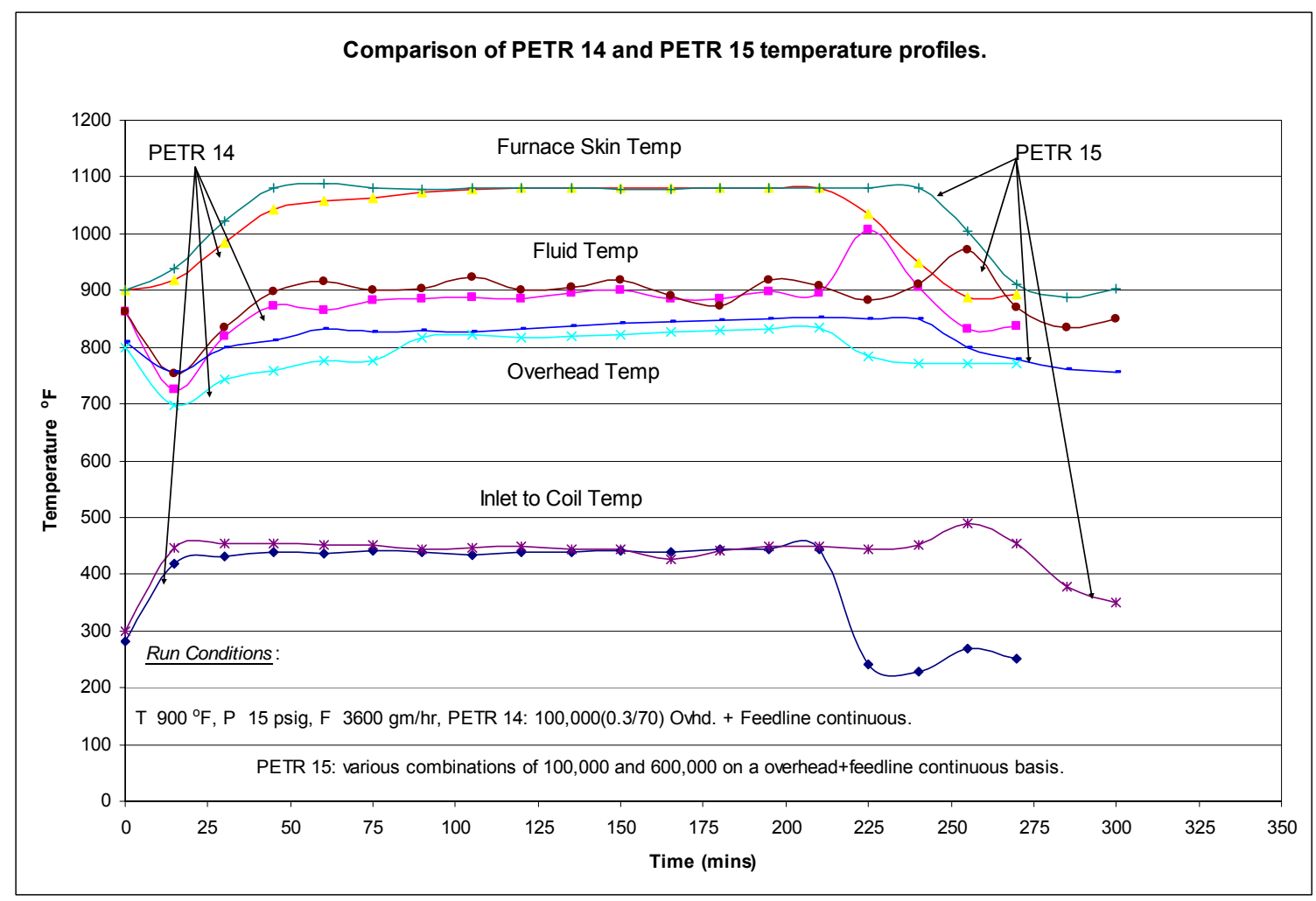

Figure 84 - Temperature profiles for PETR 14 PUAFC and PETR 15 PUAFC runs 


\section{DETAILED LIQUID ANALYSES}

\section{Scope of work:}

This study analyzes the liquid products from Chevron, Marathon, Petrobras, Citgo, Equilon and Suncor resids for both the $3 \mathrm{ft}$ drum pilot unit (PU) and the 6ft drum pilot unit (PUAF).

In the previous report, the only available data were the distillation and detailed hydrocarbon analysis (DHA) data for the PU runs. These PU runs were performed without the use of antifoaming agents. In the second phase of studies, a $6 \mathrm{ft}$ drum with a 0.25 inch furnace coil were used. The use of antifoaming agents (PUAF) were also incorporated into the study.

The distillation plots of the weight percent (\%) of the feed versus the bottom and overhead temperatures have been generated using the available PUAF resids. These plots were also repeated using the simulation distillation data, Sim Dis, from the 6ft pilot unit. The distillation data trends exhibited by both the $3 \mathrm{ft}$ and $6 \mathrm{ft}$ pilot units will be compared and discussed.

The PiONA contents of the resids have been analyzed at the boiling point ranges IBP-113०F, 113$430^{\circ} \mathrm{F}$, and $400-430^{\circ} \mathrm{F}$. Plots evaluating the individual PiONA components based on the data from the 0.25 inch coiled $3 \mathrm{ft}$ pilot unit will be compared with that of the 0.25 inch coiled the $6 \mathrm{ft}$ (PUAF) drums. The overall outcome of the DHA analysis is to be able to predict what type of PiONA component would be dominant at a certain temperature and pressure, and how a change in the temperature and pressure would affects its production.

The sulfur analysis has only been conducted on the PU resids. When the DHA analysis of the PUAF liquids have been completed, then the sulfur analysis will begin. The weight percent (\%) of sulfur in the different PU resids have been plotted against the fluid temperatures and pressures, at the different cuts. The resulting trends will be discussed.

Finally the densities, API, of the resids have been correlated to the different temperature cuts. The effects of temperature and pressure on the density, API, will be discussed. 


\section{Liquids Obtained Using $3 \mathrm{ft}$ Coke Drum Pilot Unit Runs}

In the first phase of study, coking runs were made using a $3 \mathrm{ft}$ pilot unit drum, PU, with both 0.25 and $3 / 8$ inch furnace coils. These PU runs were performed without the use of antifoaming agents. Table 30 through Table 35 show the PU runs available in the compiled database. All analysis in the report is based solely on the available sample runs. A key has been provided to interpret the data.

\begin{tabular}{|c|l|}
\multicolumn{1}{c|}{ Key } \\
\hline & 0.25 inch \\
\hline & 0.375 inch \\
\hline NO & Data is available \\
\hline NO $650+$ & No data is available \\
\hline
\end{tabular}

In general, there was no sulfur analysis conducted for all the resids using the 0.375 inch coil.

\begin{tabular}{|l|c|c|c|c|c|c|c}
\cline { 2 - 8 } \multicolumn{1}{c|}{} & \multicolumn{5}{c|}{ Data Type } & \multicolumn{2}{c}{ Detailed Hydrocarbon Analysis } \\
\hline CHEVRON & Distillation & Sim Dis & Density & Sulfur & IBP - 113 & $113-400$ & $\mathbf{4 0 0}-\mathbf{4 3 0}$ \\
\hline CHVPU 1 FS1 & & & & NO & & & \\
\hline CHVPU 2 PT1 & NO & & & NO & & & \\
\hline CHVPU 2A PT1A & & & & NO & & & \\
\hline CHVPU 3 PT2 & & & & NO & & & \\
\hline CHVPU 4 PT3 & & & & NO & & & \\
\hline CHVPU 5 PT4 & & & & NO & & & \\
\hline CHVPU 6 PT5 & & & & NO & & & \\
\hline CHVPU 10FS2 & & & & & & & \\
\hline CHVPU 11PT11 & & & & & & & \\
\hline CHVPU 12PT12 & & & & NO & & & \\
\hline CHVPU 13PT13 & & & & & & & \\
\hline CHVPU 14PT14 & & & & & & & \\
\hline
\end{tabular}

Table 30: Pilot Unit Chevron Resids 


\begin{tabular}{|c|c|c|c|c|c|c|c|}
\hline & \multicolumn{4}{|c|}{ Data Type } & \multicolumn{3}{|c|}{ Detailed Hydrocarbon Analysis } \\
\hline MARATHON & Distillation & Sim Dis & Density & Sulfur & IBP-113 & $113-400$ & $400-430$ \\
\hline MARPU 8 & NO & NO & NO & NO & NO & & \\
\hline MARPU 9 BT1 & & & & NO & & & \\
\hline MARPU 9A BT1A & & & & NO & & & \\
\hline MARPU 10 BT2 & & & & NO & & & \\
\hline MARPU 10A BT2A & & & & NO & & & \\
\hline MARPU 11 BT3 & & & & NO & & & \\
\hline MARPU 11A BT3A & & & & NO & & & \\
\hline MARPU 12 PT2 & & & & NO & NO & NO & NO \\
\hline MARPU 14 PT4 & & & & NO & & & \\
\hline MARPU 15 PT5 & & & & NO & & & \\
\hline MARPU 16 PT6 & & & & NO & & & \\
\hline MARPU 17A PT7A & & & & NO & & & \\
\hline MARPU 18 PT8 & & & & NO & & & \\
\hline MARPU 19 PT9 & & & & NO & & & \\
\hline MARPU 19A PT9A & & & & NO & & & \\
\hline MARPU 21 PT11 & & & & NO & & & \\
\hline \multicolumn{8}{|l|}{ MARPU 22FS3 } \\
\hline \multicolumn{8}{|l|}{ MARPU 23 PT23 } \\
\hline \multicolumn{8}{|l|}{ MARPU 24 PT24 } \\
\hline \multicolumn{8}{|l|}{ MARPU 25 RS10 } \\
\hline \multicolumn{8}{|l|}{ MARPU 26 RS20 } \\
\hline MARPU 27 PT27 & & & & NO & NO & NO & NO \\
\hline MARPU 28 PT28 & & & & NO & NO & NO & NO \\
\hline
\end{tabular}

Table 31: Pilot Unit Marathon Resids

\begin{tabular}{|c|c|c|c|c|c|c|c|}
\hline & \multicolumn{4}{|c|}{ Data Type } & \multicolumn{3}{|c|}{ Detailed Hydrocarbon Analysis } \\
\hline SUNCOR & Distillation & Sim Dis & Density & Sulfur & IBP-113 & $113-400$ & $400-430$ \\
\hline SUNPUI PT- & & & & & & & \\
\hline SUNPU2FSI & & & & & & & \\
\hline SUNPU 3PT3 & & & & & & & \\
\hline SUNPU A PTA & & & & & & & \\
\hline SUNPU 6 SO2 & & & & & & & \\
\hline SUNPU 7 PT & & & & & & & \\
\hline
\end{tabular}

Table 32: Pilot Unit Suncor Resids 


\begin{tabular}{|l|c|c|c|c|c|c|c}
\cline { 2 - 8 } \multicolumn{1}{c|}{} & \multicolumn{5}{c|}{ Data Type } & \multicolumn{2}{c}{ Detailed Hydrocarbon Analysis } \\
\hline \multicolumn{1}{c|}{ PETROBRAS } & Distillation & Sim Dis & Density & Sulfur & IBP-113 & $\mathbf{1 1 3}-\mathbf{4 0 0}$ & $\mathbf{4 0 0}-\mathbf{4 3 0}$ \\
\hline PETPU 1 PT1 & & & & NO & & & \\
\hline PETPU 2B PT2B & NO & & & NO & & & \\
\hline PETPU 3 * & & NO & & NO & & & \\
\hline PETPU 4 PT4 & & & & NO & & & \\
\hline PETPU 5 PT5 & & & & NO & & & \\
\hline PETPU 6 PT6 & & & & NO & & & \\
\hline PETPU 7 BT1 & & & & NO & & & \\
\hline PETPU 8 PT8 & & & & NO & & & \\
\hline PETPU 9 PT9 & & & & NO & & & \\
\hline PETPU 10PT10 & & & & & & & \\
\hline PETPU12FS & & & & & & & \\
\hline PETPU 13PT13 & NO & & & & & & \\
\hline
\end{tabular}

Table 33: Pilot Unit Petrobras Resids

*No Overhead Temperatures

\begin{tabular}{|c|c|c|c|c|c|c|c|}
\hline \multirow[b]{2}{*}{ CITGO } & \multicolumn{4}{|c|}{ Data Type } & \multicolumn{3}{|c|}{ Detailed Hydrocarbon Analysis } \\
\hline & Distillation & Sim Dis & Density & Sulfur & IBP- 113 & $113-400$ & $400-430$ \\
\hline CITPU 1 PT1 & NO & & NO & NO & NO & NO & NO \\
\hline CITPU 2A PT2A & & & NO & NO & & & \\
\hline CITPU 3 PT3 & & & NO $650+$ & NO & & & \\
\hline CITPU 4 PT4 & & & NO & NO & NO & NO & NO \\
\hline CITPU 5 PT5 & NO & & NO & NO & NO & NO & NO \\
\hline CITPU 6 PT6 & & & NO $650+$ & NO & & & \\
\hline CITPU 7 PT 7 & & & NO $650+$ & NO & & & \\
\hline CITPU 8 PT8 & & & & NO & & & \\
\hline CITPU 10 PT10 & & & NO $650+$ & NO & & & \\
\hline CITPU 15 PT15 & & & NO $650+$ & NO & & & \\
\hline \multicolumn{8}{|l|}{ CITPU 16 PT 16} \\
\hline \multicolumn{8}{|l|}{ CIPU $-P$ - } \\
\hline CITP 18 P 10 & & & NO $650+$ & & & & \\
\hline \multicolumn{8}{|l|}{ CITPU 19P119 } \\
\hline \multicolumn{8}{|l|}{ CITPV 20 P 120} \\
\hline 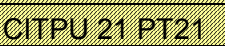 & & & & & & & \\
\hline
\end{tabular}

Table 34: Pilot Unit Citgo Resids

\begin{tabular}{|c|c|c|c|c|c|c|c}
\cline { 2 - 8 } \multicolumn{1}{c|}{} & \multicolumn{3}{c|}{ Data Type } & \multicolumn{2}{c}{ Detailed Hydrocarbon Analysis } \\
\hline EQUILON & Distillation & Sim Dis & Density & Sulfur & IBP-113 & $\mathbf{1 1 3 - 4 0 0}$ & $\mathbf{4 0 0}-\mathbf{4 3 0}$ \\
\hline EQPU 8PT8 & & & & & & & \\
\hline EQPU 9PT9 & NO & NO & & NO & NO & NO & NO \\
\hline EQPU 10PT10 & & & & & & & \\
\hline EQPU 12FS1 & & & & & & & \\
\hline EQPU 13 SO1 & NO & NO & & NO & NO & NO & NO \\
\hline EQPU 14 SO2 & & & & & & & \\
\hline
\end{tabular}

Table 35: Pilot Unit Equilon Resids 


\section{Liquids Obtained Using 6 ft Coke Drum Pilot Unit Runs}

Tables 7-12 show the PUAF runs available in the compiled database. All analysis in the report is based solely on the available sample runs. Table 36 through Table 41 show the PUAF runs available in the compiled database. All analysis in the report is based solely on the available sample runs.

\begin{tabular}{|l|l|}
\multicolumn{1}{c|}{ Key } \\
\hline & 0.25 inch \\
\hline NO & Data is available \\
\hline & No data is available \\
\hline
\end{tabular}

No sulfur analyses have been conducted on any of the PUAF runs and detailed hydrocarbon analysis is still in progress.

\begin{tabular}{|c|c|c|c|c|c|c|c|}
\hline & \multicolumn{4}{|c|}{ Data Type } & \multicolumn{3}{|c|}{ Detailed Hydrocarbon Analysis } \\
\hline CHEVRON & Distillation & Sim Dis & Density & Sulfur & IBP- 113 & $113-400$ & $400-430$ \\
\hline CHEV I PUAF & & & & NO & NO & NO & NO \\
\hline CHEV 2 PUAF RST & & & & NO & NO & NO & NO \\
\hline CHEV 3 PUAF & & & & NO & NO & NO & NO \\
\hline CHEVA PUAF - & NO & NO & NO & NO & NO & NO & NO \\
\hline CHEV 5 PUAF & & & & NO & NO & NO & NO \\
\hline CHEV GPUAF & & & & NO & NO & NO & NO \\
\hline CHEV TA PUAF & & & & NO & NO & NO & NO \\
\hline CHEV 8 PUAF & & & & NO & & & \\
\hline CHEV 9PUAF & & & & NO & & & \\
\hline CHEV 10 PUAF & & & & NO & & & \\
\hline CHEV II PUAF & NO & & NO & NO & & NO & NO \\
\hline
\end{tabular}

Table 36: PUAF Chevron Resids *No Normalized wt\% (overhead) temperatures

\begin{tabular}{|l|l|l|l|c|c|c|c|}
\cline { 2 - 7 } \multicolumn{1}{c|}{} & \multicolumn{5}{c|}{ Data Type } & \multicolumn{2}{c}{ Detailed Hydrocarbon Analysis } \\
\hline MARATHON & Distillation & Sim Dis & Density & Sulfur & IBP-113 & $\mathbf{1 1 3 - 4 0 0}$ & $\mathbf{4 0 0 - 4 3 0}$ \\
\hline MARA 1 PUAF & & & & NO & & & \\
\hline MARA2 PUAF & & & & NO & & & \\
\hline MARA 3 PUAF & & & NO & & & \\
\hline MARA 4 PUAF & & & & NO & NO & & \\
\hline MARA 5 PUAF & & & & NO & NO & & \\
\hline MARA 6 PUAF & NO & & NO & & & \\
\hline MARA 7 PUAF & & & NO & NO & & \\
\hline
\end{tabular}

Table 37: PUAF Marathon Resids 


\begin{tabular}{|c|c|c|c|c|c|c|c|}
\hline & \multicolumn{4}{|c|}{ Data Type } & \multicolumn{3}{|c|}{ Detailed Hydrocarbon Analysis } \\
\hline SUNCOR & Distillation & Sim Dis & Density & Sulfur & IBP-113 & $113-400$ & $400-430$ \\
\hline SUN 1 PUAF & & & & NO & NO & NO & NO \\
\hline SUN2 PUAF & & & & NO & NO & NO & NO \\
\hline SUN 3 PUAF & & & & NO & NO & NO & NO \\
\hline SUN 4 PUAF & & & & NO & NO & NO & NO \\
\hline SUN 5 PUAF & & & & NO & NO & NO & NO \\
\hline SUN 6 PUAF & & & & NO & NO & NO & NO \\
\hline SUN 7 PUAF & & & & NO & NO & NO & NO \\
\hline SUN 8 PUAF & & & & NO & NO & NO & NO \\
\hline SUN 9 PUAF & & & & NO & NO & & \\
\hline SUN 10 PUAF & & & & NO & NO & & \\
\hline SUN IIPUAF & NO & & NO & NO & NO & NO & NO \\
\hline SUN 12 PUAF & & & & NO & NO & & \\
\hline SUN 13 PUAF & & & & NO & & & \\
\hline
\end{tabular}

Table 38: PUAF Suncor Resids

\begin{tabular}{|c|c|c|c|c|c|c|c|}
\hline & \multicolumn{4}{|c|}{ Data Type } & \multicolumn{3}{|c|}{ Detailed Hydrocarbon Analysis } \\
\hline PETROBRAS & Distillation & Sim Dis & Density & Sulfur & IBP-113 & $113-400$ & $400-430$ \\
\hline PETR I PUAF & & & & NO & & & \\
\hline PETR2 PUAF & & & & NO & & & \\
\hline PETR 3 PUAF & & & & NO & & & \\
\hline PETR A PUAF & & & & NO & NO & & \\
\hline PETR 5 PUAF & & & & NO & & & \\
\hline PETR G PUAF & & & & NO & & & \\
\hline PETR P PUAF & & & & NO & & & \\
\hline PETR 8 PUAF & & & & NO & & & \\
\hline PETR 9PUAF I & & & & NO & & & \\
\hline PETR 10 PUAF I & NO & & NO & NO & & & \\
\hline PETR 11 PUAF I & NO & & NO & NO & NO & NO & NO \\
\hline PETR 12 PUAF I & NO & & NO & NO & NO & NO & NO \\
\hline PETR 13 PUAF C & NO & & NO & NO & NO & NO & NO \\
\hline PETR 14 PUAF C & NO & NO & NO & NO & NO & NO & NO \\
\hline PETR 15 PUAF C & NO & NO & NO & NO & NO & NO & NO \\
\hline PETR 16 PUAF I & NO & NO & NO & NO & NO & NO & NO \\
\hline
\end{tabular}

Table 39: PUAF Petrobras Resids

\begin{tabular}{|c|c|c|c|c|c|c|c|}
\hline & \multicolumn{4}{|c|}{ Data Type } & \multicolumn{3}{|c|}{ Detailed Hydrocarbon Analysis } \\
\hline EQUILON & Distillation & Sim Dis & Density & Sulfur & IBP-113 & $113-400$ & $400-430$ \\
\hline EO DUAF & & & NO & NO & NO & NO & NO \\
\hline EQ 2 PUAF & & & & NO & NO & NO & NO \\
\hline EQ 3 PUAF & & & & NO & NO & NO & NO \\
\hline EQ A PUAF & & & & NO & & & \\
\hline EQ 5 PUAF & & & & NO & NO & & \\
\hline EQ6 PUAF & & & & NO & & & \\
\hline EQ 7 PUAFI & NO & NO & NO & NO & NO & NO & NO \\
\hline EQ 8 PUAFC & NO & NO & NO & NO & NO & NO & NO \\
\hline EQSOI PUAF & & & & NO & NO & NO & NO \\
\hline
\end{tabular}

Table 40: PUAF Equilon Resids 


\begin{tabular}{|c|c|c|c|c|c|c|c|}
\hline & \multicolumn{4}{|c|}{ Data Type } & \multicolumn{3}{|c|}{ Detailed Hydrocarbon Analysis } \\
\hline CITGO & Distillation & Sim Dis & Density & Sulfur & IBP-113 & $113-400$ & $400-430$ \\
\hline CIT I PUAF & & & & NO & & & \\
\hline CIT 2 PUAF & & & & NO & & & \\
\hline CIT 3 PUAF & & & & NO & & & \\
\hline CIT 4 PUAF & & & & NO & & & \\
\hline CIT 5 PUAF & & & & NO & & & \\
\hline CIT 6 PUAF & & & & NO & & & \\
\hline CIT T PUAF & & & & NO & & & \\
\hline CIT 8 PUAF & & & & NO & & & \\
\hline CIT 9 PUAF & & & & NO & NO & & \\
\hline CIT 10 PUAF- & & & & NO & NO & & \\
\hline CIT- IIUAF & & & & NO & & & \\
\hline CIT-12PUAF- & & & & NO & & & \\
\hline
\end{tabular}

Table 41: PUAF Citgo Resids

\section{Distillation:}

The pilot unit runs were conducted at bottom feed temperatures of $900 \mathrm{oF}$ and $930 \mathrm{oF}$, and the average overhead temperature was monitored. To ensure that the average overhead temperature can be substituted with the feed temperatures, the effects of the temperatures on the weight percent of the feed had to be investigated.

Using the data obtained from the $3 \mathrm{ft}$ pilot unit runs, the weight percent (\%) of the feed for the boiling point ranges IBP- $113^{\circ} \mathrm{F}, 113-400^{\circ} \mathrm{F}, 400-430^{\circ} \mathrm{F}, 430-650^{\circ} \mathrm{F}$, and $650^{\circ} \mathrm{F}+$ were plotted against the bottom temperatures $\left(900^{\circ} \mathrm{F}\right.$ and $\left.930^{\circ} \mathrm{F}\right)$ at $15 \mathrm{psig}$ and $40 \mathrm{psig}$, respectively (Figure 85 and Figure 86 ). These plots were also constructed using the average overhead temperature in place of the bottom temperature (Figure 87 and Figure $88)$.

All four plots were repeated using the Sim Dis data for the $3 \mathrm{ft}$ pilot unit and is illustrated in Figure 89 through Figure 92. 


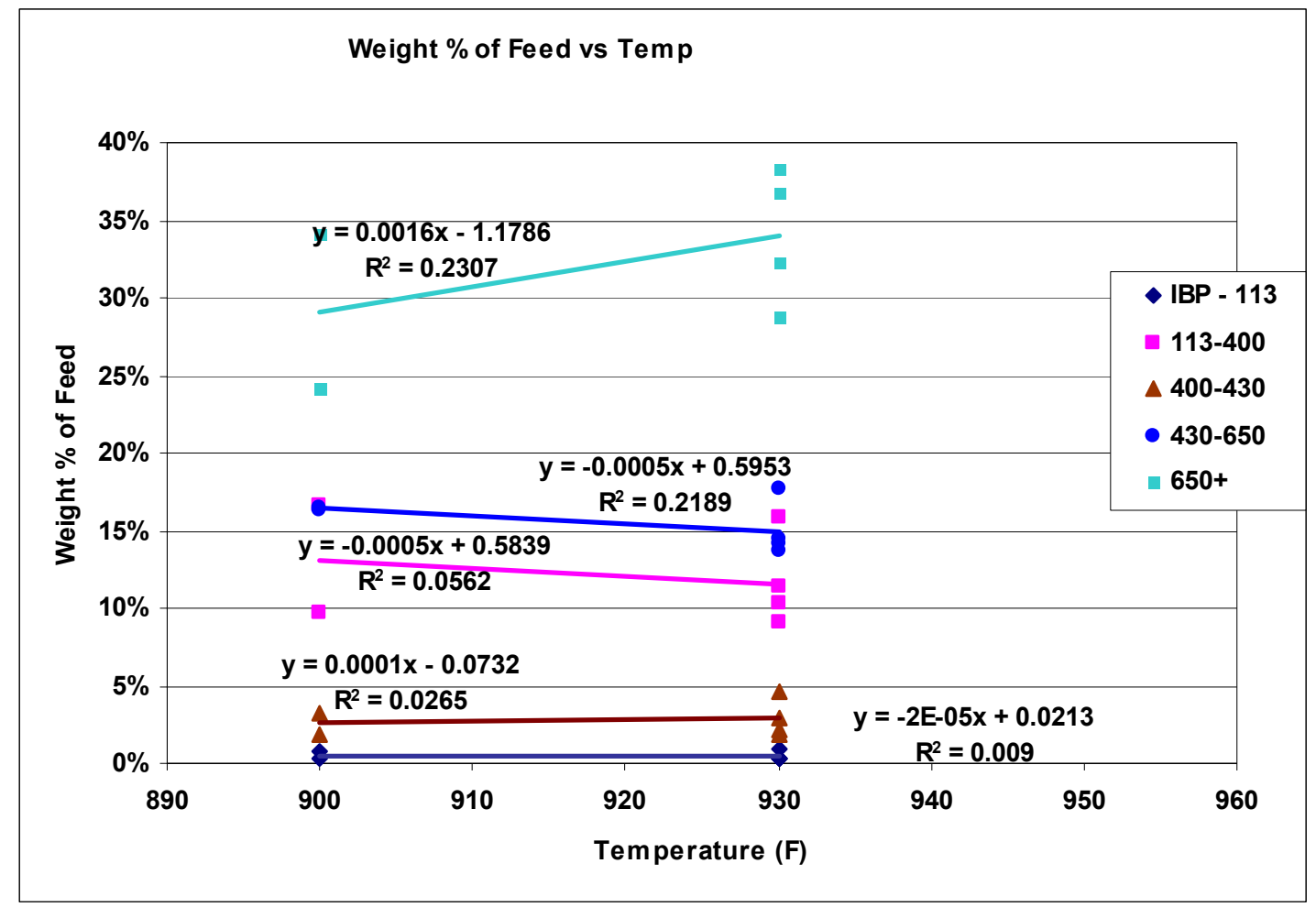

Figure 85: PU Distillation at 15psig with bottom temperatures of 900F and 930F

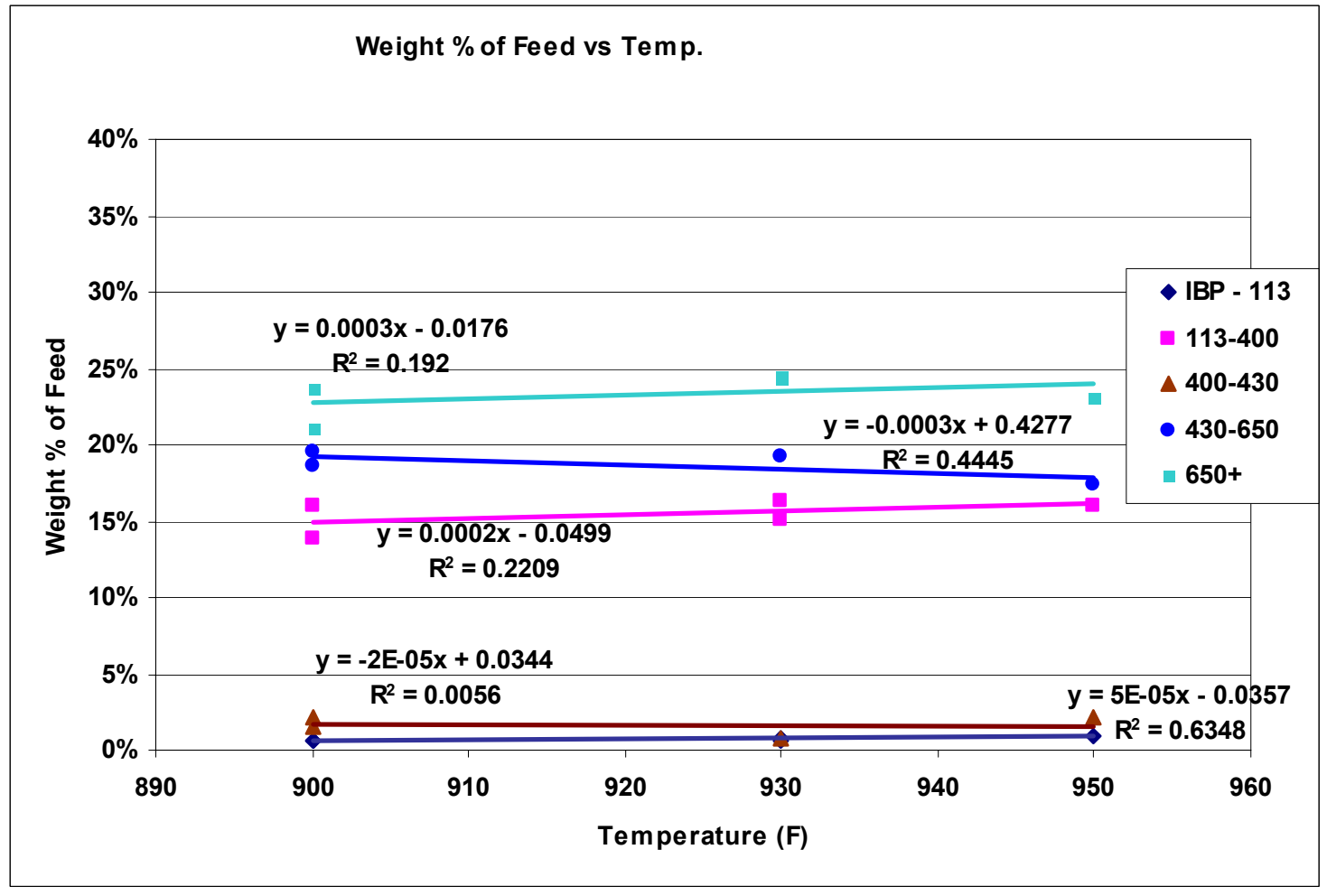

Figure 86: PU Distillation at 40psig with bottom temperatures of 900F and 930F 


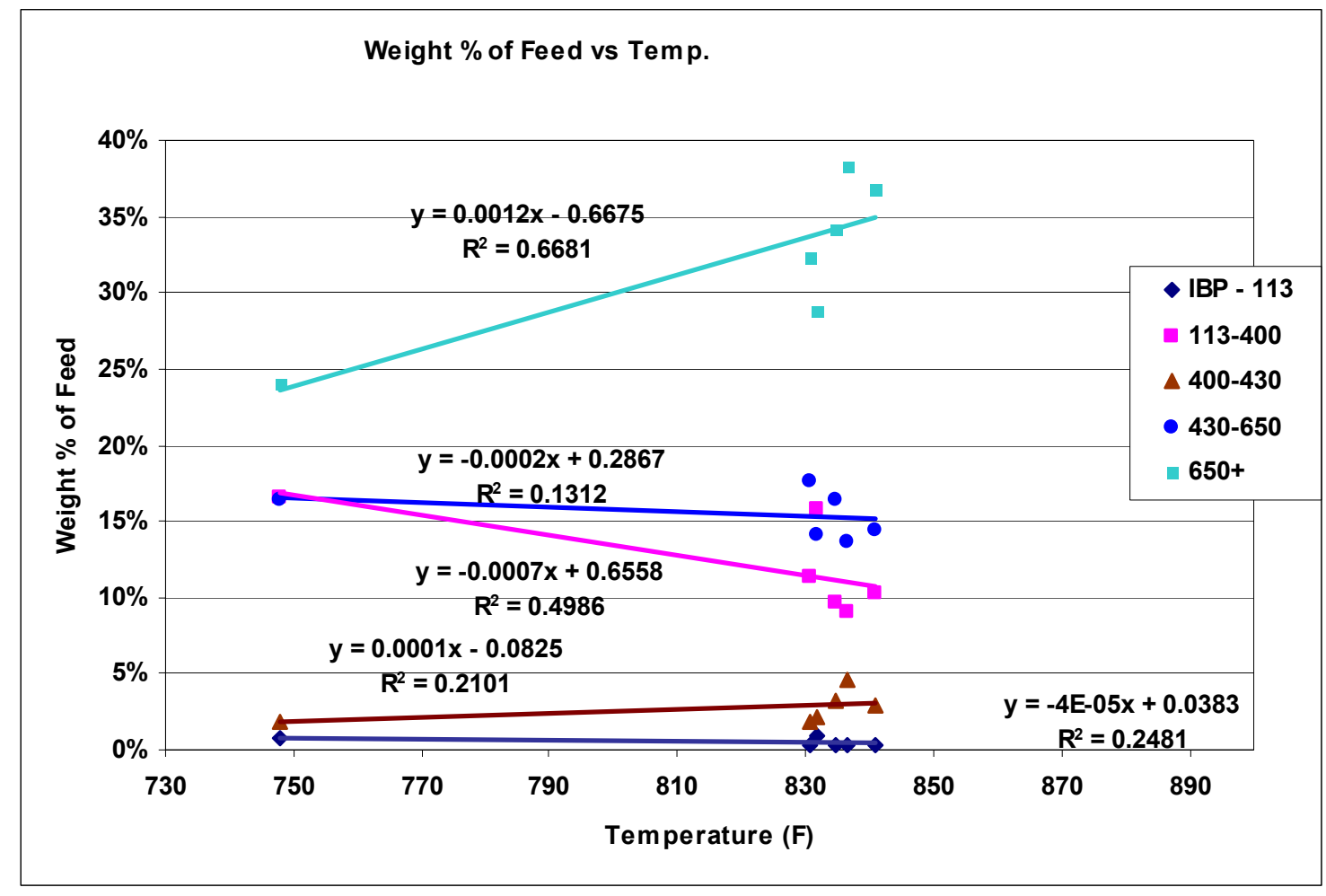

Figure 87: PU Distillation at 15psig with average overhead temperatures

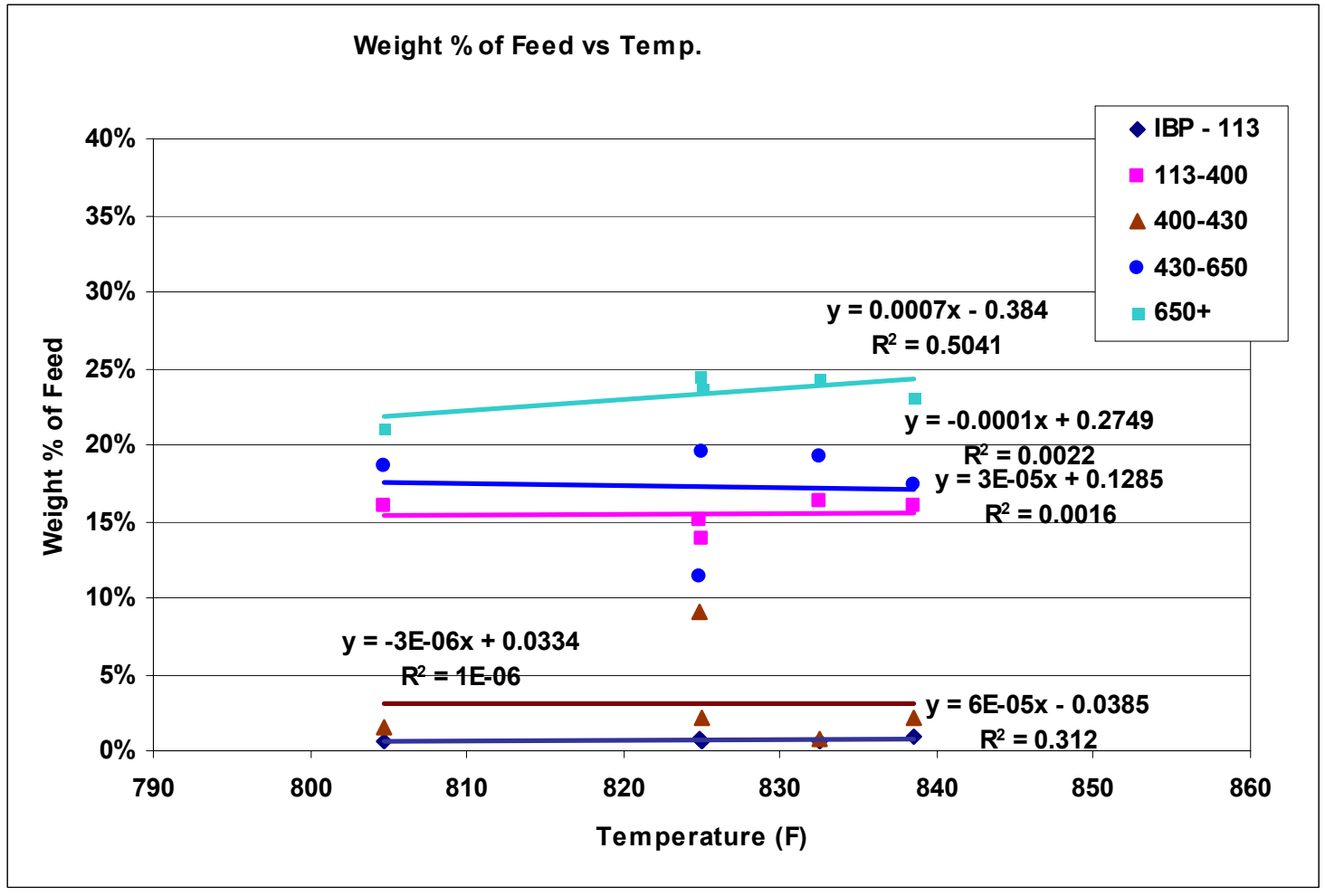

Figure 88: PU Distillation at 40psig with average overhead temperatures 


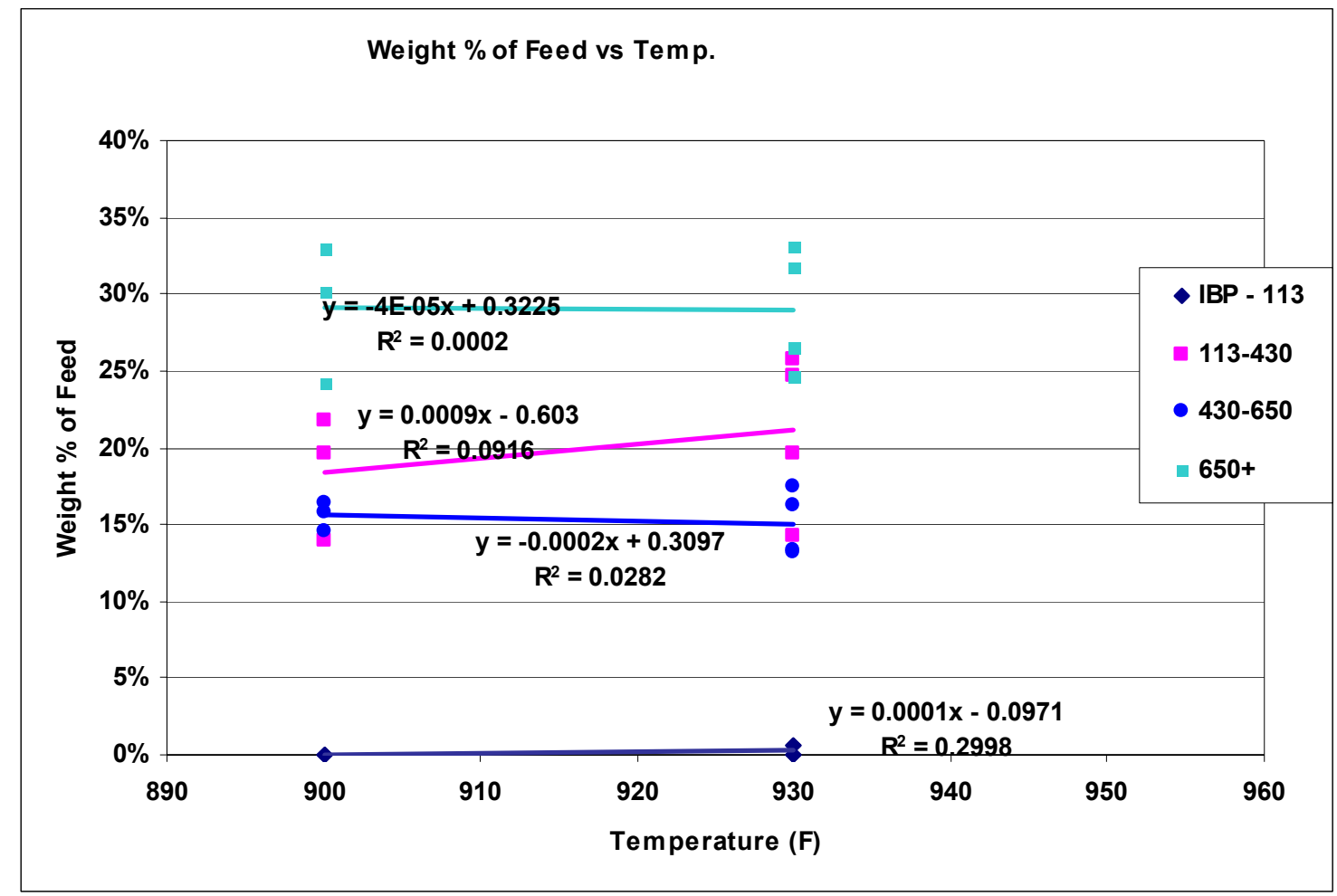

Figure 89: PU Sim. Distillation at 15psig with bottom temperatures of 900F and 930F

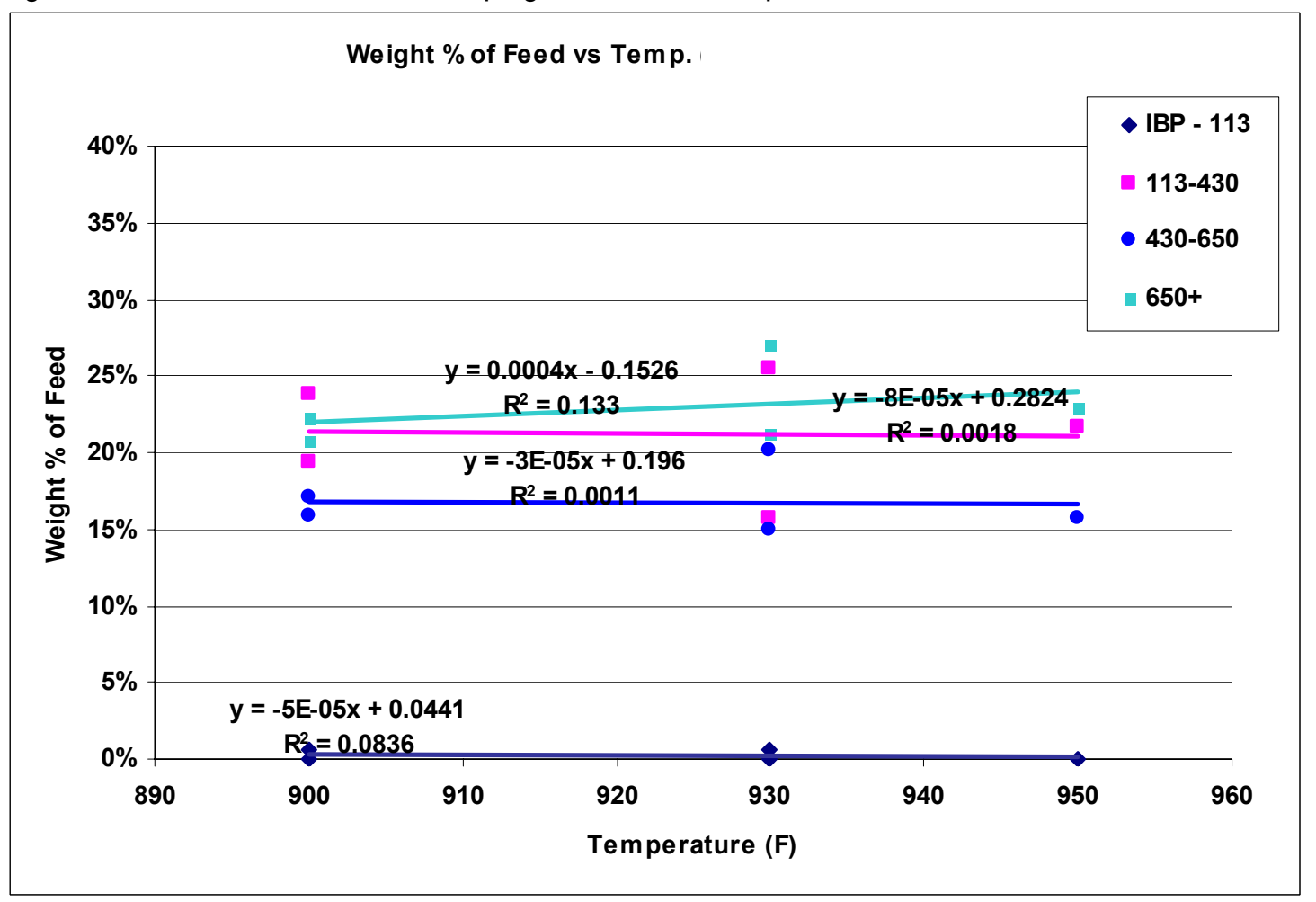

Figure 90: PU Sim. Distillation at 40psig with bottom temperatures of 900F and 930F 


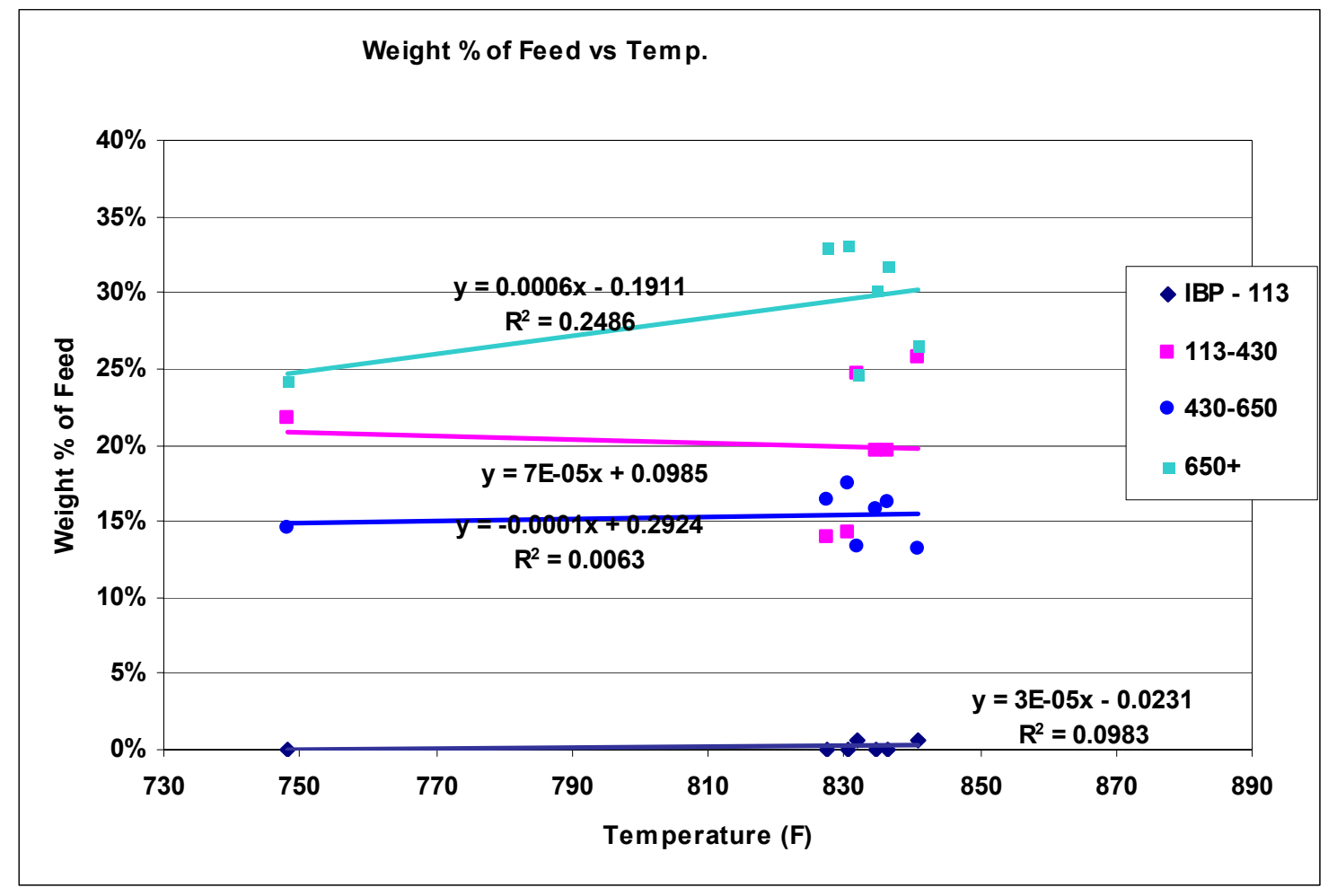

Figure 91: PU Sim. Distillation at 15psig with average overhead temperatures

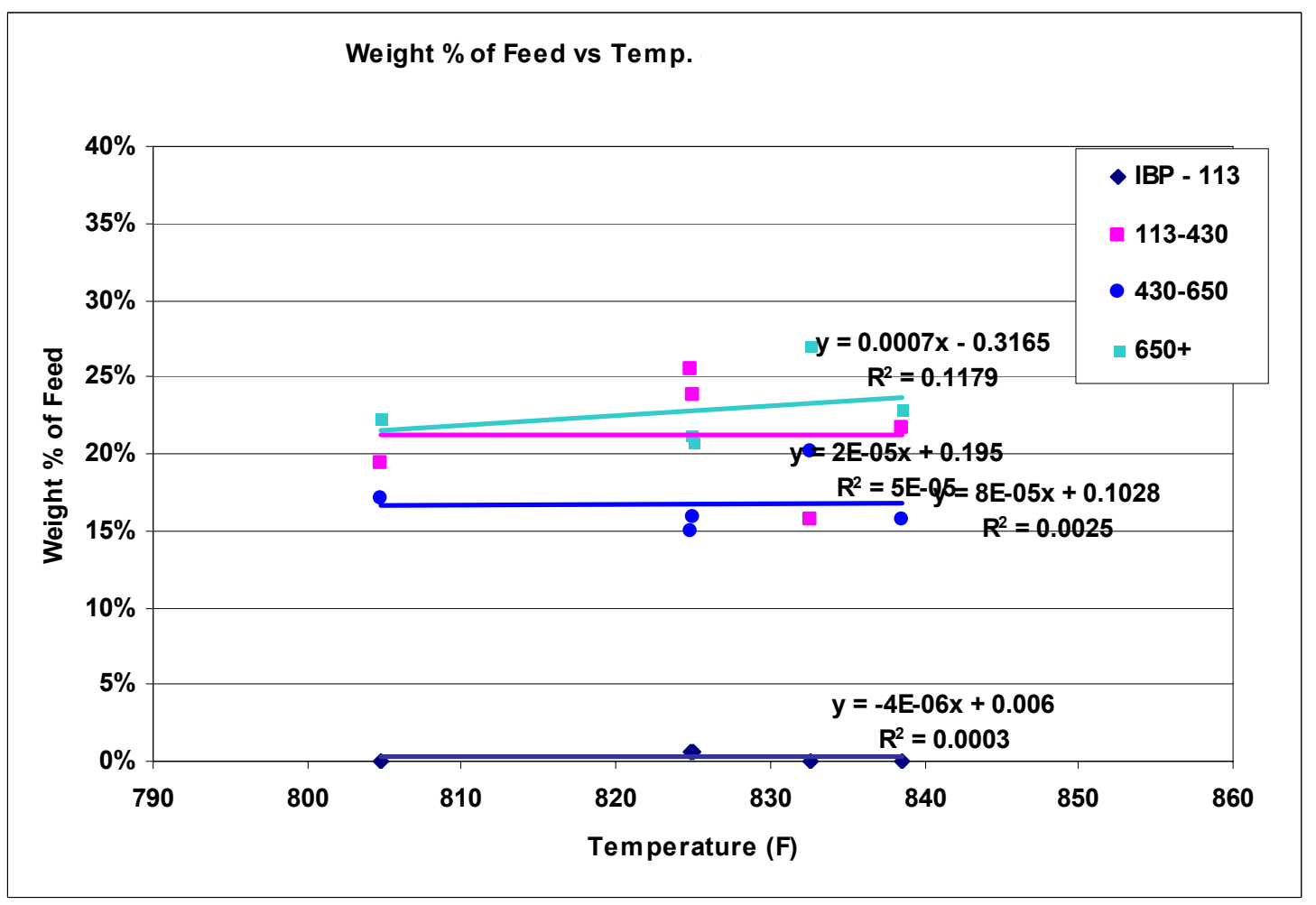

Figure 92: PU Sim. Distillation at 40psig with average overhead temperatures 
The slopes of the distillation data plots in Figure 85 through Figure 92 are represented in the matrixes below. Most of the resids had similar trends for both the bottom and overhead temperatures. Using the Suncor resid as a reference, it is seen that the correlations were quite consistent among each resid group.

\section{PU Distillation}

\section{Bottom Temperature}

\begin{tabular}{|c|c|c|c|c|c|}
\hline Sample & IBP - 113 & $\mathbf{1 1 3 - 4 0 0}$ & $\mathbf{4 0 0 - 4 3 0}$ & $\mathbf{4 3 0}-\mathbf{6 5 0}$ & $\mathbf{6 5 0 +}$ \\
\hline CHV & - & - & + & - & + \\
\hline MAR & + & - & + & + & - \\
\hline PET & - & - & - & - & + \\
\hline CIT & - & - & - & - & + \\
\hline EQU & - & + & - & + & - \\
\hline SUN & - & Only One Data Available
\end{tabular}

Table 42: PU Bottom temperature at 15

Table 43: PU Bottom temperature at 40 psig

\section{Overhead Temperature}

\begin{tabular}{|c|c|c|c|c|c|}
\hline Sample & IBP - 113 & $\mathbf{1 1 3}-\mathbf{4 0 0}$ & $\mathbf{4 0 0}-\mathbf{4 3 0}$ & $\mathbf{4 3 0}-\mathbf{6 5 0}$ & $\mathbf{6 5 0 +}$ \\
\hline CHV & - & - & + & - & + \\
\hline MAR & + & + & - & - & + \\
\hline PET & - & - & - & - & + \\
\hline CIT & - & - & - & - & + \\
\hline EQU & \multicolumn{7}{|c|}{ Only One Data Available } \\
SUN & - & + & - & + & - \\
\hline
\end{tabular}

\begin{tabular}{|c|c|c|c|c|c}
\hline Sample & IBP - 113 & $\mathbf{1 1 3 - 4 0 0}$ & $\mathbf{4 0 0 - 4 3 0}$ & $\mathbf{4 3 0 - 6 5 0}$ & $\mathbf{6 5 0 +}$ \\
\hline $\mathrm{CHV}$ & + & + & - & + & + \\
\hline MAR & + & + & + & - & + \\
\hline PET & - & + & + & + & + \\
\hline CIT & + & + & + & - & + \\
\hline EQU & + & + & + & + & + \\
SUN & + & + & + & - & + \\
\hline
\end{tabular}

\begin{tabular}{|c|c|c|c|c|c}
\hline Sample & IBP - 113 & $\mathbf{1 1 3 - 4 0 0}$ & $\mathbf{4 0 0 - 4 3 0}$ & $\mathbf{4 3 0 - 6 5 0}$ & $\mathbf{6 5 0 +}$ \\
\hline CHV & + & + & - & - & + \\
\hline MAR & + & + & + & - & + \\
\hline PET & - & - & + & - & + \\
\hline CIT & + & + & + & - & + \\
\hline EQU & + & + & + & + & + \\
SUN & + & + & + & - & + \\
\hline
\end{tabular}

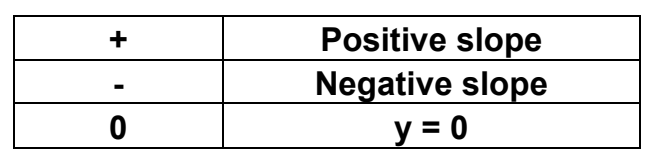

$y=0$

SUN

Table 44: PU Overhead Temperature at $15 \mathrm{psig}$

Table 45: PU Overhead Temperature at 40 psig 
As with the distillation data, the slopes of the Sim Dis data in Figure 89 through Figure 92 were incorporated into the matrices in below. Again, using the Suncor resid as a reference, the correlations among each resid group are quite consistent.

\section{PU Simulation Distillation \\ The weight $\%$ of feed vs. temperature curve slopes}

\section{Bottom Temperature}

\begin{tabular}{|c|c|c|c|c|}
\hline Sample & IBP - 113 & $\mathbf{1 1 3 - 4 3 0}$ & $\mathbf{4 3 0}-\mathbf{6 5 0}$ & $\mathbf{6 5 0 +}$ \\
\hline CHV & + & + & - & - \\
\hline MAR & 0 & - & + & + \\
\hline PET & 0 & + & - & + \\
\hline CIT & 0 & + & - & + \\
\hline EQU & \multicolumn{4}{|c|}{ Only One Data Available } \\
SUN & 0 & - & - & - \\
\hline
\end{tabular}

Table 46: PU Sim Dis at bottom temperature (15 psig)

Table 47: PU Sim Dis at bottom temperature (40 psig)

Overhead Temperature

\begin{tabular}{|c|c|c|c|c|}
\hline Sample & IBP - 113 & $\mathbf{1 1 3}-\mathbf{4 3 0}$ & $\mathbf{4 3 0}-\mathbf{6 5 0}$ & $\mathbf{6 5 0 +}$ \\
\hline CHV & + & - & + & + \\
\hline MAR & 0 & + & - & + \\
\hline PET & 0 & + & - & + \\
\hline CIT & 0 & + & - & + \\
\hline EQU & \multicolumn{5}{|c|}{ Only One Data Available } \\
SUN & 0 & - & - & - \\
\hline
\end{tabular}

\begin{tabular}{|c|c|c|c|r|}
\hline Sample & IBP - 113 & $\mathbf{1 1 3 - 4 3 0}$ & $\mathbf{4 3 0 - 6 5 0}$ & $\mathbf{6 5 0}$ \\
\hline CHV & - & + & + & + \\
\hline MAR & - & - & + & + \\
\hline PET & - & - & - & + \\
\hline CIT & + & + & - & + \\
\hline EQU & 0 & + & + & + \\
SUN & 0 & - & - & + \\
\hline
\end{tabular}

Table 48: PU Sim Dis at overhead temperature (15 psig)

Table 49: PU Sim Dis at overhead temperature (40 psig)

\begin{tabular}{|c|c|}
\hline+ & Positive slop \\
\hline- & Negative slop \\
\hline $\mathbf{0}$ & $\mathbf{y = 0}$ \\
\hline
\end{tabular}

\begin{tabular}{|c|c|c|c|c|}
\hline Sample & IBP - 113 & $\mathbf{1 1 3 - 4 3 0}$ & $\mathbf{4 3 0 - 6 5 0}$ & $\mathbf{6 5 0 +}$ \\
\hline CHV & - & - & - & + \\
\hline MAR & - & - & - & + \\
\hline PET & + & - & - & + \\
\hline CIT & + & + & - & + \\
\hline EQU & 0 & + & - & + \\
SUN & 0 & - & - & + \\
\hline
\end{tabular}

0 
To ensure that the similarities between the bottom and overhead temperatures were not restricted to the pilot unit ( $3 \mathrm{ft}$ drum); the $6 \mathrm{ft}$ PUAF distillation and simulation distillation data were analyzed at both the bottom and average overhead temperatures for the different boiling cuts at 15 psig and 40 psig. The resulting slopes are represented the matrixes in the tables below for the PUAF distillation data, and that of the PUAF Sim Dis data is on the next page. Using the Suncor resid as a reference, it is seen that the correlations were consistent among each resid group.

PUAF Distillation

\section{Bottom Temperature}

\begin{tabular}{|c|c|c|c|c|c|}
\hline Sample & IBP - 113 & $113-400$ & $\mathbf{4 0 0 - 4 3 0}$ & $\mathbf{4 3 0 - 6 5 0}$ & $\mathbf{6 5 0 +}$ \\
\hline CHV & - & - & + & - & + \\
\hline MAR & + & - & + & - & + \\
\hline PET & - & - & - & - & + \\
\hline CIT & - & - & - & - & + \\
\hline EQU & - & + & - & + & + \\
\hline SUN & - & - & + & - & + \\
\hline
\end{tabular}

Table 50: PUAF Bottom temperature at 15 psig Table 51: PUAF Bottom temperature at 40 psig

\section{Overhead Temperature}

\begin{tabular}{|c|c|c|c|c|c|}
\hline Sample & IBP - 113 & $\mathbf{1 1 3 - 4 0 0}$ & $\mathbf{4 0 0 - 4 3 0}$ & $\mathbf{4 3 0 - 6 5 0}$ & $\mathbf{6 5 0 +}$ \\
\hline CHV & + & - & + & - & + \\
\hline MAR & + & - & + & - & + \\
\hline PET & - & - & - & - & + \\
\hline CIT & + & - & - & - & + \\
\hline EQU & - & + & - & + & + \\
\hline SUN & - & - & + & - & + \\
\hline
\end{tabular}

\begin{tabular}{|c|c|c|c|c|c}
\hline Sample & IBP - 113 & $\mathbf{1 1 3 - 4 0 0}$ & $\mathbf{4 0 0 - 4 3 0}$ & $\mathbf{4 3 0 - 6 5 0}$ & $\mathbf{6 5 0 +}$ \\
\hline CHV & - & - & + & - & + \\
\hline MAR & + & + & - & + & - \\
\hline PET & - & - & + & - & + \\
\hline CIT & - & - & - & - & + \\
\hline EQU & + & + & + & - & + \\
\hline SUN & + & + & - & - & + \\
\hline
\end{tabular}

\begin{tabular}{|c|c|c|c|c|c}
\hline Sample & IBP - 113 & $\mathbf{1 1 3 - 4 0 0}$ & $\mathbf{4 0 0 - 4 3 0}$ & $\mathbf{4 3 0 - 6 5 0}$ & $\mathbf{6 5 0 +}$ \\
\hline $\mathrm{CHV}$ & + & - & + & - & + \\
\hline MAR & + & + & - & + & - \\
\hline PET & + & - & - & - & + \\
\hline CIT & + & + & + & - & + \\
\hline EQU & + & + & + & - & + \\
\hline SUN & + & + & - & - & + \\
\hline
\end{tabular}

\begin{tabular}{|c|c|}
\hline+ & Positive slope \\
\hline- & Negative slope \\
\hline $\mathbf{0}$ & $\mathbf{y}=\mathbf{0}$ \\
\hline
\end{tabular}

Table 52: PUAF Overhead temperature at 15 psig Table 53: PUAF Overhead temperature at 40 psig 


\section{Bottom Temperature}

\begin{tabular}{|c|c|c|c|c|}
\hline Sample & IBP - 113 & $113-430$ & $\mathbf{4 3 0}-\mathbf{6 5 0}$ & $650+$ \\
\hline CHV & + & + & - & - \\
\hline MAR & - & - & - & - \\
\hline PET & - & + & - & - \\
\hline CIT & + & + & + & - \\
\hline EQU & - & + & + & - \\
\hline SUN & + & - & + & - \\
\hline
\end{tabular}

Table 54: PUAF Sim Dis Bottom temperature (15 psig)

Table 55: PUAF Sim Dis Bottom temperature (40 psig)

\section{Overhead Temperature}

\section{Table 16c: 15 psig}

\begin{tabular}{|c|c|c|c|c|}
\hline Sample & IBP - 113 & $113-430$ & $\mathbf{4 3 0}-\mathbf{6 5 0}$ & $\mathbf{6 5 0 +}$ \\
\hline CHV & - & + & - & - \\
\hline MAR & - & - & - & - \\
\hline PET & - & + & - & - \\
\hline CIT & + & + & + & - \\
\hline EQU & - & + & + & - \\
\hline SUN & + & - & + & - \\
\hline
\end{tabular}

Table 16d: 40 psig

\begin{tabular}{|c|c|c|c|c}
\hline Sample & IBP - 113 & $113-430$ & $430-650$ & $650+$ \\
\hline CHV & - & + & + & - \\
\hline MAR & \multicolumn{5}{|c}{ Only one data point } \\
\hline PET & + & + & - & - \\
\hline CIT & - & + & + & - \\
\hline EQU & + & + & - & - \\
\hline SUN & - & + & - & - \\
\hline
\end{tabular}

Table 56: PUAF Sim Dis Overhead temperature (15 psig )

Table 57: PUAF Sim Dis Overhead temperature (40 psig)

Both the PU and PUAF distillation and simulated distillation data indicated that the feed and overhead temperatures would exhibit similar trends at the same pressure. This observation reduces the work of having to repeat analyzing data at both the bottom and overhead temperatures. 


\section{Distillation: Feed Rate Analysis}

A feed rate of $1200 \mathrm{~g} / \mathrm{hr}$ was used for all of the resids run in the $3 \mathrm{ft}$ pilot unit, therefore the effect of changes in the feed rate on the distillation data could not be analyzed. On the contrary, the $6 \mathrm{ft}$ pilot unit was run at different flow rates ranging from $1200 \mathrm{~g} / \mathrm{hr}$ to $4800 \mathrm{~g} / \mathrm{hr}$. For brevity, only the Chevron PUAF samples at both 15psig and 40psig will be discussed.

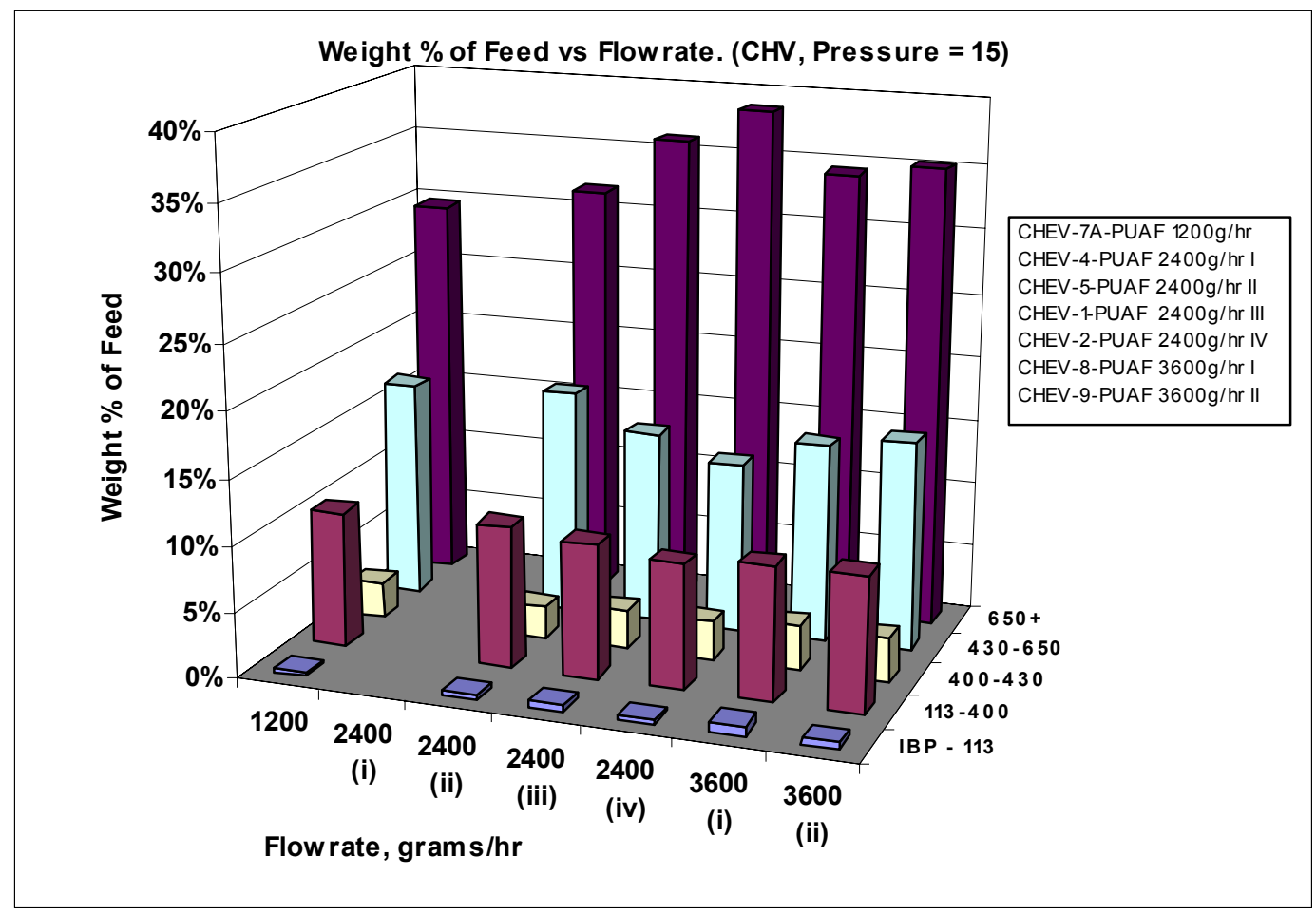

Figure 93: Flow rate analysis of Chevron PUAF samples at 15psig

In Figure 93 above, the 650+oF cut had the highest weight percent of feed, followed by the $430-650^{\circ} \mathrm{F}$ cut, then the $113-400^{\circ} \mathrm{F}$ cut and $400-430^{\circ} \mathrm{F}$ cut. The IBP-1130 $\mathrm{F}$ had the least weight percent of feed. This trend was the same for the $1200 \mathrm{~g} / \mathrm{hr}, 2400 \mathrm{~g} / \mathrm{hr}$ and $3600 \mathrm{~g} / \mathrm{hr}$ flow rates. 


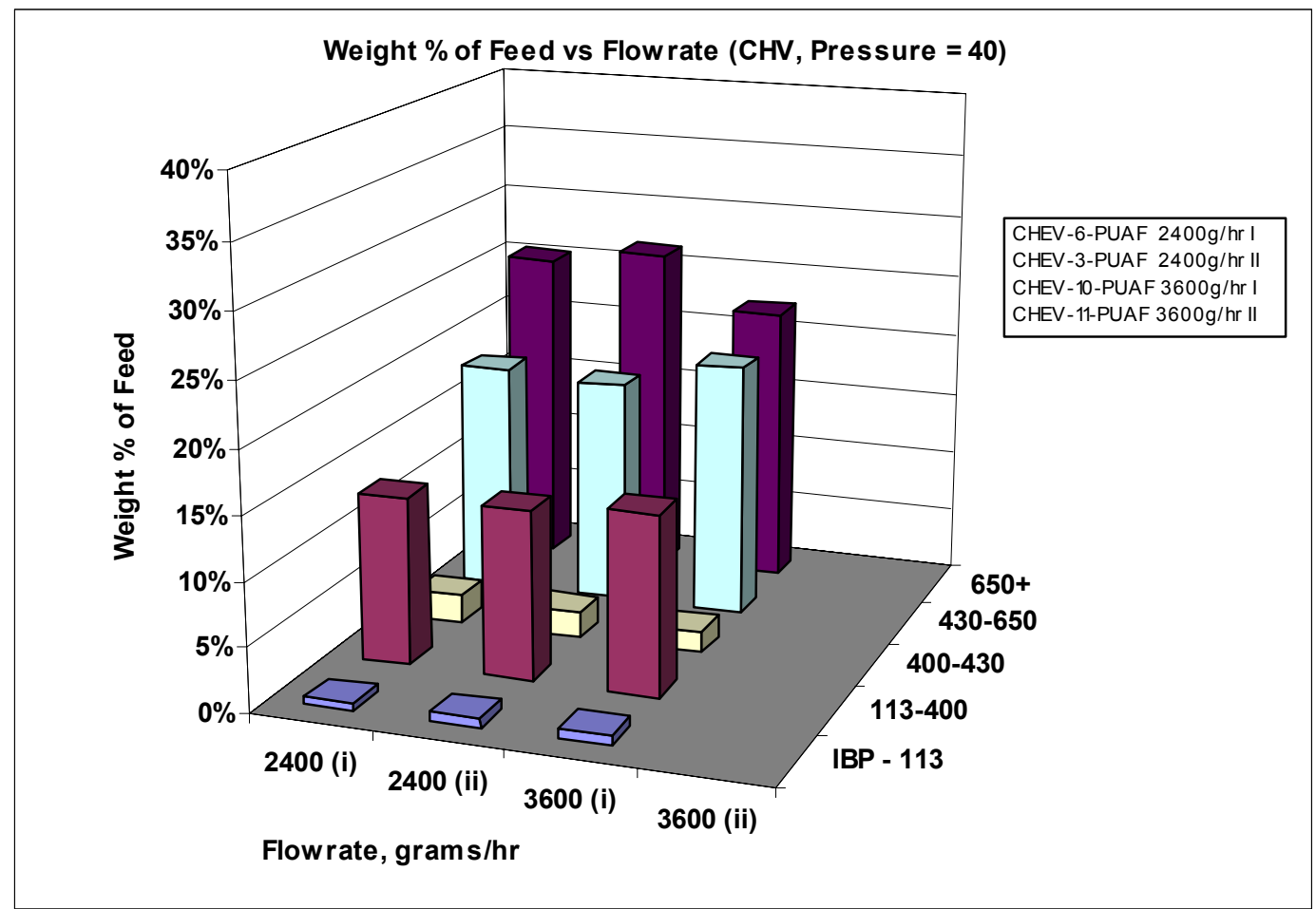

Figure 94: Flow rate analysis of Chevron PUAF samples at 40psig

Again in Figure 94, at 40psig, the $650+0 \mathrm{~F}$ cut had the highest weight percent of feed, followed by the $430-650^{\circ} \mathrm{F}$ cut, then the $113-400^{\circ} \mathrm{F}$ cut and $400-430^{\circ} \mathrm{F}$ cut. The IBP-113ㅇ $\mathrm{F}$ had the least weight percent of feed. This trend was the same for the $2400 \mathrm{~g} / \mathrm{hr}$ and $3600 \mathrm{~g} / \mathrm{hr}$ flow rates.

In conclusion, it has been observed that changing the flow rate does not affect the distribution of the weight percent of feed in the different temperature cuts.

The effect of the changing the flow rates on the PiONA components at the different DHA temperature cuts will be analyzed in the DHA section of the report. 


\section{Detailed Hydrocarbon Analysis (DHA)}

As stated previously, the overall outcome of the DHA analysis is to be able to predict what type of PiONA component would be dominant at a certain temperature and pressure, and how a change in the temperature and pressure would affects its production.

DHA analyses were conducted for both the PU and PUAF liquid sub products. The effect of temperature and pressure on the mass percent will be discussed for each type of PiONA component at the three cuts. For brevity, only the results for the chevron resid will be discussed.

In general, it is observed that the IBP- $1130 \mathrm{~F}$ cut has the highest mass percent of paraffin, followed by the $113-400^{\circ} \mathrm{F}$ and then the $400-430^{\circ} \mathrm{F}$, for the Chevron runs.

At $15 \mathrm{psig}$, the $113-400^{\circ} \mathrm{F}$ cut has the highest amount of Iso-paraffin followed by the IBP$113^{\circ} \mathrm{F}$, then the $400-430^{\circ} \mathrm{F}$. The same trends were seen when the pressure is raised to $40 \mathrm{psig}$.

Regardless of pressure, the lowest temperature cut (IBP-1130F) contained the largest amounts of olefins.

The middle temperature cut (113-400 ${ }^{\circ}$ ) contained the largest amount of naphthene, while the 400-430 $\mathrm{F}$ cut contained the smallest amount of naphthene.

The most aromatics for the Chevron runs were found in the 400-430 $\mathrm{F}$ cut followed by the $113-400^{\circ} \mathrm{F}$ cut then the IBP-1130F cut.

The majority of the oxygenate present in the Chevron samples were in the IBP-1130F cut. There were no traces of oxygenates in the $400-430^{\circ} \mathrm{F}$ cut.

PiONA plots were also constructed for the Marathon, Petrobras, Citgo, Equilon and Suncor liquid samples. The effects of temperature and pressure on the mass percent of each PiONA component have been complied into a matrix form. The order of decreasing mass percent (\%) of component is from 1 to 3 . A key is provided below to interpret the DHA tables

\footnotetext{
1 Highest mass percent of component

2

3 Lowest mass percent of component
} 


\begin{tabular}{|c|c|c|c|c|c|c|c|c|c|c|c|c|c|c|c|c|c|c|c|}
\hline \multicolumn{20}{|c|}{ DHA PU TEMPERATURE ANALYSIS } \\
\hline \multicolumn{2}{|l|}{$900 \mathrm{~F}$} & \multicolumn{3}{|c|}{ CHEVRON } & \multicolumn{3}{|c|}{ MARATHON } & \multicolumn{3}{|c|}{ PETROBRAS } & \multicolumn{3}{|c|}{ CITGO } & \multicolumn{3}{|c|}{ EQUILON } & \multicolumn{3}{|c|}{ SUNCOR } \\
\hline & & $\begin{array}{l}\text { IBP- } \\
113\end{array}$ & $\begin{array}{l}113- \\
400 \\
\end{array}$ & $\begin{array}{r}400- \\
430 \\
\end{array}$ & $\begin{array}{c}\text { IBP- } \\
113 \\
\end{array}$ & $\begin{array}{l}113- \\
400 \\
\end{array}$ & $\begin{array}{r}400- \\
430 \\
\end{array}$ & $\begin{array}{c}\text { IBP- } \\
113 \\
\end{array}$ & $\begin{array}{l}113- \\
400 \\
\end{array}$ & $\begin{array}{c}400- \\
430 \\
\end{array}$ & $\begin{array}{l}\text { IBP- } \\
113 \\
\end{array}$ & $\begin{array}{l}113- \\
400 \\
\end{array}$ & $\begin{array}{c}400- \\
430 \\
\end{array}$ & $\begin{array}{l}\text { IBP- } \\
113 \\
\end{array}$ & $\begin{array}{c}113- \\
400 \\
\end{array}$ & $\begin{array}{l}400- \\
430 \\
\end{array}$ & $\begin{array}{l}\text { IBP- } \\
113 \\
\end{array}$ & $\begin{array}{l}113- \\
400 \\
\end{array}$ & $\begin{array}{r}400- \\
430 \\
\end{array}$ \\
\hline \multirow[t]{2}{*}{ Paraffin } & $\begin{array}{c}15 \\
\text { psig }\end{array}$ & 1 & 2 & 3 & \multicolumn{3}{|c|}{$\begin{array}{c}\text { No samples were } \\
\text { run }\end{array}$} & \multicolumn{3}{|c|}{$\begin{array}{c}\text { No samples were } \\
\text { run }\end{array}$} & 1 & 3 & 2 & \multicolumn{3}{|c|}{ No samples were run } & 1 & 2 & 3 \\
\hline & $\begin{array}{r}40 \\
\text { psig }\end{array}$ & 1 & 2 & 3 & 1 & 2 & 3 & 1 & 2 & 3 & 1 & 3 & 2 & 1 & 2 & 3 & 1 & 2 & 3 \\
\hline \multirow[t]{2}{*}{ Iso-Paraffin } & $\begin{array}{c}15 \\
\text { psig }\end{array}$ & 2 & 1 & 3 & \multicolumn{3}{|c|}{$\begin{array}{c}\text { No samples were } \\
\text { run }\end{array}$} & \multicolumn{3}{|c|}{$\begin{array}{c}\text { No samples were } \\
\text { run }\end{array}$} & 2 & 1 & 3 & \multicolumn{3}{|c|}{ No samples were run } & 2 & 1 & 3 \\
\hline & $\begin{array}{c}40 \\
\text { psig }\end{array}$ & 2 & 1 & 3 & 2 & 1 & 3 & 2 & 1 & 3 & 2 & 1 & 3 & 2 & 1 & 3 & 2 & 1 & 3 \\
\hline \multirow[t]{2}{*}{ Olefin } & $\begin{array}{c}15 \\
\text { psig }\end{array}$ & 1 & 2 & 3 & \multicolumn{3}{|c|}{$\begin{array}{c}\text { No samples were } \\
\text { run }\end{array}$} & \multicolumn{3}{|c|}{$\begin{array}{c}\text { No samples were } \\
\text { run }\end{array}$} & 1 & 2 & 3 & \multicolumn{3}{|c|}{ No samples were run } & 1 & 2 & 3 \\
\hline & $\begin{array}{c}40 \\
\text { psig }\end{array}$ & 1 & 2 & 3 & 1 & 2 & 3 & 1 & 2 & 3 & 1 & 2 & 3 & 1 & 2 & 3 & 1 & 2 & 3 \\
\hline \multirow[t]{2}{*}{ Naphthenes } & $\begin{array}{c}15 \\
\text { psig }\end{array}$ & 2 & 1 & 3 & \multicolumn{3}{|c|}{$\begin{array}{c}\text { No samples were } \\
\text { run }\end{array}$} & \multicolumn{3}{|c|}{$\begin{array}{c}\text { No samples were } \\
\text { run }\end{array}$} & 2 & 1 & 3 & \multicolumn{3}{|c|}{ No samples were run } & 2 & 1 & 3 \\
\hline & $\begin{array}{c}40 \\
\text { psig }\end{array}$ & 2 & 1 & 3 & 2 & 1 & 3 & 2 & 1 & 3 & 2 & 1 & 3 & 2 & 1 & 3 & 2 & 1 & 3 \\
\hline \multirow[t]{2}{*}{ Aromatics } & $\begin{array}{c}15 \\
\text { psig }\end{array}$ & 3 & 2 & 1 & \multicolumn{3}{|c|}{$\begin{array}{c}\text { No samples were } \\
\text { run }\end{array}$} & \multicolumn{3}{|c|}{$\begin{array}{c}\text { No samples were } \\
\text { run }\end{array}$} & 3 & 2 & 1 & \multicolumn{3}{|c|}{ No samples were run } & 3 & 2 & 1 \\
\hline & $\begin{array}{c}40 \\
\text { psig }\end{array}$ & 3 & 2 & 1 & 3 & 2 & 1 & 3 & 2 & 1 & 3 & 2 & 1 & 3 & 2 & 1 & 3 & 2 & 1 \\
\hline \multirow[t]{2}{*}{ Oxygenates } & $\begin{array}{l}15 \\
\text { psig }\end{array}$ & 1 & 2 & 3 & \multicolumn{3}{|c|}{$\begin{array}{c}\text { No samples were } \\
\text { run }\end{array}$} & \multicolumn{3}{|c|}{$\begin{array}{c}\text { No samples were } \\
\text { run }\end{array}$} & \multicolumn{3}{|c|}{$\begin{array}{c}\text { No Oxygenates } \\
\text { present }\end{array}$} & Nos & les we & & 1 & 2 & 3 \\
\hline & $\begin{array}{c}40 \\
\text { psig } \\
\end{array}$ & 1 & 2 & 3 & 1 & 2 & 3 & 1 & 2 & 3 & & $\begin{array}{l}\text { xygen } \\
\text { oresen }\end{array}$ & & 1 & 2 & 3 & 1 & 2 & 3 \\
\hline
\end{tabular}

\section{Table 58: DHA PU Temperature Analysis at 900F}

For the $900^{\circ} \mathrm{F}$ feed temperature at $15 \mathrm{psig}$ and $40 \mathrm{psig}$, the IBP-1130F cut had a high concentration of paraffin, olefin, and oxygenates, followed by iso-paraffins and naphthenes in medium amounts, while aromatics are in minimal proportions. The $113-400^{\circ} \mathrm{F}$ cut for all six resids had high quantities of iso-paraffins and naphthenes. For the Chevron, Marathon, Petrobras, Equilon, and Suncor resids, the 113-400\% $\mathrm{F}$ cut had medium amounts of paraffin, olefins, aromatics, and oxygenates. In the Citgo resid, the 113-400 $\mathrm{F}$ cut had paraffin in minimal proportions. The 400-430 $\mathrm{F}$ cut, for most of the resids, had a high concentration of aromatics and contained small amounts of paraffin, iso-paraffins, olefins, naphthenes, and oxygenates. The Citgo resid had medium amounts of paraffin present in the $400-430^{\circ} \mathrm{F}$ cut and no oxygenates present in any of the temperature cuts. 


\begin{tabular}{|c|c|c|c|c|c|c|c|c|c|c|c|c|c|c|c|c|c|c|c|}
\hline \multirow[t]{2}{*}{$930 \mathrm{~F}$} & & \multicolumn{3}{|c|}{ CHEVRON } & \multicolumn{3}{|c|}{ MARATHON } & \multicolumn{3}{|c|}{ PETROBRAS } & \multicolumn{3}{|c|}{ CITGO } & \multicolumn{3}{|c|}{ EQUILON } & \multicolumn{3}{|c|}{ SUNCOR } \\
\hline & & $\begin{array}{l}\text { IBP- } \\
113\end{array}$ & $\begin{array}{l}113- \\
400\end{array}$ & $\begin{array}{l}400- \\
430\end{array}$ & $\begin{array}{l}\text { IBP- } \\
113\end{array}$ & $\begin{array}{l}113- \\
400\end{array}$ & $\begin{array}{l}400- \\
430\end{array}$ & $\begin{array}{l}\text { IBP- } \\
113\end{array}$ & $\begin{array}{l}113- \\
400\end{array}$ & $\begin{array}{l}400- \\
430\end{array}$ & $\begin{array}{l}\text { IBP- } \\
113\end{array}$ & $\begin{array}{l}113- \\
400\end{array}$ & $\begin{array}{l}400- \\
430\end{array}$ & $\begin{array}{l}\text { IBP- } \\
113\end{array}$ & $\begin{array}{l}113- \\
400\end{array}$ & $\begin{array}{l}400- \\
430\end{array}$ & $\begin{array}{l}\text { IBP- } \\
113\end{array}$ & $\begin{array}{l}113- \\
400\end{array}$ & $\begin{array}{l}400- \\
430\end{array}$ \\
\hline \multirow[t]{2}{*}{ Paraffin } & $\begin{array}{c}15 \\
\text { psig }\end{array}$ & 1 & 2 & 3 & \multicolumn{3}{|c|}{$\begin{array}{c}\text { No samples were } \\
\text { run }\end{array}$} & \multicolumn{3}{|c|}{$\begin{array}{c}\text { No samples were } \\
\text { run }\end{array}$} & 1 & 3 & 2 & 1 & 2 & 3 & 1 & 2 & 3 \\
\hline & $\begin{array}{l}40 \\
\text { psig }\end{array}$ & 1 & 2 & 3 & 1 & 2 & 3 & 1 & 2 & 3 & 1 & 3 & 2 & 1 & 2 & 3 & 1 & 2 & 3 \\
\hline \multirow[t]{2}{*}{ Iso-Paraffin } & $\begin{array}{l}15 \\
\text { psig }\end{array}$ & 2 & 1 & 3 & \multicolumn{3}{|c|}{$\begin{array}{c}\text { No samples were } \\
\text { run }\end{array}$} & \multicolumn{3}{|c|}{$\begin{array}{c}\text { No samples were } \\
\text { run }\end{array}$} & 2 & 1 & 3 & 2 & 1 & 3 & 2 & 1 & 3 \\
\hline & $\begin{array}{l}40 \\
\text { psig }\end{array}$ & 2 & 1 & 3 & 2 & 1 & 3 & 2 & 1 & 3 & 2 & 1 & 3 & 2 & 1 & 3 & 2 & 1 & 3 \\
\hline \multirow[t]{2}{*}{ Olefin } & $\begin{array}{l}15 \\
\text { psig }\end{array}$ & 1 & 2 & 3 & \multicolumn{3}{|c|}{$\begin{array}{c}\text { No samples were } \\
\text { run }\end{array}$} & \multicolumn{3}{|c|}{$\begin{array}{c}\text { No samples were } \\
\text { run }\end{array}$} & 1 & 2 & 3 & 1 & 2 & 3 & 1 & 2 & 3 \\
\hline & $\begin{array}{l}40 \\
\text { psig }\end{array}$ & 1 & 2 & 3 & 1 & 2 & 3 & 1 & 2 & 3 & 1 & 2 & 3 & 1 & 2 & 3 & 1 & 2 & 3 \\
\hline \multirow[t]{2}{*}{ Naphthenes } & $\begin{array}{l}15 \\
\text { psig }\end{array}$ & 2 & 1 & 3 & \multicolumn{3}{|c|}{$\begin{array}{c}\text { No samples were } \\
\text { run }\end{array}$} & \multicolumn{3}{|c|}{$\begin{array}{c}\text { No samples were } \\
\text { run }\end{array}$} & 2 & 1 & 3 & 2 & 1 & 3 & 2 & 1 & 3 \\
\hline & $\begin{array}{l}40 \\
\text { psig }\end{array}$ & 2 & 1 & 3 & 2 & 1 & 3 & 2 & 1 & 3 & 2 & 1 & 3 & 2 & 1 & 3 & 2 & 1 & 3 \\
\hline \multirow[t]{2}{*}{ Aromatics } & $\begin{array}{l}15 \\
\text { psig }\end{array}$ & 3 & 2 & 1 & \multicolumn{3}{|c|}{$\begin{array}{c}\text { No samples were } \\
\text { run }\end{array}$} & \multicolumn{3}{|c|}{$\begin{array}{c}\text { No samples were } \\
\text { run }\end{array}$} & 3 & 2 & 1 & 3 & 2 & 1 & 3 & 2 & 1 \\
\hline & $\begin{array}{l}40 \\
\text { psig }\end{array}$ & 3 & 2 & 1 & 3 & 2 & 1 & 3 & 2 & 1 & 3 & 2 & 1 & 3 & 2 & 1 & 3 & 2 & 1 \\
\hline \multirow[t]{2}{*}{ Oxygenates } & $\begin{array}{l}15 \\
\text { psig }\end{array}$ & 1 & 2 & 3 & \multicolumn{3}{|c|}{$\begin{array}{c}\text { No samples were } \\
\text { run }\end{array}$} & \multicolumn{3}{|c|}{$\begin{array}{l}\text { No samples were } \\
\text { run }\end{array}$} & \multicolumn{3}{|c|}{$\begin{array}{c}\text { No Oxygenates } \\
\text { present }\end{array}$} & 1 & 2 & 3 & 1 & 2 & 3 \\
\hline & $\begin{array}{l}40 \\
\text { psig }\end{array}$ & 1 & 2 & 3 & 1 & 2 & 3 & 1 & 2 & 3 & & $\begin{array}{l}\text { Xygen } \\
\text { oresen }\end{array}$ & & 1 & 2 & 3 & 1 & 2 & 3 \\
\hline
\end{tabular}

\section{Table 59: DHA PU Temperature Analysis at 930F}

The $930^{\circ} \mathrm{F}$ feed temperature at $15 \mathrm{psig}$ and 40psig, the IBP-1130F cut had a high concentration of paraffin, olefin, and oxygenates, followed by iso-paraffins and naphthenes in medium amounts, and aromatics in minimal proportions. The $113-400^{\circ} \mathrm{F}$ cut for all six resids had high quantities of iso-paraffins and naphthenes. For the Chevron, Marathon (40psig), Petrobras (40psig), Equilon, and Suncor resids, the 113-400 ${ }^{\circ}$ cut had medium amounts of paraffin, olefins, aromatics, and oxygenates. In the Citgo resid, the 113-400 $\mathrm{F}$ cut had paraffin in minimal proportions. The 400$430{ }^{\circ} \mathrm{F}$ cut, for most of the company resids, had a high concentration of aromatics and contained small amounts of paraffin, iso-paraffins, olefins, naphthenes, and oxygenates. The Citgo resid had medium amounts of paraffin present in the $400-430 \circ \mathrm{F}$ cut and no oxygenates present in any of the temperature cuts. No samples were run at 15 psig for Marathon and Petrobras. 


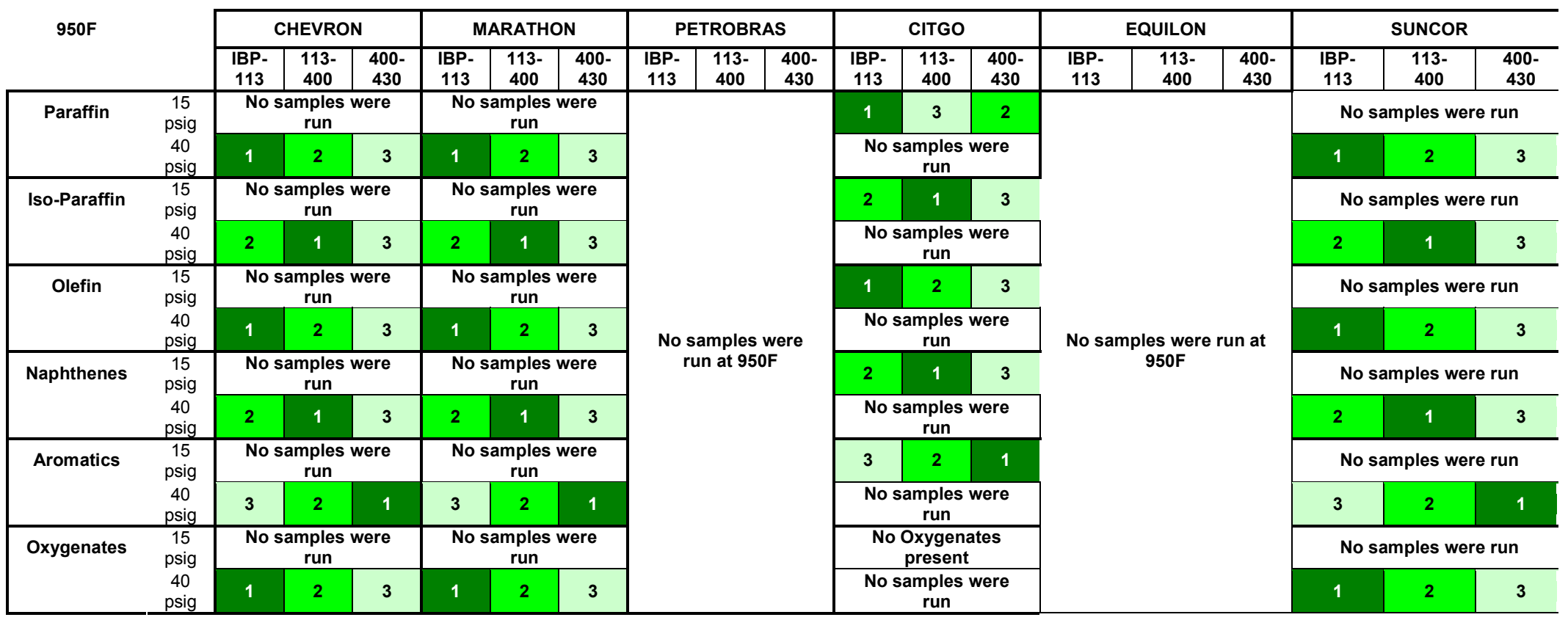

\section{Table 60: DHA PU Temperature Analysis at 950F}

No Petrobras and Equilon samples were run at $950^{\circ} \mathrm{F}$. No samples were run at $15 \mathrm{psig}$ for Chevron, Marathon and Suncor, and no samples were run at 40psig for Citgo. At 40psig, the IBP-1130F cut had a high concentration of paraffin, olefin, and oxygenates in the Chevron, Marathon and Suncor resids, followed by iso-paraffins and naphthenes in medium amounts, and aromatics in minimal proportions. The 113-400 $\mathrm{F}$ cut for Chevron, Marathon and Suncor had high quantities of iso-paraffins and naphthenes, and paraffins, olefins, aromatics, and oxygenates in medium amounts. The 400-430 $\mathrm{F}$ cut for Chevron, Marathon and Suncor had a high concentration of aromatics and contained small amounts of paraffins, iso-paraffins, olefins, naphthenes, and oxygenates. The Citgo resids, at 950F, were run at 15psig. Its IBP-1130F cut had high quantities of paraffin, and olefin, medium amounts of iso-paraffins and naphthenes, and minimal amounts of aromatics. The 113-400\% $\mathrm{F}$ cut had minimal amounts of paraffin, and contained mostly iso-paraffins and naphthenes, and at the 400-430 $\mathrm{F}$ cut, had mostly aromatics present. The Citgo resid had no oxygenates present at 15 psig. 
PiONA plots were constructed using the PUAF data for all six resids. The effects of temperature and pressure on the mass percent of each PiONA component were complied into a matrix form. The order of decreasing mass percent (\%) of component is labeled from 1 to 3 . The key used in interpreting the PU DHA data allows applies to the PUAF DHA data.

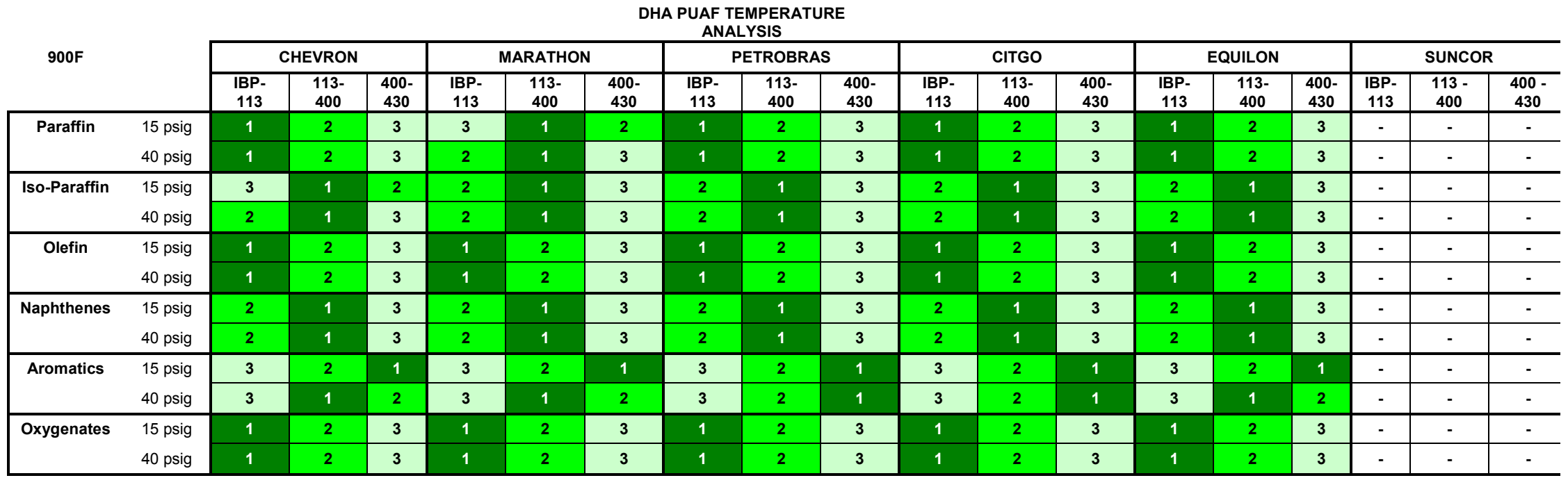

Table 61: DHA PUAF Temperature Analysis at 900F

Since PUAF DHA has not been run on most of the Suncor sample, it is not analyzed in the matrix. Petrobras, Citgo, and Equilon exhibited identical trends. These three resids contained large amounts of paraffin, olefins, and oxygenates at the IBP-1130 $\mathrm{F}$ cut, mostly iso-paraffins and naphthenes in the 113-400 $\mathrm{F}$ cut, and predominantly aromatics in the 400-430 $\mathrm{F}$ cut. The Chevron resid showed almost the same trends, but the $\mathrm{IBP}-113^{\circ} \mathrm{F}$ cut contained minimal amounts of iso-paraffins at $15 \mathrm{psig}$. The $113-400^{\circ} \mathrm{F}$ cut had iso-paraffins in high concentrations and the $400-430^{\circ} \mathrm{F}$ cut had average amounts of iso-paraffins. The Marathon 113-400 $\mathrm{F}$ cut had large quantities of paraffins, iso-paraffins, and naphthenes. 


\begin{tabular}{|c|c|c|c|c|c|c|c|c|c|c|c|c|c|c|c|c|c|c|c|}
\hline \multicolumn{2}{|l|}{$930 \mathrm{~F}$} & \multicolumn{3}{|c|}{ CHEVRON } & \multicolumn{3}{|c|}{ MARATHON } & \multicolumn{3}{|c|}{ PETROBRAS } & \multicolumn{3}{|c|}{ CITGO } & \multicolumn{3}{|c|}{ EQUILON } & \multicolumn{3}{|c|}{ SUNCOR } \\
\hline \multirow{2}{*}{ Paraffin } & 15 ncis & 1 & 2 & 3 & 3 & 1 & 2 & 1 & $\overline{2}$ & 2 & 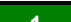 & 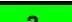 & 2 & & & & & & \\
\hline & 40 psig & - & - & - & - & - & - & 1 & 2 & 3 & 1 & 2 & 3 & - & - & - & - & - & - \\
\hline \multirow[t]{2}{*}{ Iso-Paraffin } & $15 \mathrm{psig}$ & 3 & 1 & 2 & 2 & 1 & 3 & 2 & 1 & 3 & 3 & 1 & 2 & - & - & - & 2 & 1 & 3 \\
\hline & 40 psig & - & - & - & - & - & - & 2 & 1 & 3 & 3 & 1 & 2 & - & - & - & - & - & - \\
\hline \multirow[t]{2}{*}{ Olefin } & $15 \mathrm{psig}$ & 1 & 2 & 3 & 1 & 2 & 3 & 1 & 2 & 3 & 1 & 2 & 3 & - & - & - & 1 & 2 & 3 \\
\hline & 40 psig & - & - & - & - & - & - & 1 & 2 & 3 & 1 & 2 & 3 & - & - & - & - & - & - \\
\hline \multirow[t]{2}{*}{ Naphthenes } & $15 \mathrm{psig}$ & 2 & 1 & 3 & 2 & 1 & 3 & 2 & 1 & 3 & 2 & 1 & 3 & - & - & - & 2 & 1 & 3 \\
\hline & 40 psig & - & - & - & - & - & - & 2 & 1 & 3 & 2 & 1 & 3 & - & - & - & - & - & - \\
\hline \multirow[t]{2}{*}{ Aromatics } & 15 psig & 3 & 2 & 1 & 3 & 2 & 1 & 3 & 2 & 1 & 3 & 2 & 1 & - & - & - & 3 & 2 & 1 \\
\hline & 40 psig & - & - & - & - & - & - & 3 & 2 & 1 & 3 & 2 & 1 & - & - & - & - & - & - \\
\hline \multirow[t]{2}{*}{ Oxygenates } & $15 \mathrm{psig}$ & 1 & 2 & 3 & 1 & 2 & 3 & 1 & 2 & 3 & 1 & 2 & 3 & - & - & - & 1 & 2 & 3 \\
\hline & 40 psig & - & - & - & - & - & - & 1 & 2 & 3 & 1 & 2 & 3 & - & - & - & - & - & - \\
\hline
\end{tabular}

Table 62: DHA PUAF Temperature Analysis at 930F

The PUAF DHA has not been run on most of the Equilon samples at $930^{\circ} \mathrm{F}$ so it is not analyzed in the matrix. The Petrobras and Citgo resid exhibited similar trends with the exception of the iso-paraffin production. At both 15 and $40 \mathrm{psig}$, the IBP-1130F cut contained iso-paraffin in minimal amounts for Citgo, and average amounts for Petrobras. No PUAF DHA data is available for Chevron, Marathon and Suncor at 40 psig.

The majority of the resids had identical correlations at both $15 \mathrm{psig}$ and $40 \mathrm{psig}$, for the different bottom temperatures. Based on the available data, a general trend can be seen in which the IBP-1130F consisted primarily of paraffins, olefins and oxygenates. The $113-400 \mathrm{~F}$ cut had predominantly iso-paraffins and naphthenes, and the 400-430 $\mathrm{F}$ cut had a high concentration of aromatics present. 


\section{Detailed Hydrocarbon Analysis (DHA): Feed Rate Analysis}

The effects of changing feed rates and pressure on the mass percent of each PiONA component were constructed for all the resids and have been condensed into a matrix format. The key below can be used to decipher the matrix and are labeled 1 to 3 in order of decreasing mass percent (\%) of component.

\section{Highest mass percent (\%) of component \\ 2 \\ 3 Least mass percent (\%) of component}

No samples were run at $1200 \mathrm{~g} / \mathrm{hr}$ for all the six PUAF company resids. Chevron, Equilon and Suncor resids were not run at 2400g/hr.

In general, Marathon, Petrobras, and Citgo had identical trends for iso-paraffins, olefins, naphthenes, aromatics, and oxygenates. The IBP$113^{\circ} \mathrm{F}$ cut for Petrobras and Citgo consisted primarily of paraffin, while high quantities of paraffin were in the $113-400^{\circ} \mathrm{F}$ cut for the Marathon resid.

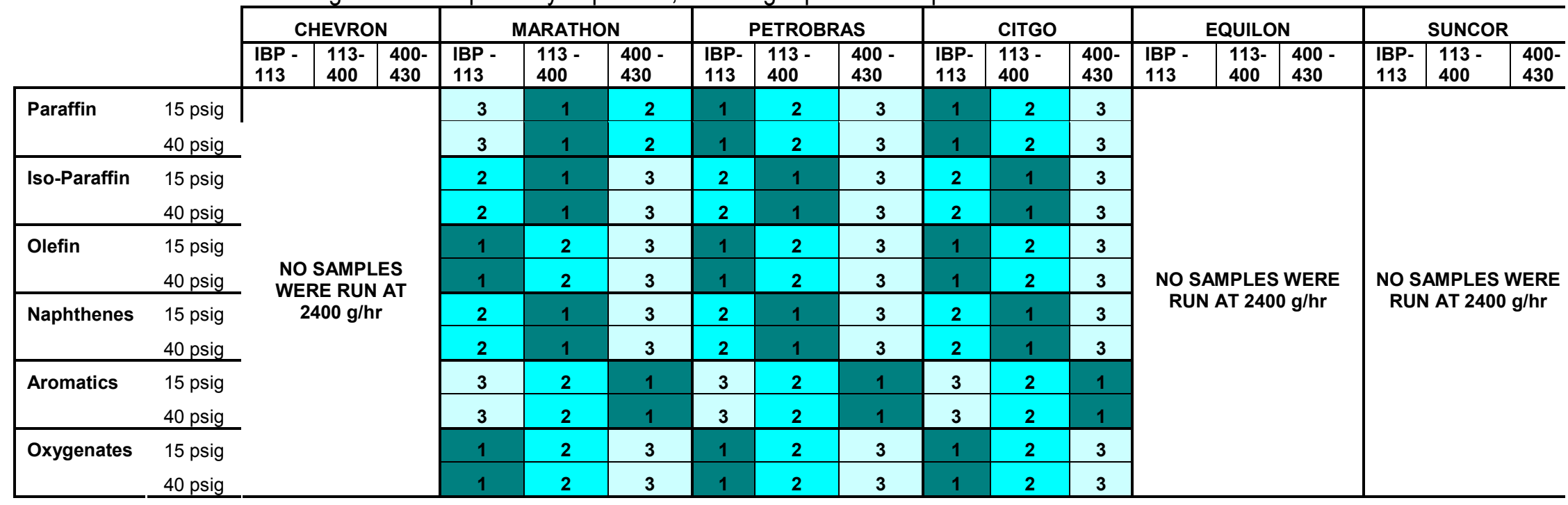

Table 63: DHA PUAF Flow Rate Analysis at 2400g/hr 


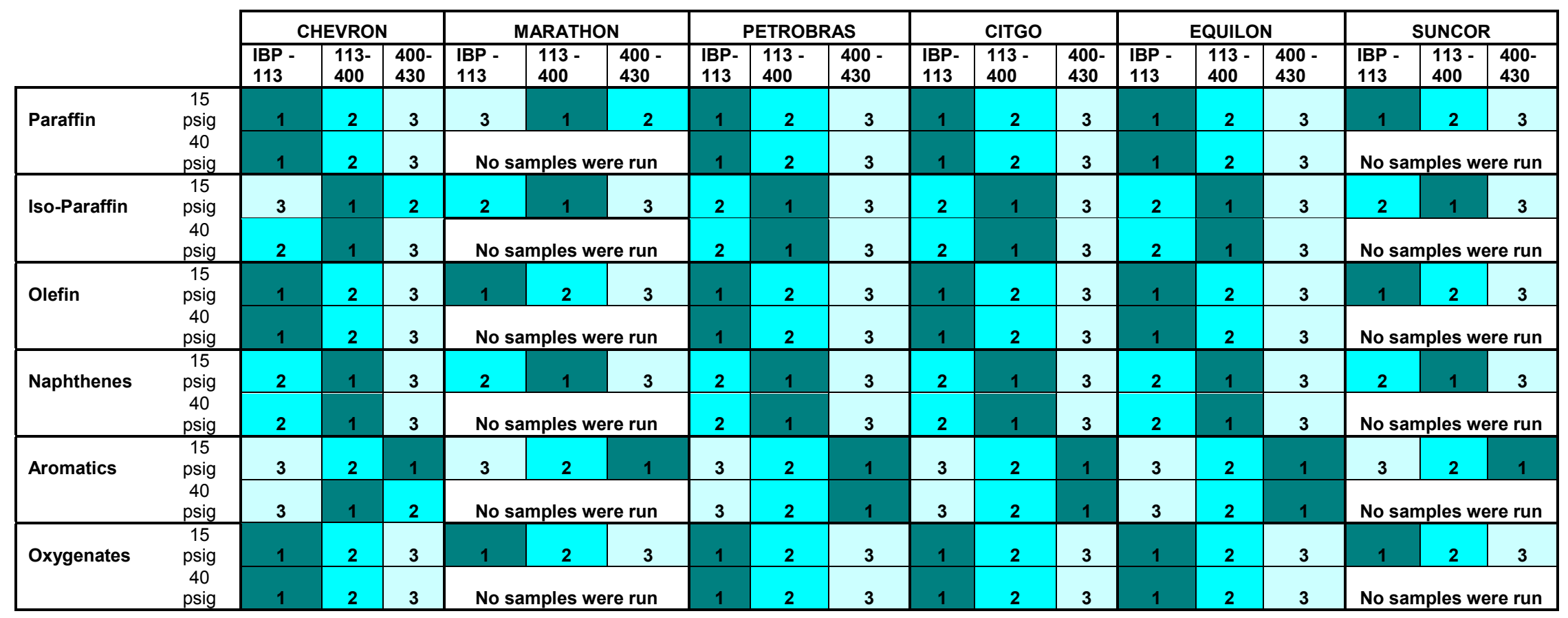

Table 64: DHA PUAF Flow Rate Analysis at 3600g/hr

No samples were run at $3600 \mathrm{~g} / \mathrm{hr}$ and $40 \mathrm{psig}$ for both Marathon and Suncor resids. At a flow rate of $2400 \mathrm{~g} / \mathrm{hr}$ and $3600 \mathrm{~g} / \mathrm{hr}$, the Marathon resids produced identical trends for all cuts at 15 psig. The Petrobras, Citgo and Equilon resids produced similar trends. The Chevron resid produced similar trends with Petrobras, Citgo and Equilon with the exception of the iso-paraffin production at 15 psig and aromatics production at 40 psig. At $15 \mathrm{psig}$, the IBP-113F cut had minimal amounts of paraffin present, while at $40 \mathrm{psig}$, the $113-400^{\circ} \mathrm{F}$ cut had high amounts of aromatics. 


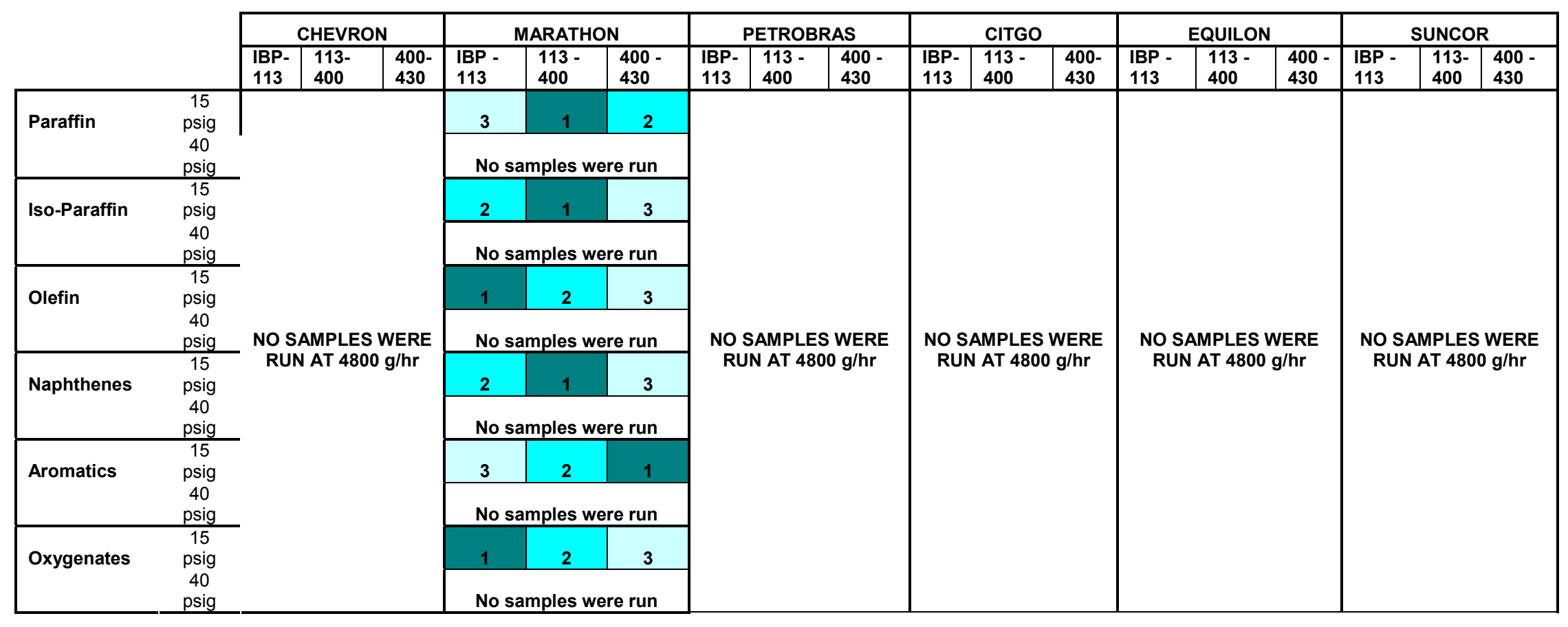

Table 65: DHA PUAF Flow Rate Analysis at $4800 \mathrm{~g} / \mathrm{hr}$

No samples were run at $4800 \mathrm{~g} / \mathrm{hr}$ for Chevron, Petrobras, Citgo, Equilon and Suncor resids, none were run for Marathon at 40 psig. At a feed rate of $4800 \mathrm{~g} / \mathrm{hr}$ and $15 \mathrm{psig}$, the Marathon resids produced identical trends with $2400 \mathrm{~g} / \mathrm{hr}$ and $3600 \mathrm{~g} / \mathrm{hr}$ for all cuts at $15 \mathrm{psig}$.

In conclusion, by comparing the Petrobras and Citgo resids at $15 \mathrm{psig}$ and $40 \mathrm{psig}(2400 \mathrm{~g} / \mathrm{hr}$ and $3600 \mathrm{~g} / \mathrm{hr})$ and Marathon resids at $15 \mathrm{psig}$ $(2400 \mathrm{~g} / \mathrm{hr}, 3600 \mathrm{~g} / \mathrm{hr}$, and $4800 \mathrm{~g} / \mathrm{hr})$, it is observed that changing the feed rate does not affect the concentration of each PiONA component at the different temperature cuts. 


\section{Sulfur Analysis}

The weight percent of sulfur was plotted for the liquid, gas, water and coke fractions for the resids at $15 \mathrm{psig}$ and $40 \mathrm{psig}$ and at feed temperatures of $900^{\circ} \mathrm{F}$ and $930^{\circ} \mathrm{F}$. The sulfur analysis has only been run for the $3 \mathrm{ft}$ pilot unit drum and the analysis for the $6 \mathrm{ft}$ pilot unit drum is still pending. For brevity, only the Chevron sulfur data obtained using the 0.25 inch coil in the $3 \mathrm{ft}$ pilot unit will be displayed.

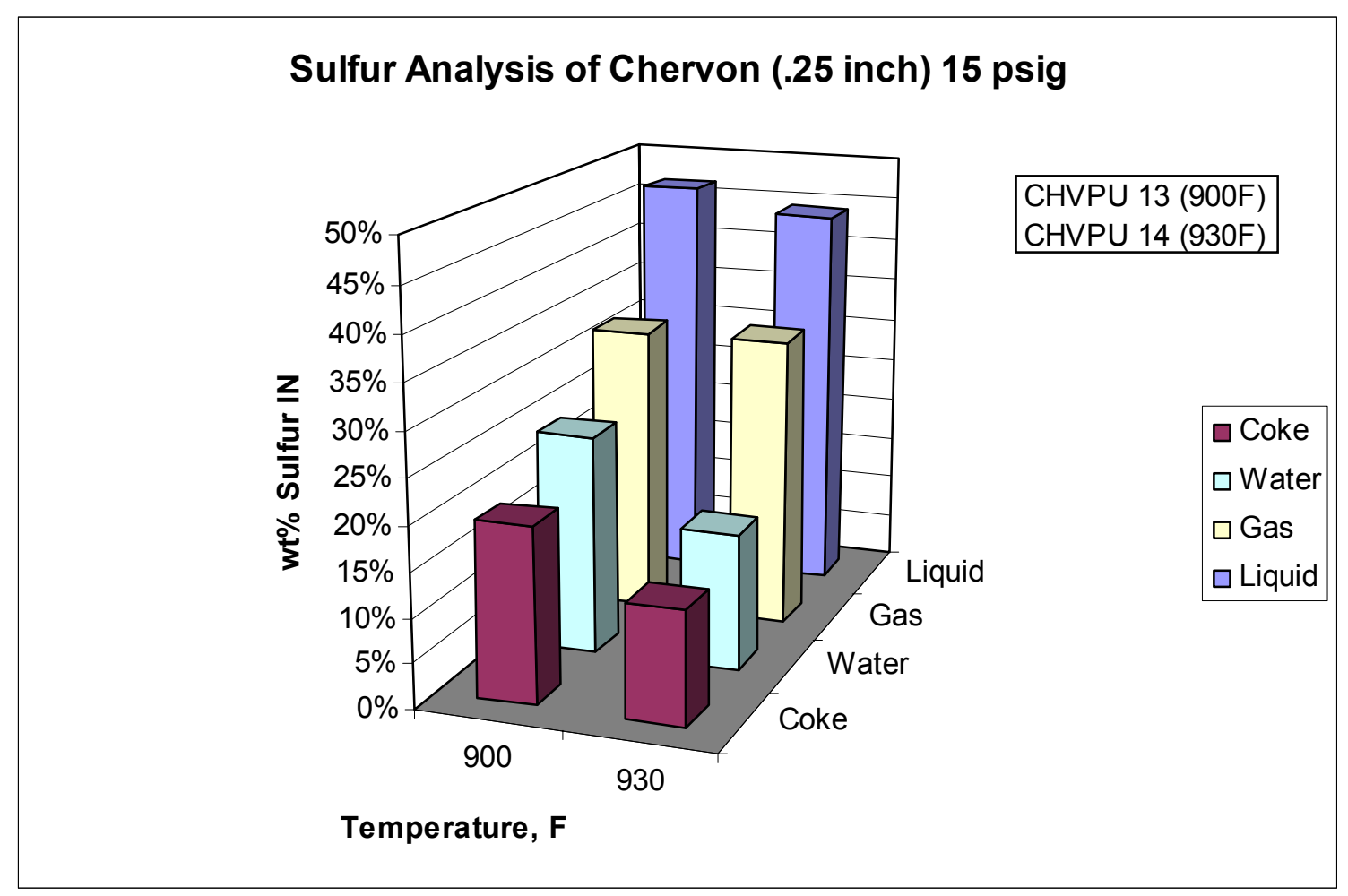

Figure 95: PU Sulfur Analysis at 15 psig

From Figure 95, it is observed that the liquid cut contained the largest amount of sulfur and the coke cut contained the smallest amount of sulfur. These trends were observed at both $900^{\circ} \mathrm{F}$ and $930^{\circ} \mathrm{F}$. 


\section{Sulfur Analysis of Chervon (.25 inch) 40 psig}

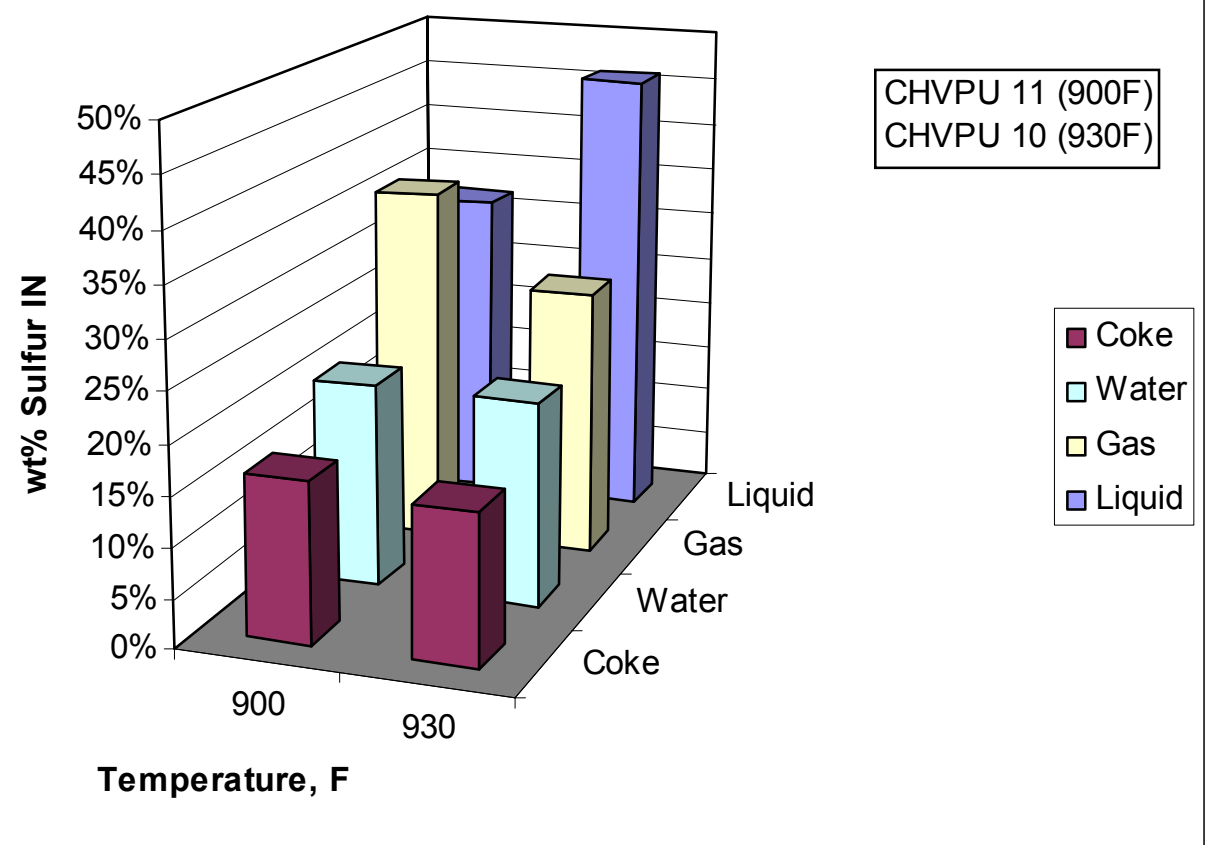

Figure 96: PU Sulfur Analysis at 40 psig

Figure 96 shows that at $930^{\circ} \mathrm{F}$ the liquid cut contained the largest amount of sulfur and the coke cut contained the smallest amount of sulfur. At $900^{\circ} \mathrm{F}$, the gas cut contained largest of the sulfur present followed by the liquid cut.

The effects of temperature and pressure on the weight percent of sulfur contained in the liquid, gas, water and coke cuts were constructed using only sulfur data that was available, the results have been condensed into a matrix format. The key below can be used to decipher the matrix and are labeled 1 to 4 in order of decreasing weight percent (\%) of sulfur in.

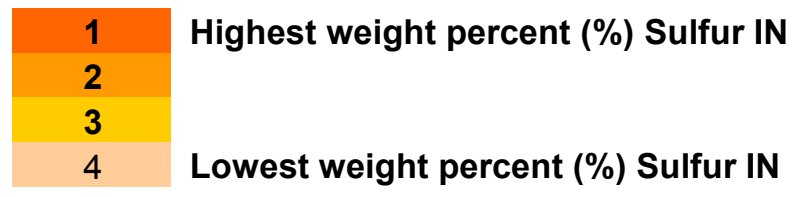




\section{PU SULFUR ANALYSIS $\quad 0.25$ inch}

\begin{tabular}{|c|c|c|c|c|c|c|c|c|c|c|c|c|c|c|c|c|c|c|c|c|c|c|c|c|}
\hline \multirow[b]{2}{*}{ sure } & \multicolumn{4}{|c|}{ CHEVRON } & \multicolumn{4}{|c|}{ MARATHON } & \multicolumn{4}{|c|}{ PETROBRAS } & \multicolumn{4}{|c|}{ CITGO } & \multicolumn{4}{|c|}{ EQUILON } & \multicolumn{4}{|c|}{ SUNCOR } \\
\hline & Liquid & Gas & Water & Coke & Liquid & Gas & Water & Coke & Liquid & Gas & Water & Coke & Liquid & Gas & Water & Coke & Liquid & Gas & Water & Coke & Liquid & Gas & Water & Coke \\
\hline ssig & 1 & 2 & 3 & 4 & \multicolumn{4}{|c|}{ No samples were run } & \multicolumn{4}{|c|}{ No samples were run } & 3 & 2 & 4 & 1 & \multicolumn{4}{|c|}{ No samples were run } & 1 & 2 & 4 & 3 \\
\hline ssig & 2 & 1 & 3 & 4 & 2 & 1 & 4 & 3 & 1 & 2 & 3 & 4 & 3 & 2 & 4 & 1 & 3 & 2 & 4 & 1 & 2 & 1 & 4 & 3 \\
\hline
\end{tabular}

Table 66: PU Sulfur Analysis (0.25 inch coil) at 900F

\begin{tabular}{|c|c|c|c|c|c|c|c|c|c|c|c|c|c|c|c|c|c|c|c|c|c|c|c|c|}
\hline \multirow[b]{2}{*}{ sure } & \multicolumn{4}{|c|}{ CHEVRON } & \multicolumn{4}{|c|}{ MARATHON } & \multicolumn{4}{|c|}{ PETROBRAS } & \multicolumn{4}{|c|}{ CITGO } & \multicolumn{4}{|c|}{ EQUILON } & \multicolumn{4}{|c|}{ SUNCOR } \\
\hline & Liquid & Gas & Water & Coke & Liquid & Gas & Water & Coke & Liquid & Gas & Water & Coke & Liquid & Gas & Water & Coke & Liquid & Gas & Water & Coke & Liquid & Gas & Water & Coke \\
\hline sig & 1 & 2 & 3 & 4 & \multicolumn{4}{|c|}{ No samples were run } & \multicolumn{4}{|c|}{ No samples were run } & 1 & 3 & 4 & 2 & 2 & 3 & 4 & 1 & 1 & 2 & 4 & 3 \\
\hline sig & 1 & 2 & 3 & 4 & 1 & 3 & 4 & 2 & 1 & 2 & 3 & 4 & 1 & 3 & 4 & 2 & 2 & 3 & 4 & 1 & 2 & 1 & 4 & 3 \\
\hline
\end{tabular}

Table 67: PU Sulfur Analysis (0.25 inch coil) at 930F

\begin{tabular}{|c|c|c|c|c|c|c|c|c|c|c|c|c|c|c|c|c|c|c|c|c|c|c|c|c|}
\hline \multirow[b]{2}{*}{ sure } & \multicolumn{4}{|c|}{ CHEVRON } & \multicolumn{4}{|c|}{ MARATHON } & \multicolumn{4}{|c|}{ PETROBRAS } & \multicolumn{4}{|c|}{ CITGO } & \multicolumn{4}{|c|}{ EQUILON } & \multicolumn{4}{|c|}{ SUNCOR } \\
\hline & Liquid & Gas & Water & Coke & Liquid & Gas & Water & Coke & Liquid & Gas & Water & Coke & Liquid & Gas & Water & Coke & Liquid & Gas & Water & Coke & Liquid & Gas & Water & Coke \\
\hline ssig & \multirow{2}{*}{\multicolumn{4}{|c|}{ No samples were run }} & & sam! & es were & & \multirow{2}{*}{\multicolumn{4}{|c|}{ No samples were run }} & 2 & 3 & 4 & 1 & \multirow{2}{*}{\multicolumn{4}{|c|}{ No samples were run }} & \multicolumn{4}{|c|}{ No samples were run } \\
\hline sig & & & & & 2 & 3 & 4 & 1 & & & & & \multicolumn{4}{|c|}{ No samples were run } & & & & & 1 & 2 & 4 & 3 \\
\hline
\end{tabular}

Table 68: PU Sulfur Analysis (0.25 inch coil) at 950F

Table 66, Table 67 , and Table 68 show the PU sulfur analysis data at 900 $\mathrm{F}, 930^{\circ} \mathrm{F}$ and $950^{\circ} \mathrm{F}$ respectively. From comparing the tables, there are fluctuations in the amount of sulfur produced for each cut at the different temperatures and pressures. No conclusive remarks can be made until the sulfur analysis is run for the $6 \mathrm{ft}$ pilot unit (PUAF) drum and the resulting trends are compared with that of the $3 \mathrm{ft}$ pilot unit (PU) drum. 


\section{Density Analysis}

The density in API was plotted for five temperature cut, IBP-113ㅇ, $113-400^{\circ} \mathrm{F}, 400-430^{\circ} \mathrm{F}, 430$ $650^{\circ} \mathrm{F}$, and $650{ }^{\circ} \mathrm{F}$, at pressures of $15 \mathrm{psig}$ and $40 \mathrm{psig}$ and bottom temperatures of $900^{\circ} \mathrm{F}$ and $930^{\circ} \mathrm{F}$. For brevity, only the Chevron density data for both the $3 \mathrm{ft}$ and $6 \mathrm{ft}$ pilot unit will be discussed.

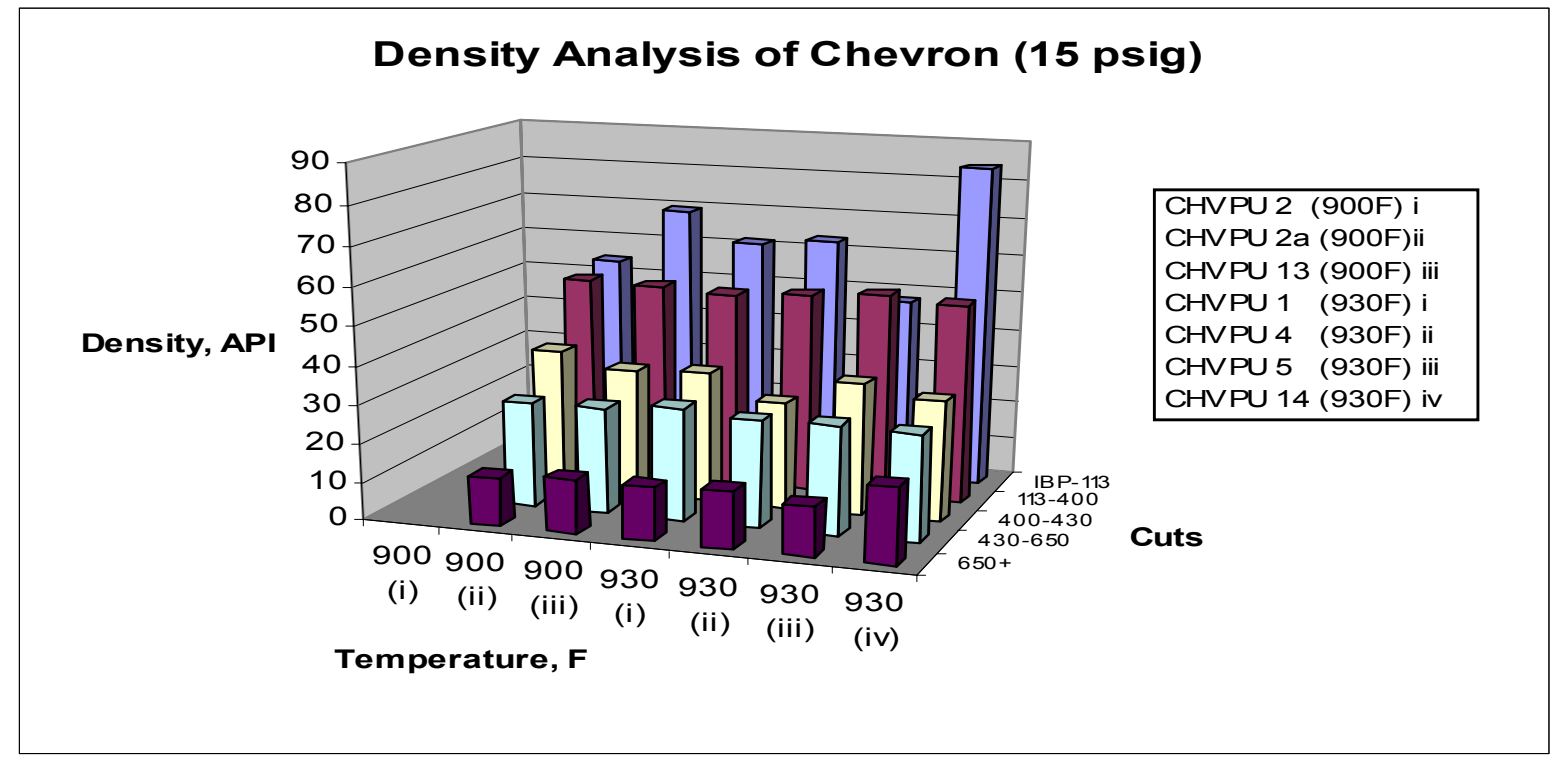

Figure 97: PU Chevron Density Analysis at 15 psig

From Figure 97, it is observed that the density API, decreases as the boiling point cuts increases. These trends were observed at both $900^{\circ} \mathrm{F}$ and $930^{\circ} \mathrm{F}$.

\section{Conclusions}

The distillation and simulated distillation data showed similar trends at the same pressure for both feed and overhead temperatures. This reduces the amount of analytical work required. It was observed that changing the feed rate, 1200 to $3600 \mathrm{gm} / \mathrm{hr}$ did not affect the distribution of the weight \% of feed in the different temperature coils nor did it affect the concentration of each PiONA component at the different temperature cuts. Although still on progress, the overall outcome of the DHA analysis is to be able to predict what type of PiONA component would affect its production. Based on the preliminary analysis conducted, this goal appears achievable. 
D. FOAMING STUDIES

\section{Foam density determination/Time of collapse}

This section deals with the foam density determination and also compares the time of collapse for different resides for different type of antifoam injection types.

\section{a) Chevron - Overhead injection}

The Chevron 5 run was used to establish a value for the foam density in the first phase of the foaming studies. As shown in Figure 98, a foam column 54 inches in height with a density of approximately $0.1 \mathrm{gm} / \mathrm{cm}$ existed after one hour. Since the height continued to grow, antifoam was injected continuously (100,000 cSt-5\% AF in sun diesel) after 71 minutes of coking and wasn't stopped until the 121 minute mark. As shown in Figure 99, by 90 minutes the foam height was suppressed 14 inches. A total of $1.4 \mathrm{cc}$ of antifoam had been injected. After another 44 minutes of antifoam injection (2.5 additional cc's) the foam height was suppressed an additional 10 inches for a total suppression of 24 inches, as shown in Figure 100. This suppression can also be seen on the density versus elapsed time plot shown in Figure 101 through Figure 106. For these runs, based on what was being collapsed, a good number for foam density is less than $0.1 \mathrm{gm} / \mathrm{cc}$ to $0.2 \mathrm{gm} / \mathrm{cc}$.

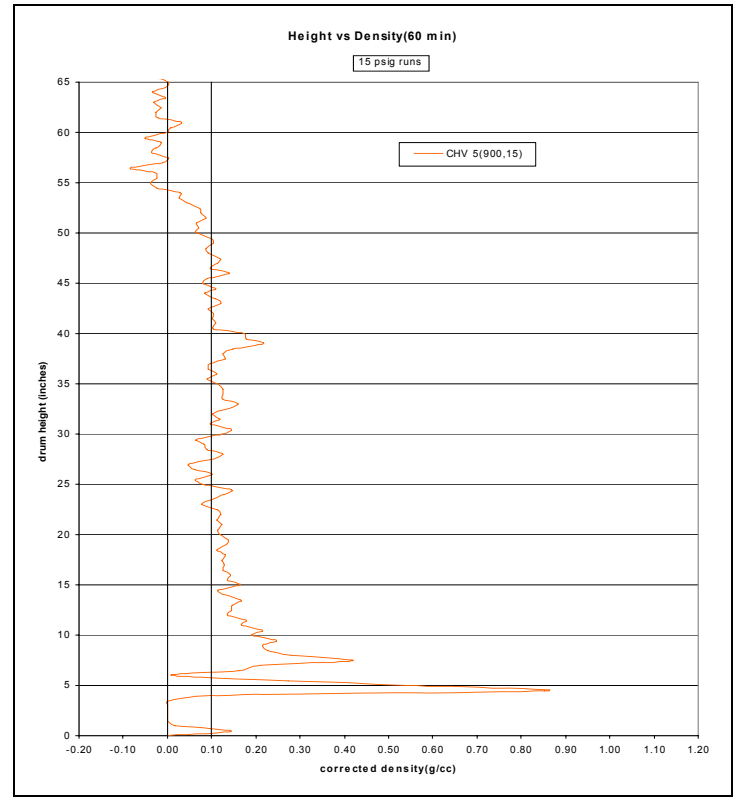

Figure 98 - Chevron Anti-Foaming Runs - Height vs. Density (Temperature and Pressure Effects on Foaming)

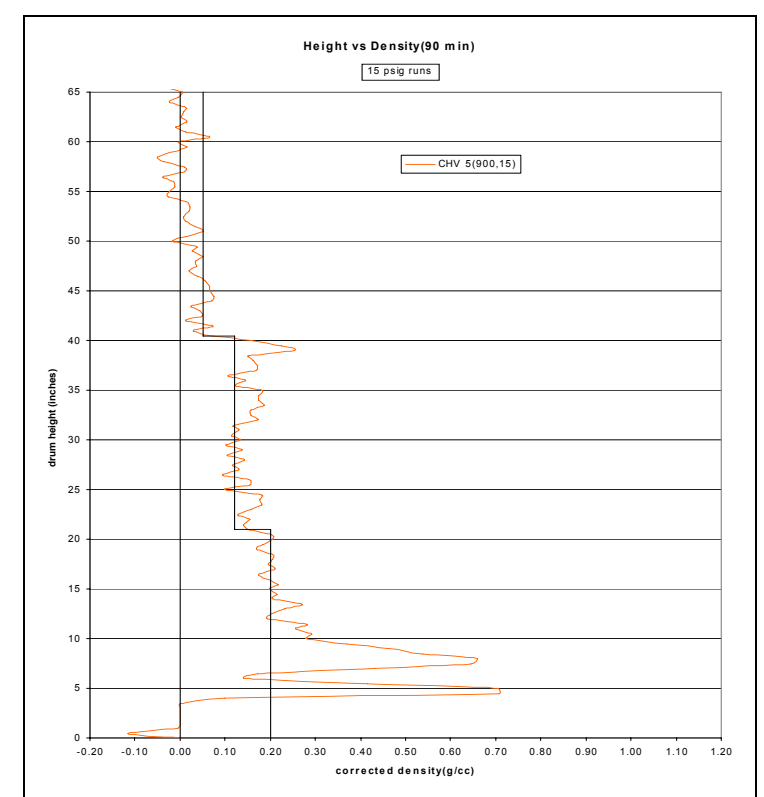

Figure 99 - Chevron Anti-Foaming Runs - Height vs. Density (Temperature and Pressure Effects on Foaming) 


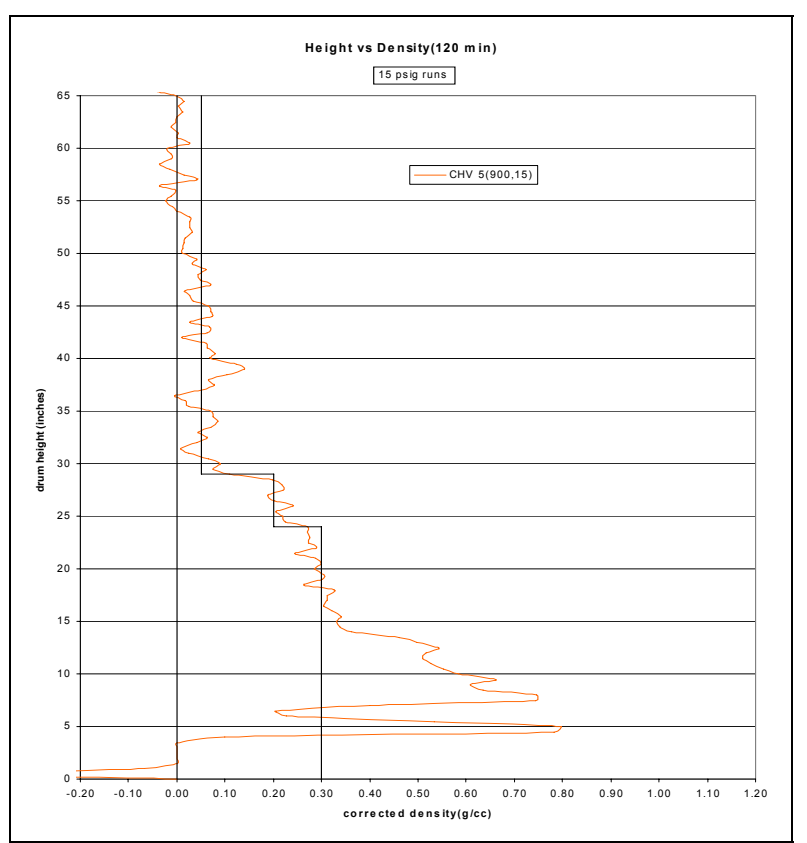

Figure 100 - Chevron Anti-Foaming Runs - Height vs. Density (Temperature and Pressure Effects on Foaming)

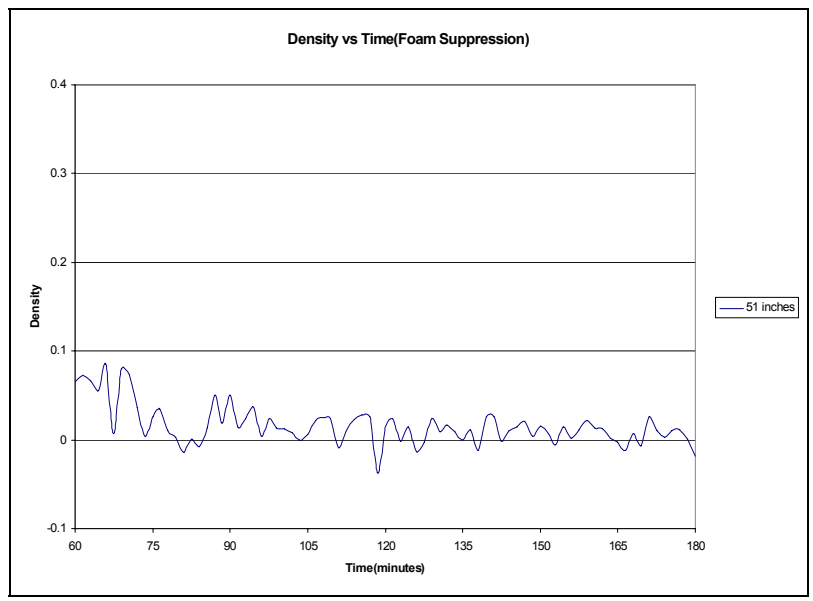

Figure 101 - Chevron Anti-Foaming Runs - Density vs. Time (Foam Suppression)

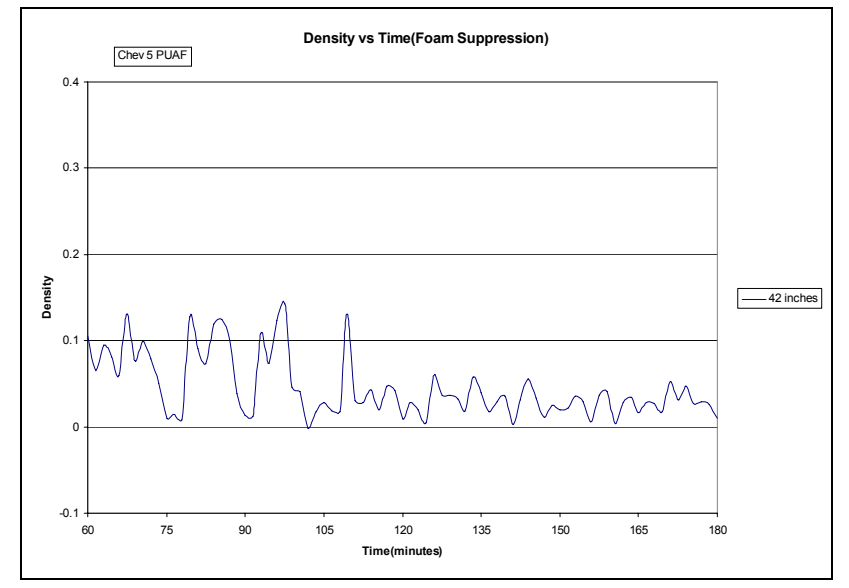

Figure 102 - Chevron Anti-Foaming Runs - Density vs. Time (Foam Suppression) 


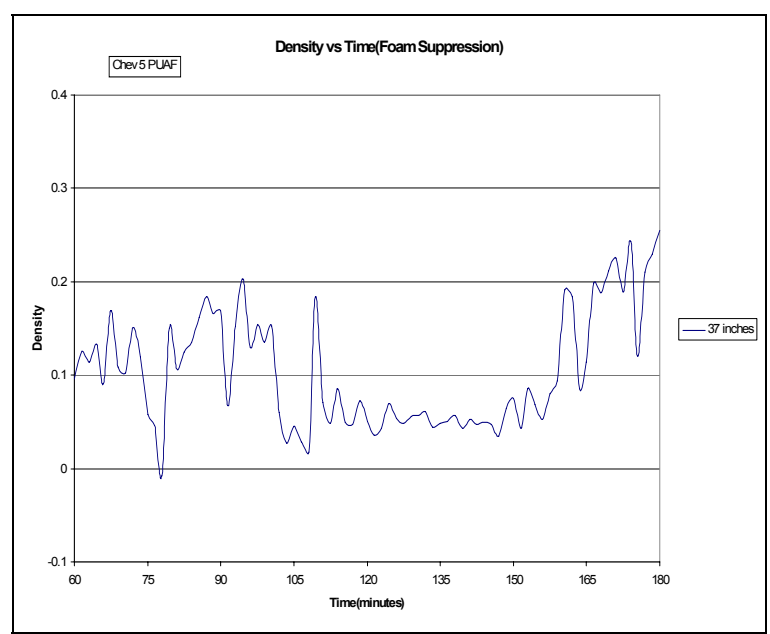

Figure 103 - Chevron Anti-Foaming Runs - Density vs. Time (Foam Suppression)

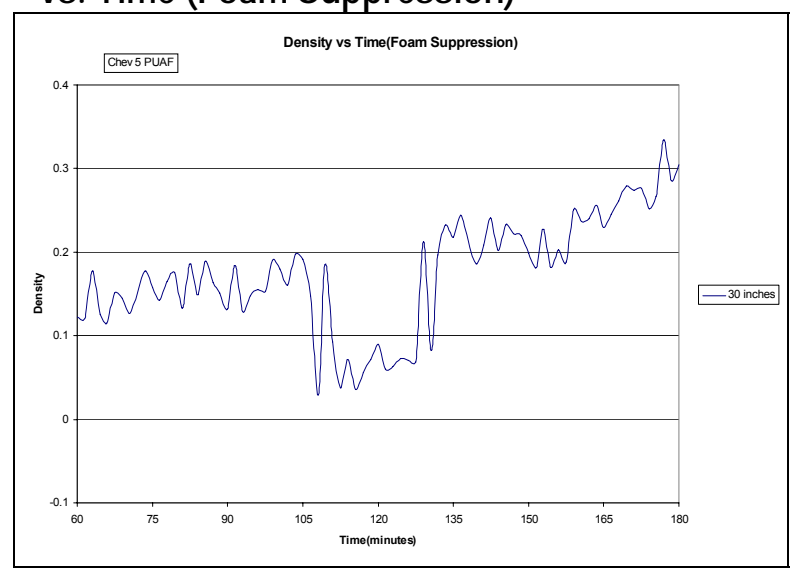

Figure 105 - Chevron Anti-Foaming Runs - Density vs. Time (Foam Suppression)

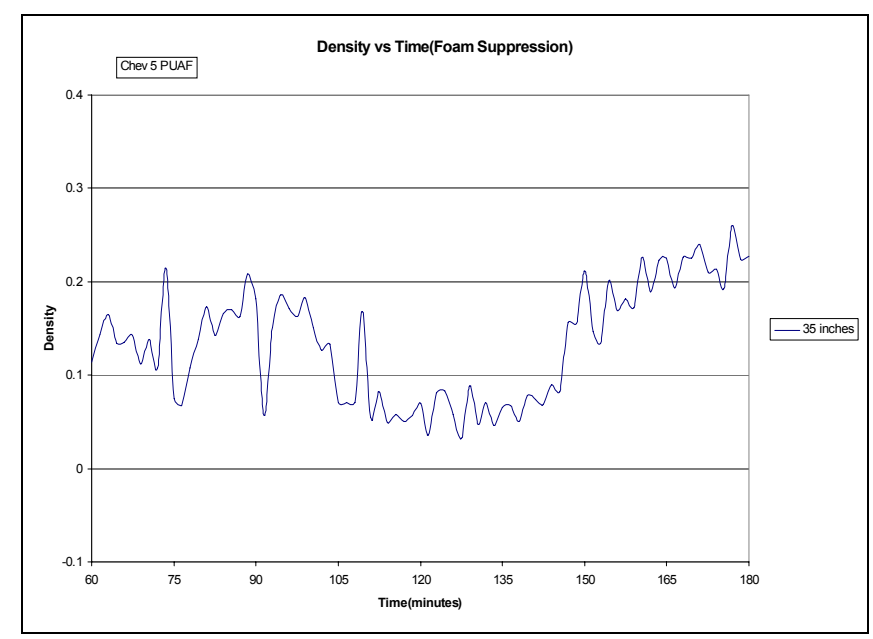

Figure 104 - Chevron Anti-Foaming Runs - Density vs. Time (Foam Suppression)

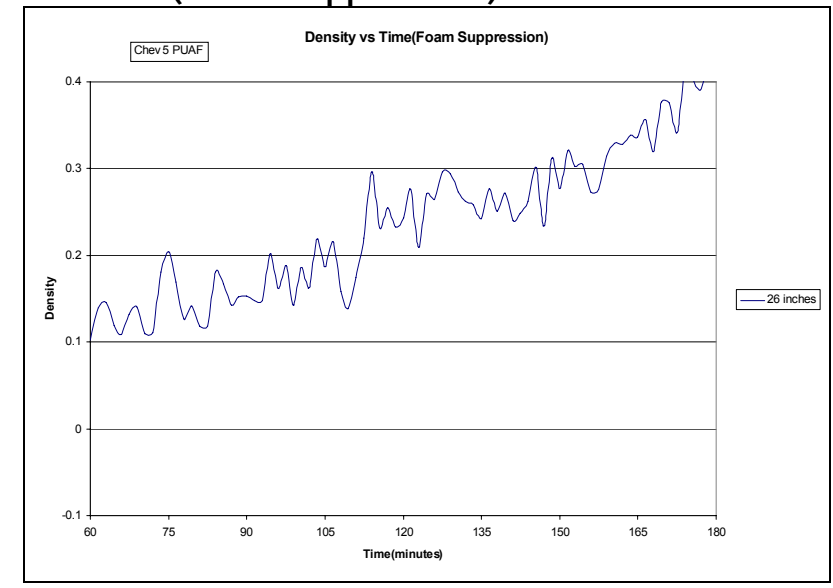

Figure 106 - Chevron Anti-Foaming Runs - Density vs. Time (Foam Suppression)

\section{b) Petrobras - Feedline injection}

Feed line injection of antifoam was used for the Petrobras tests. As shown in Figure 107 the collapse of a foam column with a $0.2 \mathrm{gm} / \mathrm{cc}$ density was instantaneous using 100,000 cSt antifoam (30 $\mathrm{ml} / \mathrm{AF} / 70$ sun diesel) $\mathrm{ml}$ same as observed in the refinery when antifoam is injected. The collapse occurred between two gamma traces that were 1.5 minutes apart.

The injection sequence is shown in Figure 108. In this test, foam injection began 25 minutes into the run using overhead injection. Injection overhead continued for approximately 20 minutes without any effect. At that point, injection was switched to the feed line. Collapse was seen 8 minutes later after injecting another $1.8 \mathrm{cc}$ 's of antifoam. This suppression can also be seen on the density vs. elapsed time plot shown in Figure 109 through Figure 114. For this run, based on what is being collapsed, $0.1 \mathrm{gm} / \mathrm{cc}$ to $0.2 \mathrm{gm} / \mathrm{cc}$ is still a good number for foam density. Tests continued with feed line injection of antifoam until a new injection system was installed that will be able to pump carrier fluids overhead at a higher rate. 

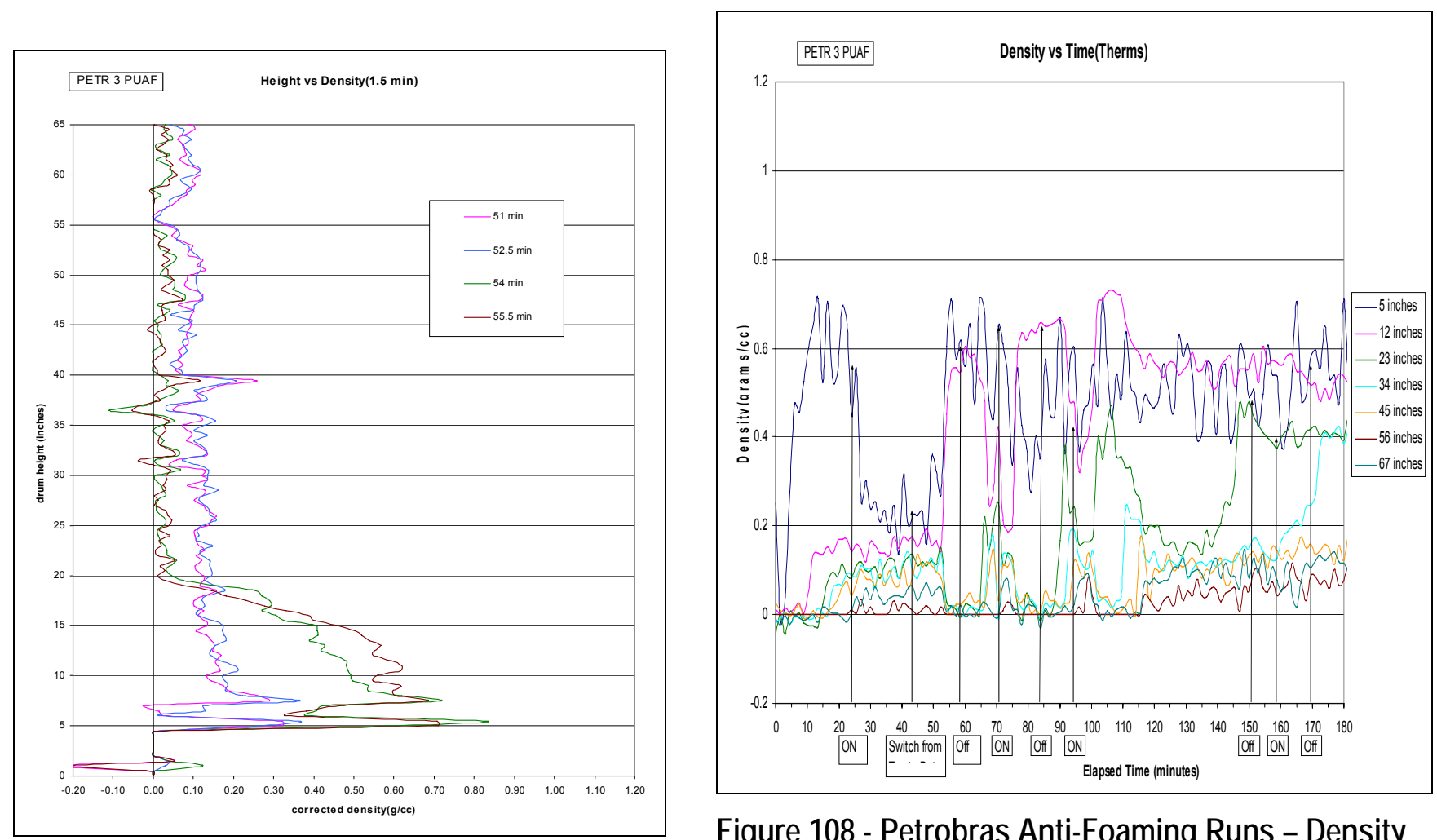

Figure 107 - Petrobras Anti-Foaming Runs - Height Figure 108 - Petrobras Anti-Foaming Runs - Density vs. Density (Temperature and Pressure Effects on Foaming) 


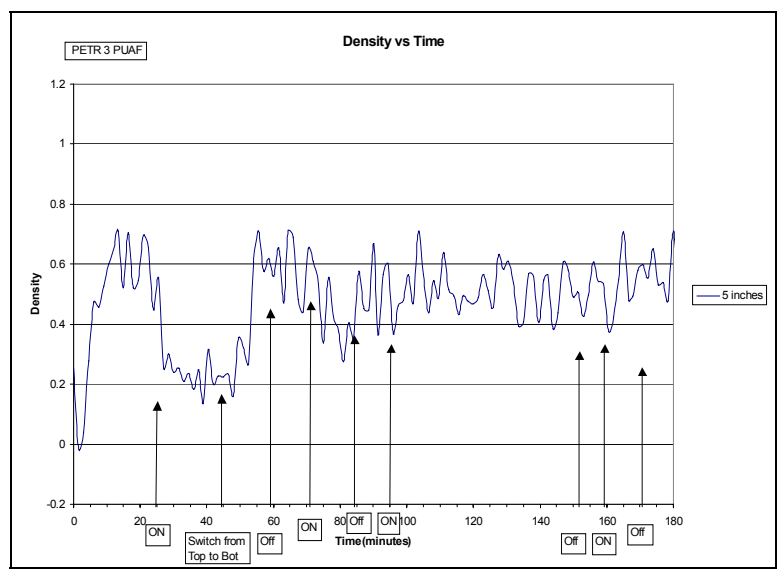

Figure 109 - Petrobras Anti-Foaming Runs Density vs. Time (Foam Suppression)

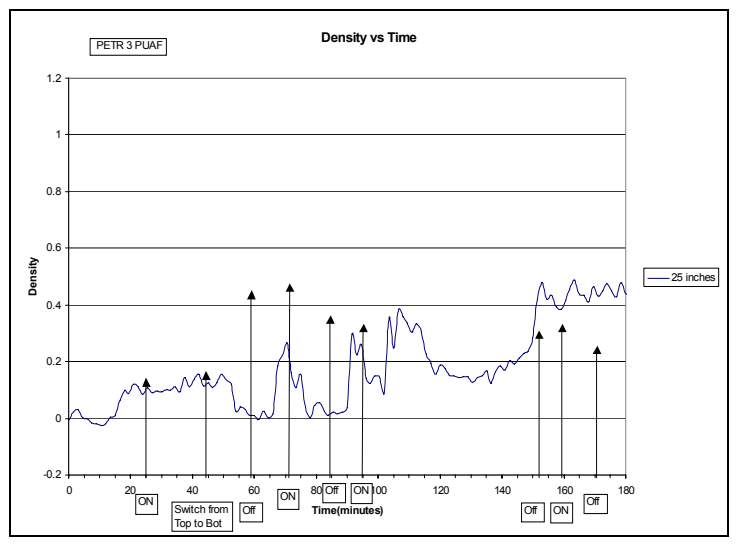

Figure 111 - Petrobras Anti-Foaming Runs Density vs. Time (Foam Suppression)

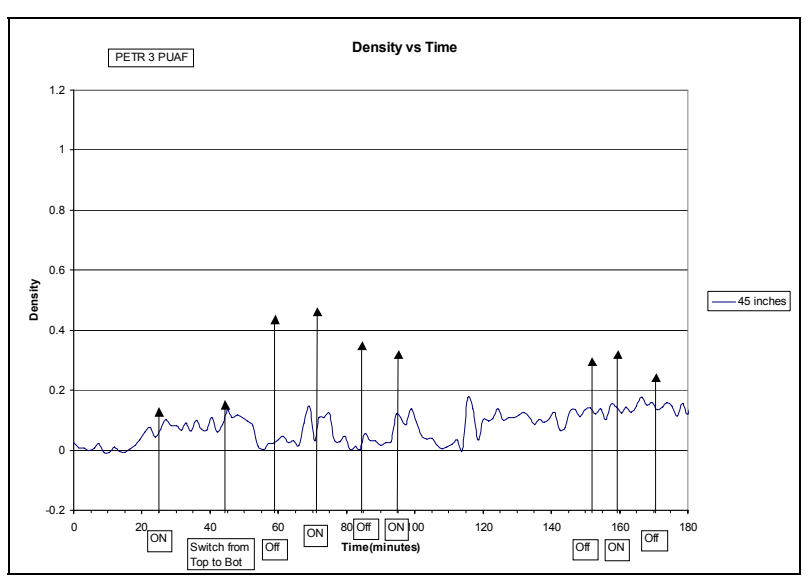

Figure 113 - Petrobras Anti-Foaming Runs Density vs. Time (Foam Suppression)

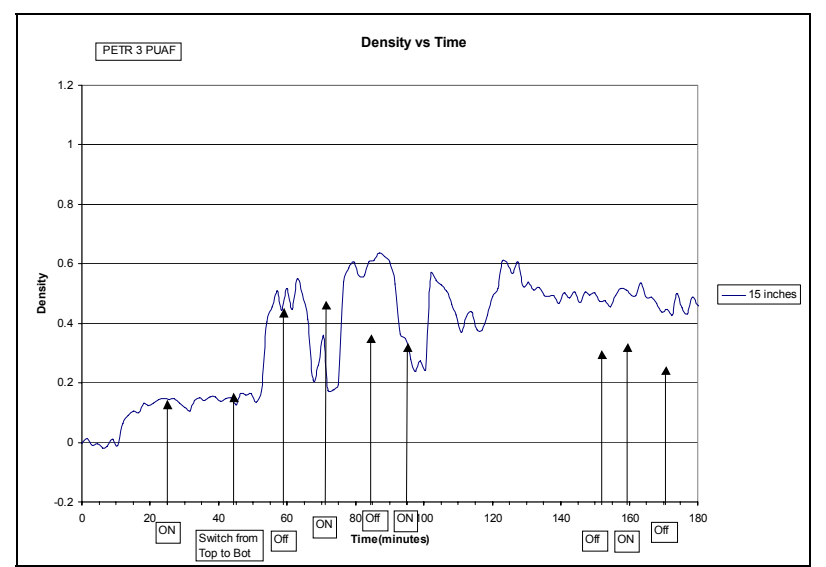

Figure 110 - Petrobras Anti-Foaming Runs - Density vs. Time (Foam Suppression)

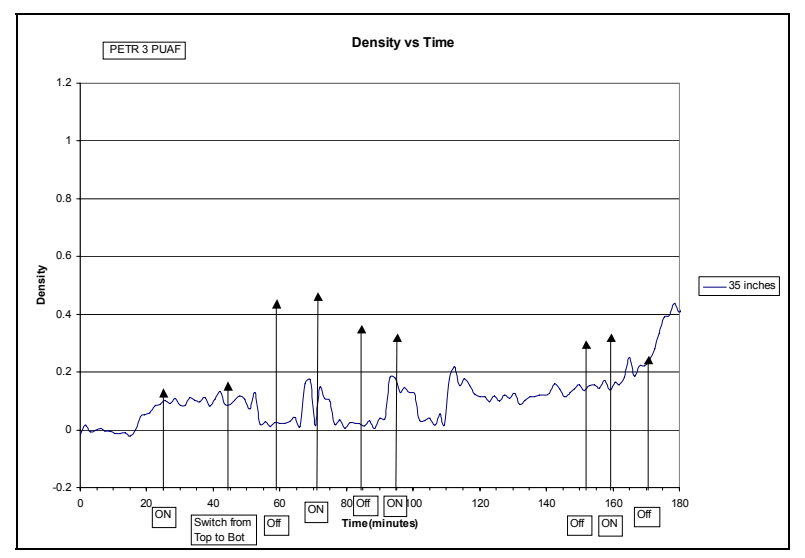

Figure 112 - Petrobras Anti-Foaming Runs - Density vs. Time (Foam Suppression)

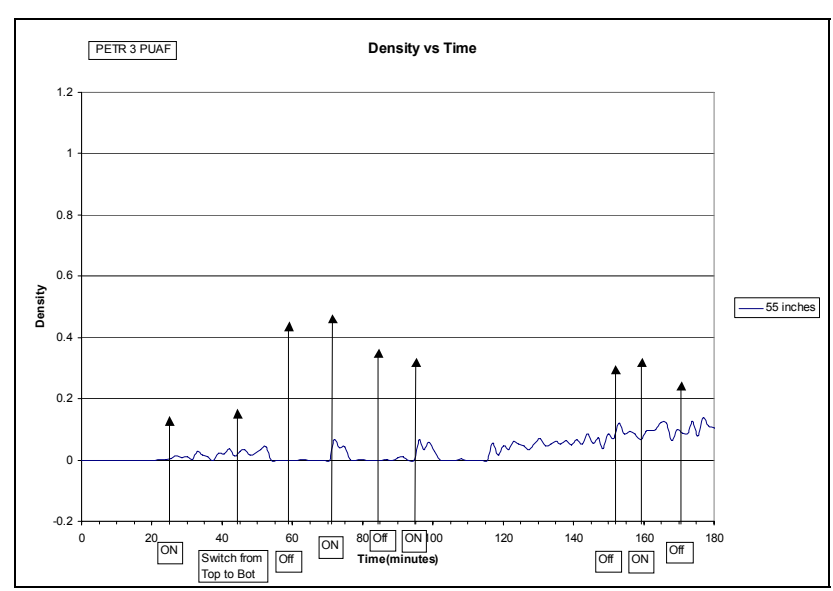

Figure 114 - Petrobras Anti-Foaming Runs - Density vs. Time (Foam Suppression) 


\section{Comparison of Antifoam Injection Techniques}

Five runs were made to examine different approaches of injecting antifoam. Antifoam was mixed with the feed, injected in the feed line and injected overhead. For overhead injection, both low $(1 \mathrm{ml}$ $\mathrm{AF} / 300 \mathrm{ml}$ carrier) concentrations and high $(30 \mathrm{ml} \mathrm{AF} / 70 \mathrm{ml}$ carrier) concentrations were used for the 100,000 cSt antifoam. Continuous antifoam injection was used for both the overhead and feed line injection tests.

The Suncor resid was first used to compare feed vs. overhead injection of the $100,000 \mathrm{cSt}$ antifoam. These tests were conducted at a temperature of $930^{\circ} \mathrm{F}$, a pressure of $15 \mathrm{psig}$ at a feed rate of $3600 \mathrm{gm} / \mathrm{hr}$. In the Suncor 3 run the antifoam was injected overhead while for the Suncor 4 run the antifoam was injected in the feed. The data for these runs are presented in Figure 115 and Figure 116 as density vs. elapsed time at 5 -inch intervals in the drum. Two preliminary observations can be made. First, as shown in Figure 115 the densities fluctuated wildly for the overhead injection case (antifoam injection began at the 165 minute mark) whereas as shown in Figure 116 when the antifoam is injected in the feed the fluctuations are more subdued. These fluctuations were also seen in the Suncor 2 run that was conducted in the same manner. It can also be seen that the coke produced when the antifoam is injected in the feed is denser than when it is injected overhead. This will be discussed in more detail later. Other tests need to be conducted before any firm conclusions are drawn.

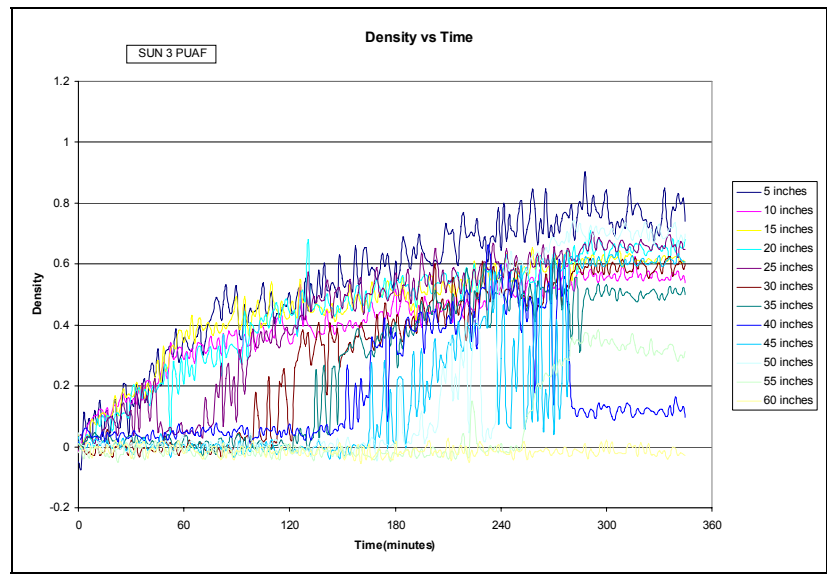

Figure 115 - Suncor Anti-Foaming Runs - Density vs. Time (Overhead Injected Antifoam)

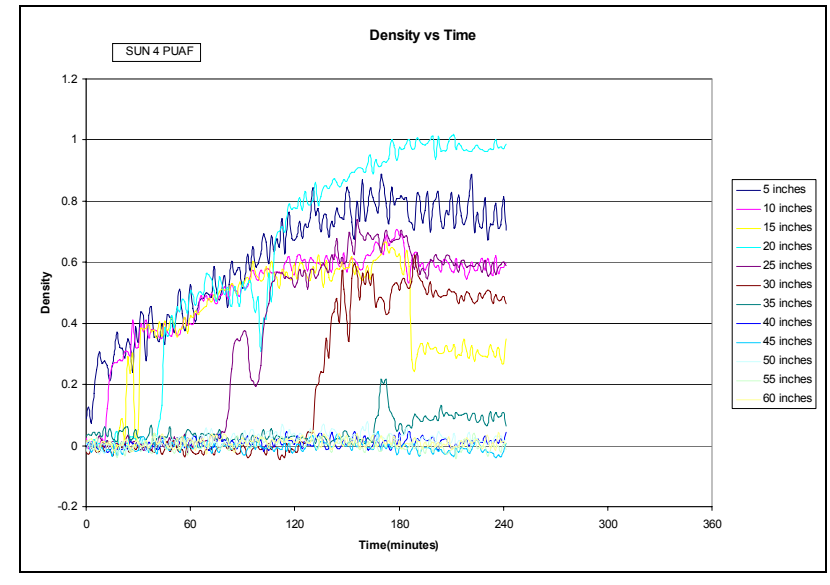

Figure 116 - Suncor Anti-Foaming Runs - Density vs. Time (Feed Injected Antifoam) 
Comparison of the five runs is shown in Figure 117. Figure 117 shows that no foaming was occurring when the antifoam was injected in the feed or in the feed line. It was noted that there is a much smaller fluctuation in the density $(+/-0.05 \mathrm{gm} / \mathrm{cc})$ at a given height in the drum when antifoam is injected in the feed or feed line whereas when no antifoam is injected, the contents in the drum are much more reactive with density swings of $+/-0.3 \mathrm{gm} / \mathrm{cc}$ going from liquid to gas sinusoidally. Injection of antifoam at low concentrations (close to commercial rates) did not control the foaming very well. It must be kept in mind that based on earlier discussions it appears that the antifoam is being carried out of the drum. However, when a high concentration of the $100,000 \mathrm{cSt}$ antifoam was used, the foam behaved similarly to the ones when antifoam was injected in the feed and feed line. It is anticipated that when the antifoam injection facility is modified to be able to pump more viscous carriers, the antifoam control will be the same as that observed when injected in the feed or feed lines. At this time, no explanation can be provided as to why the high concentration of $(600,000 \mathrm{cSt})$ antifoam, did not perform as well as the 100,000 cSt high concentration antifoam. Additional runs are planned.

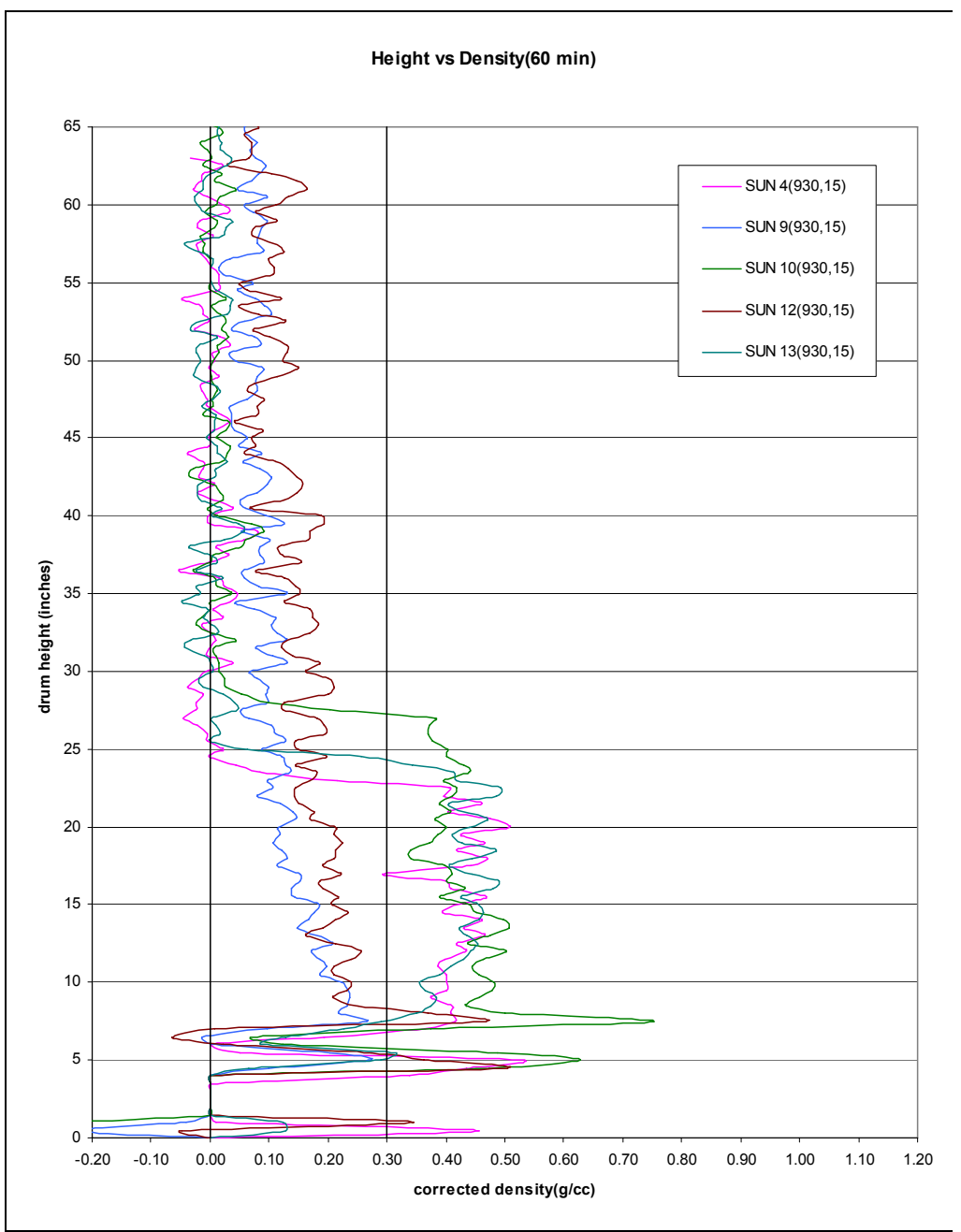

Figure 117 - Comparison of Density traces for all 5 runs after 60 minutes of coking 


\section{Antifoam Optimization Studies}

The antifoam optimization studies began with the resid from Petrobras. Eight tests were conducted: four tests were conducted with different antifoam/carrier concentrations using the 100,000 cSt antifoam; two tests were conducted to compare continuous overhead to continuous feedline injection; and 2 tests were conducted with the $600,000 \mathrm{cSt}$ antifoam to compare its effectiveness to the 100,000 cSt antifoam. The amount of antifoam used for each run is shown in Table 69. In general, the contents in the drum were allowed to foam until the drum was two-thirds full before antifoam was injected. Injection continued until the column was knocked back to one-half the drum height. Since scans are taken every 1.5 minutes, rigorous control could not be applied using this procedure.

Table 69 - Antifoam Injection Quantities

\begin{tabular}{|c|c|c|c|c|c|c|c|c|c|c|c|c|c|}
\hline \multirow[b]{2}{*}{ Run \# } & \multirow[b]{2}{*}{ AF Mixture } & \multicolumn{11}{|c|}{ Injection } & \multirow{2}{*}{$\begin{array}{c}\text { Total } \\
\text { Injected }\end{array}$} \\
\hline & & 1 & 2 & 3 & 4 & 5 & 6 & 7 & 8 & 9 & 10 & 11 & \\
\hline Petrobas 9 & $30 / 70$ & 4.639 & 2.876 & 2.928 & 7.930 & 3.472 & & & & & & & 21.845 \\
\hline Petrobas 10 & $3 / 70$ & 0.852 & 0.401 & & & & & & & & & & 1.253 \\
\hline Petrobas 11 & $0.3 / 70$ & 0.031 & 0.025 & 0.046 & 0.052 & 0.057 & & & & & & & 0.211 \\
\hline \multirow{3}{*}{ Petrobas 12} & $0.03 / 70$ & 0.006 & & & & & & & & & & & 0.0057 \\
\hline & $0.3 / 70$ & & 0.076 & 0.100 & 0.037 & 0.105 & 0.028 & & & & & & 0.346 \\
\hline & $3 / 70$ & & & & & & & 1.491 & 0.593 & 0.213 & 0.380 & 0.355 & 3.032 \\
\hline
\end{tabular}

The first antifoam optimization test was conducted using a 30/70 antifoam/carrier mixture. Antifoam was injected 5 times during the run. As shown in Figure 118 through Figure 120, the antifoam was injected on an as-needed basis for a period of 3 to 4 minutes with the amount of antifoam varying from 3.3 to 5.4 grams. In each case, the foam was collapsed. As shown in Figure 121, antifoam was injected later in the run at the 148 minute mark providing a smaller collapse.

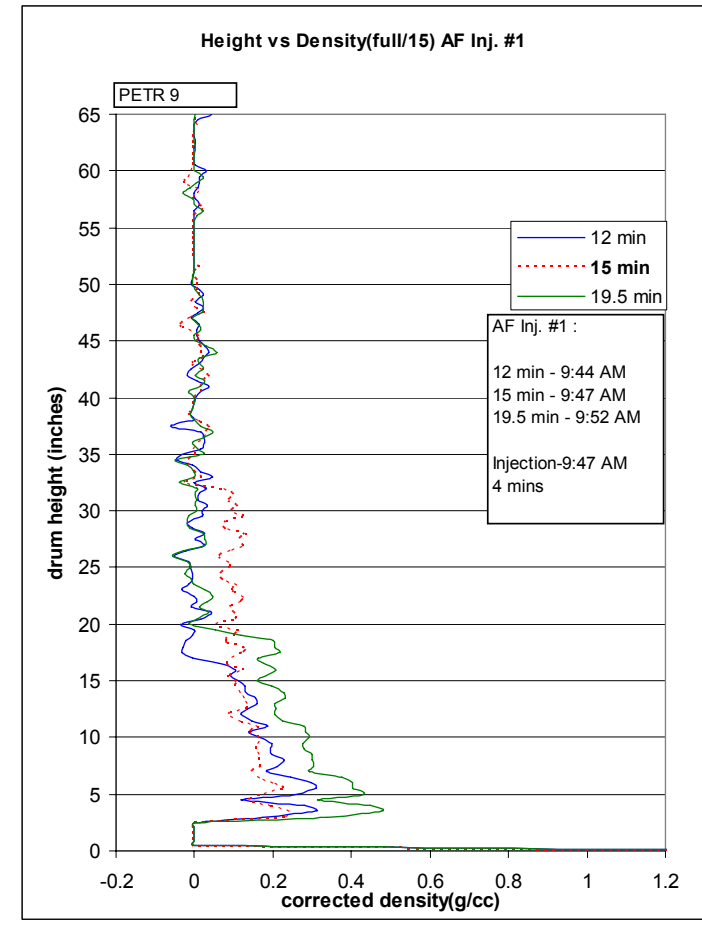

Figure 118 - PETR 9 - Antifoam Injection Response \#1 After 15 Minutes of Coking

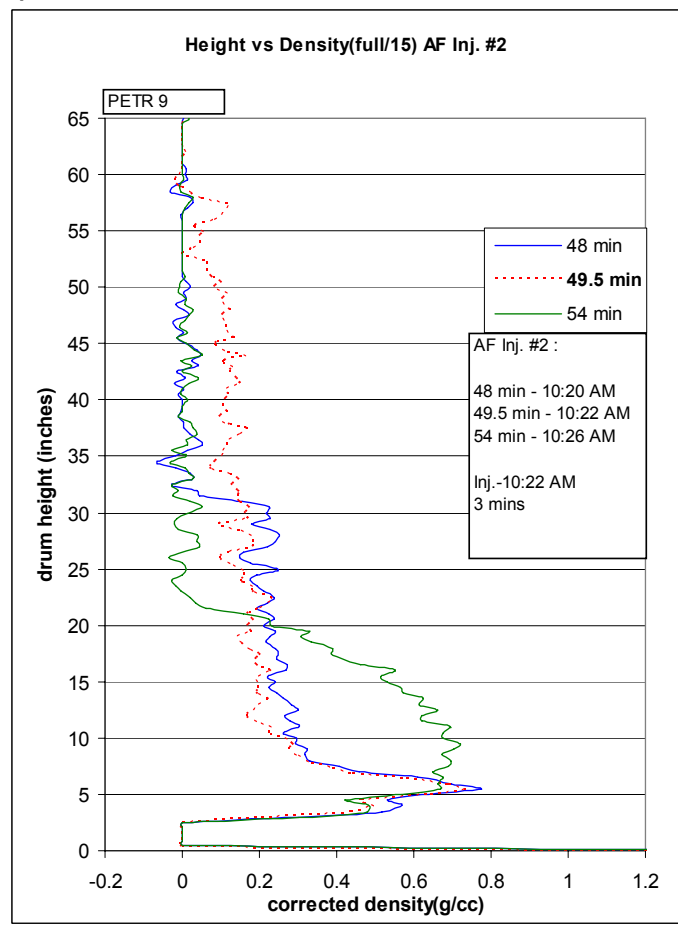

Figure 119 - PETR 9 - Antifoam Injection Response \#2 After 50 Minutes of Coking 


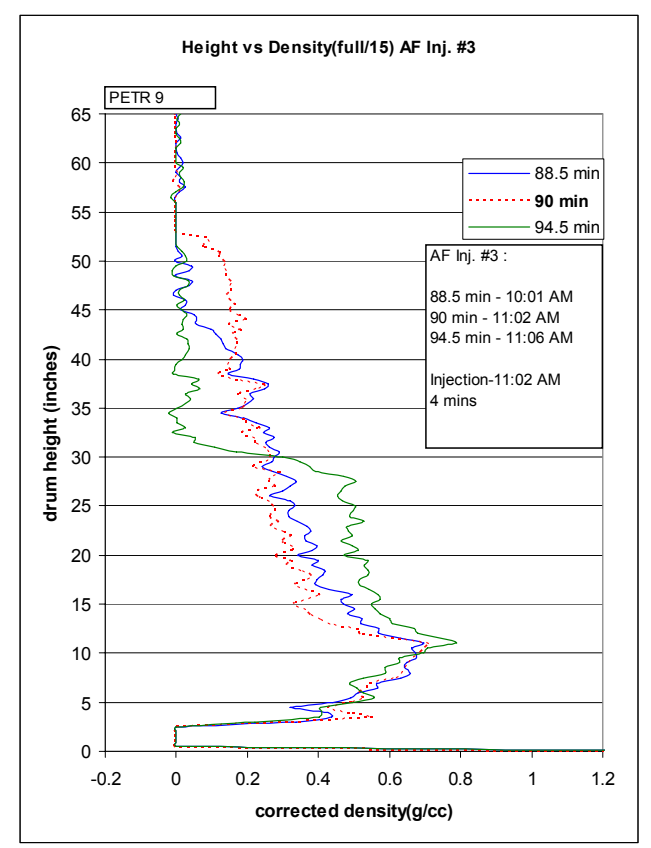

Figure 120 - PETR 9 - Antifoam Injection Response \#3 After 90 Minutes of Coking

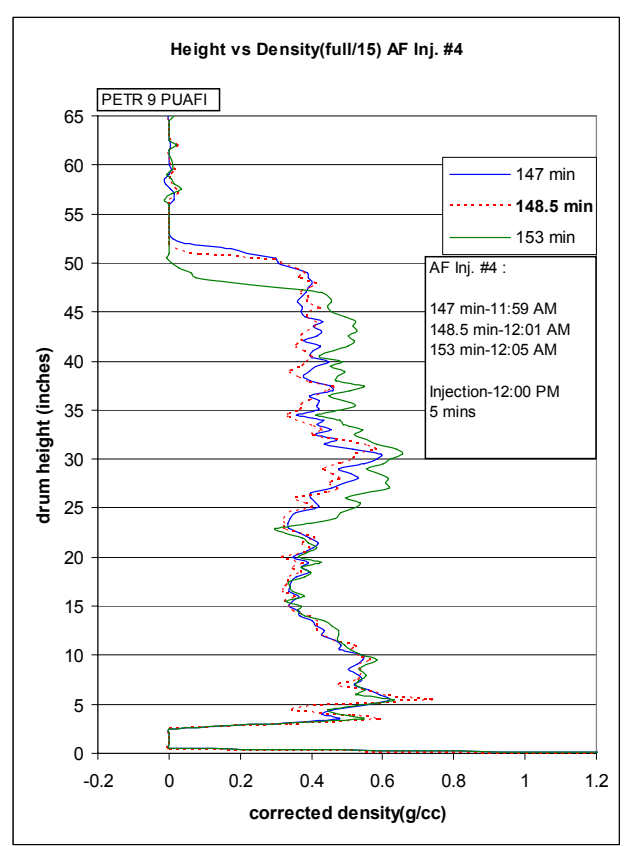

Figure 121 - PETR 9 - Antifoam Injection Response \#4 After 148 Minutes of Coking

The second run was conducted using an antifoam/carrier mixture of $3 / 70$. Injections to collapse the foam were only carried out twice as shown in Figure 122 and Figure 123, but effectively in each case. The first injection utilized 0.99 grams of antifoam while the second injection utilized 0.46 grams. No other injections were required to control the foam even though the contents foamed for the first 60 minutes.

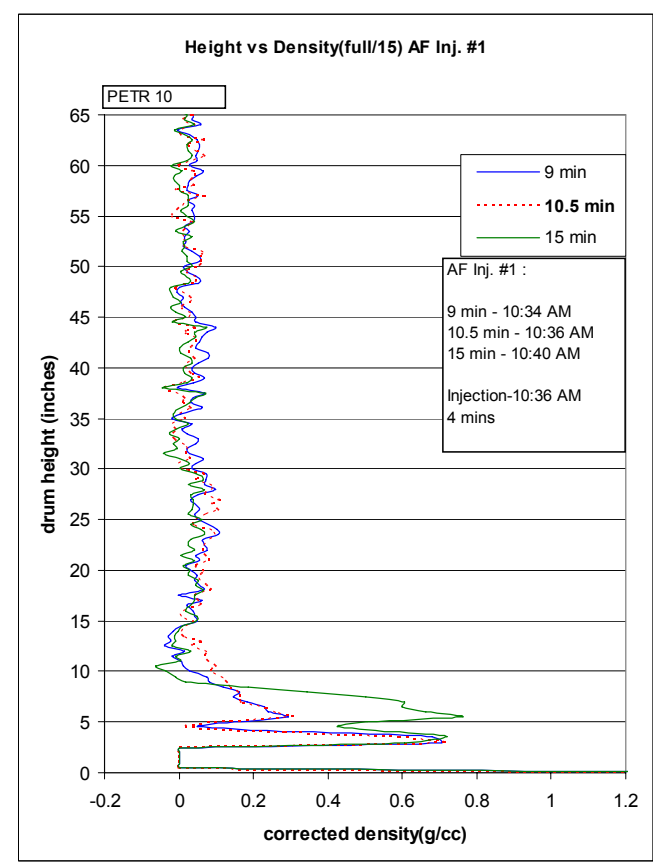

Figure 122 - PETR 10 - Antifoam Injection Response \#1 After 10 Minutes of Coking

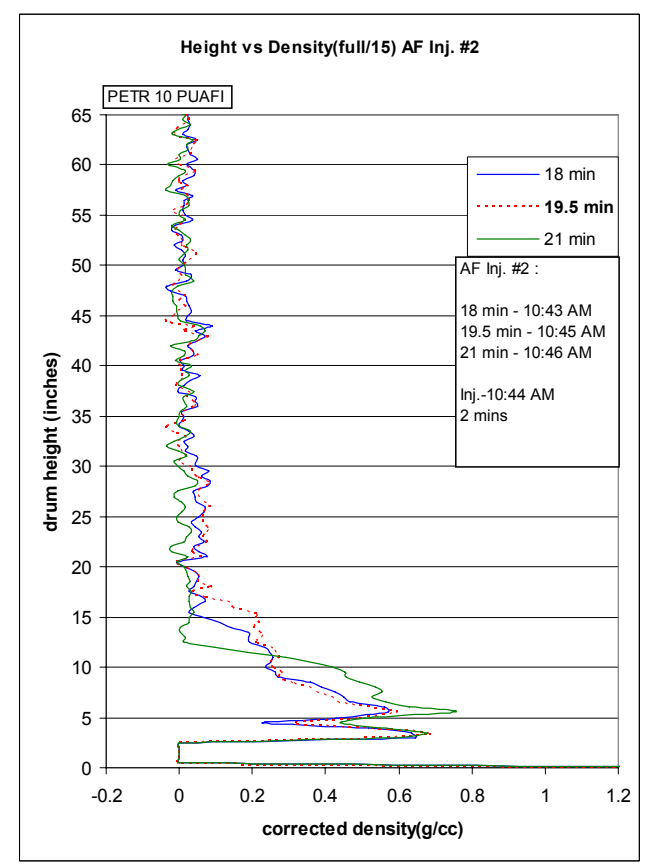

Figure 123 - PETR 10 - Antifoam Injection Response \#2 After 20 Minutes of Coking 
In the third run, an antifoam/carrier mixture of 0.3 to 70 was used. Five injections were utilized as shown in Figure 124 through Figure 128. Very little antifoam was used each time, 0.02 to 0.06 grams; however, in each case collapse was effective.

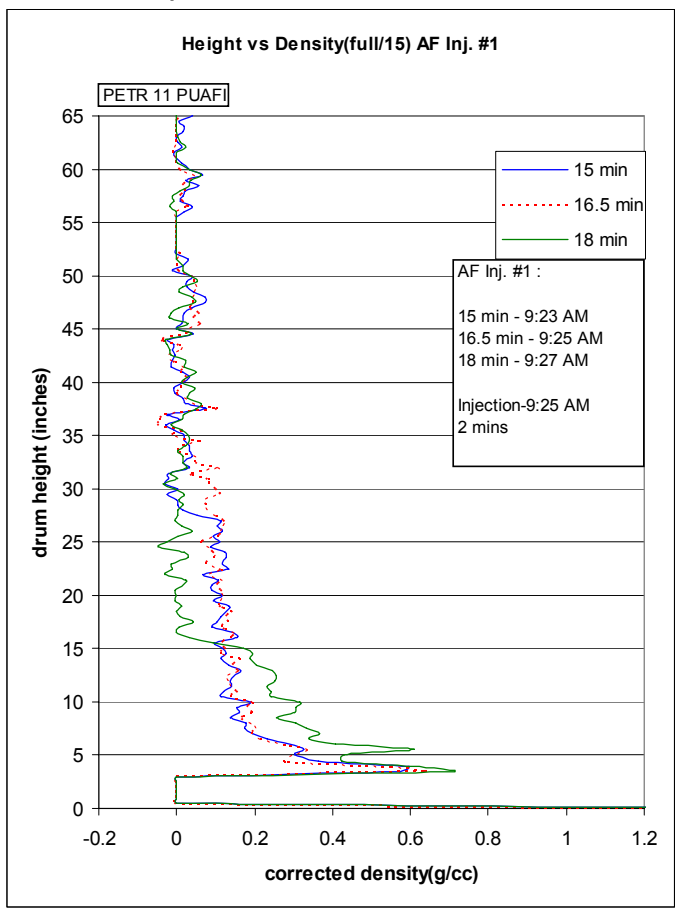

Figure 124 - PETR 11 - Antifoam Injection Response \#1 After 16 Minutes of Coking

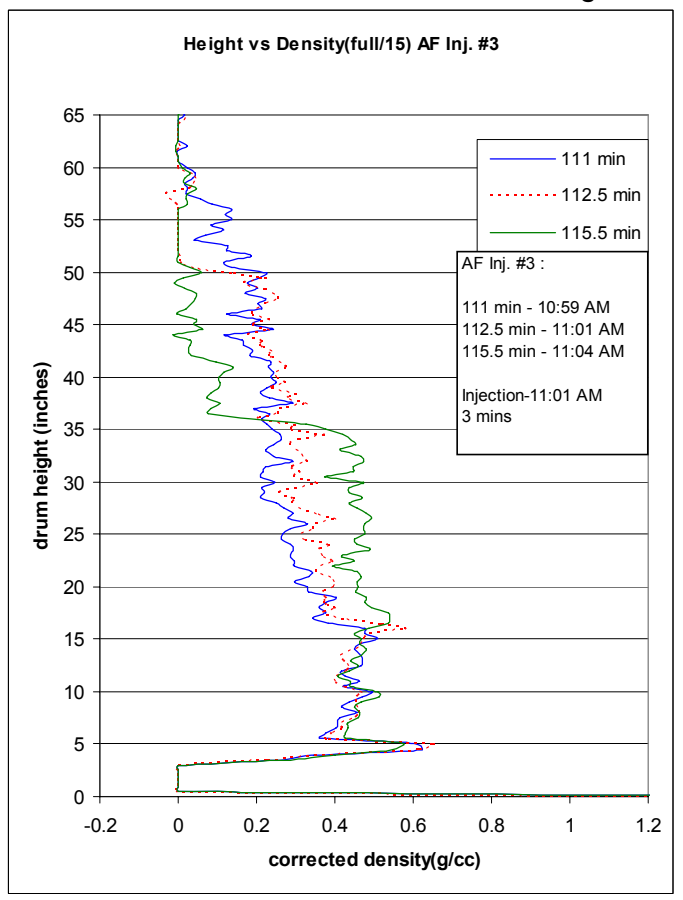

Figure 126 - PETR 11 - Antifoam Injection Response \#3 After 112 Minutes of Coking

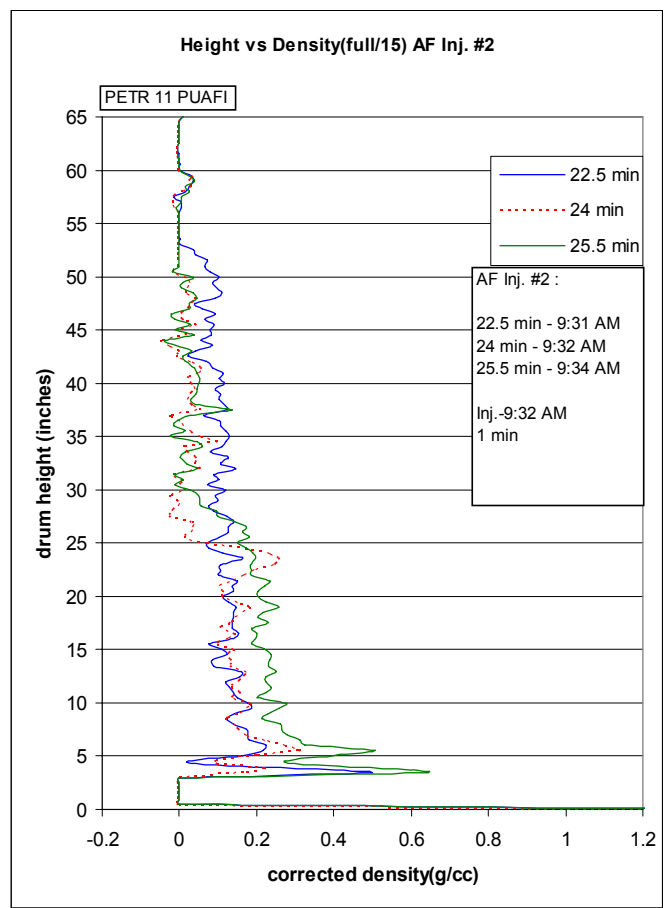

Figure 125 - PETR 11 - Antifoam Injection Response \#2 After 24 Minutes of Coking

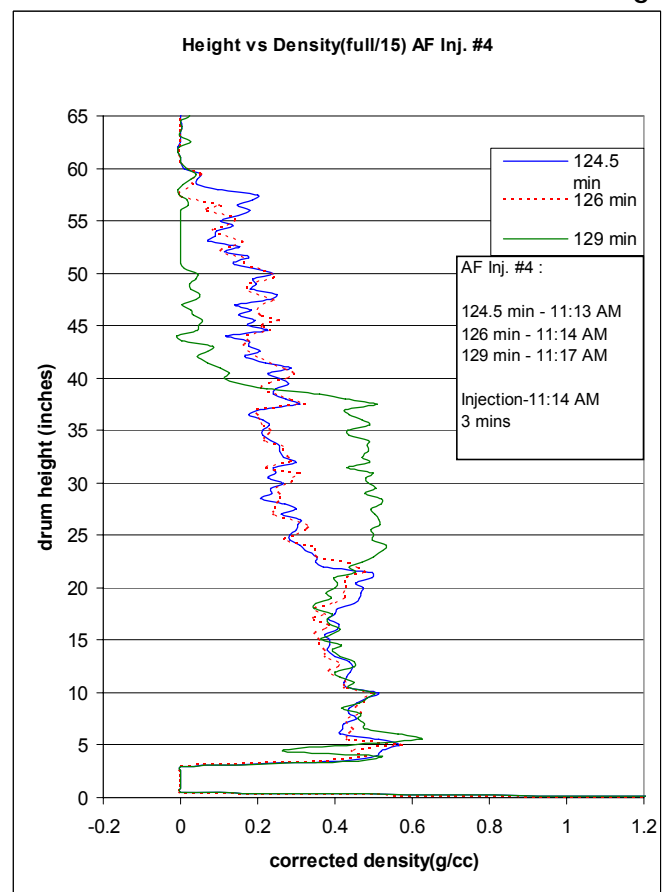

Figure 127 - PETR 11 - Antifoam Injection Response \#4 After 126 Minutes of Coking 


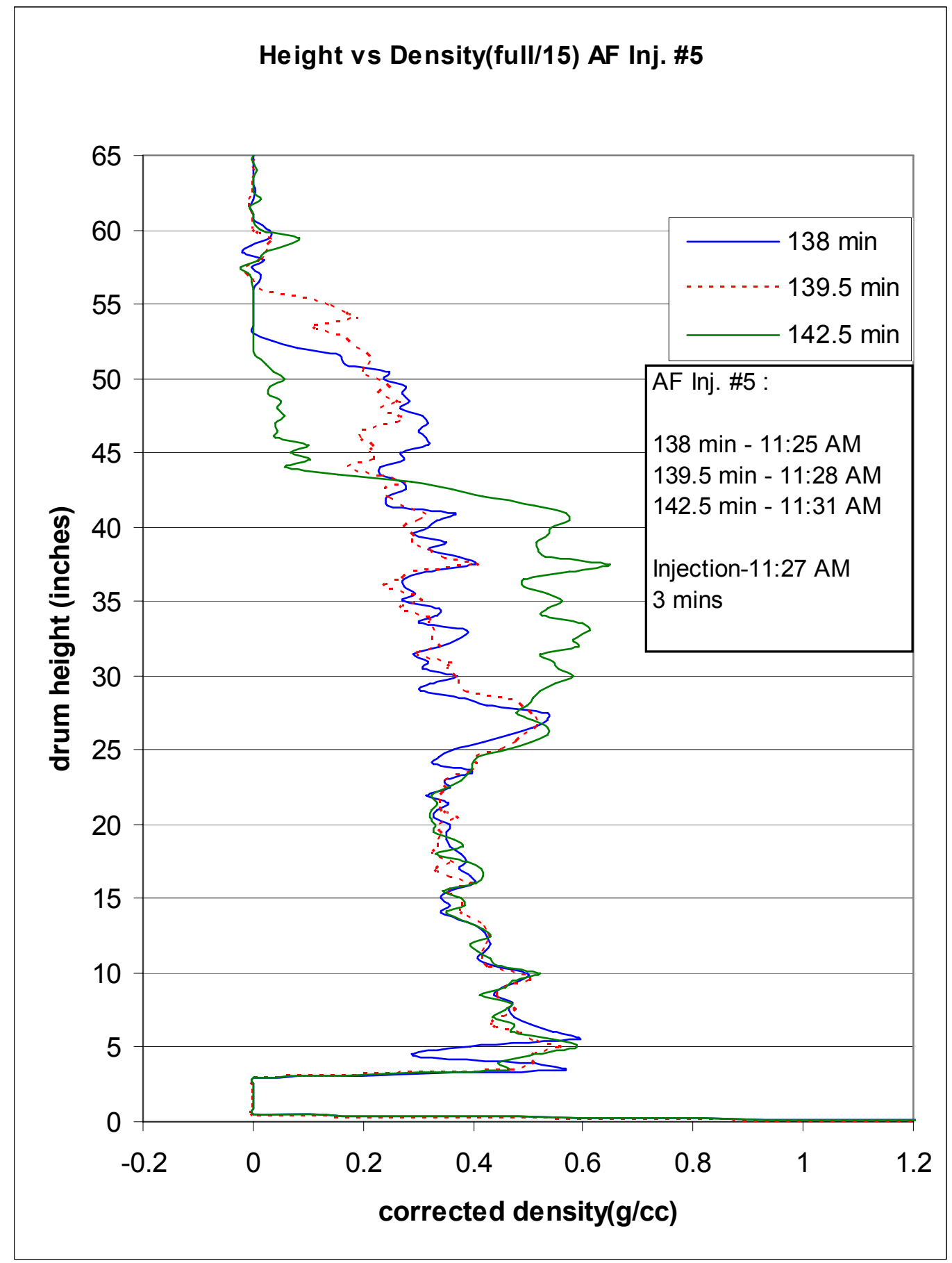

Figure 128 - PETRO 11 Antifoam Injection \#5 Response After 139 Minutes of Coking

The final run was with an antifoam/carrier mixture of $0.03 / 70$. This concentration was not effective in collapsing the foam. As a result, the antifoam/carrier was switched to $0.3 / 70$ and the test continued. 


\section{Impact of Antifoam on Coke Density}

Comparison of the gamma traces showed the density to increase with an increase in antifoam/carrier concentration. A similar trend in coke density was observed with the Suncor resid.

\section{Continuous vs. Feedline Injection}

Petrobras 13 and 14 were run to compare continuous overhead injection to continuous feedline injection using the 100,000 cSt antifoam. For these tests, antifoam was injected for 2 minutes and then shut off for 8 minutes. This injection procedure was repeated throughout the run. Plotted in each figure are 5 density traces, each at a different height in the drum. 2 traces are from the top of the drum while 3 traces are from the bottom of the drum. Note that as the foam is collapsed (decrease in density in upper two traces) there is a corresponding increase in the density at the bottom of the drum. Note the cyclical nature of the events. Better control was observed with feedline injection for the first 80 minutes; however, after that it was necessary to inject the antifoam overhead to control foaming. No explanation as to why this was necessary can be provided at this time. Further insight may be gained once the liquid and coke samples from this run are analyzed.

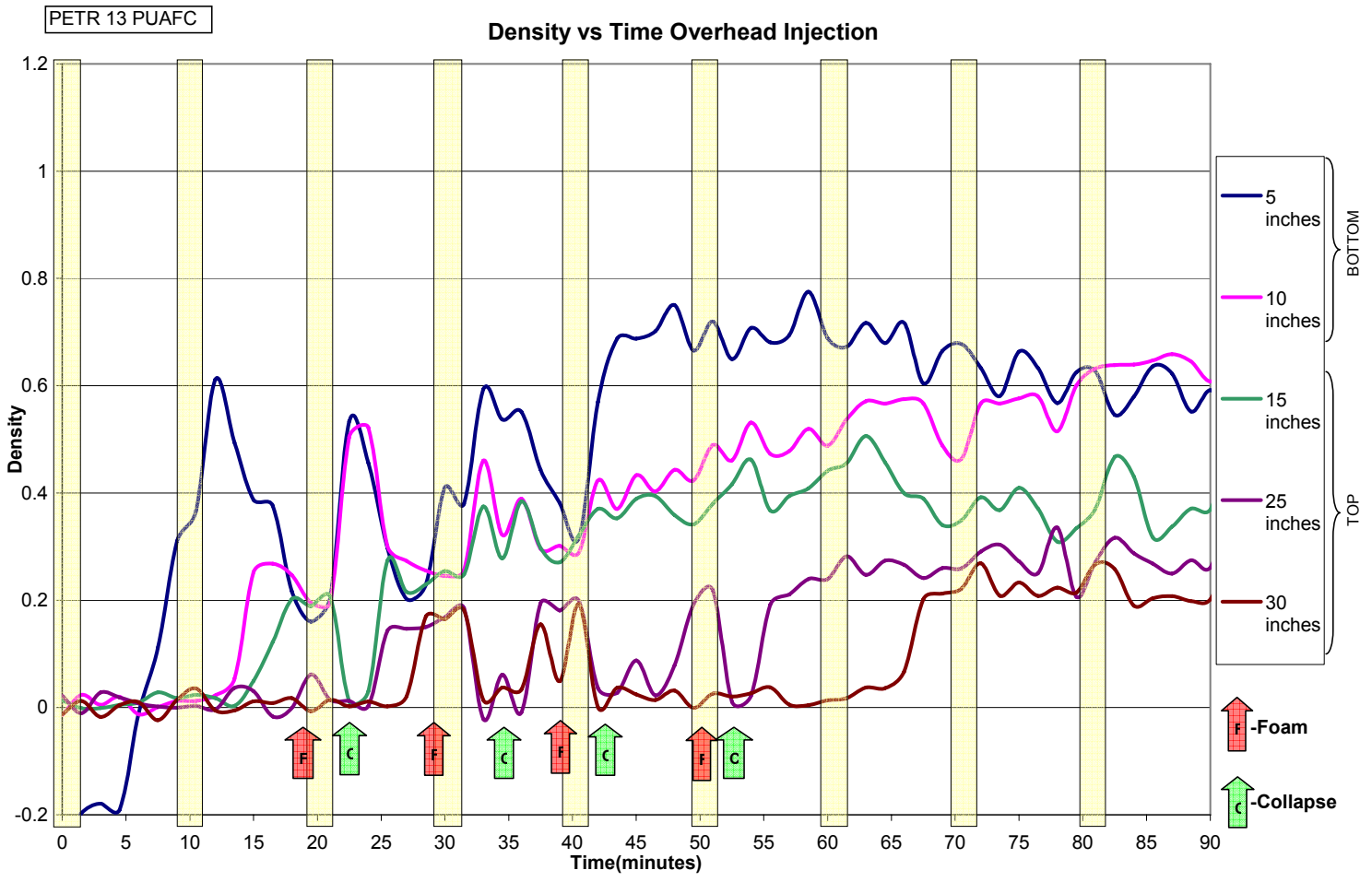

Figure 129 - Continuous Overhead Antifoam Injection For PETR 13 Run 


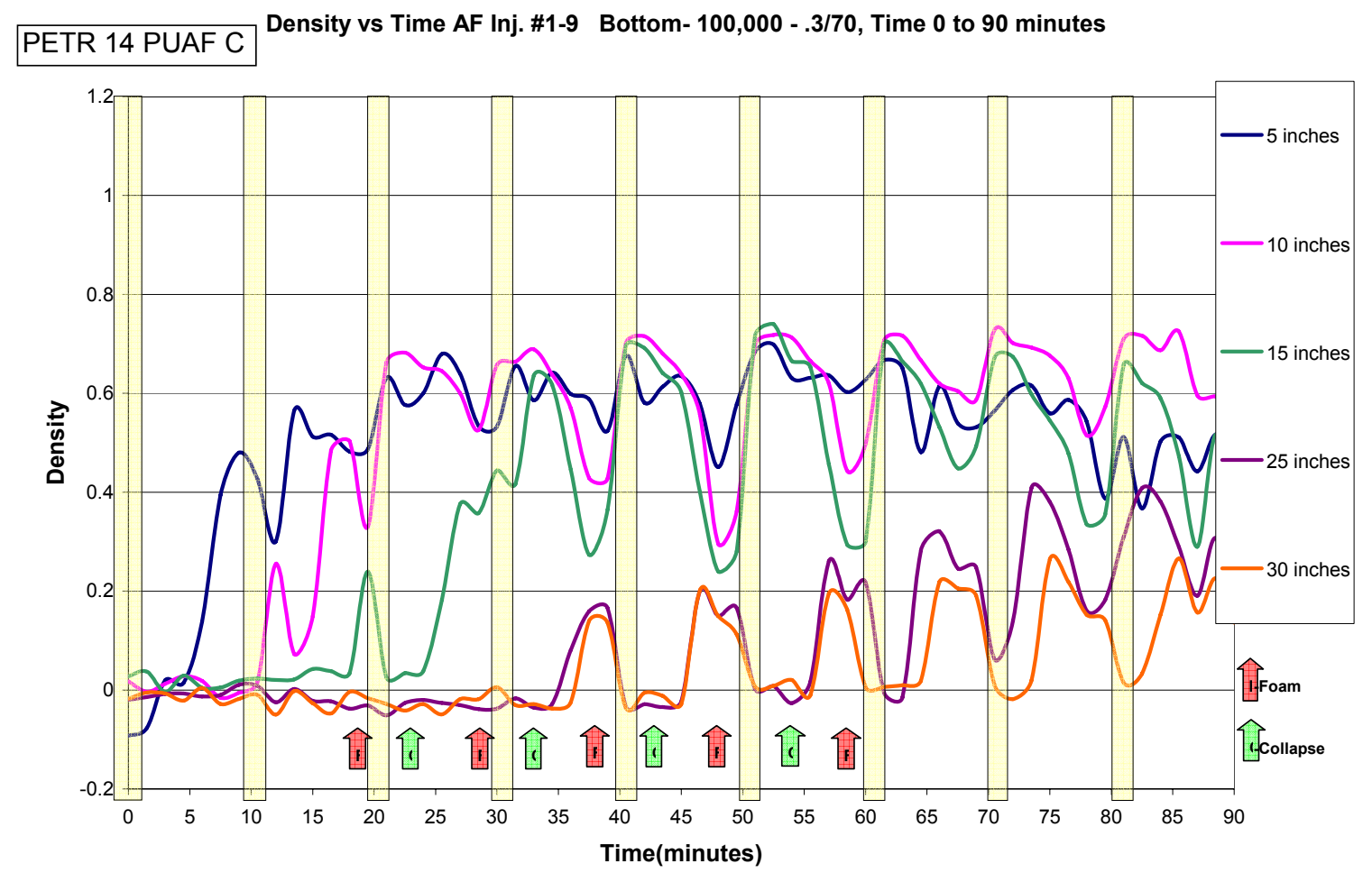

Figure 130 - Continuous Feedline Antifoam Injection for PETR 14 Run

A series of optimization tests was conducted to compare the effectiveness of the $600,000 \mathrm{cSt}$ antifoam to the $100,000 \mathrm{cSt}$ antifoam. The first test was begun using an antifoam/carrier concentration of $0.12 / 70$ mixture which is less than what is used commercially. As shown in Figure 131, suppression was obtained early in the run, but the injection period was 18 minutes rather than the 2 to 3 observed for the 100,000 cSt antifoam. Within minutes of shutoff, the drum began foaming again. From fear of foaming over, and the inability to process the data on the fly, we switched to the $100,000 \mathrm{cSt}$ antifoam to suppress the foaming. 


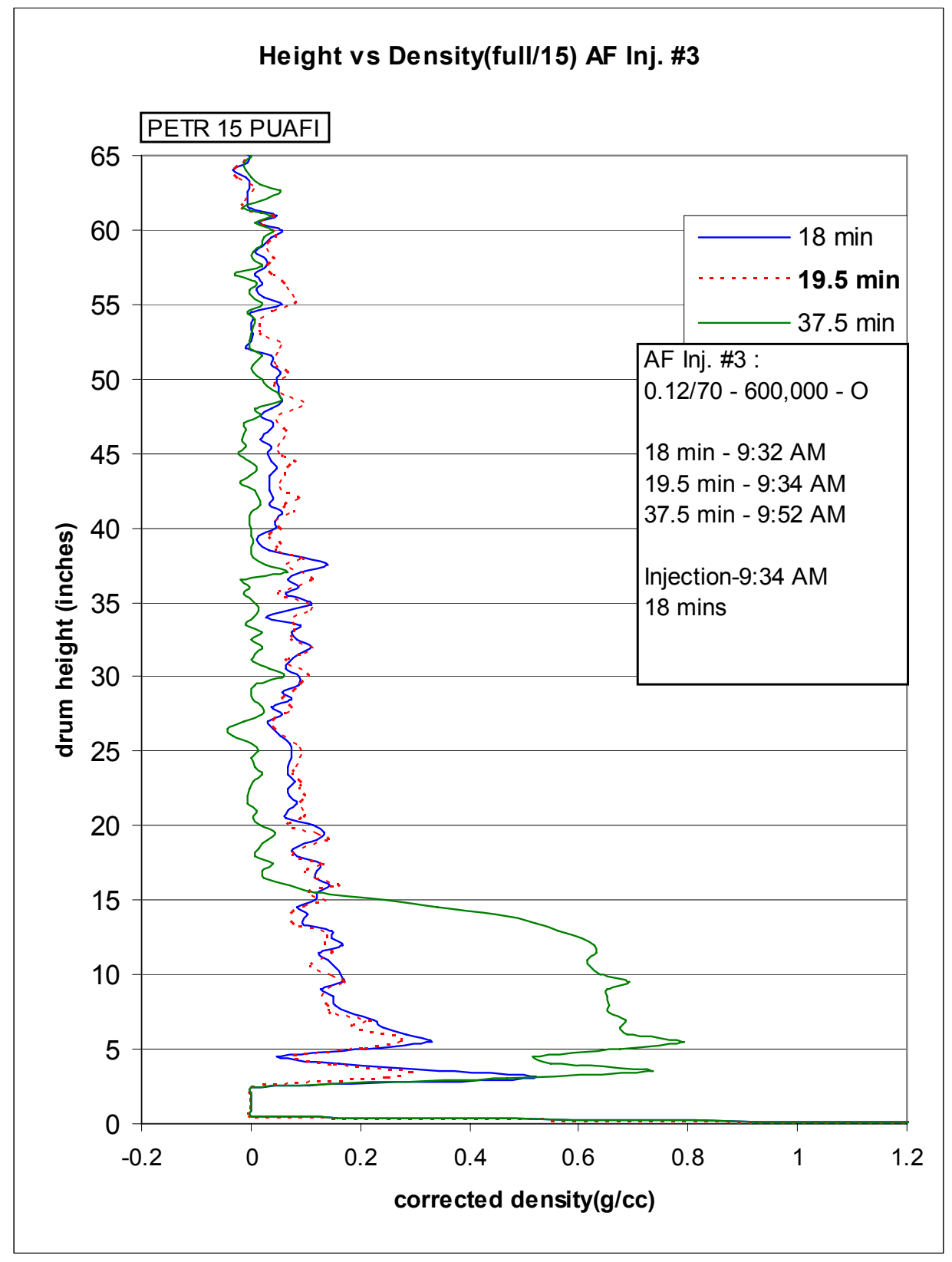

Figure 131 - PETR 15 - 600,000 cSt Antifoam Injection Response \#1 After 18 Minutes of Coking 


\section{Time to Rise and Time to Collapse}

It would be useful to have some sort of correlation between feed characteristics and overall foaming tendency in a coke drum. It has been hypothesized for years that feeds with higher levels of naphthenic acids will foam more severely. Correlations of foaming tendency with acid number, napthenate content by FTIR and asphaltene content will be undertaken. Asphaltene content is a feed parameter that is likely to correlate to foam stability.

Ranking foaming tendency will be attempted using one or more of the following objective indicators:

1. Total amount of defoamer used.

2. Total number of defoamer injections during a run, i.e. injection frequency

3. Speed of foam reappearance after defoamer injection (sort of a corollary of 2)

4. Time to formation of first foam front

Hopefully, more than one of these criteria will give the same rankings, which will build some confidence in the objective ranking. Subjective judgment of those who ran the tests will also be used to see if the subjective judgment generally agrees with the objective criteria. Comparisons will be made only across runs using similar defoamer injection methods.

Three resids have been studied, Petrobras, Chevron and Equilon. The data from these runs are plotted as density at a given height in the drum vs. time. Continuous Feedline and continuous overhead injection for the Chevron Resid using the 100,000 cSt antifoam is compared in Figure 133 and Figure 134. Note that after injection, the foam collapsed but within a short period of time foaming resumed. Figure 135 and Figure 136 show the results for collapsing the foam when a 600,000 cSt antifoam is used at an equivalent concentration to the $100,000 \mathrm{cSt}$ antifoam. Note that the time to rise was a lot longer than when the $100,000 \mathrm{cSt}$ antifoam was used. This observation provides support that at equivalent concentrations, fewer injections of antifoam would be required.

Continuous Feedline injection was utilized with the Equilon resid. As shown in Figure 137, little foaming was observed with this resid. Note that when continuous injection was used there appears to be an increase in the coke density. It would be interesting to conduct similar tests, but with increasing $\mathrm{cm}$ concentrations of antifoam to see if it compacts the coke density as discussed in the previous section. This study is in its early stages. Additional results will be presented in future reports. 


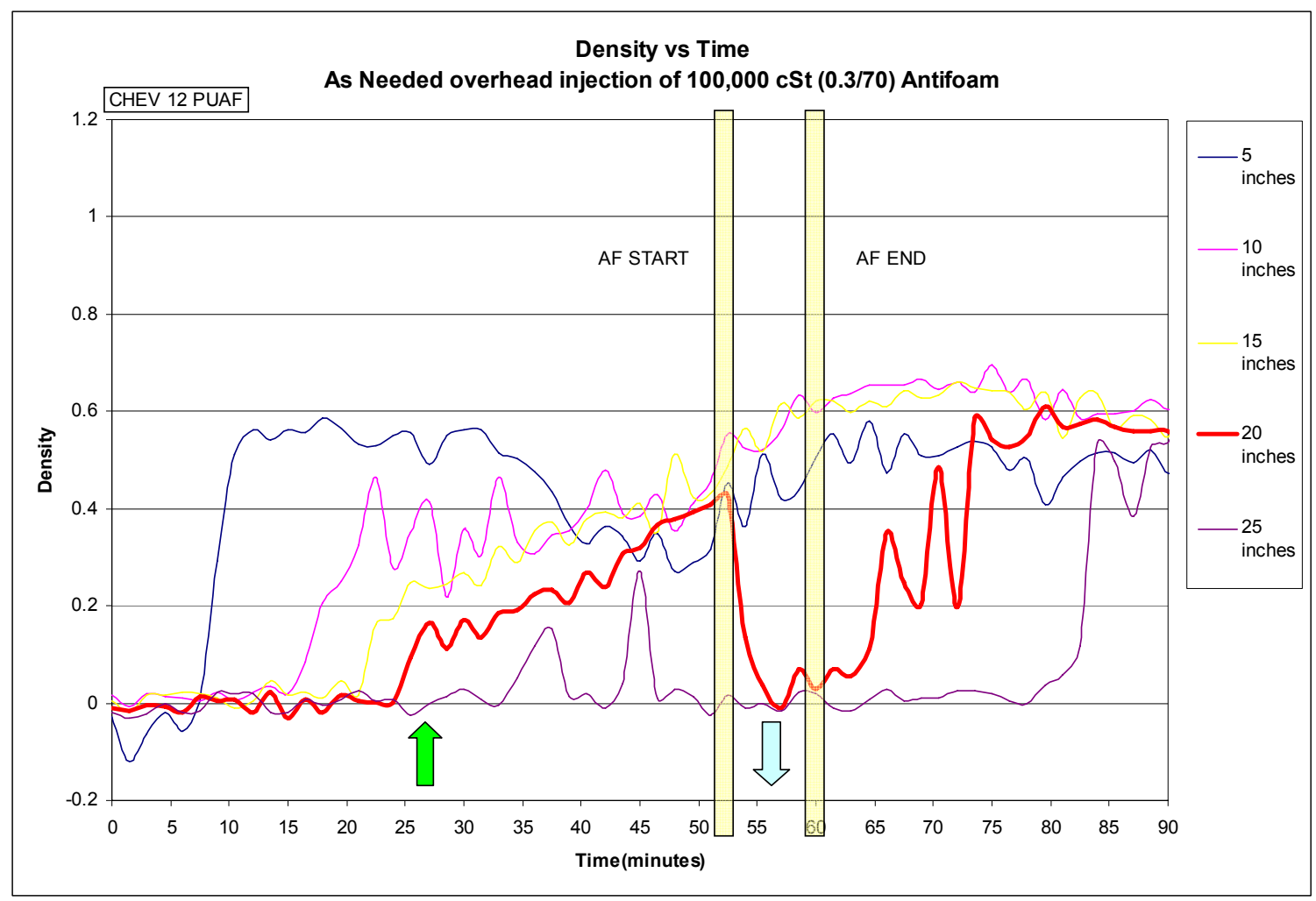

Figure 132 - Rise and Collapse of Foam for CHEV 12 PUAFI

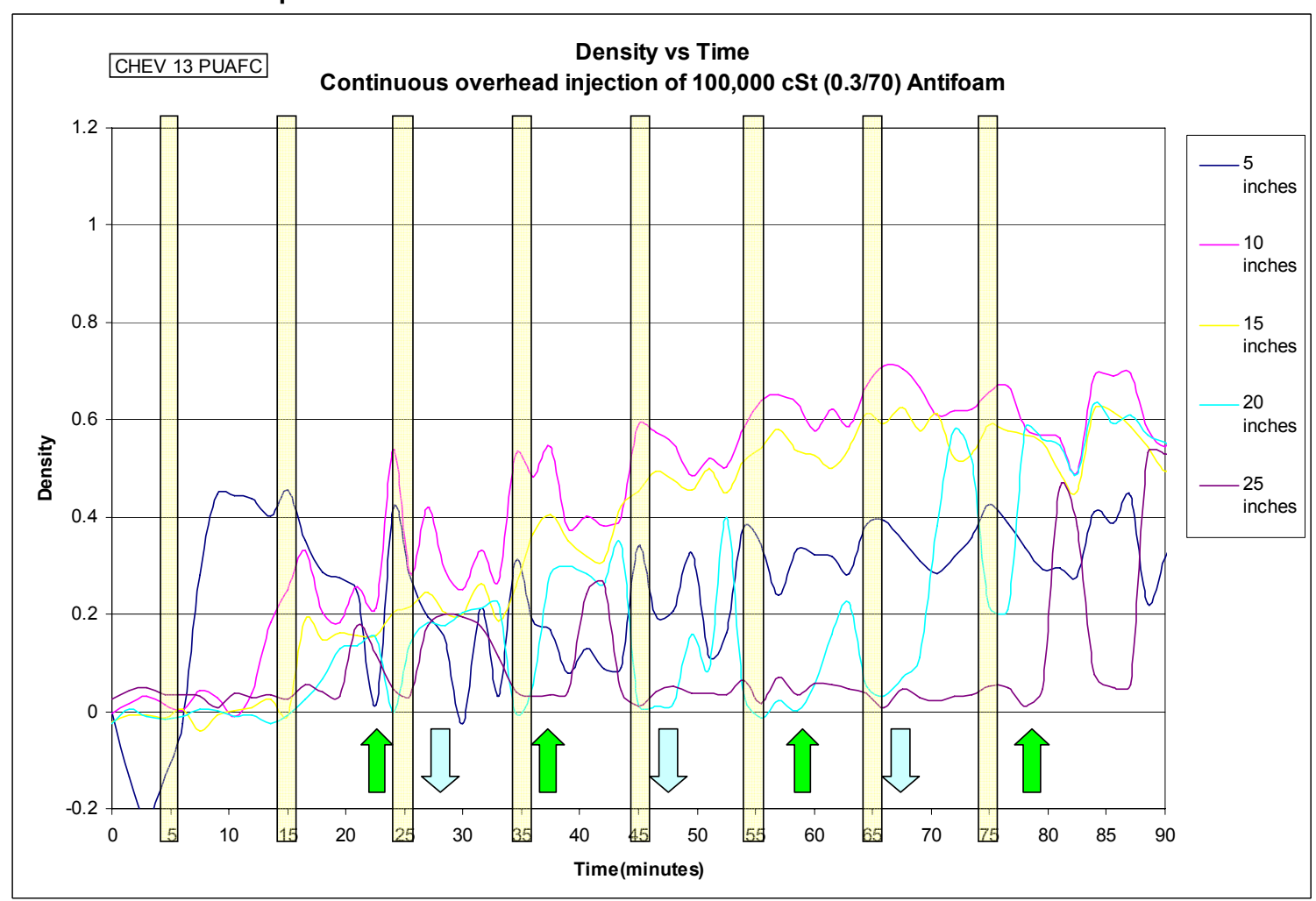

Figure 133 - Rise and Collapse of Foam for CHEV 13 PUAFC 


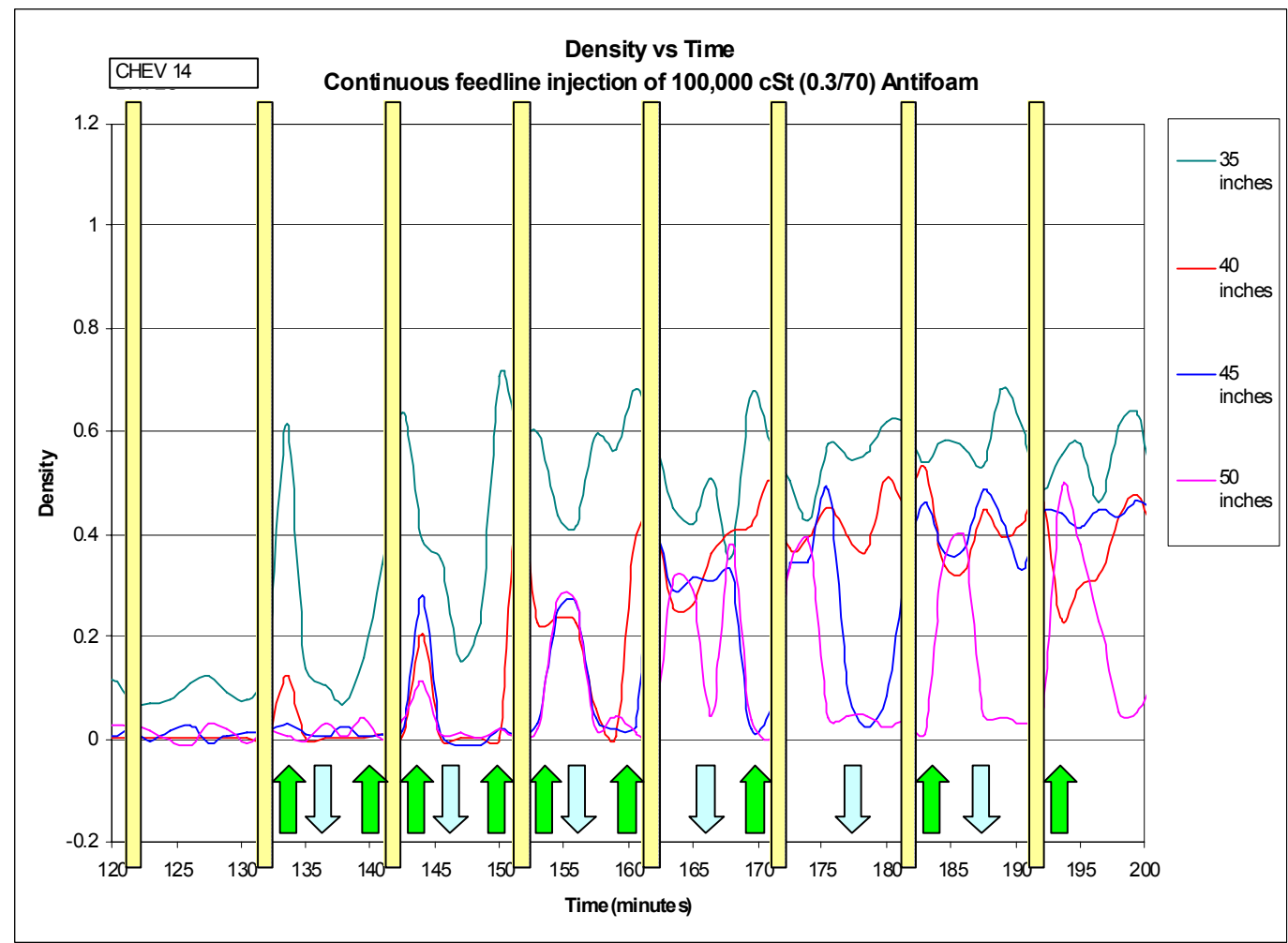

Figure 134 - Rise and Collapse of Foam for CHEV 14 PUAFC

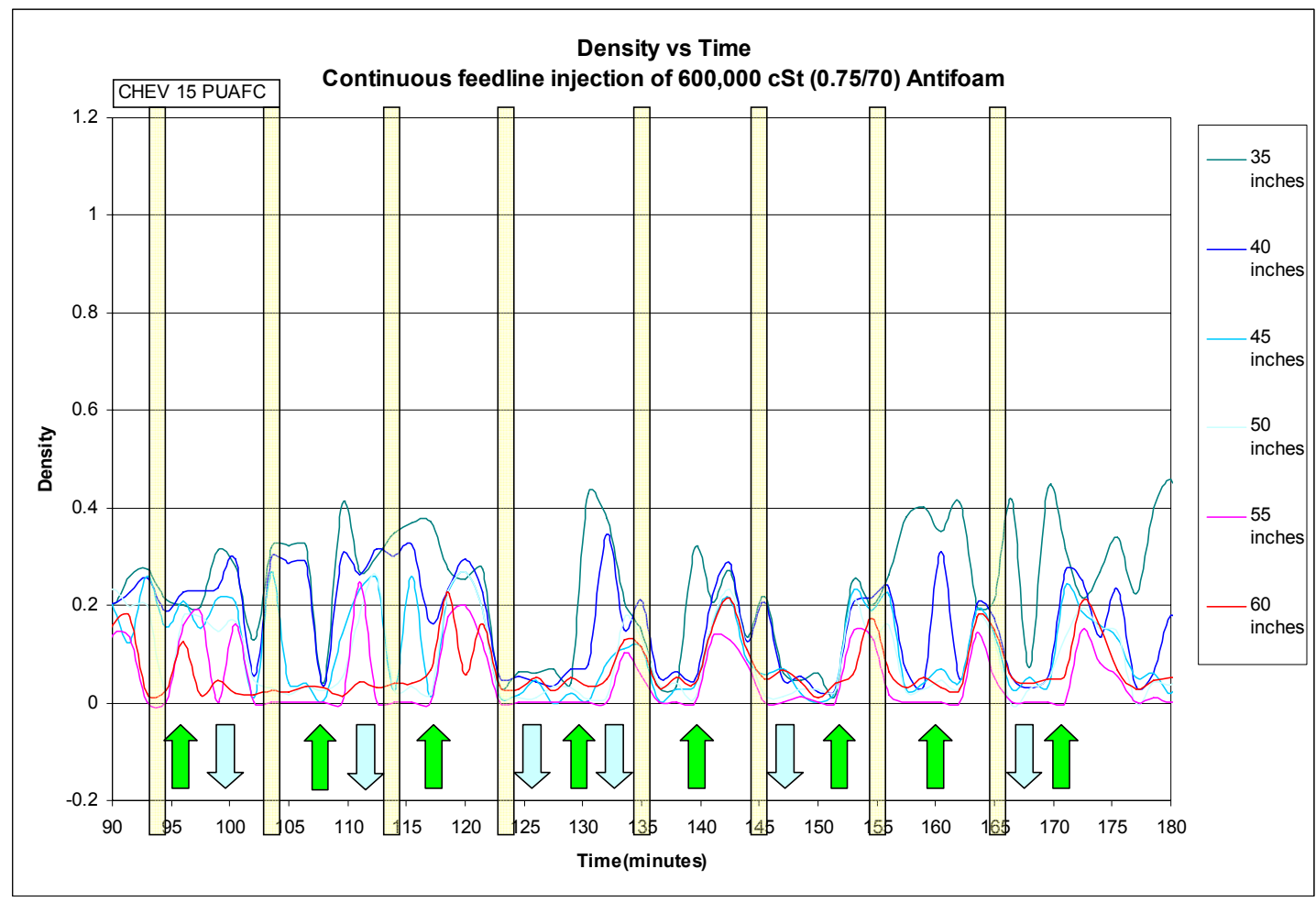

Figure 135 - Rise and Collapse of Foam for CHEV 15 PUAFC 


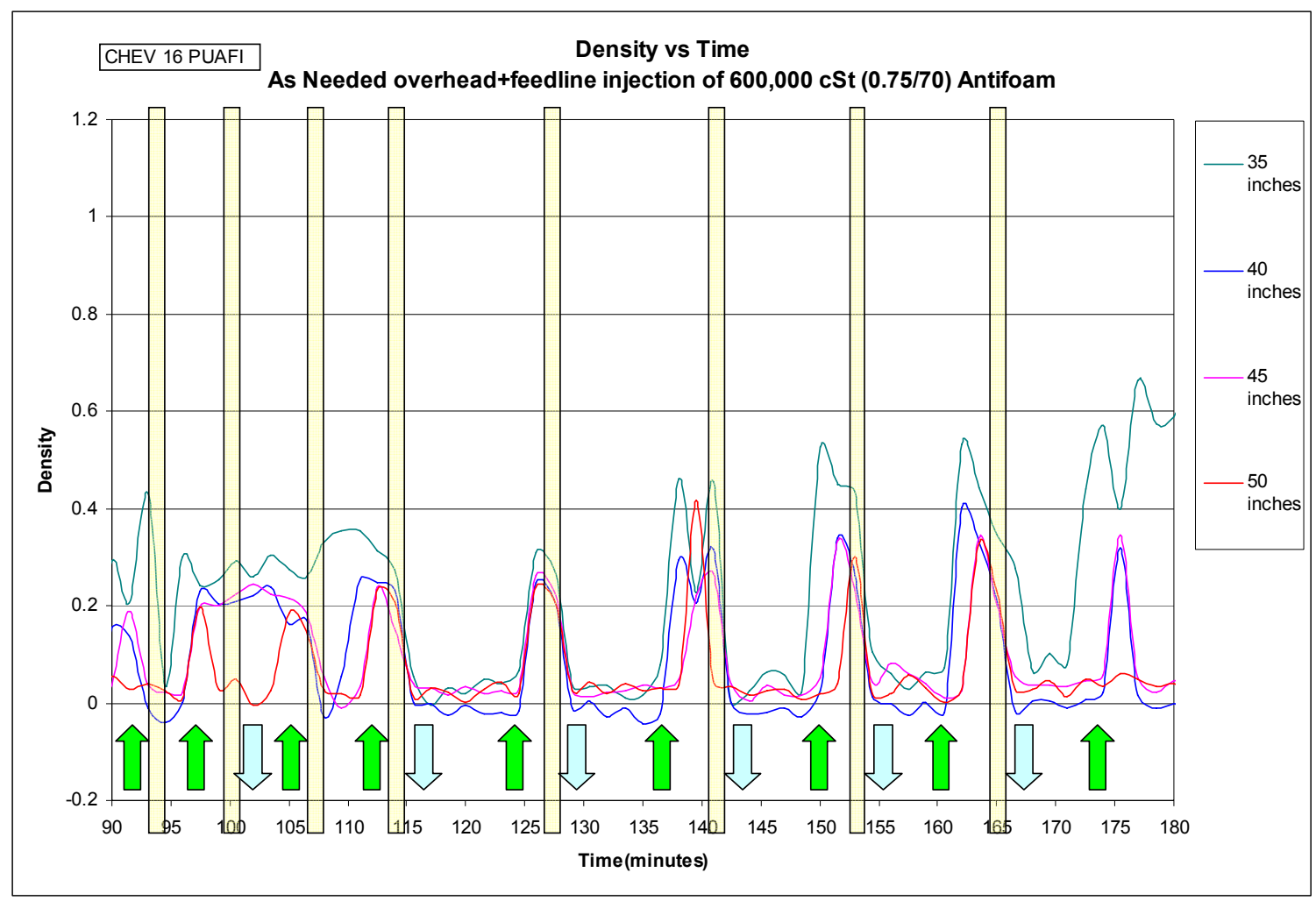

Figure 136 - Rise and Collapse of Foam for CHEV 16 PUAFI

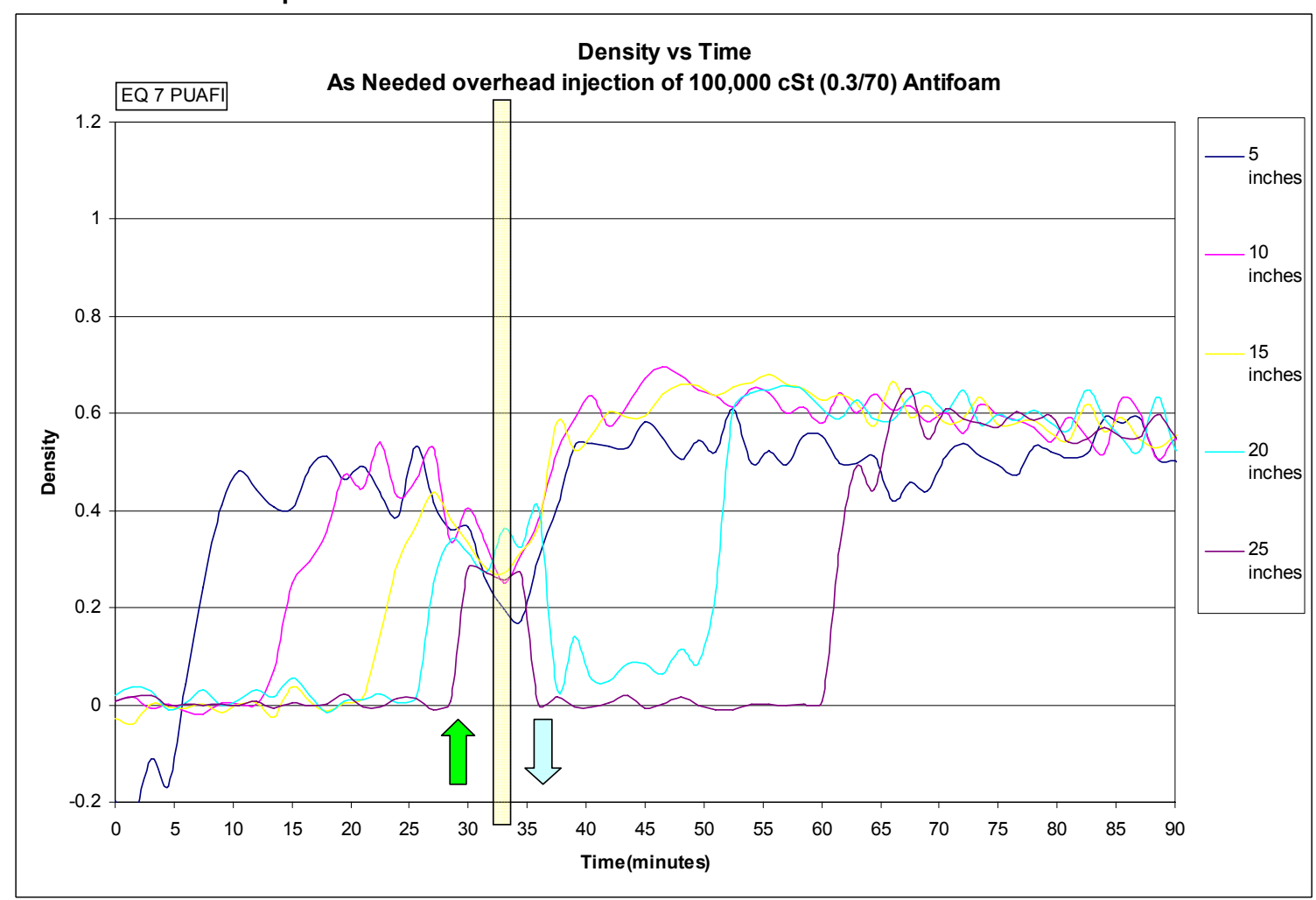

Figure 137 - Rise and Collapse of Foam for EQU 7 PUAFI 
The University of Tulsa

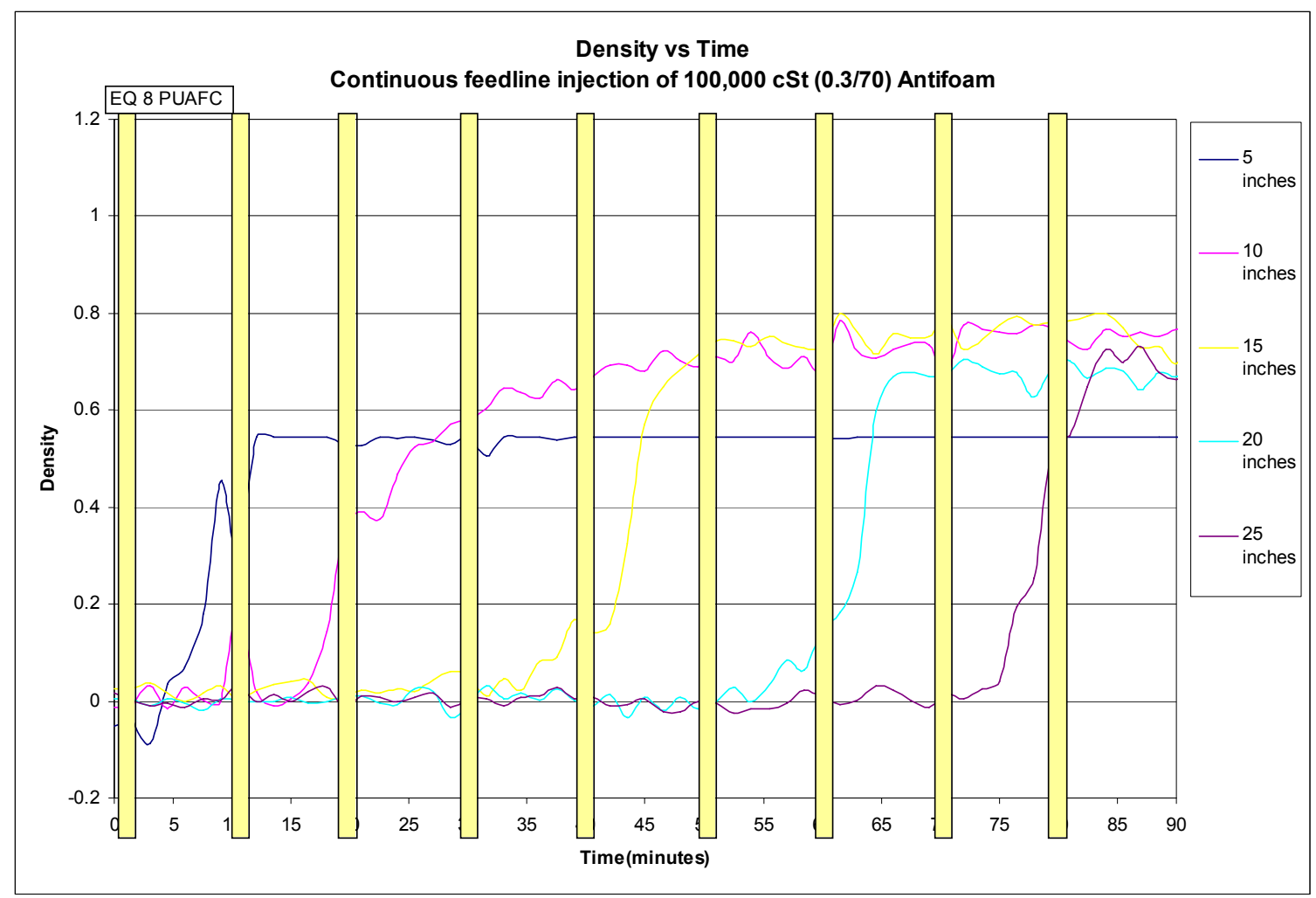

Figure 138 - Foam was not observed during EQU 8 PUAFC 


\section{Quantification of Bubbly Liquid and Foam Layers}

Different runs are considered to depict the build up of coke, bubbly liquid and foam layers with time. The data of resid density at different heights inside the drum is provided by the Gamma Densitometer. At each antifoam injection, a plot of drum height (inches) versus corrected density ( $\mathrm{gm} / \mathrm{cc}$ ) depicts the foam volume collapse at that particular antifoam injection. Based on the density values the height of coke, bubbly liquid and foam layer is calculated. The basic criteria for density values for coke is in the range of $0.56(\mathrm{gm} / \mathrm{cc})$ to $0.6(\mathrm{gm} / \mathrm{cc})$ and above, bubbly liquid layer is in the range of $0.35(\mathrm{gm} / \mathrm{cc})$ to $0.45(\mathrm{gm} / \mathrm{cc})$ and foam is in the range of $0.2(\mathrm{gm} / \mathrm{cc})$ to $0.35(\mathrm{gm} / \mathrm{cc})$. Operator's observation during the run is taken into consideration. Respective drum height of coke, bubbly liquid and foam layer are plotted against time to show the build up of these layers with coking time. It indicates the foaming characteristic of resids with coking times. The studies of type and method of antifoam used can be enhanced by observing the formation of these layers with time. The following plots show the collapse of foam during that particular antifoam injection. The data is plotted before the antifoam injection, at injection and after injection to determine the foam volume collapse and efficacy of antifoam during that injection. Similarly the densities and drum heights of coke, bubbly liquid layer and foam are calculated for Chevron, Equilon and Petrobras runs.

CHEV 12 PUAFI was run at a temperature of $900^{\circ} \mathrm{F}$, a pressure of $15 \mathrm{psig}$ and at a feed rate 3600 $\mathrm{gm} / \mathrm{hr}$. This run was an as-needed overhead injection of $100,000 \mathrm{cSt}(0.3 / 70)$ antifoam. A total of $147.25 \mathrm{cc}$ of antifoam was injected during the run. The first injection of antifoam was made 53 minutes into the run and it was continued for seven minutes (see Figure 139). It is seen that the foam collapsed within 4 minutes of injection. The second injection was made 149 minutes into the run for a total time of 4 minutes (see Figure 140). The collapse of the foam can be seen at the end of the injection. The third injection of antifoam was made 169 minutes into the run for a total time of 4 minutes (see Figure 141). The foam collapse can be seen at the end of this injection. The fourth injection was made 184 minutes into the run for a total time of 3 minutes (see Figure 142). Injection \# 5 was made 196 minutes into the run for a total time of 3 minutes (see Figure 143). Substantial collapse of foam was seen during this injection. There was a rise in the foam volume during injection \# 6 (see Figure 144), but the foam collapsed at the end of the injection. Injection \# 7 was made 237 minutes into the run for a total time of 5 minutes (see Figure 145). Around 10 inches of foam drum height collapse was seen during this injection. The last injection, injection \# 8 was made 296 minutes into the run during the steam strip for a total time of 6 minutes (see Figure 146). A total of $22.75 \mathrm{cc}$ of antifoam was injected during the steam strip process.

Figure 149, Figure 147 and Figure 148 show the buildup of coke, bubbly liquid and foam as a function of time for Chevron runs 12 through 14 respectively. These plots show a foam layer that is 7 to 10 inches thick. Also note for Chevron 13 where continuous overhead injection was used there was a collapse of foam for a period up to 50 minutes during the run. Being that this was a continuous overhead injection run, more antifoam was injected than what was needed. Similar results were seen when continuous Feedline injection shown in Figure 148.

This data is plotted in Figure 150 and Figure 151. For the Equilon resid the foam layer was very small and/or was not detectable as shown in Figure 150 and Figure 151.

A much thicker foam layer, approximately 20 inches was determined for the Petrobras resid as shown in Figure 152 through Figure 155. 


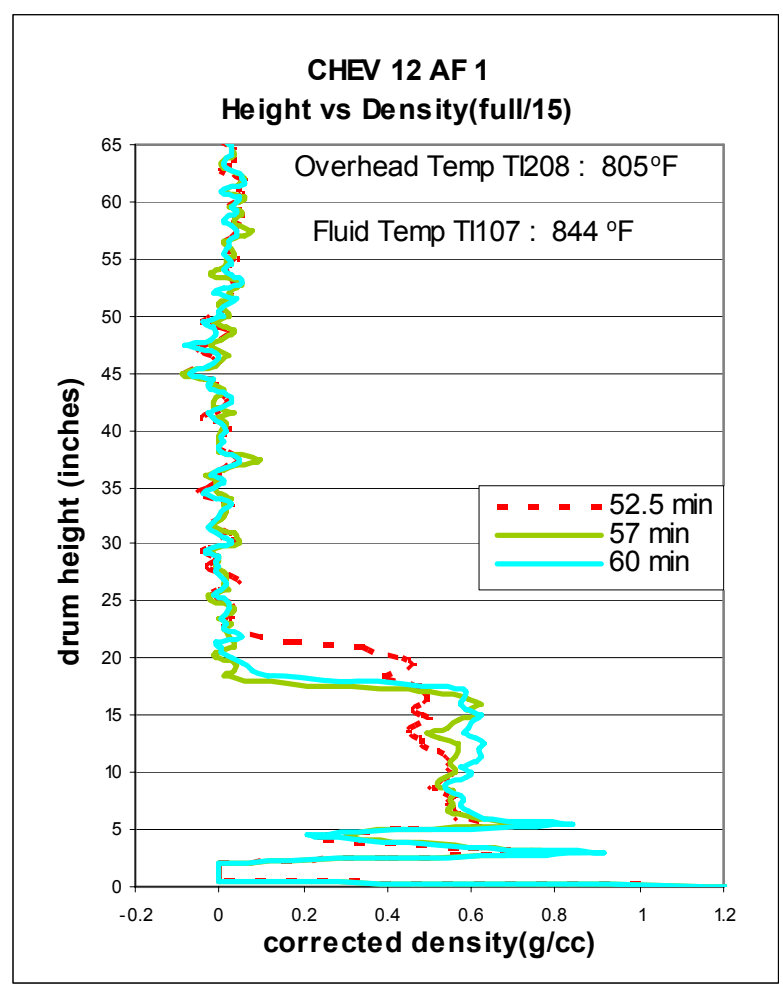

Figure 139 - Chev 12 PUAFI, Injection \# 1

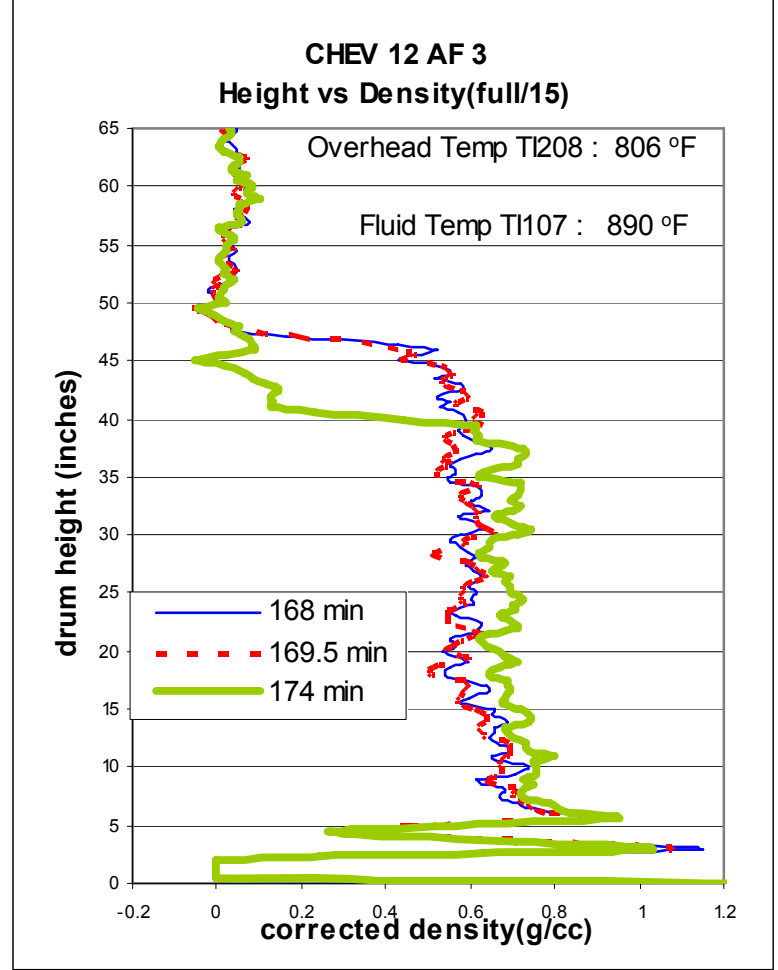

Figure 141 - Chev 12 PUAFI, Injection \# 3

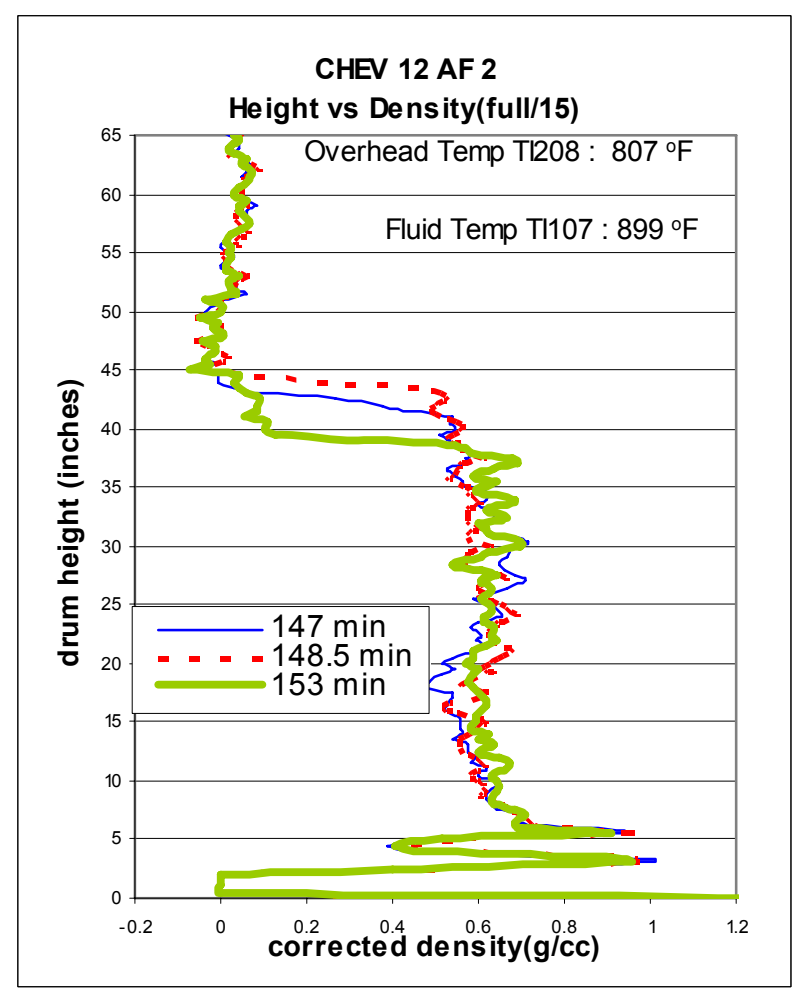

Figure 140 - Chev 12 PUAFI, Injection \# 2

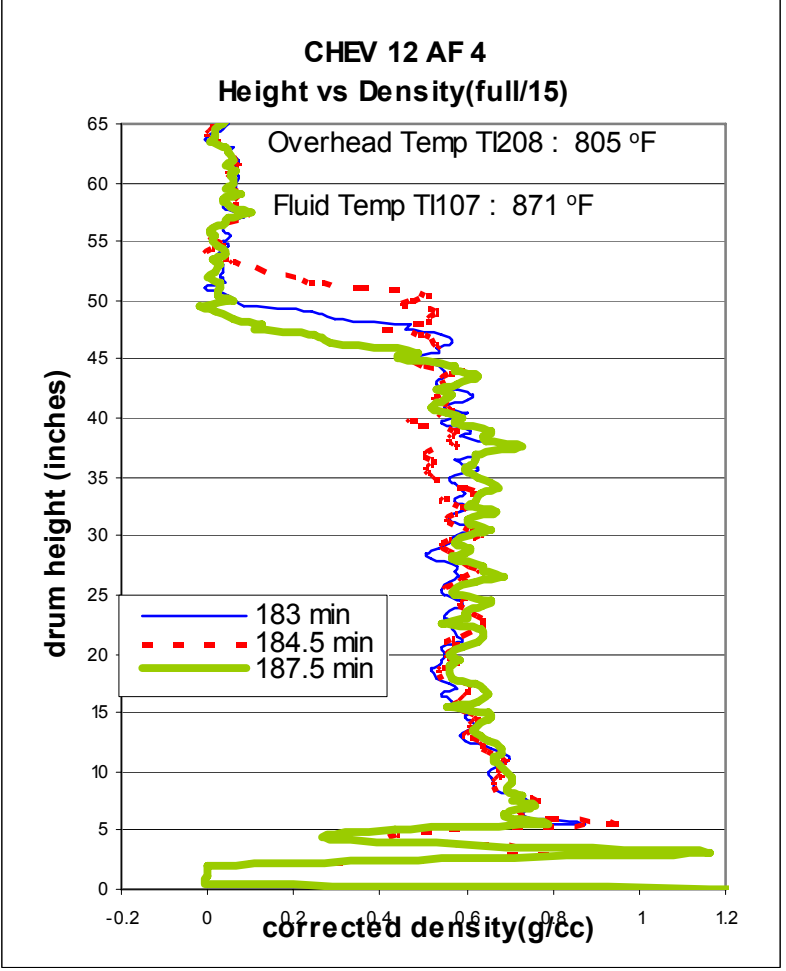

Figure 142 - Chev 12 PUAFI, Injection \# 4 


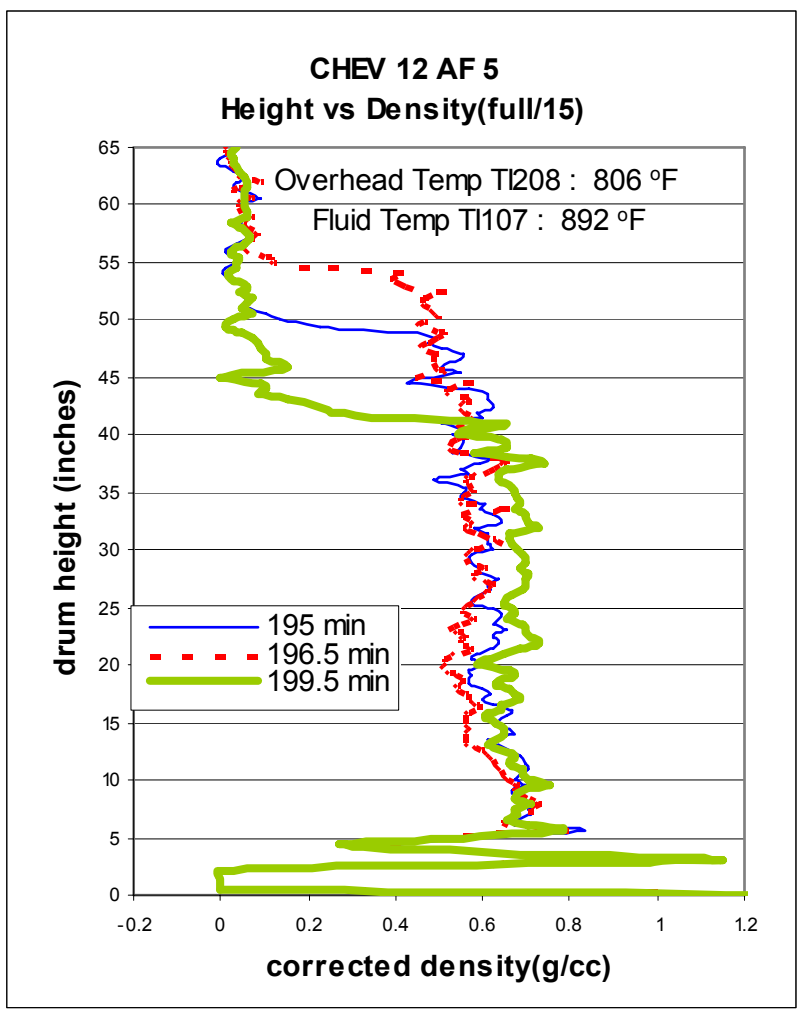

Figure 143 - Chev 12 PUAFI, Injection \# 5

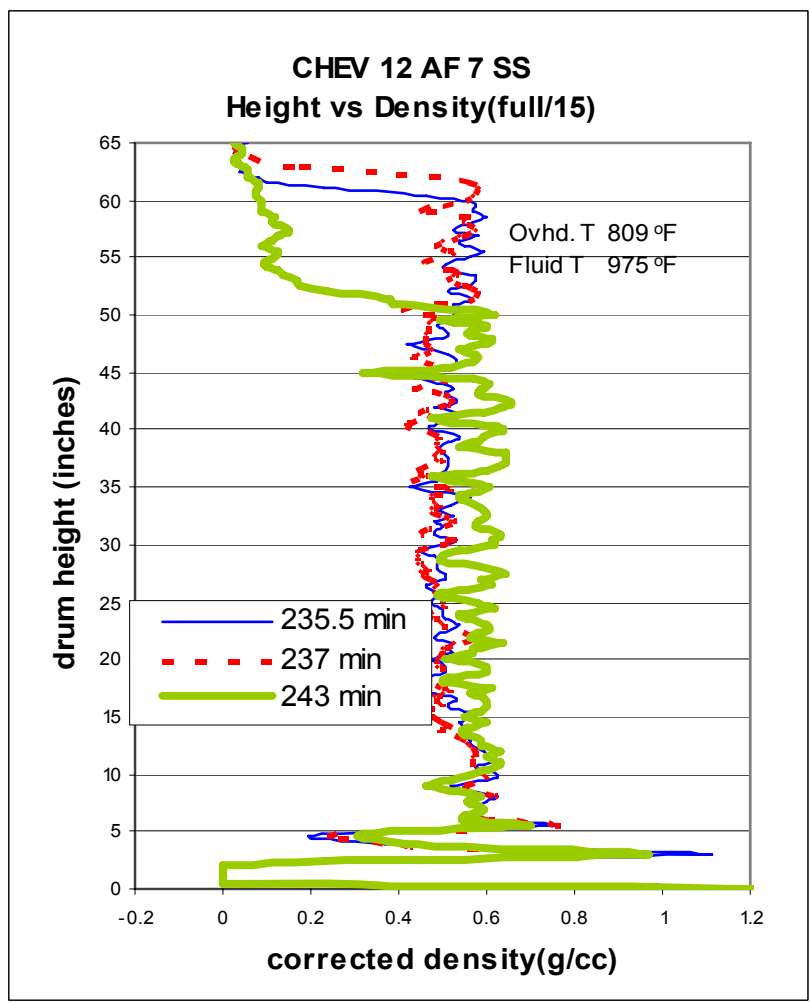

Figure 145 - Chev 12 PUAFI, Injection \# 7

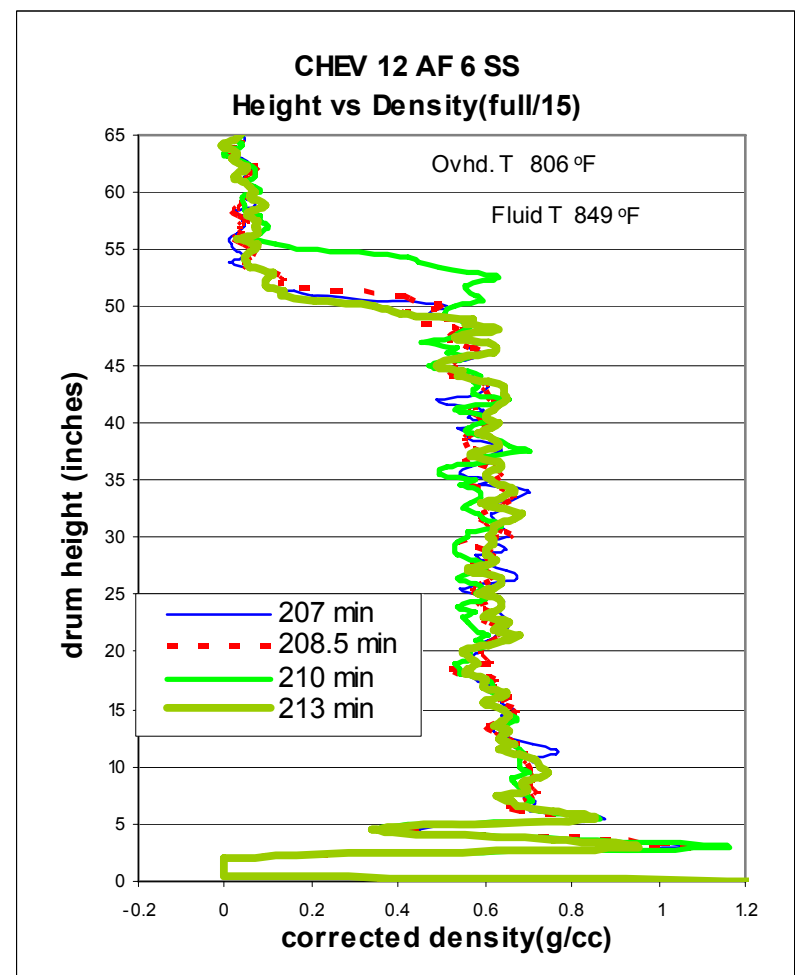

Figure 144 - Chev 12 PUAFI, Injection \# 6

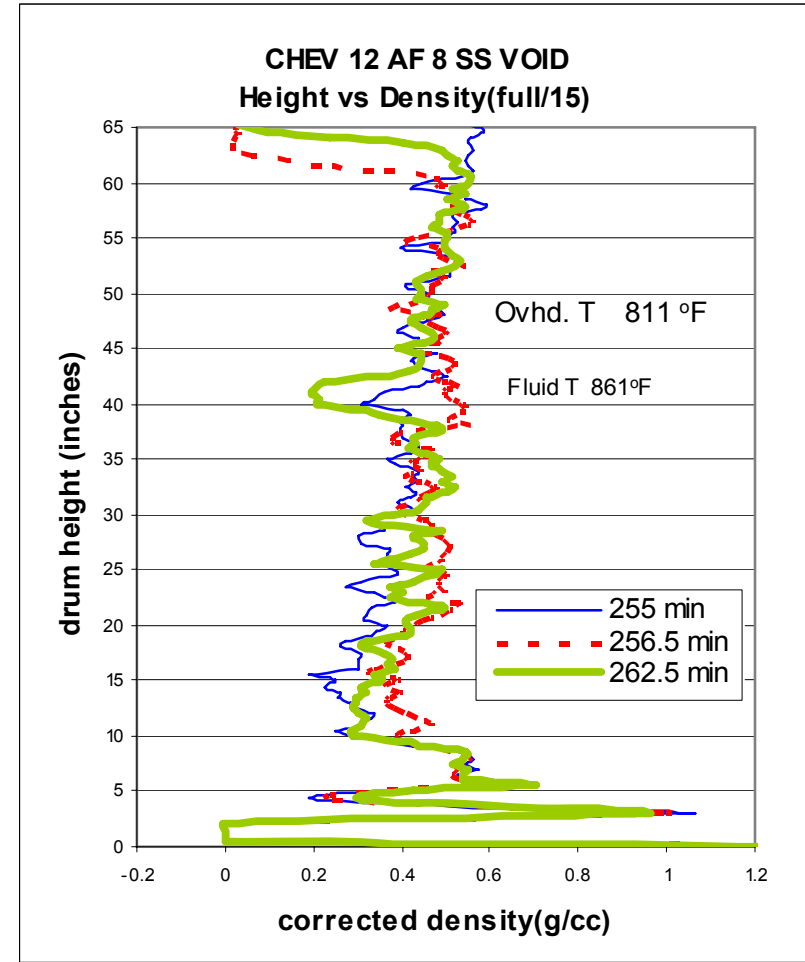

Figure 146 - Chev 12 PUAFI, Injection \# 8 


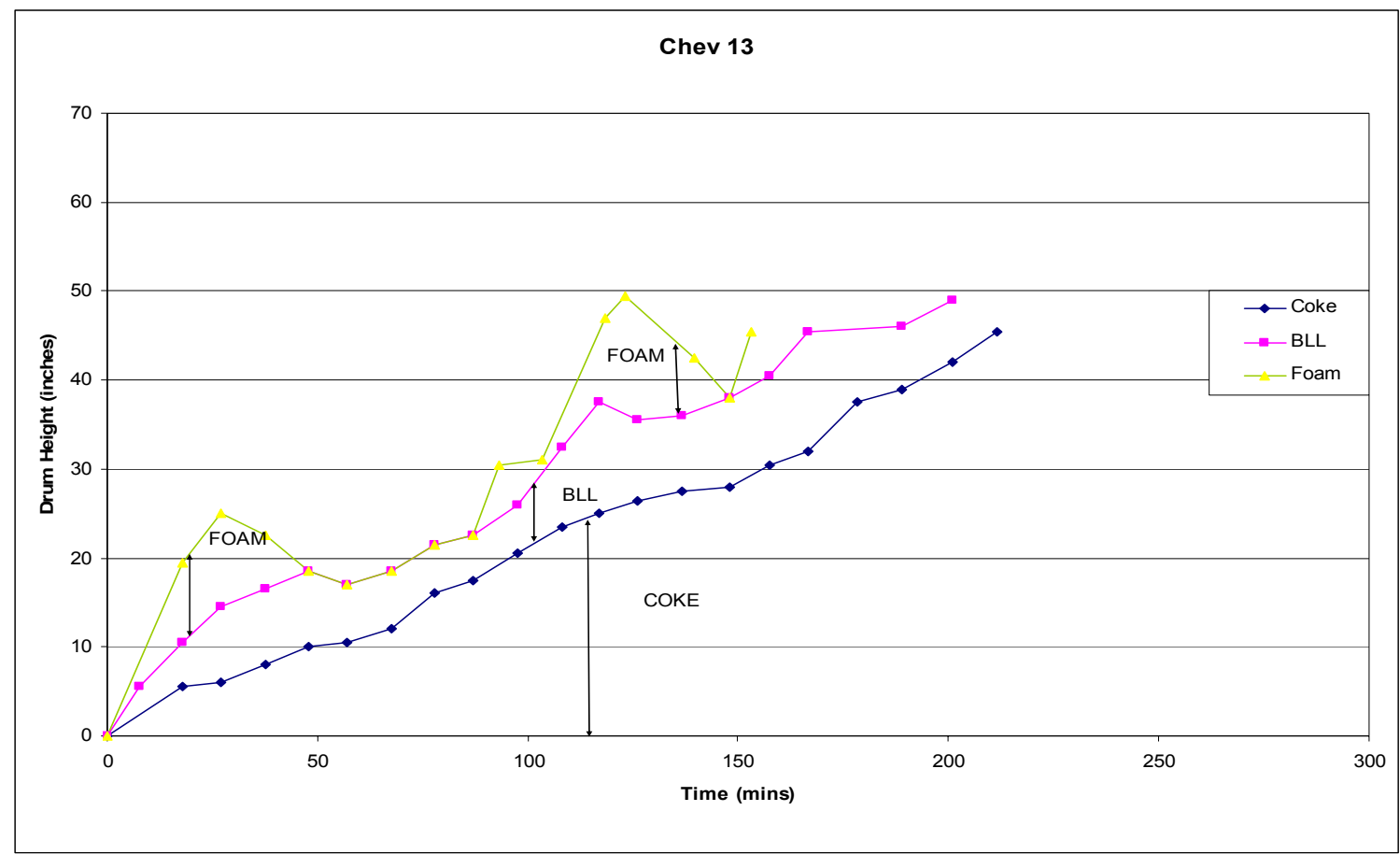

Figure 147 - Build-up of coke, bubbly liquid and foam layer with coking time for CHEV 13 PUAFC

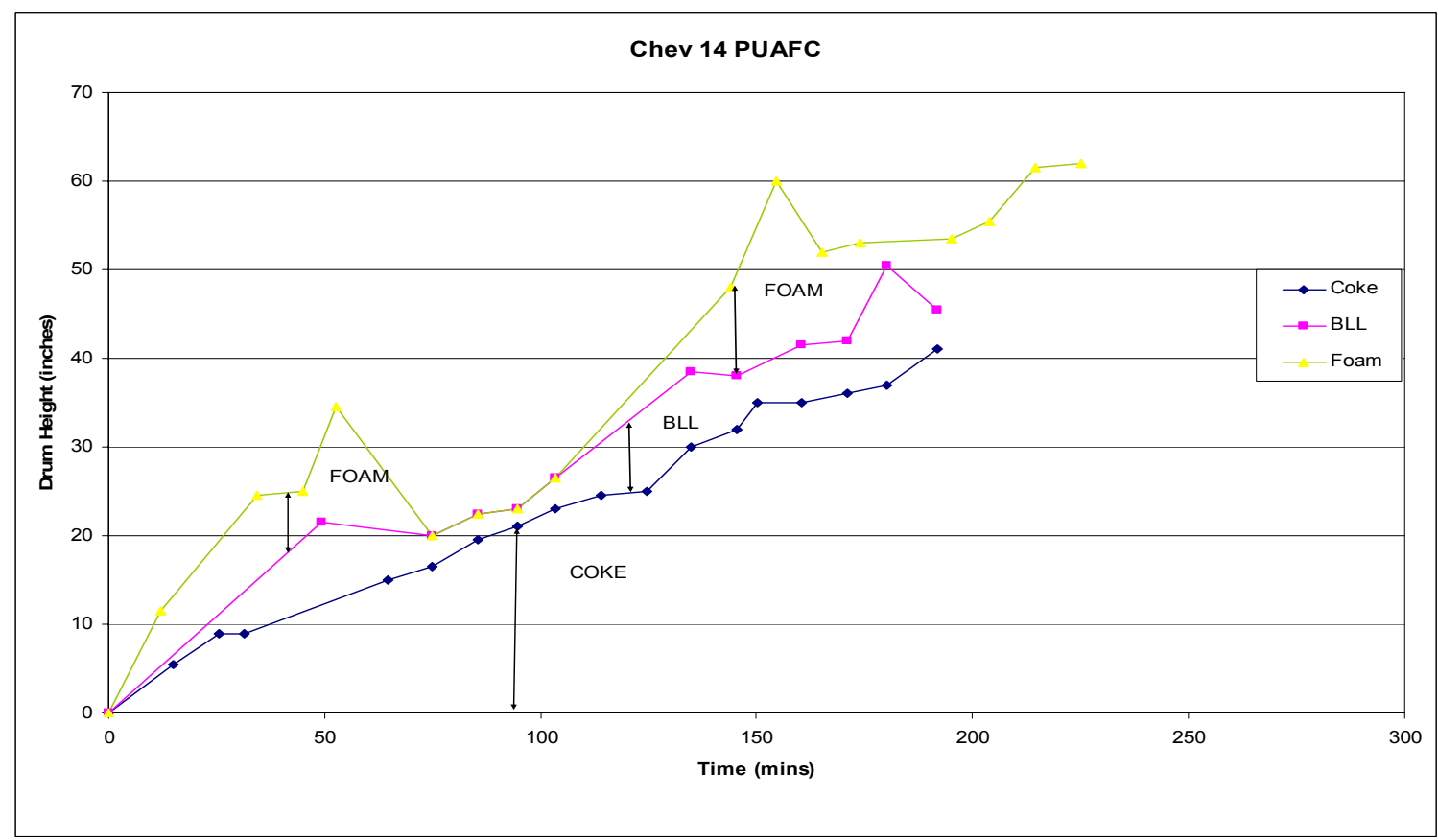

Figure 148 - Build-up of coke, bubbly liquid and foam layer with coking time for CHEV 14 PUAFC 


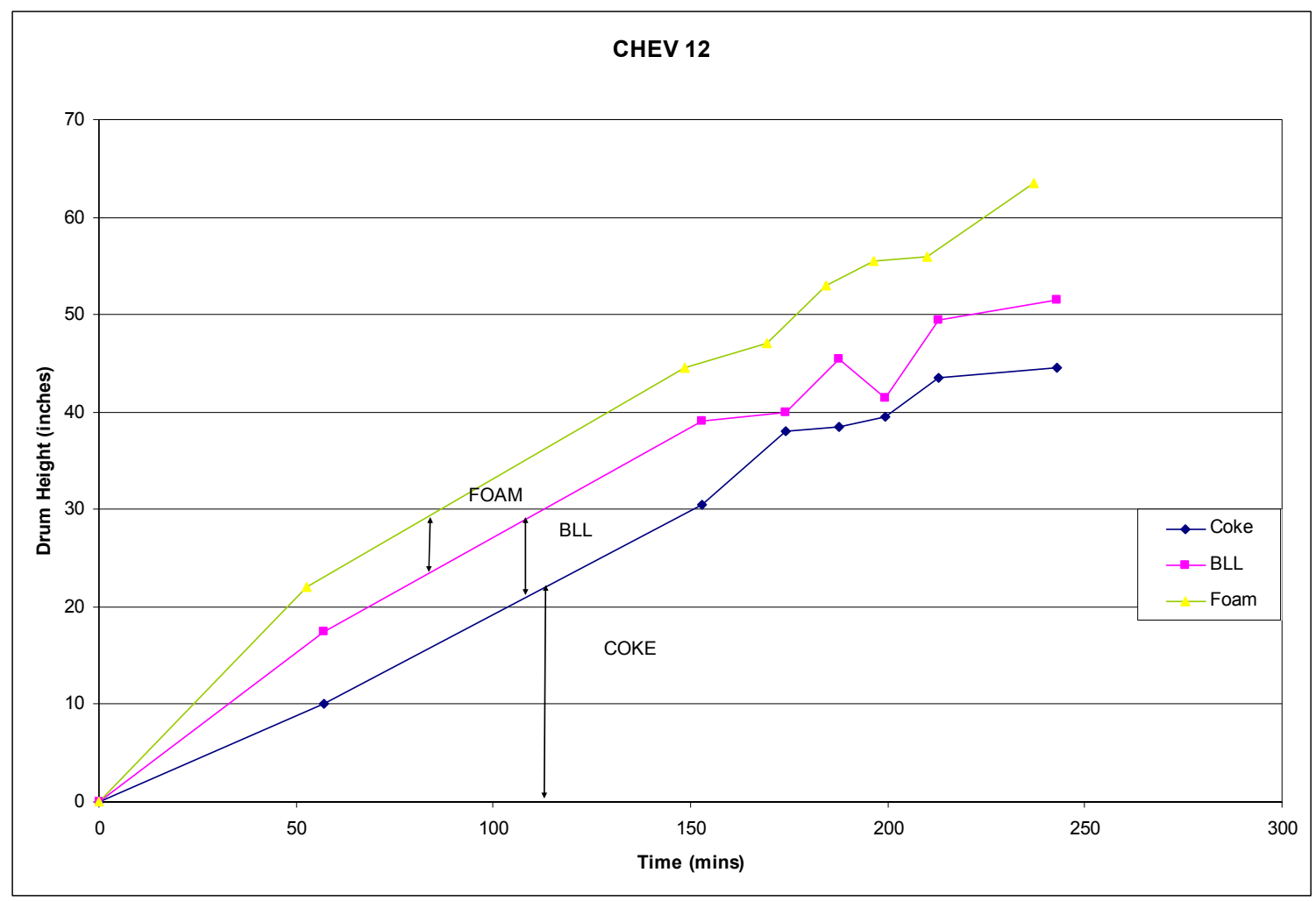

Figure 149 - Build-up of coke, bubbly liquid and foam layer with coking time for CHEV 12 PUAFI 


\section{Equilon Runs:}

EQU 5 run was carried out at a temperature of $930^{\circ} \mathrm{F}$, a pressure of $40 \mathrm{psig}$ and a feed rate of $3600 \mathrm{gm} / \mathrm{hr}$, whereas EQU 6 run was carried out at a temperature of $900^{\circ} \mathrm{F}$, a pressure of $40 \mathrm{psig}$ and a feed rate of $3600 \mathrm{gm} / \mathrm{hr}$. EQU 5 was an as-needed overhead injection of 100,000 cSt (30/70) antifoam and EQU 6 was an as-needed feedline injection of 100,000 cSt (30/70) antifoam. As can be seen in Figure 80, Equilon required more heat input to the feedline to attain the higher temperature and the overhead temperature was very high compared to EQU 6. Run EQU 6 required less heat input to the feedline but the overhead temperature dropped remarkably thereby stripping more during the steam strip.

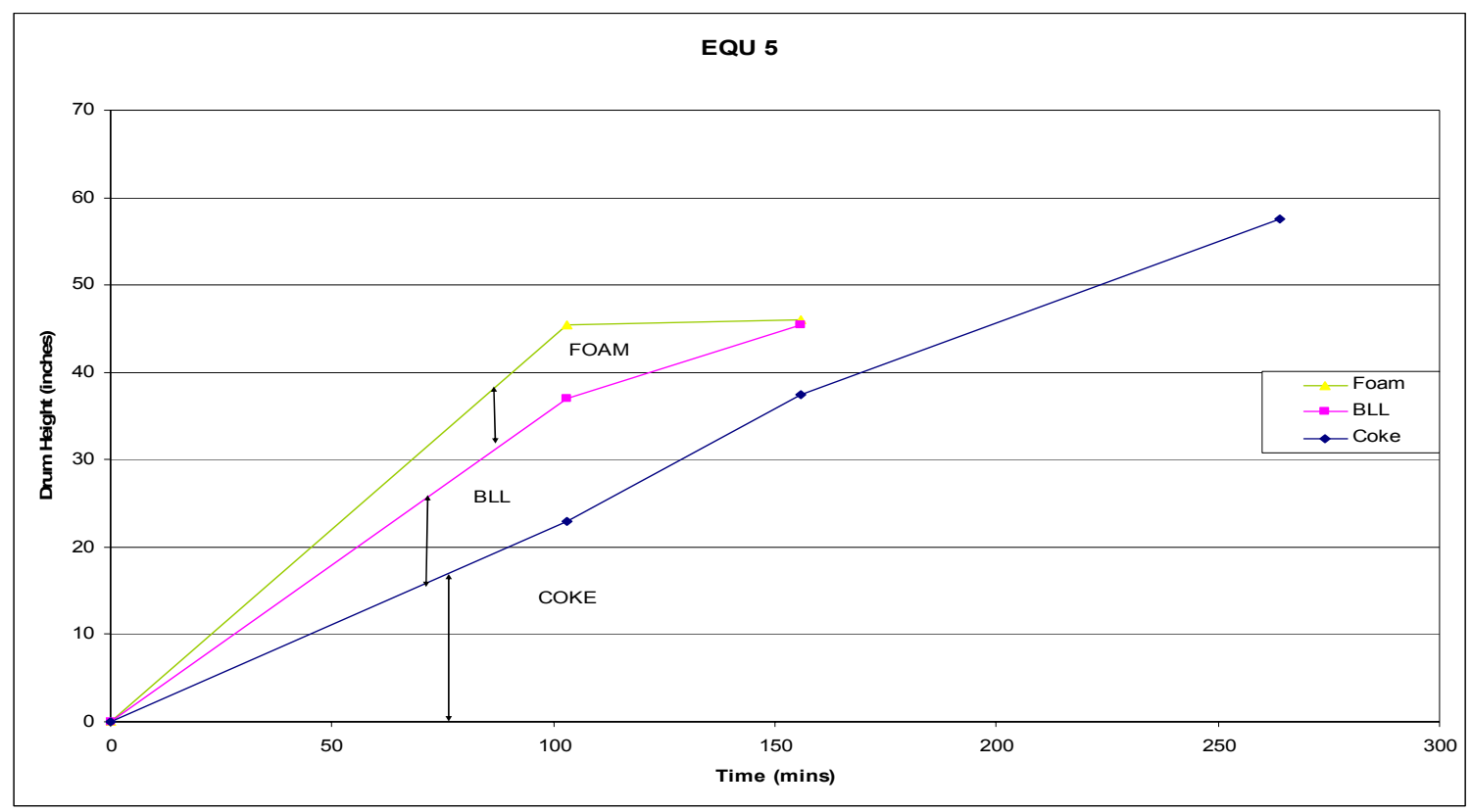

Figure 150 - Build-up of coke, bubbly liquid and foam layer with coking time for EQU 5 PUAFI 


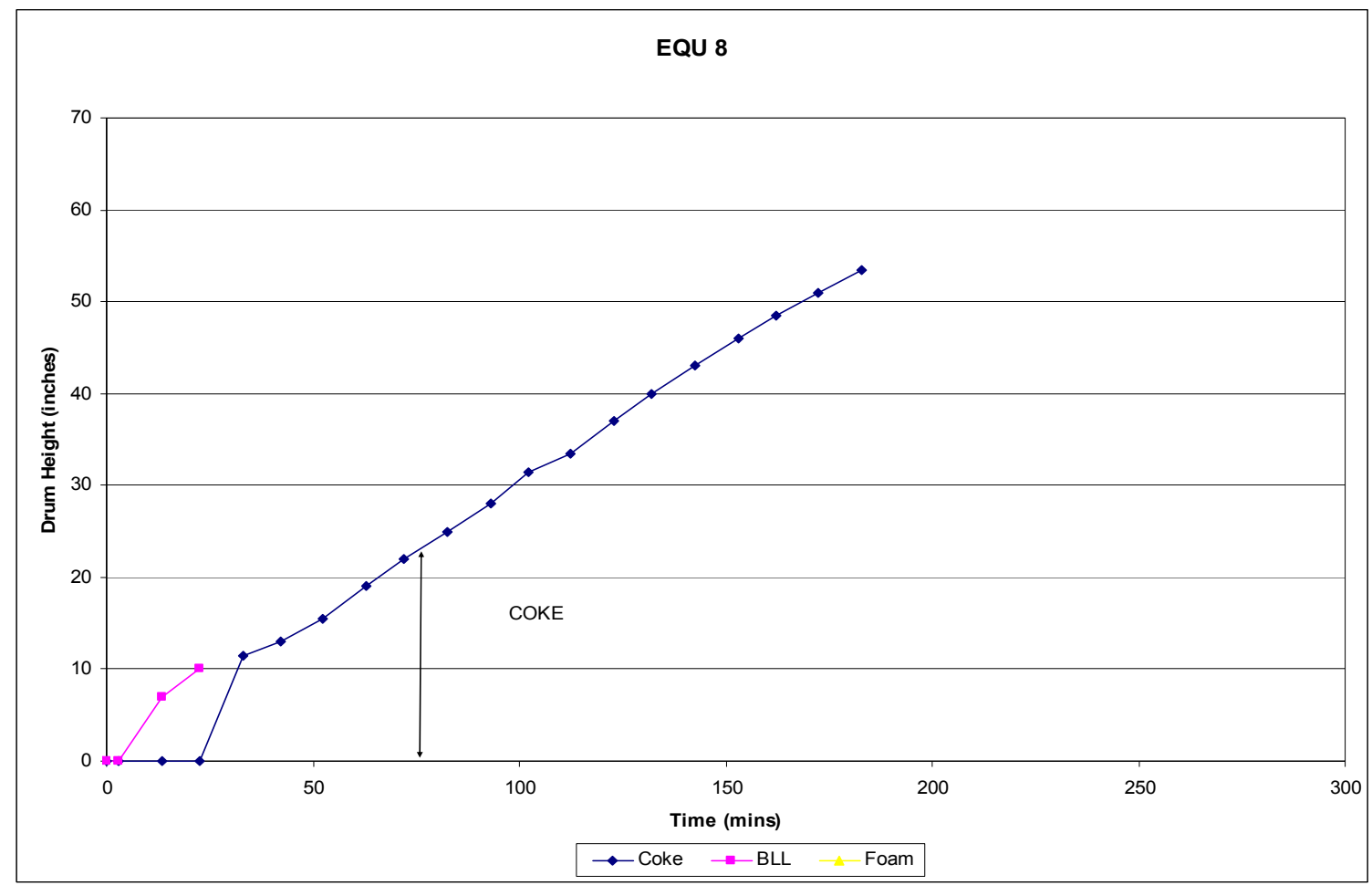

Figure 151 - Build-up of coke, bubbly liquid and foam layer with coking time for EQU 8 PUAFC

Runs PETR 3 and PETR 13 were carried out at a temperature of $900^{\circ} \mathrm{F}$, a pressure of $15 \mathrm{psig}$ and a feed rate of $3600 \mathrm{gm} / \mathrm{hr}$. PETR 3 was an as-needed overhead+feedline injection of 100,000 cSt (30/70) antifoam, whereas PETR 13 was a continuous overhead injection of 100,000 cSt (0.3/70) antifoam. As can be seen in Figure 83, PETR 3 required less heat input to the inlet coil, and had a warmer overhead temperature. PETR 13 on the other hand required more heat input to the inlet coil and had a comparatively cooler overhead temperature. The fluid and the furnace skin temperature were the same for both the runs. 


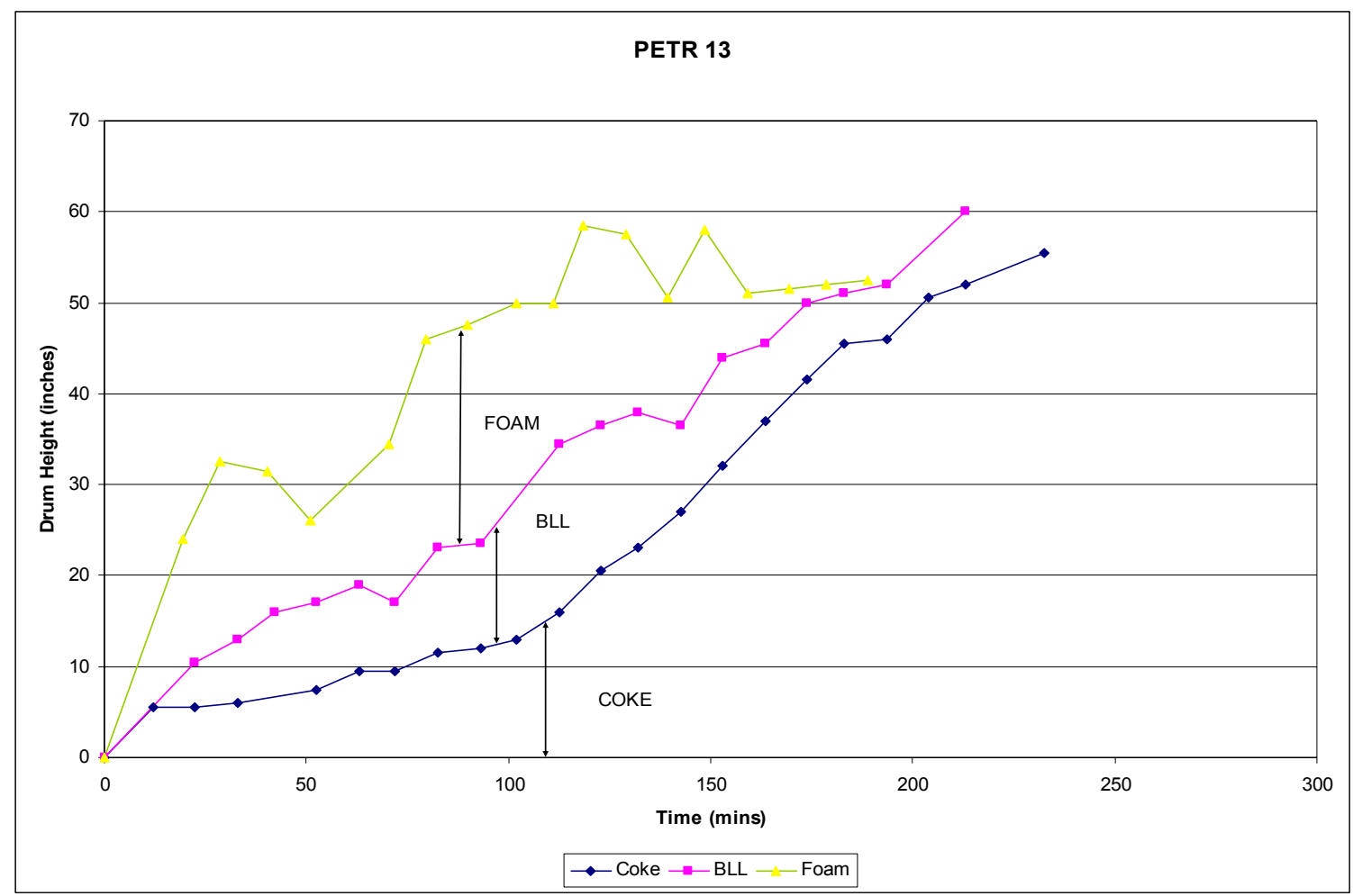

Figure 152 - Build-up of coke, bubbly liquid and foam layer with coking time for PETR 13 PUAFC

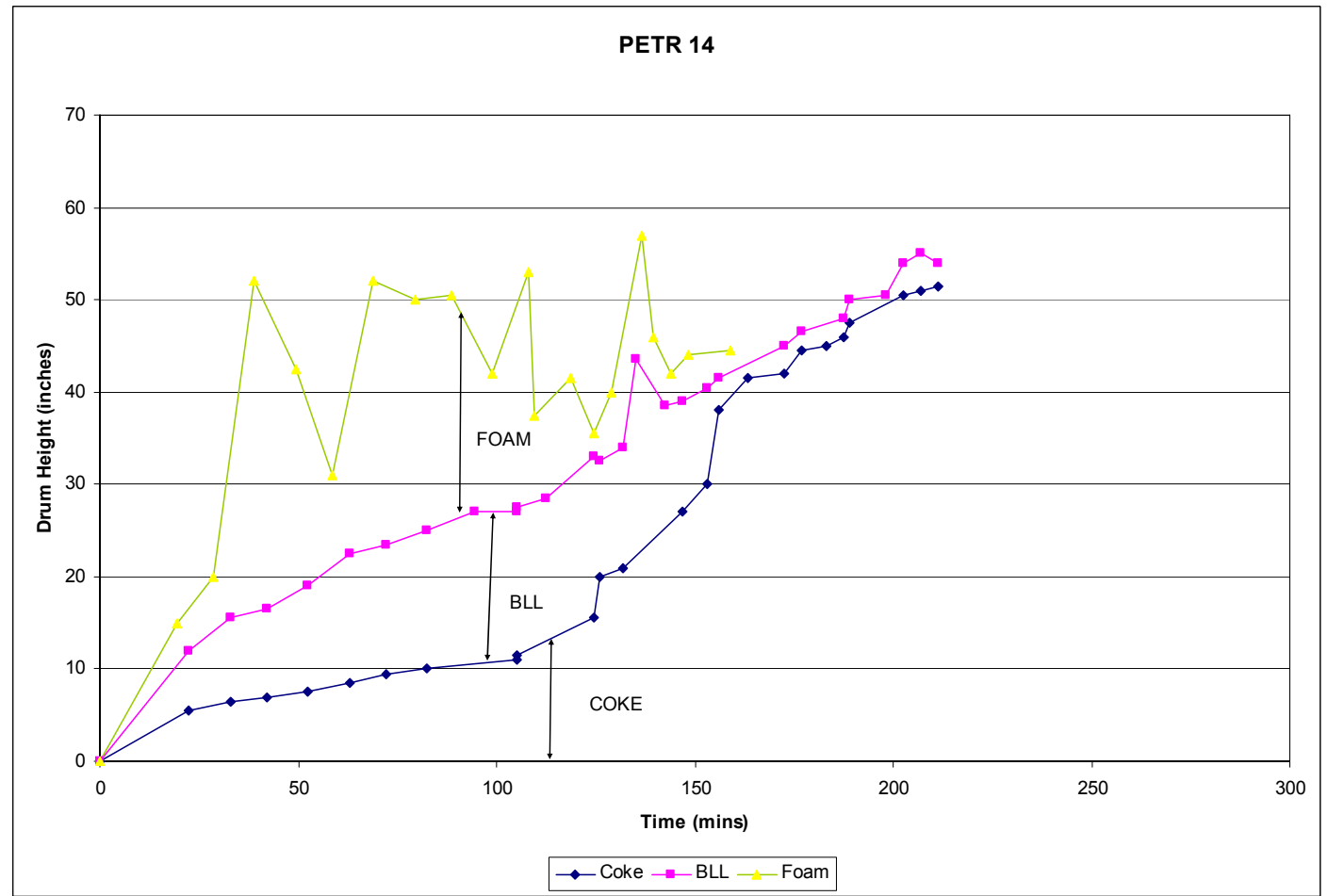

Figure 153 - Build-up of coke, bubbly liquid and foam layer with coking time for PETR 14 PUAFC 


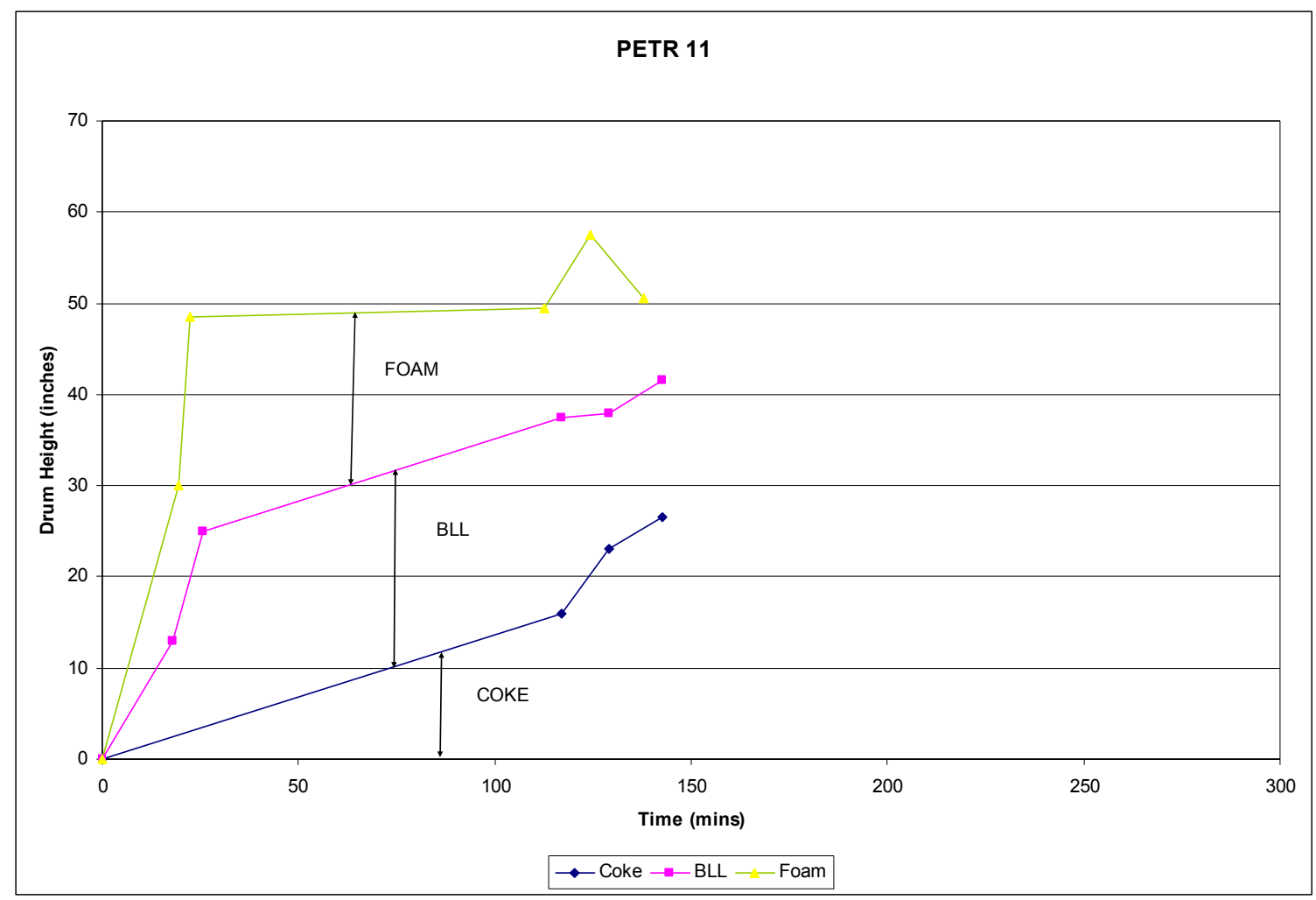

Figure 154 - Build-up of coke, bubbly liquid and foam layer with coking time for PETR 11 PUAFI

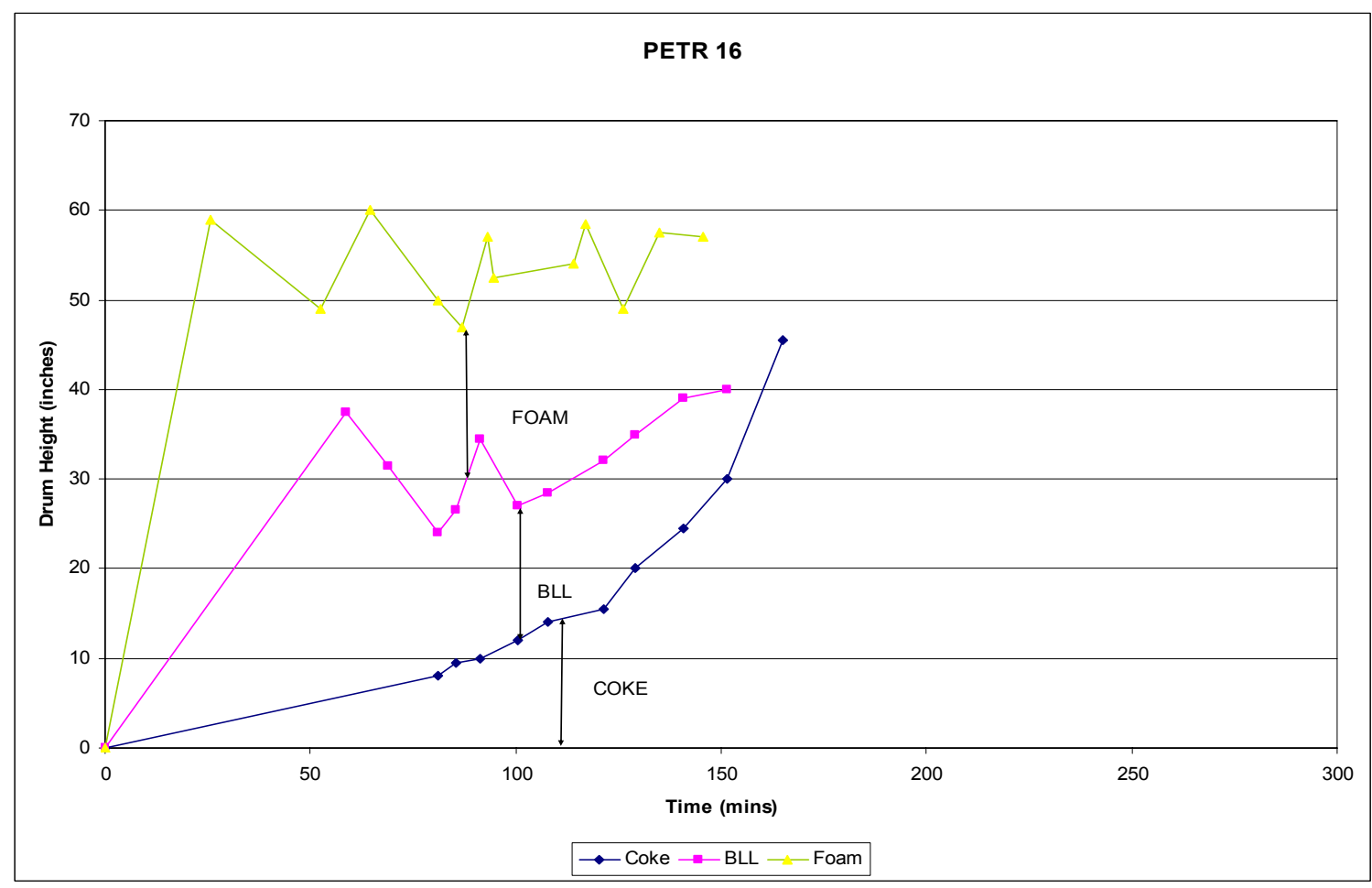

Figure 155 - Build-up of coke, bubbly liquid and foam layer with coking time for PETR 16 PUAFI 


\section{Para Metric Studies}

The number of Pilot unit Antifoam runs conducted for each resid is tabulated in Table 70. Feedstock properties for each of the used resids are provided in Table 71.

Table 70 - Pilot Unit Antifoam Runs Considered by Resid

\begin{tabular}{|c|c|}
\hline Resid & \# of runs \\
\hline Chevron & 10 \\
\hline Citgo & 12 \\
\hline Equilon & 7 \\
\hline Suncor & 12 \\
\hline Petrobras & 12 \\
\hline Marathon & 7 \\
\hline Total & 60 \\
\hline
\end{tabular}

Table 71 - Resid Properties

\begin{tabular}{|c|c|c|c|c|c|c|c|c|}
\hline Resid & API & NMR & Structure & C7 Asphaltenes wt\% & MCRT wt\% & C7 Asphaltenes/MCR & \multicolumn{2}{|c|}{ Morphology } \\
\hline & & Saturate/aromatics & & & & & Proposed & Observed \\
\hline Chevron & 5.7 & 2.4 & Napthenic & 8.75 & 20.25 & 0.43 & Sponge & Sponge/Shot \\
\hline Marathon & 10.3 & 2.8 & Paraffinic & 2.35 & 16.25 & 0.14 & Sponge & Sponge \\
\hline Petrobras & 6.5 & 2.4 & Paraffinic & 8.56 & 21.77 & 0.39 & Sponge & Sponge \\
\hline Citgo & 4.6 & 1.9 & Napthenic & 15.27 & 25.74 & 0.59 & Shot & Sponge/Shot \\
\hline Equilon & 0.5 & 2.3 & Intermediate & 24.60 & 29.4 & 0.84 & Shot & Shot \\
\hline Suncor & 2.9 & 2.5 & Aromatic & 12.97 & 21.15 & 0.61 & Shot & Shot \\
\hline
\end{tabular}

Table 71 gives the proposed morphology of the coke based on the rule of thumb, if the value of the $\mathrm{C} 7+$ Asplatenes/MCR $>0.5$ then the resid forms shot coke. The observed morphology agrees with the rule of thumb. From Table 71 it is also observed that the Napthenic structured resids made a mixture of shot and sponge coke, Paraffinic resids made pure sponge coke, Aromatic resids made pure shot coke, while Intermediate structured resids made a mixture of Agglomerated and Large BB shot coke.

In this study, the coke morphology of each resid will be discussed separately later in the report. 
Coke Morphology

i) Data Analysis:

The morphology of coke that is produced can be broadly classified as Sponge coke, Shot coke and Needle coke. In the foaming studies only Sponge coke and Shot coke are observed. The morphology study is aided by the use of data from the gamma densitometer that is plotted in three different ways.

a) Height vs Density plotted over set time period,

b) Height vs Time for a given density in the coke drum, and

c) Density vs Time plotted for a set height in the coke drum.

In the study of Pilot unit test runs, the data is analyzed by a new method of plotting. The data is plotted by picking the highest height in the column at which the resid (foam/liquid/coke) has a certain density. This height trace for given density is plotted with respect to time for a given test run.

Approximation: Height of the column for a given density is picked up only if two consecutive points (each varying by $1 / 2$ in) below it, has value greater than the given density.

The plots given below show the highest height trace for a given density through out the test run. Both if the test runs are conducted at same operating conditions $(930,15,3600 \mathrm{~g} / \mathrm{hr})$. Marathon test run made sponge coke and the Citgo test run made shot coke.

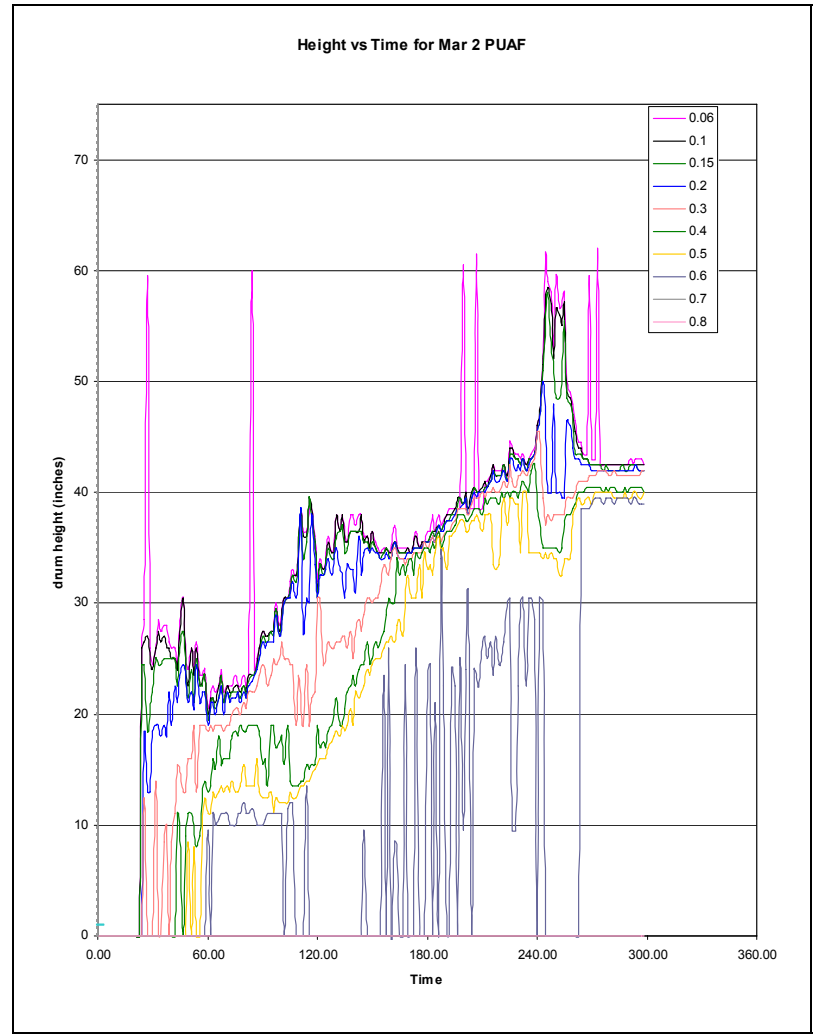

Figure 156 - Marathon Anti-Foaming runs - Height vs Time (Sponge coke from Mar 2 PUAF)

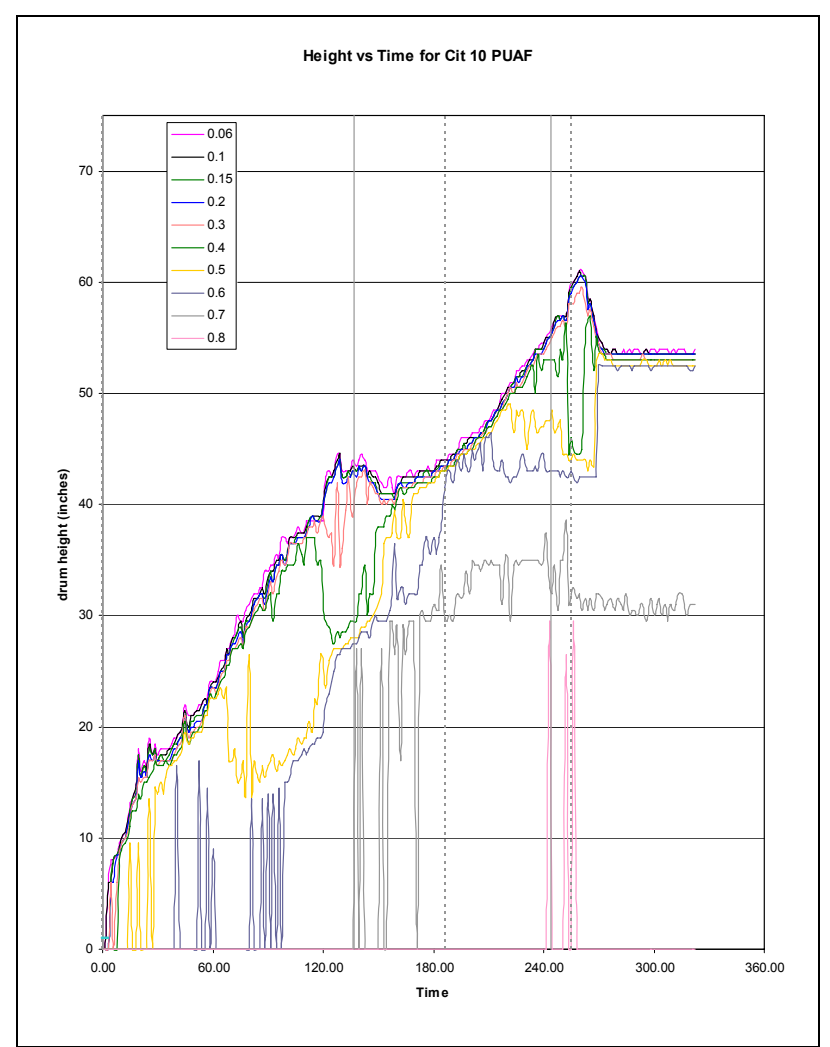

Figure 157 - Citgo Anti-Foaming Runs - Height vs. Time (shot coke from Cit 10 PUAF) 


\section{(i) Sponge coke}

Sponge coke is named after its sponge like structure, generally made by low asphaltenic feeds (in this study where the asphaltenic content is $<24 \mathrm{wt} \%$ ), and resids that have a value of $\mathrm{C} 7+$ Asphaltenes/MCR $<0.5$. It is soft and can be easily crushed. The density of Sponge coke is generally less than that of shot coke because the structure of sponge coke is more porous than that of shot coke. Figure 158 and Figure 159 gives the digital photos of sponge coke formed from Petrobras and Marathon resids. Figure 3 gives the CT scan of the sponge coke made by Petrobras resid, which clearly shows the tree structured coke formation.

Literature review shows that sponge coke is formed at low temperature, higher pressure and low superficial velocities as the environment at these conditions is not turbulent. Petrobras and Marthon resids made pure sponge coke irrespective of operating conditions as these resids are low asphaltenic. Chevron made sponge coke in the middle and top portions of the drum when the feed rate was 1200 $\mathrm{gm} / \mathrm{hr}$ (superficial velocity $0.06 \mathrm{ft} / \mathrm{s}$ ) and $2400 \mathrm{gm} / \mathrm{hr}$ (superficial velocity $0.11 \mathrm{ft} / \mathrm{s}$ ). Citgo made sponge coke for low temperature $\left(900^{\circ} \mathrm{F}\right)$ and feed rate of $2400 \mathrm{gm} / \mathrm{hr}($ superficial velocity $0.11 \mathrm{ft} / \mathrm{s})$ runs.

Figure 161 and Figure 162 shows Height vs. Time traces for these resids as a factor of density. These traces have a definite slope after the first unsteady state (foaming) period of 90-120 min, demonstrating a linear growth of the bed.

Figure 163 and Figure 164 show Height vs. Density traces for sponge coke made by Petrobras and Marathon resids respectively. It is observed that the coke formed is fairly uniform in density after the initial foaming period (0-80 min for PET 4PUAF run and 0-110 min for MAR 2 PUAF run). The densities at the bottom grew up 0.6-0.7 gm/cc and allowed the resid to coke up above the drum to almost similar density as sponge coke has a good porous structure through which the resid can pass.

Petrobras and Marathon made sponge coke throughout the drum. 


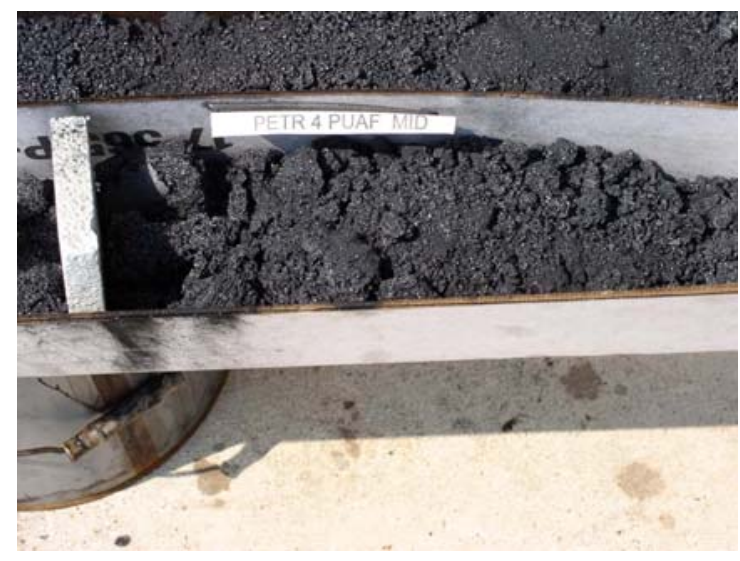

Figure 158 - Photo of Sponge Coke from PETR 4 PUAF

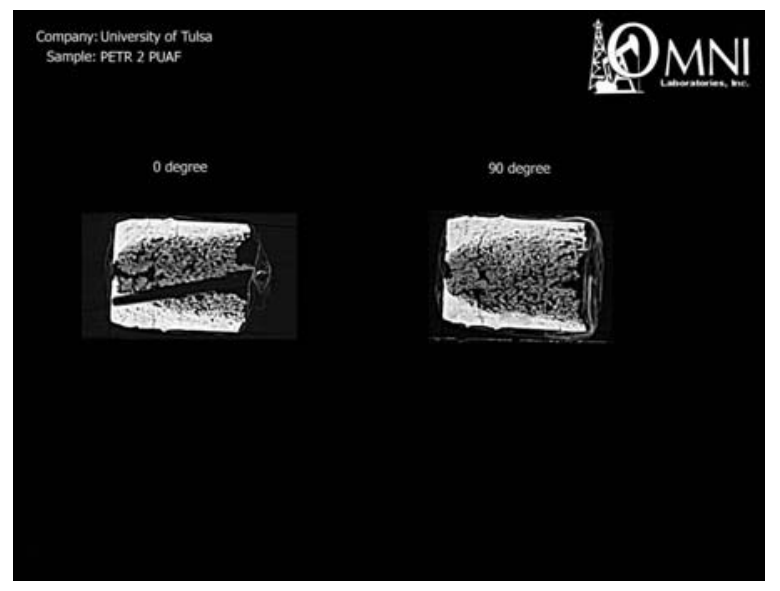

Figure 160 - CT scan of sponge coke made by Petrobras resid.

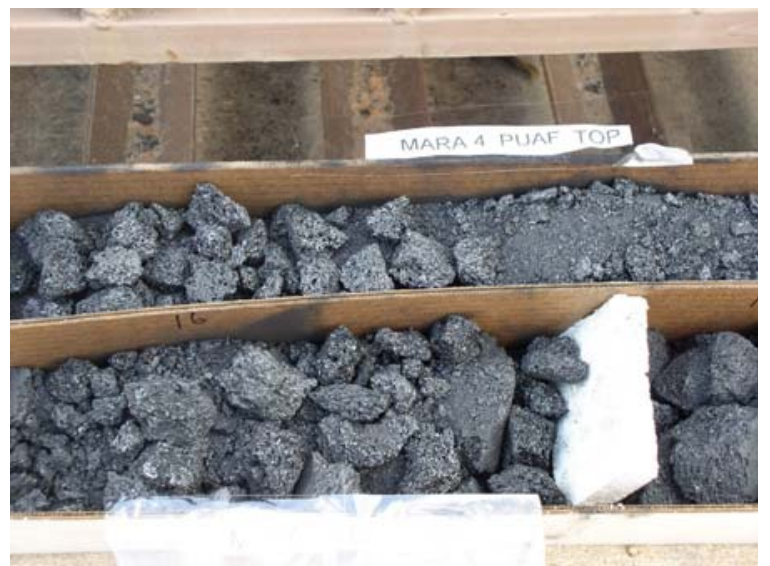

Figure 159 - Photo of Sponge Coke from MAR 4 PUAF) 


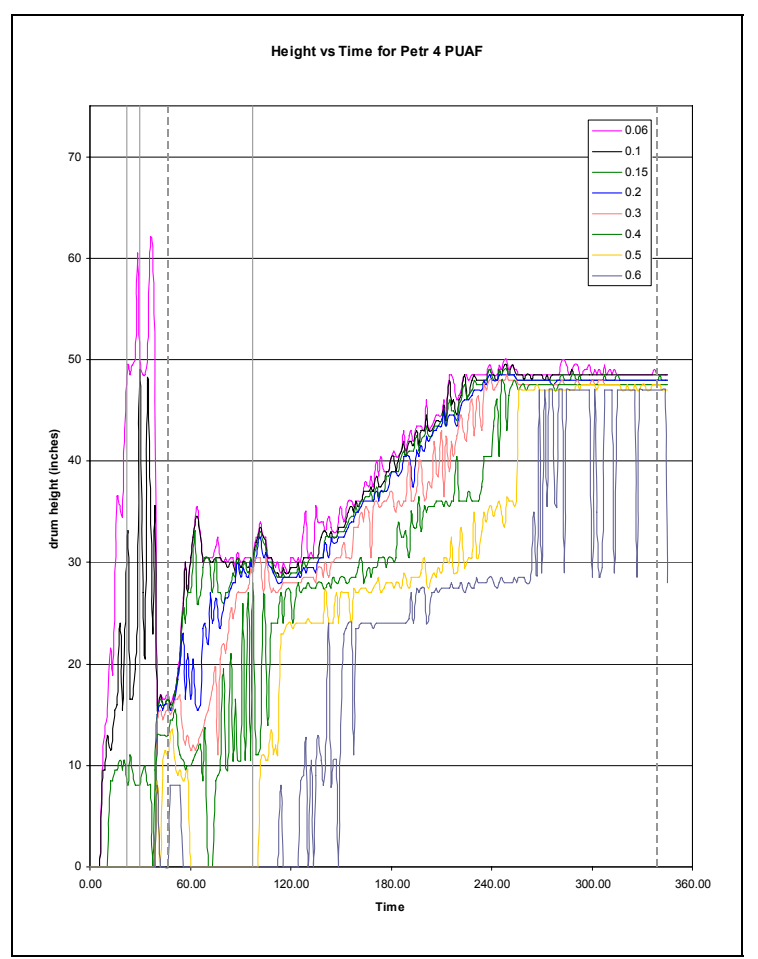

Figure 161 - Petrobras Anti-Foaming - Height vs. Time (Sponge Coke for PETR 4 PUAF)

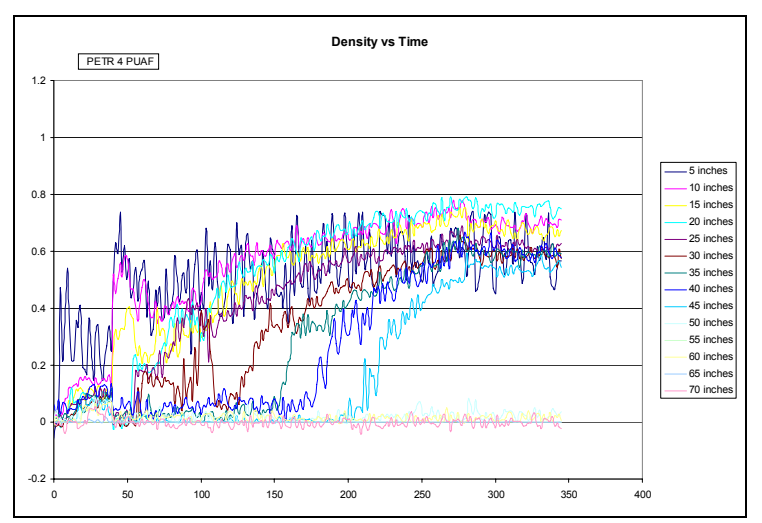

Figure 163 - Petrobras Anti-Foaming -Density vs. Time - (Sponge Coke for PETR 4 PUAF

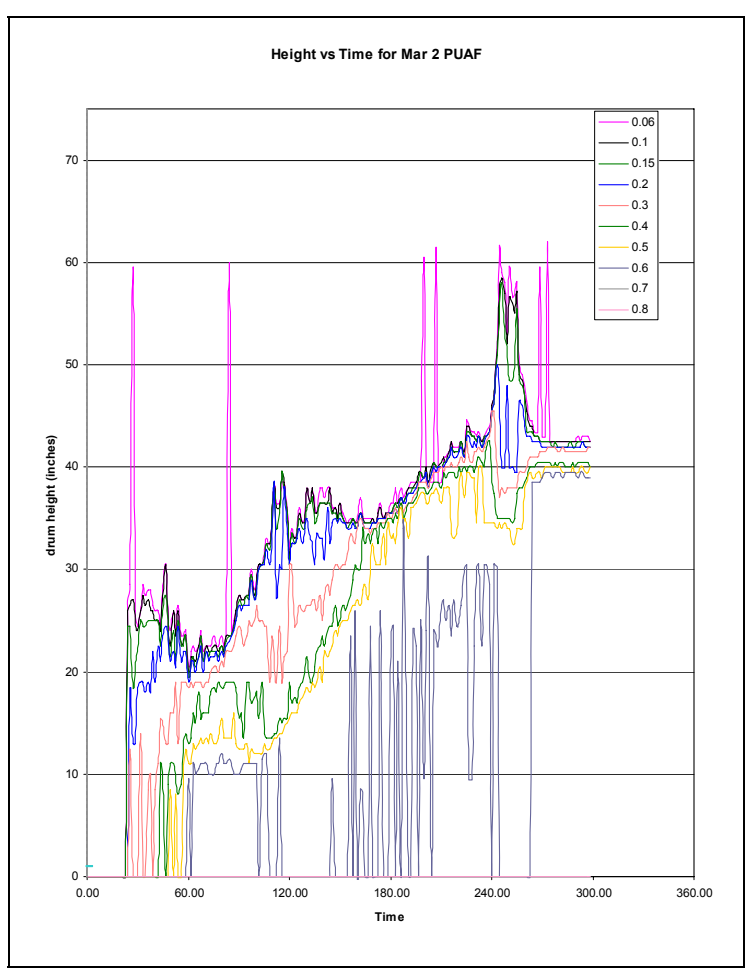

Figure 162 - Marathon Anti-Foaming - Height vs. Time (Sponge Coke for MAR 2 PUAF)

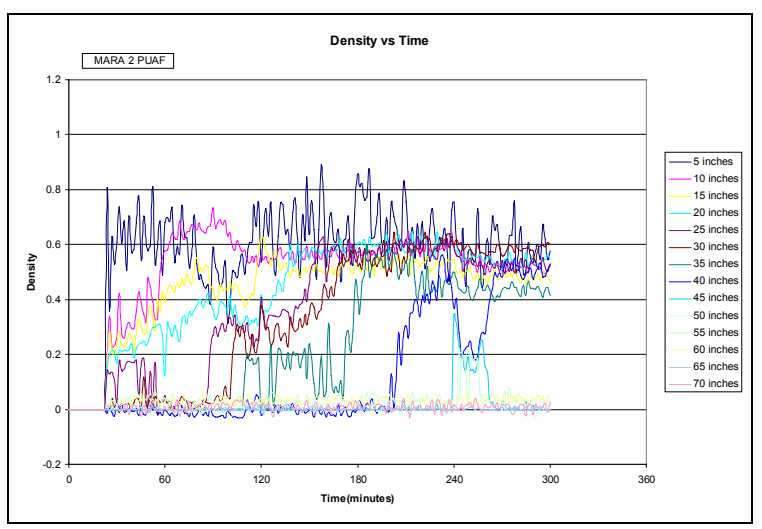

Figure 164 - Marathon Anti-Foaming - Density vs. Time (Sponge Coke for MAR 2 PUAF)

(i) Petrobras Resid:

The morphology of coke for the Petrobras resid did not change with a change in operating variables. The Petrobras resid is Paraffinic and it made sponge coke as reported in the literature.

\section{Effect of Temperature}

Consider the Height vs Time plots for a given density in the coke drum, the density traces can be classified as Foam (density $<0.2 \mathrm{gm} / \mathrm{cc}$ ), Liquid (density $>0.2$ and $<0.5 \mathrm{gm} / \mathrm{cc}$ ) and coke (density $>0.5 \mathrm{gm} / \mathrm{cc}$ ) layers. Figure 165 and Figure 166 show the density traces for the Petrobras resid at the same operating conditions (40 psig, $2400 \mathrm{~g} / \mathrm{hr}$ ) except that the temperature is increased from $900^{\circ} \mathrm{F}$ to $930^{\circ} \mathrm{F}$. 


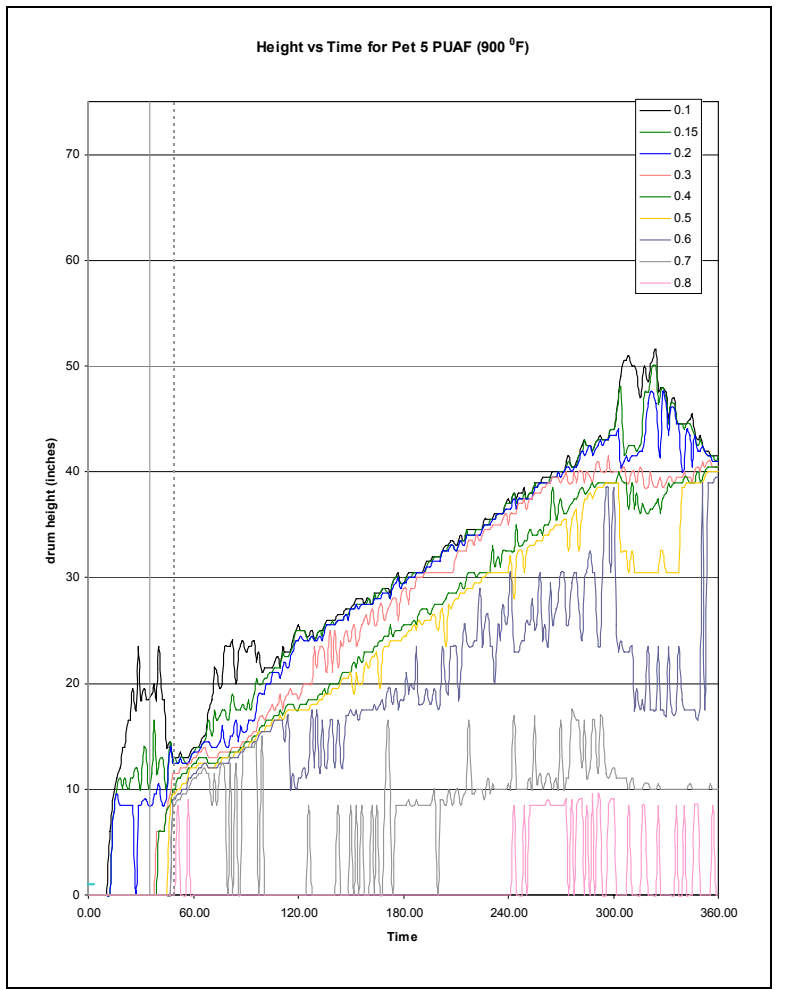

Figure 165 - Petrobras Anti-Foaming Runs Height vs. Time (Sponge Coke from PET 5 PUAF)

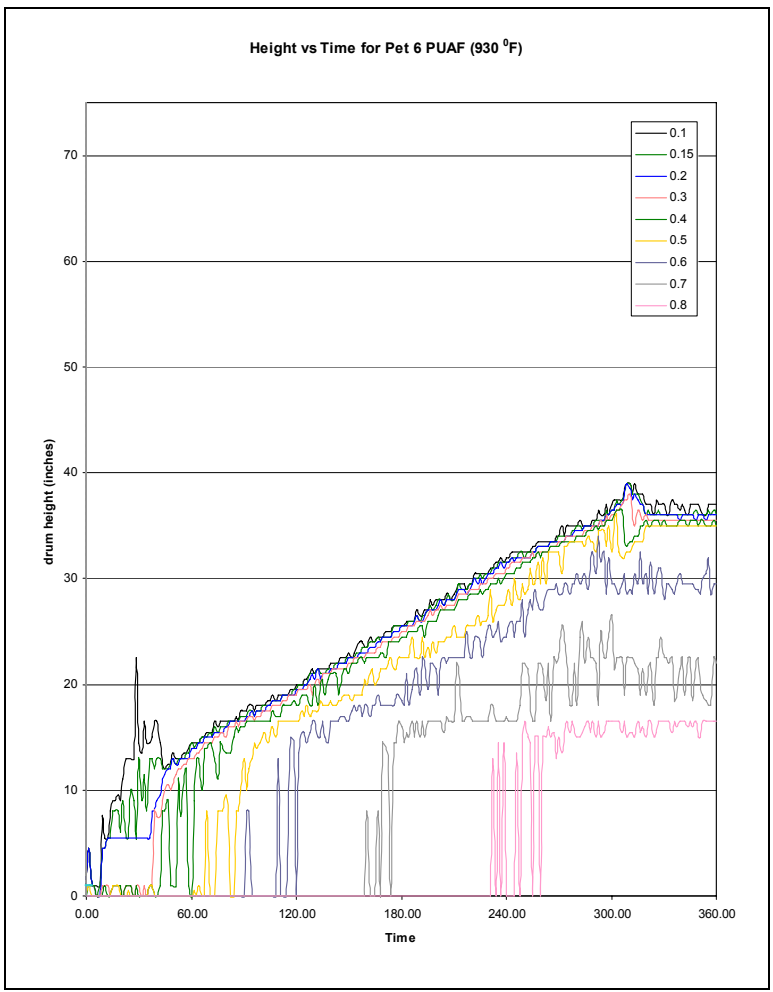

Figure 166 - Petrobras Anti-Foaming Runs Height vs. Time (Sponge Coke from PET 6 PUAF)

For the Petrobras resid, the liquid layer (density $>0.2<0.5 \mathrm{gm} / \mathrm{cc}$ ) decreased with an increase in temperature because at higher temperatures coking occurs more rapidly.

It is observed that with increase in feedrate from $2400 \mathrm{gm} / \mathrm{hr}$ to $3600 \mathrm{gm} / \mathrm{hr}$ rate of coke growth $\mathrm{dh} / \mathrm{dt}$ increased from 0.09 to $0.16 \mathrm{in} / \mathrm{min}$.

\section{Effect of operating conditions on coke morphology}

Bulk and gamma densities were calculated for 8 Petrobras antifoam test runs which were conducted at varying operating conditions. Bulk density is obtained by dividing the weight of coke deposited in the drum with the volume occupied by the coke in the drum. Gamma density is taken from the average of the density values for last three traces of steam stripping. The average difference between Gamma density from the plots and the Bulk density is $0.13 \mathrm{gm} / \mathrm{cc}$. The Bulk density is always greater than the gamma density.

Some of the reasons for these differences are: 
1) The weight of the coke taken is the difference of initial and total weights of the drum, not the exact weight of the coke in the volume considered for calculating density, i.e. coke coating on the walls of the upper part of the drum is also added.

2) The Gamma densitometer scans the drum vertically on a straight line capturing a thin section of the coke morphology and may miss the morphology changes that can occur throughout in the coke drum.

The Coke density was found to increase with an increase in both temperature and pressure while the density was found to decrease with an increase in superficial velocity.

\section{Effect of Feedrate:}

With an increase in the feed rate, the coke density decreased. Corresponding temperature profiles for PET 2 and PET 4 are shown in Figure 167 and Figure 168 respectively. These two plots demonstrate that a lower density coke is formed when the temperature profiles are more uniformly distributed in the drum, than the case when higher density coke is formed. With an increase in feed rate a lot of foaming is observed (PET 4 test run), causing the temperatures throughout the drum to be uniform.

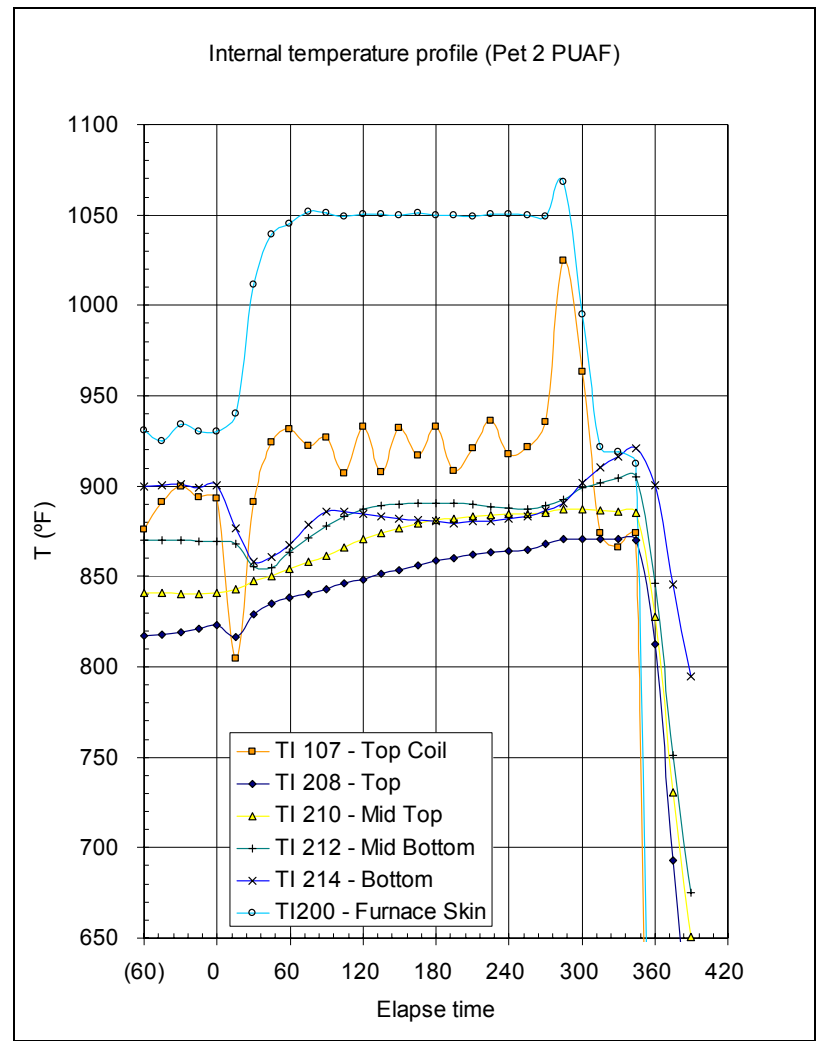

Figure 167 - Petrobras Anti-Foaming Runs - Temperature Profile (High density Sponge Coke from PET 2 PUAF)

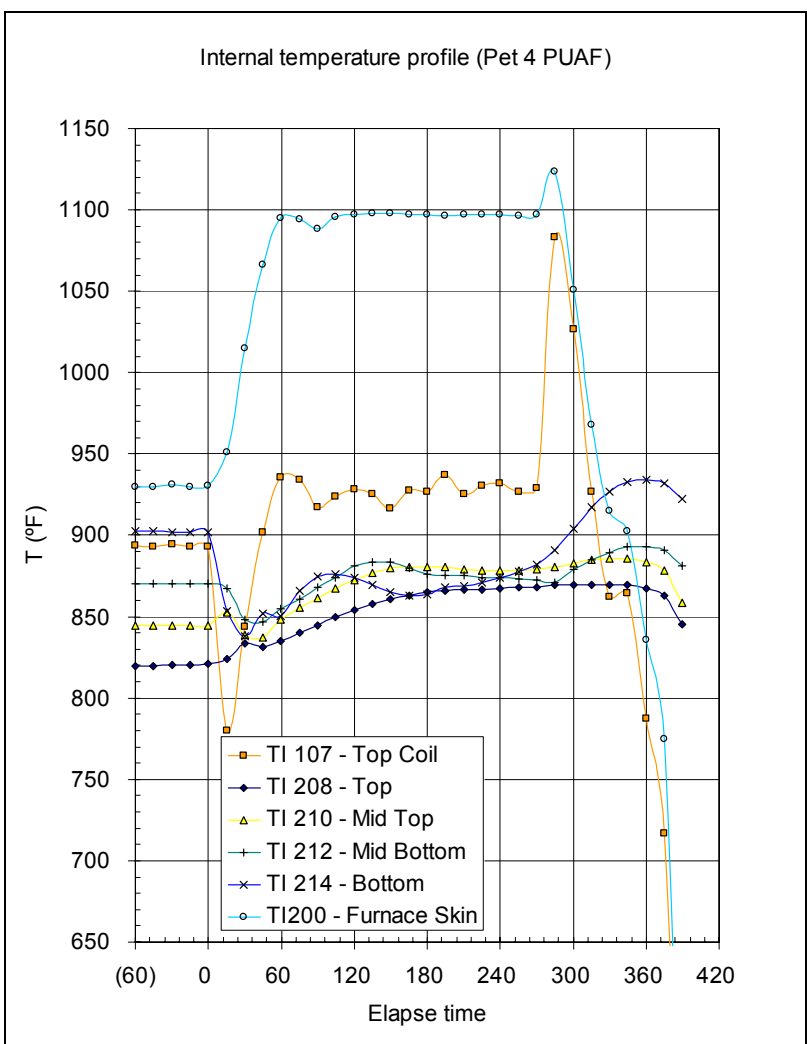

Figure 168 - Petraobras Anti-Foaming Runs - Temperature Profile (Lower Density Sponge Coke from PET 4 PUAF)

\section{Foaming tendencies for Petrobras resid:}

Increase of temperature decreased foaming as it decreases the height of liquid layer for Petrobras resid. Pressure chage did not have much impact on foaming for Petrobras resid. An increase in superficial velocity from $0.11 \mathrm{ft} / \mathrm{s}$ to $0.15 \mathrm{ft} / \mathrm{s}$ increased foaming for all sets of temperature and pressure for Petrobras Resid. Temperature appears to be more dominant variable for Petrobras resid. 
In the case of Petrobras resid, antifoam concentration as low as $0.3 \mathrm{~m} / 70 \mathrm{ml}$ was effective in knocking back foam.

\section{(ii) Marathon Resid:}

The Marathon resid also made pure sponge coke irrespective of the operating conditions. This resid is also paraffinic.

\section{Effect of Temperature}

The liquid layer decreased with an increase in temperature. Figure 169 and Figure 170 show the density traces for the Marathon resid at the same operating conditions (15 psig, $2400 \mathrm{~g} / \mathrm{hr}$ ) with temperature increasing from $900^{\circ} \mathrm{F}$ to $930^{\circ} \mathrm{F}$. All the $900^{\circ} \mathrm{F}$ had a thicker liquid layer than their $930^{\circ} \mathrm{F}$ counterparts. The $40 \mathrm{psig}$ runs also foam more than the $15 \mathrm{psig}$ runs at $900^{\circ} \mathrm{F}$.

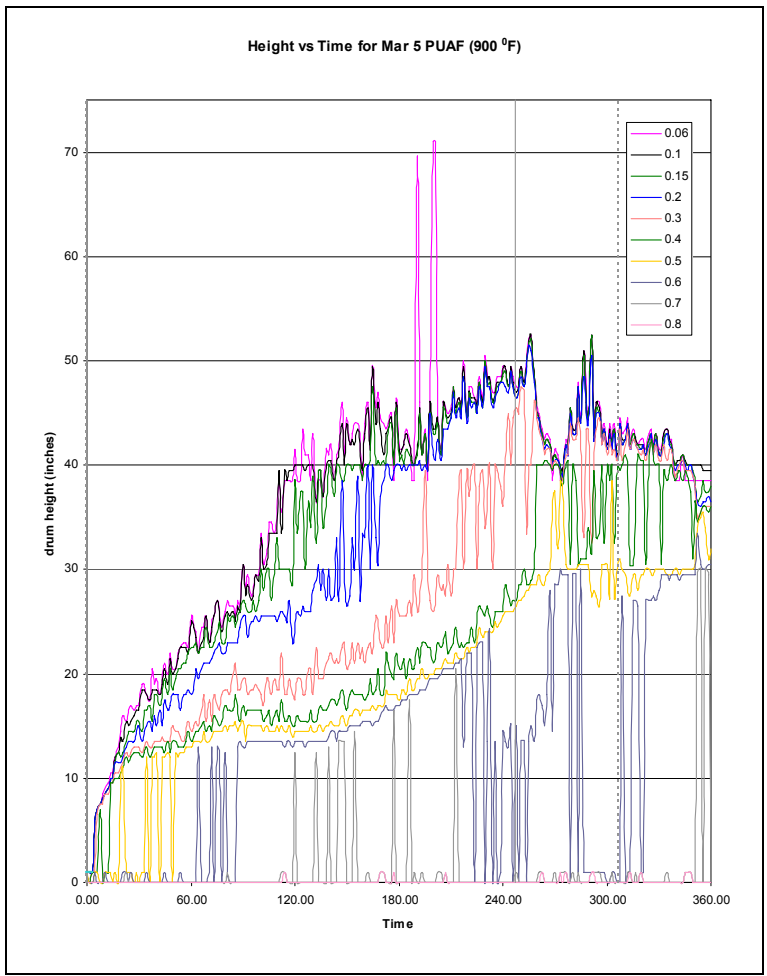

Figure 169 - Marathon Anti-Foaming runs Height vs. Time (Sponge Coke from MAR 5 PUAF)

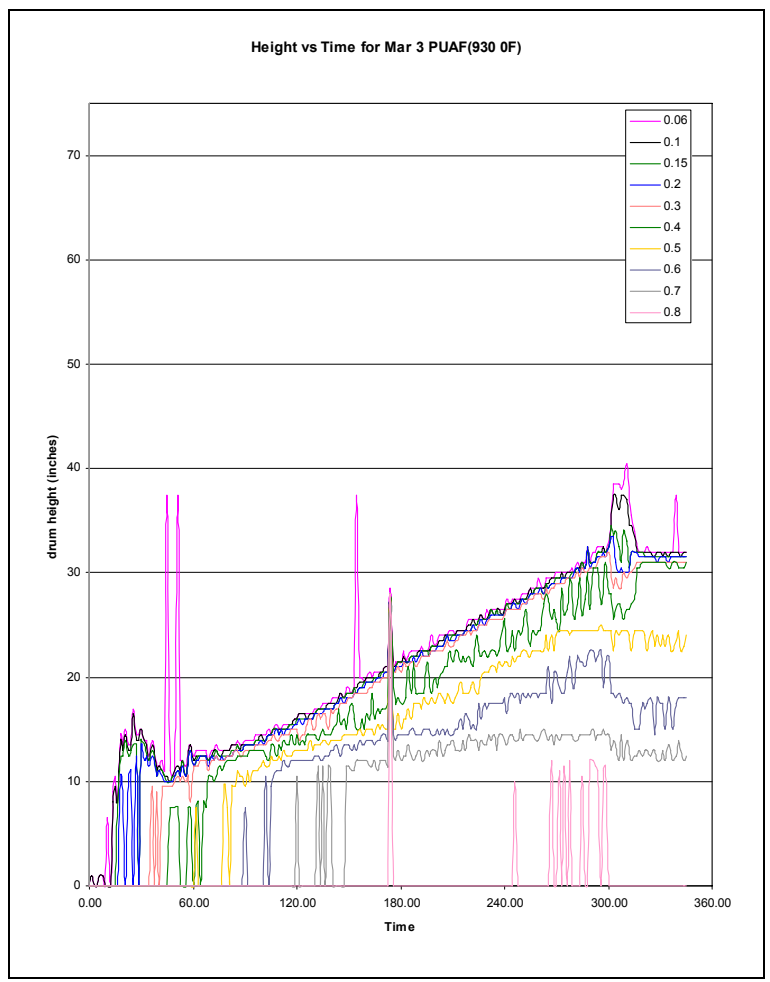

Figure 170 - Marathon Anti-Foaming Runs Height vs. Time (Sponge Coke from MAR 3 PUAF)

It was observed that both the Marathon and Petrobras resids have nearly the same liquid layer height for a given set of temperature and pressure. 


\section{Effect of operating conditions on coke morphology}

The Bulk density of Coke was found to decrease slightly with an increase in temperature at $15 \mathrm{psig}$ pressure where as gamma density increased with increase in temperature. At 40 psig both bulk and gamma density increased with an increase in temperature. An increase in the pressure increased the density of the coke formed; however this observation is based on one run at each pressure. An increase in superficial velocity didn't have much impact on the density of the coke made for the Marathon resid.

For both Marathon and Petrobras resids bulk density ranged from $0.6-0.8 \mathrm{gm} / \mathrm{cc}$ and gamma density ranged from $0.45-0.65 \mathrm{gm} / \mathrm{cc}$ approximately. The average difference between Bulk and gamma densities for petrobras and marathon resids are $0.13 \mathrm{gm} / \mathrm{cc}$ and $0.16 \mathrm{gm} / \mathrm{cc}$ respectively.

\section{Effect of Feedrate:}

Consider the three Marathon test runs at same operating conditions ( $930{ }^{\circ} \mathrm{F}, 15 \mathrm{Psig}$ ) but varying by feedrate, Mar 3 Puaf is a $2400 \mathrm{~g} / \mathrm{hr}$, Mar 2 Puaf is a $3600 \mathrm{~g} / \mathrm{hr}$ and Mar 4 Puaf is a $4800 \mathrm{~g} / \mathrm{hr}$ test runs as shown in Figure 171 through Figure 174. An increase in superficial velocity resulted in increased foaming and also increased the slope of the bubbly liquid layer curve.

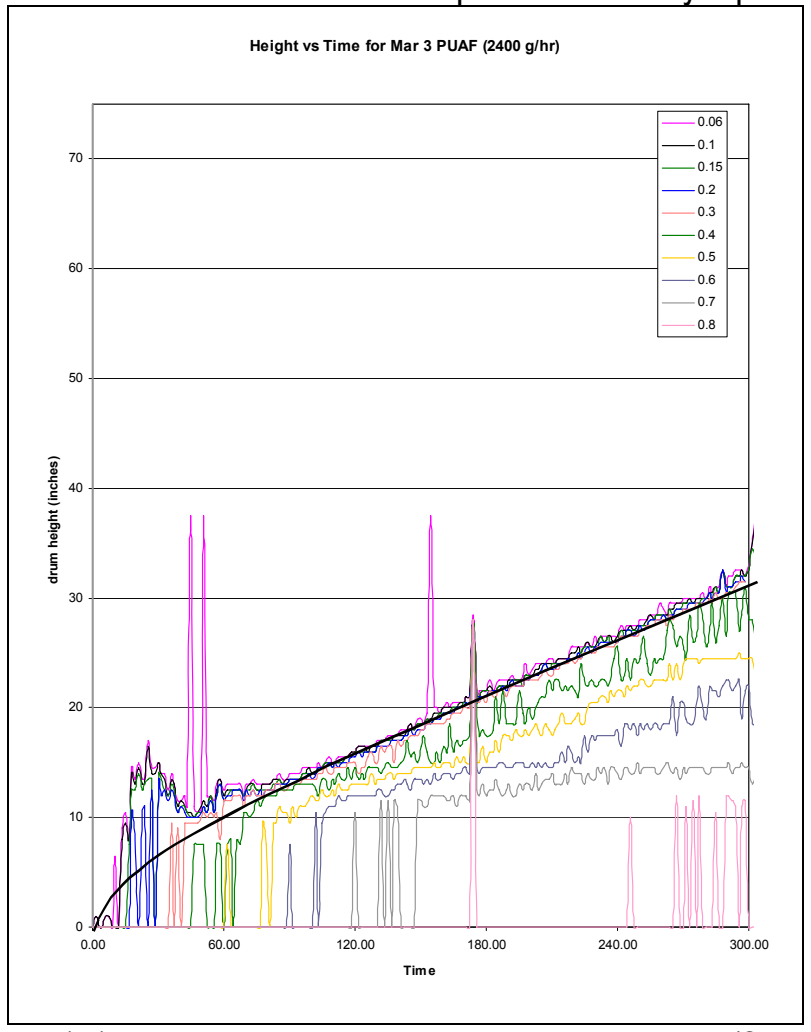

Figure 171 - Marathon Anti-Foaming runs - Height vs. Time (Sponge coke from MAR 3 PUAF)

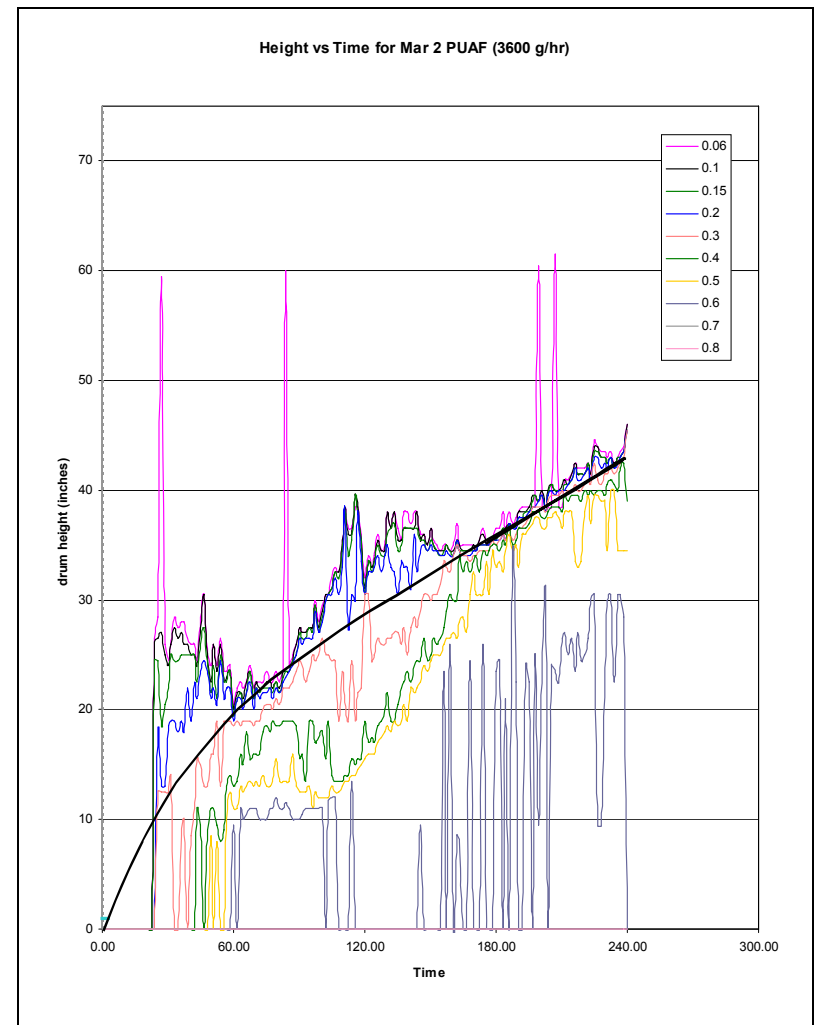

Figure 172 - Marathon Anti-Foaming runs - Height vs. Time (Sponge coke from MAR 2 PUAF) 


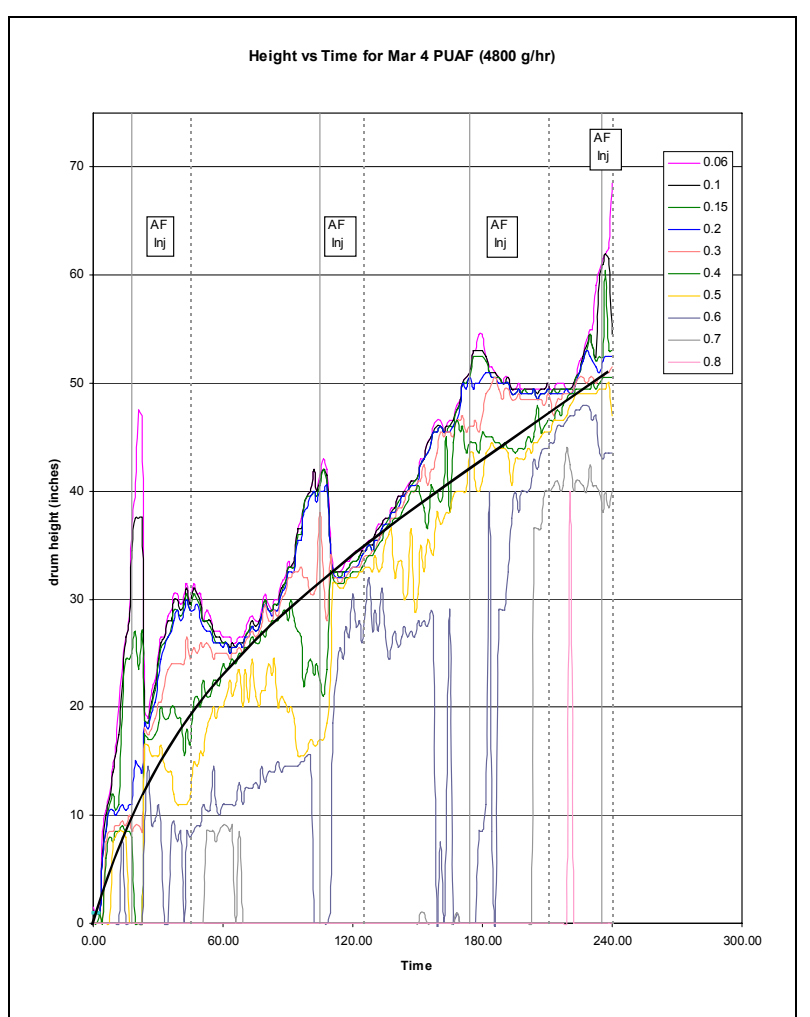

Figure 173 - Marathon Anti-Foaming runs - Height vs. Time (Sponge coke from MAR 4 PUAF)

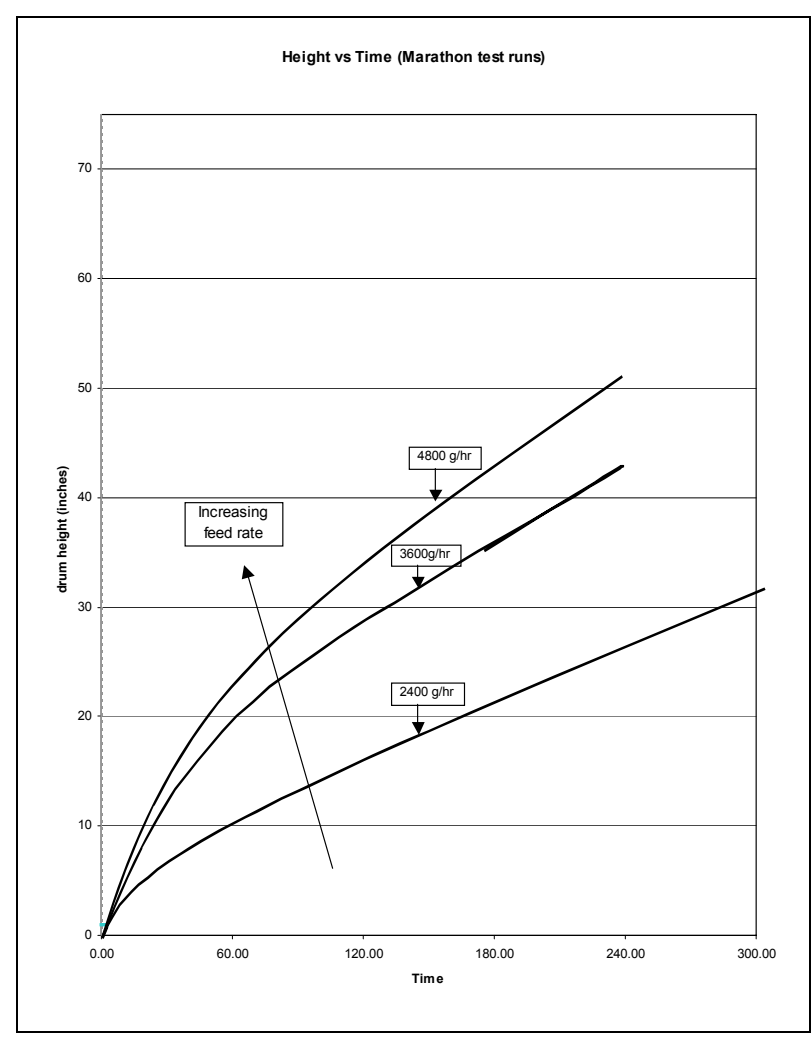

Figure 174 - Marathon Anti-Foaming runs - Height vs. Time (Sponge coke)

\section{Foaming tendencies for Marathon resid :}

Lower temperature and lower pressure caused foaming for Marathon.

An increase in temperature decreased foaming as it decreased the liquid layer for marathon resid. Pressure didn't have much impact on foaming for marathon resid. Increase in superficial velocity increased foaming. Temperature appears to be more dominant variable for this resid.

b) Shot coke

\section{Coke Sizing}

Coke sizing is a procedure of visually inspecting the coke to determine a percentage of the coke, which is to be considered shot coke. Great Lakes Carbon provided the procedure, and a short lesson on the analysis was provided. Generally the procedure is fairly simple. However, the inherent error is due to the fact that the analysis is subjective in that the observations can vary depending on the person performing the analysis. The procedure used for the coke sizing is as follows:

\section{SHOT COKE DETERMINATION}


1. Take the sample as prepared according to the Shot Coke Sample Preparation.

2. Take the +4 mesh fraction and separate into shot coke and sponge coke fractions. The visual guidelines for separation are described as follows:

Shot Coke includes small ball-shaped particles about 2-5 mm. diameter; individual round particles which may be bird-egg shape; lumps of bonded or agglomerated shot particles; and lumps which are of high density with shot particles or circular domains surrounded with coke. Photos of Sponge coke and Shot coke are given in Figure 175 and Figure 176.

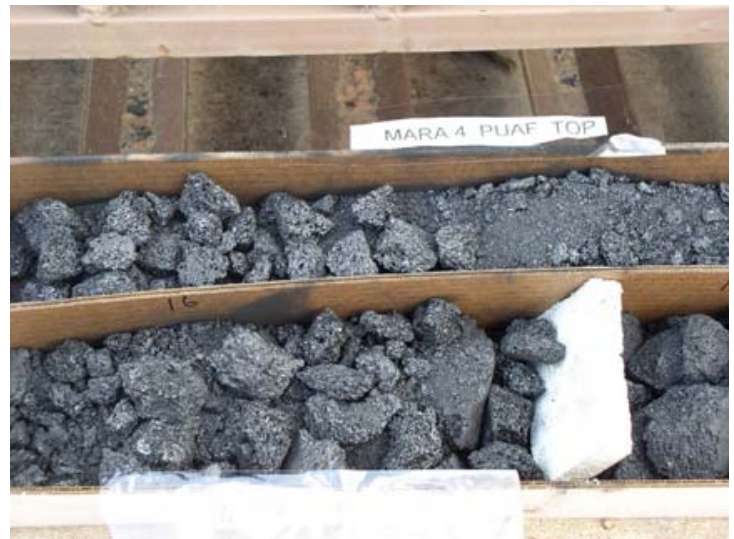

Figure 175 - Photo of Sponge Coke from MAR 4 PUAF

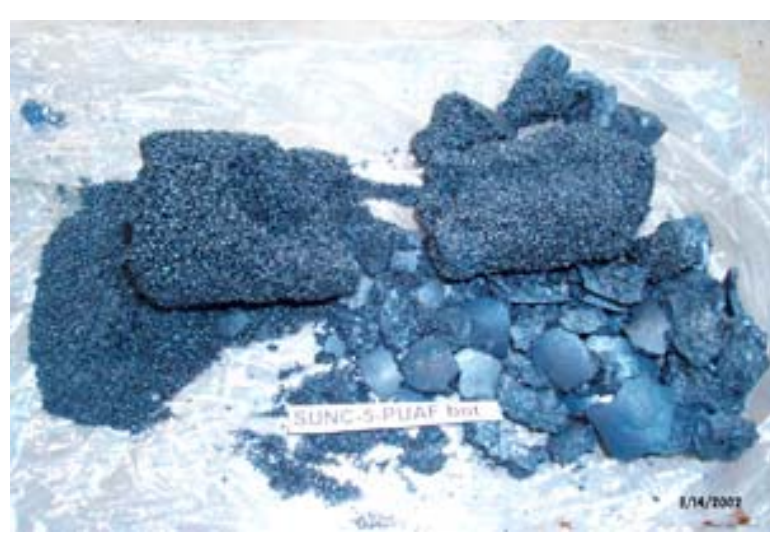

Figure 176 - Photo of Shot coke from SUN 5 PUAF Bottom

3. Take the $-4 /+10$ mesh fraction and riffle it down with the small counter-top riffler in the lab to obtain $\sim 10$ 15 grams of sample. Divide the total $4 / 10 \mathrm{M}$ fraction weight by the riffled sample weight to obtain a riffle factor $(R)$.

4. Inspect the $4 / 10 \mathrm{M}$ fraction and separate into shot and sponge coke fractions as described in step 2.

5. Due to the difficulty in identification, it is not necessary to inspect the $-10 \mathrm{M}$ fraction for the presence of individual shot particles. In our calculation, the $\%$ shot content of the $-10 \mathrm{M}$ fraction is assumed to be equal to that of the cumulative $+10 \mathrm{M}$ fraction.

6. The percent shot content is calculated as follows:

$\%$ Shot Content $=+4 \mathrm{M}$ shot weight $+\mathrm{R}^{*}(4 / 10 \mathrm{M}$ shot weight $){ }^{*} 100$

Cumulative + 10M sample weight

The Coke sizing is done for portions of samples from three different test runs in which the transition of sponge from shot is clearly observed. The results are given in Table 72 given below. 
Table 72 Coke sizing

\begin{tabular}{|l|c|}
\hline \multicolumn{1}{|c|}{ Sample } & $\%$ Shot \\
\hline CHEV 2 PUAF Bottom & $95.0 \%$ \\
\hline CHEV 3 PUAF Top & $30.5 \%$ \\
\hline CIT 7 PUAF Bottom & $59.1 \%$ \\
\hline
\end{tabular}

Shot coke is generally made by high asphaltenic feeds and can either be made as spheres of different size or agglomerated into a hard dense mass. Agglomerated shot coke is harder to remove from the coke drum, where as the BB shot is very loosely packed and is easily removed from the drum. The density of shot coke is generally greater than the sponge coke (by a value of $0.1-0.3 \mathrm{gm} / \mathrm{cc}$ ) as its structure is less porous. The digital photo for shot coke is shown in Figure 177 and a Boroscope photo is shown in Figure 178. The CT scan for shot coke is shown in Figure 179 and Figure 180.

Literature review shows that shot coke is formed at high temperature, low pressure and low superficial velocities as the environment at these conditions is highely turbulent. The Suncor Resid made shot coke irrespective of operating conditions as this resid is aromatic by its nature. Chevron, Citgo and Equilon made shot coke at higher temperature, lower pressure and higher superficial velocities (superficial velocities $>=0.15 \mathrm{ft} / \mathrm{s})$. 


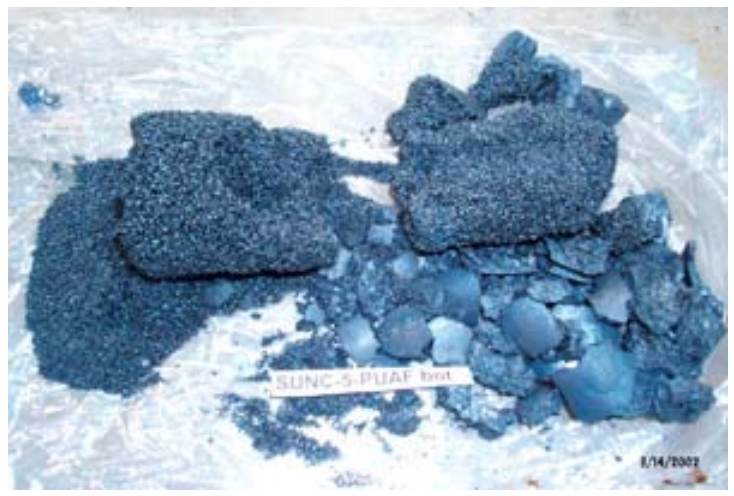

Figure 177 - Suncor Anti-Foaming Runs - Coke Picture (SUN 5 PUAF Bottom)

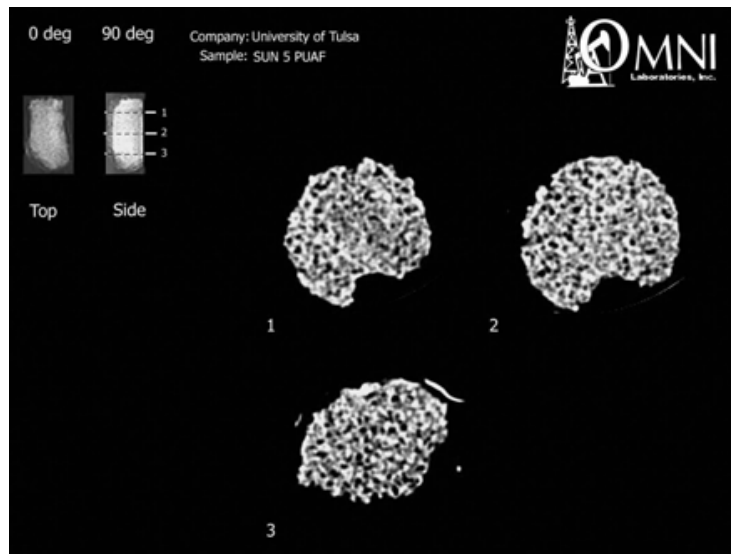

Figure 179 - Suncor Anti-Foaming Runs - CT Scan (Sun 5 PUAF Bottom)

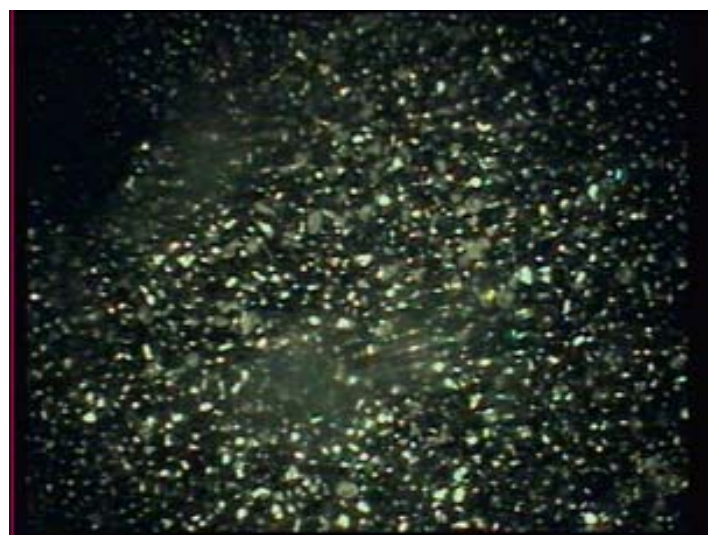

Figure 178 - Suncor Anti-Foaming Runs - Coke Picture (SUN 5 PUAF Bottom)

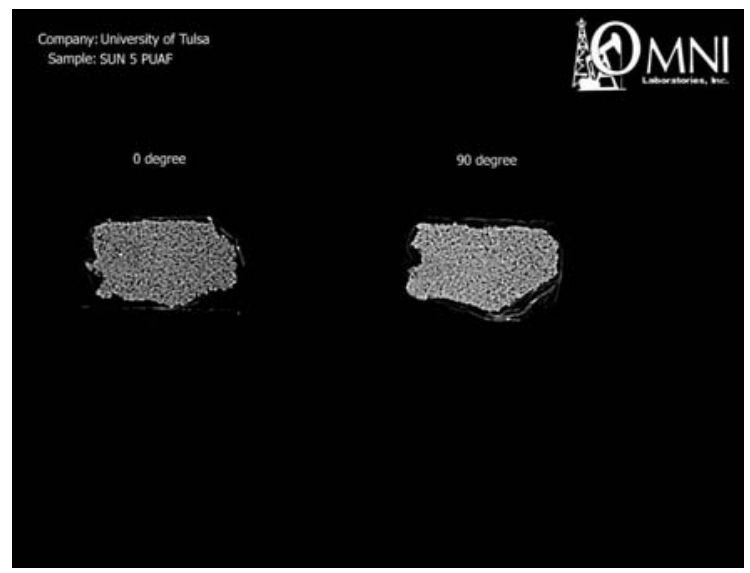

Figure 180 - Suncor Anti-Foaming Runs - CT Scan (Sun 5 PUAF Bottom)

\section{Sponge vs. shot coke:}

The MAR 3 run made sponge coke throughout and the EQ 1 run made shot coke. Both the test runs are at the same operating conditions $\left(930^{\circ} \mathrm{F}, 15 \mathrm{psig}, 2400 \mathrm{~g} / \mathrm{hr}\right)$. Figure 181 and Figure 182 show how the densities of sponge coke and shot coke vary during a test run. Sponge coke has a good porous structure that allows the resid to continually flow through the coke as a function of time. This is shown in Figure 181 where the higher density traces follow the lower density traces (slope is nearly the same). Shot coke has a tendency to agglomerate in the drum, which is shown by Figure 182 where the lower density traces, once they reach a certain height, stay there (no growth in coke height vs time) allowing the coke below to become denser. Also for this run, when the resid breaks through this agglomerated portion, coke begins to accumulate above this layer as a function of time. 


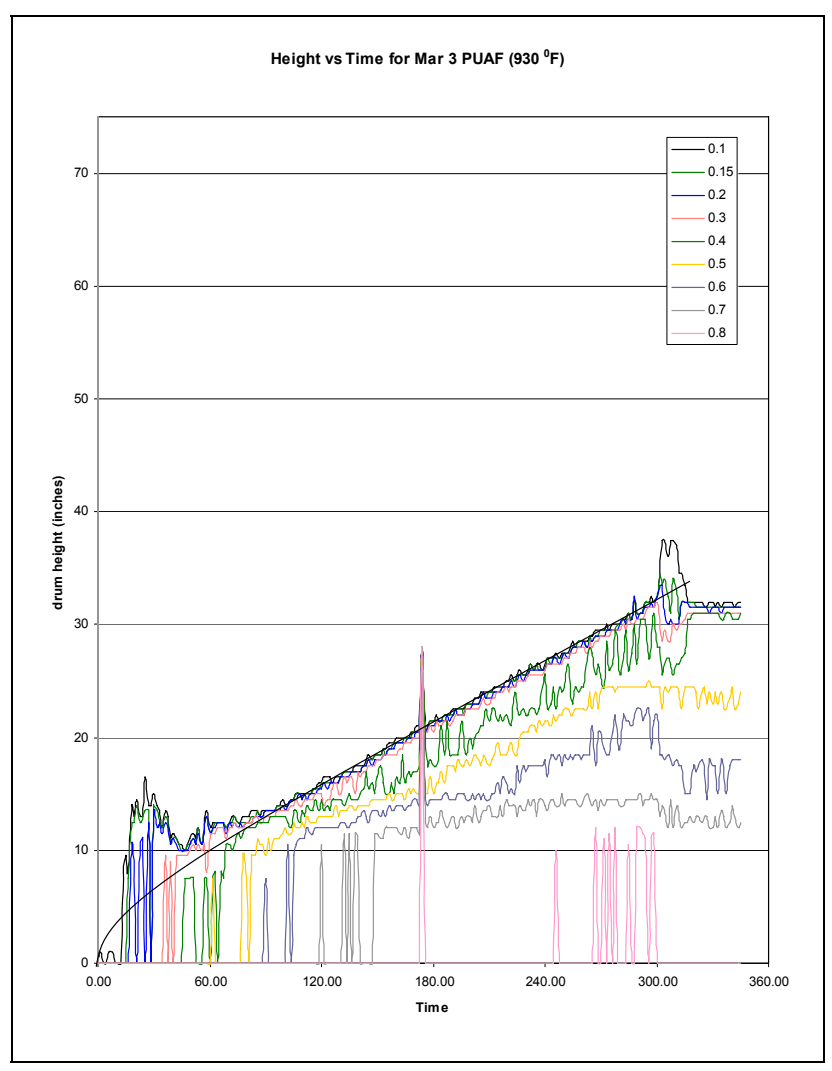

Figure 181 - Marathon Anti-Foaming runs - Height vs. Time (Sponge coke from MAR 3 PUAF)

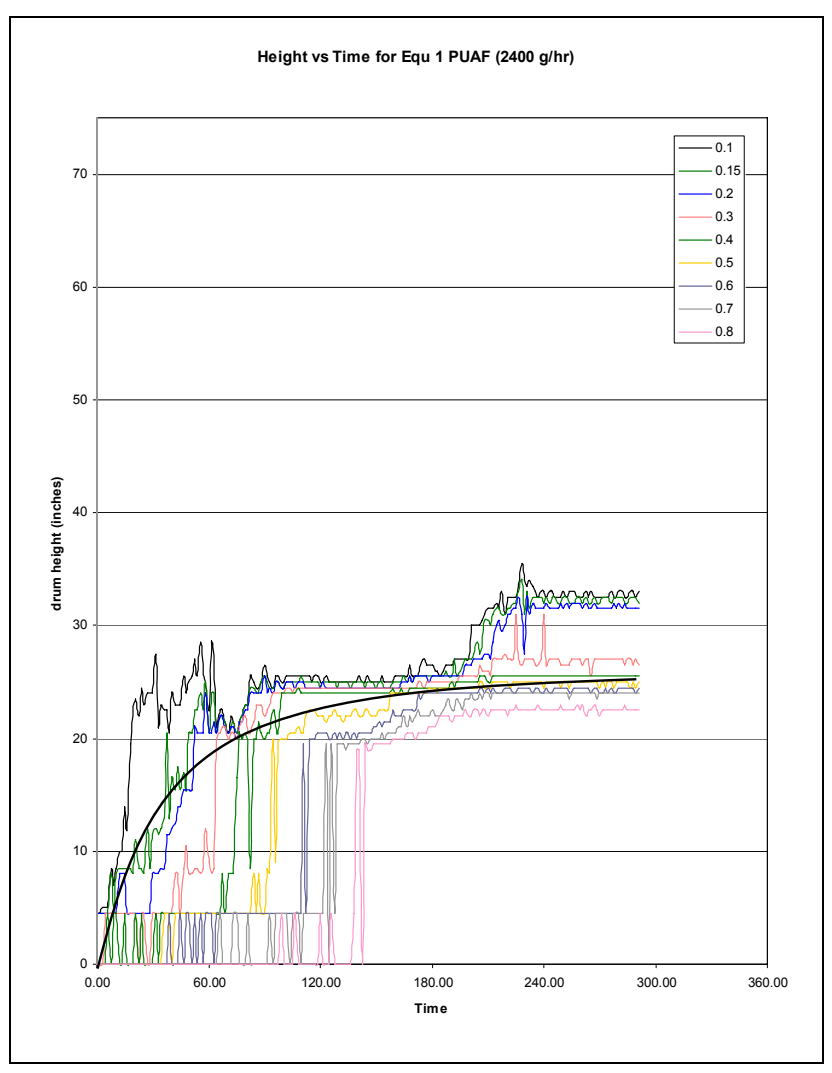

Figure 182 - Equilon Anti-Foaming Runs - Height vs. Time (Shot coke from EQ 1 PUAF)

\section{(i) Suncor resid:}

The Suncor resid made shot coke throughout the runs; however, the morphology did vary from Agglomerated shot coke to BB's with increase in temperature and decrease in pressure.

\section{Agglomerated shot vs. BB shot}

The test runs considered for this comparison are SUN 2 which made agglomerated shot coke and SUN 3 which made a fine loose BB shot. Both the test runs are at same operating conditions $\left(930^{\circ} \mathrm{F}, 15\right.$ psig, $3600 \mathrm{~g} / \mathrm{hr}$ ). Figure 183 shows agglomerated shot coke, where after a period of time, the coke level after reaching certain height, just grows denser. Figure 184 shows BB shot coke which has tendency to continuously grow in height in the drum with time, similar to sponge, the only difference being a lot of fluctuations of height in the column.

Figure 185 and Figure 186 show the temperature profiles for SUN 2 and SUN 3 antifoam runs respectively. The difference in coke morphology at the same operating conditions can be explained by comparing the temperature profiles for the bottom of the drum (TI-214) shown in Figure 187 and fluid inlet temperatures (TI-107) as shown in Figure 188. The temperature in the bottom of the drum is different by about $20-30^{\circ} \mathrm{F}$ between SUN 3 and SUN 2 for the first two hours as shown in Figure 187. Figure 183 
shows that the antifoam is injected in the beginning of the test run and the foam thus collapsed and suppressed the bottom temperature (TI-214). Figure 184 shows that SUN 3 didn't foam badly in the beginning and the antifoam was injected only in the later part of the test run, which allowed quick recovery of the bottom temperature (TI-214). The lower temperatures at the bottom of the drum allow the molten mass at the bottom to solidify into dense agglomerated coke, whereas higher temperatures at the bottom of the drum tend to vaporize or crack the molten liquid and forms BB's.

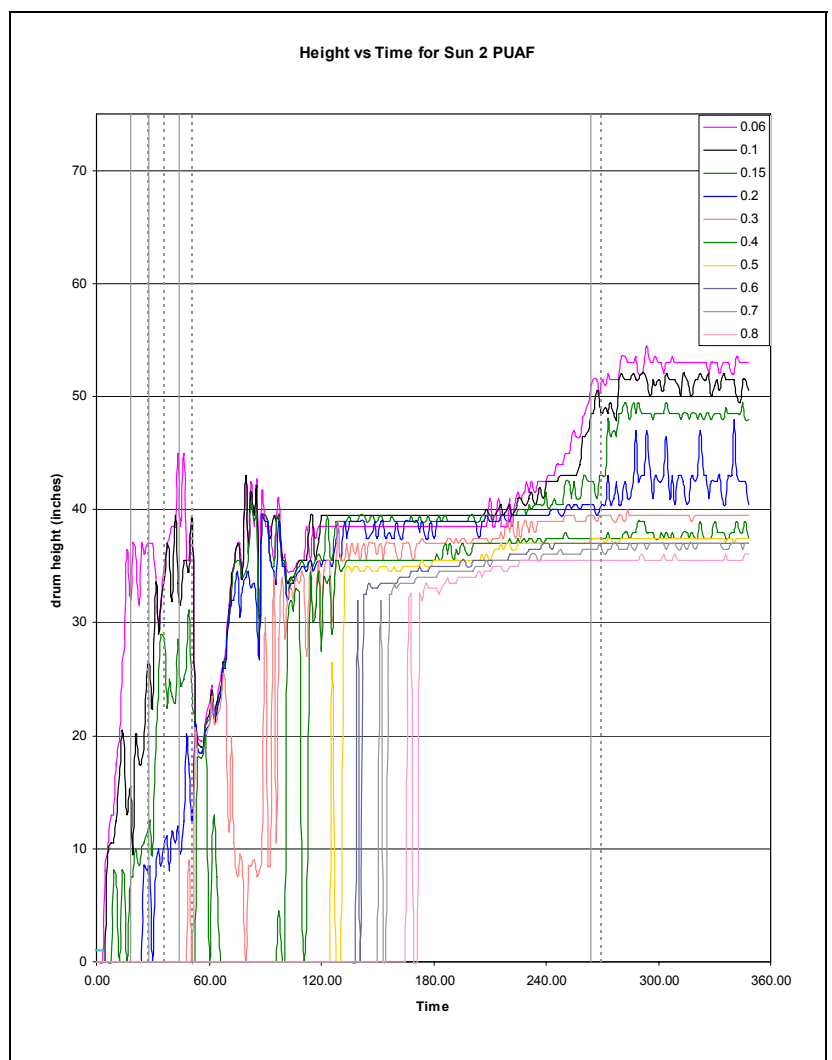

Figure 183 - Suncor Anti-Foaming Runs - Height vs. Time (Aggl Shot Coke from SUN 2 PUAF)

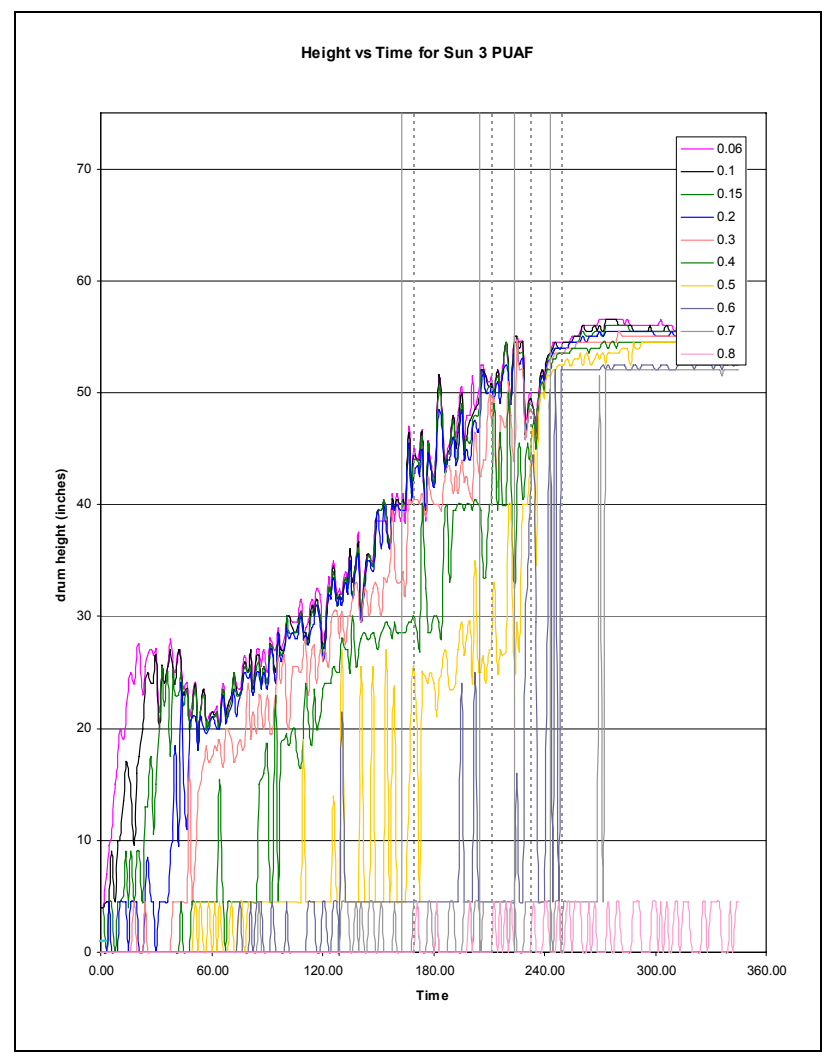

Figure 184 - Suncor Anti-Foaming Runs - Height vs. Time (BB Shot Coke from SUN 3 PUAF) 


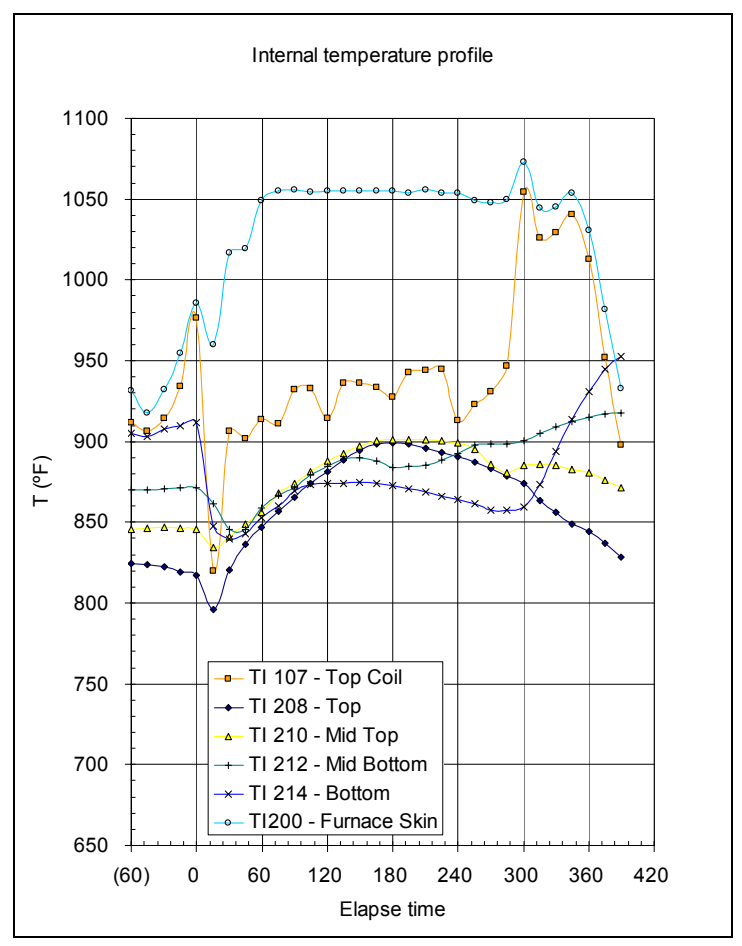

Figure 185 - Temperature Profile for SUN 2 PUAF

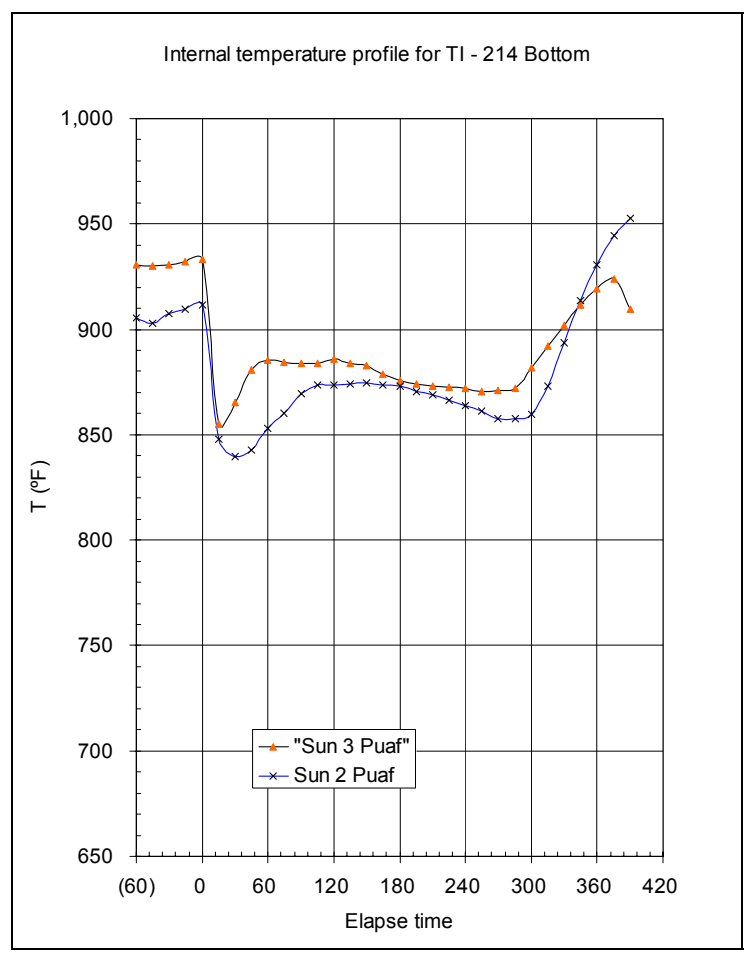

Figure 187 - TI-214 Bottom Temperature Comparison for Suncor Runs

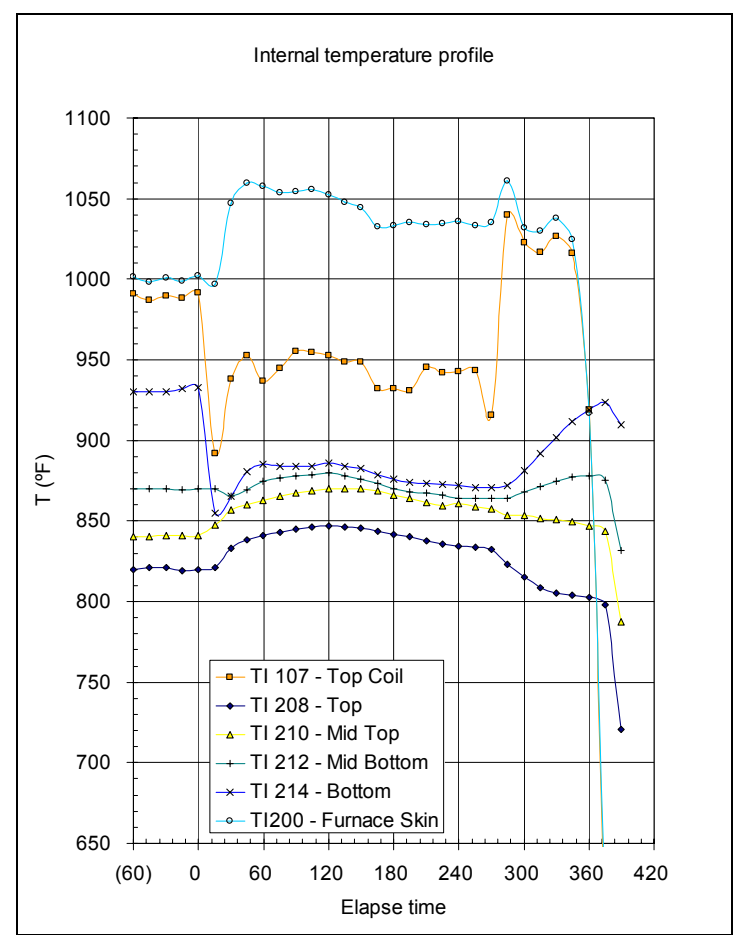

Figure 186 - Temperature Profile for SUN 3 PUAF

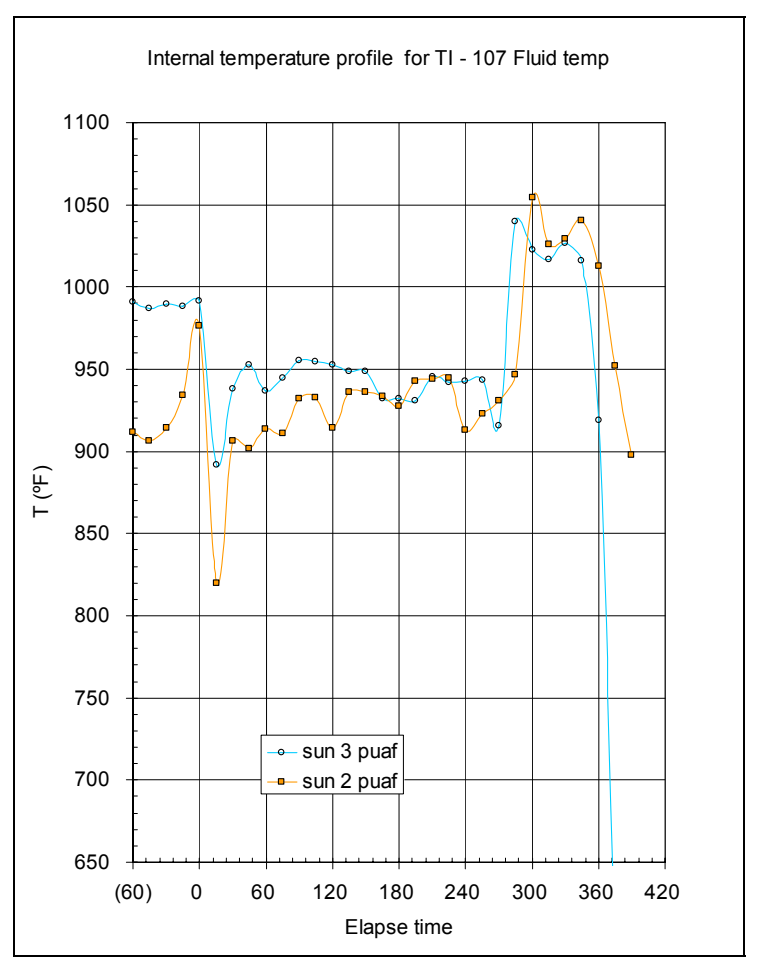

Figure 188 - Tl-107 Fluid Temperature Comparison for Suncor Runs 


\section{Effect of operating Conditions on Coke Morphology:}

\section{Temperature:}

With an increase in temperature from $900^{\circ} \mathrm{F}$ to $930^{\circ} \mathrm{F}$ the $\%$ of $\mathrm{BB}$ 's formed decreased, which contradicts the rule of thumb that at higher temperature more BB's are formed. The reason could be because the two test runs are at a higher pressure (40 psig).

It was seen that there was not much of a change in the liquid layer with change in pressure or temperature. The foam layer increased with increase of temperature at $15 \mathrm{psig}$ and it decreased with increase in temperature at $40 \mathrm{psig}$.

\section{Feed rate:}

Error! Reference source not found. shows the effect of increasing feed rate for Suncor runs, where the other operating conditions such as temperature $\left(930^{\circ} \mathrm{F}\right)$ and pressure $(15 \mathrm{psig})$ are the same. With an increase in feed rate from $2400 \mathrm{~g} / \mathrm{hr}$ to $3600 \mathrm{~g} / \mathrm{hr}$ the \% of BB's formed decreased. Increase in feed rate increases the time required for the temperature to get back to the desired fluid temperature, which lowers the amount of BB's formed in the coke drum.

\section{Effect of Antifoam injection}

The amount of BB's formed increased with an increase in either the amount of antifoam used or concentration of antifoam used. For the SUN 13 run, the feed line injection resulted in complete elimination of BB's, which formed in the prior runs when the antifoam injection was overhead and possibly carried out of the drum.

\section{Effect of operating conditions on Density of coke:}

Considering the density columns, it was inferred that the increase in temperature, pressure or feed rate increases the coke density. For shot coke the discrepancy of increase in density due to increase in feed rate, from the sponge coke is due to the formation of dense agglomerated shot coke at higher feed rates.

\section{Foaming tendencies for Suncor resid:}

Increase in temperature decreased foaming for Suncor resid while an increase in pressure and superficial velocities increased foaming for Suncor resid. Pressure appears to be more dominant variable for Suncor resid.

\section{(ii) Equilon resid:}

Equilon made mixture of agglomerated shot, BB's and sponge coke. The BB's formed varied from fine BB's to small spheres of different sizes. 


\section{Effect of operating Conditions on Coke Morphology:}

Temperature:

An increase in temperature from $900^{\circ} \mathrm{F}$ to $930^{\circ} \mathrm{F}$ caused the $\%$ of BB's formed to increase. Considering all the four runs higher temperature more shot coke is formed.

Both foam and liquid layers increased with increase of temperature at $15 \mathrm{psig}$ and it decreased with increase in temperature at 40 psig.

Note: The observations are based on only one test run at certain set of temperature and pressures.

Pressure:

An increase in pressure eliminated the BB's and also reduced the \% of shot coke formed.

Feed rate:

With an increase in feed rate from $2400 \mathrm{~g} / \mathrm{hr}$ to $3600 \mathrm{~g} / \mathrm{hr}$ the amount of shot coke as well as \% of BB's has increased.

\section{Effect of operating conditions on Density of coke:}

Data available for the Bulk densities did not have a specific trend for either the temperature or pressure as the values didn't change much.

\section{Foaming tendencies for Equilon resid:}

The severest foaming was seen at high pressure and higher feed rate runs. Figure 189 and Figure 190 shows the Height vs. Time plots for given density for the EQ 5 and EQ 6 runs. Pressure appears to be more dominant variable for Equilon resid. 


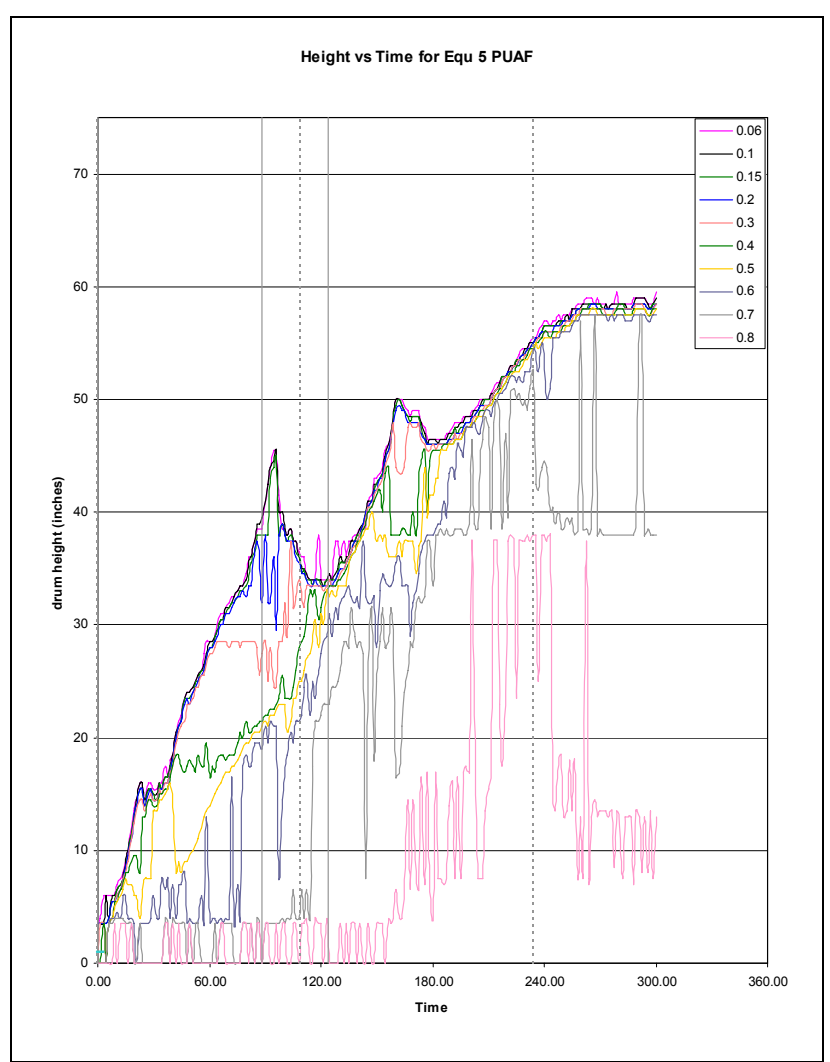

Figure 189 - Equilon Anti-Foaming Runs - Height vs. Time (EQ 5 PUAF)

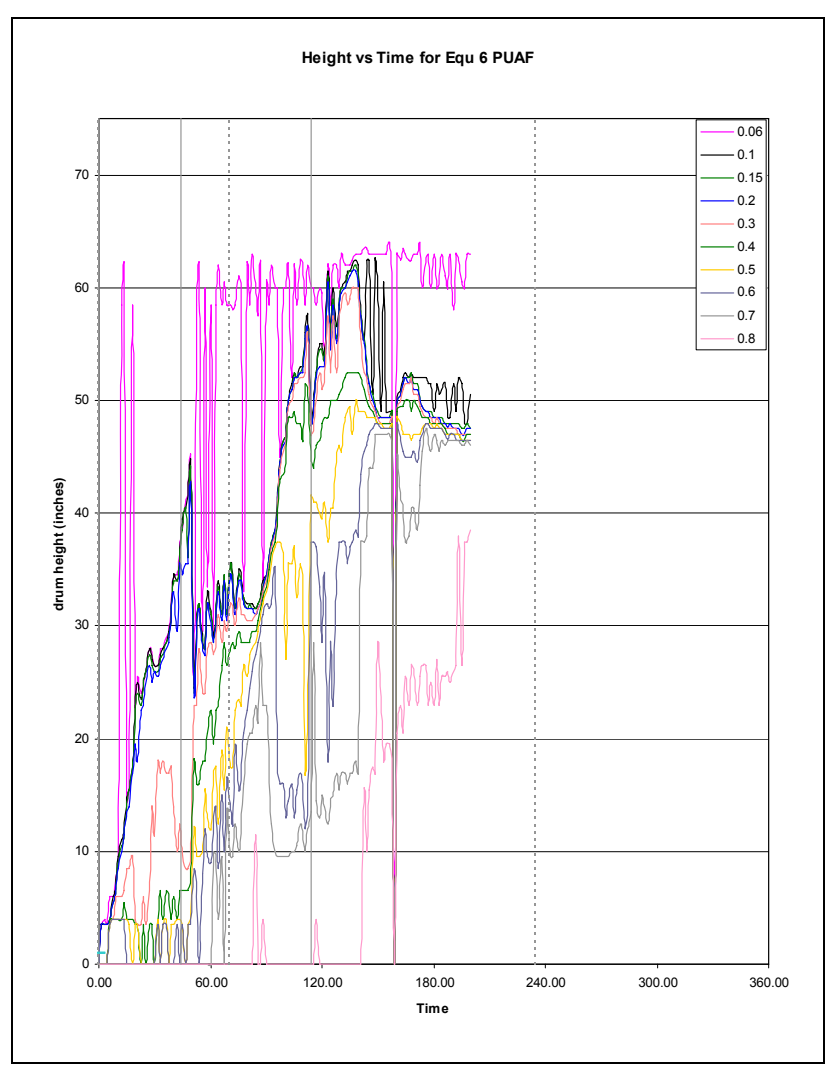

Figure 190 - Equilon Anti-Foaming Runs - Height vs. Time (EQ 6 PUAF)

(iii) Chevron resid:

Chevron made sponge coke at the top and middle portions and agglomerated shot coke in the bottom. This kind of mixture of sponge and shot coke formation might be because it is a naphthenic structured resid.

\section{Sponge vs. shot coke:}

The CHEV 6 run made $85 \%$ sponge coke while the CHEV 8 run made 100\% agglomerated shot coke. Figure 191 and Figure 192 show how the densities of the sponge coke and the shot coke vary during a test run. 


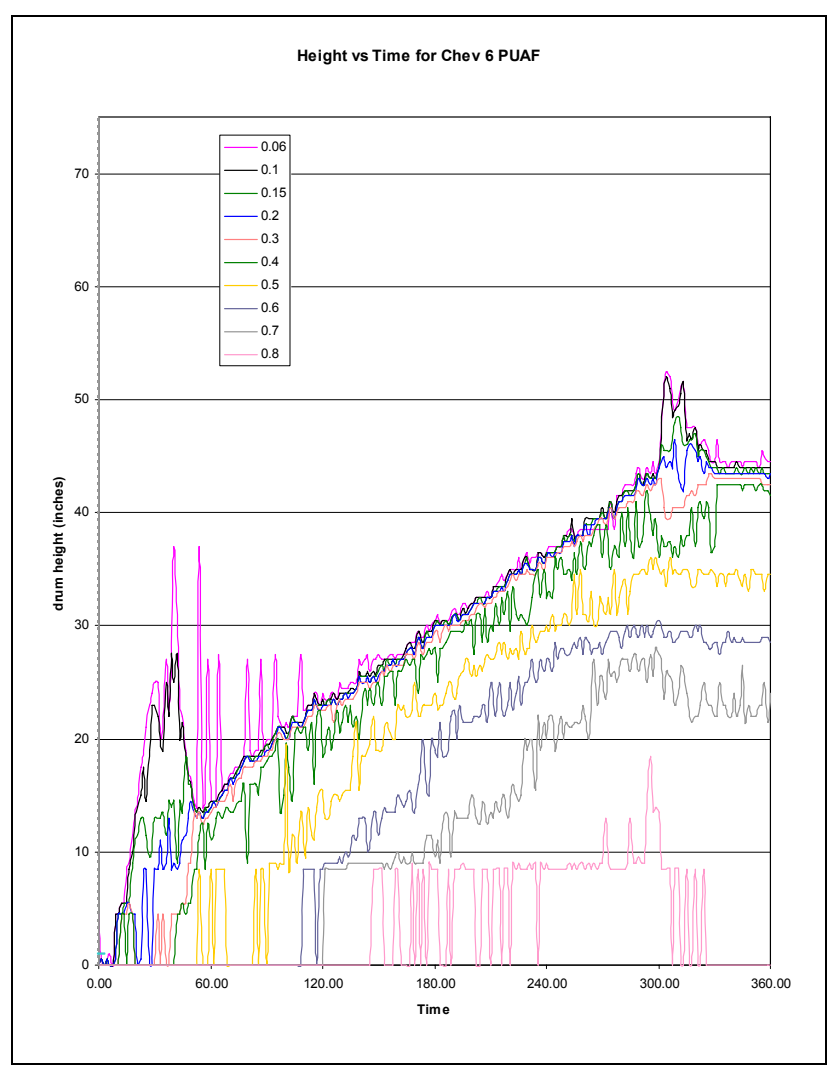

Figure 191 - Chevron Anti-Foaming Runs - Height vs. Time (Sponge Coke from CHEV 6 PUAF)

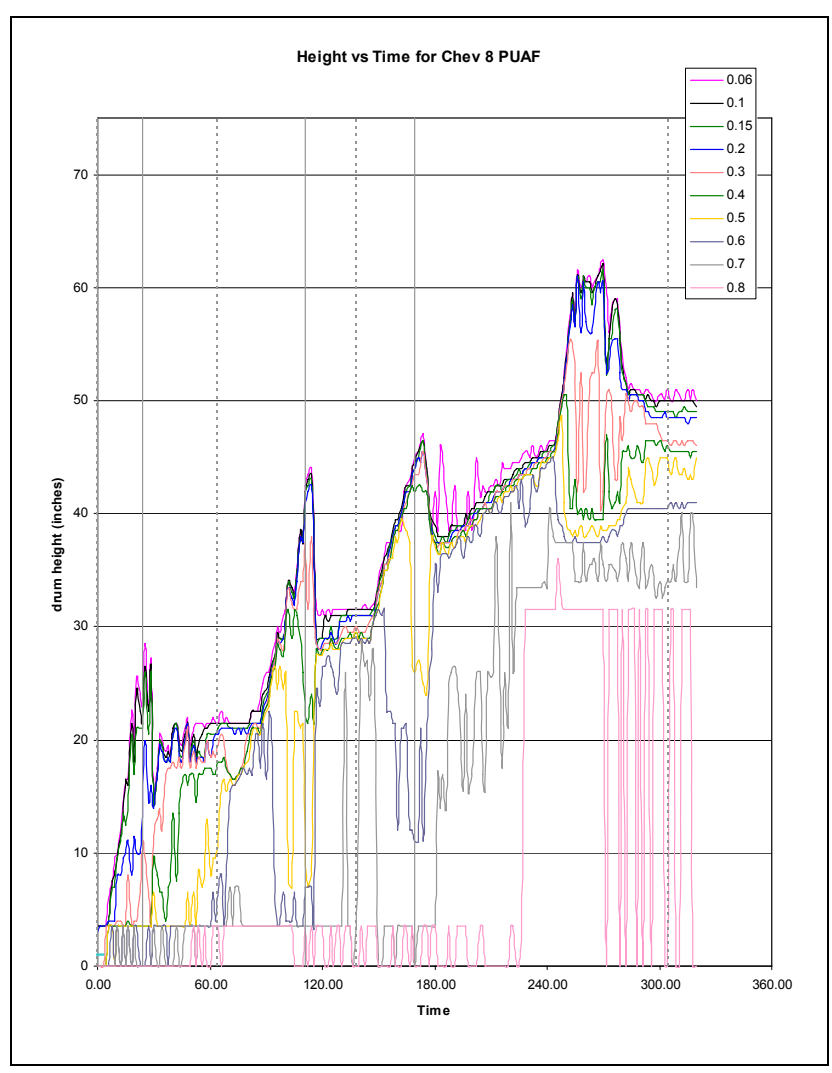

Figure 192 - Chevron Anti-Foaming Runs - Height vs. Time (Aggl Coke from CHEV 8 PUAF)

Sponge coke has a very porous structure allowing the coke height to continually increase with time, which is shown in Figure 191 where the higher density traces followed the lower density traces ( slope is nearly same). Shot coke has a tendency to agglomerate in the drum, which is shown by Figure 192 where the lower density traces, once they reach a certain height, stay there allowing the coke below to become denser. Also for this run, once the resid breaks through this agglomerated portion, the coke height begins to increase on a continual basis.

\section{Effect of operating Conditions on Coke Morphology:}

Temperature:

For the $15 \mathrm{psig}$ runs it was observed that an increase in temperature from $900^{\circ} \mathrm{F}$ to $930^{\circ} \mathrm{F}$ reduced the $\%$ of agglomerated shot formed. The 4 tests at higher pressure (40 psig) showed an increase in temperature from $900^{\circ} \mathrm{F}$ to $930^{\circ} \mathrm{F}$ increased the $\%$ of agglomerated shot coke formed.

The foam layer did not change much with increase in temperature and pressure. Liquid layer decreased slightly at $15 \mathrm{psig}$ and quite significantly at $40 \mathrm{psig}$ with an increase in temperature. 
Pressure:

For thr $900^{\circ} \mathrm{F}$ tests it is observed that an increase in pressure from 15 psig to 40 psig reduced the $\%$ of agglomerated shot formed. At a higher temperature of $930^{\circ} \mathrm{F}$, an increase in pressure from $15 \mathrm{psig}$ to 40 psig increased the \% of agglomerated shot coke formed.

Feed rate:

\section{Effect of operating conditions on Density of coke:}

An increase in bulk density with an increase in temperature was ran for the $2400 \mathrm{~g} / \mathrm{hr}$ runs, but there was a decrease in density with an increase in temperature for the $3600 \mathrm{~g} / \mathrm{hr}$ runs. A slight increase in density with an increase in pressure was seenfor all the other operating conditions. A decrease in density with an increase in feed rate except for the $900^{\circ} \mathrm{F}$ and $40 \mathrm{psig}, 3600 \mathrm{~g} / \mathrm{hr}$ run which foamed badly and produced a denser coke with an increase in the feed rate were seen.

\section{Foaming tendencies for Chevron Resid:}

At low superficial velocities there is not much foaming observed for the Chevron test runs. Figure 193 and Figure 194 show the Height vs. Time plots for given density for the CHEV 8 and CHEV 10 runs respectively. The lower temperature runs were the worst foamers when the Chevron resid was used. Also of the two runs considered below the higher pressure run was worst foamer. Pressure appears to be dominant variable for chevron resid. 


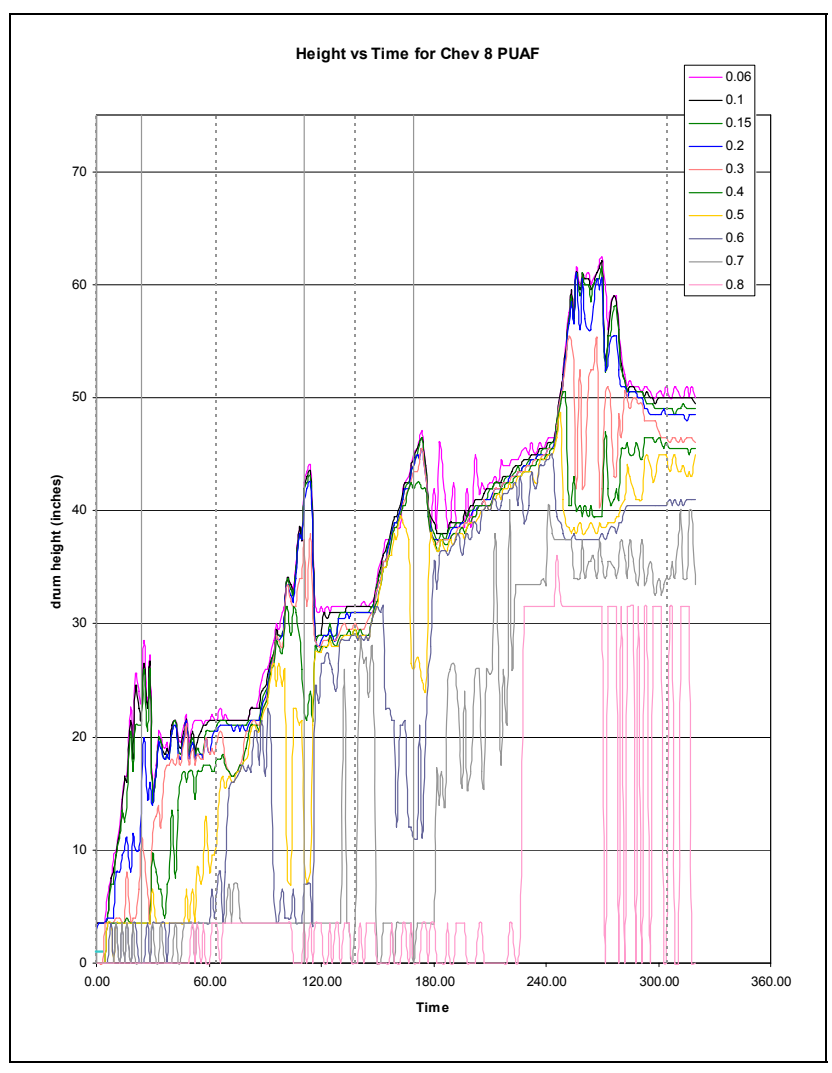

Figure 193 - Chevron Anti-Foaming runs - Height vs. Time (CHEV 8 PUAF)

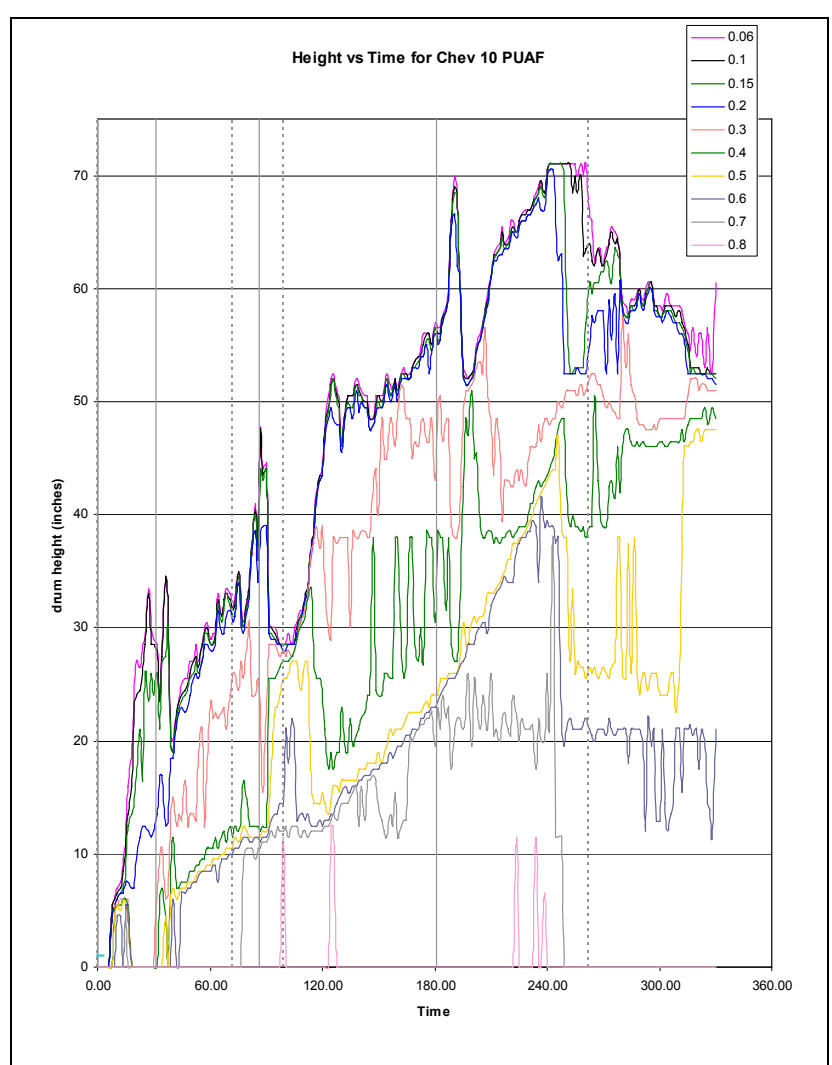

Figure 194 - Chevron Anti-Foaming Runs - Height vs. Time (CHEV 10 PUAF)

(iv) Citgo resid:

The Citgo resid made agglomerated shot coke with some portions of BB's at either high temperatures or higher feed rate(superficial velocities $>=0.15 \mathrm{ft} / \mathrm{s}$ ). The Citgo resid also made sponge coke at low temperature and lower feed rate runs. This kind of mixture of sponge and shot coke formations might be because it is a naphthenic structured resid.

Sponge vs. shot coke:

The CIT 8 run made $100 \%$ sponge coke while CIT 11 made 100\% agglomerated shot coke. Figure 195 and Figure 196 show how the densities of sponge coke and shot coke vary during a test run. 


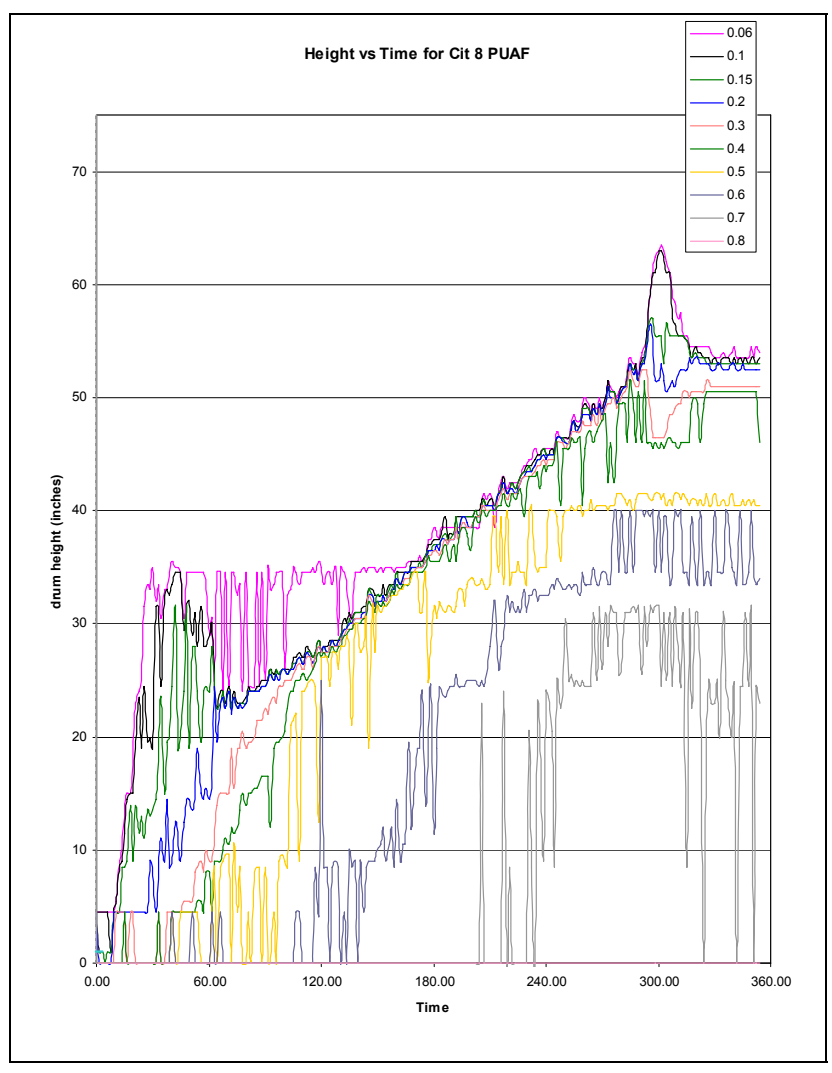

Figure 195 - Citgo Anti-Foaming runs - Height vs. Time (Sponge Coke from CIT 8 PUAF)

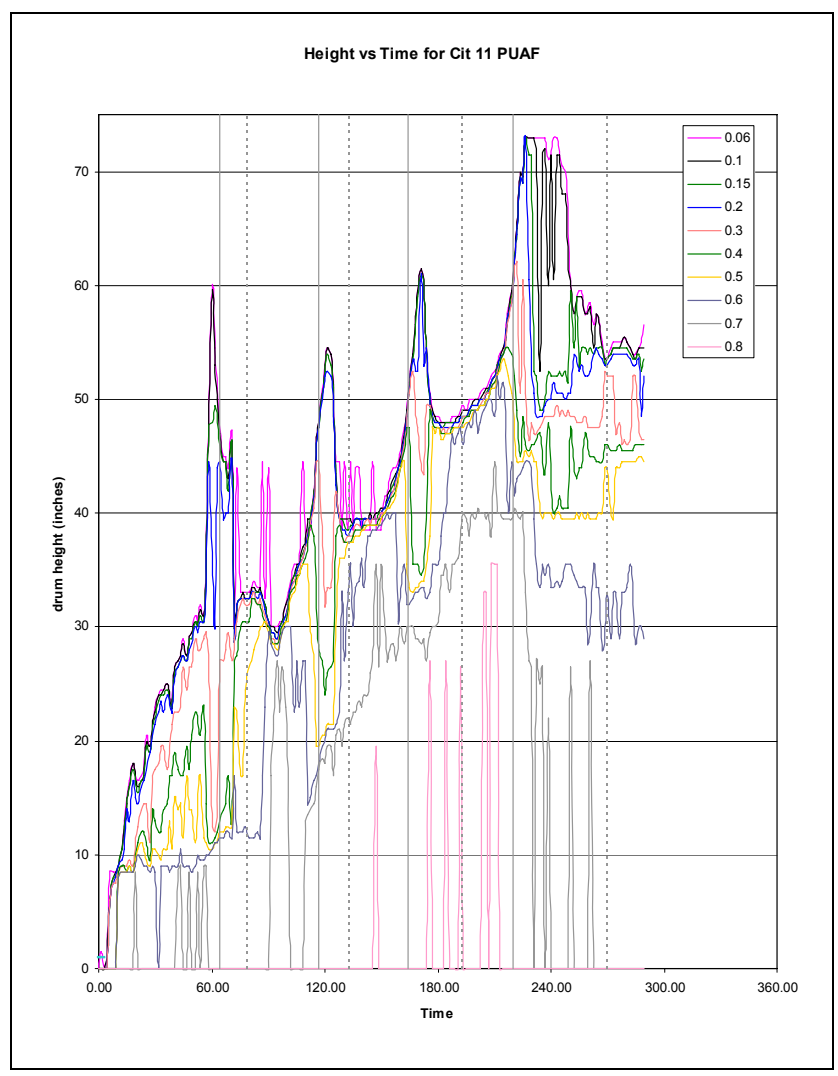

Figure 196 - Citgo Anti-Foaming runs - Height vs. Time (Aggl Coke from CIT 11 PUAF)

Sponge coke has a porous structure that allows the coke height to continually grow as a function of time, which is shown in Figure 195 where the higher density traces followed the lower density traces (slope is nearly same). Shot coke has a tendency to agglomerate in the drum, which is shown by Figure 196 where the lower density traces, once they reach a certain height, stay there allowing the coke below to become denser. Note though that the agglomerated shot was formed after each antifoam injection. Also for this run, when the resid breaks through this agglomerated portion, the coke height begins to grow again.

\section{Effect of operating Conditions on Coke Morphology:}

\section{Temperature:}

At low pressure $(15 \mathrm{psig})$ and low flowrate $(2400 \mathrm{~g} / \mathrm{hr})$ an increase in temperature from $900^{\circ} \mathrm{F}$ to $930^{\circ} \mathrm{F}$ increased the $\%$ of both agglomerated shot and BB's. At low pressure and higher feed rates (15 psig and $3600 \mathrm{~g} / \mathrm{hr}$ respectively), an increased in temperature increases the \% of BB's. At a higher pressure (40 psig) the coke morphology didn't change with an increase in temperature; however the morphology changed from sponge coke to shot coke when the feed rate was increased from 2400 to 3600 $\mathrm{g} / \mathrm{hr}$. 
Both foam and liquid layers decreased with with increase of temperature at $15 \mathrm{psig}$ and they did not change much with increase in temperature at 40 psig.

\section{Pressure:}

At lower feed rates $(2400 \mathrm{~g} / \mathrm{hr})$ and lower temperature $\left(900^{\circ} \mathrm{F}\right)$ where sponge coke is also formed, an increase in pressure from $15 \mathrm{psig}$ to $40 \mathrm{psig}$ reduced the \% of agglomerated shot formed, increasing the sponge coke \%. At higher temperature $\left(930^{\circ} \mathrm{F}\right)$ run times are not equal to make any observation. The higher feed rate $(3600 \mathrm{~g} / \mathrm{hr})$ runs foamed badly and the run times were shorter to make any comparisons.

Feed rate:

Increasing the feed rate makes more shot coke for any given set of temperature and pressure.

\section{Effect of operating conditions on Density of coke:}

An increase in bulk density was seen with an increase in temperature except for one run which was less than $3 \mathrm{hrs}$. An increase in density was seen with an increase in pressure for all operating conditions. Feed rate change didn't have a specific trend on the density of coke formed.

\section{Foaming tendencies for Citgo Resid:}

At low superficial velocities when Citgo resid made sponge coke, an increase in temperature decresed foaming and temperarute appeared to be the more dominant variable. When test runs having feedrate of $3600 \mathrm{gm} / \mathrm{hr}$ were considered, Cit 9 and Cit 11 runs were the worst foamers. Figure 193 and Figure 194 show the Height vs. Time plots for given density for the Cit 9 and Cit 11 runs respectively. The lower temperature runs were the worst foamers when the Citgo resid was used. Also of the two runs considered below higher pressure run was worst foamer. Pressure appears to be dominant variable for Citgo resid. 


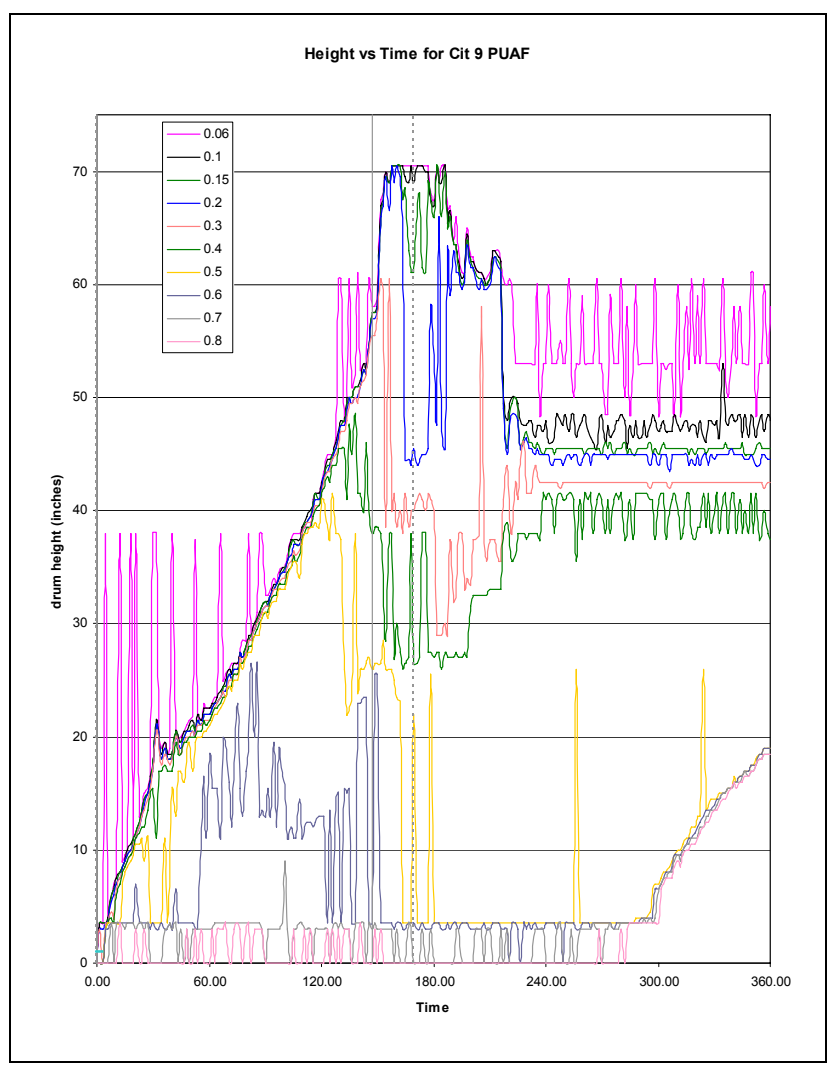

Figure 197 - Citgo Anti-Foaming runs - Height vs. Time (Cit 9 PUAF)

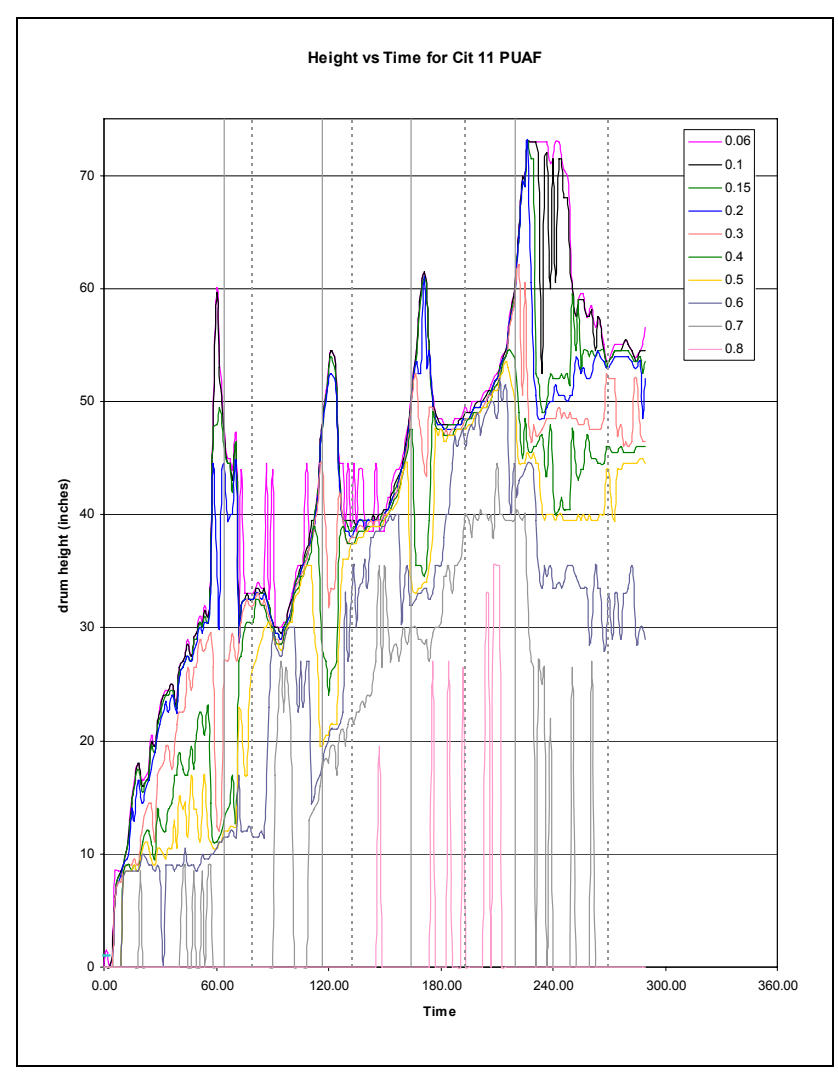

Figure 198 - Citgo Anti-Foaming Runs - Height vs. Time (Cit 11 PUAF)

\section{Recycle runs with Suncor and Marathon resids}

Table 73 gives the pilot unit foaming studies data for Suncor runs with recycle. Suncor 6, 14, 15 $(5 \% \mathrm{RC}), 16(10 \% \mathrm{RC})$ runs were carried out at a temperature of $900 \mathrm{\circ}$, a pressure of $15 \mathrm{psig}$ and a feed rate of $2400 \mathrm{gm} / \mathrm{hr}$. Suncor $17(15 \% \mathrm{RC})$ was run at industry conditions, at a temperature of $928 \mathrm{oF}, \mathrm{a}$ pressure of $38 \mathrm{psig}$ and a feed rate of $2400 \mathrm{gm} / \mathrm{hr}$. Figure 199 shows the comparison of furnace skin temperatures for these runs. It is observed that with an increase in recycle, the heat input required increased. It is observed that with an increase in the amount of recycle the density of the coke formed decreases. Suncor $18(15 \% \mathrm{RC})$ and $19(5 \% \mathrm{RC})$ runs were carried out at industry conditions, at a temperature of $928 \mathrm{OF}$, a pressure of $38 \mathrm{psig}$ and a feed rate of $3600 \mathrm{gm} / \mathrm{hr}$. At these conditions recycle appears to have little effect on density. Suncor $28(100 \%$ RC) was run at a temperature of $930 \mathrm{oF}$, a pressure of $40 \mathrm{psig}$ and a feed rate of $2400 \mathrm{gm} / \mathrm{hr}$. Suncor runs with and without recycle made shot coke irrespective of operating conditions. The coke yields were in the range of $24.5-27 \%$, the liquid yields were in the range of $61.5-63 \%$, and the gases were in the range of 10 to $12 \%$. There was not much difference observed in the overall SimDis data with the increase in recycle at 900 oF and 15 psig. For the higher pressure and temperature run, Suncor 17, an increase in gasoline and a decrease in gas oil was seen. There was around $6 \%$ increase in coke and $6 \%$ decrease in liquid with 100\% recycle for Suncor run 28. 
Table 73 - Pilot unit foaming studies data for Suncor runs

\begin{tabular}{|c|c|c|c|c|c|c|c|c|c|c|c|c|c|}
\hline Run & Date & $T$ & $P$ & $\mathrm{~F}$ & Type of AF & Methe & od Total Amt. of (cc) & Actual AF used & $\#$ of in. & First Faam| & Re-appearance & $\Delta \mathrm{T}$ & Steam Strip \\
\hline & & OF & psig & $g m / h r$ & & & Defoamer(AF+D) & (cc) & & Front(ming & of Foam(min) & min & Behaviour \\
\hline SUNC14 & 9/11/2003 & 900 & 15 & 2400 & $100,000 \operatorname{cst}(0.3 \mathrm{AF} / 70 \mathrm{D})$ & 0 & 112 & 0.49 & 11 & 25.5 & 36 & 11 & Average Void \\
\hline SUNC 15 (5\%RC) & 9/17/2003 & 900 & 15 & 2400 & $100,000 \operatorname{cst}(0.3 \mathrm{AF} / 70 \mathrm{D})$ & 0 & 80 & 0.35 & 8 & 42 & 78 & 36 & Good \\
\hline SLNC 16(10\% RC) & 9/25/2003 & 900 & 15 & 2400 & $100,000 \mathrm{cSt}(0.3 \mathrm{AF} / 70 \mathrm{D})$ & 0 & 90 & 0.39 & 9 & 31.5 & 66 & 35 & Cood \\
\hline SUNC 17 (15\% RC) & 10112003 & 928 & 38 & 2400 & $100,000 \mathrm{cSt}(0.3 \mathrm{AF} / 70 \mathrm{D})$ & 0 & \multicolumn{6}{|c|}{ No Foam was observed during this nun, hence antifioam was not imjected. } & Cood \\
\hline SUNC 18 (15\% RC) & 10622003 & 928 & 38 & 3600 & $100,000 \mathrm{cSt}(0.3 \mathrm{AF} / 70 \mathrm{D})$ & 0 & 60 & 0.26 & 5 & 15 & 30 & 15 & Cood \\
\hline SUNC 19 (5\% RC) & 11/112003 & 928 & 38 & 3600 & $100,000 \operatorname{cst}(0.3 \mathrm{AF} / 70 \mathrm{D})$ & 0 & 20 & 19.91 & 2 & 22.5 & 37.5 & 15 & Good \\
\hline SUNC28 (100\% RC) & 3242004 & 930 & 40 & 2400 & $100,000 \operatorname{cSt}(0.3 \mathrm{AF} / 70 \mathrm{D})$ & \multicolumn{7}{|c|}{\begin{tabular}{l|l}
0 & No Foam was observed during this run, hence antifoam was not imjected.
\end{tabular}} & Cood \\
\hline
\end{tabular}

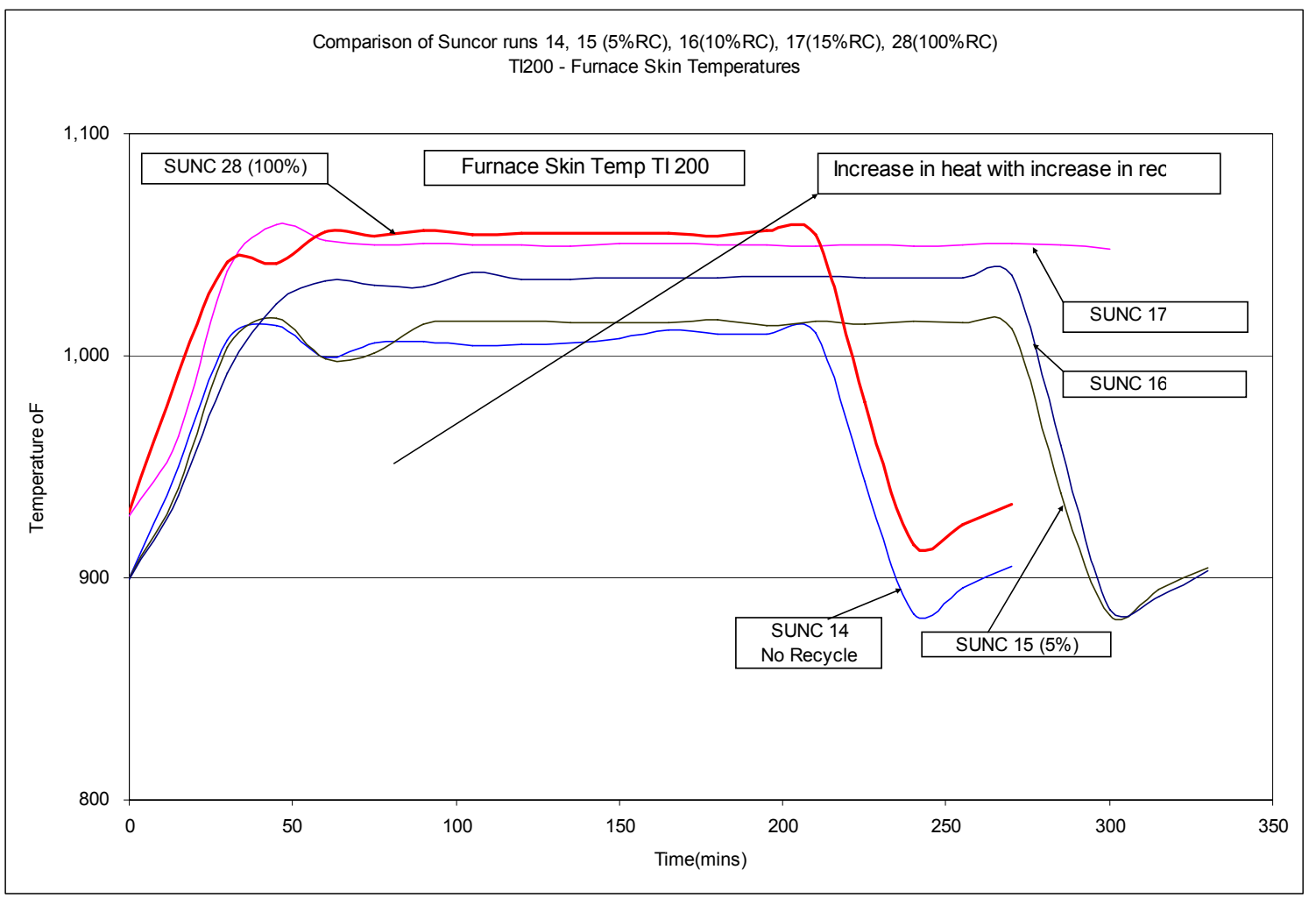

Figure 199 - Furnace Skin temperature comparisons for Suncor runs

The second phase of the Marathon runs were carried out during the last quarter of 2003 and continued into the first quarter of 2004. Table 74 shows the foaming studies data for the Marathon runs. Marathon $8,9(5 \% \mathrm{RC})$ and $10(10 \% \mathrm{RC})$ runs were carried at a temperature of $900 \mathrm{o}$, a pressure of 15 $\mathrm{psig}$ and a feed rate of $2400 \mathrm{gm} / \mathrm{hr}$. During these runs, foam was not observed and hence antifoam was not injected. Figure 200 shows the temperature profile for these runs. It is observed that with the addition of recycle in the feed, the amount of heat required to attain the desired run temperature increases. The runs with recycle produced a coke with a slightly lower density compared to runs with no recycle, although for all practical purposes not much change was seen. For the $3600 \mathrm{gm} / \mathrm{hr}$ runs little change in density with an increase in recycle was observed as well. It was noted that the mass of bed was lifted during the steam strip process. The coke yields were in the range of $20-22 \%$, the liquid yields were in the range of $68-$ 
$70 \%$, and the gases were in the range of 9 to $11 \%$. With an increase in recycle concentration, an increase in gasoline was seen. There was not much difference observed in diesel and gas oils. Marathon 17 $(100 \% \mathrm{RC})$ was run at a temperature of $930 \mathrm{oF}$, a pressure of $40 \mathrm{psig}$ and a feed rate of $2400 \mathrm{gm} / \mathrm{hr}$. With $100 \%$ recycle and at higher temperature and pressure, it is observed that Marathon has the highest liquid yields and lowest coke yields. The $100 \%$ recycle for the Marathon resid produced more liquids whereas with the Suncor resid at 100\% recycle more coke was produced. This can be attributed to higher asphaltene content property of the resid. The Suncor resid has almost twice the asphaltene content as the Marathon resid.

Table 74 - Pilot unit foaming studies data for Marathon runs

\begin{tabular}{|c|c|c|c|c|c|c|c|c|c|c|c|c|c|}
\hline Ruln & Date & T & P & $\mathrm{F}$ & Type of AF & Method & Total Amt. of (cc) & Actual AF used & $\#$ of inj. & First Foam & Re-appearance & $\Delta \mathrm{T}$ & Steam Strip \\
\hline & & op & psig & $g m h \mathrm{hr}$ & & & Defoamer(AF-D) & (cc) & & Front(min & in of Foam(min) & $\min$ & Behaviour \\
\hline MARA \&PUAFI & 11/1822003 & 900 & 15 & 2400 & 100,000 cst $(0.3 \mathrm{ml} \mathrm{AF} / 70 \mathrm{ml})$ & 0 & \multicolumn{6}{|c|}{ No Foam was observed during this run, hence antifoam was not impected. } & Cood \\
\hline $\operatorname{MARA} 9(5 \% \mathrm{RC})$ & 111212003 & 900 & 15 & 2400 & 100,000 cst $(0.3 \mathrm{~m} / \mathrm{AF} / 70 \mathrm{ml} \mathrm{D})$ & 0 & \multicolumn{6}{|c|}{ No Foam was observed duringo this run, hence antifoam was not impected. } & cood \\
\hline MARA 10 (10\%:RC) & 1222003 & 900 & 15 & 2400 & 100,000 cst $(0.3 \mathrm{ml} \mathrm{AF} / 70 \mathrm{ml})$ & 0 & \multicolumn{6}{|c|}{ No Foam was observed during this run, hence antifoam was not impected. } & Cood \\
\hline MARA $11(5 \%$ RC) & 12/192003 & 900 & 15 & 3600 & 100,000 cst $(0.3 \mathrm{~m} / \mathrm{AF} / 70 \mathrm{ml} \mathrm{D})$ & $\mathrm{OHF}$ & 155 & 0.68 & $j$ & 169 & 180 & 11 & Average \\
\hline MARA 12 (10\%:RC) & 182004 & 900 & 15 & 3600 & 100,000 cst $(0.3 \mathrm{~m} / \mathrm{AF} / 70 \mathrm{ml} \mathrm{D})$ & 0 & 205 & 0.89 & 17 & 8 & 18 & 10 & Average \\
\hline MARA $17(100 \%$ RC) & $3 / 262004$ & 930 & 40 & 2400 & $100,000 \cot (3 \mathrm{ml} \mathrm{AF/70} \mathrm{m} \mathrm{m})$ & \multicolumn{7}{|c|}{\begin{tabular}{l|l}
0 & No Foam was observed during this run, hence antififoam was not imected.
\end{tabular}} & Cood \\
\hline
\end{tabular}

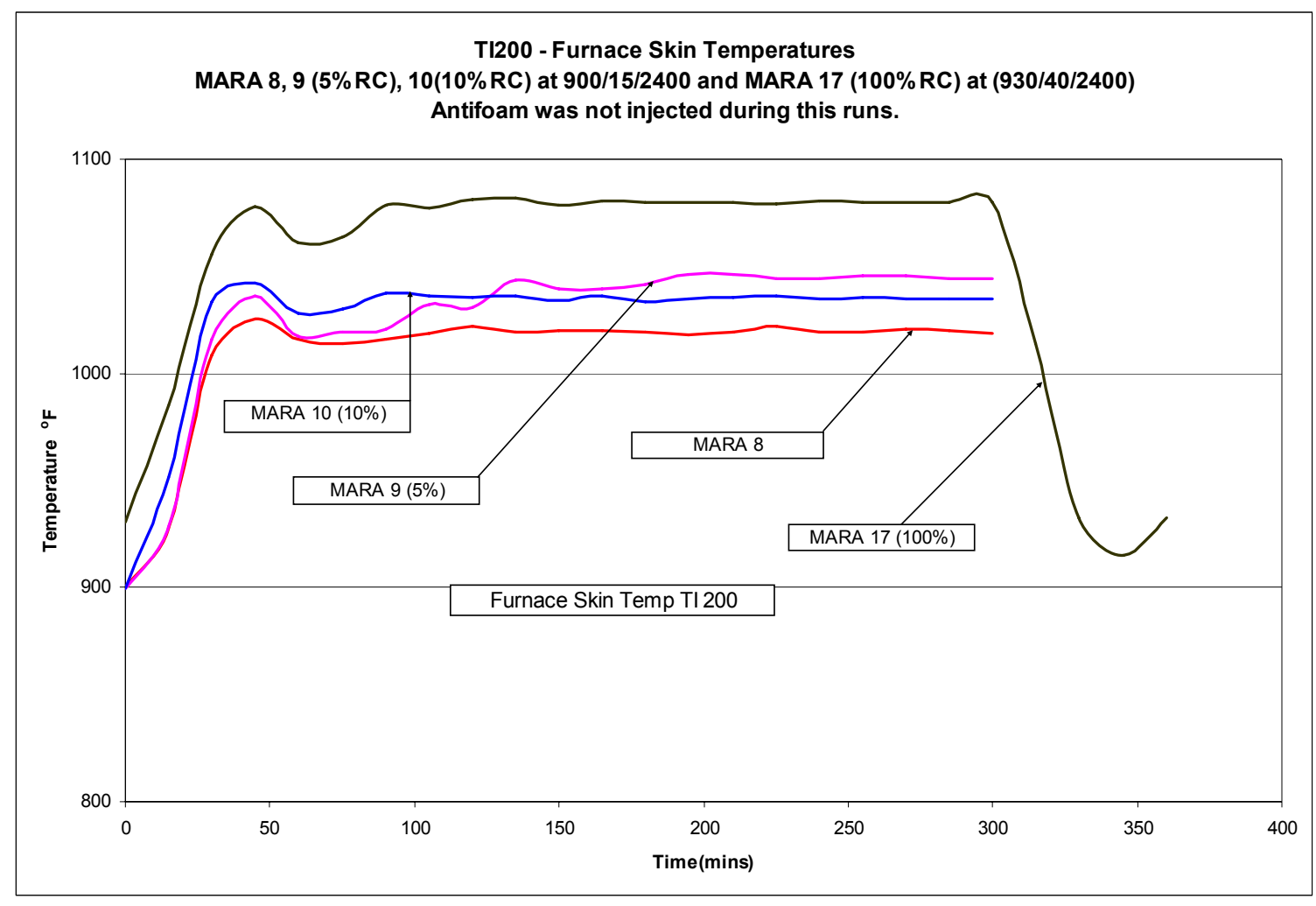

Figure 200 - Temperature Profile for Marathon 8, 9 (5\%RC) and $10(10 \% R C)$ runs 


\section{Foaming Tendencies for Suncor Recycle Runs}

Not much foaming was observed with $5 \%$ recycle. At a drum height of 30 inches, some collapse of foam was observed. It was observed in that after several antifoam injections, the time for re-appearance of foam is longer compared to the initial appearance time. In other words, the time of foam suppression after antifoam injection was 1, 3, 7, 10 and 10 minutes, thereby increasing with each injection. Less foaming was observed with $15 \%$ recycle hence a total of 5 injections were made of low concentration antifoam. Suncor run 28 with $100 \%$ recycle was carried out at a temperature of $930{ }^{\circ} \mathrm{F}$, a pressure of $15 \mathrm{psig}$ and a feed rate of $2400 \mathrm{gm} / \mathrm{hr}$. Foaming was not observed during this run and hence antifoam was not injected. In general the time to rise of foam for the Suncor recycle runs is usually in the range $12-15$ minutes. The time of collapse of foam at different drum heights is usually in the range of $35-40$ minutes. Hence it can be said that Suncor resid with recycle mixed in the feed shows little to moderate foaming tendencies.

\section{Foaming Tendencies for Marathon Recycle Runs}

The Marathon runs $8,9(5 \% \mathrm{RC})$ and $10(10 \% \mathrm{RC})$ were carried out at a temperature of $900 \mathrm{\circ}$, a pressure of $15 \mathrm{psig}$ and a feed rate of $2400 \mathrm{gm} / \mathrm{hr}$. Under these operating conditions, the Marathon resid did not foam and hence antifoam was not injected. Foam was not observed during these runs. The Marathon $11(5 \% \mathrm{RC})$ and $12(10 \% \mathrm{RC})$ runs were carried out at a temperature of $900 \mathrm{\circ}$, a pressure of 15 psig and a feed rate of $3600 \mathrm{gm} / \mathrm{hr}$. During these runs, foam was observed and hence 100,000 cSt antifoam with a $(0.3 / 70)$ concentration was injected through the overhead on an as needed basis. For these runs, little change in density was seen with the addition of recycle. It can be observed that once the foam rose beyond the $2 / 3^{\text {rd }}$ level in the coke drum, it became very difficult to control. Note that with continuous injection of antifoam during the end of the Marathon $11(5 \% R C)$ run, the foam rose and collapsed through out the injection period. It is interesting to note that during run 11, antifoam was not injected during the first 3 hours of the run and hence the density continued to decrease from bottom to top of the drum. There is no clear indication of coke density and the bubbly liquid and foam layers until the 225 minute mark when the antifoam injection collapsed the bubbly liquid layer. The Marathon 12 run used continuous antifoam injection. A total amount of $205 \mathrm{cc}$ was injected. The density versus time plot for the last 2 hours of the run shows the density through out the drum was approximately $0.6 \mathrm{gm} / \mathrm{cc}$. This antifoam injection procedure made a much more uniform coke bed than what was made in Marathon run 11. It is also interesting to note that during the Marathon 11 run, there was foam at the 50 inch height level inside

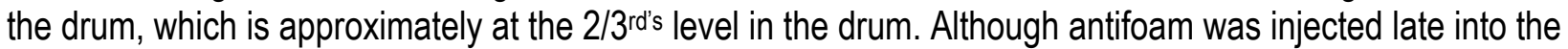
run, a sustained injection of antifoam made the run progress 70 more minutes, thereby increasing the volume of coke bed produced by as much as $30 \%$ at the end of the run. Marathon run 17 with $100 \%$ recycle was carried out at a temperature of $930{ }^{\circ} \mathrm{F}$, a pressure of $15 \mathrm{psig}$ and a feed rate of $2400 \mathrm{gm} / \mathrm{hr}$. Foaming did not occur during this run and hence antifoam was not injected. Marathon resid at low feed rates of $2400 \mathrm{gm} / \mathrm{hr}$ with or without recycle did not show any foaming tendencies. Table 75 gives the foaming tendencies data for the Marathon runs. It shows the time to rise and collapse of foam during antifoam injection times at different heights in the coke drum. Among all the resids the Marathon resid foams the least and makes sponge coke irrespective of operating conditions. Table 76 gives a summary of recycle runs for thr Marathon and Suncor resids. 
The University of Tulsa

Table 75 - Foaming tendencies data for Marathon runs

\begin{tabular}{|c|c|c|c|c|c|c|}
\hline Run \# & Feed Rate & Drum Height & Time to Rise & Time to Collapse & Re-appearance of Foam & $\Delta \mathrm{T}$ \\
\hline & gm/hr & inches & mins into the run & mins into the run & mins into the run & $\min$ \\
\hline MARA 8 & 2400 & \multicolumn{5}{|c|}{ No foam w as observed and hence antifoam w as not injected. } \\
\hline MARA $9(5 \% R C)$ & 2400 & \multicolumn{5}{|c|}{ No foam w as observed and hence antifoam w as not injected. } \\
\hline & & & & & & \\
\hline MARA $10(10 \% R C)$ & 2400 & \multicolumn{5}{|c|}{ No foam w as observed and hence antifoam w as not injected. } \\
\hline \multirow[t]{3}{*}{ MARA $11(5 \% R C)$} & 3600 & 50 & 169.5 & 228 & & 58.5 \\
\hline & & 55 & 181 & 183 & 184.5 & 2 \\
\hline & & 60 & 180 & 184.5 & 195 & 4.5 \\
\hline \multirow[t]{4}{*}{ MARA $12(10 \% R C)$} & 3600 & 20 & 15 & 57 & 61.5 & 42 \\
\hline & & 25 & 18 & 20 & 36 & 2 \\
\hline & & 30 & 21 & 28 & 30 & 7 \\
\hline & & 35 & 160.5 & 165 & & 4.5 \\
\hline MARA $17(100 \%$ RC) & 2400 & \multicolumn{5}{|c|}{ No foam w as observed and hence antifoam w as not injected. } \\
\hline
\end{tabular}

Table 76 - Summary of recycle runs for Marathon and Suncor resids

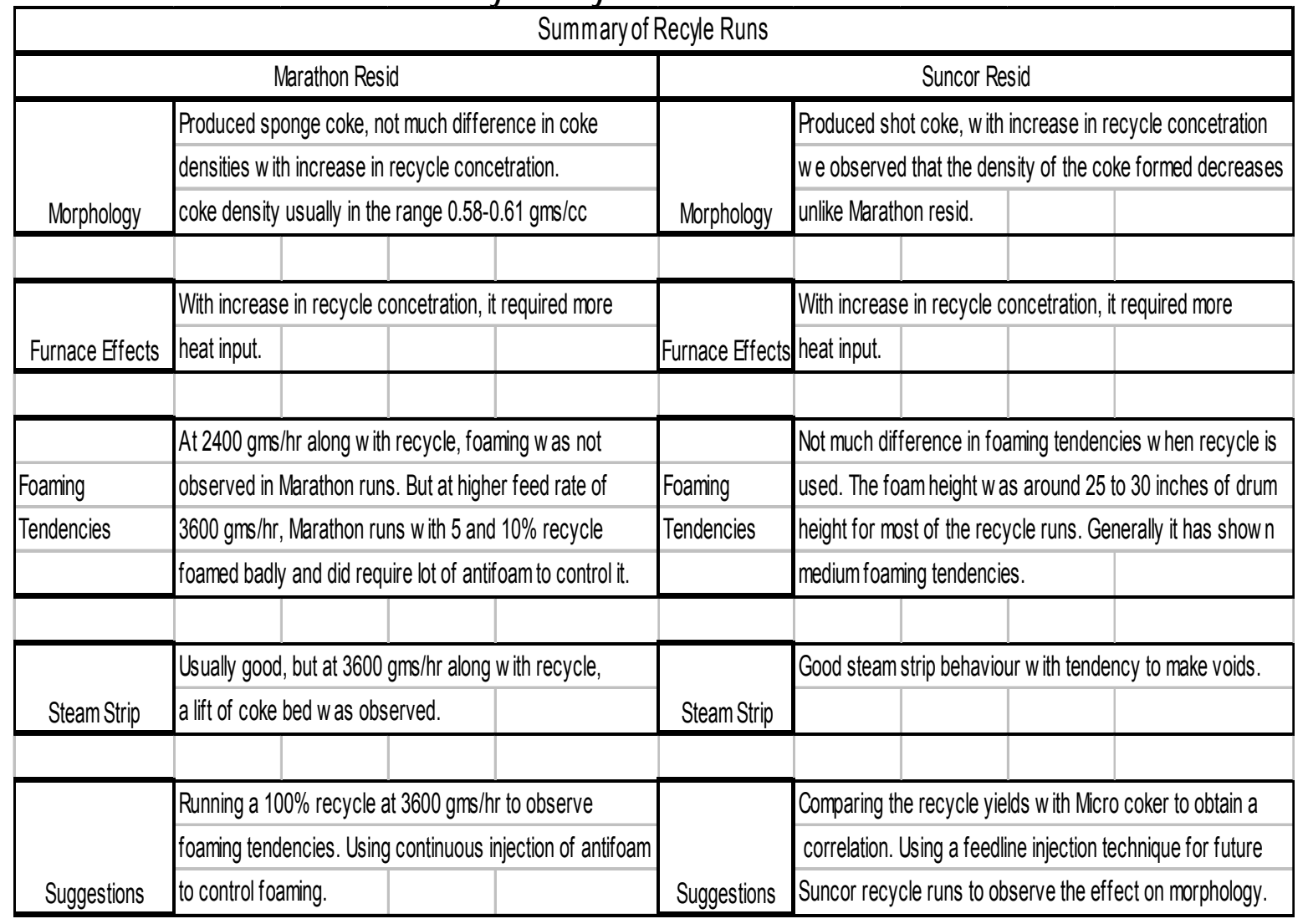




\section{Superficial Velocity Studies}

These tests were conducted to understand the effects of superficial velocity on morphology and foaming tendencies. Three resids were used for these tests namely Marathon, Suncor and Chevron.

\section{Suncor Superficial Velocity Runs}

The Suncor resid makes shot coke irrespective of operating conditions. It has shown moderate foaming tendencies compared to other resids. Suncor test runs were carried out at different feed rates to analyze the foaming tendencies and to study the morphology of the coke formed. Table 77 gives the foaming studies data for the Suncor superficial velocity tests.

\begin{tabular}{|c|c|c|c|c|c|c|c|c|c|c|c|c|c|}
\hline Run & Date & $T$ & $P$ & $\mathrm{~F}$ & Type of AF & Method & Todal Amt. of (cc) & Actual AF used & \# of ing & First Foam & Re-appearance & $\Delta T$ & Steam Strip \\
\hline & & $O_{\mathrm{F}}$ & psig g & $\mathrm{gm} / \mathrm{hr}$ & & & Defoamer(AF+D) & $(c c)$ & & Front(min & of Foam(min) & $\min$ & Behaviour \\
\hline SUNC1 PUAFI & $225 / 2002$ & 930 & \begin{tabular}{|l|l}
15 & 2 \\
\end{tabular} & 2400 & 100,000 cSt( $5 \%$ AF in sun diesel) & 0 & 18 & 0.9 & 3 & 30 & 60 & 30 & Good \\
\hline SUNC 20 PUAFV & $25 / 2004$ & 930 & 15 & 1200 & $100,000 \mathrm{cSt}(0.3 \mathrm{AF} / 70 \mathrm{D})$ & 0 & \multicolumn{5}{|c|}{ No Foam was observed during this run, hence antifoam was not injected. } & & Good \\
\hline SUNC 10 PUAFC & $7 / 17 / 2002$ & 930 & 15 & 3600 & $100,000 \mathrm{cSt}(30 \mathrm{AF} / 70 \mathrm{D})$ & 0 & 48.2 & 14.46 & c & 24 & 38 & 14 & Good \\
\hline & & & & & $100,000 \mathrm{cSt}(0.3 \mathrm{AF} / 70 \mathrm{D})$ & 0 & 280 & 1.22 & 6 & & & \multirow[b]{2}{*}{10} & \multirow[b]{2}{*}{ Good } \\
\hline SUNC25 PUAFV & 3/42004 & 930 & 15 & 4800 & $100,000 \mathrm{cSt}(30 \mathrm{AF} / 70 \mathrm{D})$ & 0 & 20 & 0.84 & 1 & 15 & 25 & & \\
\hline SUNC 14 PUAFI & 9/11/2003 & 900 & 15 & 2400 & $100,000 \mathrm{cSt}(0.3 \mathrm{AF} / 70 \mathrm{D})$ & 0 & 112 & 0.49 & 11 & 25.5 & 36 & 11 & AverageV/Void \\
\hline SUNC 22 PUAFV & $2 / 172004$ & 900 & 15 & 3600 & $100,000 \mathrm{cSt}(0.3 \mathrm{AF} / 70 \mathrm{D})$ & 0 & 205 & 0.89 & 9 & 10 & 18 & 8 & Good \\
\hline SUNC7 PUAFI & $5 / 23 / 2002$ & 900 & 40 & 2400 & $100,000 \mathrm{cSt}(0.3 \mathrm{AF} / 70 \mathrm{D})$ & 0 & \multicolumn{5}{|c|}{ No Foam was observed during this run, hence antifoam was not injected. } & & Good \\
\hline SUNC 23 PUAFV & 22202004 & 900 & 40 & 3600 & $100,000 \mathrm{cSt}(0.3 \mathrm{AF} / 70 \mathrm{D})$ & 0 & 200 & 0.87 & 6 & 19.5 & 32 & 13 & Good \\
\hline SUNC 26 PUAFV & 3/162004 & 930 & 40 & 4800 & $100,000 \mathrm{cSt}(3 \mathrm{AF} / 70 \mathrm{D})$ & 0 & 70 & 2.94 & 7 & 10.5 & 30 & 20 & Good \\
\hline SUNC 27 PUAFV & 3/19/2004 & 930 & 40 & 6000 & $100,000 \operatorname{cst}(3 \mathrm{AF} / 70 \mathrm{D})$ & 0 & 173 & 7.26 & 4 & 19.5 & 29 & 9.5 & Good \\
\hline
\end{tabular}

Table 77: Suncor superficial velocity runs data.

Suncor runs 14 and 22 were carried out at a temperature of $900 \mathrm{\circ} F$, a pressure of $15 \mathrm{psig}$ and at feed rates of $2400 \mathrm{gms} / \mathrm{hr}$ and $3600 \mathrm{gms} / \mathrm{hr}$ respectively. The Suncor resid starts foaming with a tall column of mass inside the drum and gradually increases in density with time. Also the formation of a void was seen at the end of the run. Little foaming was observed at a feed rate of $2400 \mathrm{gms} / \mathrm{hr}$ for Suncor resid. It was observed that at a higher feed rate of $3600 \mathrm{gms} / \mathrm{hr}$, more foaming was seen compared to runs at lower feed rates. During the first hour, antifoam was injected in heavy doses and we see a rise and collapse of foam from 15 to 35 inches of drum height. Figure 201 shows the steam strip plots for these runs. It can be seen that run 14 made a void of 5 inches from 24 to 29 inches inside the drum and had a coke density of approximately $0.42 \mathrm{gm} / \mathrm{cc}$. Suncor run 22 had a coke density of around 0.48 to $0.52 \mathrm{gm} / \mathrm{cc}$ at drum height of 20 inches. Above that drum height the coke was very dense with a density near to 0.95 $\mathrm{gm} / \mathrm{cc}$. The coke transformed to bonded shot.

Suncor runs 7 and 23 were carried out at a temperature of $900{ }^{\circ} \mathrm{F}$, a pressure of $40 \mathrm{psig}$ and at feed rates of $2400 \mathrm{gms} / \mathrm{hr}$ and $3600 \mathrm{gms} / \mathrm{hr}$ respectively. Suncor 7 was a five hour run whereas during Suncor run 23 due to high differential pressure, the run was stopped after 3.5 hours. Increasing the run pressure from 15 psig to $40 \mathrm{psig}$, resulted in no substantial increase in coke density. Antifoam was not injected in Suncor run 7 whereas a total amount of $200 \mathrm{cc}$ of antifoam was injected overhead for Suncor run 23. No foam was observed during the Suncor 7 run. Heavy injections of antifoam were made during the first hour to collapse the foam. Continuous rise and collapse of foam was seen during this period. 
Suncor runs 1, 10, 20 and 25 were carried out at a temperature of $930{ }^{\circ} \mathrm{F}$, a pressure of $15 \mathrm{psig}$. The feed rate for each of these runs was different to understand the effect of superficial velocity. At a low feed rate of $1200 \mathrm{gms} / \mathrm{hr}$, foaming did not occur and hence antifoam was not injected in Suncor run 20. The Suncor resid tends to make a very dense coke usually from 20 to 40 inches inside the drum. With increasing feed rate, we observe that the dense coke is formed higher in the drum. For a feed rate of 2400 $\mathrm{gms} / \mathrm{hr}$, little foaming was observed and hence antifoam was only injected 3 times overhead on an as needed basis. Suncor run 10 used continuous overhead injection of 100,000 cSt with a (30/70) concentration antifoam. The antifoam was injected at a rate of $0.2 \mathrm{~m} / / \mathrm{min}$ throughout the run. The density of the coke formed was highest at 25 inches inside the drum. At $4800 \mathrm{gms} / \mathrm{hr}$ Suncor run 25 foamed badly during the first hour of the run. As needed overhead injection of the 100,000 cSt antifoam with a (0.3/70) concentration was used. A total of $280 \mathrm{cc}$ of antifoam was injected during the first hour to control foaming. It can be seen that foam was observed as high as 55 inches inside the drum. This can be attributed to the higher feed rate, as at lower feed rates we observe foam usually at the 25 to 30 inches during the first hour. It continued to foam and hence to control foaming the antifoam concentration was increased to (3/70). Only one injection of $20 \mathrm{cc}$ was made with this ten times higher concentration of antifoam. This injection controlled the foaming and no foam was observed later in the run. It has been observed that Suncor runs at higher feed rates of $3600-4800 \mathrm{gms} / \mathrm{hr}$ tend to develop a differential pressure inside the drum. Due to this build up of differential pressure, the runs were stopped well before five hours.

Suncor runs 26 and 27 were carried out at a temperature of 930 o $F$ and a pressure of 40 psig. Run 26 was run at a feed rate of $4800 \mathrm{gm} / \mathrm{hr}$ and run 27 was run at a feed rate of $6000 \mathrm{gm} / \mathrm{hr}$. The foaming studies data is shown in Table 77 for these runs. Run 26 produced a very dense coke from a drum height of 15 inches to 40 inches whereas run 27 produced the dense coke over the drum height of 20 to 45 inches. Run 27 also made a void of 5 inches at a drum height of 15 to 20 inches. Both runs used 100,000 cSt (3/70) concentration antifoam with as needed overhead injection. During run 27 at $6000 \mathrm{gm} / \mathrm{hr}, 173 \mathrm{ml}$ of total antifoam with carrier was injected during the four injections. Run 26 used a total of $70 \mathrm{ml}$ in its seven injections. It can be seen that run 27 foamed badly during the first hour compared to run 26 . It was observed that these runs foamed badly during the transient phase. Injecting antifoam overhead usually controlled foaming. After the first 70 to 90 minutes, no foam was observed. Figure 202 and Figure 203 show the coke, bubbly liquid, and foam layers for these runs. As can be seen, foaming occurred during the transient phase only.

\section{Marathon Superficial Velocity Runs}

The Marathon resid makes sponge coke irrespective of operating conditions. It has shown minimal foaming tendencies compared to other resids. Marathon runs 2, 3, 4 and 13 were carried out at a temperature of $930 \mathrm{oF}$, a pressure of $15 \mathrm{psig}$ and the feed rate was different for each run. During the runs with a feed rate of 1200,2400 and $3600 \mathrm{gms} / \mathrm{hr}$, no foam was observed and hence antifoam was not injected. During the Marathon 4 run with a feed rate of $4800 \mathrm{gms} / \mathrm{hr}$, foaming was observed and antifoam with a higher concentration of $100,000 \mathrm{cSt}$ (30/70) was injected through the feedline. A total amount of 17.7 Cc antifoam was injected during this run. Due to the higher feed rate, i.e., higher superficial velocity, foaming occurred during this run and it foamed over thereby clogging the overhead lines. A total of 144.5 grams of coke was collected from the overhead lines. No foam was observed during the Marathon 13 run. At drum heights of 5 and 10 inches only, we saw a density of around $0.7 \mathrm{gms} / \mathrm{hr}$. Due to the higher feed rate, foaming was observed during this run and the density at different drum heights fluctuated with time. During this run a 100,000 cSt antifoam with a (30/70) concentration was injected through the feedline on an as needed basis. Marathon runs $14,7,15$ and 16 were carried out at a temperature of $930{ }^{\circ} \mathrm{F}$, a pressure of $40 \mathrm{psig}$ with different feed rates. 
Table 78: Marathon superficial velocity runs data.

\begin{tabular}{|c|c|c|c|c|c|c|c|c|c|c|c|c|c|}
\hline Run & te & $\mathrm{T}$ & $P$ & F & AF & Method & $c c)$ & used & $\#$ of in & F & apous & $\Delta T$ & eam Strip \\
\hline & & OF & $g$ & $\mathrm{gm} / \mathrm{hr}$ & & & & (cc) & & & & & hhaviour \\
\hline$V$ & 112004 & 30 & 10 & 1200 & (D) & 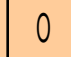 & \multicolumn{6}{|c|}{ No Foam was observed during this run, hence antifoam was not injected. } & Go \\
\hline RA & $6 / 2002$ & 930 & 15 & 2400 & 100,000 cSt (C & 0 & \multicolumn{6}{|c|}{ No Foam was observed during this run, hence antifoam was not injected. } & Good \\
\hline MARA 2 & 10/11/2002 & 930 & 15 & 3600 & 100,0 & 0 & \multicolumn{6}{|c|}{ No Foam was observed during this run, hence antifoam was not injected. } & Good \\
\hline MA & 10/18/2002 & 930 & 15 & 4800 & $100,000 \mathrm{cSt}$ & 1 & & 5.31 & 4 & 16 & $v_{1}$ & 00 & Good \\
\hline ARA 14 PUAFIVV & $1 / 21 / 2004$ & 930 & 40 & 1200 & 100,000 & 0 & \multicolumn{6}{|c|}{ No Foam was observed during this run, hence antifioam was not injected. } & Good \\
\hline MARA 7PUAFHV & 11/12/2002 & 930 & 40 & 2400 & $100,000 \mathrm{cSt}(0.3 \mathrm{~m} / \mathrm{AF} / 70 \mathrm{~m} / \mathrm{D})$ & 0 & \multicolumn{6}{|c|}{ No Foam was observed during this run, hence antifoam was not injected. } & eleragel 60 \\
\hline AARA 15 PUAFIVV & $1 / 27 / 2004$ & 930 & 40 & 3600 & $100,000 \mathrm{cSt}(0.3 \mathrm{~m} / \mathrm{AF} / 70 \mathrm{~mL})$ & $\overline{0}$ & $\bar{x}$ & 1.31 & 18 & 22.5 & $\pi$ & 23 & Good \\
\hline MARA 16 PUAFIV & 1/3012004 & 930 & 40 & 4800 & $100,000 \mathrm{cSt}(0.3 \mathrm{~m} / \mathrm{AF} / 70 \mathrm{~m} / \mathrm{D})$ & 0 & 199 & 0.87 & 5 & 15 & 20 & 5 & Good \\
\hline
\end{tabular}

Marathon 15 and 16 runs were carried at a temperature of $930 \circ \mathrm{F}$, a pressure of $40 \mathrm{psig}$ and at feed rates of $3600 \mathrm{gms} / \mathrm{hr}$ and $4800 \mathrm{gms} / \mathrm{hr}$ respectively. During these runs, foam was observed and hence 100,000 cSt antifoam with a (0.3/70) concentration was injected overhead on an as needed basis. Figure 204 shows the furnace skin temperature profile for the Marathon runs at a temperature of 930 o $F$ and a pressure of $40 \mathrm{psig}$. As can be seen, with increasing feed rate, the heat input to the furnace increased. A total of 18 antifoam injections were made during the Marathon 15 run. 300 cc's of antifoam was injected overhead. Due to regular antifoam injections, the density was approximately $0.65-0.7 \mathrm{gm} / \mathrm{cc}$ throughout the drum. In Marathon run 16, a total of 199 cc's of antifoam was injected through overhead. During this run antifoam was injected in heavy doses during the first hour. A heavy dose of $110 \mathrm{cc}$ 's of antifoam was injected continuously which collapsed the foam completely. Although this run was at a higher feed rate of $4800 \mathrm{gms} / \mathrm{hr}$, due to heavy injection of antifoam within the first hour, no foam was observed later in the run. A very dense coke was formed during the Marathon 10 run. The density of the coke at the 25 inches of height was higher compared to those observed at other drum heights. Hence it was very difficult to remove the coke from the drum.

\section{Yields comparison for Suncor and Marathon Superficial runs}

The highest liquid yields for both resids were obtained at operating conditions of $930 \circ \mathrm{F}$, a pressure of $15 \mathrm{psig}$ and a feed rate of $2400 \mathrm{gm} / \mathrm{hr}$. The Marathon resid produced more liquids whereas the Suncor resid produced more coke. The highest coke yield for the Suncor resid was obtained at operating conditions of $900 \mathrm{oF}$, a pressure of $40 \mathrm{psig}$ and a feed rate of $2400 \mathrm{gm} / \mathrm{hr}$. The Marathon resid produced the highest coke yield at operating conditions of $930{ }^{\circ} \mathrm{F}$, a pressure of $40 \mathrm{psig}$ and a feed rate of $3600 \mathrm{gm} / \mathrm{hr}$. The simulated distillation data will be analyzed to observe the yields of diesel, gasoline and gas oils for these resids. 

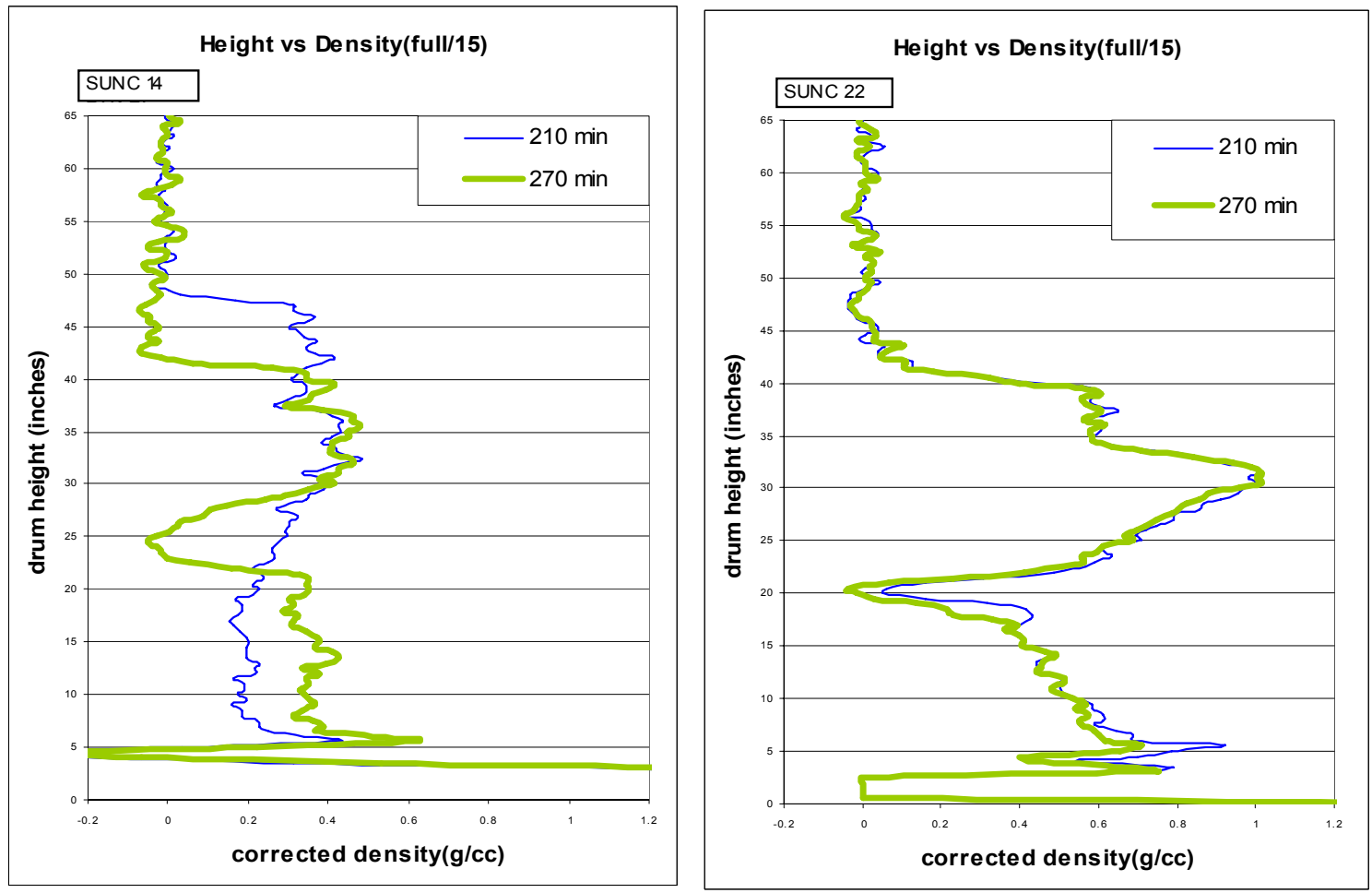

Figure 201 - Steam strip plots for Suncor runs 14 and 22

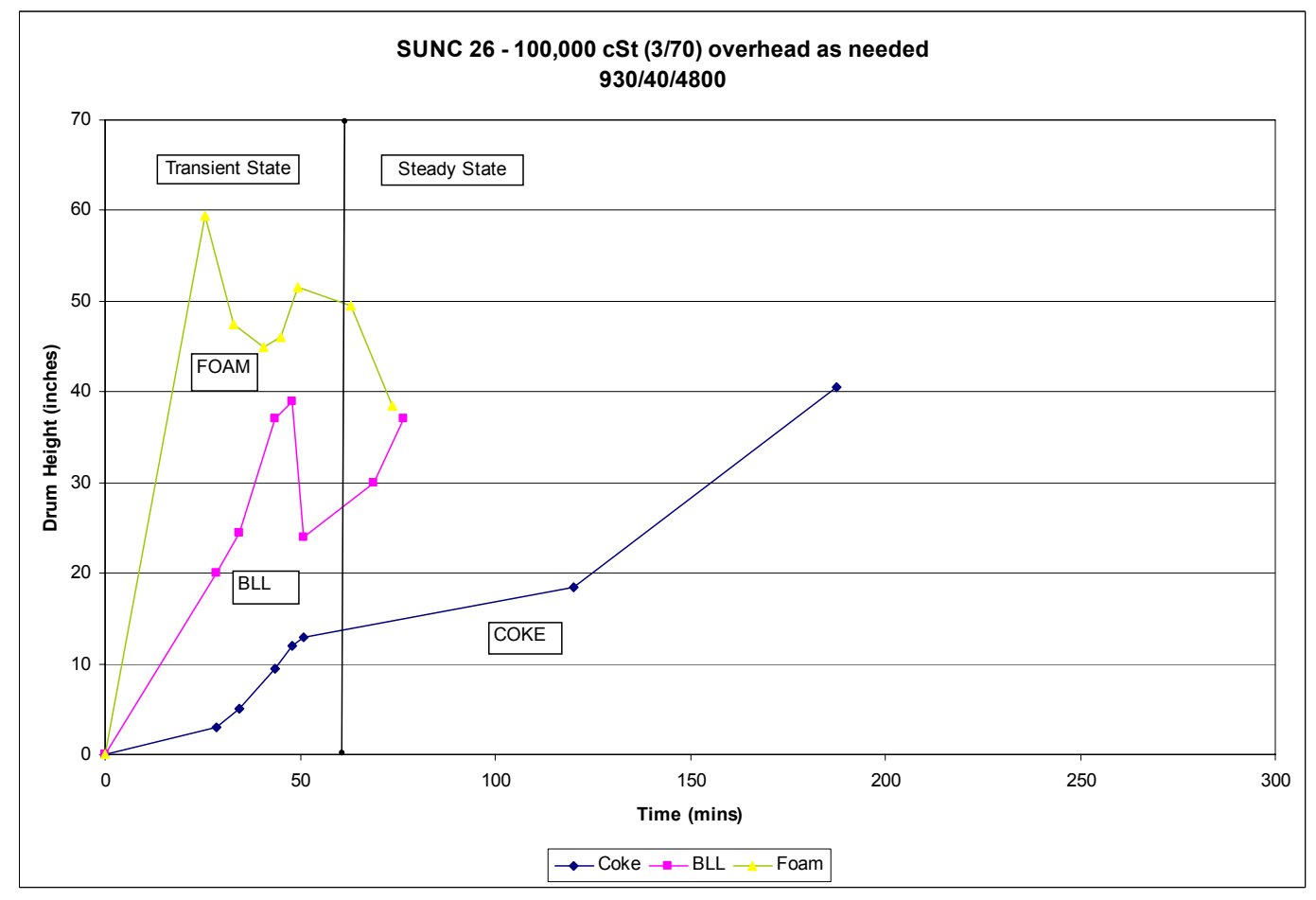

Figure 202 - Coke, BLL and Foam layer for Suncor run 26 


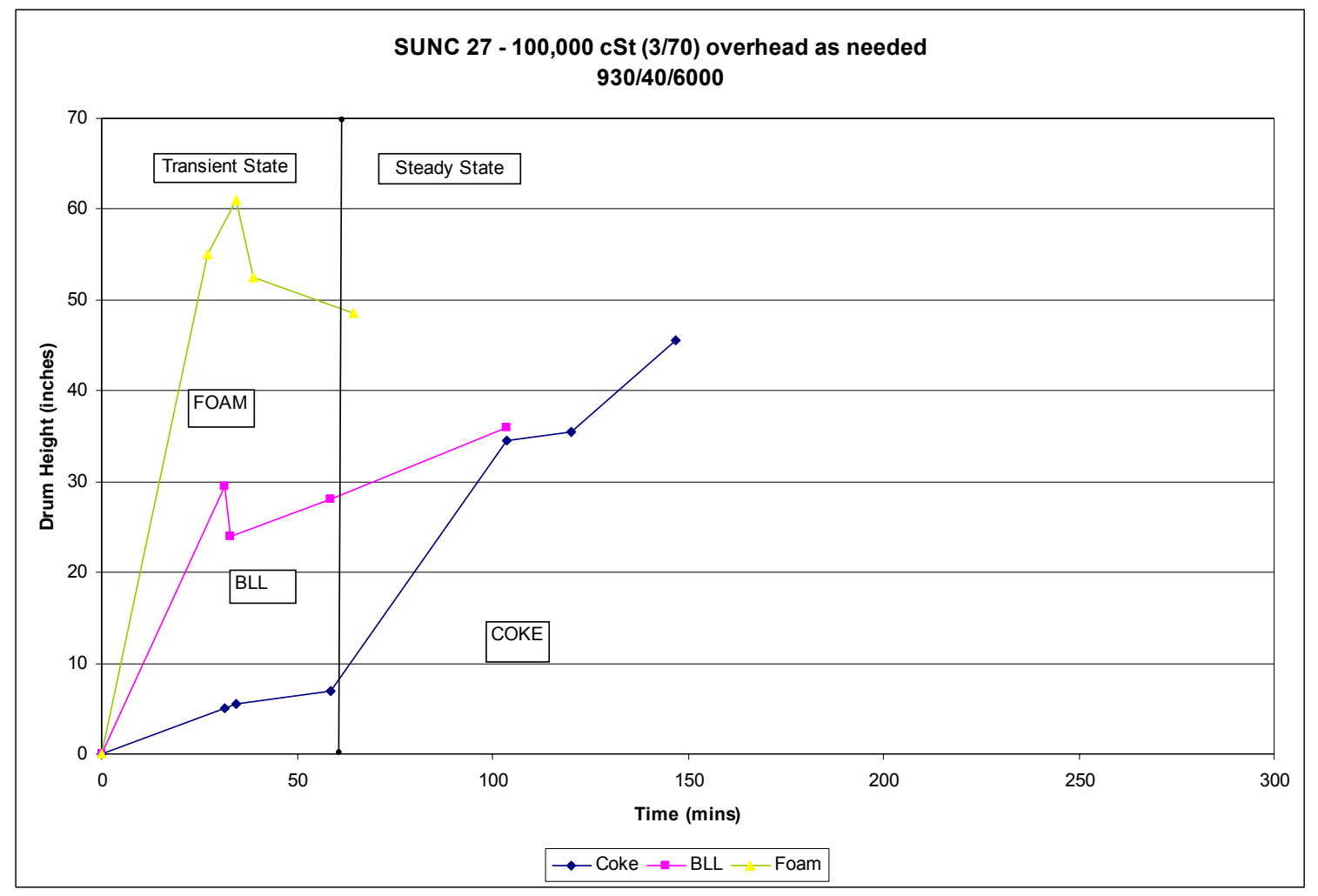

Figure 203 - Coke, BLL and Foam layer for Suncor run 27

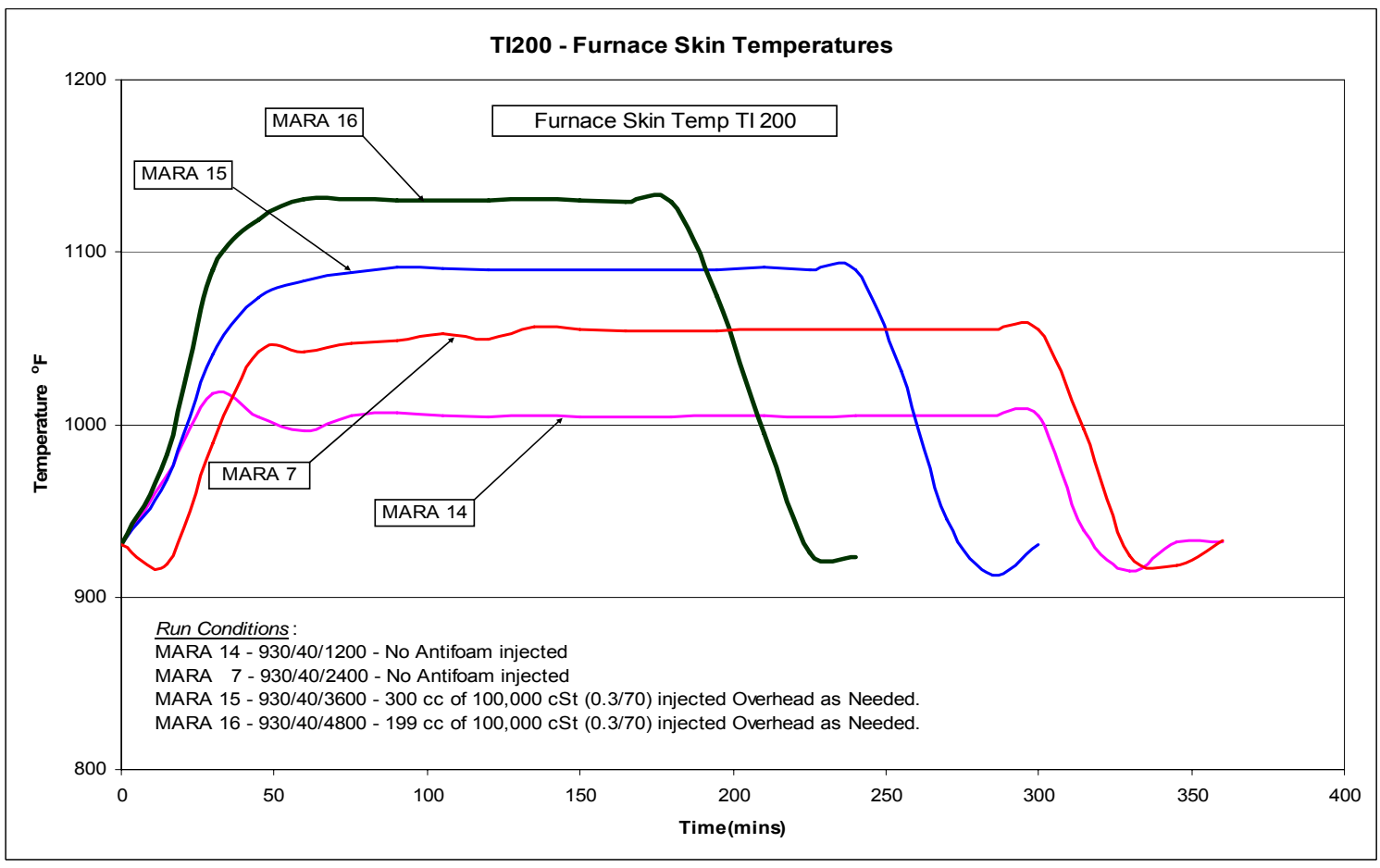

Figure 204 - Furnace skin temperature profile for Marathon runs 
Table 79 - Summary of superficial velocity runs

\begin{tabular}{|c|c|c|c|c|}
\hline \multicolumn{5}{|c|}{ Summary of Superficial Velocity Runs } \\
\hline \multicolumn{2}{|r|}{ Marathon Resid } & \multicolumn{3}{|c|}{ Suncor Resid } \\
\hline \multirow[b]{3}{*}{ Morphology } & Marathon resid produces sponge coke & \multirow[b]{3}{*}{ Morphology } & \multicolumn{2}{|c|}{ Suncor resid produces shot coke irrespective of } \\
\hline & irrespective of operating conditions. & & operating conditions. Fat coke bed a & $0-25$ inches in the \\
\hline & Coke density in the range of $0.57-0.62 \mathrm{gms} / \mathrm{cc}$ & & \multicolumn{2}{|c|}{ drum. Coke density in the range of $0.6-0.9 \mathrm{gms} / \mathrm{cc}$} \\
\hline & Higher feed rate continuous injection of antifoam & & \multicolumn{2}{|c|}{ Foaming increased at higher feed rates. Usually foaming } \\
\hline Foaming & gives better control of foaming for Marathon resid & Foaming & \multicolumn{2}{|c|}{ occurs during the transient phase only.A heavy dose of } \\
\hline \multirow[t]{2}{*}{ Tendencies } & Overall it has show $n$ medium to least foaming tendecy & Tendencies & \multicolumn{2}{|c|}{ antifoam injected during the first hour controls foaming. } \\
\hline & Does not foam at low er feed rates of $1200-2400 \mathrm{gms} / \mathrm{hr}$. & & Overall medium foaming tendencies. & \\
\hline \multirow[t]{2}{*}{ Yields } & Highest Coke yields at 930-40-3600, around $24 \%$. & Yields & \multicolumn{2}{|c|}{ Highest Coke yields at $900-40-2400$, around $28.5 \%$. } \\
\hline & Highest Liquid yields at $930-15-2400$, around $72.70 \%$. & & \multicolumn{2}{|c|}{ Highest Liquid yields at $930-15-2400$, around $67 \%$. } \\
\hline Steam Strip & Good steam strip behavior, no loss of mass & Steam Strip & \multicolumn{2}{|c|}{ Average steam strip behavior tendency to make voids. } \\
\hline \multirow[b]{3}{*}{ Suggestions } & Future runs to include more higher feed rate. & & \multicolumn{2}{|c|}{ Future runs to include more higher feed rate. } \\
\hline & Continuous injection of antifoam gives better control & & \multicolumn{2}{|c|}{ Using a higher viscosity antifoam to observe control over } \\
\hline & Using recycle at higher feed rates. & Suggestions & \multicolumn{2}{|c|}{ foaming. Using recycle at higher feed rates. } \\
\hline
\end{tabular}

\section{Parametric tests for Cerro Negro Resid}

The Cerro Negro resid was obtained during the month of March, 2004. The first phase of Cerro Negro runs were carried out in April, to observe the effect of pressure on density, foaming and morphology of the coke formed. Table 81 shows the pilot unit foaming studies data for EMCN runs. Runs 1 to 4 were carried out at a temperature of $900 \mathrm{oF}$ and a feed rate of $3600 \mathrm{gm} / \mathrm{hr}$. The pressure was increased from 15 psig to 45 psig with an increment of 10 psig for each run.

At 15 psig there was a tall column of shot coke inside the drum at the end of the run. Also a loss of mass occurred during the steam strip process from 45 to 55 inches of drum height. A drum full of light $B B$ shot coke was produced during run EMCN 1. With EMCN run 2, the pressure was increased from 15 psig to $25 \mathrm{psig}$ and a dense layer of coke was formed from a drum height of 20 to 42 inches. The morphology changed from BB coke to dense agglomerated (bonded) shot coke at that drum height. EMCN 3 was carried out at a pressure of $35 \mathrm{psig}$ and the dense layer of coke was formed at drum height of 20 to 43.5 inches. This run produced shot coke with a solid agglomerated outer wall 0.5 inches thick over the bottom 8 inches of the drum. The morphology changed from clusters of BB to loose BB's to a dense hard agglomerated coke in the top 20 inches of the drum. During EMCN run 4 the pressure was increased to 45 psig and a dense layer of coke was produced at drum height of 25 to 36.5 inches. The morphology of coke produced was BB shot coke mixed with loose BB's and dense agglomerated shot coke at the top of the drum. In runs 2 and 3 , it was observed that after around 180 minutes of run time, a differential pressure started to build up inside the drum. This differential pressure keeps increasing with time resulting in a termination of run. The same was observed with run 4 after around 150 minutes into the run. It has been observed that resids that are high in asphaltene content and that produce dense shot coke tend to develop a differential pressure inside the drum thereby abruptly terminating the run. The bonded shot coke in runs 2 
and 3 was very dense while run 4 was brittle and fairly easy to remove. The foaming tendencies during these runs are discussed in the next section.

EMCN runs 5 and 6 were carried out at a higher temperature of 930 oF and a feed rate of 3600 $\mathrm{gm} / \mathrm{hr}$. The pressure was increased from $15 \mathrm{psig}$ for run EMCN run 5 to $45 \mathrm{psig}$ for run EMCN run 6 . The foaming studies data for these runs is shown in Table 80. EMCN run 5 lasted for 225 minutes and then it was switched to steam strip process due to the build up of differential pressure inside the drum. Run 6 was a five hour run. The EMCN run 5 continued to make a dense layer of coke like those in runs 2, 3 and 4. The thick layer of coke was formed at drum height of 17 to 37 inches. The density for this layer was greater than $0.8 \mathrm{gm} / \mathrm{cc}$. It required a lot of effort ( 5 hours) to take the coke out of the drum, as the coke produced was very hard and dense. The morphology of coke produced changed from clusters of BB shot coke from 20 inches to very hard dense agglomerated shot coke at 39.5 inches of drum height. The temperature and feed rate were the same and the pressure was increased to 45 psig for EMCN run 6 . EMCN run 6 lasted for 300 minutes without the build up of differential pressure. Run 6 produced more coke that was dense throughout the drum. It was observed during the run that with time the shot coke started filling towards the bottom of the drum as well and hence we don't see a dense layer at the top of the drum. The shot coke produced during this run was very hard and dense. There was considerable difficulty in breaking the coke out of the drum.

Table 80 - Foaming studies data for Exxon Mobil Cerro Negro runs

\begin{tabular}{|c|c|c|c|c|c|c|c|c|c|c|c|c|c|}
\hline Rum & Date & T & P & $\mathrm{F}$ & Type of AF & \multicolumn{2}{|c|}{ Method Iotal Amt. of (ce } & Actud A F we & & ain & te-ppearance & LT & Stem Strip \\
\hline & & of & psig & ganhr & & & Defomere(AP-D) & (ci) & & Frontmin & f Faam(min) & min & Bethaviour \\
\hline EMCNI PUAF & 4112004 & 900 & 15 & 3600 & $100,000 \cos (3 \mathrm{AEF} / 70 \mathrm{D})$ & 0 & 46 & 1.93 & 9 & 6 & 21 & 15 & Average \\
\hline EMCN2PUAF & $4 / 62004$ & 900 & 25 & 3600 & $100,000 \operatorname{cst}(3 \mathrm{AF} / 70 \mathrm{D})$ & 0 & 126 & 5.29 & 11 & 4.5 & 27 & 23 & Cood \\
\hline EMCN3 PUAF & 4822004 & 900 & 35 & 3600 & $100,000 \mathrm{cst}(3 \mathrm{AF} / 70 \mathrm{D})$ & 0 & 45 & 1.89 & 1 & 12 & 16.5 & 4.5 & cood \\
\hline EVCNAPUAF & 41332004 & 900 & 45 & 3600 & $100,000 \cos (3 \mathrm{AEF} / 7 \mathrm{D})$ & 0 & 50 & 2.1 & j & 9 & 25 & 16 & Cood \\
\hline EMCN5 PUAF & 41152004 & 930 & 15 & 3600 & $100,000 \operatorname{cst}(3 \mathrm{AF} / 70 \mathrm{D})$ & 0 & 20 & 0.84 & 3 & 12 & 21 & 9 & Cood \\
\hline EMCNGPUAF & 420202004 & 930 & 45 & 3600 & $100,000 \mathrm{cst}(3 \mathrm{AF} / 70 \mathrm{D})$ & 0 & 20 & 0.84 & 3 & 13.5 & 25.5 & 12 & Cood \\
\hline
\end{tabular}

\section{Foaming tendencies for EMCN parametric tests}

The EMCN 1 run was carried out at a pressure of 15 psig. The foam was at a drum height of 35 to 40 inches and the rise and collapse of foam at antifoam injection times was seen. During the first hour four antifoam injections did not control foaming for EMCN Run 2. Hence 6 more antifoam injections were made during the second hour. Severe foaming continued to occur and we see continuous rise and collapse of foam at drum heights of 34 to 45 inches. It was observed that the Cerro Negro resid foamed severely during the first 70 to 90 minutes of run time. An average of $60 \mathrm{ml}$ of 100,000 cSt (3/70) concentration antifoam when injected through overhead controls foaming. Later into the run, during the steady state period, this resid tends to make a dense layer of coke at average drum heights of 20 to 45 inches. Once this dense layer is produced, foaming does not occur. Hence it is our preliminary conclusion that the reduction in superficial vapor velocity (interstitial velocity) might be the reason for foaming not to occur. Some foaming occurred during the EMCN 1 during the last hour of the run, but as we increased the 
pressure from 15 psig to 45 psig during runs EMCN 2, 3 and 4, foaming was not observed after the transient phase. Figure 205 shows the coke, bubbly liquid and foam layer for each of the EMCN runs. It can be seen that the foaming occurs during the transient phase only and then we see a growing coke layer with time.

At higher temperature of $930 \mathrm{oF}$, EMCN runs 5 and 6 showed least foaming tendencies compared to runs at low temperature. A total of 20 ml's of antifoam was injected for each of these runs. The foaming occurred during the first hour, i.e., the transient phase only. No foam was observed after the transient phase and hence antifoam was not injected during this period. For run 5 , there is a rise and collapse in densities at different drum heights whereas for run 6 , the densities at different drum heights are rising towards the coke density.
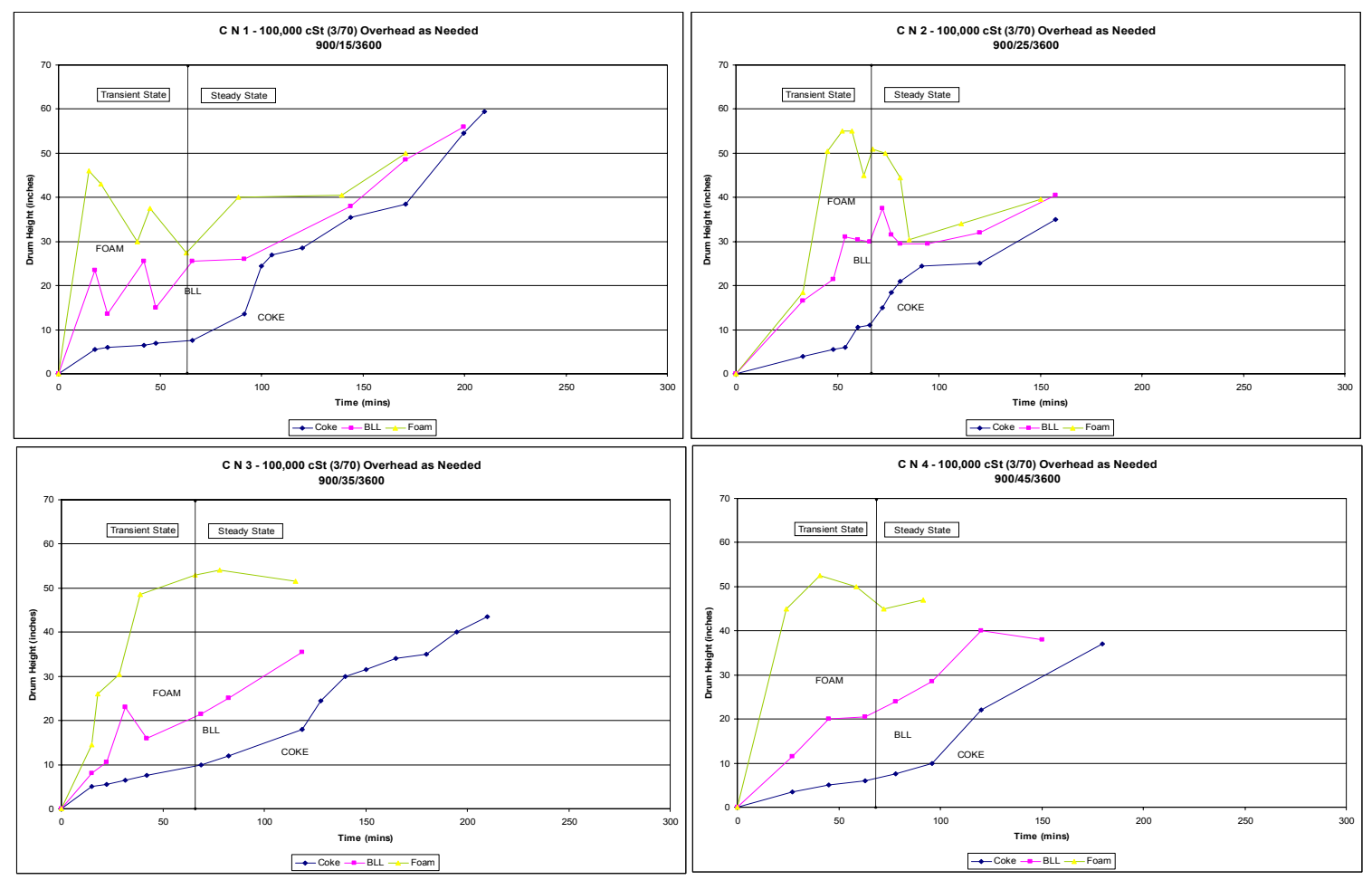

Figure 205 - Drum height of foam, bubbly liquid and coke layers with time for EMCN runs 1 to 4

\section{Parametric tests of Exxon Mobil Medium Heavy Canadian (EMHC)}

The Heavy Canadian resid was obtained from Exxon Mobil during the month of March, 2004. Runs were carried out to observe the effect of pressure on density, foaming and morphology of the coke formed. Table 81 shows the pilot unit foaming studies data for EMHC runs. 


\section{Pilot Unit Foaming Studies Data}

\begin{tabular}{|c|c|c|c|c|c|c|c|c|c|c|c|c|c|}
\hline \multirow[t]{2}{*}{ Run } & \multirow[t]{2}{*}{ Date } & $T$ & $P$ & $\mathrm{~F}$ & Type of AF & \multirow[t]{2}{*}{ Method } & \multicolumn{5}{|c|}{ Total Amt. of (cActual AF use \# of inj. First Foam Re-appearanc } & \multirow{2}{*}{$\begin{array}{l}\Delta T \\
\min \end{array}$} & \multirow{2}{*}{\begin{tabular}{|l|} 
Steam Strip \\
Behaviour \\
\end{tabular}} \\
\hline & & \multicolumn{3}{|c|}{\begin{tabular}{l|l|l|} 
of & psig gm/hr \\
\end{tabular}} & & & Defoamer(AF+D & (cc) & & Front/mil & Foam(min) & & \\
\hline EMHC 1 PUAFV & $4 / 2222004$ & 900 & 15 & 3600 & 100,000 cSt (3AF/70 D) & 0 & 20 & 0.84 & 3 & 12 & 32 & 20 & Good \\
\hline EMHC 2 PUAFV & 4/28/2004 & 900 & 25 & 3600 & 100,000 cSt (0.3 AF/70 D) & 0 & 85 & 0.37 & $4^{4}$ & 13.5 & 24 & 10.5 & Good \\
\hline EMHC3 PUAFV & $5 / 4 / 2004$ & 900 & 35 & 3600 & $100,000 \mathrm{cSt}(0.3 \mathrm{AF} / 70 \mathrm{D})$ & 0 & 90 & 0.39 & 4 & 21 & 40 & 19 & Good \\
\hline EMHC 4 PUAFV & $5 / 6 / 2004$ & 900 & 45 & 3600 & $100,000 \mathrm{cSt}(0.3 \mathrm{AF} / 70 \mathrm{D})$ & 0 & 60 & 0.26 & 4 & 20 & 32 & 12 & Good \\
\hline EMHC5 PUAFV & 6/8/2004 & 930 & 15 & 3600 & $100,000 \mathrm{cSt}(0.3 \mathrm{AF} / 70 \mathrm{D})$ & $\overline{0}$ & 30 & 0.13 & 2 & 7.5 & 34 & 26.5 & Good \\
\hline EMHC 6 PUAFV & $6 / 1012004$ & 930 & 45 & 3600 & $100,000 \mathrm{CSt}(0.3 \mathrm{AF} / 70 \mathrm{D})$ & 0 & 10 & 0.04 & 1 & 18 & 45 & 27 & Good \\
\hline EMHC 7 PUAFV & $6 / 15 / 2004$ & 900 & 35 & 2400 & $100,000 \mathrm{cSt}(0.3 \mathrm{AF} / 70 \mathrm{D})$ & 0 & No Foamw was 0 & ed during & run, h & nce antifoc & as not inject & & Good \\
\hline EMHC\& PUAFV & $6 / 17 / 2004$ & 900 & 35 & 4800 & $100,000 \mathrm{cSt}(0.3 \mathrm{AF} / 70 \mathrm{D})$ & 0 & 100 & 0.44 & 6 & 22.5 & 30 & 7.5 & Good \\
\hline EMHC9 PUAFV & $6 / 23 / 2004$ & 900 & 35 & 6000 & $100,000 \mathrm{cSt}(3 \mathrm{AF} / 70 \mathrm{D})$ & 0 & 90 & 3.78 & 8 & 18 & 28 & 10 & $\mathrm{Bad}$ \\
\hline EMHC 10 PUAFV & $6 / 29 / 2004$ & 930 & 35 & 2400 & $100,000 \mathrm{cSt}(0.3 \mathrm{AF} / 70 \mathrm{D})$ & 0 & lo Foamwas & dur & Tall, & ant & s not inject & & Good \\
\hline
\end{tabular}

Table 81: Foaming studies data for Exxon Mobil Heavy Canadian runs.

Runs 1 to 4 were carried out at a temperature of 900 oF and a feed rate of $3600 \mathrm{gm} / \mathrm{hr}$. The pressure was increased from 15 psig to 45 psig with an increment of 10 psig for each run. As can be seen, the density profile of the coke formed is the same with increasing pressure. Although at 45 psig run the coke yield was higher compared to other runs. As a result of that the density of coke formed is lesser in the region of 20 to 40 inches of drum height as compared to other runs. The morphology of coke formed changed from bonded BB shot and buck shot coke to sponge coke for EMHC run 1. Runs 2 to 4 produced sponge with a transition to hard dense bonded sponge coke at the top of the drum. EMHC runs 1 to 3 experienced a build up of differential pressure (around 20 to $35 \mathrm{psi}$ ) after 180 minutes into the run. The same was not observed during run 4 at 45 psig.

EMHC runs 5 and 6 were carried out at a temperature of 930 oF and a feed rate of $3600 \mathrm{gm} / \mathrm{hr}$. The pressure was increased from 15 psig for run 5 to 45 psig for run 6 . The density profile of the coke formed is the same for these runs. These runs produced bonded sponge coke which has a solid outer wall at the bottom and high in pitch at the top of the drum. Run 5 had a large range of operational differential pressure with first hour range being (1.84-16.5 psi), second hour (5.7-52.0) and so on. Run 6 too observed a high differential pressure due to a restriction in the feed line through out the run.

EMHC runs $3,7,8$ and 9 were carried out at a temperature of 900 oF and $35 \mathrm{psig}$ of run pressure. The feed rate was increased from $2400 \mathrm{gm} / \mathrm{hr}$ to $6000 \mathrm{gm} / \mathrm{hr}$ with an increment of $1200 \mathrm{gm} / \mathrm{hr}$ for each run. EMHC run 7 was carried out at $2400 \mathrm{gm} / \mathrm{hr}$, this run produced sponge coke with solid agglomerated outer wall. Run 8 was carried out at a feed rate of $4800 \mathrm{gm} / \mathrm{hr}$. The coke produced during this run changed the morphology from clusters of agglomerated shot coke surrounded by a solid wall at the bottom of the drum to clusters of sponge coke high in pitch towards the top of the drum. The coke produced during this run was dense and hence was difficult to remove from the drum. Run 9 was carried out at a higher feed rate of 6000 $\mathrm{gm} / \mathrm{hr}$. Due to the higher superficial velocity during this run, the drum was filled with coke within two hours of the run and had to be stopped due to the height of coke inside the drum. A loss of mass was encountered during the steam strip process which can be attributed to unreactive mass of bed inside the drum. Thus the steam strip process was stopped after 10 minutes and the drum was allowed to cook for 40-45 minutes. The stripping process was resumed after that for the remaining period of time. Error! Reference source not found. shows the loss of mass during the steam strip process for EMHC run 9. This 
run produced 72.5 inches of coke. The morphology of coke produced changed from grape clusters of buck shot coke lodged in the center at the bottom of the drum to clusters of sponge coke in the middle and dense sponge coke high in pitch towards the top of the drum.

\section{a) Foaming Tendencies for EMHC Runs}

The antifoam injection data is shown in Table 81 for EMHC runs. All runs used as needed overhead injection of antifoam. Runs 1 and 9 used a higher concentration of (3/70) antifoam whereas all the other runs used a lower concentration of $(0.3 / 70)$ antifoam. Diesel is used as the carrier for the antifoam. Runs 1 to 4 were carried out at a temperature of 900 oF and a feed rate of $3600 \mathrm{gm} / \mathrm{hr}$ with a 10 psig increase in pressure with each run. During these runs an average of four antifoam injections were made. Usually foaming occurred during the transient phase of around 60-80 minutes into the run. Foaming was not observed during the steady state period for these runs.

EMHC runs 5 and 6 were carried out at a higher temperature of 930 oF and a feed rate of 3600 $\mathrm{gm} / \mathrm{hr}$. A decrease in foaming was observed for these runs at 930 oF compared to runs at $900 \mathrm{oF}$. Irrespective of temperature, at lower feed rates of $2400 \mathrm{gm} / \mathrm{hr}$ during EMHC runs 7 and 10, foaming did not occur and hence antifoam was not injected during these runs.

During EMHC run 8 at $4800 \mathrm{gm} / \mathrm{hr}$, a total amount of $100 \mathrm{cc}$ of antifoam was injected through the overhead. Foaming was observed during the first two hours of the run. Run 9 at higher superficial velocity (6000 gm/hr of feed rate) used 10 times higher concentration of (3/70) antifoam injected overhead with as needed injection technique. During this run, the mass of bed inside the drum was highly unreacted indicating a large bubbly liquid layer. Hence some loss of mass was encountered during the steam strip process.

Usually foaming occurred during the transient phase for EMHC runs. Antifoam of $100,000 \mathrm{cSt}$ $(0.3 / 70)$ concentration is injected through overhead once the foam height reaches the $2 / 3$ rd level of drum height. The injection of antifoam collapses the foam and quantifies the bubbly liquid layer (BLL) determined by an increase in density. Based on this information, the heights of foam, bubbly liquid layer and the growth of coke layer with time are determined.

Figure 206 shows the collapse of foam during EMHC run 8 at $4800 \mathrm{gm} / \mathrm{hr}$. It depicts the drum height of the three layers of delayed coking, the foam, the bubbly liquid layer (BLL) and the coke. Figure 207 shows the collapse of foam and drum height of foam, liquid and the coke layer during EMHC run 9 and $6000 \mathrm{gm} / \mathrm{hr}$.

\section{b) $\underline{\text { Conclusion }}$}

Superficial velocity tests were carried out using the Medium Heavy Canadian resid. At a run temperature of $900 \mathrm{oF}$ and a feed rate of $3600 \mathrm{gm} / \mathrm{hr}$, with increase in pressure with each run, the density profile of the coke formed was generally the same. A morphology change for the coke produced was observed for this resid. The morphology changed from bonded shot coke to a transitional coke and finally to a dense bonded sponge coke. At a higher run temperature of $930 \mathrm{oF}$, the EMHC runs 5 and 6 developed an operational differential pressure inside the drum. These runs produced sponge coke in the center with solid agglomerated outer wall at the bottom of the drum and bonded sponge coke mixed with pitch at the top of the drum. At higher feed rates of $4800 \mathrm{gm} / \mathrm{hr}$ and $6000 \mathrm{gm} / \mathrm{hr}$, due to the higher vapor superficial velocity, 
the morphology of the coke produced transitioned from agglomerated shot coke to a transitional sponge coke and finally into a dense sponge mixed with pitch at the top of the drum. The EMHC run 9, at 6000 $\mathrm{gm} / \mathrm{hr}$ of feed rate observed a loss of mass during the steam strip process due to the build up of unreacted mass of bed inside the drum.

Usually foaming occurred during the transient phase for EMHC runs at a run temperature of 900 oF. At a higher run temperature of $930 \mathrm{oF}, \mathrm{EMHC}$ runs 5 and 6 showed least foaming tendencies. Irrespective of run temperature, runs 7 and 10, at a low feed rate of $2400 \mathrm{gm} / \mathrm{hr}$ foaming was not observed. Hence antifoam was not injected during these runs. At higher feed rates of $4800 \mathrm{gm} / \mathrm{hr}$ and $6000 \mathrm{gm} / \mathrm{hr}$, larger quantities of antifoam were needed to control foaming. At these feed rates foaming occurred during the first 120 minutes of the run. It should be noted that the higher feed rate runs only lasted 2 to 3 hours. At $6000 \mathrm{gm} / \mathrm{hr}$ run, it is speculated that it had a larger bubbly liquid layer compared to the foam layer. Generally once the steady state is attained, foaming is not observed for the Medium Heavy Canadian resid.

\section{Parametric tests of Marathon Rose Pitch (MRP)}

The Rose Pitch resid was obtained and tests were conducted to observe the effect of pressure on density, foaming and morphology of the coke formed. Table 82 shows the pilot unit foaming studies data for MRP runs.

\section{Pilot Unit Foaming Studies Data}

\begin{tabular}{|c|c|c|c|c|c|c|c|c|c|c|c|c|c|}
\hline \multirow[t]{2}{*}{ Run } & \multirow[t]{2}{*}{ Date } & \multirow{2}{*}{\begin{tabular}{|c|}
$T$ \\
$O F$ \\
\end{tabular}} & \multirow{2}{*}{\multicolumn{2}{|c|}{\begin{tabular}{|c|c|}
$\mathrm{P}$ & $\mathrm{F}$ \\
psig $\mathrm{gm} / \mathrm{hr}$ \\
\end{tabular}}} & \multirow[t]{2}{*}{ Type of AF } & \multirow[t]{2}{*}{ Method } & \multicolumn{5}{|c|}{ Total Amt. of (cAActual AF use \# of inj.).First Foan Re-appearanc } & \multirow{2}{*}{$\frac{\Delta T}{\min }$} & \multirow{2}{*}{\begin{tabular}{|l|} 
Steam Strip \\
Behaviour \\
\end{tabular}} \\
\hline & & & & & & & Defoamer(AF+D & (cc) & & Front/m & Foam(min) & & \\
\hline MRP1 PUAFV & 812412004 & 900 & 15 & 3600 & $100,000 \mathrm{CSt}(3 \mathrm{AF} / 70 \mathrm{D})$ & 0 & 10 & 0.42 & 1 & 28 & & & Good \\
\hline MRP PUAFV & $8 / 27 / 2004$ & 900 & 40 & 3600 & $100,000 \mathrm{CSt}(3 \mathrm{AF} / 70 \mathrm{D})$ & 0 & No Foam was obse & eed durin & $\overline{r u n}, 1$ & nce antifo & as not injectel & & Good \\
\hline MRP3PUAFV & $8 / 31 / 2004$ & 930 & 15 & 3600 & $100,000 \mathrm{CSt}(3 \mathrm{AF} / 70 \mathrm{D})$ & 0 & 7 & 0.29 & 2 & 54 & 69 & 14 & Good \\
\hline MRP4PUAFV & 9/222004 & 930 & 40 & 3600 & $100,000 \operatorname{cSt}(3 \mathrm{AF} / 70 \mathrm{D})$ & 0 & 10 & 0.42 & 2 & 21 & 42 & 21 & Good \\
\hline
\end{tabular}

Table 82: Pilot Unit foaming studies data for Marathon Rose Pitch runs.

MRP runs 1 and 2 were carried out at a temperature of 900 of and a feed rate of $3600 \mathrm{gm} / \mathrm{hr}$. The pressure was increased from 15 psig to $40 \mathrm{psig}$. The density profile of the coke formed was the same with increasing pressure. Run 1 produced 43 inches of shot coke. The morphology changed from Buck shot at the bottom to BB shot coke towards the top of the drum. Run 2 produced 40 inches of shot coke with the morphology changing from Buck shot coke at the bottom to a transitional shot coke in the middle of the drum and finally clusters of BB shot coke mixed with pitch towards the top of the drum.

MRP runs 3 and 4 were carried out at a temperature of 930 of and a feed rate of $3600 \mathrm{gm} / \mathrm{hr}$. The pressure was increased from 15 psig to 40 psig. Run 3 at 15 psig had less coke deposition compared to run 4 at 40 psig. Run 3 produced 27 inches of shot coke with morphology changing from Buck shot coke at bottom to clusters of BB shot coke and finally to bonded shot coke at the top of the drum. It was hard to remove the bonded (agglomerated) shot coke formed at the top of the drum. The first hour of the MRP 3 run saw a regular density profile. It is around the 90 minute mark that we saw the profile changing to a dense head in the middle of the drum. It continued to grow denser in that region until the end of the run. 
The run was stopped due to the build up of differential pressure inside the drum. The temperature profile inside the drum is explained later in the report. Run 4 produced 45 inches of shot coke. Interesting morphology was observed during this run. The bottom part of the drum produced clusters of BB shot coke with the morphology changing to dense pitch like sponge in the middle section of the drum and finally into bonded (agglomerated) shot coke towards the top of the drum.

\section{a) Foaming Tendencies for MRP Runs}

The antifoam injection data is shown in Table 82 for MRP runs. All runs used as needed overhead injection of 100,000 cSt (3/70) concentration antifoam. Moderate foaming tendencies was observed with MRP runs.

For MRP Run 1 an increase in density is observed after the collapse of foam, quantifying the bubbly liquid layer. Only one antifoam injection was needed to control foaming during this run. Foam was not observed during MRP run 2 and hence antifoam was not injected.

A deposit of some kind was observed along the wall at drum height of 35-60 inches during MRP run 3. As a result of it a bulging density profile is observed in that region. Runs 3 and 4 at a higher feed temperature of $930 \circ \mathrm{F}$ foamed more compared to runs 1 and 2 at a lower feed temperature of $900{ }^{\circ} \mathrm{F}$.

\section{b) Temperature Profile for MRP runs}

Three thermocouples were added to the drum to measure the skin temperature of the drum. These were added to establish whether the drum is being operated adiabatically. As shown in Table 83, the drum is divided into six different zones along the height of the drum. The location of thermocouples in each zone is also shown in Table 83. The drum skin thermocouples are placed between the internal thermocouples on the outer skin of the drum.

Figure 208 through Figure 211 show the drum temperature profile for MRP runs 1 to 4 . It can be observed from these plots that the drum skin temperature is approximately $20-40$ degrees cooler compared to the drum internal temperature. Hence it can be deduced that the drum is not being operated under adiabatic conditions. This brings up the question whether the coke drum should be operated based on the drum skin temperature. If so, then what would be the optimum drum skin temperature, the drum should be operated during a run. This issue was discussed during the advisory board meeting held October 20th 2004. 


\begin{tabular}{|c|c|c|c|c|}
\hline & & \multicolumn{3}{|c|}{ Thermocouple (TI) } \\
\hline & Zone & Internal & Skin & zone \\
\hline \multirow[t]{10}{*}{ Top } & 6 & 208 & 306 & 206 \\
\hline & 5 & 209 & 305 & 205 \\
\hline & & 210 & & \\
\hline & & & & \\
\hline & 4 & 211 & 304 & 204 \\
\hline & & 212 & & \\
\hline & & & & \\
\hline & 3 & 213 & 303 & 203 \\
\hline & & 214 & & \\
\hline & 2 & 215 & & 202 \\
\hline Bottom & 1 & & & 201 \\
\hline
\end{tabular}

Table 83: Location of thermocouples.

\section{c) $\underline{\text { Conclusion }}$}

Parametric tests were carried out using the Marathon Rose Pitch resid. At a run temperature of 900 oF and a feed rate of $3600 \mathrm{gm} / \mathrm{hr}$, with increase in pressure (15 to $40 \mathrm{psig}$ ), the density profile of the coke formed was generally the same. The morphology of coke produced under these operating conditions was generally buck shot coke at the bottom to clusters of BB shot coke towards the top of the drum. At 930 oF, $15 \mathrm{psig}$ and a feed rate of $3600 \mathrm{gm} / \mathrm{hr}$, the density profile produced during MRP run 3 was different compared to other runs. It produced a dense head of shot coke at drum height of 15 to 30 inches. MRP run 4 produced a mixed morphology of coke. The morphology of coke changed from BB shot coke at the bottom to a dense sponge in the middle part of the drum and finally into a bonded (agglomerated) shot coke at the top of the drum. Overall Rose Pitch resid showed moderate foaming tendencies. The foaming tendencies increased at higher run temperature of 930 oF compared to lower temperature runs. Resids like Cerro Negro and Medium Heavy Canadian have shown rigorous transient state foaming tendencies, whereas worst foaming resids like Petrobras and Chevron foam all throughout the run. Comparatively Rose Pitch resid has shown a different foaming tendency as it usually tends to foam after the first hour of the run. Based on the drum temperature profile for MRP runs 1 to 4 , it was determined that the drum is not being operated under adiabatic conditions. Hence further insight in this matter as to how to control the temperature during a coking run was sought during the advisory board meeting held October 20th 2004. 


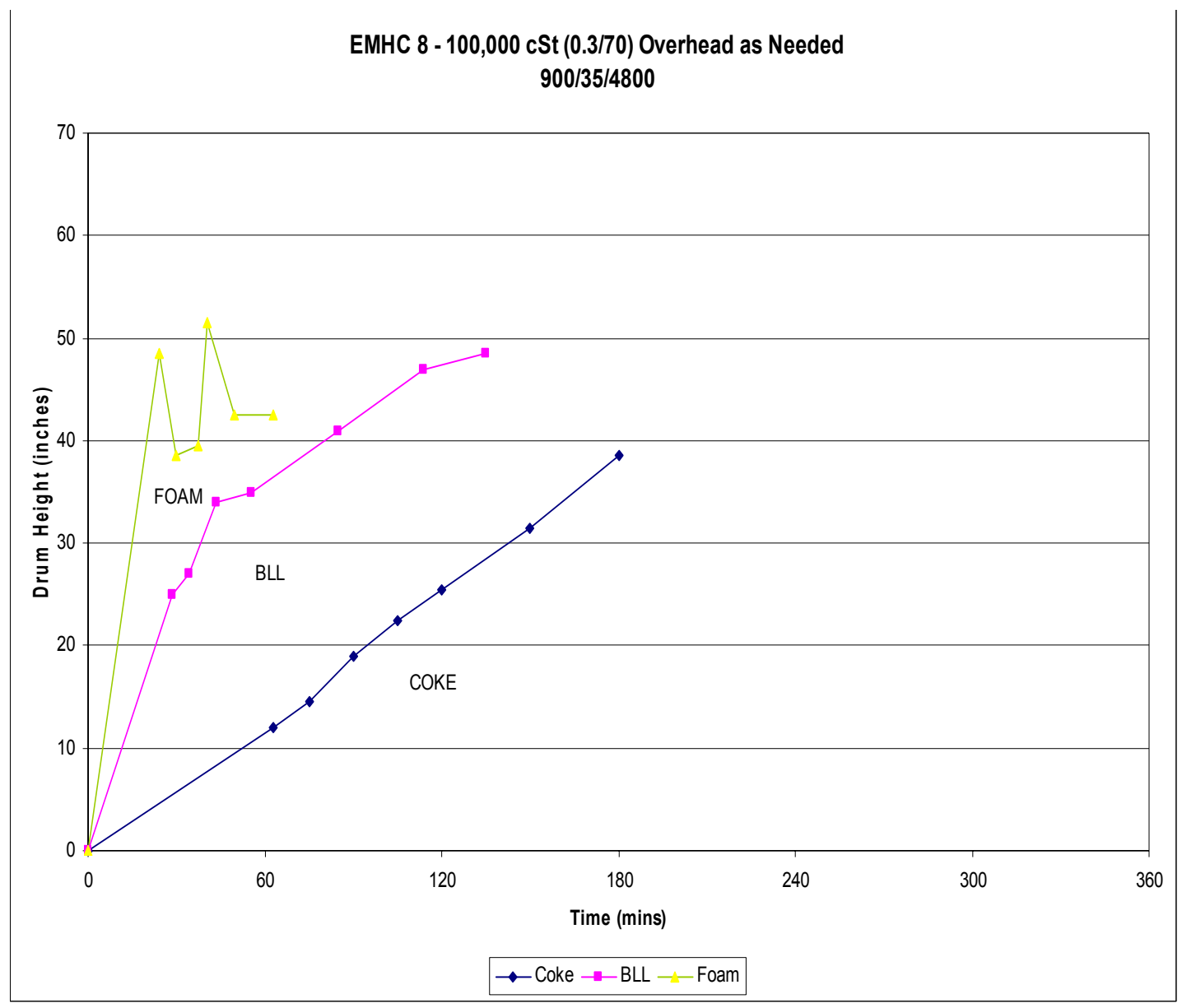

Figure 206: Drum height of foam, liquid and the coke layer during EMHC run 8. 


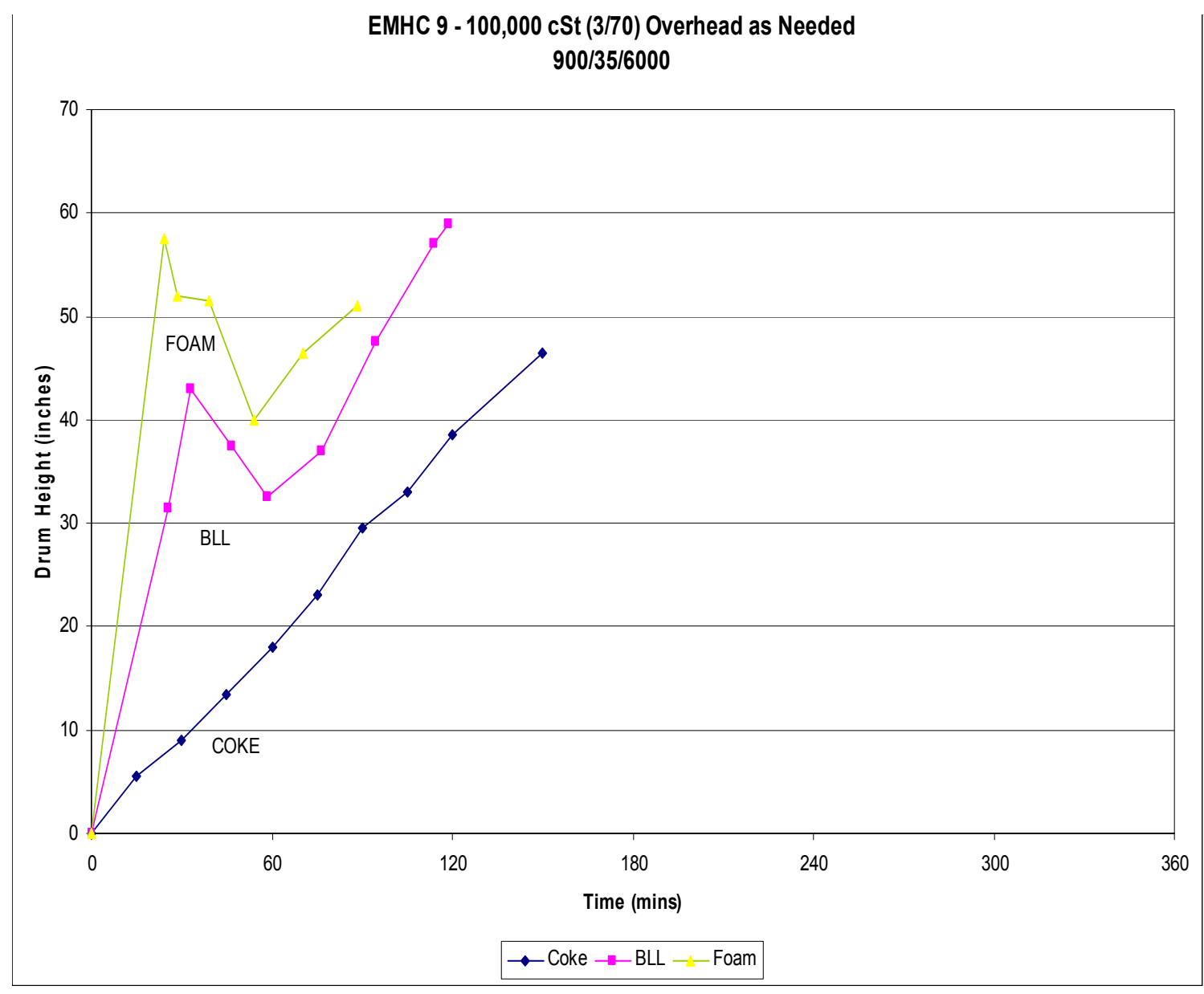

Figure 207: Drum height of foam, liquid and the coke layer during EMHC run 9. 


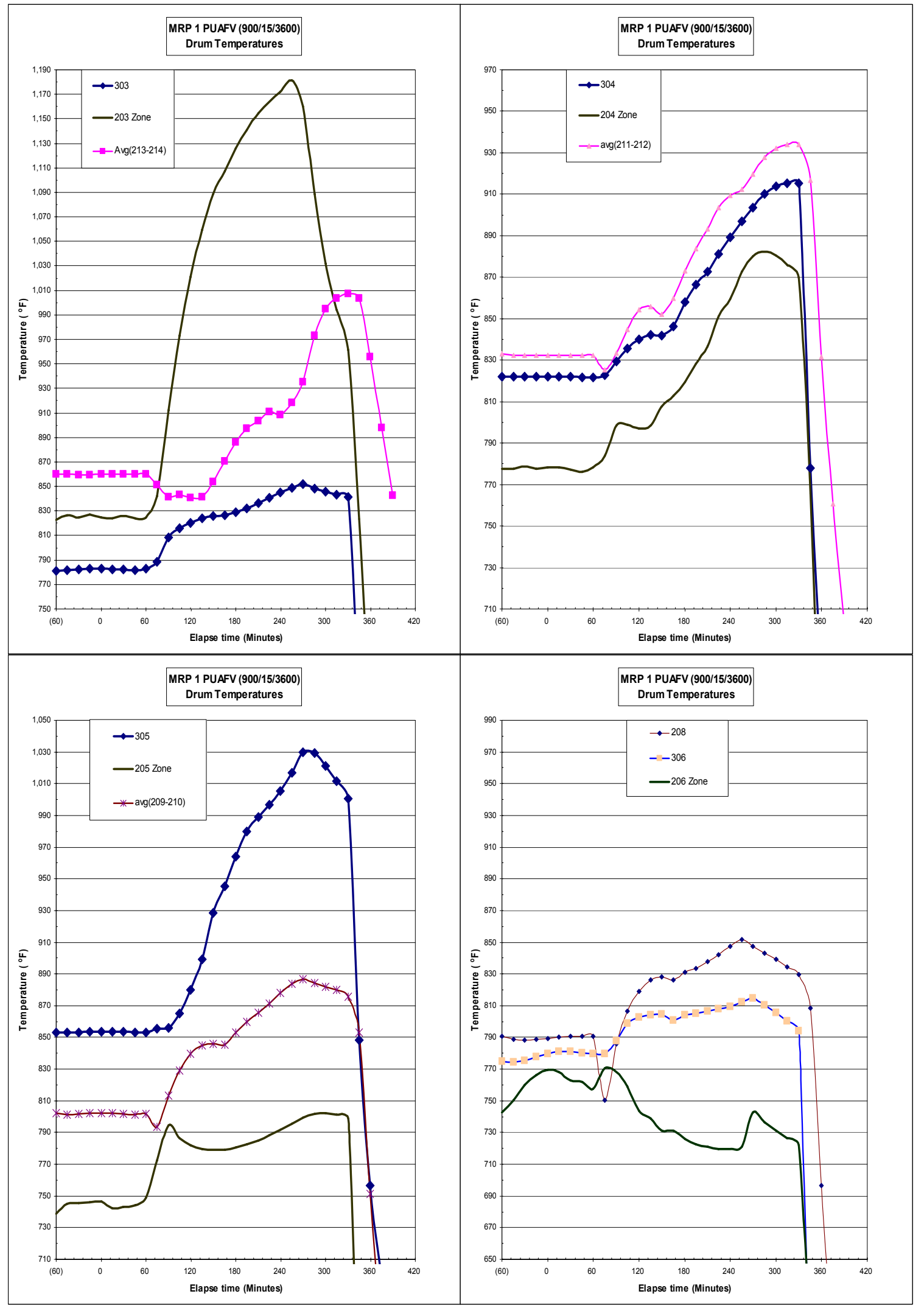

Figure 208: Drum temperature profile for MRP run 1. 
The University of Tulsa

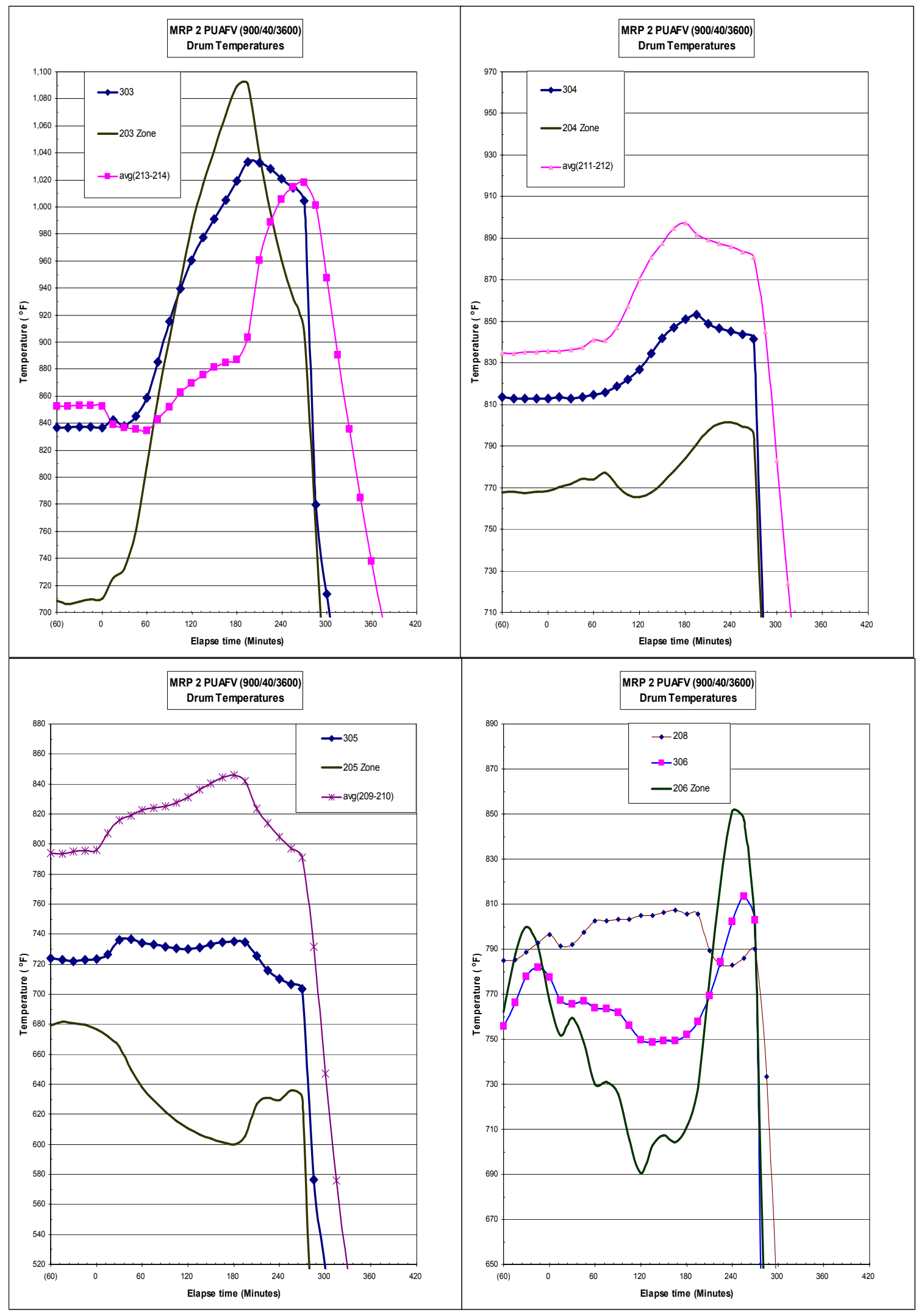

Figure 209: Drum temperature profile for MRP run 2. 


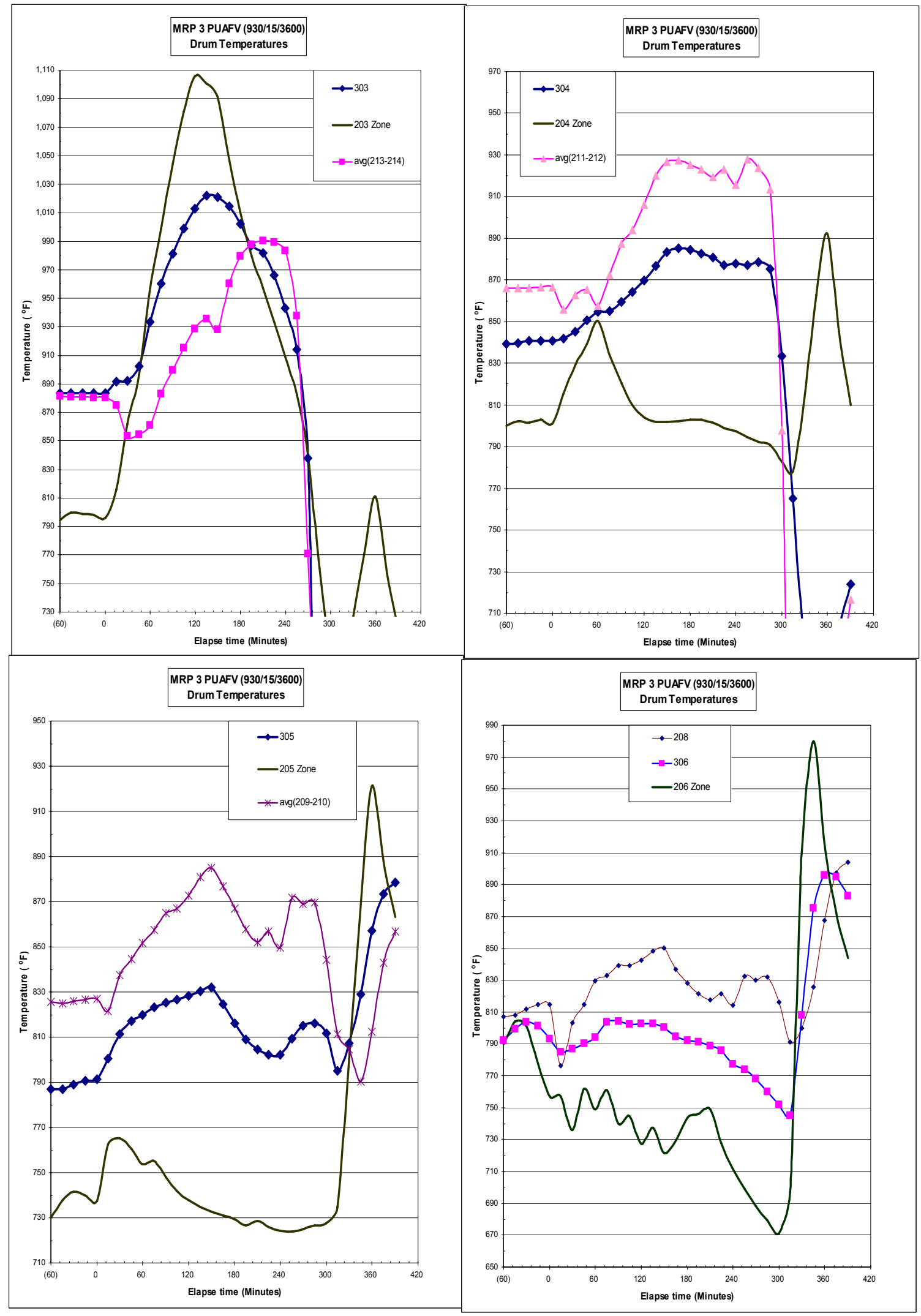

Figure 210: Drum temperature profile for MRP run 3. 


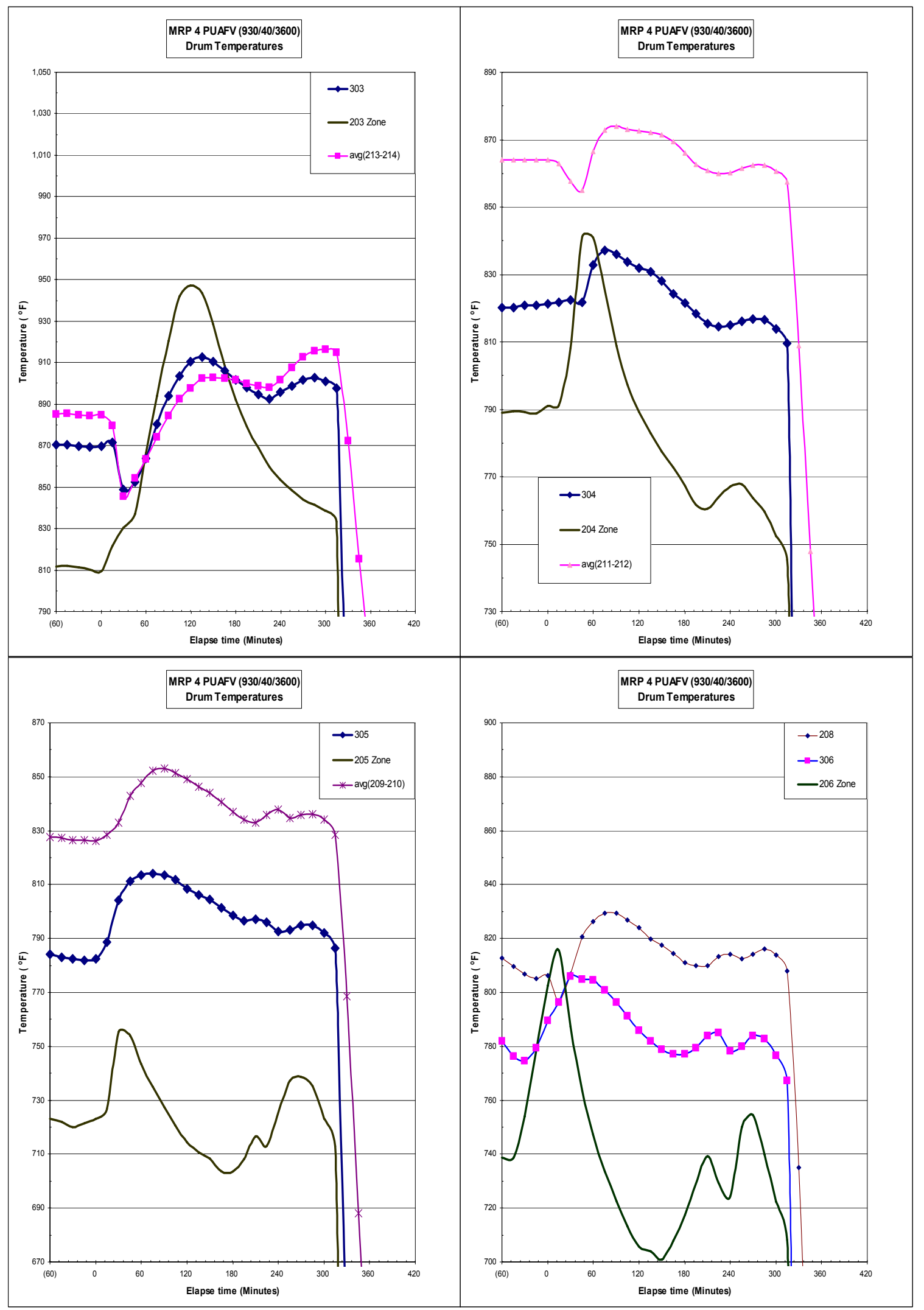

Figure 211: Drum temperature profile for MRP run 4. 
Table 84: Thermocouple locations along the coke drum height.

\begin{tabular}{|c|c|c|c|c|c|c|c|}
\hline \multicolumn{8}{|c|}{ Thermocouple (TI) } \\
\hline & Zone & Internal & Location & Drum Skin & Location & Furnace Element & Location \\
\hline & & TI & inches & TI & inches & TIC & inches \\
\hline Top & 6 & 208 & 78 & 306 & 85 & 206 & 85 \\
\hline & & & & & & & \\
\hline & 5 & 209 & 67 & 305 & 61 & 205 & 61 \\
\hline & & 210 & 56 & & & & \\
\hline & 4 & 211 & 45 & 304 & 41 & 204 & 41 \\
\hline & & 212 & 34 & & & & \\
\hline & & & & & & & \\
\hline & 3 & 213 & 23 & 303 & 17.5 & 203 & 17.5 \\
\hline & & 214 & 12 & & & & \\
\hline & & & & & & & \\
\hline & 2 & 215 & 1 & & & 202 & 3 \\
\hline Bottom & 1 & & & & & 201 & ches belov \\
\hline
\end{tabular}




\section{Conclusions}

Foam Densities typically have values less than $0.2 \mathrm{gm} / \mathrm{cc}$. However, values as high as $0.35 \mathrm{gm} / \mathrm{co}$ were observed. Feedline injection was found to be as effective as overhead injection. An optimum antifoam concentration exists.

Foam and bubbly liquid layers were quantifiable. Little or no foam layer was observed in the Equilon run. The Chevron runs had foam layers 7 to 10 " thick while the Petrobras runs had foam layers as thick as 20 ". The time to rise using the $600,000 \mathrm{cSt}$ antifoam was a lot longer when the $100,000 \mathrm{cSt}$ antifoam was used. This observation provides support that at equivalent concentrations, fewer injections, or less antifoam. Increasing concentrations of antifoam were found to increase coke density.

Paraffinic structured resids made Sponge Coke, Aromatic resids made Shot coke, Napthenic resids made mixture of shot and sponge coke and Intermediate structured resids made mixture of agglomerated and large BB's. On a resid basis, the Petrobras and Marathon resids made completely sponge coke irrespective of the operating conditions, the Suncor resid made shot coke irrespective of operating conditions, while the Equilon resid made mix of sponge, agglomerated shot and different sized BB's.

Petrobras and Marathon resids which made pure sponge coke have nearly same liquid layer and foam layer heights for a given set of temperature and pressure. With an increase in temperature the liquid layer decreased for the resids which make sponge coke. The rate of coke growth (dh/dt) with an increase in feedrate, was found to be comparable for the Petrobras (0.09-0.16 in/min) and Marathon resids (0.1$0.13)$. Foaming tendencies decreased with increase in temperature for pure sponge coke making resids (Petrobras and Marathon). Temperature appears to be the more dominant variable than pressure for foaming in case of sponge making resids. For both Petrobras and Marathon resids bulk density ranged from $0.6-0.8 \mathrm{gm} / \mathrm{cc}$ and gamma density ranged from $0.45-0.65 \mathrm{gm} / \mathrm{cc}$ approximately. The average difference between Bulk and gamma densities for Petrobras and Marathon resids are $0.13 \mathrm{gm} / \mathrm{cc}$ and 0.16 $\mathrm{gm} / \mathrm{cc}$ respectively. The density (both bulk and gamma densities) increased with an increase in temperature and pressure for sponge coke making resids.

Shot coke is formed because of more asphaltenes and turbulent conditions. An increase in temperature and/or superficial velocity increases the shot coke formation while an increase in pressure decreases shot coke formation. Agglomerated shot coke was noticed to form when it took longer to attain the desired operating temperature or after antifoam was injected. An increase in either the amount or concentration of antifoam caused an increase in percentage of BB's formed for the Suncor resid. For resids which made only shot coke (Suncor and Equilon) the foam layer increased with an increase in temperature at $15 \mathrm{psig}$ and decreased with an increase in temperature at $40 \mathrm{psig}$. An increase in pressure increased foaming for both resids and pressure appears to be dominant variable for shot coke making resids. The liquid layer did not change much for the Suncor resid.

Two of the resids, Chevron and Citgo, made variable morphologies. Both resids produced more sponge coke at low superficial velocities but more shot coke at higher superficial velocities. Foam and liquid layers were a function of operating conditions as was the density.

68 tests have been conducted with the pilot unit using the in-house resids. Studies were first conducted to determine the extent of antifoam carrying over during overhead injection using water. These studies indicated that some of the antifoam was carried over into the liquids when injected from overhead. However, the very low recovery of silicon indicates that most of the injected antifoam remained in the drum. More antifoam would be carried over during the coking process because the superficial velocity of the $\mathrm{HC}$ vapor is larger. Studies were also conducted to establish what was causing the fluctuations in the fluid in the furnace tube. By recording temperatures as a function of distance from coil inlet to outlet, it was 
hypothesized that an increase in vaporization of the fluid causes more irregularities in the flow pattern and temperature profile. When both recycle and antifoam were injected, it was noticed that the furnace had to be fired harder to achieve the desired operating temperature as compared to when only resid is injected.

Antifoam injection studies were run using both a low viscosity 100,000 cSt ( $0.3 \mathrm{ml} \mathrm{AF/} 70 \mathrm{ml}$ diesel) and a high viscosity $600,000 \mathrm{cSt}(0.75 \mathrm{ml} \mathrm{AF/} 70 \mathrm{ml}$ diesel) antifoam. In some of the tests, antifoam was injected continuously (2 min ON and 8 min OFF) while in others it was injected on as-needed basis (observation of foam determines the injection time). Antifoams were injected in the drum overhead, through the feedline, and mixed with the resid in the feed bucket. During the experiments, temperatures at the inlet to furnace coil, the fluid temperature, the furnace skin temperature, the overhead temperature and the temperature inside the coke drum near the bottom were measured. From test to test, variations were seen in the overhead temperature and the furnace coil temperatures. In general, injecting antifoam on a continuous basis reduces the overhead temperature, while injecting antifoam in the feedline requires the furnace to be fired harder to get the fluid to the desired temperature.

A partitioning study was conducted on the samples taken during the pilot unit tests in which oil and water samples were collected from the lights and heavies tank. More analytical results are needed for silicon in the liquid products but the tentative conclusion is that silicon from the antifoam injected overhead tends to carry over to the hydrocarbon liquids, while the silicon injected from the feedline tends to break down and end up in the decant water.

A detailed liquid analyses study was initiated in June 2003. This study is looking at 160 liquid samples generated in the first phase of study and those currently being generated in the continuation phase. The samples are being distilled and simulated distillation, detailed hydrocarbon analyses and sulfur analyses are run on each cut. The overall outcome of the study is to be able to predict what type of PiONA component, sulfur, etc. would be dominant at a certain temperature and pressure, and how a change in the temperature and pressure would affect its production.

Foaming runs were begun in June 2002. The first series of foaming tests were conducted using the Suncor resid to establish the differences between overhead, feed and feed line injection. The second series of tests were run using six in-house resids to gain an understanding of how pressure and temperature affect foaming as well as the impact of feed rate. This data was integrated with the results obtained during the first phase of study.

In general, the lower the temperature and pressure, and the higher the feedrate, the worse the foaming. This was especially true for the Marathon, Petrobras, and Chevron resid. However, Equilon \& Citgo foamed worse at higher pressure.

Nine antifoam optimization tests using the resid from Petrobras showed that injection of higher concentrations of antifoam/unit of carrier uses more antifoam than is required to effectively control foaming; however, the time between injection is longer and a denser coke is made. When large quantities of diesel are injected as the carrier, foaming appeared to be enhanced. Foaming resulted in uniform temperature profiles in the drum and when the temperatures in the drum were fairly uniform throughout, pure shot or a uniform sponge was made.

Continuous overhead and feed line injection are effective at controlling foaming throughout the run. Feed line injection with an antifoam/carrier concentration of $0.3 / 70$ was only effective at controlling foaming on a continuous basis for the first 80 minutes whereas the 30/70 concentration was effective throughout the run. The $0.3 / 70$ mixture was also the optimum AF concentration for controlling foaming overhead. It was also found that when 100,000 cSt and 600,000 cSt antifoams are used at equivalent concentrations, foam control is comparable; however, the time to rise was longer for the 600,000 cSt antifoam..

Two approaches were developed to quantify foam, liquid and coke heights. These approaches are being compared to test data to determine which technique, or a combination the techniques, works best. 


\section{E. PROCESS STUDIES}

\section{Recycle Test Runs}

Studies using recycle, Suncor runs 14, 15 (5\% RC), 16 (10\% RC) and SUNC 17 (15\% RC- industry conditions), were carried out in the month of September/October 2003. The Suncor 14 run was carried out at a temperature of $900{ }^{\circ} \mathrm{F}$, a pressure of $15 \mathrm{psig}$ and a feed rate of $2400 \mathrm{gm} / \mathrm{hr}$. Suncor 14 used asneeded overhead injection of $100,000 \mathrm{cSt}(0.3 / 70)$ antifoam. The Suncor 15 run which contained $5 \%$ recycle in the feed was carried out at a temperature of $900{ }^{\circ} \mathrm{F}$, a pressure of $15 \mathrm{psig}$ and a feed rate of $2400 \mathrm{gm} / \mathrm{hr}$. Figure 212 shows the comparison of temperature profiles for the Suncor 14 and 15 runs. As can be seen, Suncor 15 required more heat input to the feedline and the overhead temperature was comparatively warmer. Suncor 14 required less heat input to the feedline and had a cooler overhead temperature. The Suncor 16 run, which contained $10 \%$ recycle in the feed, was carried out at a temperature of $900 \mathrm{oF}$, a pressure of $15 \mathrm{psig}$ and a feed rate of $2400 \mathrm{gm} / \mathrm{hr}$. shows the comparison of temperature profiles for Suncor 14 and 16 runs. As can be seen, Suncor 16 required around 40-50 degrees of more heat input to the feedline compared to Suncor 14. The overhead temperature for Suncor 16 was higher compared to Suncor 14 . SUNC $17(15 \% \mathrm{RC})$ was run at industry conditions, at a temperature of $928^{\circ} \mathrm{F}$, and a pressure of $38 \mathrm{psig}$; however a feed rate of only $2400 \mathrm{gm} / \mathrm{hr}$ was used. shows the comparison of temperature profiles for Suncor 14 and 17 runs. As can be seen, SUNC 17 required around 50-60 degrees more heat input to the feedline compared to SUNC 14. Note though that the fluid temperature was $28^{\circ} \mathrm{F}$ higher for SUNC 17 compared to SUNC 14. SUNC 14 made a void of 5 inches in the drum whereas SUNC $15(5 \%$ RC), SUNC $16(10 \%$ RC) and SUNC $17(15 \%$ RC) runs showed good steam strip behavior. Comparison of Suncor runs 14, 15, 16 and 17 show that as the amount of recycle in the feed increases, the heat input to the furnace increases to maintain the same operating temperature of $900{ }^{\circ} \mathrm{F}$ as shown in Figure 213. Under the same conditions of pressure and temperature, a less dense coke was also made when recycle was used. The SUNC $17(15 \% \mathrm{RC})$ run was made at industry conditions, that is, at a temperature of 928 oF and a pressure of $38 \mathrm{psig}$. The feed rate was $2400 \mathrm{gm} / \mathrm{hr}$. In this run, the coke formed at the bottom of the drum was denser and the morphology began to change. The lower part of the drum was a mix of what looked like sponge and agglomerated shot. Another run is planned under the same conditions, but at a higher feed rate of $3600 \mathrm{gm} / \mathrm{hr}$. It is postulated that the higher feed rate will have an additional effect on the morphology, possibly changing more of it to sponge. Significant stripping was observed in the run without recycle. A void was also produced. These effects were not observed in the runs where recycle was used. 


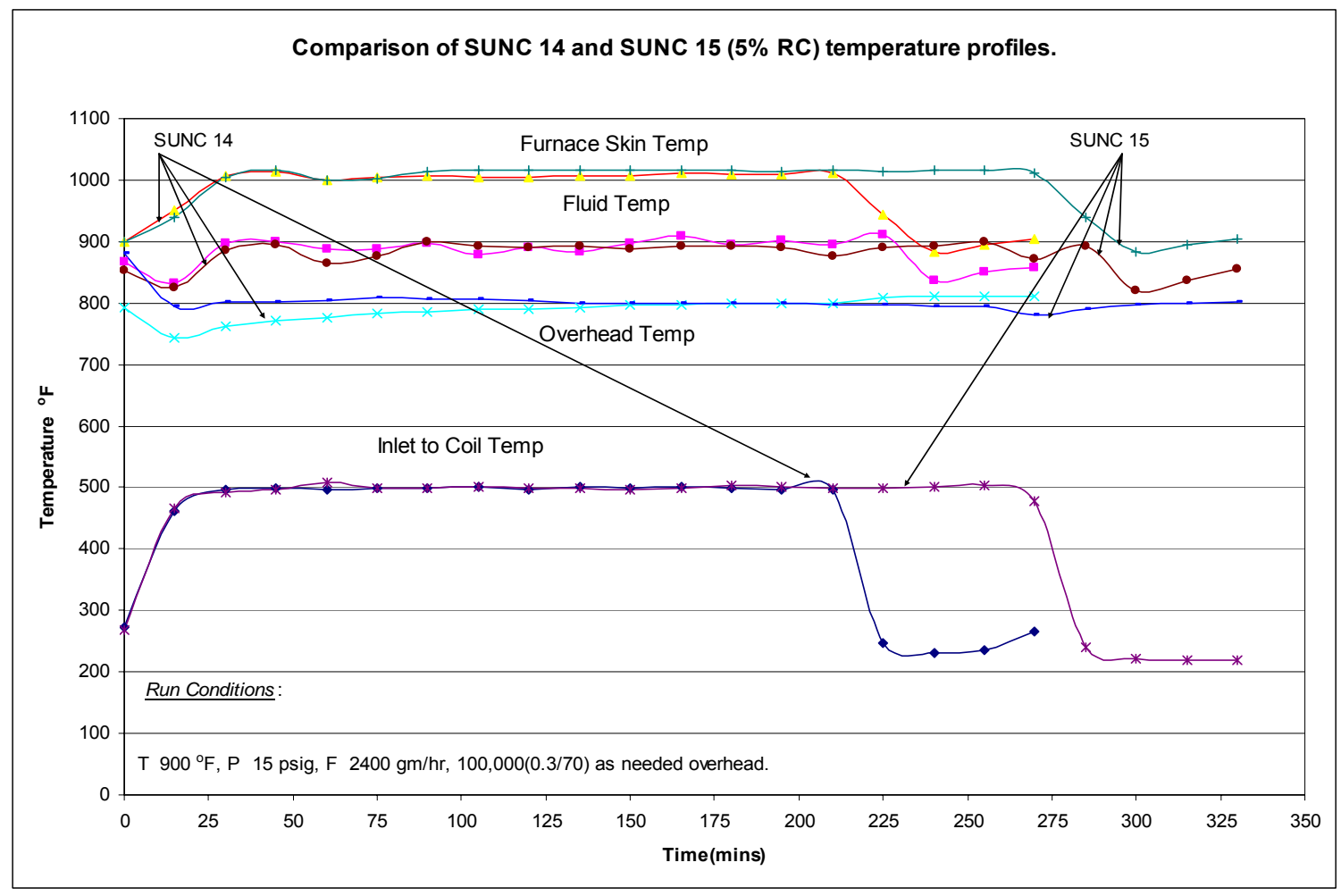

Figure 212: Temperature profiles for SUNC 14 PUAFI and SUNC 15 (5\% RC) PUAFI runs.

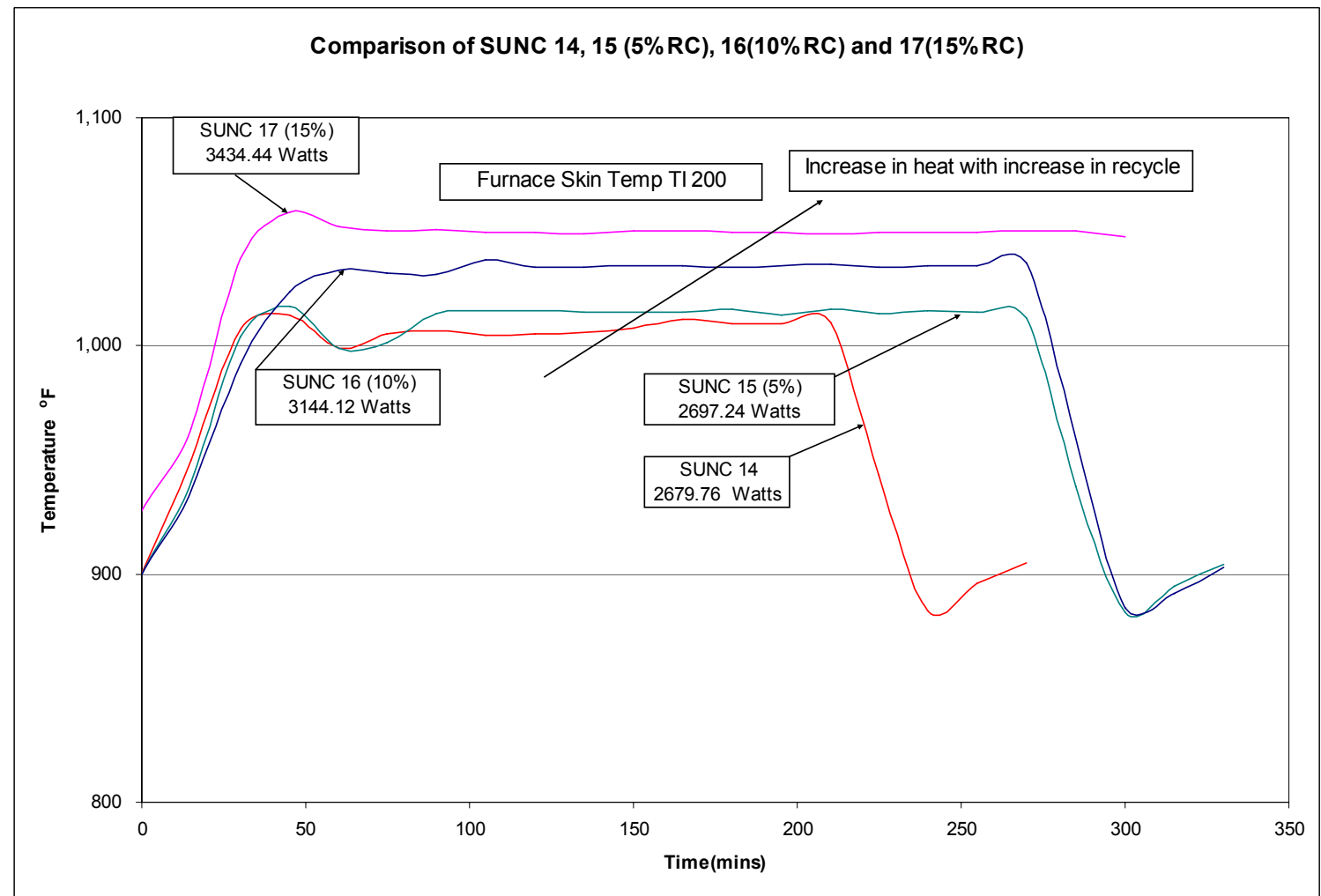

Figure 213: Furnace Skin Temperature for SUNC 14, 15, 16 and 17. 


\section{a) Conclusions:}

Preliminary observation suggests that overhead injection of antifoam lowers the overhead temperature. Further observation indicates that lower overhead temperature results in more material being stripped from the drum because of the slower reactions taking place. Feedline injection requires more heat input to the feedline to maintain equivalent fluid temperatures compared to the overhead injection of antifoam. The coking time for a particular run can be affected by the foaming characteristics of that particular resid. If the foam is too high in the drum, it affects the run length as there is a possibility of overhead lines getting clogged with time. Foam, if not controlled within a reasonable amount of time, is hard to control during the rest of the run. During antifoam injection a sudden rise of foam is observed. This property can be attributed to diesel flashing inside the coker drum. It is seen that the runs using higher viscosity $600,000 \mathrm{cSt}(0.75 / 70)$ antifoam take longer for the foam to re-appear compared to runs using the lower viscosity $100,000 \mathrm{cSt}(0.3 / 70)$ antifoam. Steam strip plots for Equilon indicate that the reduced run temperature strips the unreacted resid out of the drum. In terms of minimizing the loss of mass in the coker drum during steam strip, it is observed that asphalitic (Equilon) resids operate best at a temperature of 930 oF and a pressure of 40 psig whereas paraffinic (Petrobras) resids operated well under all conditions tested. With the addition of recycle to the feed, it is observed that the heat input requirement is higher compared to runs with no recycle. 


\section{Effect of Diesel on Overhead Temperature}

Temperature profiles for the pilot unit typically show a drop in the overhead temperature when antifoam is introduced at the top of the drum. The question is whether this temperature drop is due to the foam being knocked back, displacing the hot resid back to the bottom of the drum, or to quenching from the diesel carrier added at the top of the drum.

Figure 214 through Figure 219 show the temperature profiles at the top and bottom of the drum for runs EQ 4 PUAF, EQ 7 PUAF, and EQ 8 PUAF. All three runs were at $900^{\circ} \mathrm{F}, 15 \mathrm{psig}$, and $3600 \mathrm{~g} / \mathrm{hr}$. Run EQU 4 had no antifoam injection, while EQU 7 had intermittent antifoam injection (0.3/70 concentration, $100,000 \mathrm{cSt}$ ) and EQU 8 had continuous injection (0.3/70 concentration, 100,000 cSt). Both the runs with antifoam injection showed a significant temperature reduction at the top of the drum as compared to the case with no antifoam injection, whereas the temperature profile at the bottom of the drum looked nearly the same in every case.

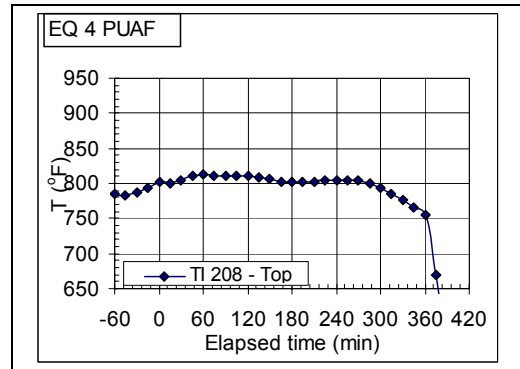

Figure 214 - Temperature vs. time at drum top, run EQ4 PUAF

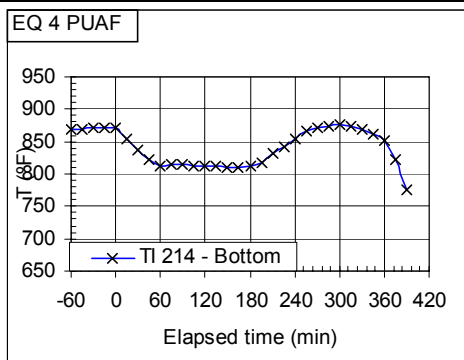

Figure 217 - Temperature vs. time at drum bottom, run EQ4 PUAF

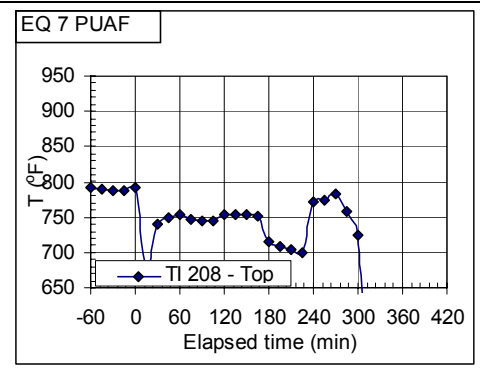

Figure 215 - Temperature vs. time at drum top, run EQ7 PUAF

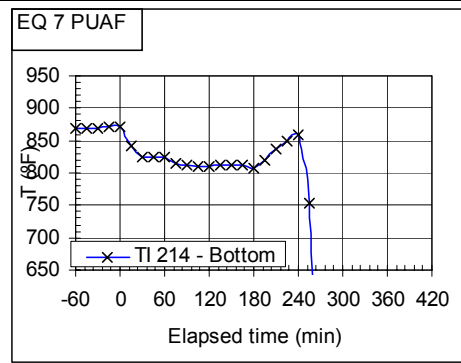

Figure 218 - Temperature vs. time at drum bottom, run EQ7 PUAF

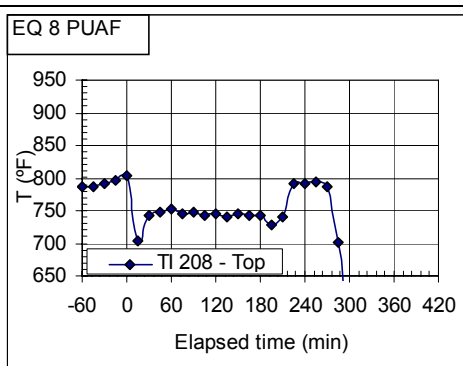

Figure 216 - Temperature vs. time at drum top, run EQ8 PUAF

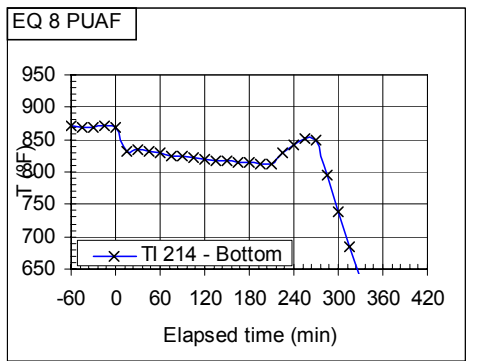

Figure 219 - Temperature vs. time at drum bottom, run EQ8 PUAF

Run EQU 7 had a total of $66 \mathrm{~g}$ of diesel added with the antifoam, while run EQU 8 had a total of 95 $\mathrm{g}$ of diesel added with the antifoam. Assuming that the diesel has a mean heat of vaporization of 180 $\mathrm{Btu} / \mathrm{lb}$, an average boiling temperature of $540^{\circ} \mathrm{F}$, and a heat capacity of $0.65 \mathrm{Btu} / \mathrm{lb} /{ }^{\circ} \mathrm{F}$, a rough estimate can be made of the cooling provided by the diesel injection. The calculated cooling for run EQU 7 is $\sim 70$ 
Btu and the cooling for run EQU 8 is $\sim 100 \mathrm{Btu}$. This amount of cooling, if introduced instantaneously to the bed, could lower the bed temperature by as much as 15-20( $F$ (assuming a heat capacity for the bed material of $0.5 \mathrm{Btu} / \mathrm{lb} /(\mathrm{F})$. In the case of run EQU 8 , where this material was introduced slowly over 3 hours, the bed temperature effect from the diesel ought to be negligible. For run EQU 7, however, the antifoam injections were made in several large doses. Table 85 shows the antifoam injection rates for EQU 7 along with the estimated temperature drop, based on the above assumptions and the estimated bed mass as a function of time. It can be seen that the first antifoam injection causes a significant temperature drop, because the mass of the material in the bed is rather small. Subsequent antifoam injections have much smaller effects. Figure 215 shows the large temperature drop at the top of the bed from the first antifoam injection, followed by a temperature recovery and then a relatively stable profile. The results are consistent with this analysis, although it should be noted that the initial temperature drop for run EQU 7 $\left(\sim 100^{\circ} \mathrm{F}\right)$ is significantly larger than predicted. It can be concluded that most of the temperature drop observed following antifoam addition is probably the result of the hot foam moving to the bottom of the bed, although the initial antifoam addition probably contributes some toward this cooling due the thermal effect of the diesel carrier addition.

Table 85 - Bed cooling for run EQU 7 PUAF

\begin{tabular}{|r|c|c|c|c|}
\hline $\begin{array}{c}\text { Run Time } \\
\text { (hrs) }\end{array}$ & $\begin{array}{c}\text { Total Inj. Amt. } \\
\text { (g) }\end{array}$ & $\begin{array}{c}\text { diesel injected } \\
\text { (lb) }\end{array}$ & $\begin{array}{c}\text { est. cooling } \\
\text { (Btu) }\end{array}$ & $\begin{array}{c}\text { estimated bed } \\
\text { temp. drop (F) }\end{array}$ \\
\hline $0: 33$ & 23.2 & 0.051 & 24.8 & 28 \\
\hline $1: 38$ & 8.6 & 0.019 & 9.2 & 4 \\
\hline $2: 01$ & 17.4 & 0.038 & 18.5 & 6 \\
\hline $2: 24$ & 8.6 & 0.019 & 9.2 & 2 \\
\hline $2: 37$ & 8.6 & 0.019 & 9.2 & 2 \\
\hline
\end{tabular}

\section{Steam Stripping Studies}

Gamma densitometer traces before and after steam stripping show the loss of mass from the coke bed due to the stripping steam. This loss of mass is due to the volatile matter that is stripped from the coke. Figure 220 show the gamma densitometer trace for run SUN 6 PUAF. It can be seen that there is a notable loss of material, mostly between 6 and 12 inches bed height, just below the layer of agglomerated shot at the top of the bed. This loss of material resulted in the bed slumping by approximately 2 inches. For most runs where shot agglomeration occurred, the loss of material from steam stripping occurs primarily below the agglomerated shot section. For runs that made sponge coke, the loss of material is often more uniformly distributed, as illustrated in Figure 221 for run PETR 5 PUAF. Note that this run also showed some slumping of the bed following steam stripping. On the other hand, run PETR 9 PUAF, shown in Figure 222, had significant bed compaction from steam stripping, resulting in the bed slumping by nearly 5 inches. This slumping actually caused an increase in the coke bed density, mostly at the bottom of the bed but to a lesser extent in the middle of the bed (between 30 and 35 inches bed height). There are also some runs such as CIT 7 PUAF which show some loss of material but no slumping of the bed, and runs such as SUN 1 PUAF which show very little loss of material from steam stripping. 
The University of Tulsa

Height vs Density(full/15)

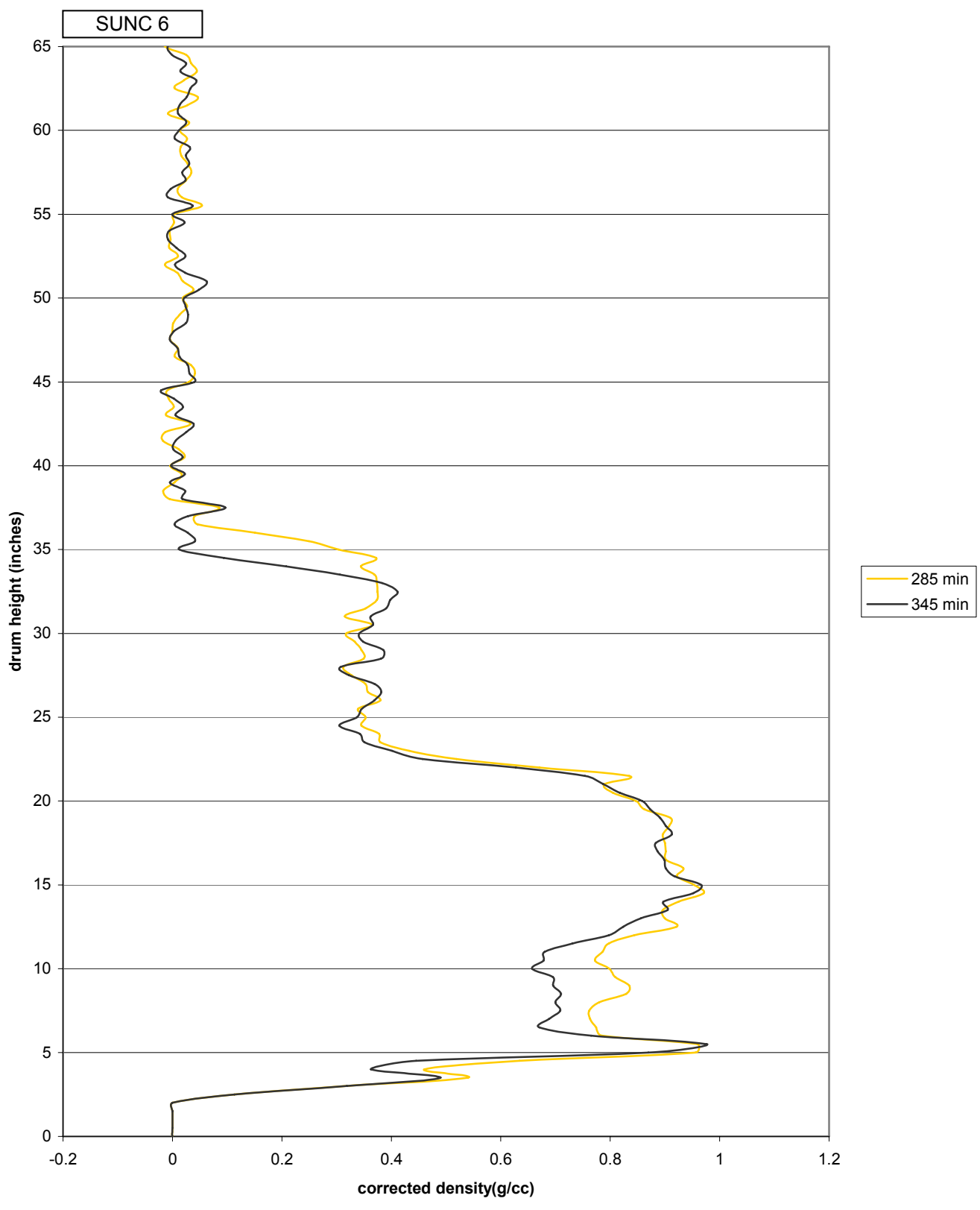

Figure 220 - Gamma densitometer traces for run SUN 6 PUAF before and after steam stripping 
Height vs Density(full/15)

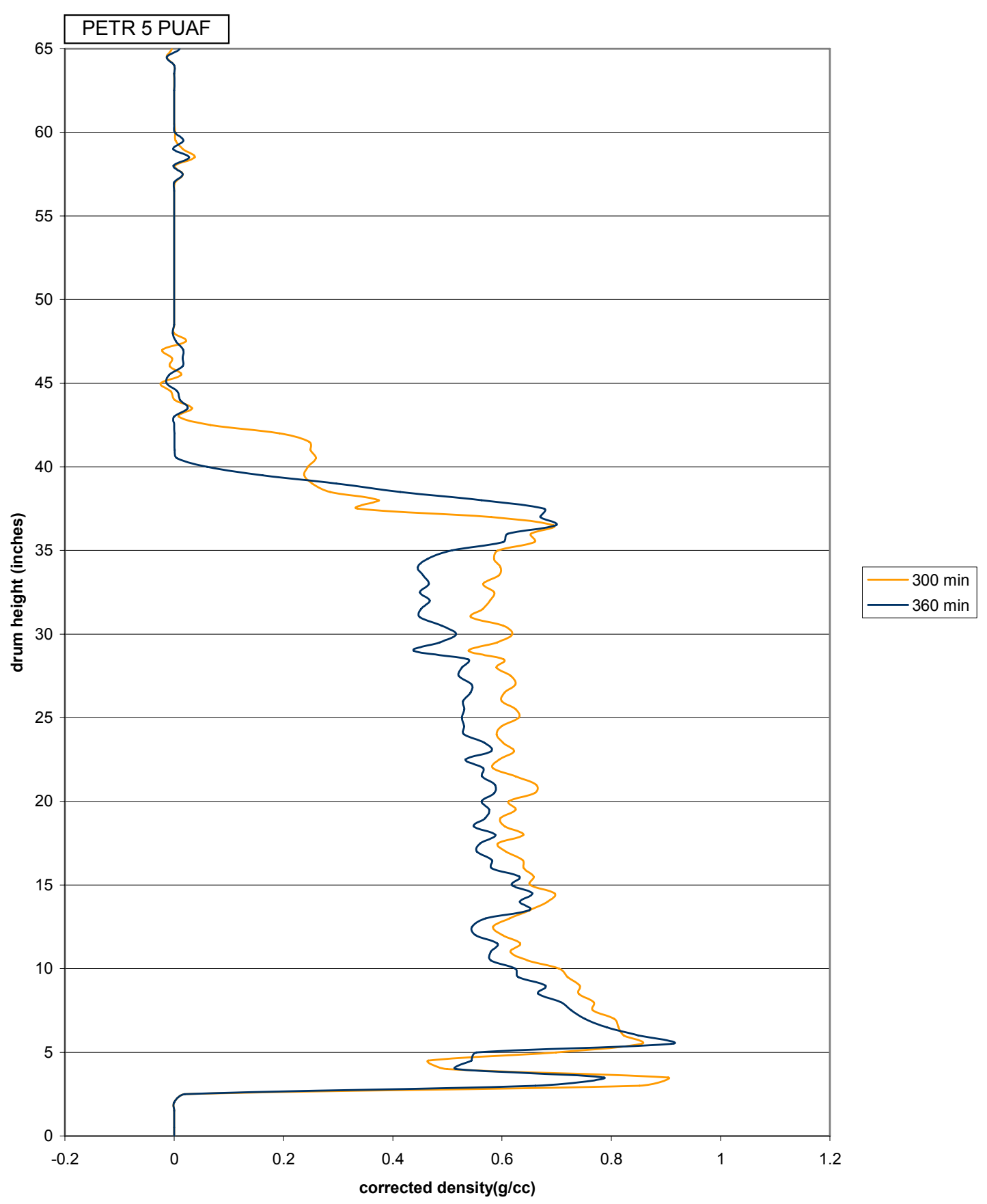

Figure 221 - Gamma densitometer traces for run PETR 5 PUAF before and after steam stripping 


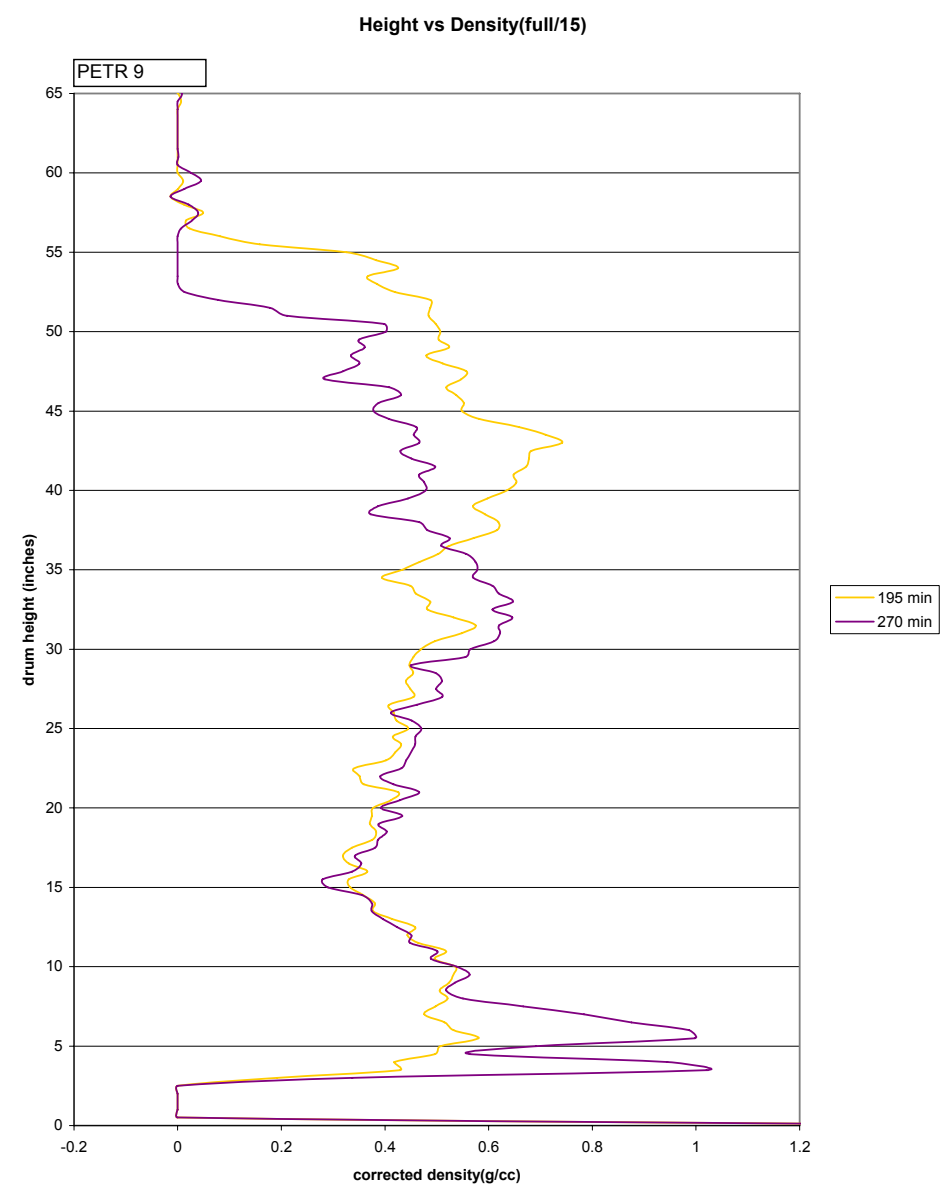

Figure 222 - Gamma densitometer traces for run PETR 9 PUAF before and after steam stripping

\footnotetext{
A definite tendency toward more material loss for lower temperatures and higher flow rates was observed.
}

Gamma densitometer plots illustrating the steam stripping effects for runs PETR 8-10 and EQU 7-8 are shown in the following figures. The Equilon gamma scans shown in Figure 225 shows that a great deal of material has been stripped out of the bed by steam stripping. These scans can be compared to EQU 4 PUAF; all three runs were made at $900^{\circ} \mathrm{F}, 15 \mathrm{psig}$, and $3600 \mathrm{~g} / \mathrm{hr}$. The loss of material is somewhat less for EQU4. This can be attributed to the higher temperature at the top of the bed for this run, due to the absence of antifoam usage, as discussed above in Figure 214 to Figure 216. Apparently the low overhead temperatures $\left(\sim 750^{\circ} \mathrm{F}\right)$ experienced in runs EQU $7 \& 8$ did not result in complete conversion to coke for these reaction times (2.75 hrs for EQU 7 and 3 hrs for EQU 8). 


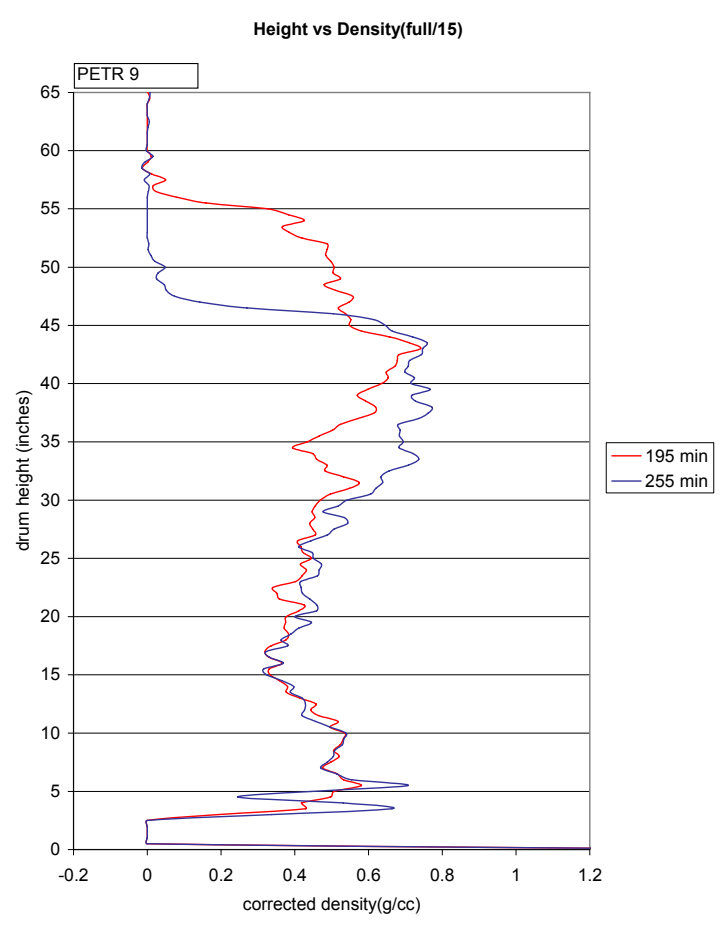

Figure 223 - Gamma densitometer traces for run PETR 9 PUAF before and after steam stripping

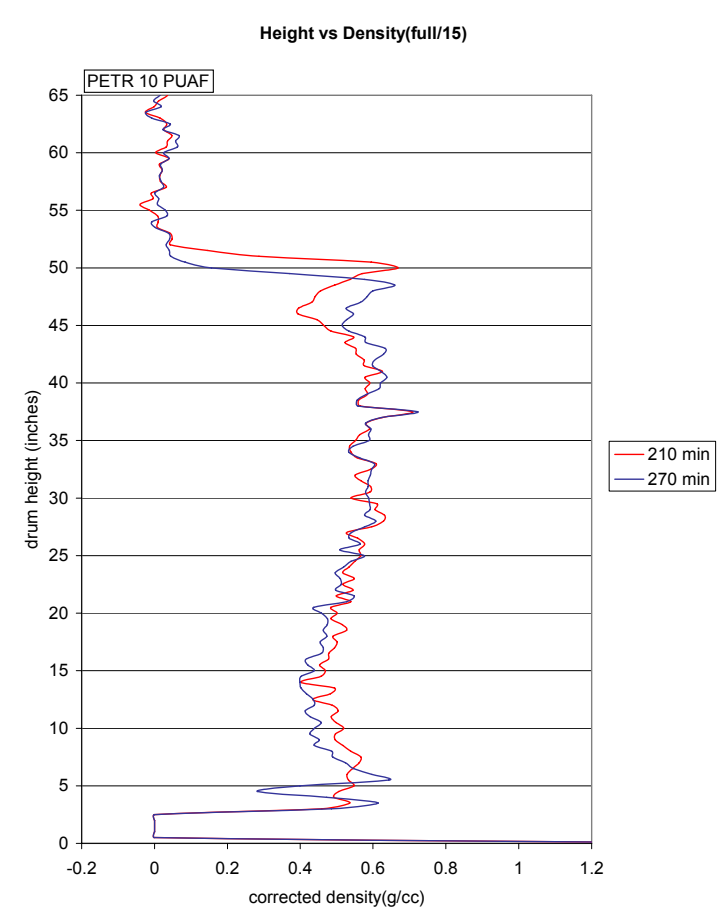

Figure 224 - Gamma densitometer traces for run PETR 10 PUAF before and after steam stripping

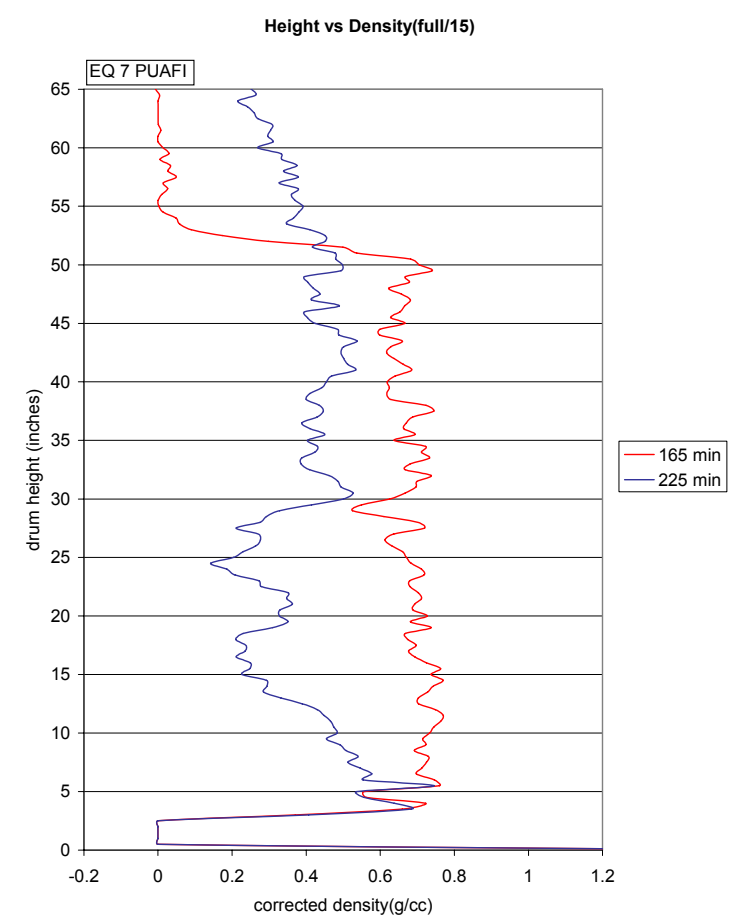

Figure 225 - Gamma densitometer traces for run EQU 7 PUAF before and after steam stripping 


\section{Conclusions}

Preliminary observation suggests that overhead injection of antifoam lowers the overhead temperature. Further observation indicates that lower overhead temperature results in more material being stripped from the drum because of the slower reactions taking place. Feedline injection requires more heat input to the feedline to maintain equivalent fluid temperatures compared to the overhead injection of antifoam. The coking time for a particular run can be affected by the foaming characteristics of that particular resid. If the foam is too high in the drum, it affects the run length as there is a possibility of overhead lines getting clogged with time. Foam, if not controlled within a reasonable amount of time, is hard to control during the rest of the run. During antifoam injection a sudden rise of foam is observed. This property can be attributed to diesel flashing inside the coker drum. It is seen that the runs using higher viscosity $600,000 \mathrm{cSt}(0.75 / 70)$ antifoam take longer for the foam to re-appear compared to runs using the lower viscosity $100,000 \mathrm{cSt}(0.3 / 70)$ antifoam. Steam strip plots for Equilon indicate that the reduced run temperature strips the unreacted resid out of the drum. In terms of minimizing the loss of mass in the coker drum during steam strip, it is observed that asphaltic (Equilon) resids operate best at a temperature of $930^{\circ} \mathrm{F}$ and a pressure of 40 psig whereas paraffinic (Petrobras) resids operated well under all conditions tested. With the addition of recycle to the feed, it is observed that the heat input requirement is higher compared to runs with no recycle.

A rough estimate was made of the cooling of the drum due to injection of the diesel antifoam carrier. Calculations show that most of the temperature drop observed following antifoam addition is probably the result of the hot foam moving to the bottom of the bed, although the initial antifoam addition probably contributes some toward this cooling due to the thermal effect of the diesel carrier addition. 
The University of Tulsa 


\section{F. QUENCHING STUDIES}

Discussed below are the pilot unit process studies regarding coke cooling and foaming during coking. Coke cooling was analyzed in three different ways: (1) by looking at its temperature profiles, (2) by looking at its cooling rates for the cases when the coke bed is cooled with nitrogen and with the furnace door closed or opened, and when the coke bed is quenched with water, and (3) by observing some general trends from the coke bed cooling rates. The foaming issue was analyzed by looking at the drum temperature profiles during coking and observing differences between profiles with and without foaming taking place. The effect of foaming on the type of coke produced is also addressed. Unless otherwise specified, most of the studies are related to the 6 foot drum.

\section{Cooling Temperature Profiles}

In this section, cooling of the coke bed was looked into by analyzing the drum temperature profiles after steam stripping was completed to see how different coke beds cooled as a function of thermocouple height in the drum. In general, the coke beds were either cooled using nitrogen or water. For the first case the furnace door was either left closed after the run ended or it was opened after steam stripping ended.

\section{a) Open Furnace Door}

To see how the coke bed temperature varied at each thermocouple height as a function of time for the case when the furnace door was opened, we plotted CHV 3 PUAF as shown in Figure 226 below.

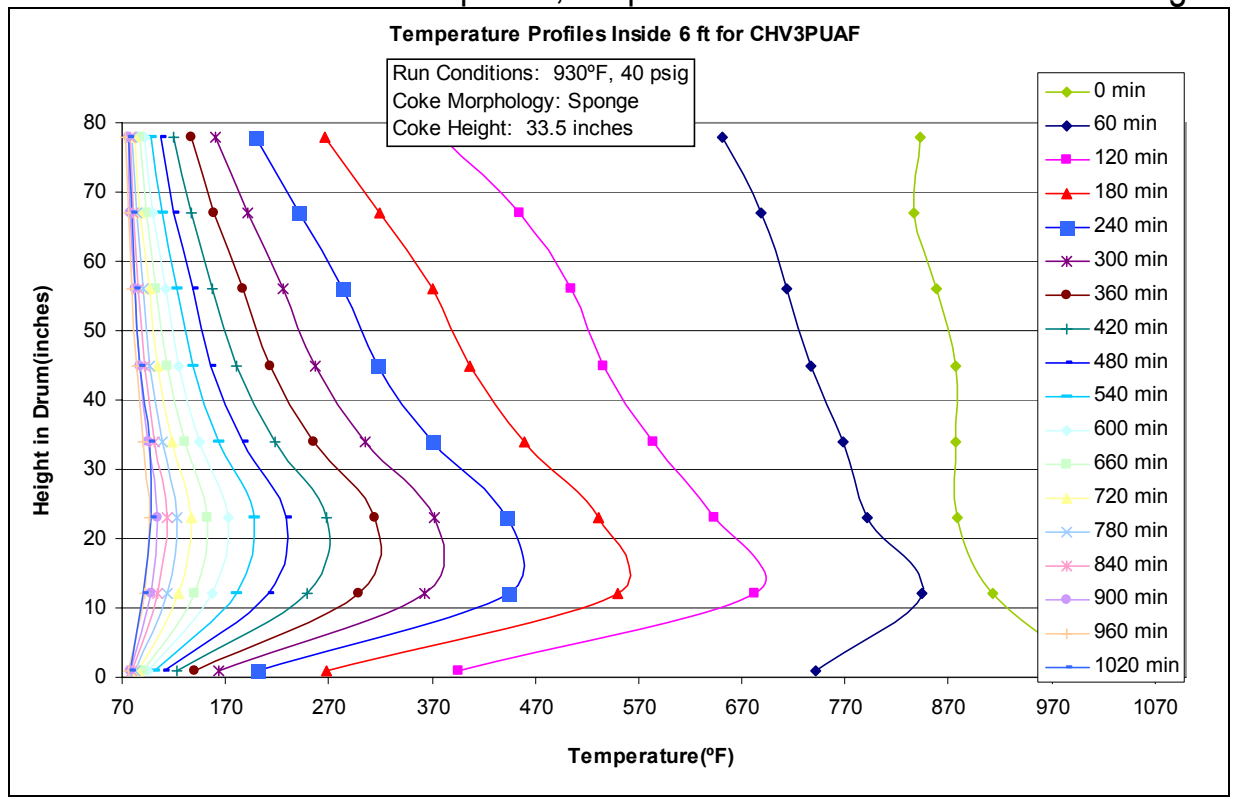

Figure 226 - Cooling Temperature Profiles as a Function of Thermocouple Heights for a Chevron Run Allowed to Cool for 17 Hours

From the figure it can be seen that the temperature profiles of the coke bed decrease unsteadily as cooling time progresses until the temperature profile of the entire drum is almost vertical, that is - the entire 
coke bed reaches room temperature. It is seen too, that most of the cooling takes place during the first few hours after the furnace door is opened and after that the cooling is more uniform and steady.

Another observation made from the temperature profiles plotted as a function of thermocouple height is that regardless of the amount of coke produced, the conditions at which the run was operated, and the coke morphology produced, the profiles looked very similar as long as the cooling procedure was the same. To illustrate this, see Figure 227 below which corresponds to a run made in the 3 foot drum.

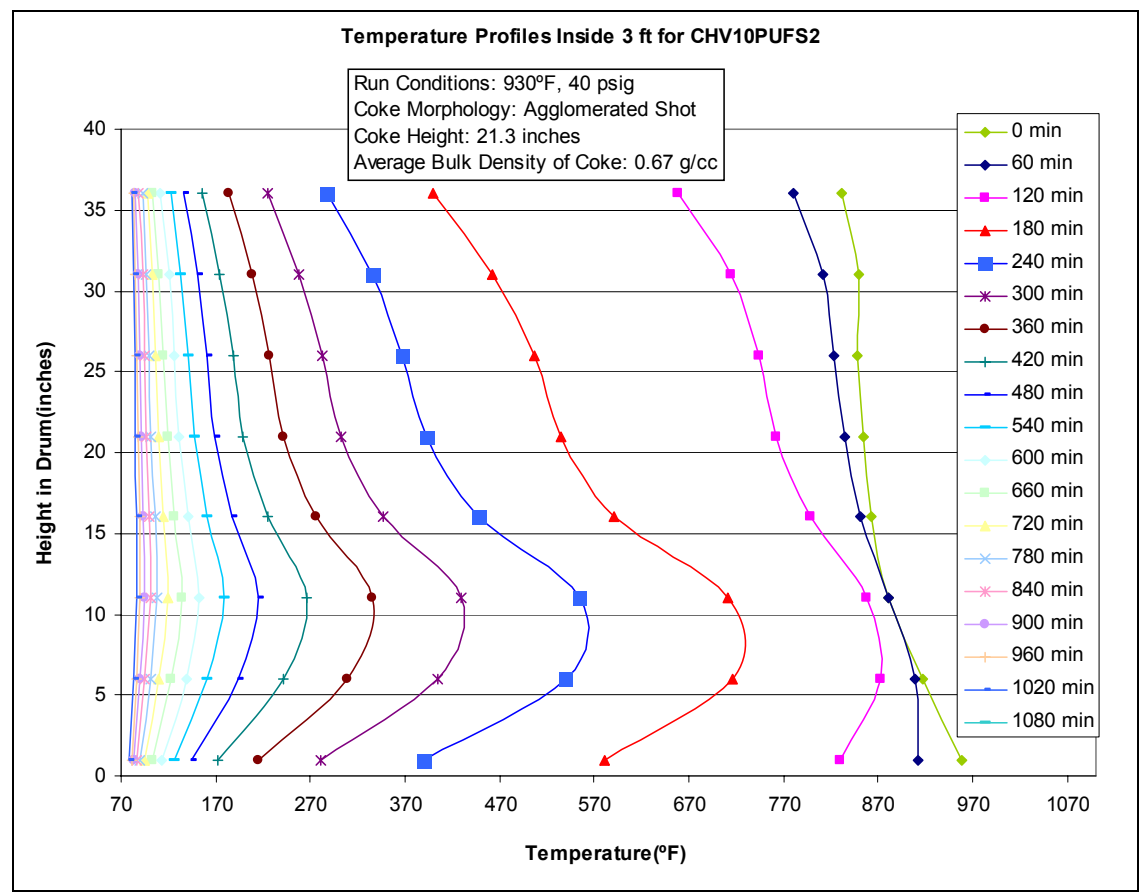

Figure 227 - Cooling Temperature Profiles as a Function of Thermocouple Heights for a Chevron Run Allowed to Cool for 17 Hours

From the figure it is seen that the profiles indicate that the furnace door was opened and that the same pattern of cooling occurs; large temperature drop in the beginning and a more uniform and steady cooling afterwards.

\section{b) Closed Furnace Door}

In contrast, when the furnace door was left closed after the run ended, as was the case with CIT3 PUAF and a few other runs, the drum temperature profiles decreased more steadily but much slower than when the furnace door was opened after steam stripping for an hour. 


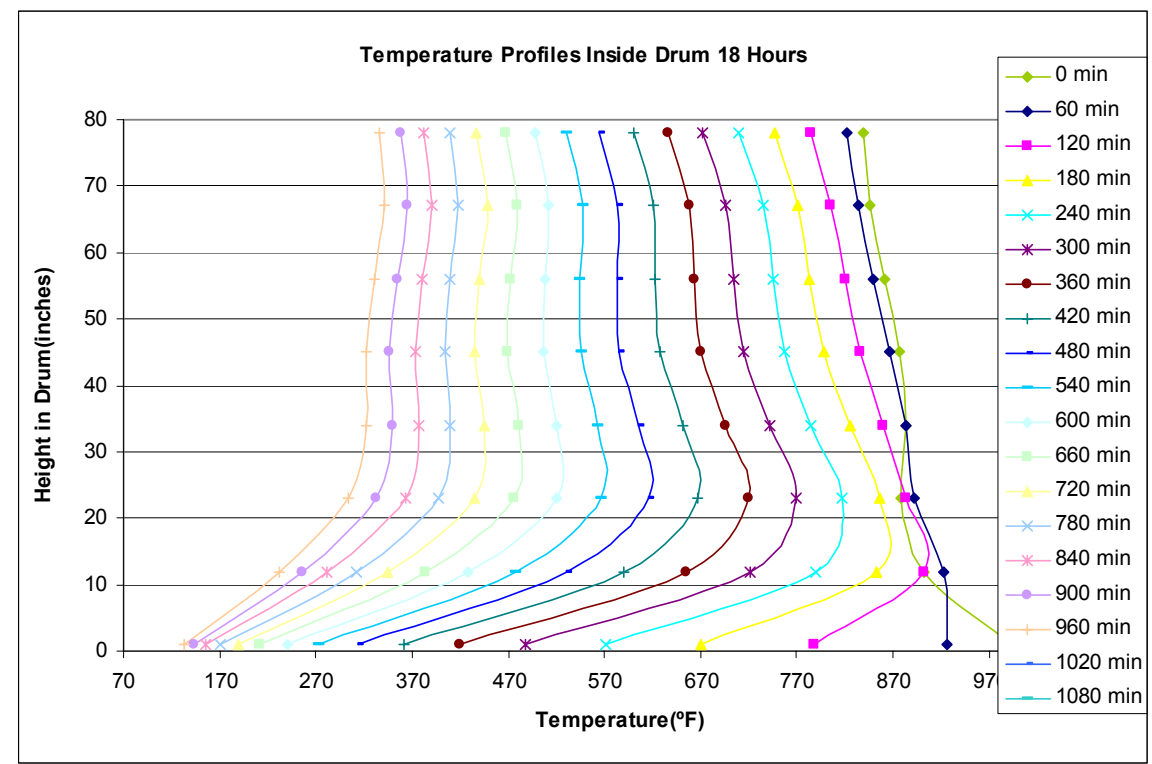

Figure 228 - Cooling Temperature Profiles as a Function of Thermocouple Heights for a Citgo Run Allowed to Cool for 16 Hours

As shown in Figure 228 above, it was observed that from 3:41 pm (the time when steam stripping ended) until 8:00 am next day, the drum cooled only to approximately $170^{\circ} \mathrm{F}$. This shows that there is a significant difference in the cooling profiles when the furnace door is left closed and when the door is opened after the run is over. This is to be expected because when the furnace door is left closed, cooling of the coke bed takes place solely due to the continuous flow of Nitrogen which is only about $0.5 \mathrm{SCFH}$; on the other hand, when the furnace door is opened a great deal of the cooling takes place due to free convection resulting from the exposure of the drum to air. This issue will be discussed further in a later section.

\section{c) Water Quenching}

As mentioned earlier, a third procedure used to cool the coke bed was to quench the coke bed with water after one hour of steam stripping. Plotting the cooling temperatures as a function of thermocouple heights in the drum revealed a third type of temperature profiles. As can be seen in Figure 229 below, a run that was quenched with water shows drastic cooling during the entire cooling period especially in the bottom part of the drum. 


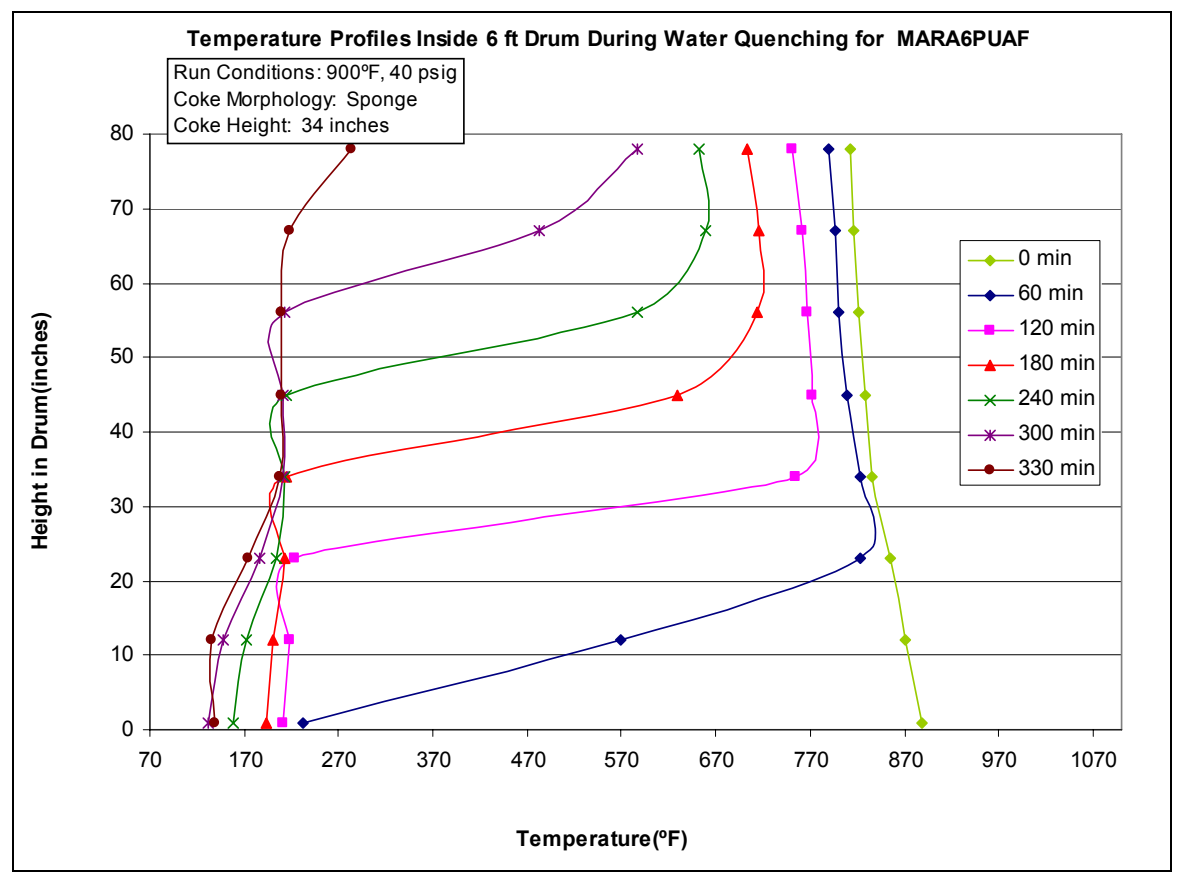

\section{Figure 229 - Cooling Temperature Profiles as a Function of Thermocouple Heights for a Marathon Run Allowed to Cool for 5 Hours}

From the discussion above, it was seen that as long as the cooling procedure used between runs was the same the cooling profiles of the coke bed were very similar. However, the rates at which each individual run cooled were different for each run and this is due to the individual properties of the coke produced in a test run, different coke morphologies, and different run conditions. This issue is discussed next.

\section{Cooling Rates}

The rates at which the coke beds cooled were analyzed and grouped by coke morphology and/or coke density and by run conditions. To analyze the rates at which coke cooled for different runs, the cooling temperature data was plotted as a function of time for zones or sections of the coke bed that had similar morphologies. The runs were grouped by coke morphology/density, run pressure and run temperature, and coke particle size. The focus of the studies was on the open furnace door case and the water quenching case.

a) Open Furnace Door

(i) Coke Morphology/Density/Particle Size Effects

A typical plot of cooling rates for a run cooled with the furnace door opened is shown in Figure 230 below. Different resids showed different cooling rates and a few are shown next. 


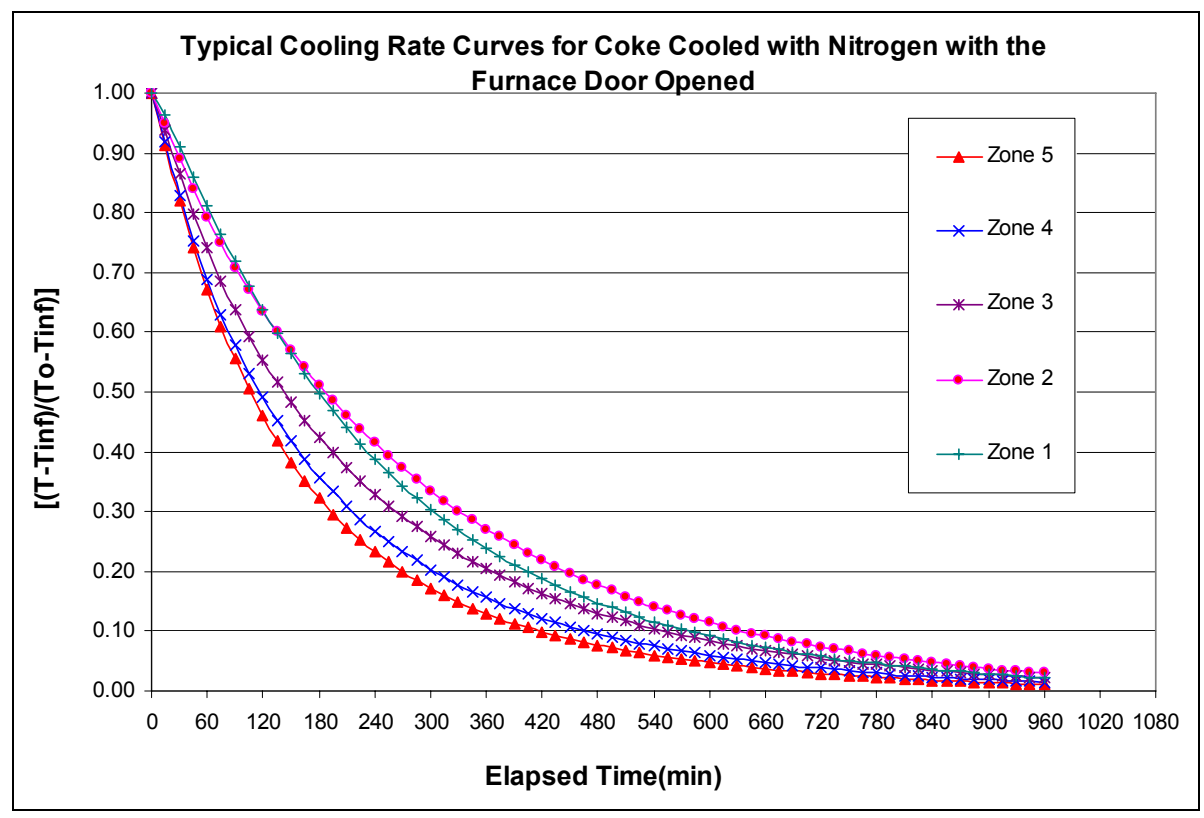

\section{Figure 230 - Typical Cooling Rate Curves of Coke Cooled with Nitrogen and with Furnace Door Opened}

To study the effect of coke morphology effects on the cooling rates the following morphologies were used: hard sponge and soft sponge, agglomerated shot, and BB shot surrounded by agglomerated shot. The sizes of the BB shot pellets varied and for one of the resids the effect of particle size was addressed. For the Chevron resid, sponge coke cooled faster than shot coke and, with a few deviations, this observation was repeatedly observed for the other resids as well.

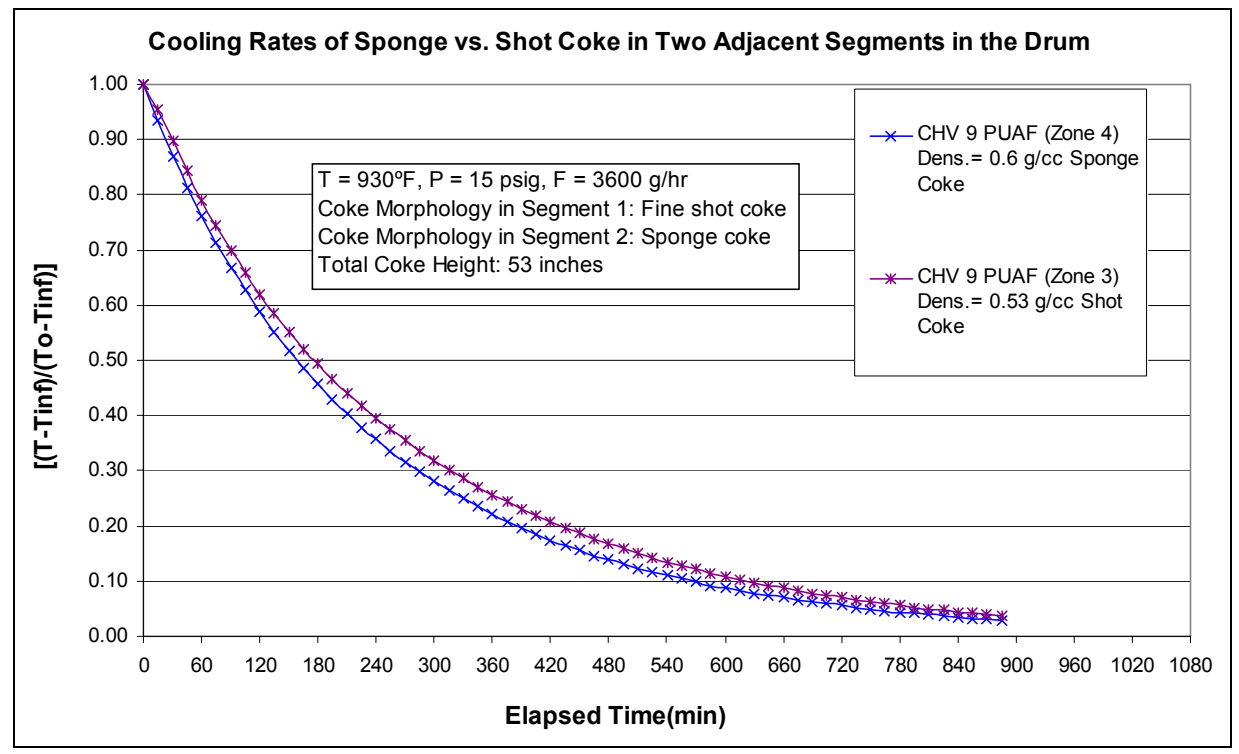

\section{Figure 231 - Effect of Coke Morphology on Cooling Rates for Chevron}

This observation was to be expected because as its name itself indicates, sponge coke has a very porous microstructure with walls and pores of various sizes. Shot coke on the other hand, has ribbon-like 
anisotropic domains arranged in concentric patterns to form shot-like coke which is much more compact in structure than sponge coke. For that reason, it is expected that the more porous structure will cool faster than the more compact structure, shot coke.

Because coke morphology is closely linked to coke density it was seen that sometimes sponge coke did not cool faster than shot coke as anticipated. An explanation for that behavior is that the denser coke, regardless if it is sponge or coke, will take longer to cool than the less dense coke. This observation is illustrated in Figure 232 below.

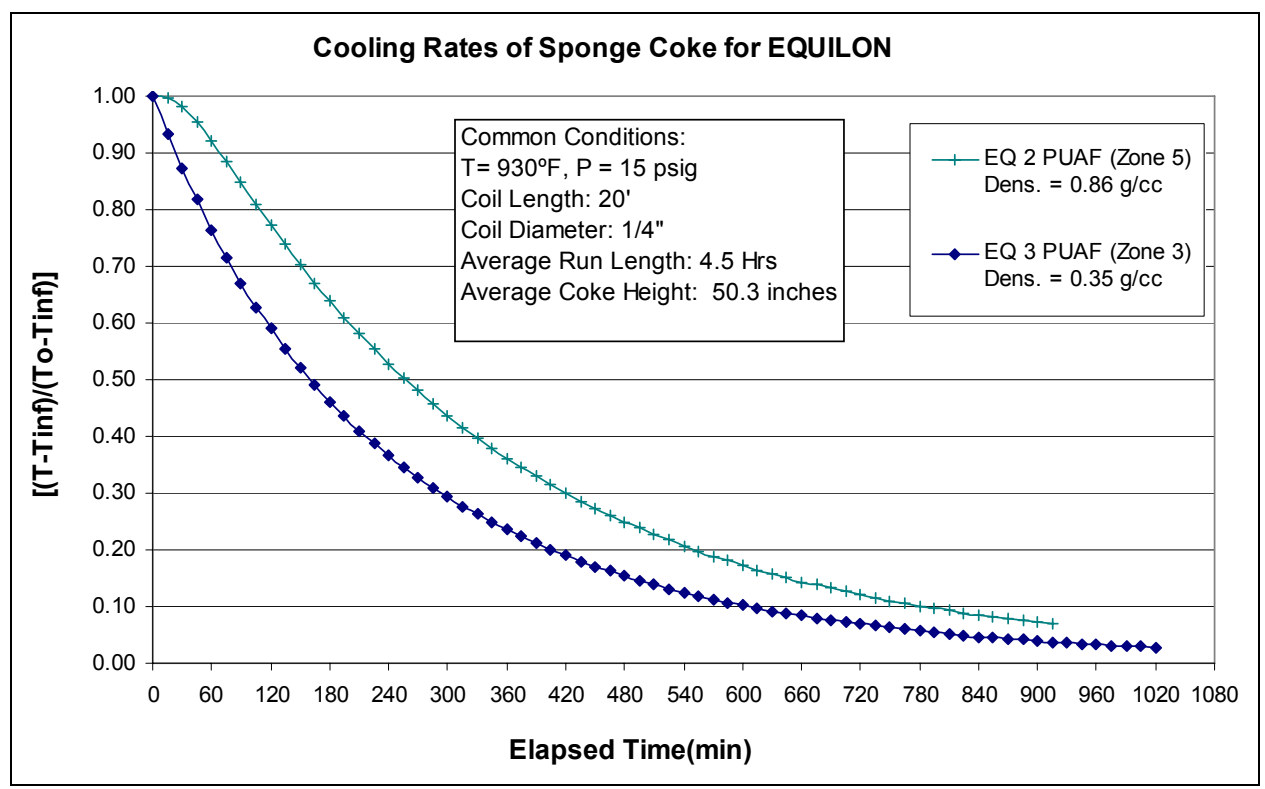

Figure 232 - Effect of Coke Density on Cooling Rates for Equilon

Notice in the figure how the denser sponge coke takes longer to cool compared to the less dense coke of the same morphology.

As mentioned previously, for one of the resids (Equilon), another observation made was that even though the coke morphology produced between two runs was agglomerated shot coke with BB's, the denser coke cooled much faster than the less dense coke. This again is the opposite of what had been seen earlier and therefore another plausible explanation was in line, see Figure 233 below. 


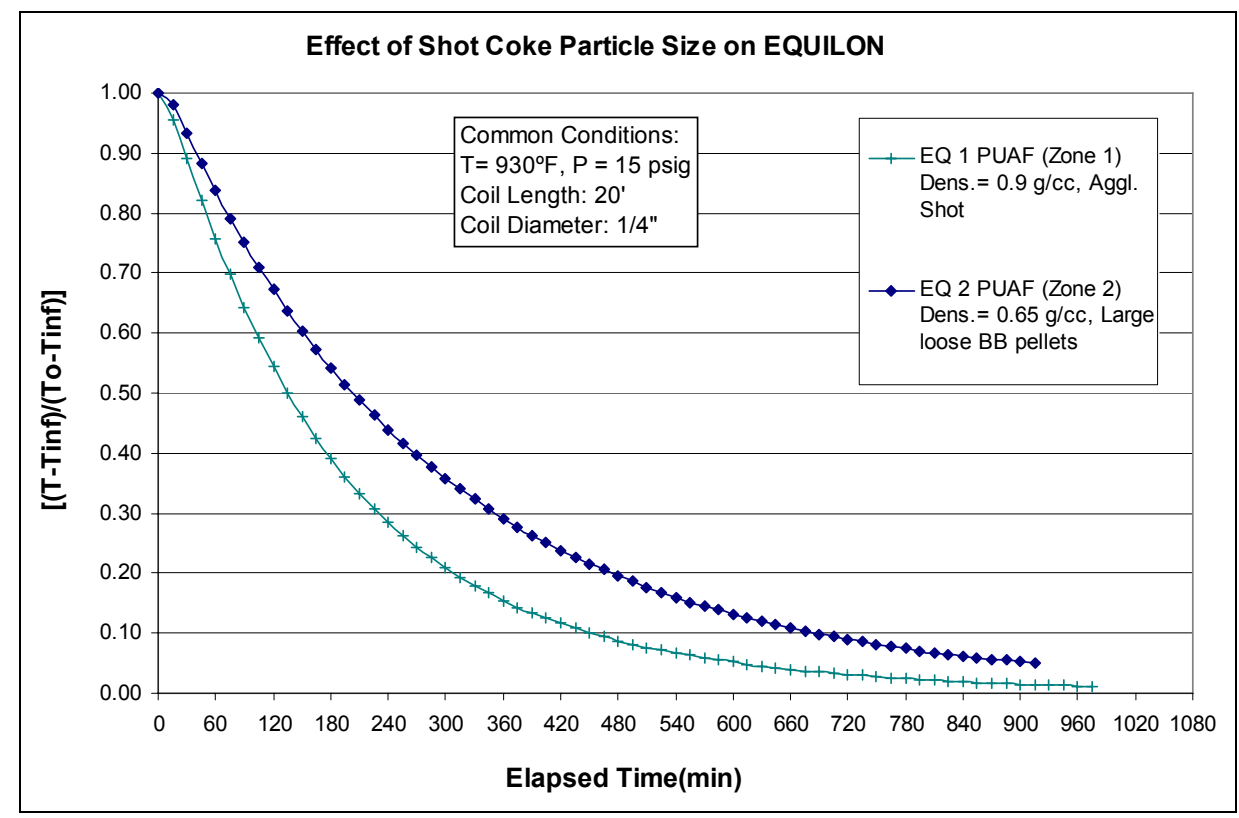

Figure 233 - Effect of Coke Particle Size on Cooling Rates for Equilon

A closer look at the morphologies produced by these runs revealed that even though the morphology was the same for both runs, the sizes of the coke particles were dramatically different. While for one run the shot spheres were very small and clustered, the other run produced large, loose, BB-like shot pellets. The large BB pellets, though with a smaller density, cooled much slower than the agglomerated shot particles of a much denser nature. An explanation for why the large BB pellets cooled much slower than the compact shot particles can be given by taking into account the microstructure of the BB pellets. Figure 234 below shows a microscopic view of one of the pellets. It is speculated that because of the large size of these pellets, the heat inside the pellet is retained longer and it takes longer to cool them.

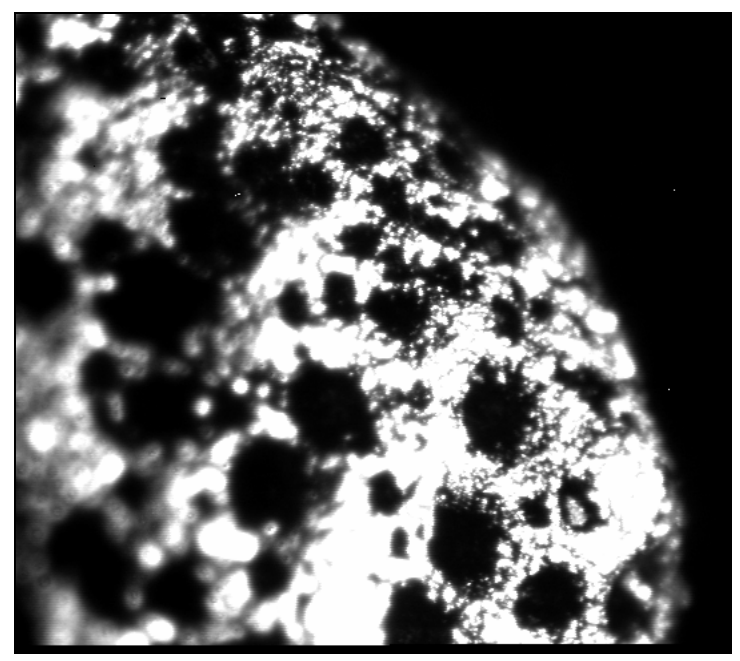

Figure 234 - Photo of a Microscopic View of a Large BB Pellet

From these considerations, it is reasonable to say that when a general trend does not hold for a certain comparison, there may be other variables affecting the way a certain coke morphology with a certain density cools which causes it to deviate from the established trend. 


\section{(ii) Pressure Effects}

In the studies of the 6 foot drum it was consistently observed that the 15 psig runs made coke morphologies than were less dense the 40 psig runs. Based on that observation and by knowing the densities at each coke zone in the drum, it was possible to conclude that in general the lower pressure runs have higher cooling rates because they produce less dense morphologies. This observation is shown in Figure 235 and Figure 236.

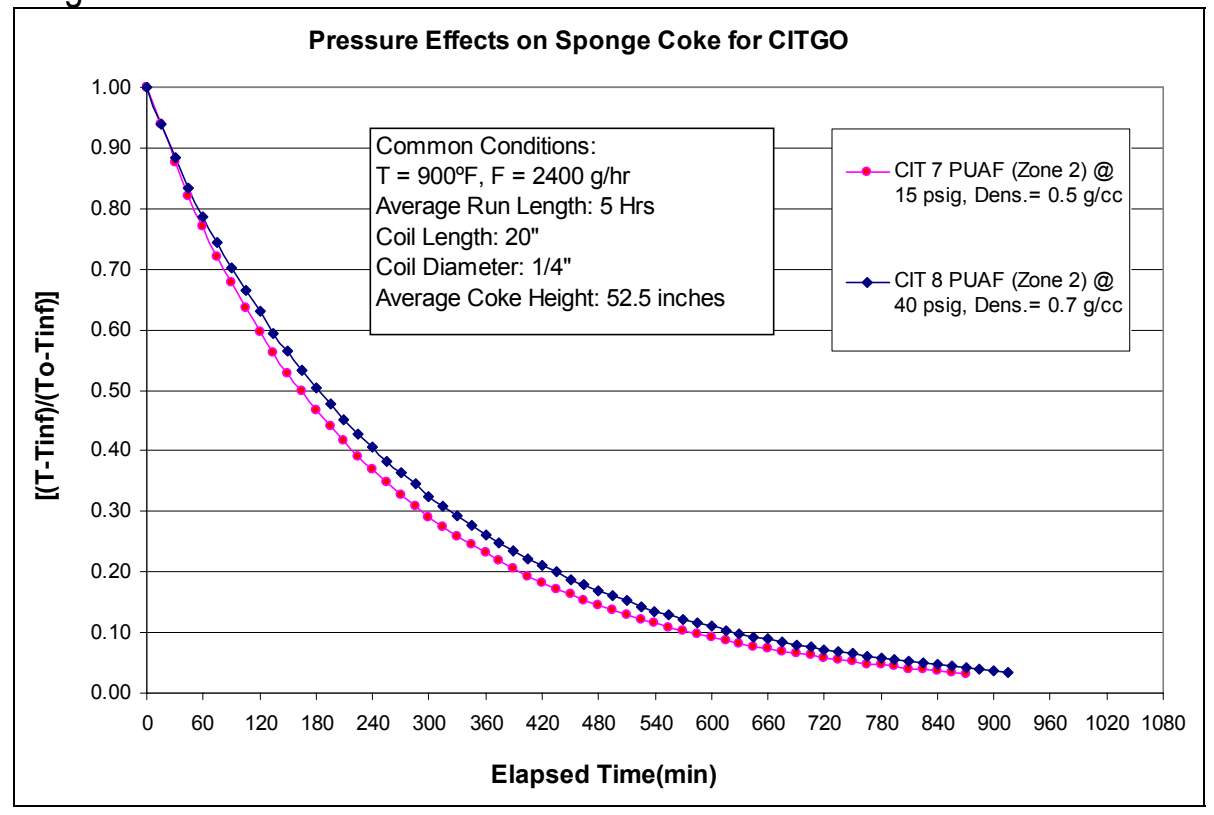

Figure 235 - Effect of Pressure on Cooling Rates of Sponge Coke for Citgo Resid

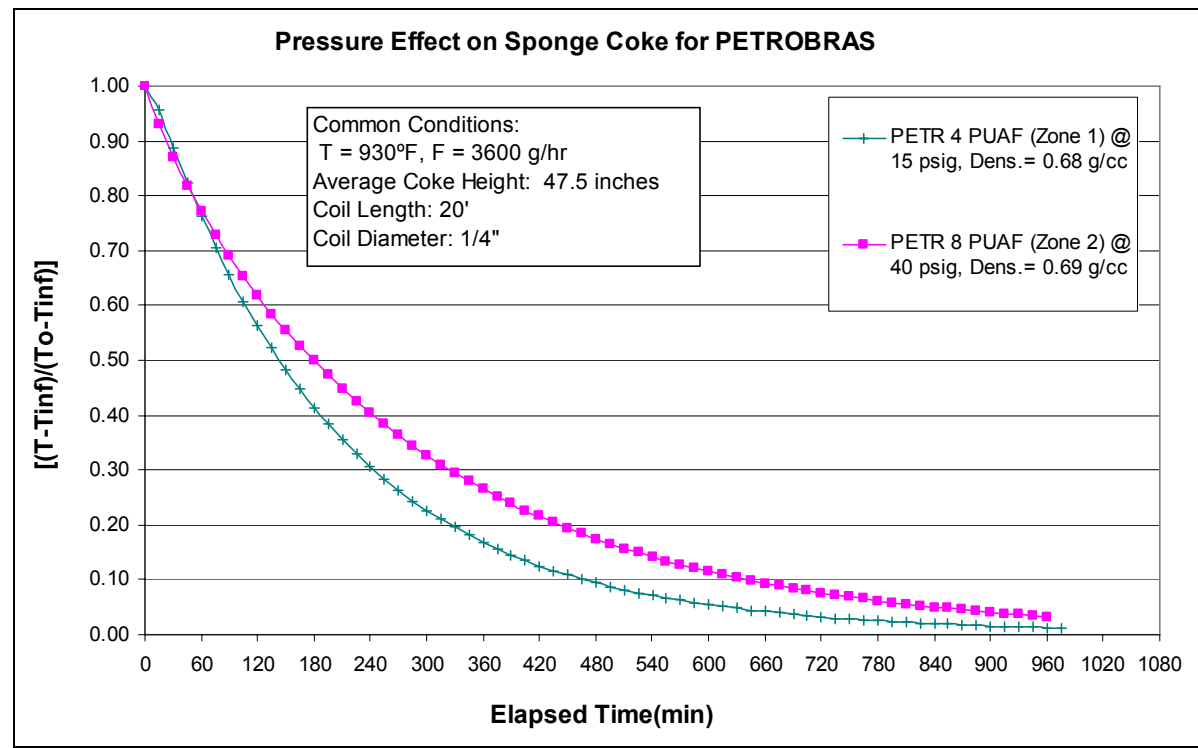

Figure 236 - Effect of Pressure on Cooling Rates of Sponge Coke for Petrobras Resid 
In summary, lower pressure runs tended to make lower density coke morphologies compared to the higher densities produced by high pressure runs. Because of this, in general, the lower pressure coke cools faster than the higher pressure coke. Deviation from this trend might be due to the permeability and porosity as well as particle size of the coke morphology involved.

\section{(iii) $\underline{\text { Temperature Effects }}$}

A consideration of the temperature effects on the cooling rates for the different resids available showed that there was no apparent correlation between temperature and the rate at which the coke cooled. Citgo and Equilon did not have any runs available for the temperature studies. Chevron, Marathon, Petrobras and Suncor did have some runs available, but because of the inconsistency of the results it was not possible to draw any conclusions. The difficulty in establishing a general trend for temperature and cooling rates was, once again, a proof that run temperature may not have a direct or indirect effect on coke cooling rates.

\section{(iv) Open Furnace Door After Quenching}

In addition to analyzing the cooling rates of coke when it was cooled with nitrogen and with the furnace door opened, and those for when the coke bed was cooled with water, the effect of opening the furnace door, after quenching was over, was also analyzed. It was found that cooling the coke bed with the furnace door opened after the bed had been quenched with water, increased the rate at which that bed cooled compared to cooling the bed with the furnace door opened without quenching it. As the next figure shows, there is a sharp difference between the cooling rates for each situation.

In Figure 237 below, it is seen that cooling the drum with water first, and then turning the oven on for a while, and after that cooling the drum with the door opened, significantly altered the cooling rates of the coke bed. This observation was made upon comparing a run that had been water-cooled first and then heated back up and allowed to cool by free convection, with a run that was simply cooled by free convection. Both runs were initially at a temperature of around $900^{\circ} \mathrm{F}$. 


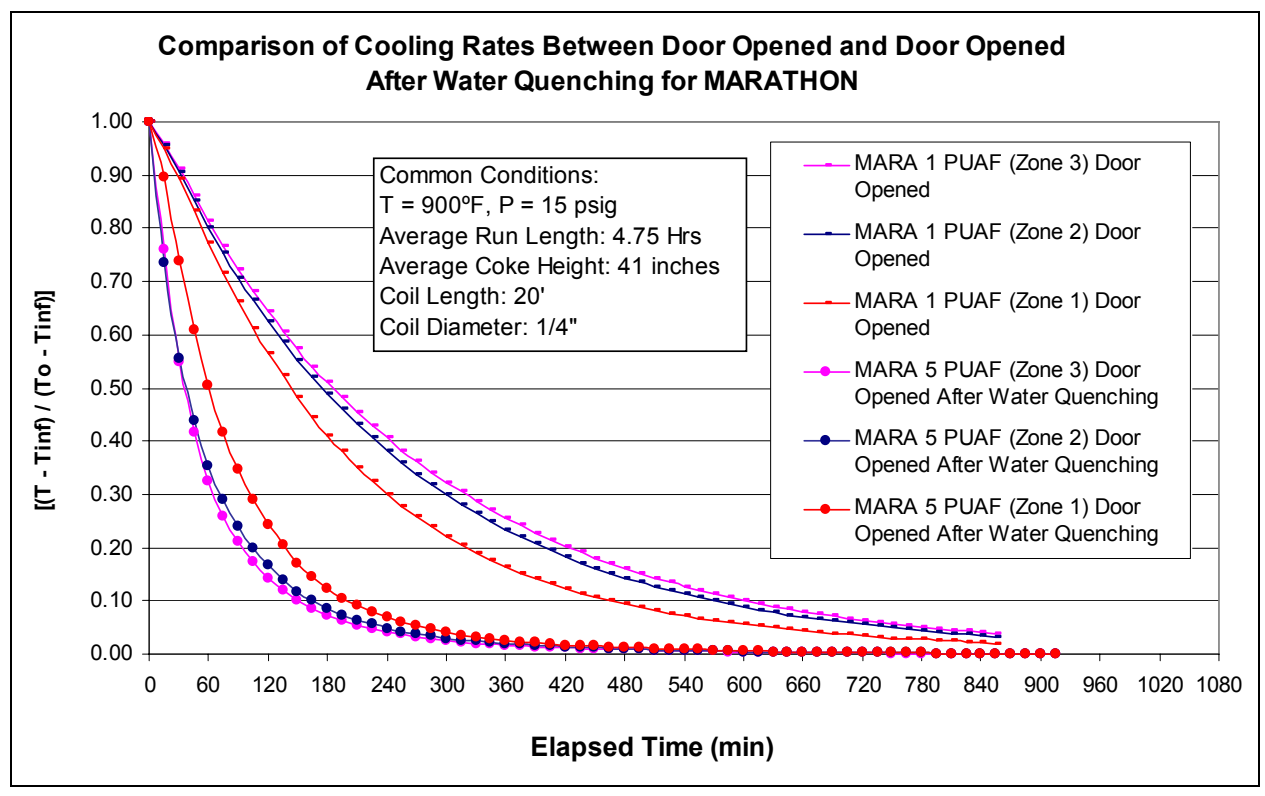

Figure 237 - Comparison of Cooling Rates between a Run with Furnace Door Opened After Steam
Stripping and a Run with Furnace Door Opened After Water Quenching

The behavior of the cooling rates between these two cases can be explained by surmising that during water quenching, which is done at very high rates, the structure of the coke bed is substantially altered. If this is the case, the coke mass may have more flow channels and less molten material which would allow the coke bed to cool much faster than a coke bed that has not been water quenched at all. Also, it is possible that more volatiles are stripped out and that the drum contents are not uniformly heated. A confirmation that this might be the case was seen when analyzing an issue with steam stripping for a few runs. This issue will be addressed in a later section.

\section{Cooling Trends}

From what was discussed the trends observed during cooling were:

- Sponge coke cools faster than shot coke. Any deviation from this trend might be related to the density of the individual coke morphology.

- High density coke cools slower than low density coke regardless of the coke morphology. Deviations from this trend could be linked to particle size, and coke properties.

- Lower-pressure runs tend to produce lower density coke which in turn cools faster than the higher density coke produced by the higher-pressure runs.

- No apparent trend between coke cooling rates and run temperature appears to exist.

\section{Overhead vs. Bottom Drum Quench}

The water quenching procedure was added recently in the project and only a few runs operated in the pilot unit were quenched with water. As the procedure is improved, more runs are now being quenched and in different ways. At this point, nine runs were quenched with water. All the runs produced sponge coke, except for the Chevron run, and were operated under different conditions. The water injection rates 
and volumes were also different for each run. For the majority of the quenched runs the water was injected at the bottom of the drum - that is, the water was injected at the feed line. In order to see how different the cooling rates would be if water were injected at a different point, water was injected overhead for two of the nine runs. Looking at each individual run showed that during water cooling the cooling rates behave completely different from those discussed in the previous subsections.

For the cases when the water was injected from the bottom of the drum, the temperature of the bottom thermocouple decreases drastically upon contact with the water. This thermocouple is located at the thick metal piece of the drum and thus the rapid cooling is explained. When water quenching starts, the coke mass is extremely hot and once water comes in contact with it steam is formed and it causes the temperature of the coke located just above to increase slightly before it starts to drop slowly but steadily. Now, considering zone by zone, above the bottom thermocouple, it is observed from the plots that the water first percolates through the channels and pores of the coke in one zone until it fills the entire coke mass; by that time the large drop in temperature is seen. After this large drop in temperature, very little cooling takes place. While water is cooling that zone, since it comes into contact with a very hot coke mass it vaporizes and the vapor rises to the next zone. The vapor initiates the cooling process of the new zone and when water reaches that zone and fills its channels and pores, the temperature again drops abruptly. This phenomenon repeats itself during the time water is being injected until the coke bed is filled with water and cold enough that no more steam forms.

On the other hand, when water is injected overhead, cooling of the coke bed is very unsteady. It was seen that despite using a very large quantity of water and injecting it at very high flow rates, the cooling is not significant and it takes a much longer time to quench. By comparing both plots, there seems to be an optimum water flow rate above which much of cooling is not accomplished. It appears that beyond that optimum flow rate more steam is produced instead and very little cooling takes place. From these observations, it is evident that injecting the quench water from the bottom of the drum is much more effective and time saving in achieving cooling of the coke bed than injecting the water overhead. However, analysis of water samples to find metal traces in the water may show advantages or disadvantages of both types of injection. If the longer procedure (overhead injection) contains fewer metals it might be more feasible to use it than the shorter procedure (bottom injection) because of less environmental constraints. In other words, there may exist an economic versus environmental issue and it must be addressed and taken into consideration when choosing the best procedure to use. 


\section{Conclusions}

From the cooling studies it was observed that different coke morphologies have different cooling rates. Sponge coke seems to cool faster than shot coke. The density of the coke affects the way it cools; denser coke in general cools slower than a less dense coke morphology. Particle size and structure also have an effect on cooling rates. Large, loose BB shot coke pellets seem to take longer to cool than smaller, more clustered particles. Run pressure also seemed to have an effect on the way the produced coke bed cooled. The lower pressure runs in general produced less dense coke morphologies, which in turn cooled faster than the denser morphologies produced by the higher-pressure runs.

Cooling temperature profiles of coke reveal the cooling procedure used. Cooling the coke bed with nitrogen and with the furnace door opened is more effective than cooling it with the door shut. When cooling the coke bed with the furnace door opened a large temperature drop takes place in the first few hours and then the drop is more uniform and less dramatic until the bed is at approximately room temperature. When cooling the coke bed with the furnace door shut the cooling is very uniform and the coke bed is only at approximately at $170^{\circ} \mathrm{F}$ after about 18 hours of cooling. For most of the runs the cooling profiles look similar as long as the coke bed is cooled by the same cooling procedure. The cooling rates however, are different for each run.

Water quenching seems to be the most effective way to cool the coke bed at a relatively short period of time. Several factors such as water injection rate, injection time, total amount of water injected and injection point have an effect on the way a certain coke bed cools. Injecting the water from the bottom of the drum is more effective than injecting it overhead. 


\section{Modeling Studies}

\section{A. Model DEVELOPMENT}

Progress continues in developing an Integrated Delayed Coker Simulator. The proposed overall structure for the delayed coker software is shown in Figure 238. The current model is mainly correlated data. In the long-run, it is proposed that we transition from correlated data to more mechanistic modeling of the delayed coking process.

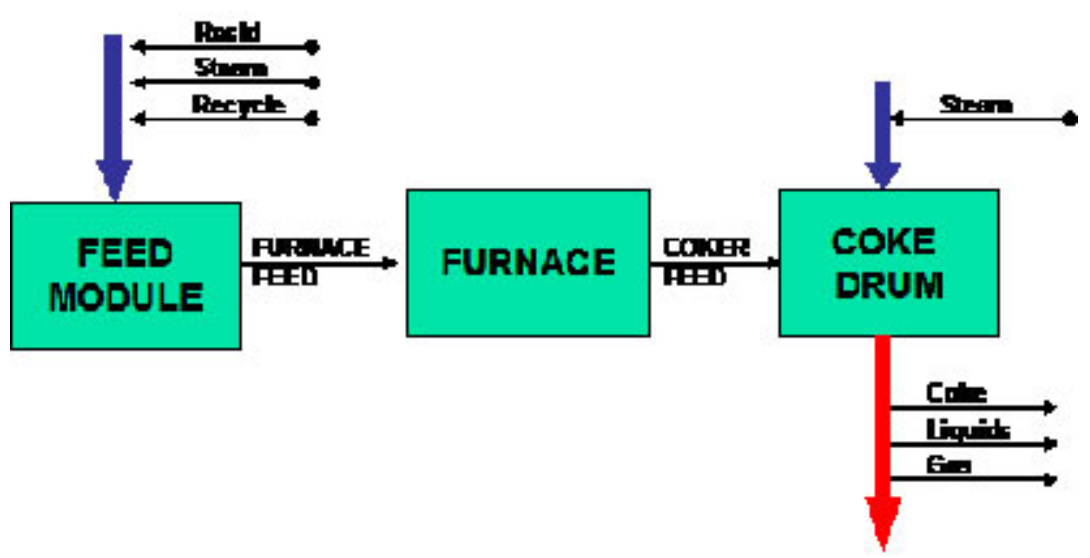

Figure 238 - Delayed Coking Optimization Simulator Structure

Figure 239 shows the optimization simulator spreadsheet as it presently exists, available on the TU Delayed Coking web site. The current optimization simulator spreadsheet is limited to predicting overall yields and liquid sub-yields from our developed correlations, given the input feedstock properties. This spreadsheet will be enhanced to allow prediction of liquid, gas, and coke properties. The proposed additions with their present status are shown in Table 86. 


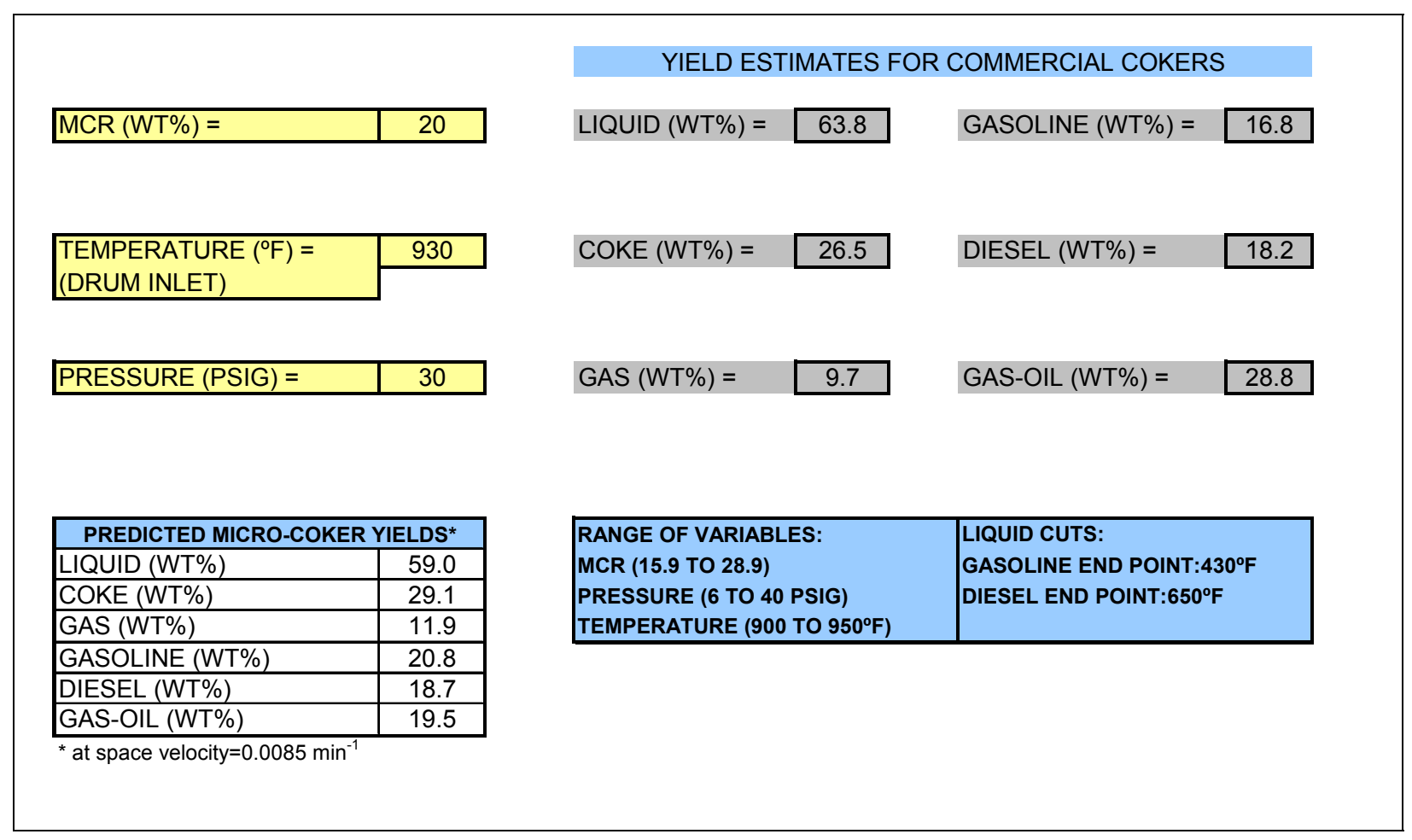

Figure 239 - Delayed Coking Optimization Simulator Spreadsheet 
Table 86 - Status of Delayed Coking Product Correlations

\begin{tabular}{|c|c|c|}
\hline \multicolumn{3}{|c|}{ YIELD CORRELATIONS } \\
\hline & Type & Status \\
\hline & Overall Yields & $\begin{array}{l}\text { correlation done; needs updating with } \\
\text { newest data }\end{array}$ \\
\hline & Sub-yields & $\begin{array}{l}\text { correlation done for gasoline, diesel, and } \\
\text { gasoil needs updating with newest data } \\
\text { need to correlate entire SimDis curve }\end{array}$ \\
\hline \multicolumn{3}{|c|}{ LIQUID QUALITY CORRELATIONS } \\
\hline & Type & Status \\
\hline oil) & API gravity (gasoline, diesel, gas & $\begin{array}{l}\text { correlation done; needs updating with } \\
\text { newest data }\end{array}$ \\
\hline & Overall sulfur & correlation done \\
\hline gas oil) & Sub-yield sulfur (gasoline, diesel, & need to redo PFPD analysis \\
\hline & PiONA (on gasoline) & $\begin{array}{l}\text { correlation done; needs updating with } \\
\text { newest data }\end{array}$ \\
\hline & RON (on gasoline) & $\begin{array}{l}\text { correlation done; needs updating with } \\
\text { newest data }\end{array}$ \\
\hline & Silicon & in progress \\
\hline & Ammonia (in condensate) & in progress \\
\hline & Other Elements analysis (V, Ni) & needs to be done \\
\hline \multicolumn{3}{|c|}{ GAS QUALITY CORRELATIONS } \\
\hline & Type & Status \\
\hline & $\mathrm{H} 2 \mathrm{~S}$ & in progress \\
\hline & Olefins & in progress \\
\hline & Molecular weight & in progress \\
\hline & $\mathrm{H} 2$ & in progress \\
\hline \multicolumn{3}{|c|}{ COKE QUALITY CORRELATIONS } \\
\hline & Type & Status \\
\hline & VM & correlation done \\
\hline & Coke density & needs to be done \\
\hline & $\mathrm{C} / \mathrm{H} / \mathrm{N}$ & in progress \\
\hline & Elemental analysis (Si, S, V, Ni) & needs to be done \\
\hline
\end{tabular}

\section{B. SULFUR DISTRIBUTION}

Sulfur content of the coke, total hydrocarbon liquids, and decant and quench water samples were sent to Baker Petrolite to obtain the coke data, hydrocarbon liquids data and the ICP water data and the 
values obtained from these analytical tests are used in the material balance to determine sulfur present in the product yields. The distribution of the sulfur from the coker feed to the coker products was determined using a material balance for each individual resid, namely Chevron, Equilon, Marathon, Citgo, Suncor, Petrobras, Exxon Mobil Cerro Negro, and Exxon Mobil Heavy Canadian. The sulfur distribution showed different trends for each resid which implies that the distribution of sulfur is affected not only by the various process parameters such as feed temperature, pressure, overhead temperature etc., but also by individual feedstock properties. The amount of sulfur (in grams) in each product is determined by multiplying the value obtained from each product sample from analytical tests with the total measured weight of the product. Then the total weight percent of sulfur in each product is obtained by dividing the amount of sulfur in each product by the sum of the total sulfur for all products (liquids, coke, gas and decant water and quench water) and multiplying by 100 . This procedure for normalizing the sulfur results based on total recovered sulfur gave more satisfactory results than normalizing based on total feed sulfur, because the sulfur content of the feed samples varied more than the accuracy of measuring the sulfur in the products.

\section{Sulfur Distribution Reproducibility}

The reproducibility of sulfur distribution data was checked for each individual resid at the same operating conditions i.e., same feed temperature and pressure. In general, almost all the resids varied within ten weight percent maximum for the weight percent of sulfur ending up in the liquids for the same combination of operating conditions of $900^{\circ} \mathrm{F}, 930^{\circ} \mathrm{F}$ and $15 \mathrm{psig}$ and $40 \mathrm{psig}$. The same ten percent variations at the maximum are observed in the case of sulfur going to the coke as well as the gas fraction. These variations may be due to other factors such as run being conducted at different feed flow rate, run length, etc at the same run temperature and pressure. Some pilot unit runs showed significant sulfur content in the decant water. Most of the runs which contained sulfur in the decant water were runs that foamed over. It is hypothesized that for these runs the $\mathrm{pH}$ of the decant water may have been unusually high. The solubility of $\mathrm{H} 2 \mathrm{~S}$ in water is known be much higher at alkaline $\mathrm{pH}$ levels, so a significant portion of the $\mathrm{H} 2 \mathrm{~S}$ in the gas may end up in the decant water if the $\mathrm{pH}$ is high.

Effect of Temperature and Pressure on Sulfur distribution

The data for weight percent of sulfur in the products analyzed by Baker Petrolite was used to analyze the effect of both the feed and overhead temperatures $\left({ }^{\circ} \mathrm{F}\right)$, and the corresponding pressures (psig) on the sulfur distribution in the product yields.

The sulfur yields of each individual resid were averaged per temperature-pressure combination to get the effect of these physical properties on the amount of sulfur recovered in the products. Checking at the reproducibility of the data, a variation of around 3-10\% percent in the sulfur yields in the products was seen. Therefore more than ten percent change in sulfur yields in the products can be considered a significant change, indicating that the operating conditions might have a significant effect on sulfur distribution.

\section{Individual Correlations for the Sulfur in Products}

Individual correlations for sulfur yields in the products were completed for eight resids (Chevron, Citgo, Equilon, Marathon, Petrobras, Suncor, Cerro Negro and Heavy Canadian). Initially, these sulfur yields were correlated with the overhead temperature and pressure to determine the dependence of sulfur distribution among the hydrocarbon liquids, coke, gas and decant water, with the operating conditions (mainly overhead temperature and pressure). Figure 240 through Figure 247 show comparisons between the experimental and predicted sulfur model yields in products for all the eight resids. 


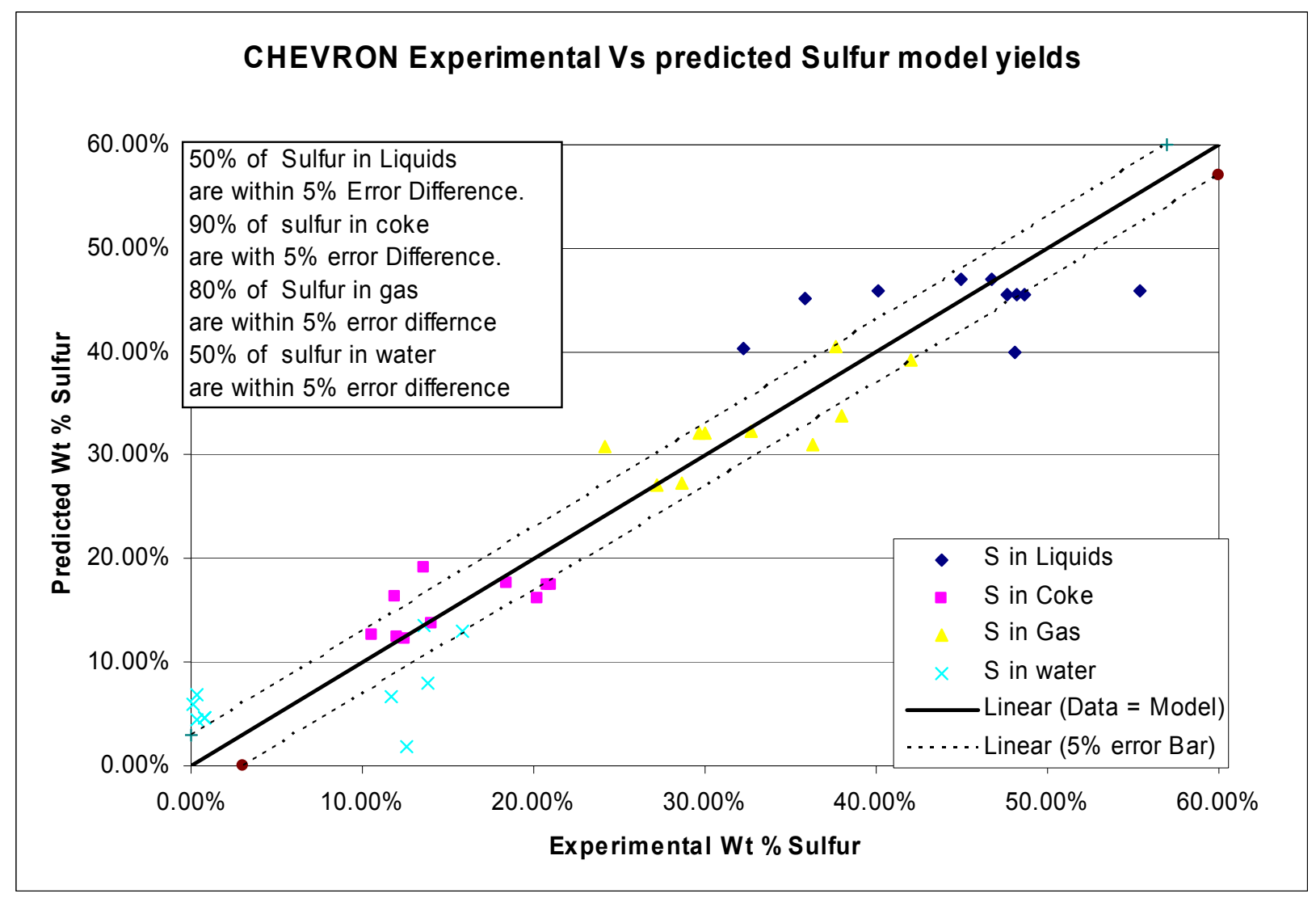

Figure 240 - Chevron- Experimental vs Predicted Sulfur Model Yields 


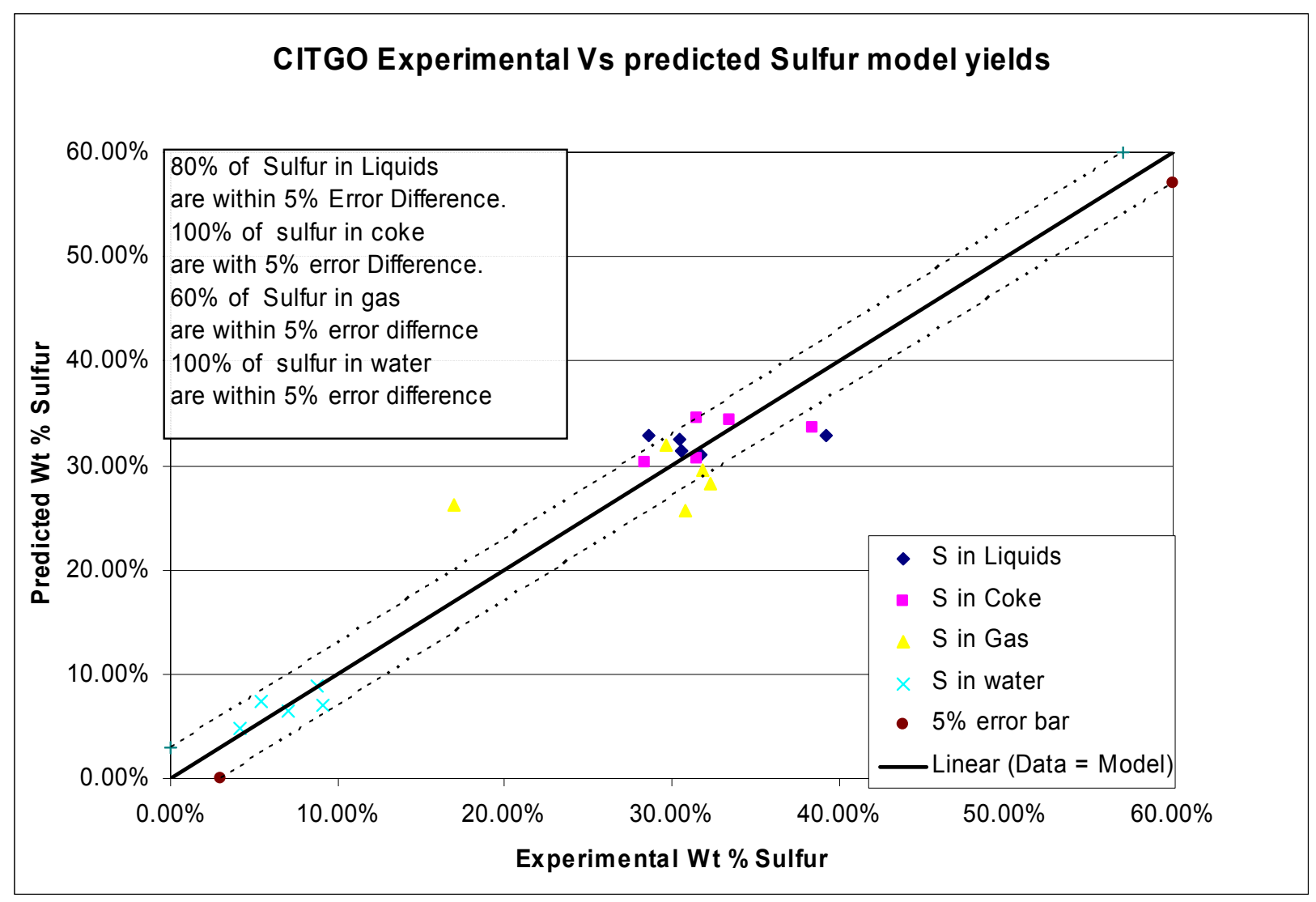

Figure 241 - Citgo- Experimental vs Predicted Sulfur Model Yields 


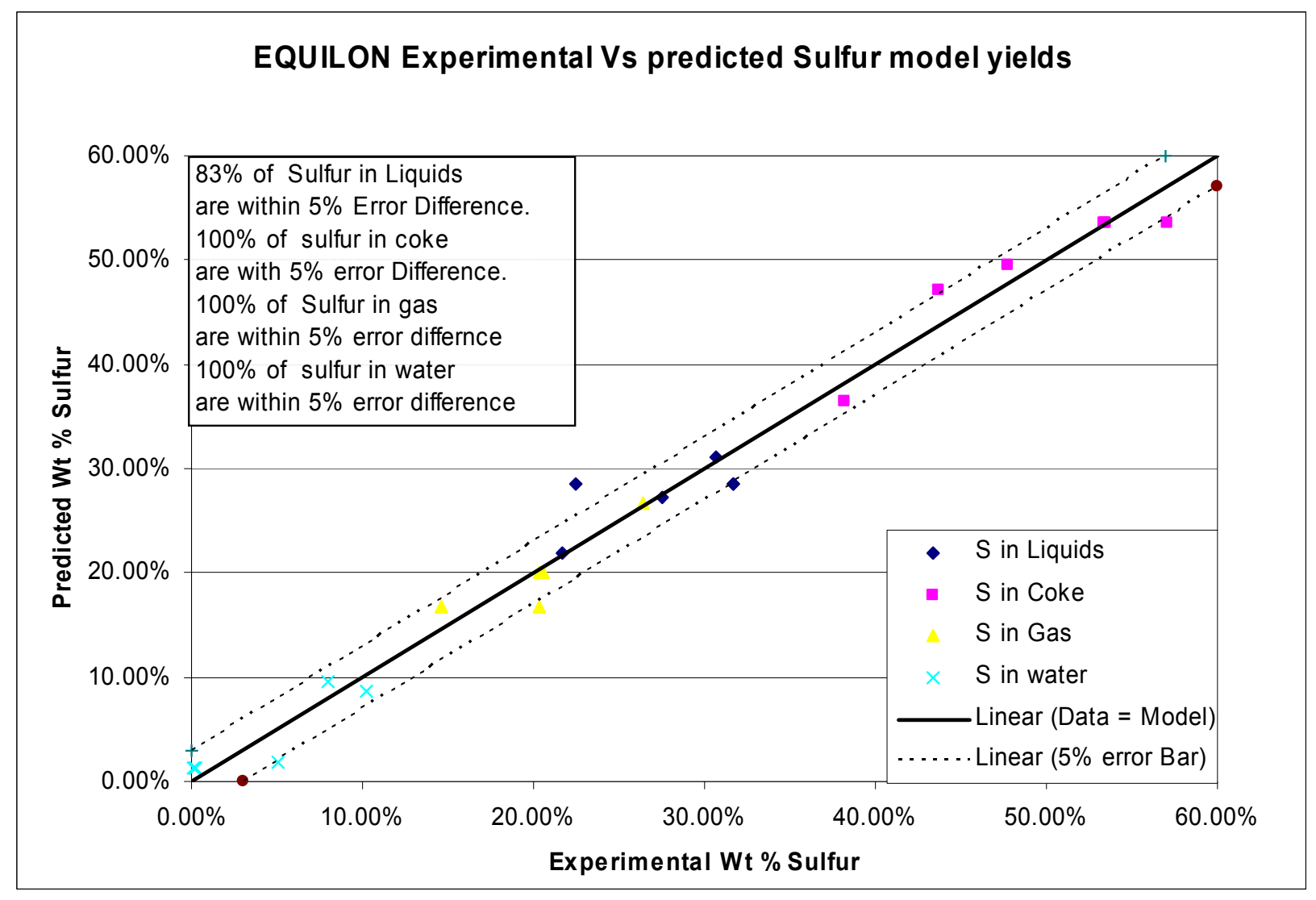

Figure 242 - Equilon- Experimental vs Predicted Sulfur Model Yields 


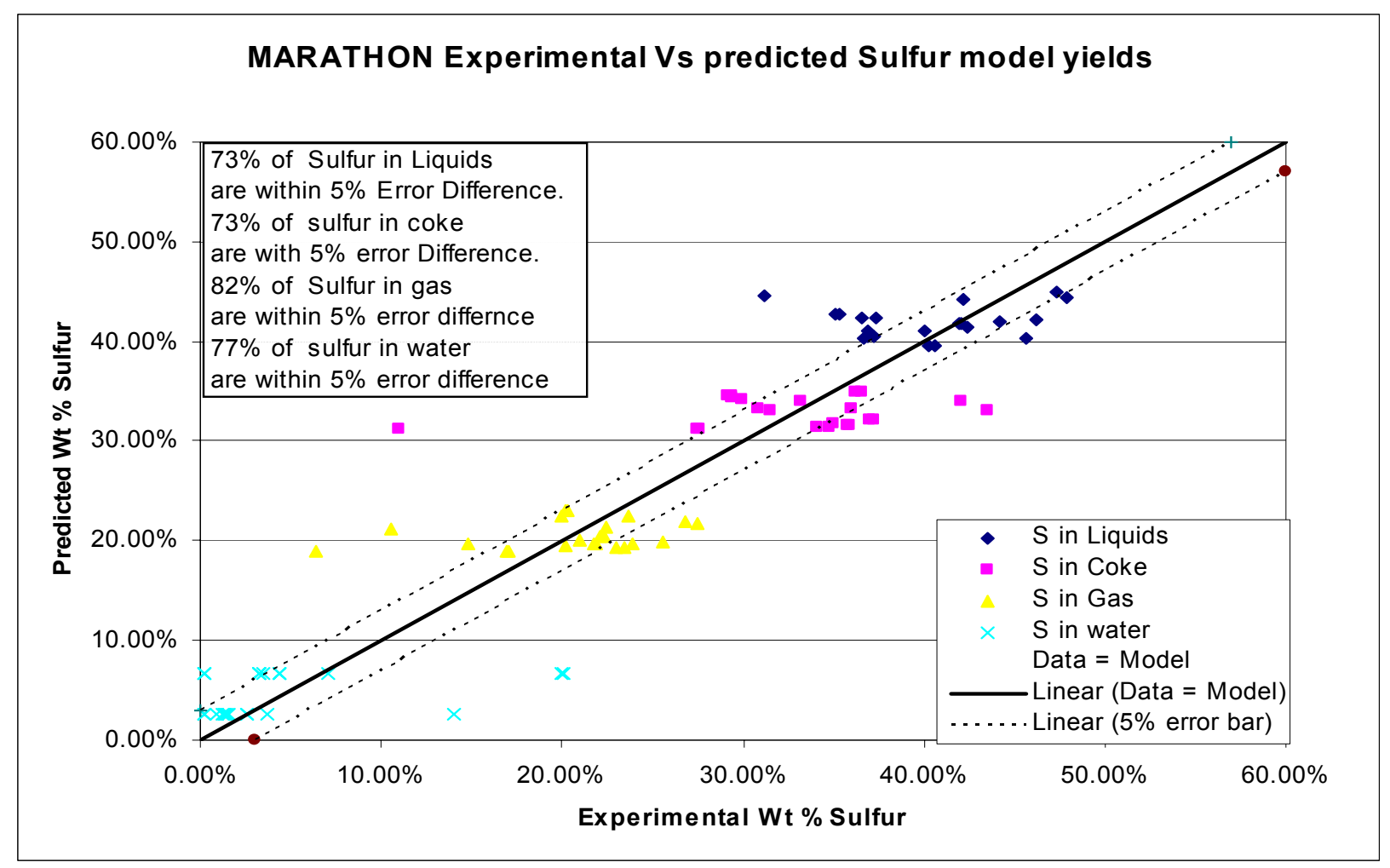

Figure 243 - Marathon- Experimental vs Predicted Sulfur Model Yields 


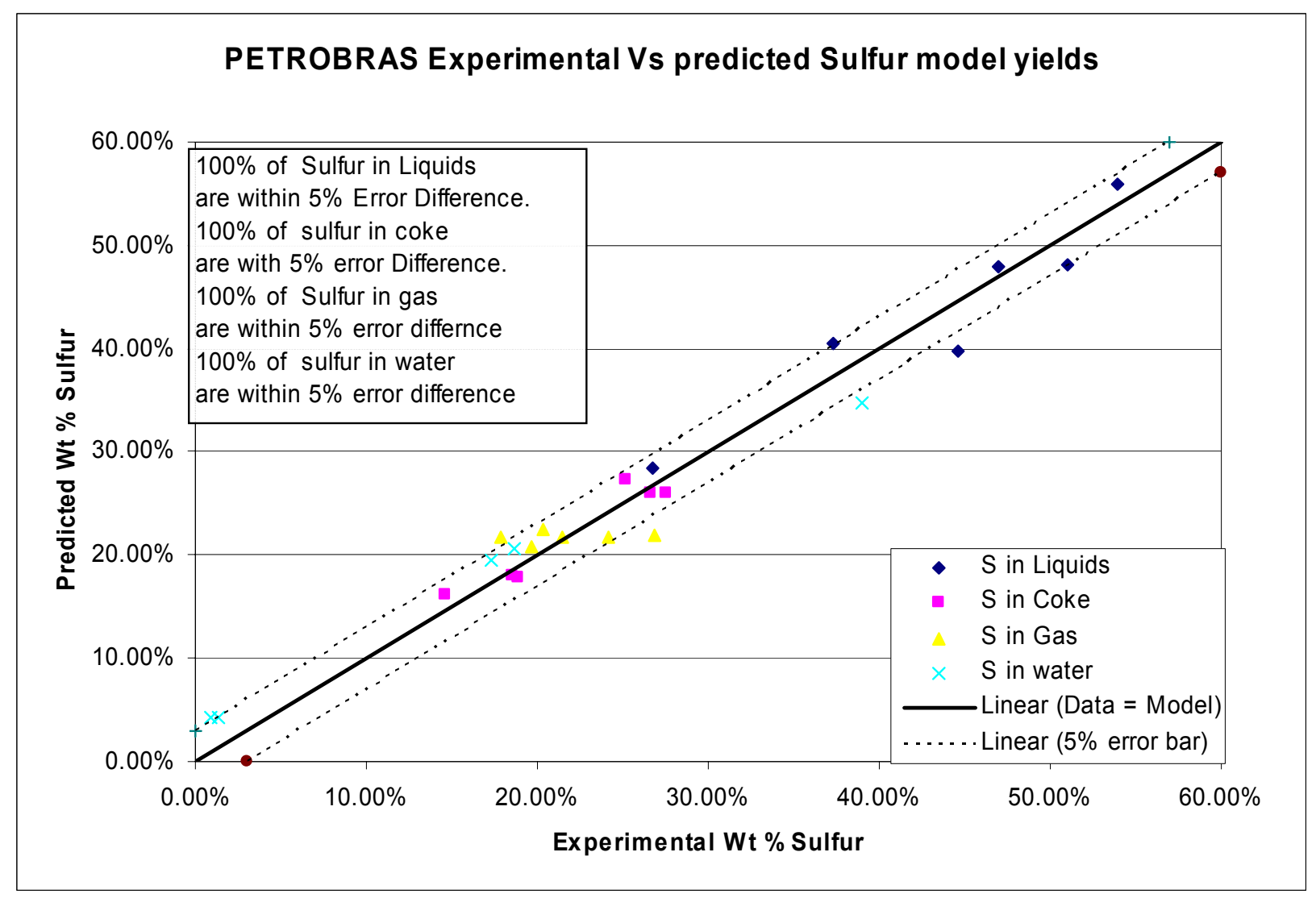

Figure 244 - Petrobras- Experimental vs Predicted Sulfur Model Yields

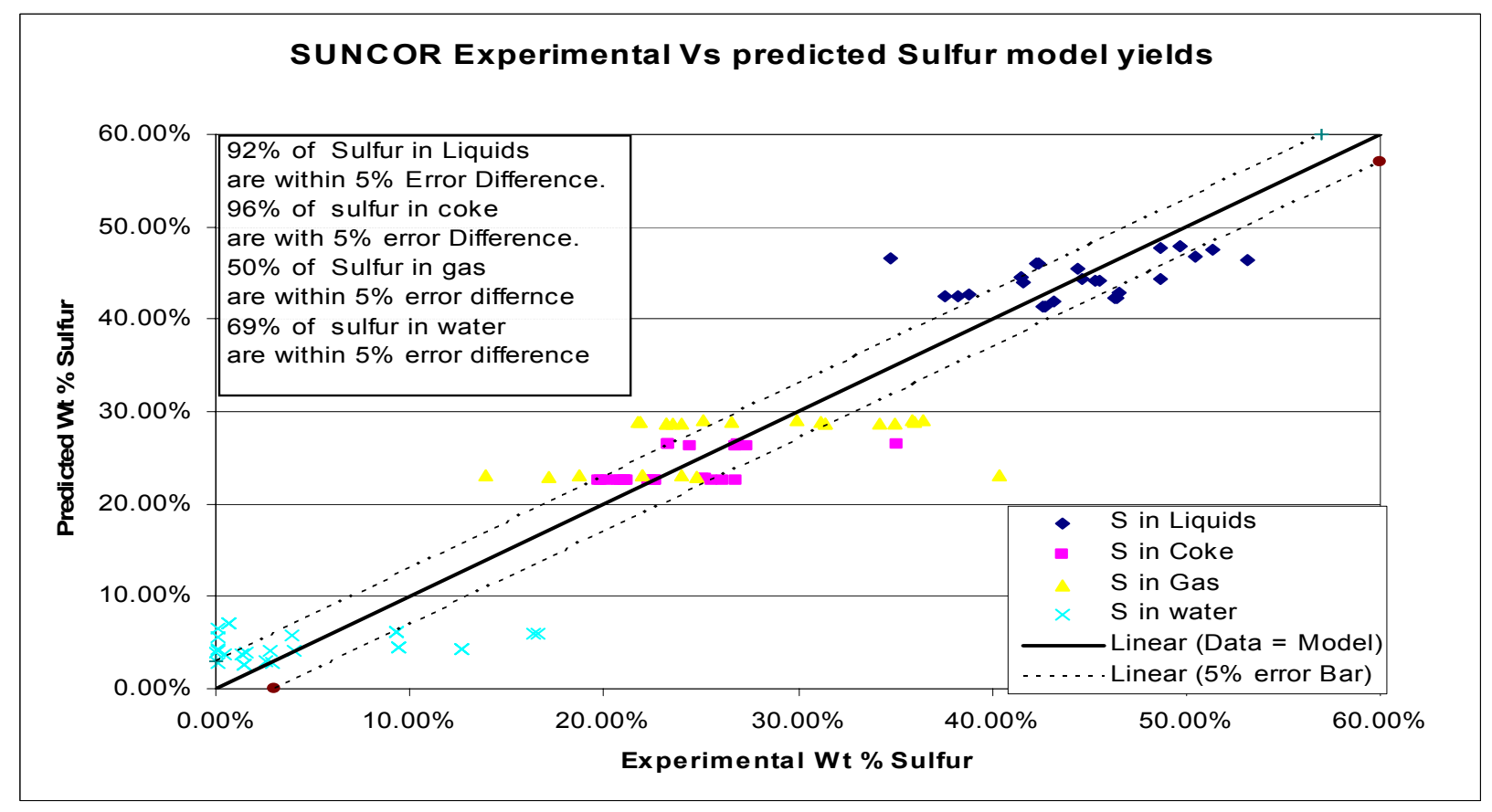

Figure 245 - Suncor- Experimental vs Predicted Sulfur Model Yields 


\section{EMCN Experimental Vs predicted Sulfur model yields}

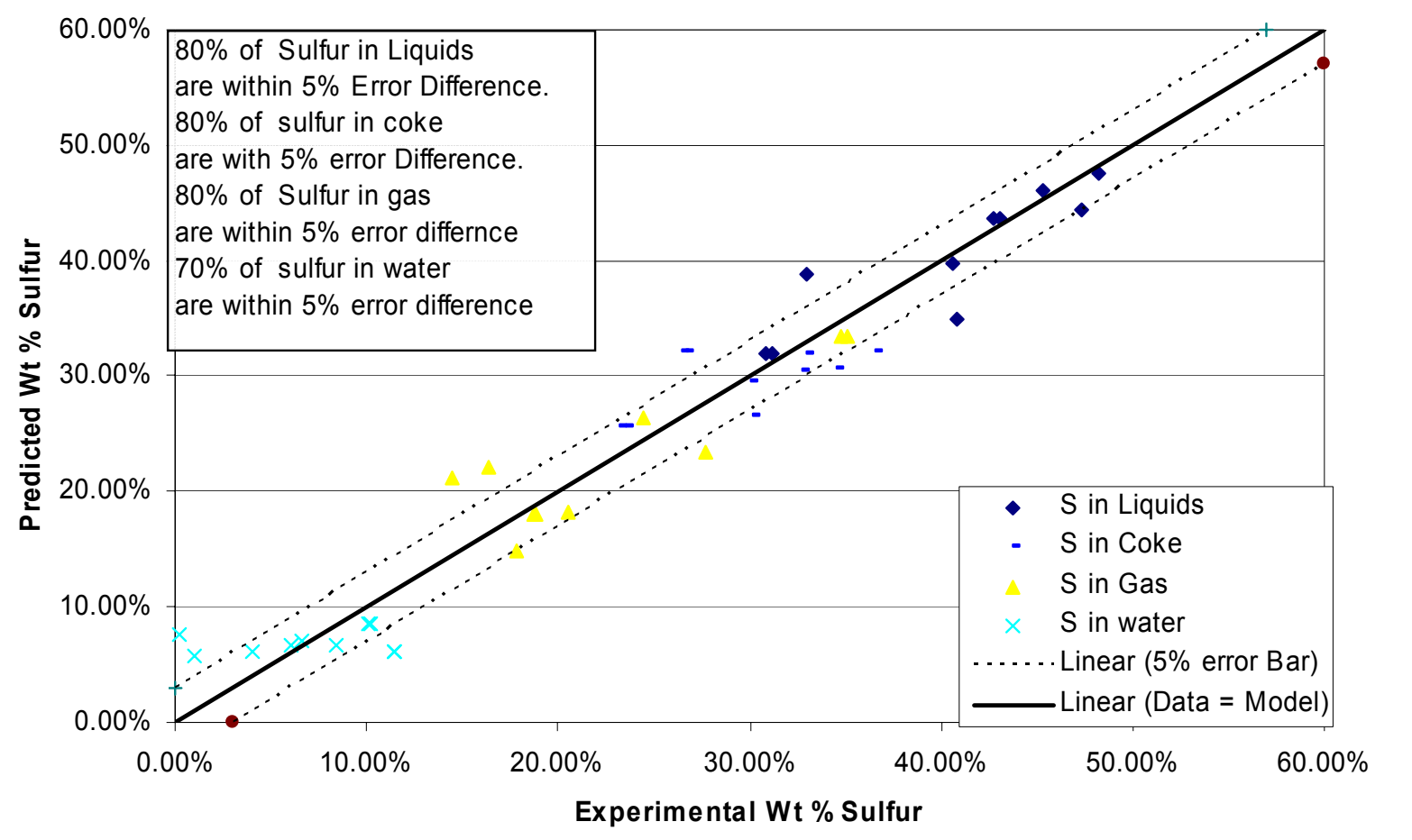

Figure 246 - EMCN- Experimental vs Predicted Sulfur Model Yields 


\section{EMHC Experimental Vs predicted Sulfur model yields}

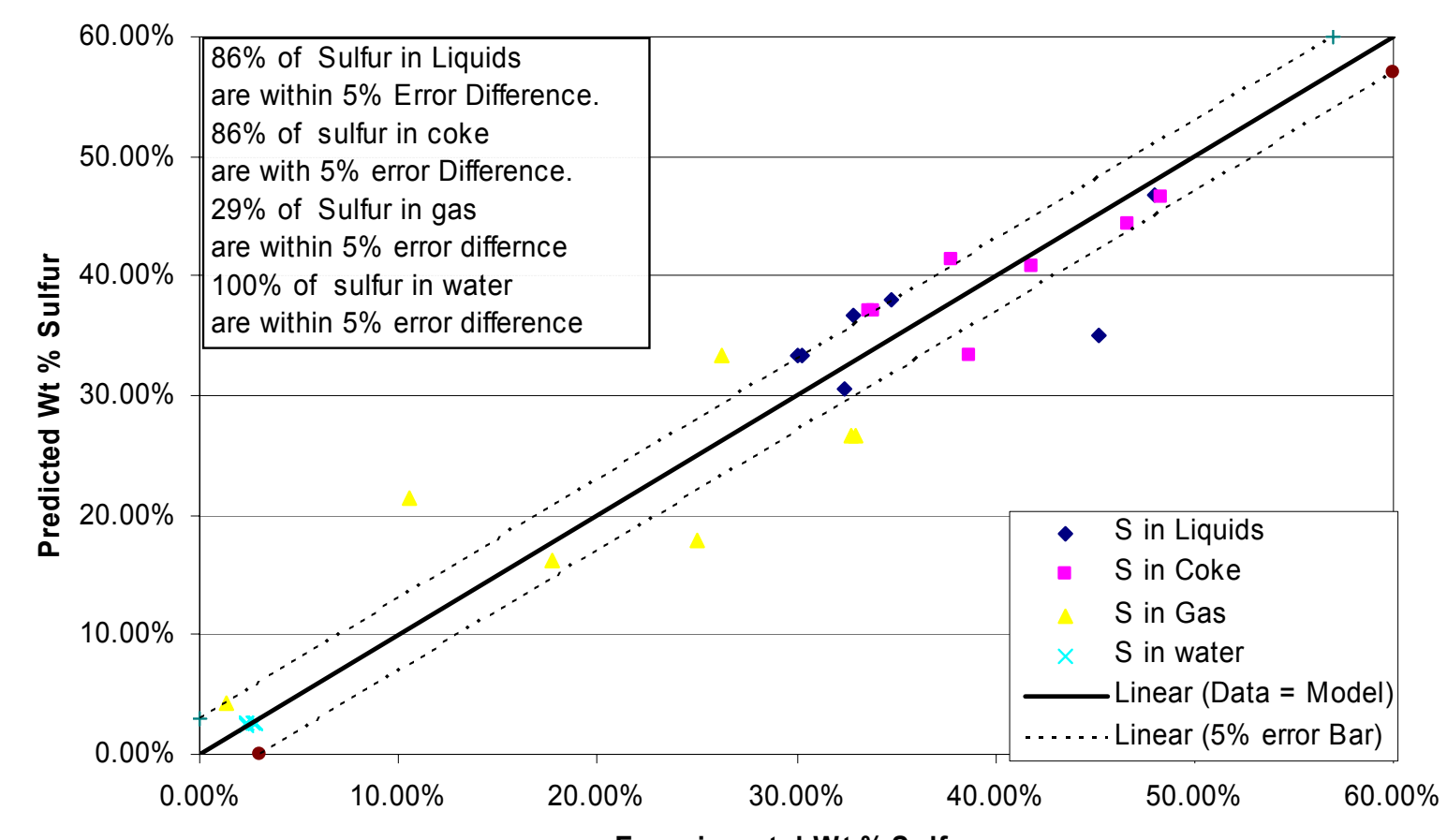

Experimental Wt \% Sulfur

Figure 247 - EMHC- Experimental vs Predicted Sulfur Model Yields

\section{Conclusions}

The complete material balance was done for sulfur from the data obtained from analytical tests of product samples and then the sulfur distribution among the products was plotted for each individual resid. The effect of feed temperature, pressure, average overhead temperature and quenching on sulfur distribution was determined. Individual correlations were developed for each resid considering the overhead temperature and pressure.

The resids showed around 10\% (maximum) variation when checked for reproducibility in the sulfur distribution. The individual correlations between the sulfur weight percent in the coker products indicate that sulfur distribution is dependent on various parameters and also it is resid dependent.

\section{Sulfur Correlations Combining Sulfur in Gas and Water}

Individual correlations for sulfur yields in the products were modified by combining together sulfur yields in gas and decant water, as it was reasoned that sulfur in the decant water should be present due to absorption of $\mathrm{H} 2 \mathrm{~S}$ from the gas. Figure 248 and Figure 249 shows the experimental vs. predicted sulfur yields plots for all the eight resids considering sulfur yields in gas and water as one stream.

Equilon, Petrobras, Suncor, EMCN and EMHC resid showed a fairly good linear relationship for the weight percent sulfur in gas and water with the overhead temperature and pressure, whereas other resids had a poor adjusted $R^{2}$ values indicating that there is no linear relationship observed between the selected parameters. But except for Chevron, Citgo and Marathon resids, for most of the resids the weight percent 
sulfur in gas and water was predicted well within the five percent error bar. This illustrates that there might be some non-linear relationship present between the weight percent sulfur in gas and water and the overhead temperature and pressure. Overall, the individual correlations between the sulfur weight percent in the coker products indicate that sulfur distribution is dependent on various other parameters and also it is resid dependent. 

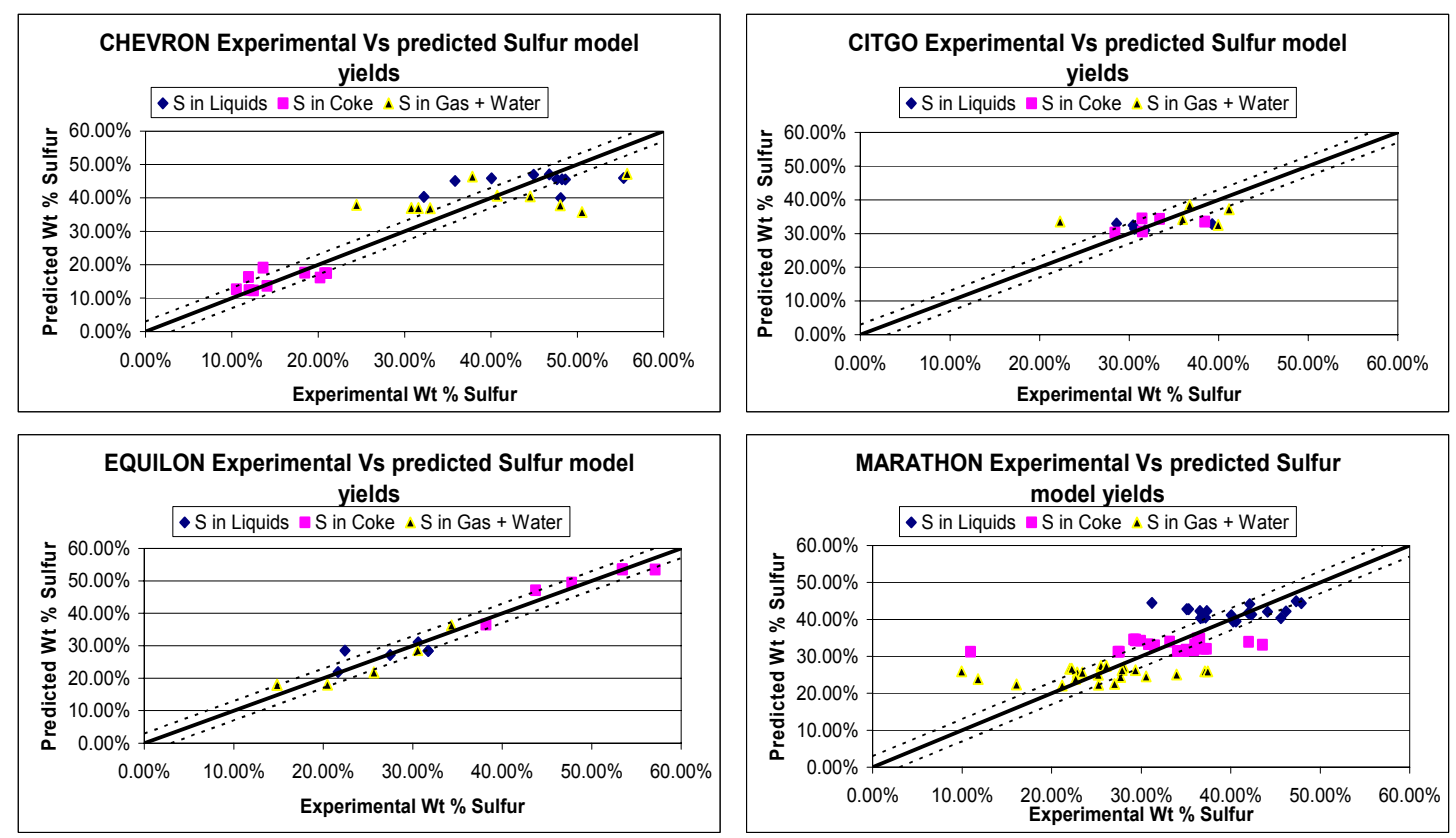

Figure 248 - Modified Experimental vs. Predicted Sulfur Yields
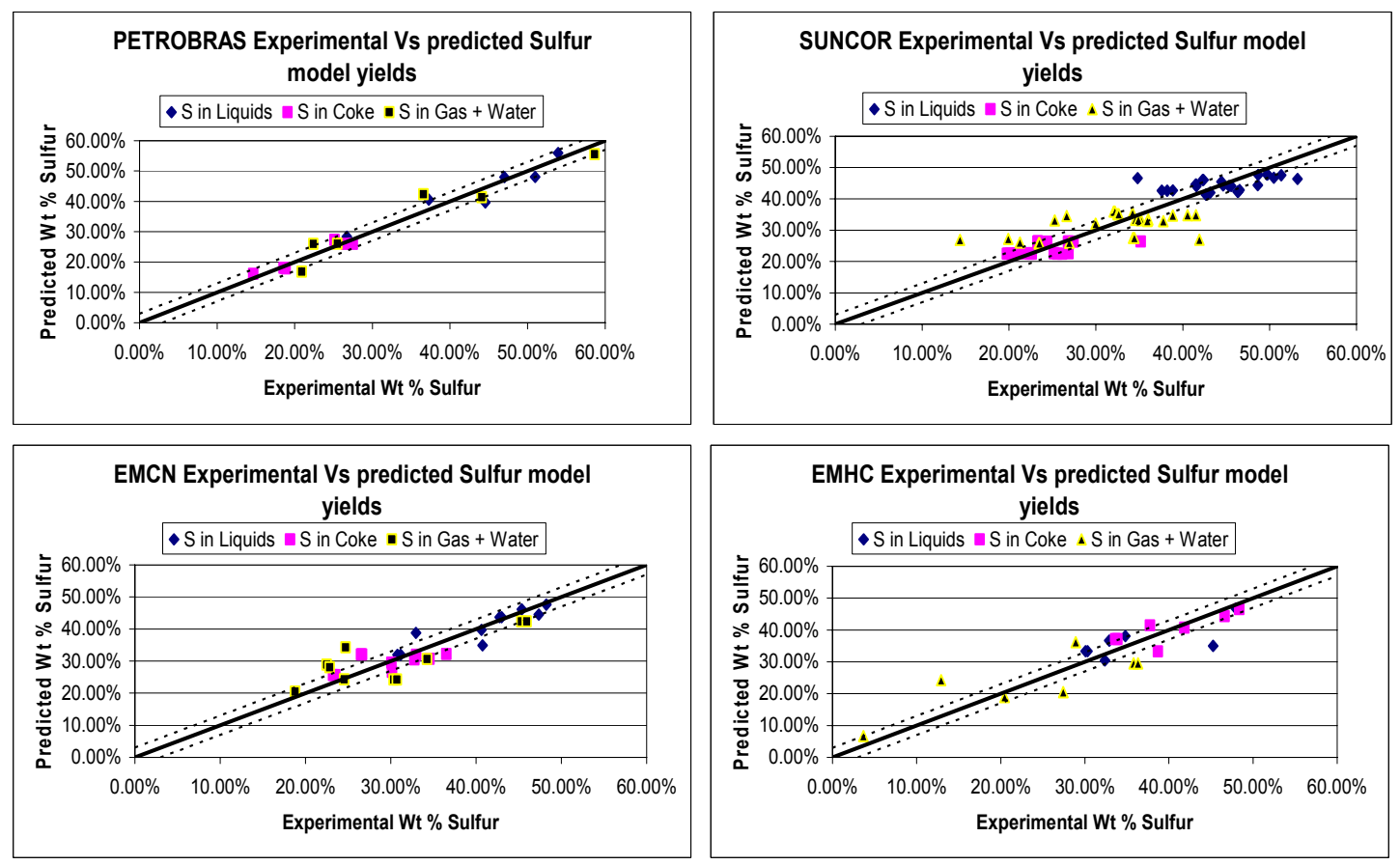

Figure 249 - Modified Experimental vs. Predicted Sulfur Yields

\section{Volatile Matter Analysis}

Volatile matter in coke plays an important role in determining the quality of coke. The coke yield and quality are influenced not only by the feedstock, but also by a number of process factors; the 
temperature is the principal factor determining whether the coke will have a low content of volatile matter. The distribution of volatile matter in the coke bed is studied and the effect of various operating conditions on the percentage volatiles is determined. Preliminary studies are also done to determine whether the coke morphology affects the content of volatile matter in the coke.

\section{Volatile Matter Distribution}

Samples from top and bottom sections of the coke bed were sent to Baker Petrolite for determining the volatile matter content present in the coke. The percent volatiles data from the analytical tests obtained from Baker Petrolite were analyzed for eight different resids: Chevron, Citgo, Equilon, Marathon, Petrobras, Suncor, EMCN and EMHC. The distribution of volatiles in the coke was found to be non-uniform throughout the coke structure.

\section{Effect of Coke Morphology on \% Volatiles in Coke}

Coke morphology plays a very important role in the volatile matter distribution. It is believed that more porous the coke, more volatile matter content present in that coke. The volatile matter is not uniformly distributed throughout the coke bed which is formed inside the coke drum. The percentage volatiles are plotted based on the individual resids and then compared with the coke morphology obtained with each runs. The samples from top section of the coke bed and bottom section of the coke bed were sent for analysis. Thus the extreme end positions coke morphology (i.e., top and bottom section) are considered to compare the effect of coke morphology. From the plots of volatile matter distribution, it is found that the top section of the coke showed varied amount of volatile matter in that section. This might be due to the fact that the reaction of the coke in the top section of the coke bed might not go into completion, since some runs were shut down either due to pressure build up or due to the height of the coke in the drum. Hence this section cannot be considered for the analysis of the volatile matter in coke.

\section{Volatile Matter Correlations}

Individual correlations for weight percent volatiles in the coke were completed for eight resids namely Chevron, Citgo, Equilon, Marathon, Petrobras, Suncor, EMCN and EMHC. The percentage volatiles are initially correlated with the main operating conditions such as run temperature, pressure, overhead temperature, etc. to determine the best fit of the volatile matter model. To start with, the bottom percentage volatiles are correlated with the run temperature and pressure to determine the dependence of these operating conditions on bottom percentage volatiles.

All the run temperature coefficients as well as overhead temperature coefficients in the correlations were negative which was as expected, i.e. when the run temperature or the overhead temperature is increased the amount of volatiles present in the coke should decrease. Good correlations were found for Citgo and Equilon resids with top percentage volatiles with run temperature and pressure as well as overhead temperature and pressure with an adjusted $R^{2}$ value ranging from 0.82 to 0.97 . Poor correlations were observed for Suncor and Marathon resids with the operating conditions which clearly indicates that the operating conditions has no effect on the percentage volatiles in the coke bed. In Figure 250, the experimental and predicted values are well within the $1 \%$ error bar for Chevron, Citgo, EMCN and EMHC resids, but the points were scattered for Suncor, Marathon, Petrobras and Equilon resids with low adjusted $\mathrm{R}^{2}$ value with the run temperature and pressure for bottom \% volatiles. But in the case of top 5 volatiles with the run temperature and pressure, Citgo, EMCN and EMHC resids were within the 1\% error bar, but rest all resids show scattered points with low adjusted $R^{2}$ values. Similarly in Figure 254 through Figure 257, the Chevron, Citgo, EMCN, EMHC and Petrobras resids were within the $1 \%$ error bars, wherein remaining resids showed a scattered points when correlated with the overhead temperature and pressure 
with the bottom \% volatiles. For top \% volatiles with overhead temperature and pressure, Citgo, EMCN and EMHC resids had their experimental vs. predicted values within the $1 \%$ error bar, whereas the remaining all resids showed a scatter in the points indicating that the operating conditions had a little effect on the percentage volatiles in the coke. The low adjusted $R^{2}$ value can also be due to the mere constancy of the volatile matter data which is shown in Figure 250 through Figure 257. 


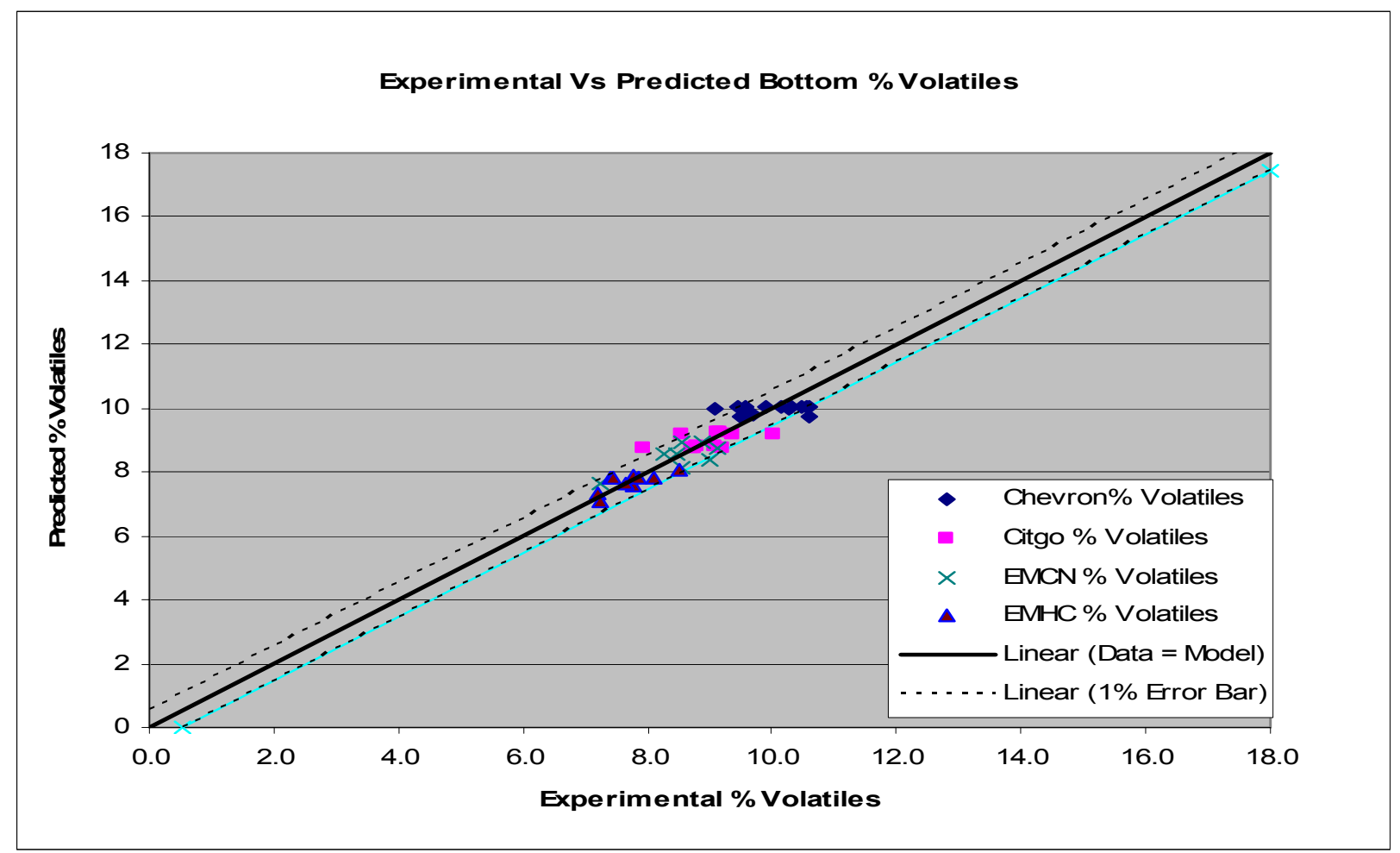

Figure 250 - Predicted vs Experimental Bottom VM Based on Run Temperature \& Pressure

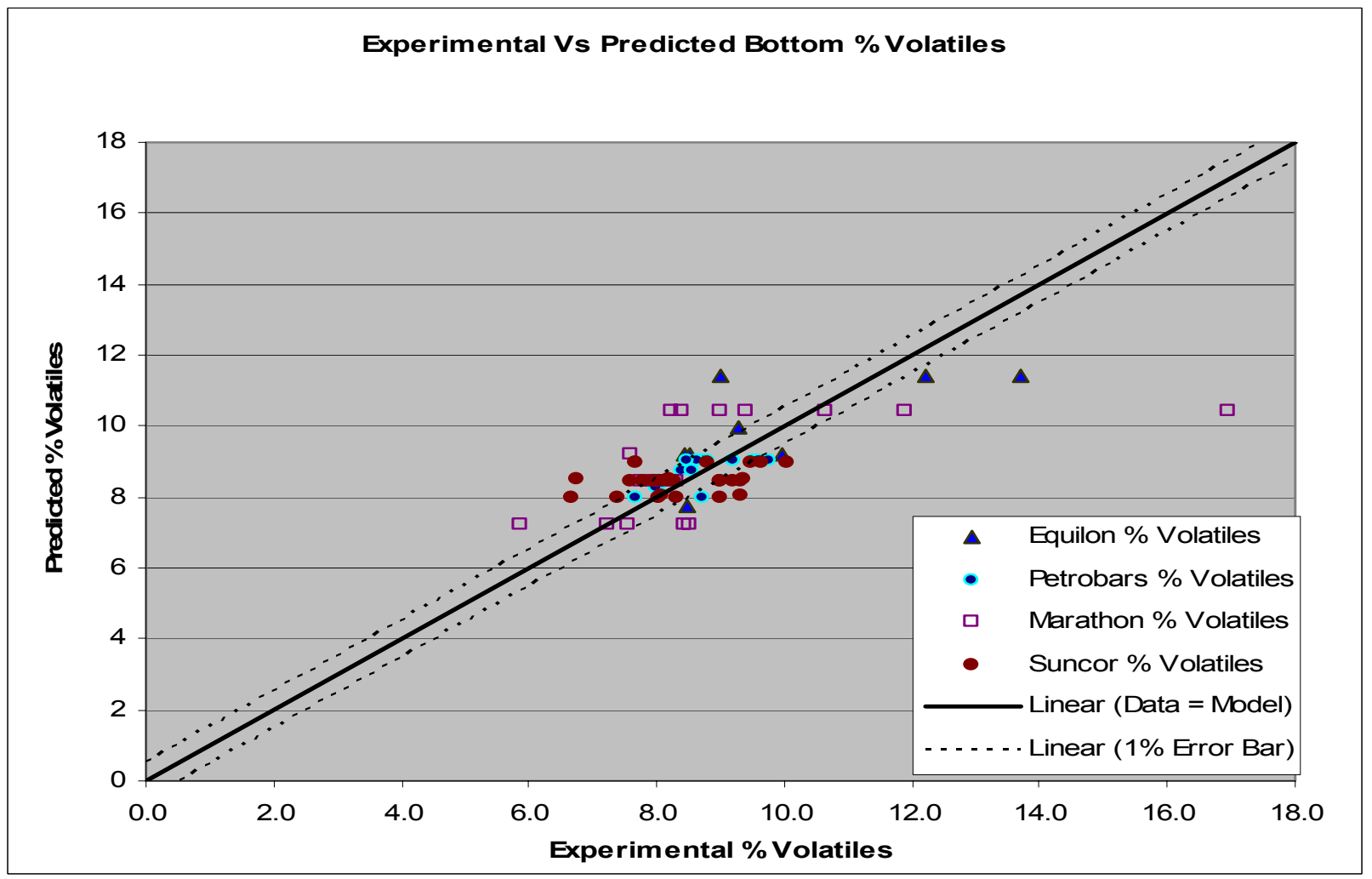

Figure 251 - Predicted vs Experimental Bottom VM Based on Run Temperature \& Pressure 


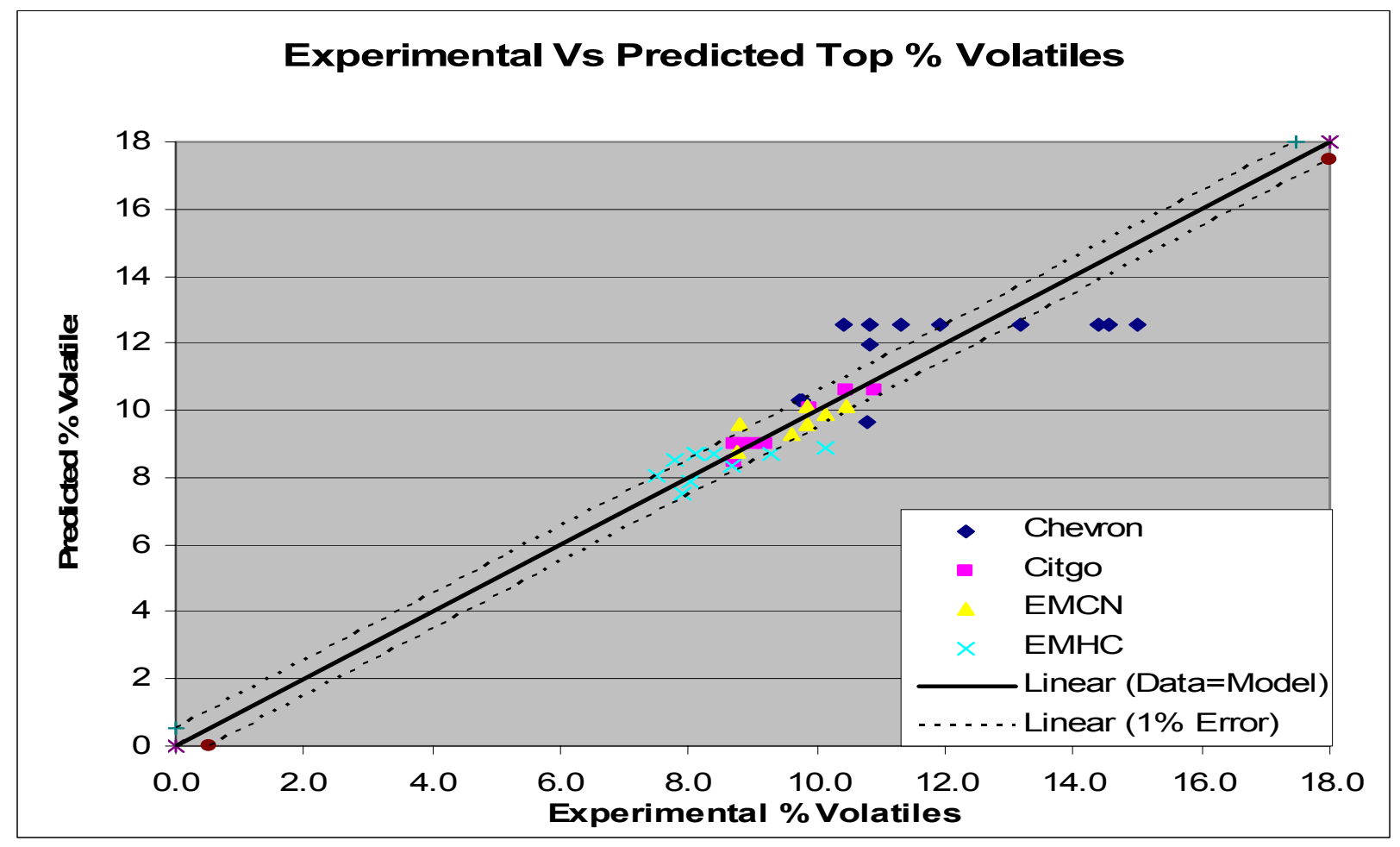

Figure 252 - Predicted vs Experimental Top VM Based on Run Temperature \& Pressure

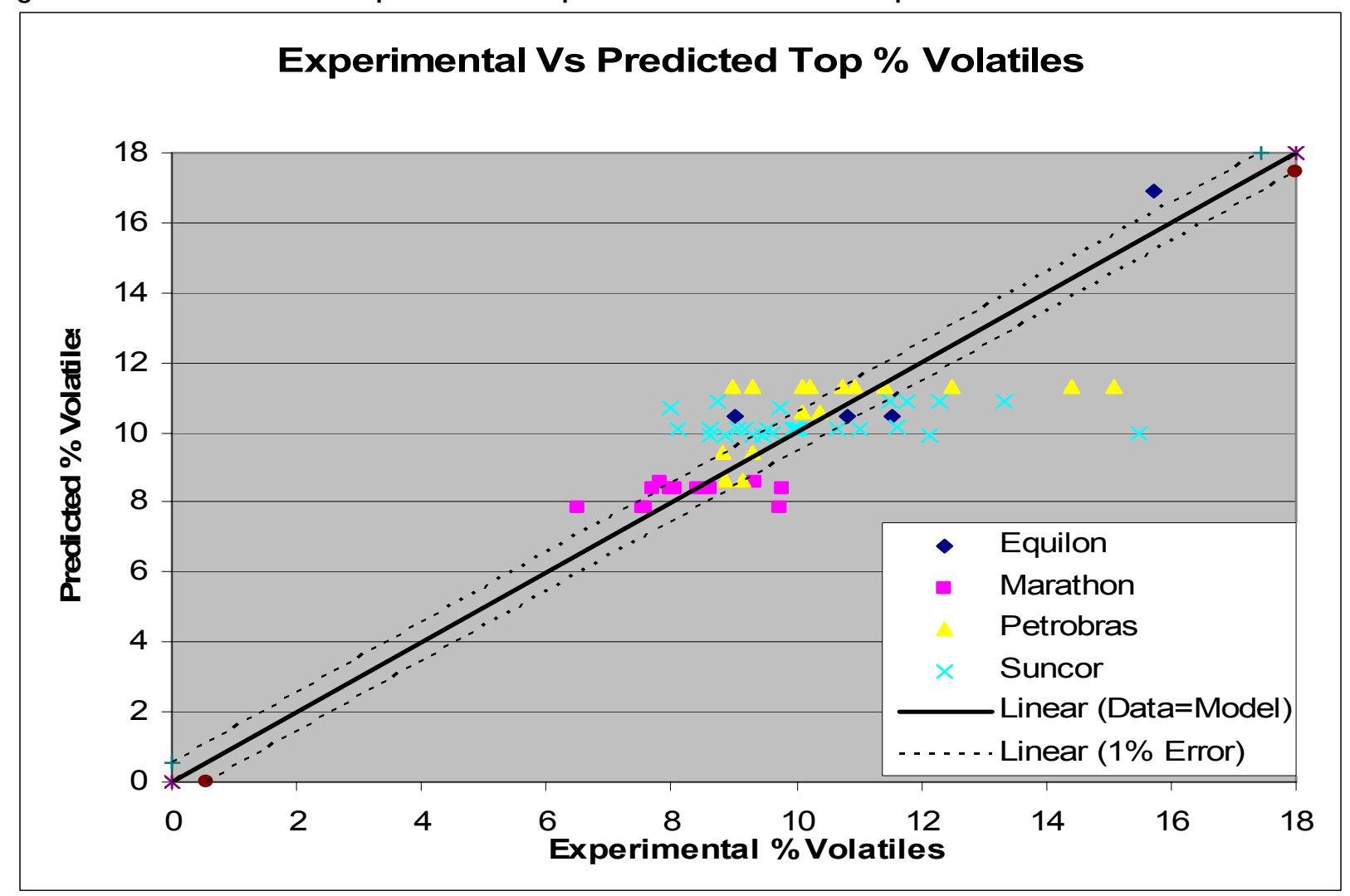

Figure 253 - Predicted vs Experimental Top VM Based on Run Temperature \& Pressure 


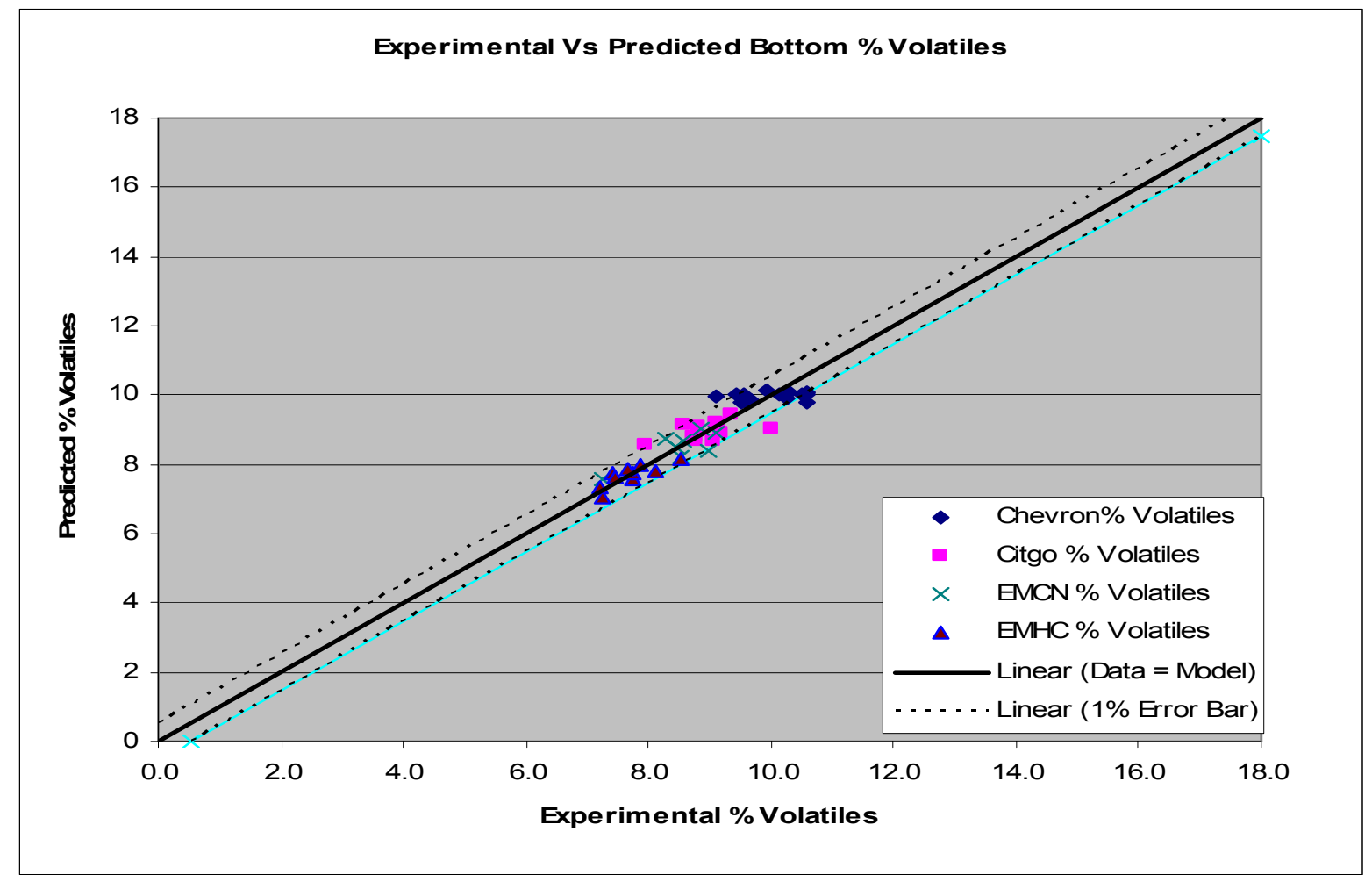

Figure 254 - Predicted vs Experimental Bottom VM Based on Overhead Temperature \& Pressure

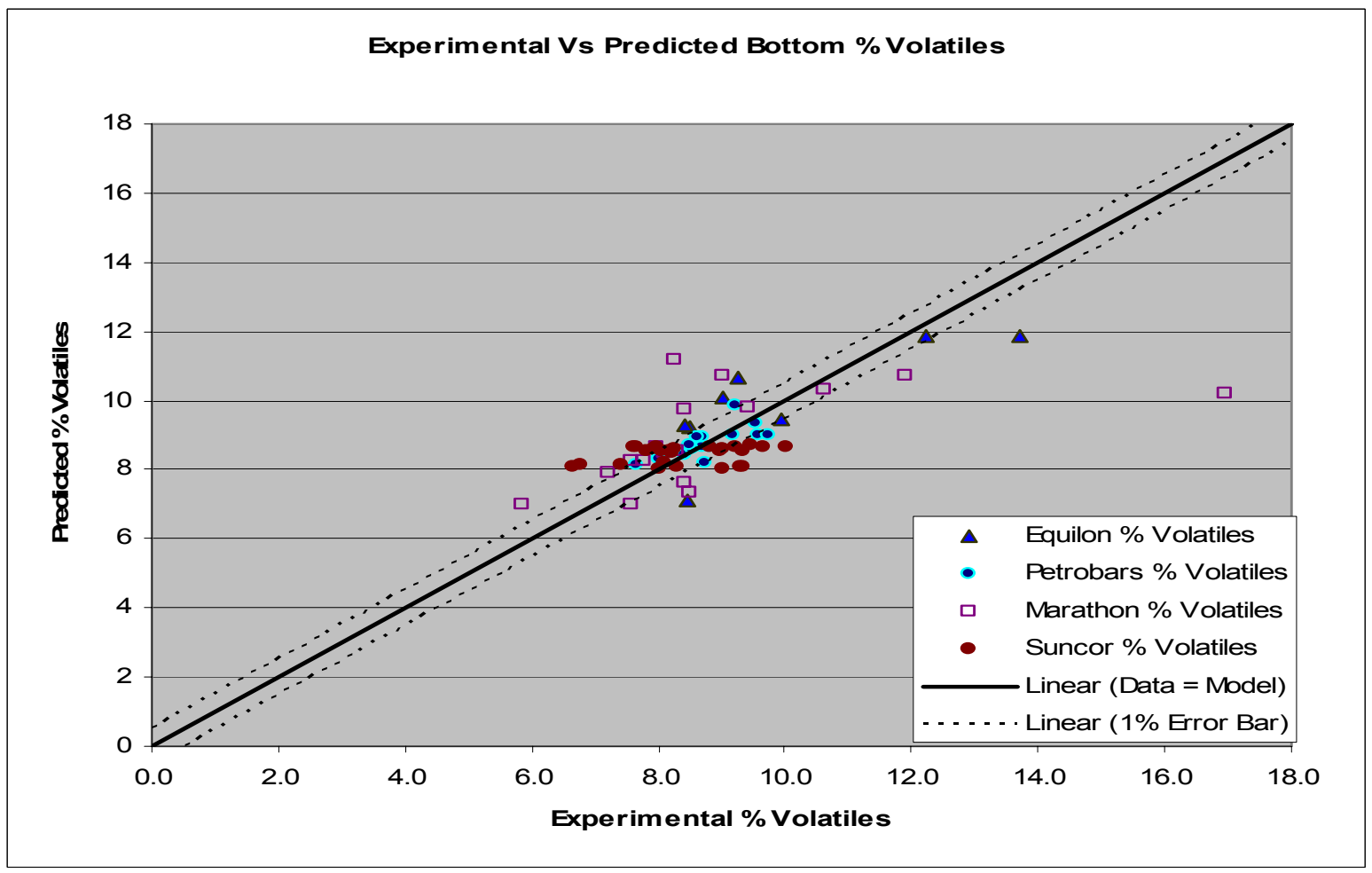

Figure 255 - Predicted vs Experimental Bottom VM Based on Overhead Temperature \& Pressure 


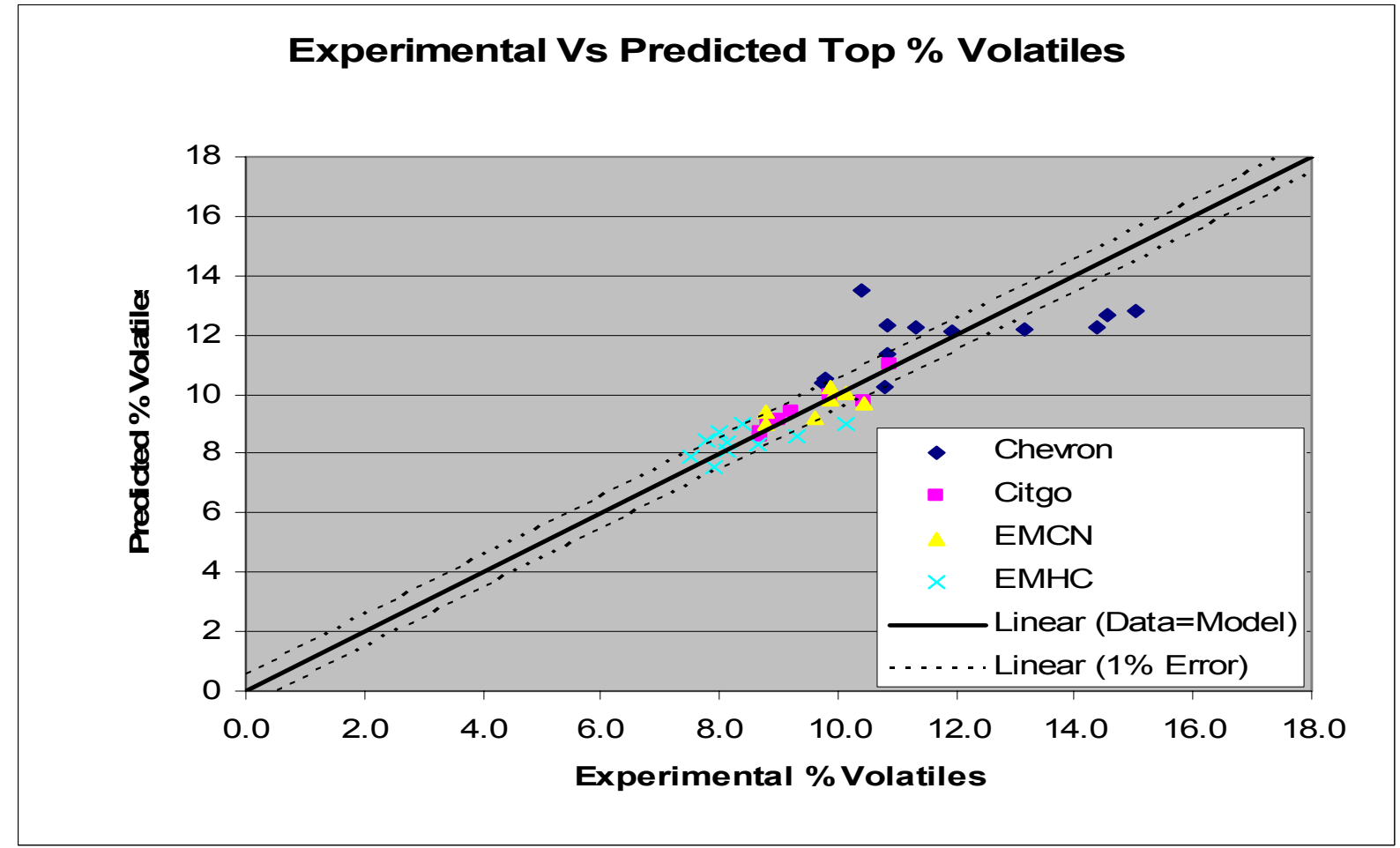

Figure 256 - Predicted vs Experimental Top VM Based on Overhead Temperature \& Pressure

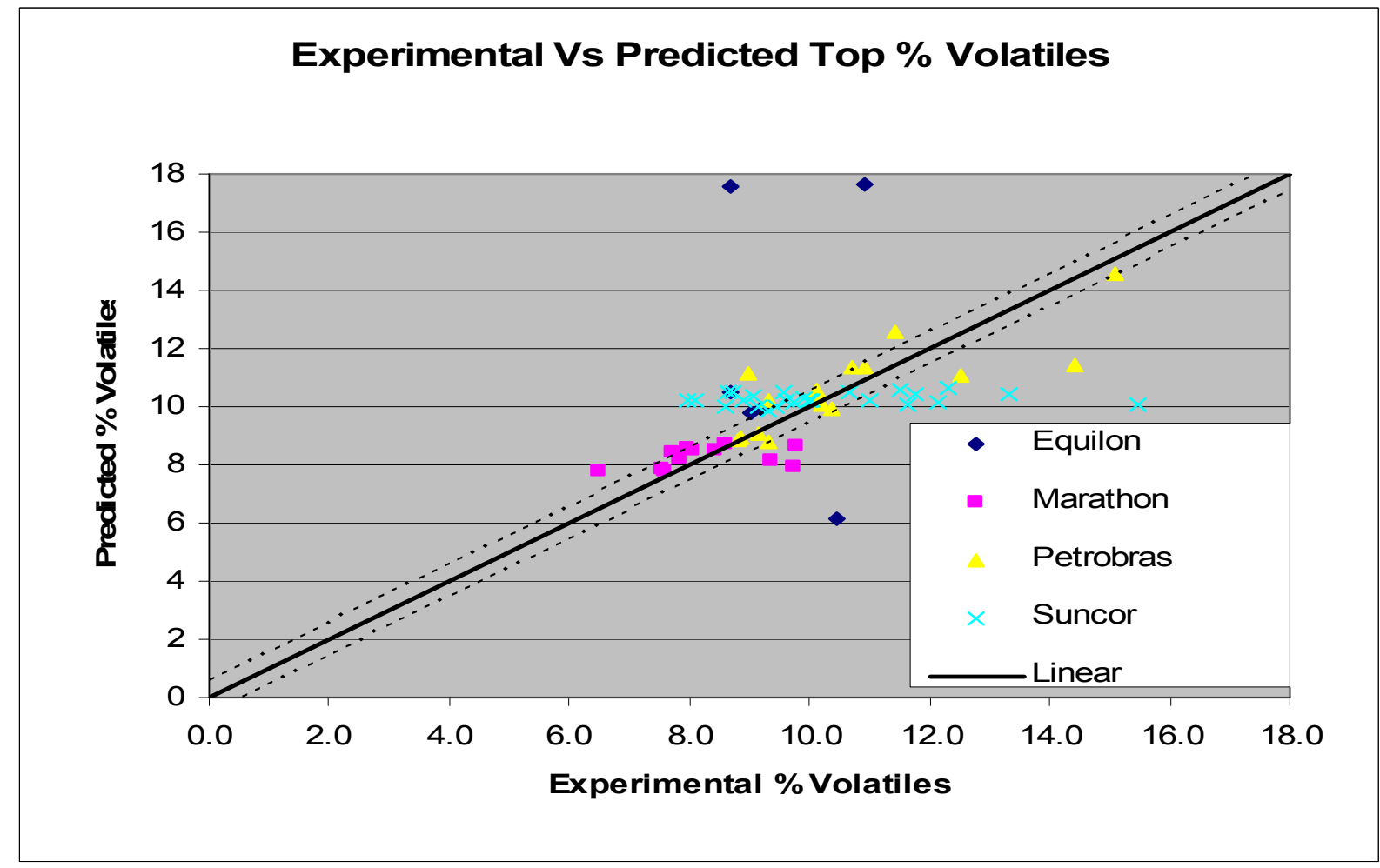

Figure 257 - Predicted vs Experimental Top VM Based on Overhead Temperature \& Pressure 


\section{Conclusions}

The volatile matter distribution in the coke was analyzed for each individual resid. Preliminary studies of the volatile matter distribution in the bed indicate that coke taken from different levels of the coking chambers was not identical in quality. The top section of the coke bed had more volatile matter than middle section. The lower section of the coke bed had the least amount of volatile matter when compared to other sections. It was found from the preliminary studies that the lower section of the coke had almost same amount of VM whereas the top section had variations due to the experimental constraints such as shut down of run either due to pressure build up or due to the height of the coke in the drum. The effect of feed temperature, pressure and the overhead temperature on the VM of the coke was determined and it was found that the bituminous part of the coke undergoes coking when the coke is held in the coke drum at high temperatures. Pressure had a varying effect on the amount of volatile matter in coke for individual resids. Then by looking at each individual resids \% volatiles distribution, coke morphology was found to have little effect on the volatile matter. This again depends on the representative samples picked from the coke bed. Individual correlations were developed considering the combination of operating conditions. The adjusted $R^{2}$ values were low which means that there was no linear relationship between the variables selected except for Equilon, Petrobras, EMCN and EMHC resids which showed some sort of linear relationship with good adjusted $\mathrm{R}^{2}$ values. Therefore, other than operating conditions, there are many other different variables to be considered for determining the amount of volatile matter content in the coke.

\section{GAS ANALYSIS}

The gas produced from the pilot unit passes through the Gas Chromatograph (GC), which is calibrated to identify over twenty components from methane (C1) to pentane (C5) single and double bonds in addition to hydrogen and hydrogen sulfide. The gas composition was analyzed using the number of moles per gram of amount fed of each component that passed through the gas chromatograph. The gas chromatograph uses the thermal conductivity detectors to identify the gas components (in mole percentage) that are determined using the ideal gas law. In addition to the above mentioned components, the gas chromatograph is calibrated to identify the hexanes and above ( $\left.66^{+}\right)$by comparing it to an already mixed sample that is included with the calibration gas.

Based on the available data, effect of temperature and effect of pressure on these gas compositions were determined and also gas composition correlations were developed selecting the overhead temperature and pressure as the parameters. The pilot unit gas composition data was compared with the available micro coker gas composition data to determine the similarity between the two units. The effect of temperature at constant pressure and effect of pressure at constant temperature on the average molecular weight of the gas composition for all the nine resids were also determined.

\section{Gas Composition Reproducibility}

The reproducibility for the pilot unit gas composition data was checked for each individual resid at the same operating conditions, i.e., at the same feed temperature and pressure. The comparisons were made between the total numbers of individual gas composition moles per total grams of amount fed for each individual runs for the same combination of operating conditions of $900^{\circ} \mathrm{F}, 930^{\circ} \mathrm{F}$ and $15 \mathrm{psig}$ and 40 psig. In general, most of the resids showed little variation among the runs which are operated at same operating conditions except for Chevron resid. All the variations among the gas compositions for all the resids were between five to ten percent maximum. These variations may be due to the other effecting 
parameters like run length, feed rate etc i.e., even though if they are run at same feed temperature and pressure, but their feed rate and run length is different in each cases.

\section{Gas Composition Correlations}

Gas composition correlations were developed for each individual compounds for all the nine resids namely Chevron, Citgo, Equilon, Marathon, Petrobras, Suncor, EMCN, EMHC and MRP using overhead temperature and pressure as parameters. To simplify the gas composition comparisons, n-butane and isobutane are grouped as C4's; n-pentane and iso-pentane are grouped as C5's; and ethylene, propylene, isobutylene, trans 2-butene, cis 2-butene, 3-methyl 1-butene, 2-methyl 1-butene, 2-methyl 2-butene, 1pentene, trans 2-pentene, cis 2-pentene are grouped as olefins. Gas Composition is expressed in terms of mole percent of the total gas composition (excluding nitrogen) in the correlations. Hydrogen, methane and olefins occupy eighty percent of the total gas composition and the remaining twenty percent gas composition contains hydrogen sulfide, ethane, propane, C4's, C5's and hexanes.

Initially, Gas Composition correlations were developed considering the whole GC data from the start of the run to the end of the run and also including the steam stripping hour (for all runs with full GC data). But the GC correlations obtained considering those data were very poor reflecting poor adjusted $\mathrm{R}^{2}$ values. Then, only the gas composition data without the first hour of the run and without the steam stripping time was considered and GC correlations for individual compounds of the gas compositions were developed taking the overhead temperature and pressure as the independent variables, since it is believed that the overhead temperature and pressure has a very obvious effect on the gas composition. Figure 258 through Figure 266 shows the model predicted versus the experimental yields of the gas composition for each individual resid with all the individual gas compositions.

In general, the adjusted $\mathrm{R}^{2}$ values for all the gas composition correlations developed were good except for few individual gas compositions among the few resids. Hydrogen had a good linear relationship with the selected overhead temperature and pressure except for chevron, Equilon and Petrobras runs whereas hydrogen sulfide and methane did not follow a linear correlation with chevron and Equilon resids. The adjusted $\mathrm{R}^{2}$ values for ethane were good for all the resids except Chevron, EMCN and MRP resids.

Propanes and pentanes have a good liner relationship with the parameters selected in case of all the resids except for chevron. Butanes showed linear relationship with all resids except for chevron, Citgo and MRP resids. Hexane showed a fairly good linear relationship with good adjusted $R^{2}$ values for all the resids based on the GC data available. Olefins showed a poor linear relationship with the overhead temperature and pressure in the case of chevron and EMHC resid. Strong conclusions cannot be drawn from these data since gas chromatograph was not working properly during some of the runs, which again questions the suitability of the available GC data. 

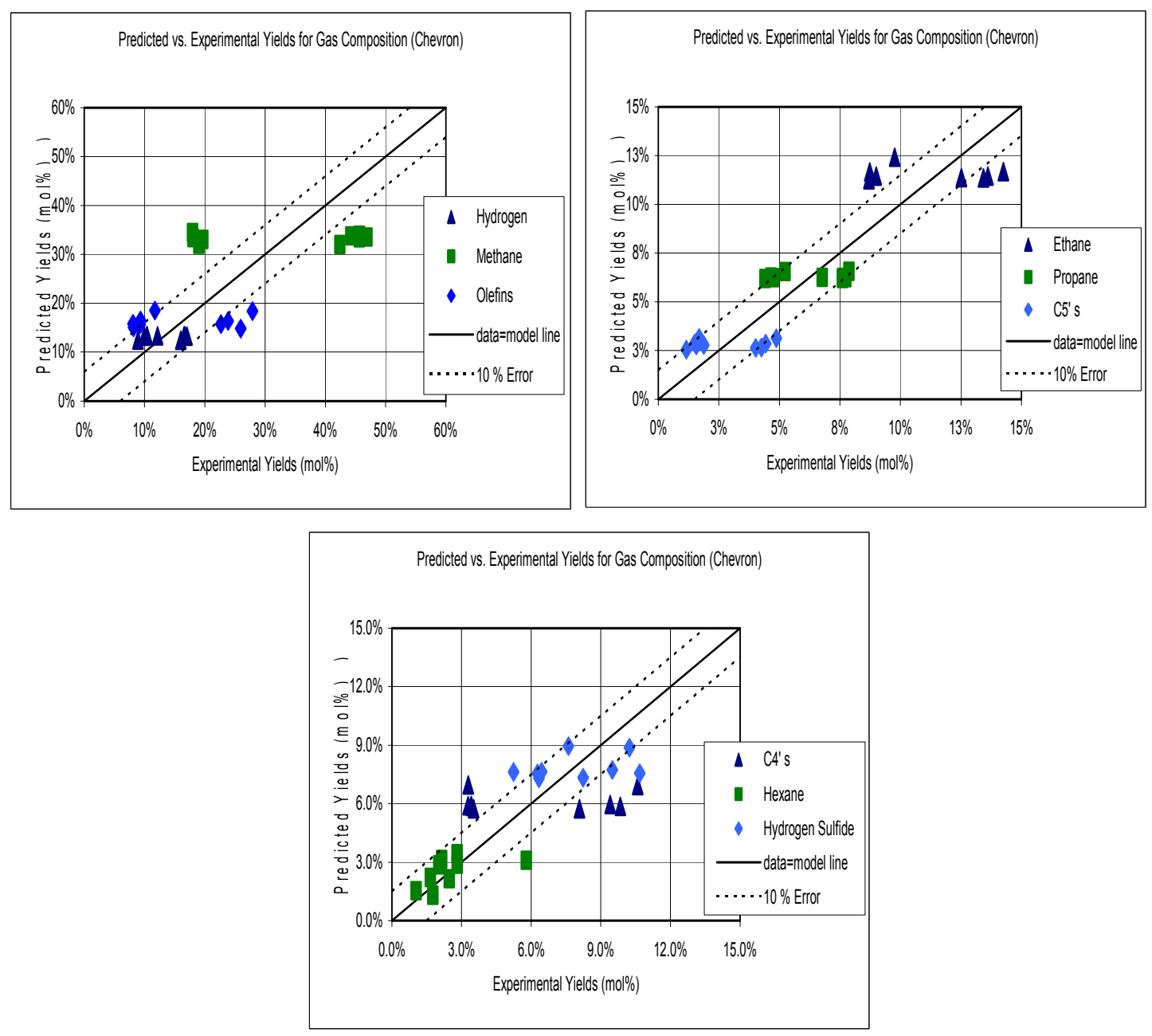

Figure 258 - Model Predicted vs. Excperimental Yields for Gas Composition (Chevron) 

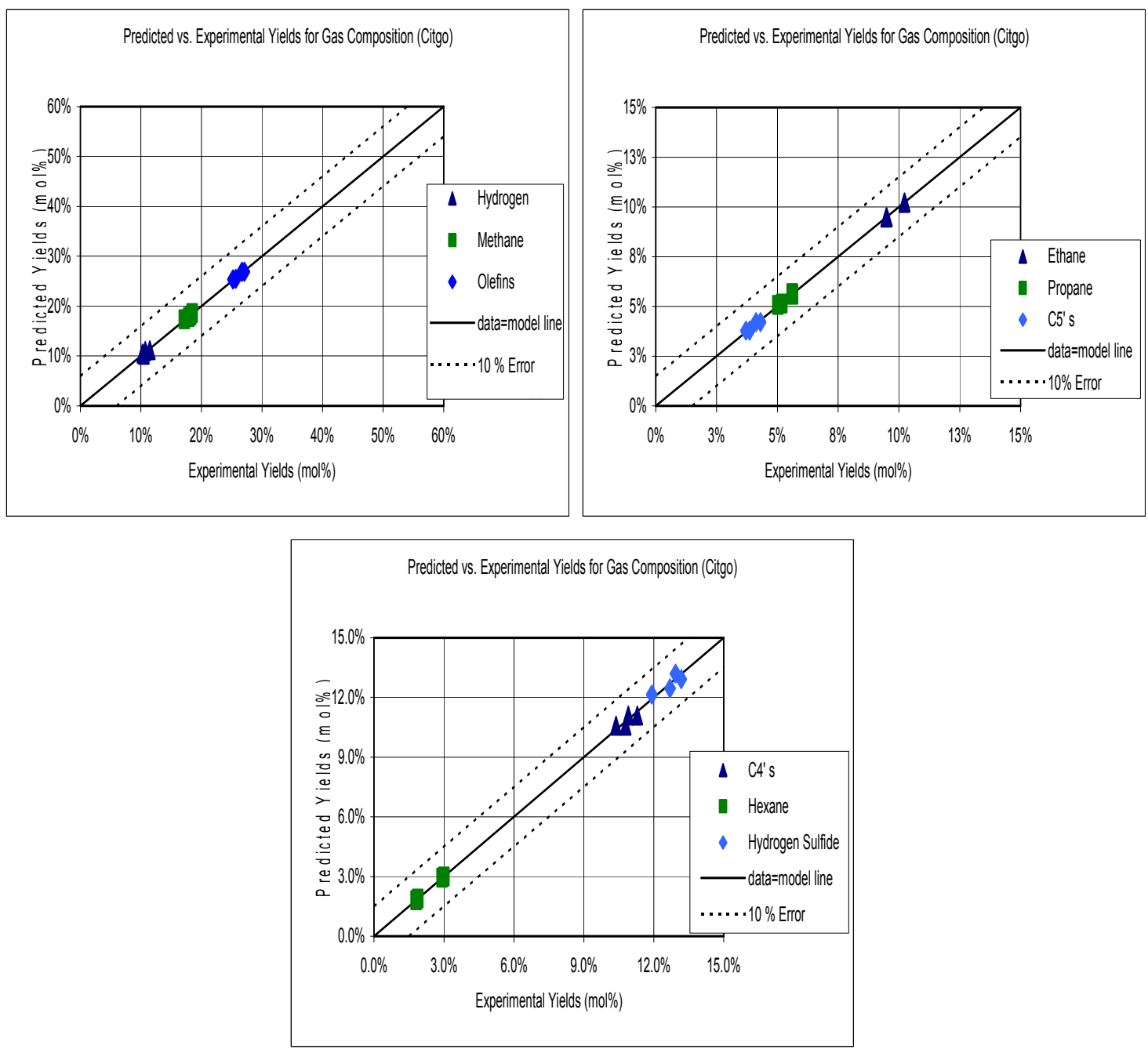

Figure 259 - Model Predicted vs. Excperimental Yields for Gas Composition (Citgo) 

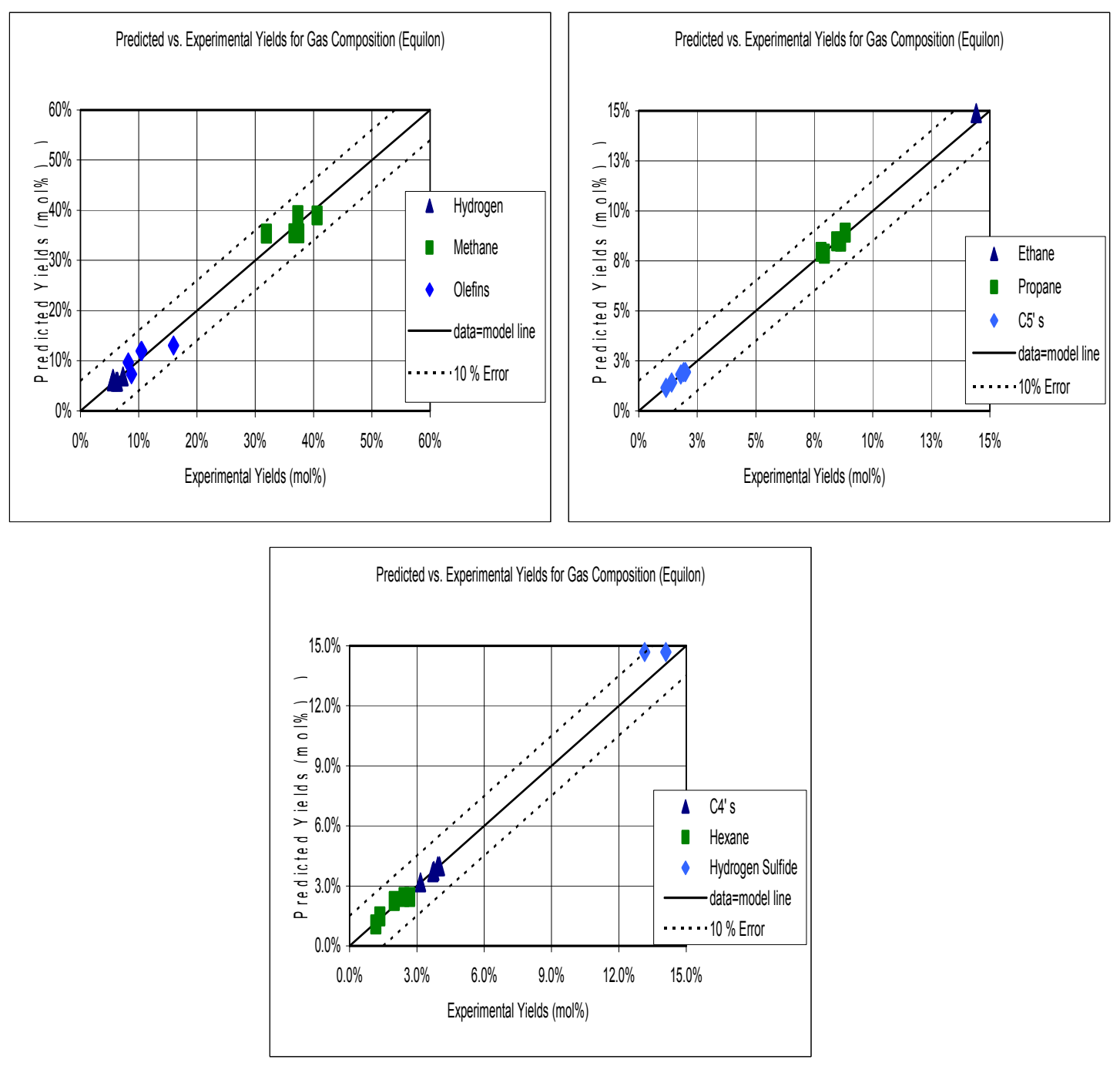

Figure 260 - Model Predicted vs. Excperimental Yields for Gas Composition (Equilon) 

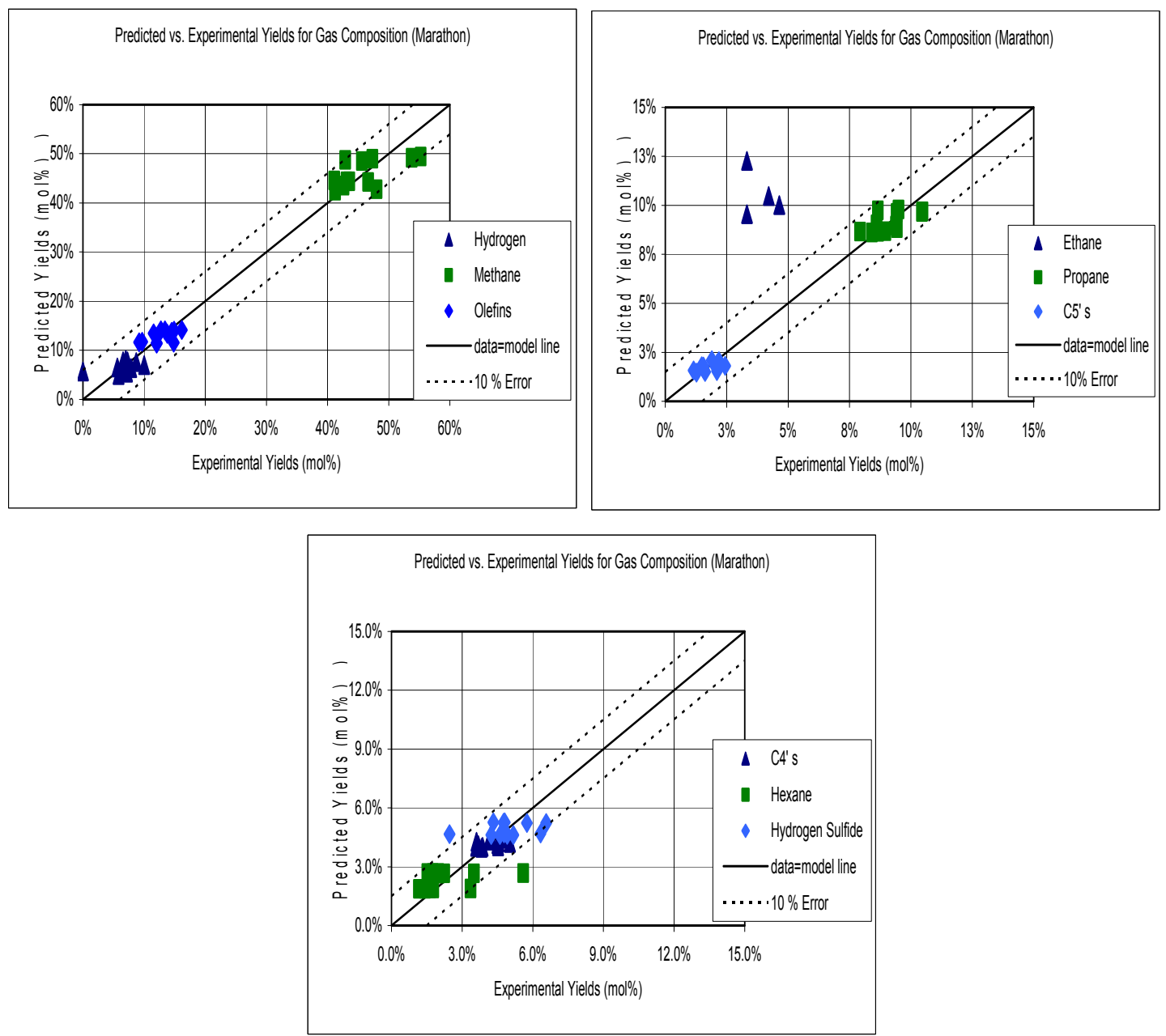

Figure 261 - Model Predicted vs. Excperimental Yields for Gas Composition (Marathon) 

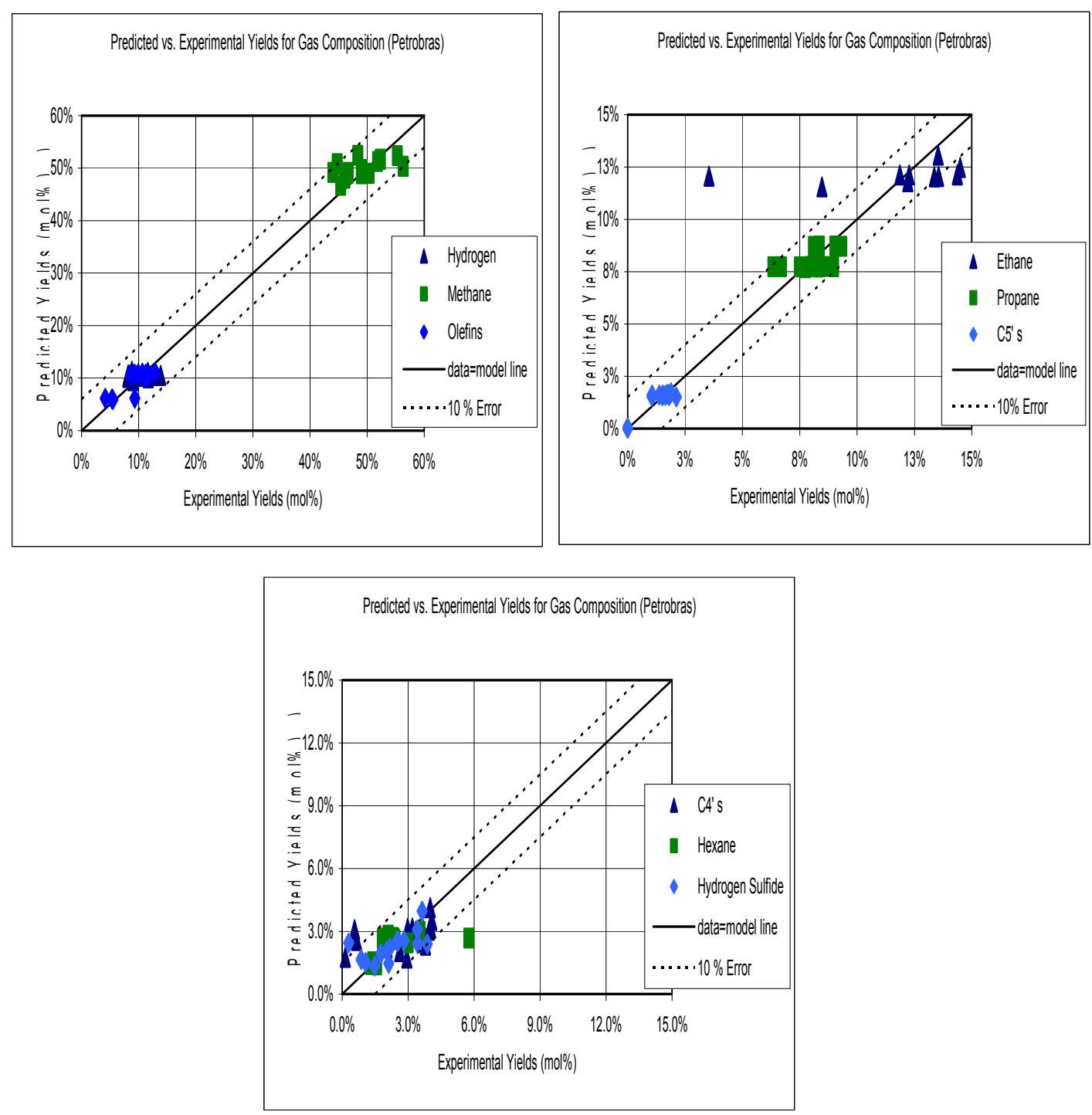

Figure 262 - Model Predicted vs. Excperimental Yields for Gas Composition (Petrobras) 

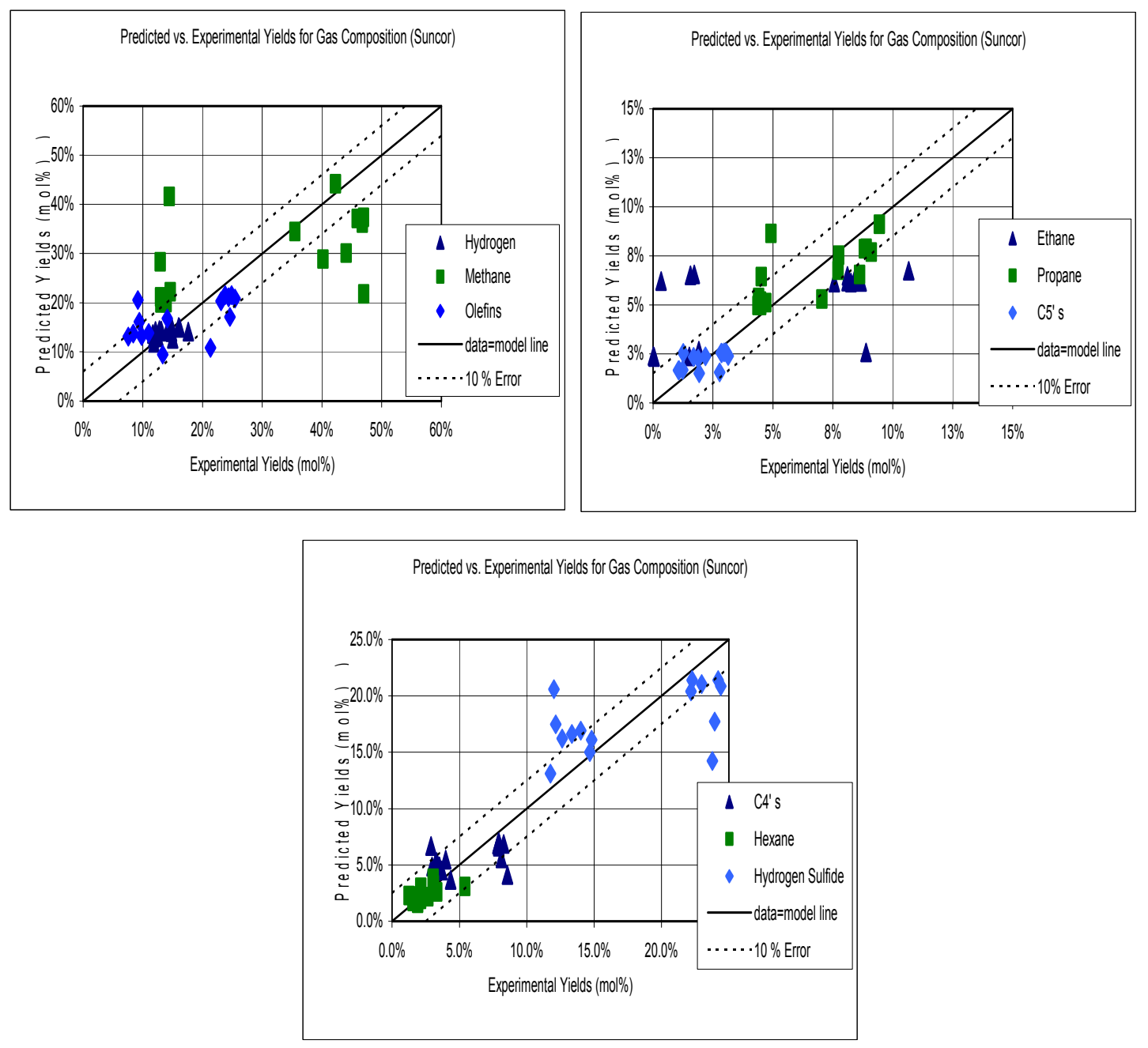

Figure 263 - Model Predicted vs. Excperimental Yields for Gas Composition (Suncor) 

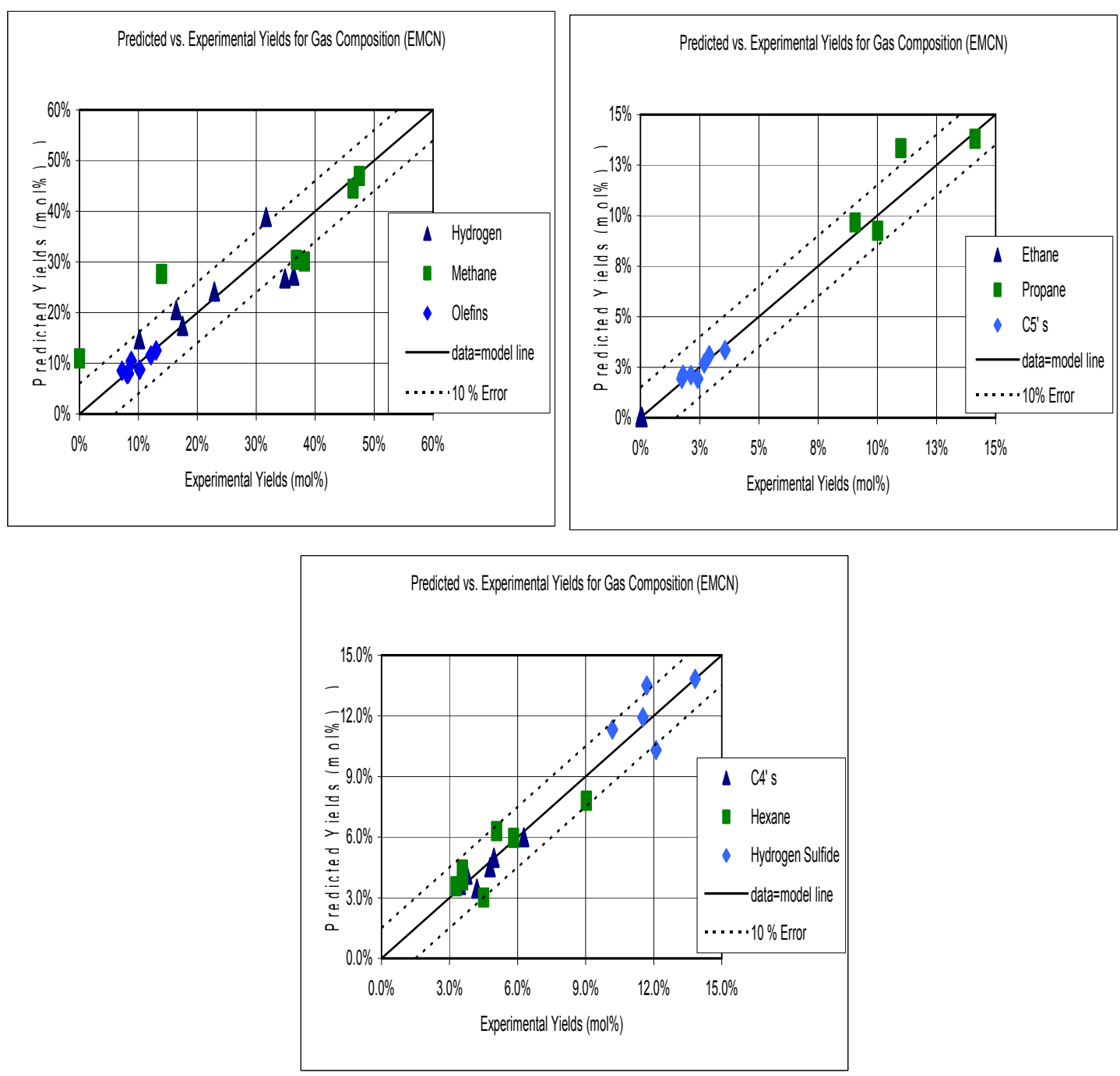

Figure 264 - Model Predicted vs. Excperimental Yields for Gas Composition (EMCN) 

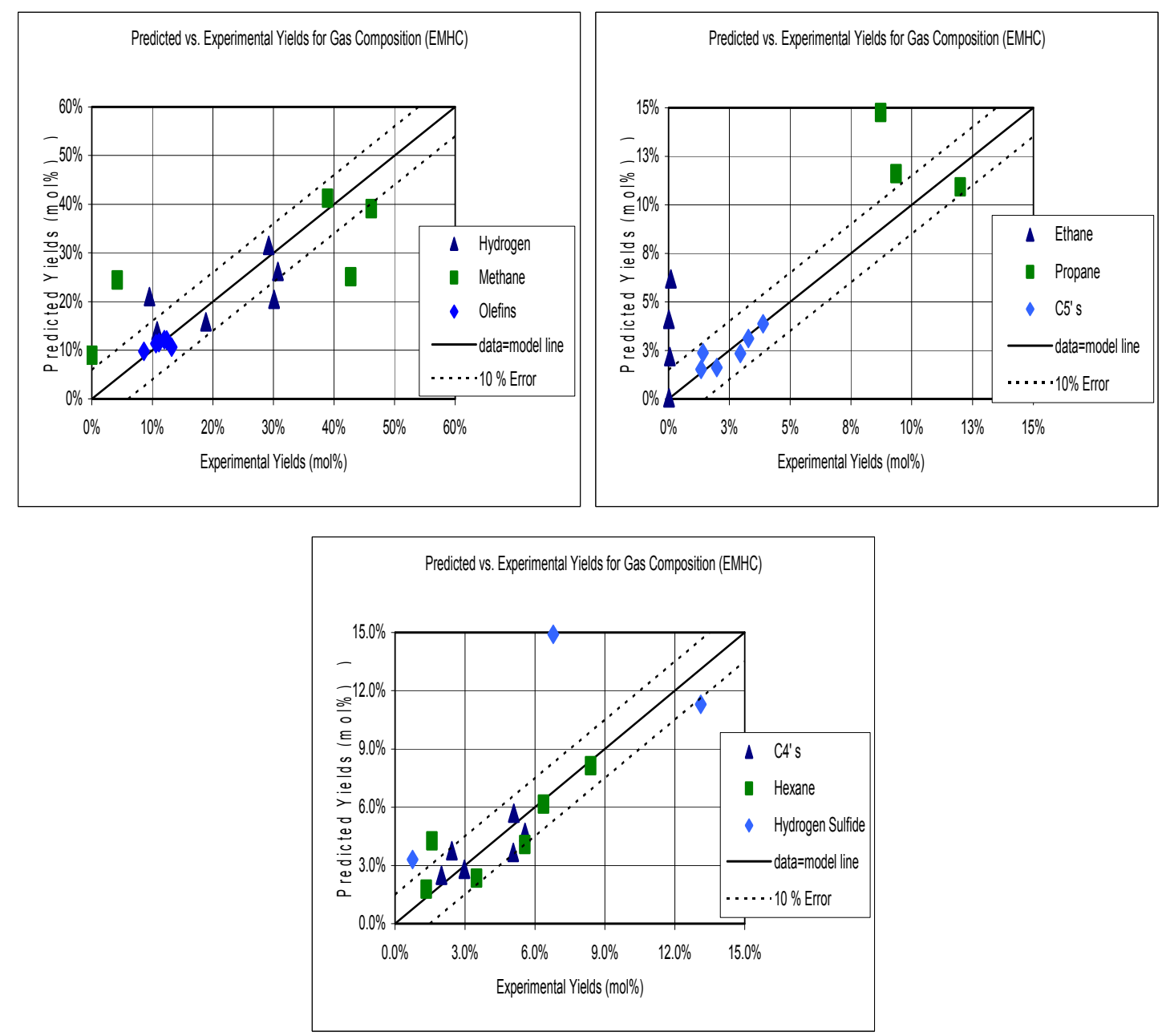

Figure 265 - Model Predicted vs. Excperimental Yields for Gas Composition (EMHC) 

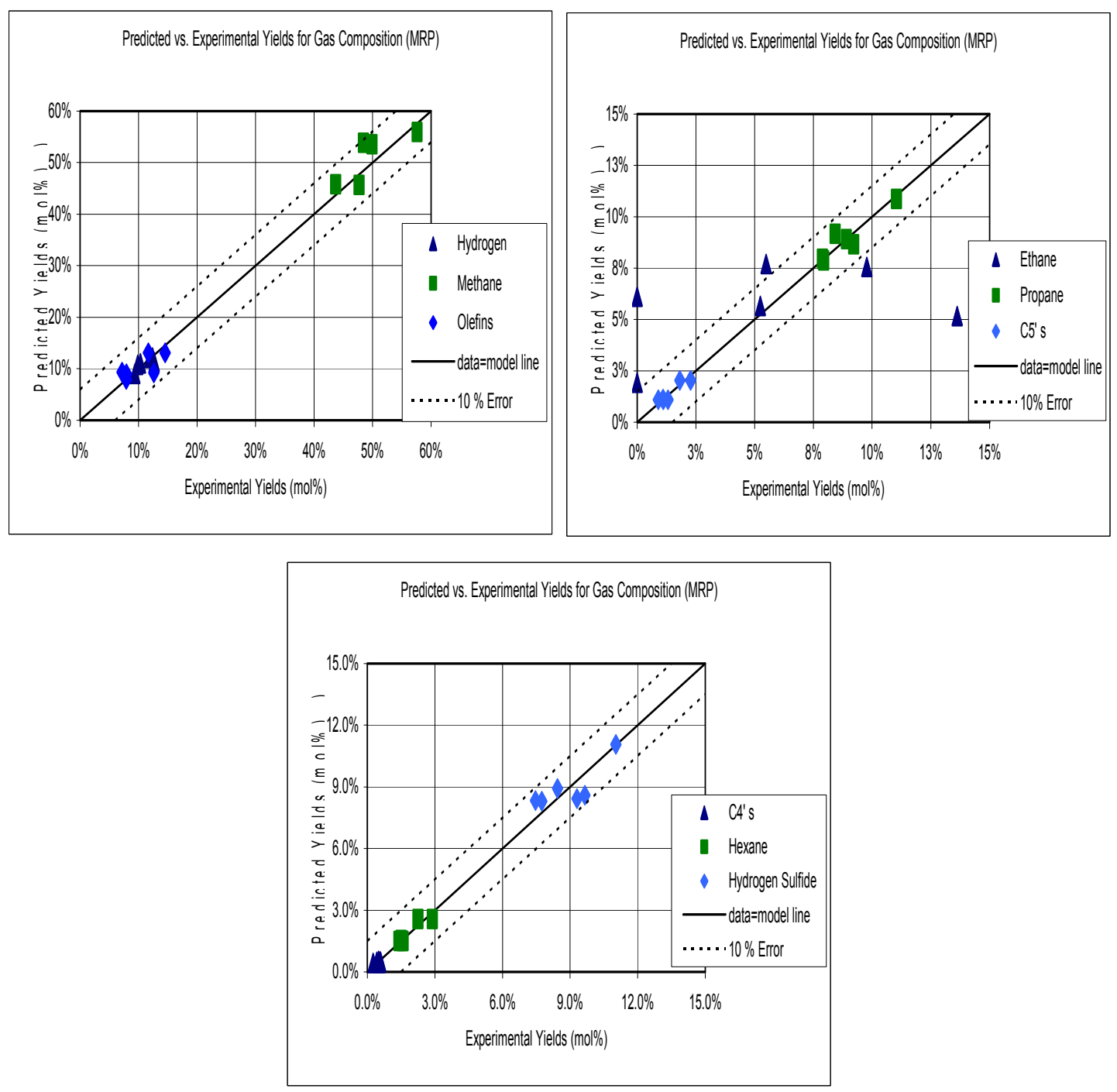

Figure 266 - Model Predicted vs. Excperimental Yields for Gas Composition (MRP)

\section{Comparison of Pilot Unit Gas Compositions with the Micro Coker}

The mole percent of the total gas composition of the selected pilot unit runs are compared with the mole percent of the total gas composition of the selected micro coker runs. The comparison between the pilot unit and micro coker gas compositions shows that the hydrogen mole percent of the total gas composition drastically reduces in the pilot unit when compared with the micro coker gas composition for all the resids with the total amount of reduction in hydrogen mole percent being different for each individual resid. The hydrogen sulfide $\left(\mathrm{H}_{2} \mathrm{~S}\right)$ mole percent of the total gas composition is comparatively more in pilot unit when compared to the micro coker. Same is the case with ethane, propane, butanes, pentanes, hexanes and olefins. Most of the time, the mole percent of methane of the total gas composition is more in pilot unit when compared with the gas composition of the micro coker, but it is not always the case. The mole percent of methane keeps fluctuating and definite conclusions cannot be drawn from the available data. The high value of the mole percent of hydrogen of the total gas composition of the micro coker runs may be due to the false readings given by the vapor line pressure gauge, which resulted in high standardized volume of gas. 
Based on these values, the gas composition correlations were developed for the micro coker runs. When these gas composition correlations of the micro coker were compared to the pilot unit gas composition correlations, there were variations in the correlations developed between the two units. This may be due to two reasons, the first one being; the middle reactor temperature was used to correlate in the model with the individual gas compositions in the micro coker. The micro-coker middle reactor temperature did not correlate well with the pilot unit overhead temperature. The second reason being; the pilot unit product or gas yields were different when compared with the micro coker product yields at the same operating conditions.

\section{Conclusions}

The gas composition analysis was carried out for all the nine resids in house using the number of moles per gram of amount fed of each component that passed through the gas chromatograph. Initially, the gas composition data reproducibility was checked selecting few of the runs that were run at the same operating conditions. This analysis showed that except for Chevron and Suncor resid, remaining all of the resids reproduced almost the same GC data when run at the same operating conditions. And also it was found that methane and olefins composition in the total gas composition are very much dependent on the run length. Based on these data, gas composition correlations were developed using the overhead temperature and pressure as parameters. The adjusted $\mathrm{R}^{2}$ values obtained from the GC correlations for most of the resids were poor indicating that there was no linear relationship existing between the individual gas composition and the selected parameters, i.e., the overhead temperature and pressure except for Citgo, Equilon and EMCN resids which showed fairly good adjusted $\mathrm{R}^{2}$ values. The pilot unit $\mathrm{GC}$ composition and correlations were then compared to the micro coker data, which showed that hydrogen mole percent of the total gas composition was low in the pilot unit, whereas the remaining components composition were more in pilot unit except for methane which showed a variation. The pilot unit gas composition correlations did not match with the micro coker GC correlations, since middle reactor temperature is used in the micro coker model which did not correlate well with the pilot unit overhead temperature and also the micro coker product yields were different when compared with the pilot unit product yields at the same operating conditions.

\section{E. C/H/N DistRIBUtION IN COKE}

\section{Analysis of $\mathrm{C} / \mathrm{H} / \mathrm{N}$ in Coke}

The major objective in the analysis of the carbon, hydrogen and nitrogen $(\mathrm{C} / \mathrm{H} / \mathrm{N})$ content present in the coke is to determine the $\mathrm{C} / \mathrm{H} / \mathrm{N}$ distribution in the coke bed and to develop correlations based on the depending operating parameters. The representative samples from the top and bottom section of the coke bed is selected from each particular run and then sent to Baker Petrolite laboratories to estimate the weight percent of carbon, hydrogen and nitrogen present in the coke sample which represents the total weight percent of carbon, hydrogen and nitrogen present in the whole coke formed during each individual run.

To determine the distribution of the weight percent of carbon, hydrogen and nitrogen along the coke bed, the coke samples from the top section and bottom section of the coke bed is sent for $\mathrm{C} / \mathrm{H} / \mathrm{N}$ analysis. There was not much variation found in the weight percent of carbon, hydrogen and nitrogen along the coke bed. The weight percent of $\mathrm{C} / \mathrm{H} / \mathrm{N}$ gets equally distributed all along the coke bed, and also it was found that temperature and pressure has a little effect on the distribution of $\mathrm{C} / \mathrm{H} / \mathrm{N}$ in coke. Few of the 
runs among all the resids had a larger variation in $\mathrm{C} / \mathrm{H} / \mathrm{N}$ weight percent between the top and bottom section of the coke bed, the reason being the bad samples (i.e., not representative samples) were sent for analysis.

\section{$\mathrm{C} / \mathrm{H} / \mathrm{N}$ Model Correlations}

The weight percent of carbon, hydrogen and nitrogen present in the coke were correlated with different run parameters like feed temperature, pressure, run length etc to determine the effect of these parameters on the carbon, hydrogen and nitrogen content present in the coke. Figure 267 and Figure 268 shows the predicted vs. experimental yields for carbon, hydrogen and nitrogen in the coke for all the eight resids. The carbon, nitrogen and hydrogen weight percent was averaged and then used in developing correlations assuming that these $\mathrm{C} / \mathrm{H} / \mathrm{N}$ concentrations were uniformly distributed all along the coke bed. Correlations were developed selecting the combination of other operating parameters such as overhead temperature, pressure, run length, feed rate etc, but the combination of these selected parameters that is, feed temperature, run length and the pressure gave fairly good adjusted $\mathrm{R}^{2}$ value when compared with the results obtained by selecting other operating parameters.

\section{Conclusions}

The weight percent of carbon, hydrogen and nitrogen data obtained from Baker Petrolite was used in the $\mathrm{C} / \mathrm{H} / \mathrm{N}$ analysis and was also used in developing correlations selecting feed temperature, pressure and run length as the independent variables. Preliminary conclusions which came out from this analysis are that the weight percent of carbon, hydrogen and nitrogen are uniformly distributed all along the coke structure or coke bed formed inside the drum. The adjusted $\mathrm{R}^{2}$ values for most of the resids were reasonably good except for few; this might be due to the constancy of the data available. 

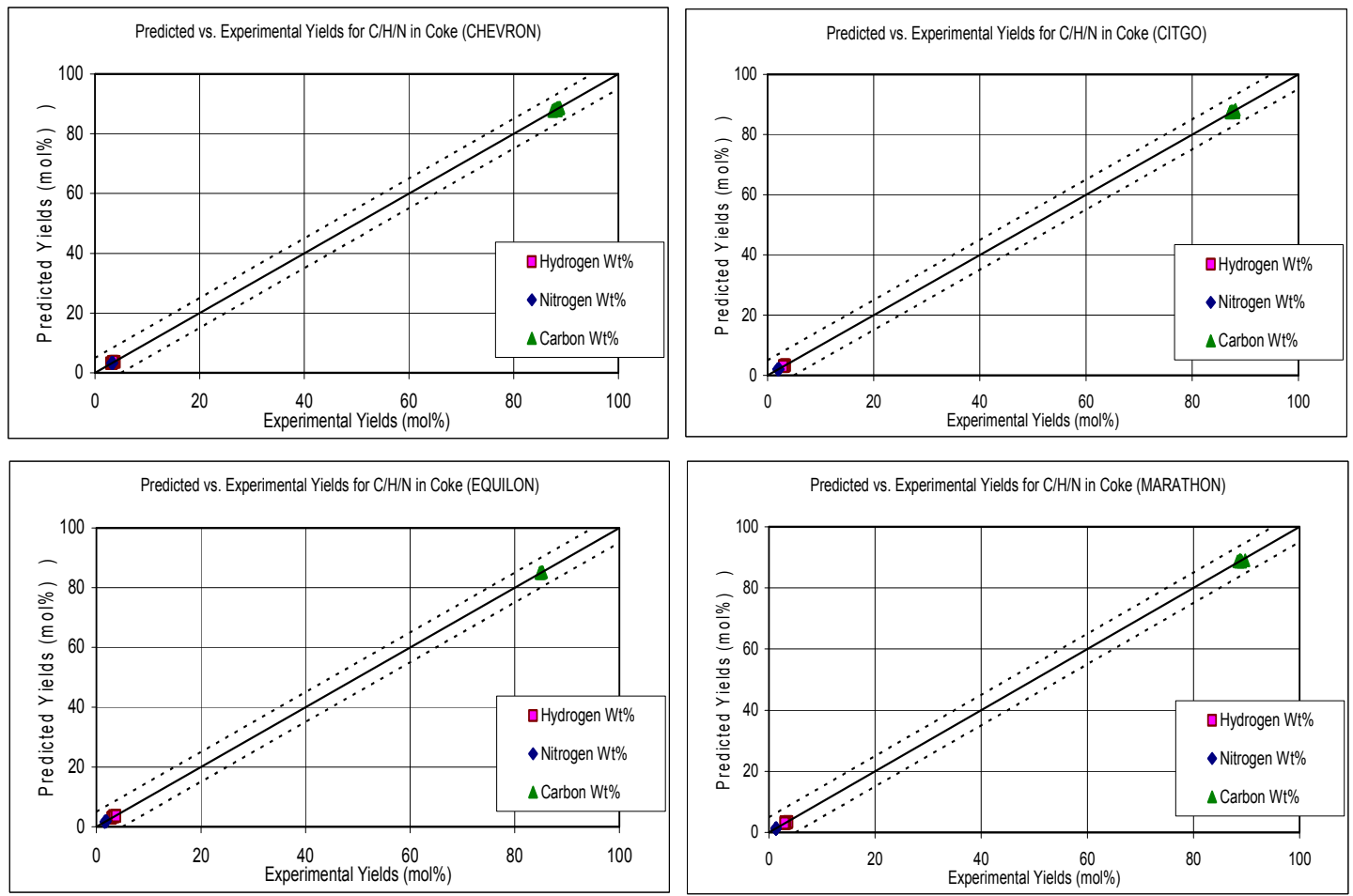

Figure 267 - Predicted vs. Experimental Yields for $\mathrm{C} / \mathrm{H} / \mathrm{N}$ in coke for all the resids
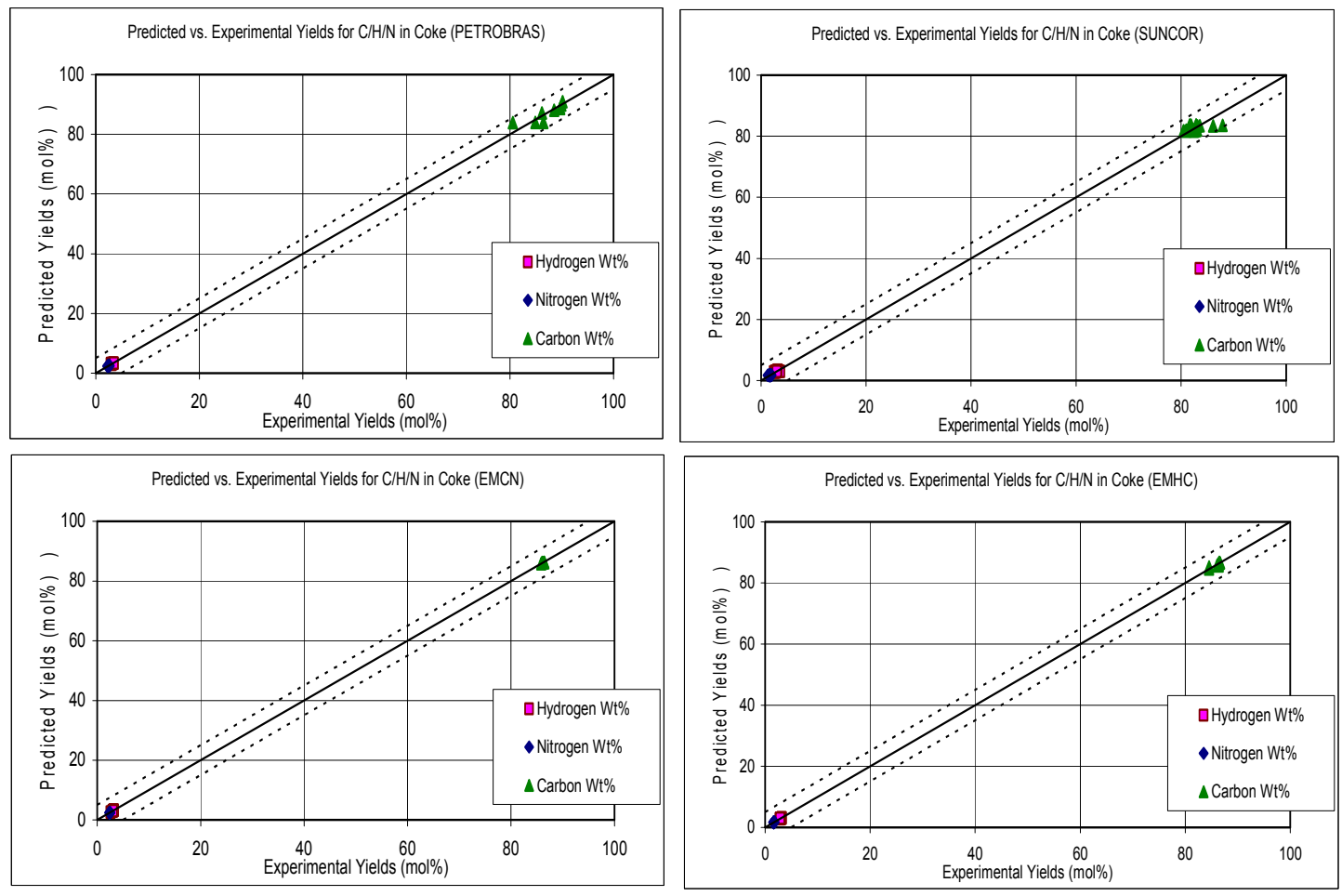

Figure 268 - Predicted vs. Experimental Yields for $\mathrm{C} / \mathrm{H} / \mathrm{N}$ in coke for all the resids 


\section{F. FOAMING MODELS}

\section{Theoretical Discussion}

\section{a) Foams and Foam Model Development}

Foams are agglomerations of gas bubbles separated from each other by thin liquid films. They belong to the colloidal system comprising of gas dispersed in liquid. A very large majority of industrial processes require the injection of materials known as antifoams to inhibit the foam growth because the foam formation and continuous growth is sometimes undesirable in chemical processes leading to fouling in equipment. Antifoams such as silica particles dispersed in carrier oil such as mineral oil are important from the standpoint of controlling and inhibiting foam. Consequently foam models that can predict how the foam-antifoam interaction will affect the foam is going to be very important as it will provide insight to rapid foam control whenever required and also optimum antifoam requirements for doing so. Presented here is the theory of two foam models, Pelton's Model and Model 2, that predicts foam volumes for different times during the run. Pelton's Model does so both in the presence and absence of antifoam and correlates foam volumes to the run operating conditions and case specific antifoam effects(if injected) whereas Model 2 interrelates the foam volumes calculated for different times during the run with important resid properties, coke morphology, antifoam effects(if injected), coke pore size distribution and Pelton's Model results.

\section{b) Literature Review of Pelton's Model}

Pelton and Goddard in literature[2] have emphasized on the dynamic foam rise test for the development of a foaming model. Literature[2] describes that for the foam test the aqueous surfactant was kept in a graduated cylinder and gas bubbles were produced by passing air or nitrogen through a frit at the bottom of the cylinder. In the experimental setup described in the literature[2], the foaming solution comprised of SDS (sodium dodecyl sulfate) in distilled water. The commercial antifoams that were used, as it states, consisted of hydrophobic silica dispersed in silicone oil and the material was emulsified with a mixture of nonionic surfactants. Then it describes that the antifoam emulsion was weighed into a freshly prepared SDS solution that was added to a graduated cylinder. Pelton and Goddard in literature[2] then go on to describe that humidified nitrogen was introduced through an ace glass pore, ASTM 25-50 $\mu \mathrm{m}$ glass frit attached to the glass tube and suspended down the center of the cylinder and the gas flow rate was controlled by a Matheson 8420 mass flow controller.

\section{c) Description of Pelton's Model}

The model foam conceptualized here consisted of the elements shown in Figure 269. The gas entered the liquid phase in the form of "primary bubbles". Also the liquid phase comprised of the antifoam emulsion droplets. The foam phase was present above the liquid phase. The primary bubbles in the liquid phase were assumed to collect the antifoam emulsion droplets by heterocoagulation. On entering the foam phase these primary bubbles were assumed to coalesce with neighboring primary bubbles leading to the 
formation of "secondary bubbles". The model requires the following input parameters: $R_{P}, R_{S}, R_{E}, V, G, Q$ for predicting the foam volumes.

Primary bubble radius is given by $R_{P}$, Secondary bubble radius is given by $R_{S}$, the antifoam emulsion droplet radius is given by $R_{E}, V$ stands for the total volume of liquid phase, $G$ stands for the volume fraction of gas in the liquid phase and $Q$ stands for the volumetric flow of gas into the cylinder. According to the literature[1], the model uses the values of the input parameters described above to calculate certain quantities eventually leading to the calculation of the number of antifoam emulsion $\operatorname{droplets}(\bar{\delta})$ and

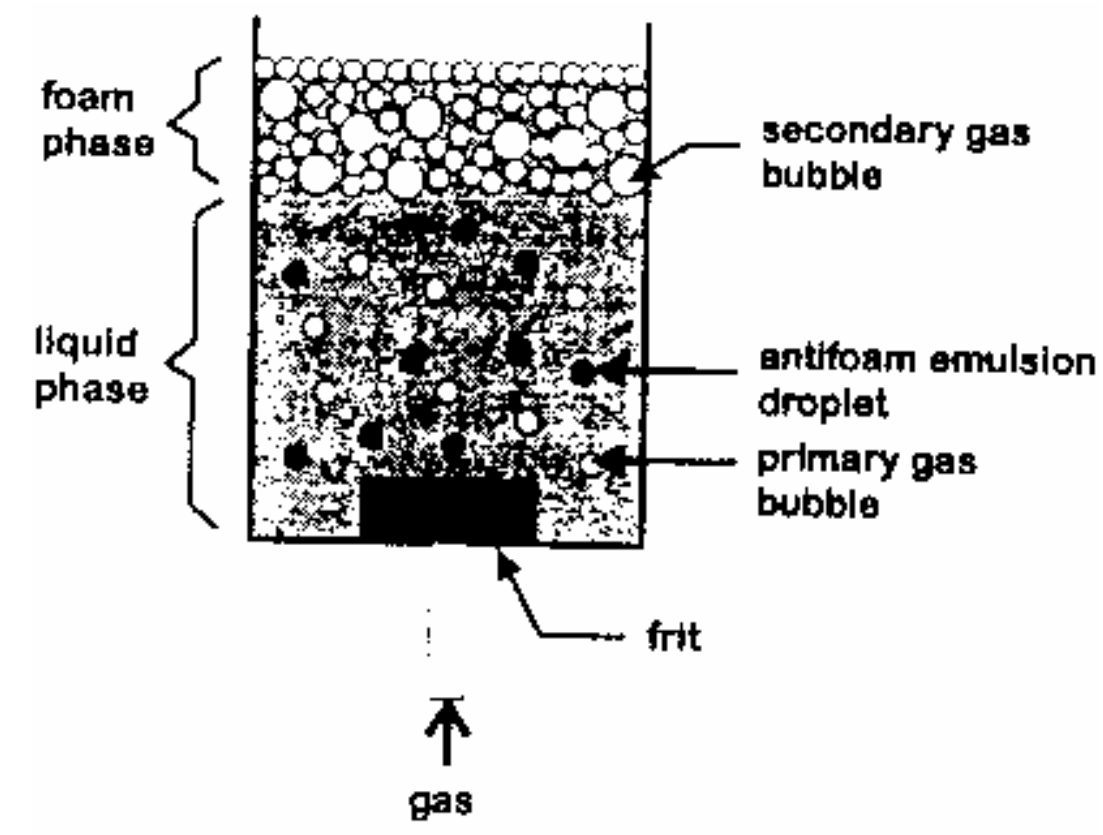

Figure 269 - Schematic Diagram showing the different elements of the Model

the rate of foam rise or fall given by $S(t)$. Once $S(t)$ and $\delta$ are calculated out, the value for $S(t)$ is substituted in the integral $\int S(t) d t$ and integrated for the time period required to get the foam volumes for different times(t). The time period chosen for doing the integrations will be explained in the later portion of this report. The quantities that are calculated and the different equations involved and the methodology for doing the model calculations are outlined as follows:

The number concentration of primary bubbles in the liquid phase is given by

$$
B=3 G / 4 \Pi R P^{3}
$$

Once $B$ is calculated, utilizing the input parameters $R_{P}, R_{S}, V, g$ which is the total number of groups in the liquid phase can be calculated. $g$ is given by

$$
g=R_{P}{ }^{3} B V / R_{S}{ }^{3}
$$


Alternately $\mathrm{g}$ can be interpreted as $\mathrm{g}=$ [number of primary bubbles/the number of primary bubbles required to produce a secondary bubble]. The concentration of antifoam emulsion droplets at time $t$ is given by

$$
E(t)=E_{o} \exp \left(-K_{s} f B t\right)
$$

where $E_{0}=$ initial antifoam concentration, Factor $K_{S}=\left(R_{P}+R_{E}\right)\left[\left(1 / R_{P}\right)+\left(1 / R_{E}\right)\right] 2 k T / 3 \eta$, where $T=$ temperature, $k=$ Boltzmann constant, $\dot{\eta}=$ viscosity of the antifoam, $f=$ coagulation efficiency factor cited in the literature[1](a value of 20,000 has been cited).

Thus after the calculation of the factor $\mathrm{K}_{\mathrm{s}}$ from model input information and run operating conditions and the choosing of a suitable value for the adjustable factor $f$, the concentration of antifoam emulsion droplets $E(t)$ can be determined for various times $(t)$. The calculation of the initial antifoam concentration $E_{0}$ from existing antifoam injection data will be explained later in the report. The average residence time of bubbles in the liquid phase, $(\mathrm{z})$ is given by

$$
\mathrm{z}=\mathrm{GV} / \mathrm{Q}
$$

The $z$ value determined thus from the model inputs $G, V, Q$ goes into the calculation of the number of antifoam emulsion droplets $(\delta)$ that heterocoagulate with the primary bubbles.

The number of antifoam emulsion droplets $\delta$ according to literature, is given by

$$
\delta=[E(t-z)-E(t)] V
$$

$E(t-z)$ is basically the antifoam emulsion concentration at time (t-z) and can be determined by replacing $t$ by (t-z) in the expression for $E(t)$ outlined earlier. Hence $E(t-z)$ is given by $E(t-z)=E_{0} \exp \left[-K_{s}\right.$ $\mathrm{fB}(\mathrm{t}-\mathrm{z})]$ where $E_{0}=$ initial antifoam concentration as before. After the successful calculation of $\delta$, utilizing the value of $g$ determined previously, the rate of foam rise or fall, $S(t)$ can be calculated as

$$
S(t)=[1-1 / g]^{\delta}
$$

The foam volume $\mathrm{V}(\mathrm{t})$ is given by $\mathrm{V}(\mathrm{t})=\int \mathrm{S}(\mathrm{t}) \mathrm{dt}$ integrated for the particular time period. The choice for the limits of the integral evaluated will be explained in the latter portion of the report. Thus, as can be seen, the model tries to predict what the foam volume is going to be at different times at different run conditions. The following flowchart explains the sequence in which the different quantities are calculated leading to the final determination of foam volumes for various times ( $\mathrm{t})$ :

\section{LITERATURE CONSULTED:}

[1] "A model of foam growth in the presence of antifoam emulsion" by Robert Pelton, 1996. 
[2] "A theory for foam growth kinetics in the presence of antifoam emulsion" by R.H.Pelton, E.D.Goddard, 1986.

[3] "Foams: theory and industrial applications" by J.J.Bikerman, Reinhold Publishing Corporation, 1953.

[4] "Identification of crude oil components responsible for foaming" by Callaghan et al., Society of Petroleum Engineers of AIME, (Paper) SPE, Jul 18, 1983.

[5] "Conditions for foam generation in homogeneous porous media" by Miller et al., SPE paper, April 2002.

[6] "Foam control methods in delayed cokers" by Kremer et al., Refining, August 2002.

[7] "Recent developments in the understanding of foam generation and stability" by P.R.Garrett, Chemical Engineering Science, v 48 n 2, Jan 1993, 367-392.

[8] Internet resources: www.jechura.com. 


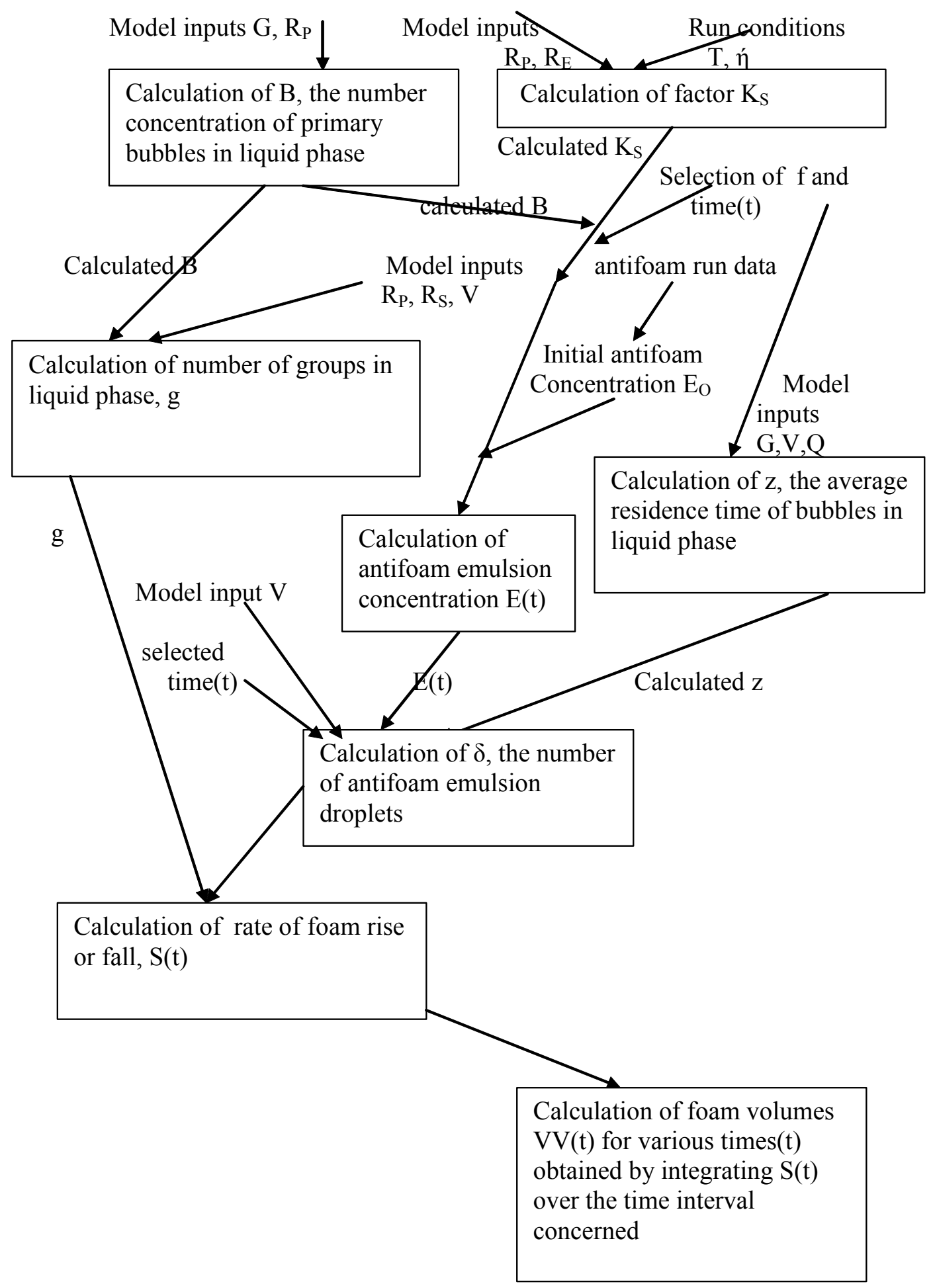

Figure 270 - Flowchart showing the sequence of the model calculations 


\section{Application of Pelton's Model to the Delayed Coking Project}

For the runs that produced shot coke, the Bikermans correlation [3] was used to determine primary bubble radius $R_{P}$ whereas for the sponge coke making runs, $R_{P}$ was chosen to be equal to the smallest void size that could be seen through the coke particle scans available for the run. The approximation for the primary bubble radius for the sponge and mixed morphology cases was chosen in the absence of any available experimental data on primary bubble radius. For mixed morphology of coke the coke particle scans were chosen to determine the primary bubble radius and the same technique that was applied for the sponge coke cases was applied to them. The secondary bubble radius $\left(R_{s}\right)$ is 10 times the primary bubble radius as literature suggests. A table is appended within the report that lists the values of the different input parameters for Pelton's model for the different runs.

The other input parameters were kept the same, that is, Antifoam emulsion droplet radius was $R_{E}$, the total volume of liquid phase was $V$ and the volumetric flow of gas into the cylinder was given by $Q$. The calculation of the parameter $\mathrm{G}$ is explained below. As literature suggests, the coagulation efficiency factor for antifoams $\mathrm{f}$, as explained earlier $=20,000$ for all the runs. The choice in the determination of the input parameters $\mathrm{V}$ and $\mathrm{G}$ was dictated by Pelton's Model conceptualization as explained in Figure 269.

Antifoam radius $\left(R_{E}\right)$ was assumed to be $3 \mu \mathrm{m}$ or $9.84^{*} 10^{-6} \mathrm{ft}$, which was a realistic value for the radius as suggested in literature[1].

The total volume of liquid phase $(\mathrm{V})$ was taken as the volume of the bubbly liquid layer that was produced on saturation. It was observed that the volume of the liquid layer does reach a saturation (becomes constant) after some time as shown in Figure 271 for the PET 2 resid. 


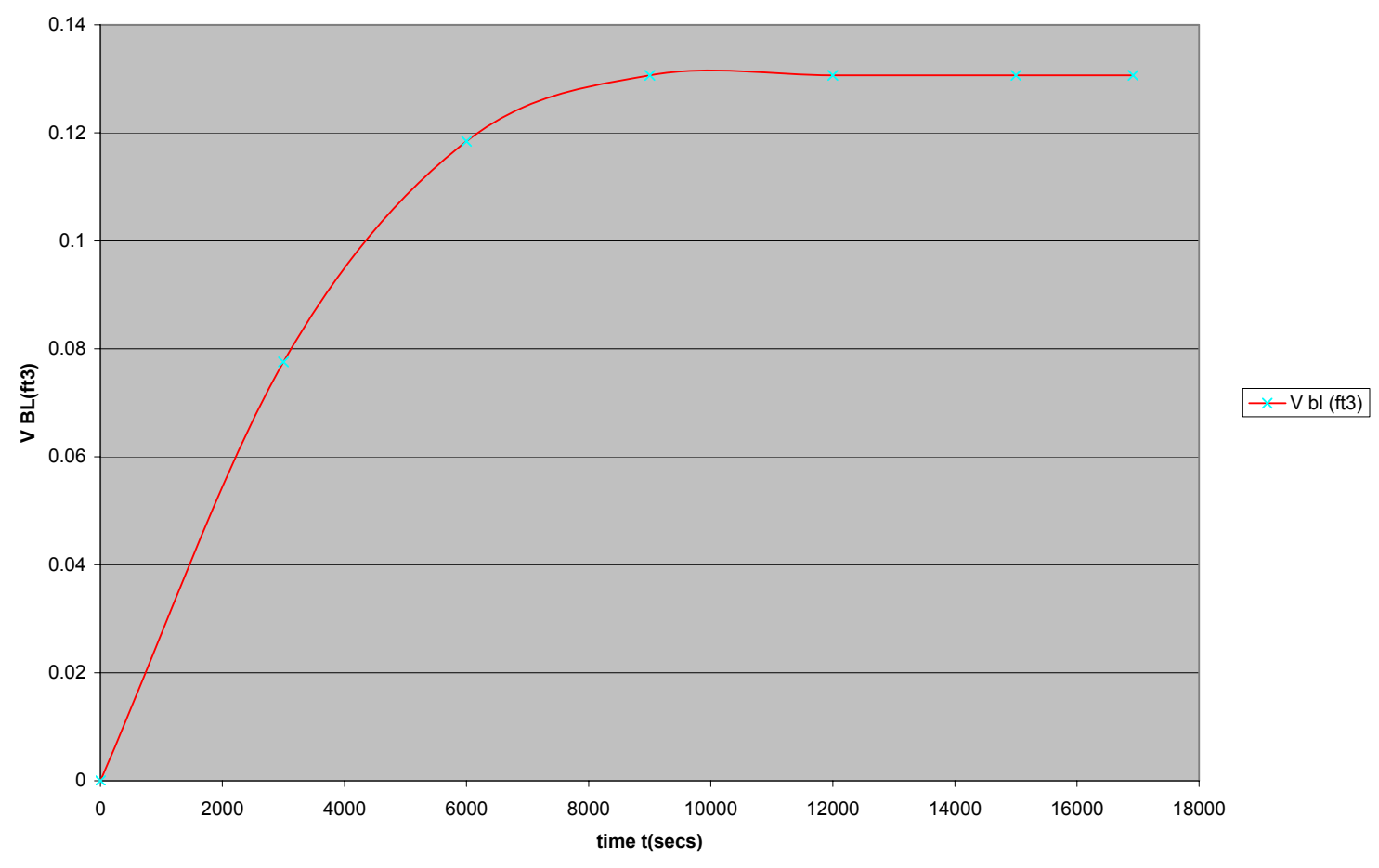

Figure 271 - Constant volume of liquid layer after 150 mins for PET 2

The parameter $(G)=$ [volume of foam produced at saturation stage /total volume of the liquid layer at that stage $(\mathrm{V})] . \mathrm{V}$ is determined as explained earlier. The volume of foam at saturation stage was determined from the foam height measured at saturation stage multiplied by the area of the coke drum.

Also $Q=$ the volumetric flow of gas into the cylinder. Now this was directly determined through the Exxonmobil idea of performing HYSYS simulation by taking in the liquid and the gas product streams for the particular run using a mixer and obtaining the vapor flowrate as the outlet stream flow rate out of that simulation. Utilizing the molecular weight of the vapors coming out (obtained through HYSYS)and the run operating conditions and using the ideal gas equation of state, $Q$ was calculated.

From antifoam (AF) data obtained from Baker Petrolite, $\dot{\eta}=84.676 \mathrm{~kg} /(\mathrm{m})(\mathrm{sec})$, Specific gravity of antifoam $=0.973$,

Here T=temperature for CIT 9 run $=755.22 \mathrm{~K}(900 \mathrm{~F}$ )as obtained from the yield sheets for CIT 9 . Also antifoam concentration for CIT 9 as obtained from CIT 9 antifoam data $=30 \mathrm{cc}$ antifoam $/ 100 \mathrm{cc}$ of solution and total antifoam used $=1.56 \mathrm{cc}$. Hence total $\mathrm{AF}$ used amount $=1.56$ (Specific gravity of AF) $=$ $1.56(0.973)=1.517$ grams AF. Also density of AF at $60 \mathrm{~F}$ from Baker Petrolite data $=60.71 \mathrm{lbs} / \mathrm{ft}^{3}$. Hence, utilizing the density of the antifoam and the amount of antifoam injected or used, the initial antifoam concentration can be calculated and is given by $\mathrm{E}_{0}=60.71 /(1.517 / 453.6)=181441 / \mathrm{ft} 3$ for $\mathrm{CIT} 9$.

Thus $B, g, E(t), \delta, S(t), V V(t)$ can all be calculated by the expressions shown earlier. After the calculation of $\delta$ was completed using the Pelton's Model equations described earlier, the foam volumes $\mathrm{V}(\mathrm{t})$ were determined for the various times $\mathrm{t}$ during the run. 
The foam heights for different times during the run were obtained from the Gamma Densitometer scans processed for the respective times. The data for obtaining the different time Gamma scans were obtained from spreadsheets from the Delayed Coking Website. Typically the foam development was around the region $<0.2 \mathrm{gm} / \mathrm{cc}$ in density determined through previous quarterly reports and the bubbly liquid region was around densities $>0.2 \mathrm{gm} / \mathrm{cc}$ and $<0.6 \mathrm{gm} / \mathrm{cc}$.

It was observed during calculation for the various runs with or without antifoam injections that the height of foam and consequently the foam volume increases and decreases during a certain period of time and this period is called the transient state. There is another period during the run preferably towards the ending stage where the foam height and consequently the foam volume is practically constant and this period is called the steady state. The limits of integration used for determination of foam volume integrals in Pelton's model are as follows:

For transient state, upper limit for foam volume integral determination for runs with no antifoam injection $=10 z / t_{c}$, where $t_{c}=$ time for which the foam volumes are calculated and the lower limit $=0$. For steady state for runs with no antifoam injection, upper limit for the integral $=\operatorname{tav}{ }^{*} F V\left(t_{\text {prev }}\right) / t_{\text {prev }}$, where $t_{a v}=\left(t_{1}+t_{2}\right) / 2, t_{1}=$ time for start of steady state, $t_{2}=$ time when the run ends, $t_{\text {prev }}=$ previous time observation just before steady state and $F V\left(t_{\text {prev }}\right)=$ foam volume determined earlier for $t=t_{\text {prev }}$. The lower limit of the integral as usual in this case is 0 . For the upper limit of the integral for runs with antifoam injections for the transient state, the upper limit stays the same $=10 z / t_{c}$ and the lower limit $=0$. For these runs with antifoam effects, for run times during the steady state and at injection time $t_{\text {inj, }}$, the upper limit $=t_{\text {prev }}{ }^{*} F V\left(t_{\text {prev }}\right) / t_{\text {inj }}$ where the terms are as explained previously. The important feature of the Pelton's model is foam volumes slowly rising as time goes on during the run with no antifoam injection and an immediate foam collapse or fall in foam volumes as the antifoam is injected. Antifoam interaction between the foam and the antifoam starts when the antifoam is injected into the system. The antifoam is basically responsible for collapsing the foam after its initial build up. Once the foam volumes are determined, the foam heights(inches) are obtained from the relationship:

Height $=F V^{*} 12 / 0.049$, Where $\mathrm{FV}=$ Foam volumes $\left(\mathrm{ft}^{3}\right)$ determined, $0.049 \mathrm{ft}^{2}=$ area of the coke drum.

\section{Concept of Model 2}

Model 2 is a continuation in the quest of producing a foam model that relates foaming tendencies to resid properties and is long sought by industries. It is the starting phase in the development of one foaming correlation that will predict foam heights for any run at all times during the run. It is basically extending the foam height results of Pelton's Model and attempts to correlate foam heights for various times during the run with important resid properties, run operating conditions of temperature and pressure, coke morphology, coke pore distribution and antifoam effects(if injected). In order to develop this model it was thus necessary to identify the key components of crude oil that do promote foaming and lead to foam growth. The crude oil components that lead to enhanced foam growth or promote the foam formation suggested in the literature[4] are carboxylic acids and phenols with molecular weight less than 400 . Thus it is proposed that the acid number, and nitrogen content (\%)of the resid are going to be the key parameters 
for correlating foam heights with resid properties. Literature also suggests that from the natural surfactant point of view, the asphaltene $\%$ and resin $\%$ are important for foaming. From the morphology aspect that can affect foaming, literature suggests that the contaminant concentrations of nickel and vanadium are relevant for foaming and also the CCR content of the resid. The coke pore size distribution in the foaming model can be accounted by the interstitial velocity which is in turn the superficial velocity divided by the void fraction of the bed. The two other parameters that are being used for developing the correlation are the run operating conditions, temperature and pressure. All the available data from appropriate spreadsheets for the run characteristics and resid key parameters are tabulated in another sheet and foam heights are calculated for various times during the run utilizing the arrived run specific correlation. Foam heights for various times during the run are the necessary output of this model.

The run specific correlation is as follows:

$\mathrm{V} 2=f^{\star} \mathrm{V} 1$

Where $\quad f=\quad\left[\left\{\mathrm{A}+(\mathrm{N} \% / 100)+(\mathrm{CCR} \% / 100)+(\mathrm{ASP} \% / 100)+(\mathrm{AR} \% / 100)+\left(\mathrm{Ni} / 10^{6}\right)+\left(\mathrm{V} / 10^{6}\right)\right\}-\right.$ $(E(t) / B)]\left(Y^{*} Q^{*} \rho^{*} A_{C}\right) /\left(F R^{*} \psi\right)$, where the different terms in the equation are as follows:

V2= Foam volumes(ft3)predicted by Model 2 for various times during the run,

V1= Foam volumes(ft3)determined through Pelton's Model correlations for the run,

$f=$ individual dimensionless correlation factor for Model 2(given by the expression) for the particular run,

$A=$ Acid number,

$\mathrm{N} \%=$ Nitrogen wt $\%$ of feed,

$\mathrm{CCR} \%=\mathrm{CCR}$ wt $\%$ of feed

ASP $\%=$ asphaltene wt $\%$ of feed

$A R \%=$ asphaltic resin wt $\%$ of feed

$\mathrm{Ni}=\mathrm{Ni}$ ppm content of feed

$\mathrm{V}=\mathrm{V}$ ppm content of feed

$E(t) / B=$ ratio determined through Pelton's Model correlations and $E(t)=$ number concentration of antifoam(1/ft3) determined for various times $t$ during the run(calculation details explained earlier in the report)

$Y=$ run specific constant factor

$=[$ Gamma densitometer foam volumes(ft3)at steady state/Model 2 predicted Foam volumes(ft3) at steady state determined through the correlation for $f$ without the run specific constant factor $Y]$ which is as follows:

$V 2=f^{*} V 1$

$f=$

$(\mathrm{E}(\mathrm{t}) / \mathrm{B})]\left(\mathrm{Q}^{*} \rho^{*} \mathrm{~A}_{\mathrm{C}}\right) /\left(\mathrm{FR}{ }^{*} \Psi\right)$

$\left[\left\{\mathrm{A}+(\mathrm{N} \% / 100)+(\mathrm{CCR} \% / 100)+(\mathrm{ASP} \% / 100)+(\mathrm{AR} \% / 100)+\left(\mathrm{Ni} / 10^{6}\right)+\left(\mathrm{V} / 10^{6}\right)\right\}-\right.$

$\mathrm{Q}=$ Pelton's model run operating conditions dependent input parameter explained earlier in the report

resids)

$\rho=$ density of the feed(which is obtained through the API information listed for the different

$A_{c}=$ area of the coke drum

$\mathrm{FR}=$ feed rate(available through the spreadsheets in the Delayed Coking Website for the runs investigated)

$\Psi=$ void fraction of the bed $=1-\left\{V_{T} /\left(V_{G}+V_{L}+V_{C}\right)\right\}$,

Where $V_{T}=$ total volume of the coke drum,

$V_{G}, V_{L}, V_{C}$ are the volumes of gas, liquids and coke produced for the run obtained through correlations suggested in literature. The different feedstock properties are also listed and available through 
the Delayed Coking Website. The correlation for $f$ has several terms with positive sign attached and the antifoam effect with a negative sign. The signs for the terms were chosen on the basis of their potential impact on the foam volumes and the respective impacts on foaming of the different terms in the equation for $f$ were all checked through available literature. As for example the antifoam effect will gradually diminish the foam volumes and hence the negative sign in the antifoam term in the correlation for $\mathrm{f}$. Once the foam volumes for Model 2 are determined, the foam heights(inches) are obtained from the relationship:

Height $=\mathrm{FV}^{*} 12 / 0.049$,

Where $\mathrm{FV}=$ Foam volumes $\left(\mathrm{ft}^{3}\right)$ determined, $0.049 \mathrm{ft}^{2}=$ area of the coke drum.

The final correlation for Model 2 takes the shape:

$\mathrm{H} 2=\mathrm{f}^{*} \mathrm{H} 1$,

Where $\mathrm{H} 2=$ Model 2 predicted foam heights(inches)determined,

$\mathrm{H} 1=$ Pelton's Model predicted foam heights(inches)determined.

$\mathrm{f}=$ same individual correlation factor for Model 2 expressed earlier.

The current correlation for the foaming model is a good starting point taking into account the various factors that different literature describes as having a potential impact on foam development and collapse and is in good agreement with the Gamma densitometer foam heights determined.

\section{Results Attained Using Model 2 and Comparison with Pelton's Model and Gamma Densitometer Findings}

Using the mathematical relationship described earlier, the individual run specific correlations for Model 2 were determined. Once the correlations for the individual runs were determined the foam height results for the various times during the run were compared with the results with Pelton's Model and the foam heights determined earlier through Gamma Densitometer findings and adjusted run specific correlations were attained.

One of the run specific comparison plots comparing adjusted Model 2 foam heights with Pelton's Model and Gamma Densitometer foam heights is shown in Figure 272 and Figure 273. 


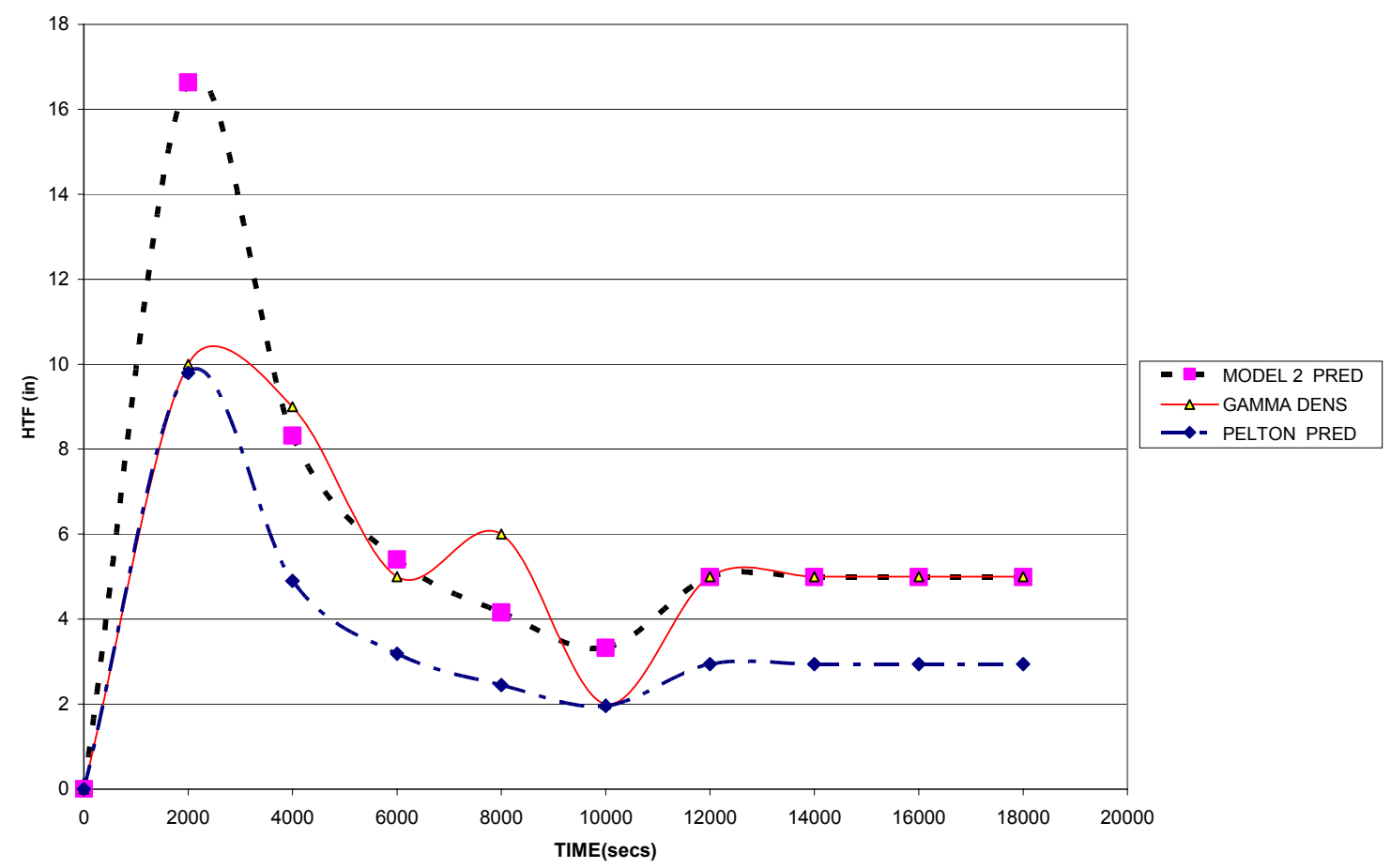

Figure 272 - Foam height comparisons done with the Models and Gamma Densitometer findings for CHEV 3 run(here the y axis represents foam heights and the x-axis, time during the run foam heights are calculated)

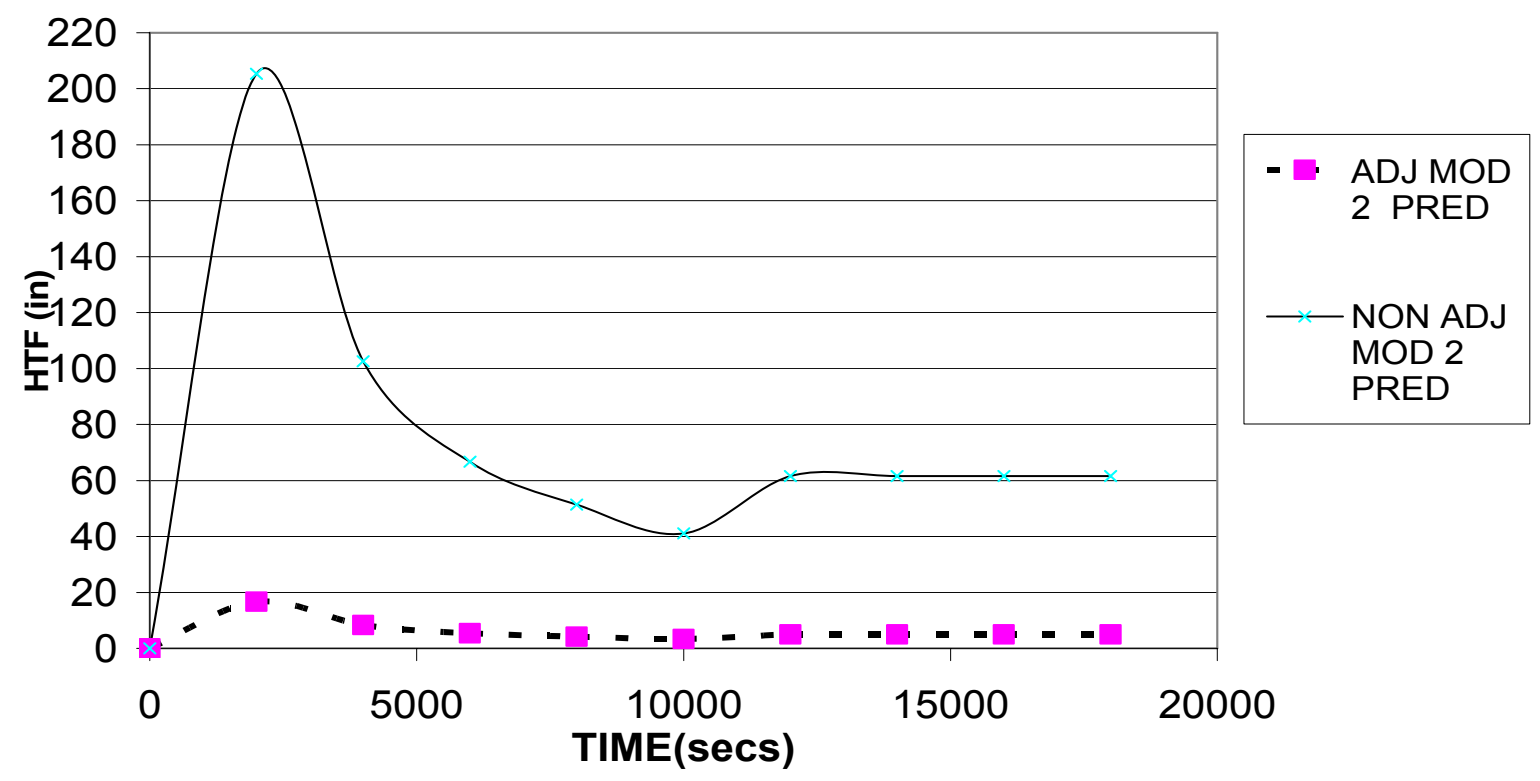

Figure 273 - Foam height comparisons done with the Model 2 Adjusted and Non adjusted for CHEV 3 run (here the $y$ axis represents foam heights and the $x$-axis, time during the run foam heights are calculated) 


\section{General Principle of Working for the Model}

The salient features of the model developed from Pelton's model are:

1. The model predicts foam heights for various times during a pilot unit run and can also be used to calculate the same for the resids at refinery conditions.

2. The model can predict foam heights in the absence of any antifoam and also predict what the foam heights are going to be after an antifoam injection.

3. The model accounts for the important driving forces behind foaming described in literature with a neat correlation involving feedstock properties that are relevant to foaming, feedrate, antifoam effects(if injected) and run specific operating conditions of temperature and pressure.

The basic inputs for the model are given by:

- $\mathrm{R}_{\mathrm{P}}$, the primary bubble radius.

- $\mathrm{R}_{\mathrm{S}}$, the secondary bubble radius.

- $\mathrm{R}_{\mathrm{E}}$, the antifoam radius.

- $\mathrm{V}$, the total volume of liquid phase.

- $G$, gas volume fraction in the liquid phase.

- $Q$, volumetric flowrate of vapors leaving.

The auxiliary inputs that the model requires are as follows:

- Temperature of the run

- Pressure

- Feedrate

- The antifoam coagulation efficiency factor, $f$

- Times(t) for which the foam heights have to be determined.

- Antifoam used amount (if used at all)

- Viscosity of the feedstock.

- Feedstock property data namely,

$\mathrm{AR}=$ Asphaltic resin $\mathrm{Wt} \%$ of the resid, $\mathrm{GO}=$ Gas oil Wt $\%$ of the resid, $\mathrm{N}=$ Nitrogen $\mathrm{Wt} \%$ of the resid, $\mathrm{ASP}=\mathrm{Asphaltene} \mathrm{Wt} \%$ and $\mathrm{Si}$ and Fe are the solid metal content of the resid in ppm.

As can be seen, foam heights for various times during the run(currently the model predicts foam heights at a time interval of 9 mins)are the output of the model. The model calculations were primarily done on Excel spreadsheets with HYSYS used as required .

\section{Important Updates in Calculation of Foam Heights with the Model}

For the pilot unit, the primary bubble radius $R_{P}$ was chosen to be equal to the smallest void size that could be measured through the coke particle photos or bottom of the coke drum actual coke samples available for the run. This approximation for the primary bubble radius was chosen in the absence of any available experimental data on primary bubble radius. The secondary bubble radius ( $\left.R_{S}\right)$ is 10 times the primary bubble radius as literature suggests. For the resids at refinery conditions, the Mercury injection pore throat size histograms were utilized to compute the weighted mean from the distributions in the micro and macro levels to obtain the values of $R_{P}$ and $R_{S}$ respectively. 
The total volume of liquid phase (V) was taken as the volume of the bubbly liquid layer that comes out from a correlation with run operating temperature, pressure and feed rate. The correlation that was obtained through regression techniques in Excel is as follows for the resids at refinery conditions:

$$
V=-2.657 T+20.633 P+0.0019(T r \times F R)
$$

where $\mathrm{V}$ is expressed in $\mathrm{ft}^{3}$, $\mathrm{T}$ is temperature expressed in degrees $\mathrm{F}, \mathrm{P}$ is pressure expressed in psig, $\mathrm{Tr}$ is the total run time in secs, FR is the feed rate in $\mathrm{lbs} / \mathrm{sec}$.

For the pilot unit, the expression for $\mathrm{V}$ obtained earlier for the resids at refinery conditions was scaled down by a factor 173716.19 and finally the magnitude was considered to get the expression for $\mathrm{V}$ which is as follows:

$$
V=\left|\left(-1.53 \times 10^{-5 T}\right)+\left(1.19 \times 10^{-4} \mathrm{P}\right)+\left(1.094 \times 10^{-8} \mathrm{Tr} \times \mathrm{FR}\right)\right|
$$

where $\mathrm{V}$ is expressed in $\mathrm{ft}^{3}, \mathrm{~T}$ is temperature expressed in degrees $\mathrm{F}, \mathrm{P}$ is pressure expressed in psig, $\mathrm{Tr}$ is the total run time in secs, FR is the feed rate in $\mathrm{lbs} / \mathrm{sec}$.

The scale down factor of 173716.9 comes out by simply taking the ratio of average refinery coke drum volume to pilot unit coke drum volume.

The parameter $(G)$ is given by the expression:

$$
\mathrm{G}=1-\left(\rho_{\mathrm{BBL}} / \rho_{\mathrm{F}}\right)
$$

where $\rho_{\mathrm{BBL}}=$ density of the bubbly liquid layer based on Gamma Scan densities for each run and $\rho_{F}=$ density of the feed (readily available from the API information for the different feedstocks).

The calculation procedure for the input parameter $Q$ remains the same as in previous report.

The foam volume change $\left(\mathrm{ft}^{3}\right)$ for each 9 min time span during a run $\Delta \mathrm{FV}$ is given by:

$$
\Delta F V=5 V_{t} Q(1-1 / g)^{\delta} A^{*}\left(e^{0.488 S V}\right) A_{c t}\left(\Delta t^{*}\right)^{2} V^{2}(t-z)(F P F)^{2}
$$

The relationship was attained through a physical understanding of foam behavior and keeping in mind the dimensional consistency of the equation on both sides. In the equation, $V_{t}$ is the total coke drum volume $\left(\mathrm{ft}^{3}\right)$,

$\Delta t^{*}=$ average time interval in secs, at which the foam height calculations were done

$=270$ secs for each run,

$A^{*}=8 \times 10^{-6}$,

$A_{C}=$ area of the coke drum $\left(\mathrm{ft}^{2}\right)$,

$t_{R}=$ total run time in secs,

SV in the exponential expression = superficial velocity of vapors(ft/sec)at drum inlet,

FPF is the foam promoting factor for each resid that is calculated by the expression given by:

$$
F P F=(A R / 100)(G O / 100)(N / 100) /(A S P / 100)(S i+F e) / 1000000
$$

where $A R=$ Asphaltic Resin $\mathrm{Wt} \%$ of the resid, 
$\mathrm{GO}=$ Gas oil Wt $\%$ of the resid,

$\mathrm{N}=$ Nitrogen $\mathrm{W} t \%$ of the resid,

$\mathrm{ASP}=$ Asphaltene $\mathrm{Wt} \%$

and $\mathrm{Si}$ and $\mathrm{Fe}$ are the solid metal content of the resid in ppm.

The respective feedstock information are obtained from readily available feedstock data for each resid. The FPF factor is dimensionless as a result of incorporating weight fractions and was built on basis of a famous mathematical Law of Joint Variations which goes as follows:

If $x$ directly varies with $y$ when $z$ is constant and if $x$ also directly varies with $1 / z$ when $y$ is constant then the product $x^{2}$ directly varies with $y / z$.

The implication of this rule is that factors that contribute to foam heights can be grouped together and inserted in the numerator of the factor FPF and factors that will deplete foam heights will go into the denominator of the factor FPF provided obviously that other factors that impact foam heights are constant. By other factors the factors that are referred are run operating temperature, pressure and feedrate and run specific antifoam effects(if injected at all). The different terms in the right hand side of the equation for foam volume change $(\Delta \mathrm{FV})$ were grouped together utilizing the law of Joint Variations. The term

$\mathrm{Q}(1-1 / \mathrm{g})^{\delta}$ comes directly out of Pelton's model correlations and is directly related to foam volume change whereas the other terms are accumulated in the following fashion:

The foam volume change $(\Delta \mathrm{FV})$ on basis of a physical understanding of foam behavior was considered to be mathematically directly related to some fraction of the total coke drum volume and also directly proportional to the probability for foam development=

$(1-1 / \mathrm{g})$ described by Pelton. $\Delta \mathrm{FV}$ is also inversely proportional to the total volume of liquid phase $(\mathrm{V})$ and to a particular cofactor of total residence time[(t-z)term in the right hand side of the equation] of a bubble leading to foam development. That particular factor comes out from the feedstock FPF factor. Thus utilizing the law of joint variations,

$$
\Delta F V=5 V_{t} Q(1-1 / g)^{\delta}(1-1 / g)\left(\Delta t^{*}\right)^{2} / V(t-z)(F P F)^{2}
$$

Now the algebraic quantity $V(1-1 / g) / A_{c} t_{R}$ represents physically the total liquid drum velocity(ft/sec)contributing to foam development. This quantity for forty eight pilot

unit runs was plotted in Excel with superficial velocities SV(ft/sec) at drum inlet computed for the runs and by utilizing the mathematical tools of Excel, the relationship attained for the maximum $R^{2}$ value was:

where, $A^{*}=8 \times 10^{-6}$.

$$
\mathrm{V}(1-1 / \mathrm{g}) / \mathrm{Act}_{\mathrm{C}}=\mathrm{A}^{*} \mathrm{e}^{0.488 \mathrm{SV}}
$$

from this relation, $(1-1 / g)=A^{*} A_{c} t_{R} e^{0.488 S V} / \mathrm{V}$ and replacing this expression for $(1-1 / g)$ in Equation(11),

$$
\Delta F V=5 V_{t} Q(1-1 / g)^{\delta} A^{*}\left(e^{0.488 S V}\right) A_{c t}\left(\Delta t^{*}\right)^{2} V^{2}(t-z)(F P F)^{2}
$$

which is Equation (10) discussed earlier. The factor 5 in the right hand side of the relation helps in obtaining foam height results in the vicinity of results attained through Gamma scans.

Once the foam volume changes are determined, the change in foam heights(inches) for each of the 9 min time spans are obtained from the relationship: 
where $\Delta F V=$ foam volume change $\left(\mathrm{ft}^{3}\right)$ determined, $0.049 \mathrm{ft}^{2}=$ area of the coke drum.

A cumulative consequtive summing technique was adopted for determining the foam height values for different times from $\Delta$ foam height for the pilot unit. For antifoam injections, a negative sign was attached for $\Delta$ foam height expression(foam height depletion)shown in Equation(12).

For the foam heights calculated for the resids at refinery conditions, the same antifoam settings like the same initial antifoam number concentration $\left(1 / \mathrm{ft}^{3}\right)$ and continuous injection from start to end were applied to get a prediction of foam heights, bubbly liquid heights and coke heights for various times during the run. The bubbly liquid height comes out from the same correlation for $\mathrm{V}\left(\mathrm{ft}^{3}\right)$ considering the magnitudes of the individual coefficients in the expression for $\mathrm{V}$ and then dividing it by the coke drum area considered for the particular resid run. The drum dimensions for the Citgo resid for refinery conditions was $27 \mathrm{ft}$ diameter, $98 \mathrm{ft}$ height. For the five other resids investigated with refinery conditions, a drum diameter of 30 $\mathrm{ft}$ and height of $80 \mathrm{ft}$ was considered. The correlation for determination of bubbly liquid heights for the resids at refinery conditions is :

$$
H_{B}=[2.657 T+20.633 P+(0.0019 \times t \times F R)] / A_{C C}
$$

where, $\mathrm{H}_{B}=$ height(ft) of bubbly liquids for a particular time $\mathrm{t}(\mathrm{secs})$,

$T=$ temperature expressed in degrees $F$,

$P$ is pressure expressed in psig,

$t$ is the time in secs for which the bubbly liquid heights are predicted,

FR is the feed rate in $\mathrm{lbs} / \mathrm{sec}$,

Acc is the area of the coke drum( $\left.\mathrm{ft}^{2}\right)$ considered for the resid run at refinery conditions.

The coke height predictions for various times during a resid run at refinery conditions were calculated by developing a correlation that describes the coke heights as the sum of mathematical contributions from the feed plus the contribution due to the linear growth rate of coke height(from pilot unit observations). The mathematical contributions were scaled up by suitable numerical coefficients determined through available refinery coke height data to get predictions for the resids at refinery conditions. For example for Citgo, the correlation developed was:

$$
H_{C}=1.1543(x)^{0.1821+4.142(G R) t,}
$$

where, $\mathrm{H}_{\mathrm{C}}=$ coke height(ft) predicted for time $\mathrm{t}(\mathrm{secs})$ for Citgo,

$\mathrm{GR}=$ coke height linear growth rate for $\mathrm{Citgo}(\mathrm{ft} / \mathrm{sec})$,

$t=$ time(secs) for which the coke heights are being predicted,

$$
x=(t \times F R) /\left(\rho_{F} \times A_{C C}\right)
$$

where $\mathrm{t}=$ times(secs),

$\mathrm{FR}=$ feed rate(lbs/sec), $\rho_{F}=$ density of the feed $\left(\mathrm{lbs} / \mathrm{ft}^{3}\right)$, 
Acc is the area of the coke drum $\left(\mathrm{ft}^{2}\right)$ considered for the Citgo run at refinery conditions. As can be seen the dimensions of the algebraic quantity $\mathrm{x}$ is $\mathrm{ft}$. A plot showing the distribution of foam heights, bubbly liquid heights and coke heights for the Citgo resid at refinery conditions has been appended in the results section. Incidentally, the total run time considered for all the resids at refinery conditions was $16 \mathrm{hrs}$ whereas in the case of Marathon, a $12 \mathrm{hr}$ total run time was considered as it was specifically known from the refinery data available.

The foam heights for different times during the pilot unit run were also determined from the Gamma densitometer scans processed for the respective times for comparison purposes. The data for obtaining the different time Gamma scans were obtained from spreadsheets from the Delayed Coking website. Antifoam interaction between the foam and the antifoam starts when the antifoam is injected into the system. The antifoam is basically responsible for collapsing the foam after its initial build up.

\section{Foam Height Results and Comparison for the Pilot Unit}

A pilot unit run specific comparison plot comparing the model and Gamma densitometer foam heights for the first Chevron resid test is shown in Figure 274.

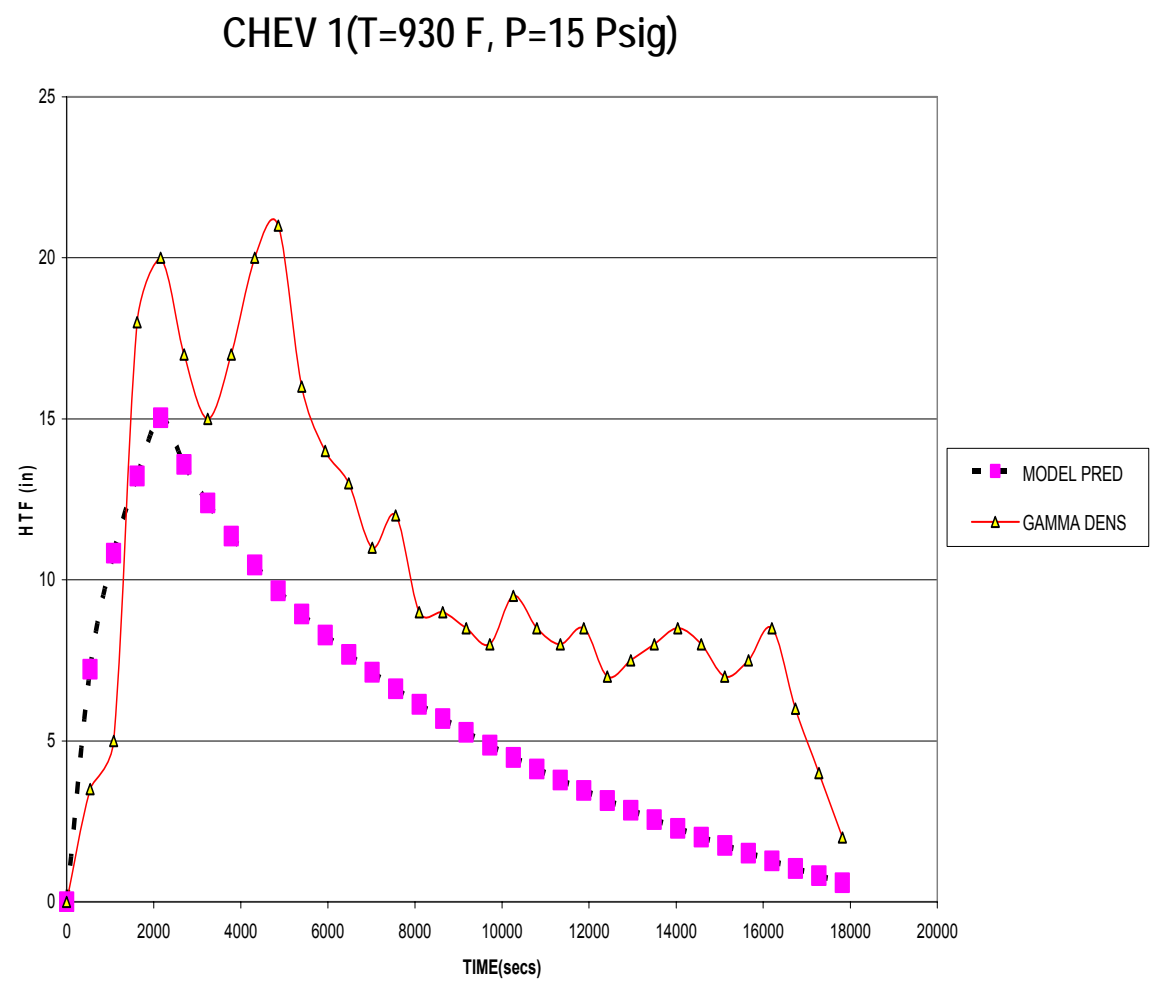

Figure 274 - Foam Height comparisons for different Chevron pilot unit runs (here the y axis represents foam heights in inches and the x-axis, time in secs, during the run foam heights were calculated) 


\section{Conclusions}

At this time, the "first pass" model is capable of predicting foaming trends for the individual pilot unit runs as well as for resids investigated at refinery conditions. This model interrelates the major variables that contribute to foam heights through a physical understanding of upward gas bubble movement in the coke drum and factors that can impede the upward movement when using the model to make predictions.

Higher foam heights are observed for Marathon, Petrobras and Chevron resids, at higher feedrates and at a lower temperature $(900 \mathrm{~F})$ and pressure( $15 \mathrm{psig})$.

While higher foam heights are observed for the Equilon and Citgo resids at higher feedrates and higher pressure(40 psig).

\section{Future Work}

The following work will be completed in order to improve the predictability of the foam model:

- Refine or innovate the existing model correlations as necessary to increase the efficiency of the model.

- Perform the Glass Coker tests as outlined in this report so that the feedstock property effect is investigated thoroughly and quantified accordingly in the prediction of foam heights.

\section{G. QUENCHING MODELS (OVERHEAD \& FEEDLINE)}

\section{Convective Cooling Modeling}

\section{a) Lumped-Heat-Capacity Model}

As already discussed, in the initial stages of the project drum cooling was achieved by flowing nitrogen through the coke bed and letting the drum cool enclosed in the ceramic material or by exposing it to free convection. In order to see how predictable the cooling rates were as a function of time, two models were developed. One model was based on a lumped-heat-capacity method in which the coke bed was assumed to be a lumped mass at a "uniform" initial temperature. Calculation of the Biot number, $B i$, yielded 0.15 which is within the acceptable limits for the method to be applicable - that is $\mathrm{Bi}<0.1$. The lumpedheat-capacity approach involved assuming that the temperature of the coke was only a function of time, thus lacking spatial resolution. This approach simplified the energy balance in the spatial and time domain to an energy balance in the time domain only. Using this simplified analysis the convective heat flux $Q$, from the coke drum to the environment equals the rate of change of internal energy of the coke - that is

$$
h_{\text {air }} A_{\text {surface }}\left(T_{\infty}-T\right)=m_{\text {coke }} C_{P} \frac{d T}{d t} \cong m_{\text {coke }} C_{P} \frac{\Delta T}{\Delta t}
$$

The following assumptions were made: (1) the wall surface temperature is the same as that of the coke bed (2) a given thermocouple reading represents the temperature of the zone it is located in, (3) the 
surface temperature of the drum is constant, (4) the drum wall thickness is negligible, and (5) the external heat transfer coefficient, $h_{\text {air }}$ and $T_{\infty}$ do not change with time.

Once the assumptions were made and the needed data were gathered, the predicted temperatures were calculated using the following equation:

$$
T^{t+\Delta t}=T^{t}+\frac{h_{\text {air }} A_{\text {surface }}\left(T_{\infty}-T^{t}\right)}{m_{\text {coke }} C_{\text {Pcoke }}} \Delta t
$$

The heat capacities estimated for the coke were around $0.5 \mathrm{Btu} /{ }^{\circ} \mathrm{F}-\mathrm{hr}$ for sponge coke and 0.6 $\mathrm{Btu} /{ }^{\circ} \mathrm{F}-\mathrm{hr}$ for shot coke. Such values were in agreement with a few literature values of approximately 0.45 $\mathrm{Btu} / \mathrm{hr} \mathrm{-}^{\circ} \mathrm{F}$. Plotting the predicted temperatures against the measured or real values showed that the method was indeed satisfactory in roughly predicting how a certain coke morphology would cool as a function of time; see Figure 275 below for illustration.

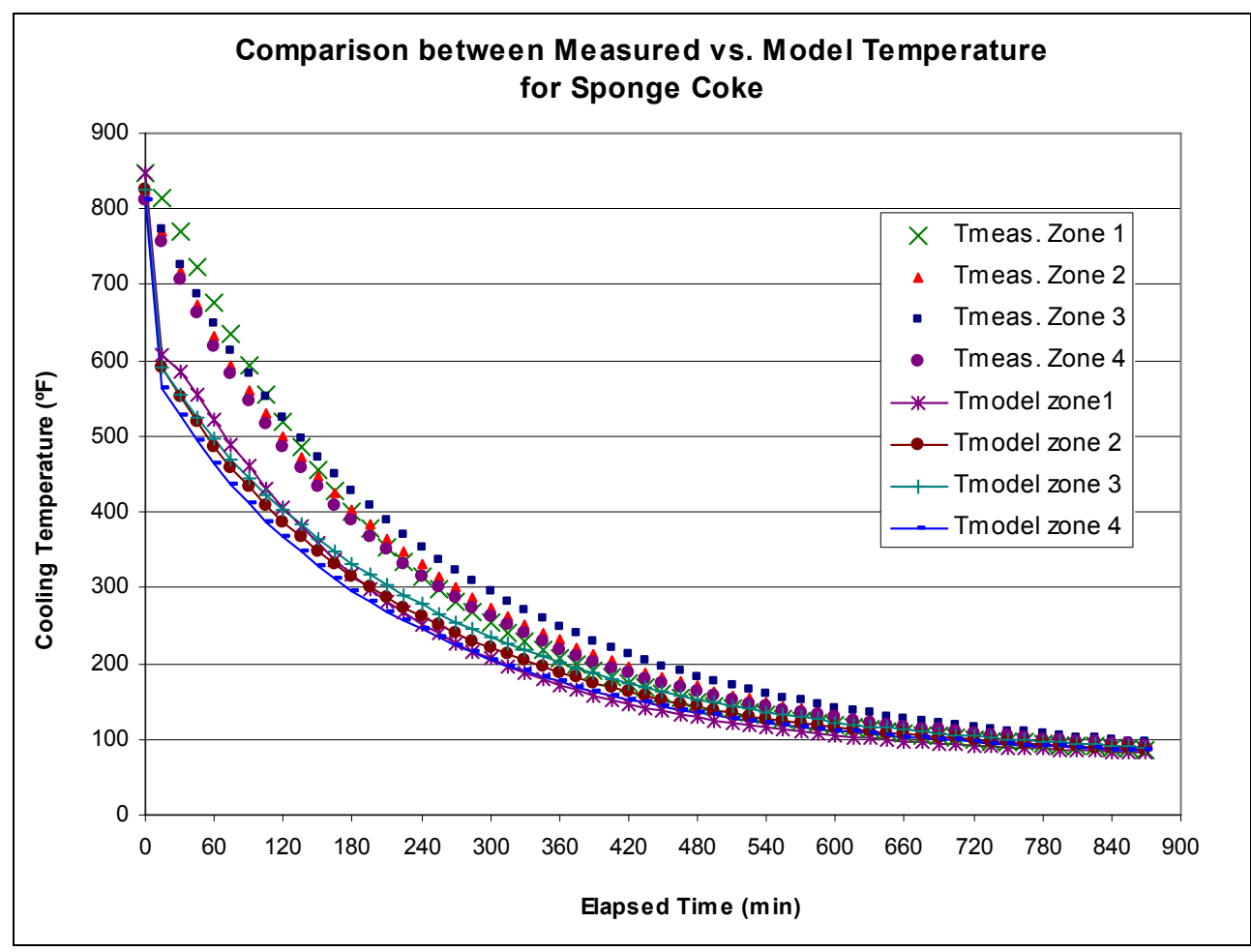

Figure 275 - Comparison between Measured and Predicted Temperature by Using the Lumped-Heat-Capacity Model (MARA 7 PUAF - Sponge Coke)

\section{b) $\underline{\text { Cooling Rate Correlations }}$}

A second way of modeling the cooling rates for the case when the coke bed was cooled with nitrogen and with the furnace door opened was to average the cooling rates of different runs that were operated under very similar conditions and that produced similar coke morphologies and then use a curve fit to model the experimental data. Using this procedure it was found that an exponential curve fit predicts the cooling of the coke bed well. The equations found for sponge and shot coke morphologies are given in the Table 87 below. 
Table 87 - 6 foot Drum Cooling Rate Correlations - Temperature

Sponge Coke (Furnace Door Opened $)=T_{\infty}+\left(T_{\text {oaverage }}-T_{\infty}\right)^{*} \operatorname{Exp}\left(-0.0039^{*} t\right)$

Shot Coke (Furnace Door Opened $)=T_{\infty}+\left(T_{\text {Oaverage }}-T_{\infty}\right)^{*} \operatorname{Exp}\left(-0.0036^{*} t\right)$

where: $T_{\text {0average }}=\frac{\sum_{i=1}^{n} T_{0 i}}{n}$ with $\mathrm{i}=1, \ldots ., \mathrm{n}$ thermocouples inside the coke bed and

$\mathrm{T}_{0 \mathrm{i}}=$ temperature reading from thermocouple $\mathrm{i}$ at $\mathrm{t}=0 \mathrm{~min}$

$T_{\infty}=$ room temperature

For both morphologies the exponential fit seemed to give a fair representation of the temperature of the coke at a specified cooling time. The next two plots show how well the exponential curve fitted the data. 


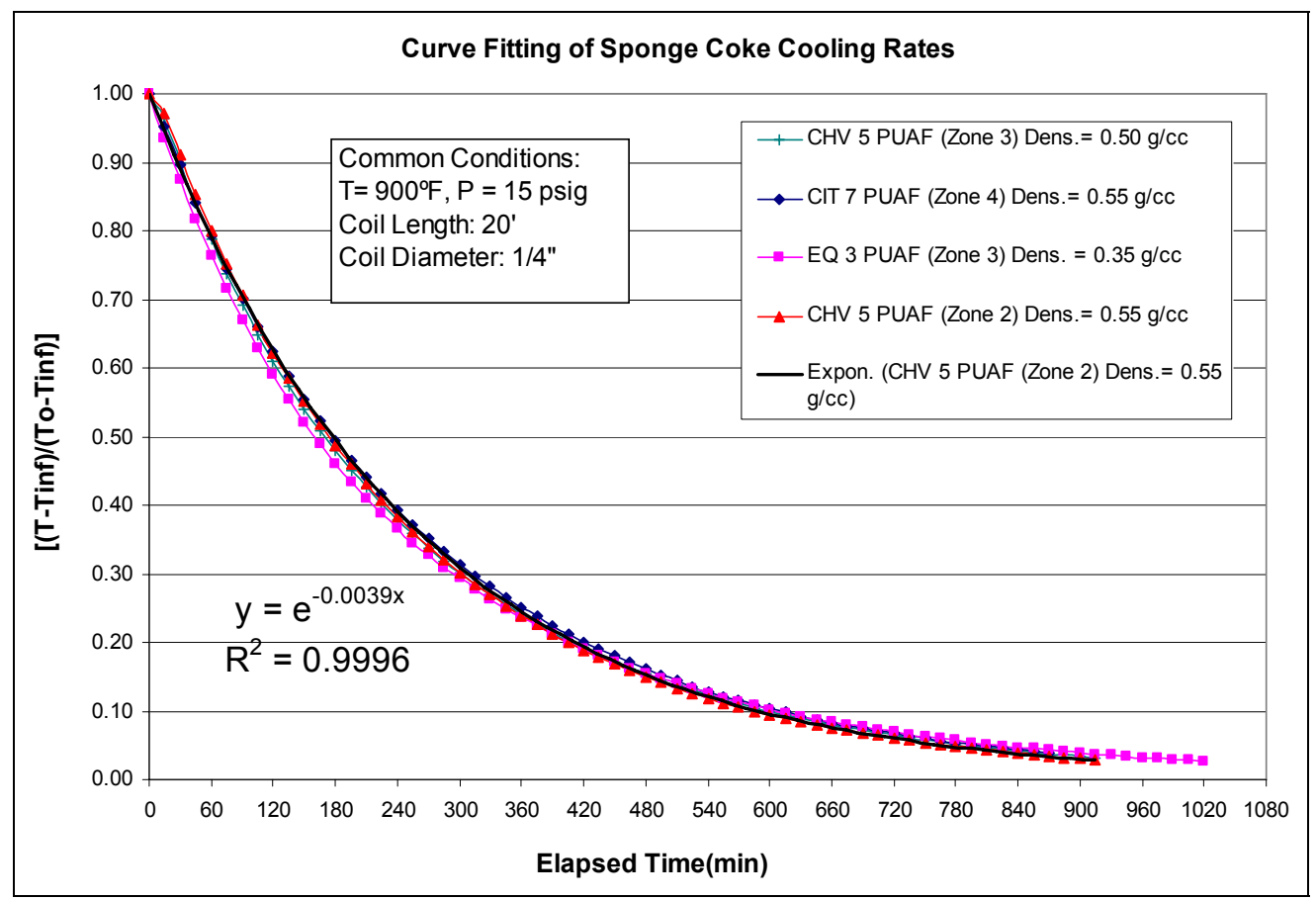

\section{Figure 276 - Individual Resid Cooling Rate Correlation for Sponge Coke}

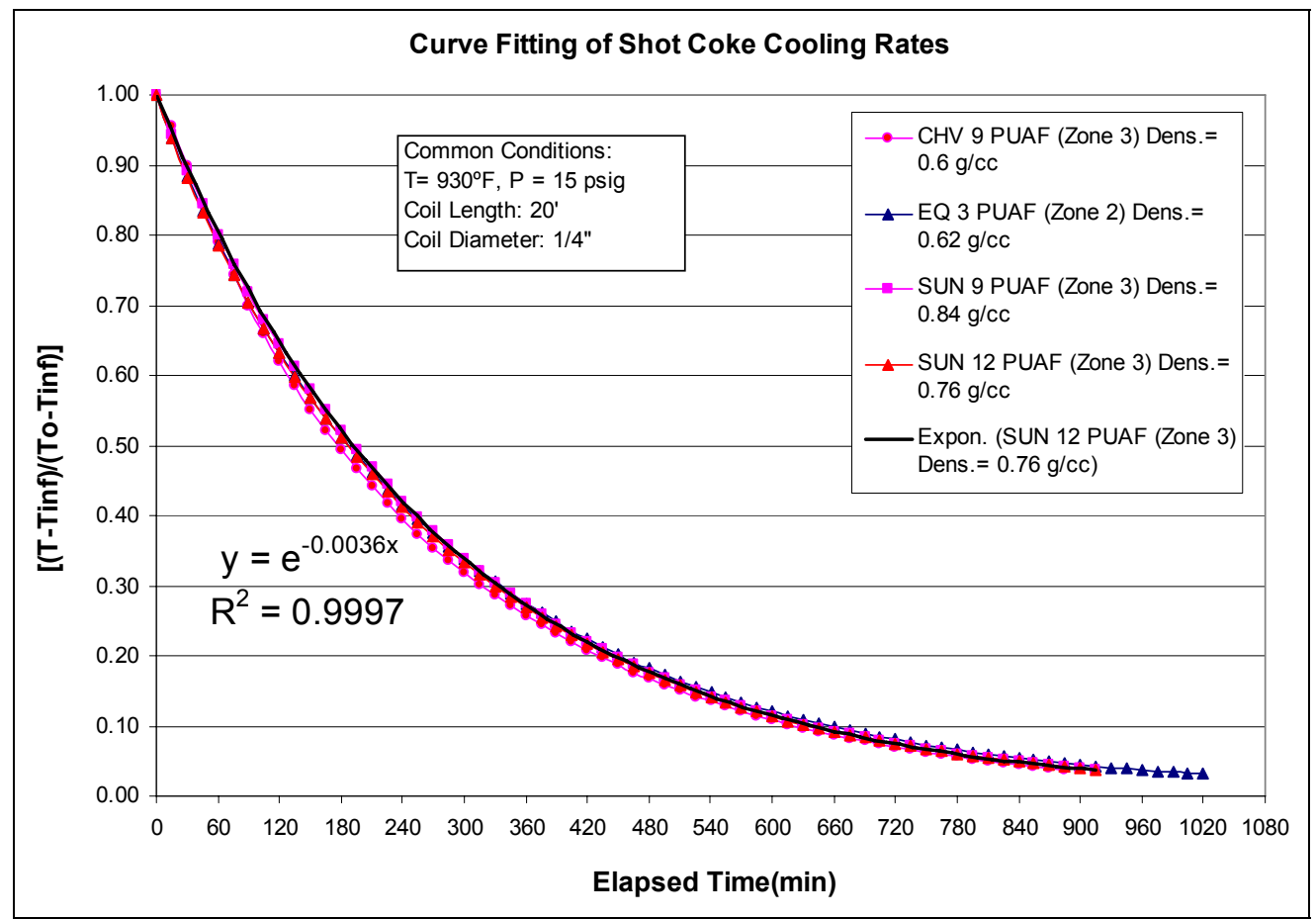

Figure 277 - Individual Resid Cooling Rate Correlation for Shot Coke

\section{Quench Model}


An attempt to correlate the cooling rates of coke, cooled with water, to time of water injection was also made. For this analysis four runs were available; one Chevron run, two Marathon runs, and one Petrobras run. The two Marathon runs produced sponge coke and were operated at $900^{\circ} \mathrm{F}$ and $15 \mathrm{psig}$ or $40 \mathrm{psig}$, respectively. One run produced a fairly uniform-density sponge coke whereas the other run produced sponge coke that varied substantially in density from bottom to top of the drum. The water injection rates and volumes were also different for each run. The Chevron run was operated at $930^{\circ} \mathrm{F}$ and $40 \mathrm{psig}$ and produced shot coke that was very uniform in density. Looking at each individual run showed that during water cooling the cooling rates behave completely different from the ones already discussed.

This data showed that when water is injected in the bottom of the drum the temperature of the bottom thermocouple decreases drastically upon contact with the water. This thermocouple is located at the thick metal piece of the drum and thus the rapid cooling is explained. When water quenching starts, the coke mass is extremely hot and once water comes in contact with it steam is formed and it causes the temperature of the coke located just above to increase slightly before it starts to drop slowly but steadily.

Considering zone by zone, it was observed that the water first percolates through the channels and pores of the coke in one zone until it fills the entire coke mass; by that time the large drop in temperature is seen; after that very little cooling takes place. While water is cooling that zone, since it comes into contact with a very hot coke mass it vaporizes and the vapor rises to the next zone. The vapor initiates the cooling process of the new zone and when water reaches that zone and fills its channels and pores, the temperature again drops abruptly. This phenomenon repeats itself during the time water is being injected until the coke bed is water filled and cold enough that no more steam forms.

For the modeling of these cooling rates an attempt was made to predict how coke cooled as a function of injection time. The model involved dividing the coke bed into one-inch differential elements of coke and performing energy balances on each segment for different possibilities of liquid water or steam entering or leaving the differential element of the coke bed. Since experimental temperature data was only available at some heights in the coke bed, it was necessary to use a fifth order polynomial to predict the temperature at every inch of coke at time $=$ zero for every run that was quenched with water.

The energy balance done on each differential element includes a heat conduction term, a term accounting for the vaporization of water, a term for the heat transfer from water to coke, as well as a term for the time change in energy of the coke. The scope of the model was to duplicate the measured temperatures by using literature values of heat capacity and thermal conductivity of the coke and then to adjust the heat transfer coefficient and coke porosity to best fit the given data.

The energy balance on the coke takes the following form:

$$
\rho C_{p, c} \frac{\partial T_{c}}{\partial t}=\left(h a_{i}\right)\left(T_{w}-T_{c}\right)+k \frac{\partial^{2} T_{c}}{\partial x^{2}}
$$

where $T_{c}$ is the coke temperature, $T_{w}$ is the temperature of the water or steam, $k$ is the thermal conductivity of the coke, $h$ is the convective heat transfer coefficient, $a_{i}$ is the interfacial area per unit volume of the coke bed, $\rho$ is the coke density, and $C_{p, c}$ is the heat capacity of the coke. The energy balance on the water is

$$
-\frac{1}{A} \frac{\partial\left(\dot{m}_{w} \hat{H}_{w}\right)}{\partial x}-\left(h a_{i}\right)\left(T_{w}-T_{c}\right)=\rho_{w} C_{p} \frac{\partial T_{w}}{\partial t}
$$

where $\dot{m}_{w}$ is the mass flow rate of water, $\hat{H}_{w}$ is the heat capacity of the water or steam per unit mass, and $A$ is the cross-sectional area of the coke bed. These coupled equations were solved in an Excel 
spreadsheet, with the additional assumptions that: (1) the coke and water are in thermal equilibrium when liquid water is present (since the heat transfer coefficient is much larger for liquid water than for steam); (2) the accumulation term for the steam is negligible (the water accumulation is non-zero only if $T=\underline{I}_{\text {sat }}$; ; and (3) the porosity, heat capacity and thermal conductivity of coke are uniform throughout the coke bed.

After setting up a routine that calculated the temperatures for each differential element for every one fifth of a minute of water injection, a plot showing the comparison between the model and the measured values was made.

The model developed worked very well in predicting the temperatures as a function of injection time for each zone. Some differences were obviously found as a theoretical model was being used to duplicate measured values. These differences are more than likely a result of assuming the same porosity, same heat capacity, and same thermal conductivity throughout the coke bed in the calculations. To get a more accurate fit to the data, it may be necessary to use different values for these parameters at different coke locations, as the coke bed is not uniform.

Although the coke bed is usually quenched from the bottom in refinery operations, quenching is occasionally done from overhead as an emergency backup, when the bottom inlet becomes plugged. For such cases, it is important to know from a safety standpoint how quickly the bed will cool. Therefore, a model for overhead quenching is of practical importance.

Work is now underway to modify the existing bottom quench model to satisfactorily describe overhead quenching. Overhead quenching is by its nature much more difficult to model than bottom quenching, because the water introduced does not initially flow through the bed, but will penetrate downward some distance into the bed before vaporizing and reversing direction to exit in the overhead line as steam. The key to successfully modeling this situation will be determining a heat transfer coefficient that will predict the rate of vaporization of the water and the rate of cooling of the coke in the top section of the bed. 


\section{Conclusions}

A lumped heat capacity model was developed for the cooling of the coke drum by free convection to the surrounding air with the furnace door open. The heat capacities estimated for the coke were around $0.5 \mathrm{Btu} /{ }^{\circ} \mathrm{F}-\mathrm{hr}$ for sponge coke and $0.6 \mathrm{Btu} /{ }^{\circ} \mathrm{F}-\mathrm{hr}$ for shot coke. These values are in agreement with a few literature values of approximately $0.45 \mathrm{Btu} / \mathrm{hr}-{ }^{-} \mathrm{F}$. Plotting the predicted temperatures against the measured or real values showed that the method was satisfactory in roughly predicting how a certain coke morphology would cool as a function of time.

Convective cooling rates were also correlated by averaging the cooling rates of different runs that were operated under very similar conditions and that produced similar coke morphologies and then using a curve fit to model the experimental data. Using this procedure it was found that an exponential curve fit predicts the cooling of the coke bed well.

A quench model was developed to predict temperature profiles when the coke bed is cooled by flowing water from the bottom. The model divides the coke bed into one-inch segments of coke and performs energy balances over the coke and steam or water on each segment. The model uses literature values of heat capacity and thermal conductivity of the coke and adjusts the heat transfer coefficient and coke porosity to best fit the given data. The model works very well in predicting the temperatures as a function of injection time for each zone. Some slight differences between the model and experimental data are probably due to assuming the same coke properties (porosity, heat capacity, and thermal conductivity) throughout the coke bed.

\section{Future work}

The current working model for bottom quenching will be modified to predict overhead quenching. Key modifications will include an accounting of bed penetration, estimation of heat transfer coefficient, and flow reversal. A few more overhead quenching runs will be made to allow testing of the overhead quench model once its development is complete. The results will be distributed as a topical report.

\section{H. DetaILED HydRocarbon ANALySIS MOdELS}

Detailed liquid analyses conducted on the pilot unit liquids include sulfur analysis, silicon analysis, API gravity, and Detailed Hydrocarbon Analysis (DHA) on the lighter liquids, which includes PIONA and RON analysis.

\section{API gravity}

API gravity for the liquid sub-products was correlated with overhead temperature, pressure, and the micro-carbon residue of the feed. A plot of model vs. experimental API gravity is shown in Figure 278 . Note that API gravity is predicted within $\pm 10 \%$ for nearly all the data. 


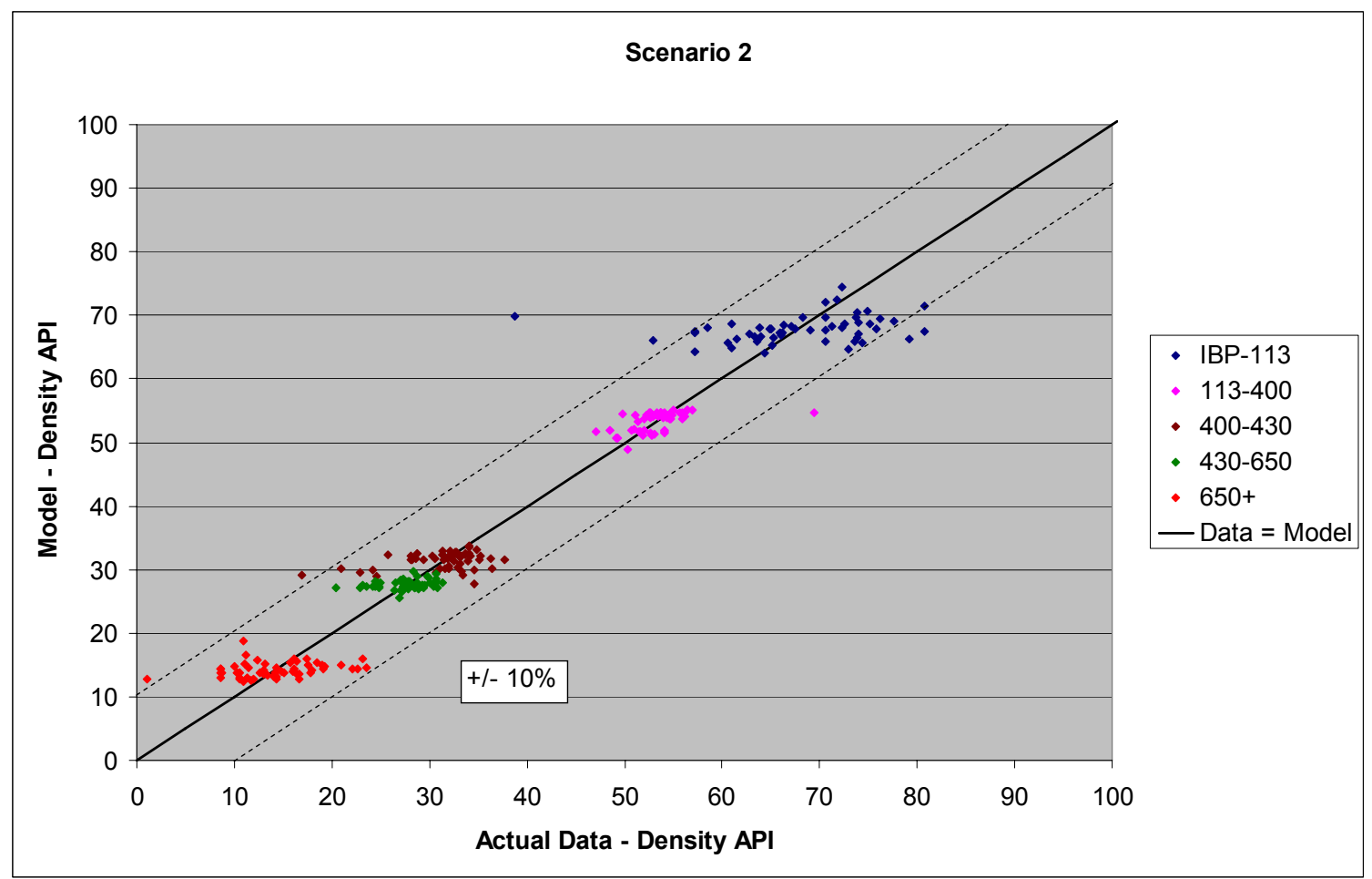

Figure 278 - Actual vs. Predicted API Gravity of Liquid Sub-Products

\section{PIONA correlations}

Paraffin, iso-paraffin, olefin, naphthene, and aromatic content for the IBP-113 ${ }^{\circ} \mathrm{F}, 113-$ $400^{\circ} \mathrm{F}$, and $400-430^{\circ} \mathrm{F}$ cuts were found from DHA using the HP6890a high temperature gas chromatograph. Correlations were produced both for the raw data and for the normalized data (since there was a fair $\%$ of unknowns, especially for the $400-430^{\circ} \mathrm{F}$ cut). It was found however, that normalizing the PIONA numbers did not improve the correlation. Comparisons of the model predictions with experimental data are presented in Figure 279 to Figure 284. 
PIONA Distribution Correlation (Suncor): Total Composition - Unnormalized

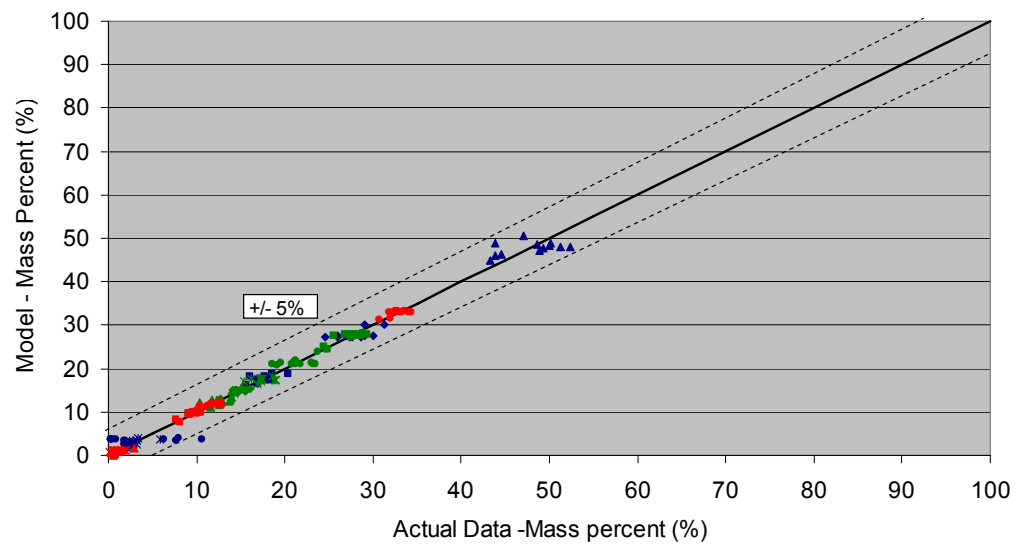

- Paraffin (IBP-113)

- Iso-paraffin (IBP-113)

- Olefin (BP-113)

* Naphthene (IBP-113)

- Aromatics (IBP-113)

- Paraffin (113-400)

- Iso-paraffin (113-400)

- Olefin (113-400)

* Naphthene (113-400)

- Aromatics (113-400)

- Paraffin (400-430)

- Iso-paraffin (400-430)

- Olefin (400-430)

- Aromatics (400-430)

* Naphthene (400-430)

—Data $=$ Model

\section{Figure 279 - Suncor PIONA Distribution Correlation (Un-normalized)}

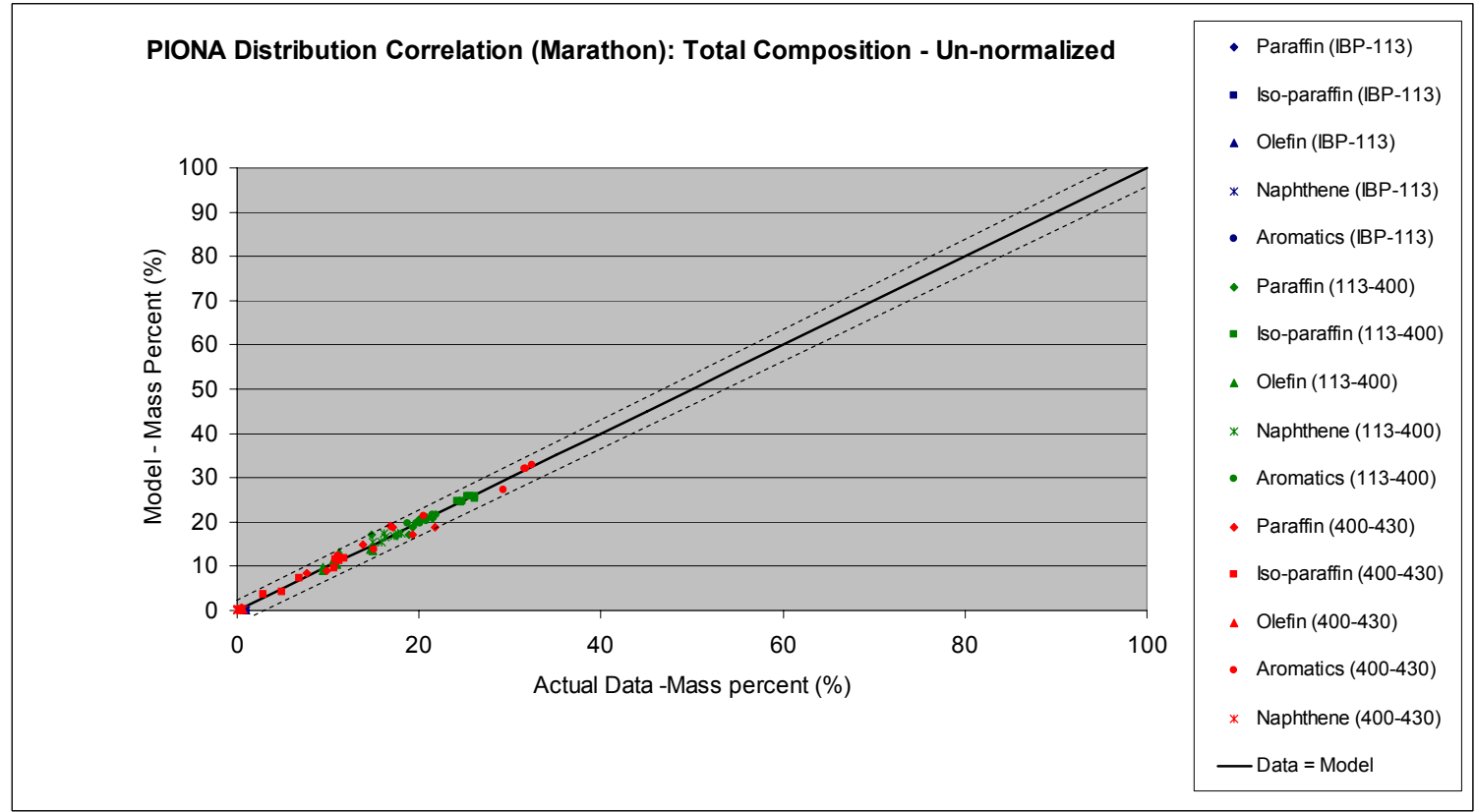

Figure 280 - Marathon PIONA Distribution Correlation (Un-normalized) 


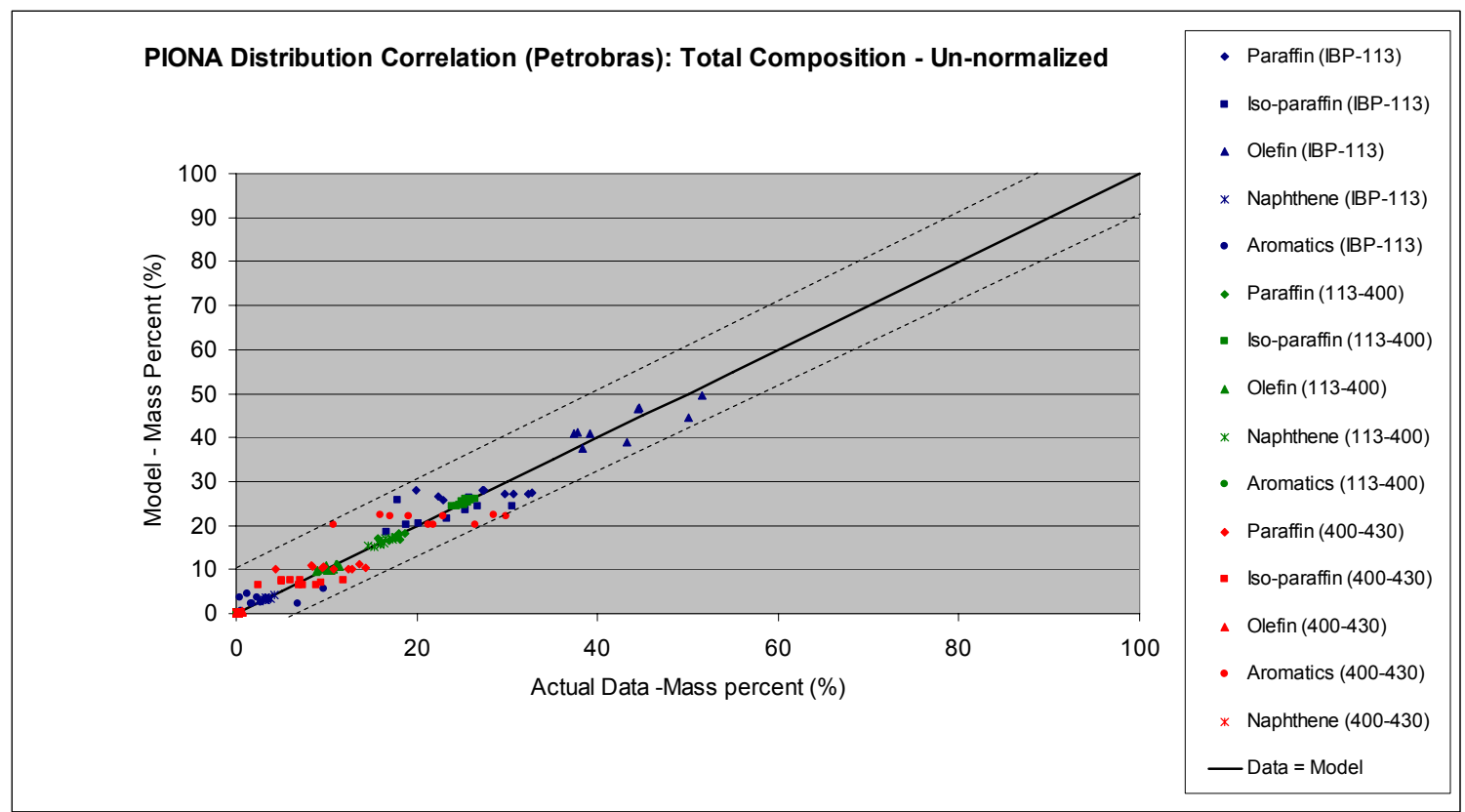

\section{Figure 281 - Petrobras PIONA Distribution Correlation (Un-normalized)}

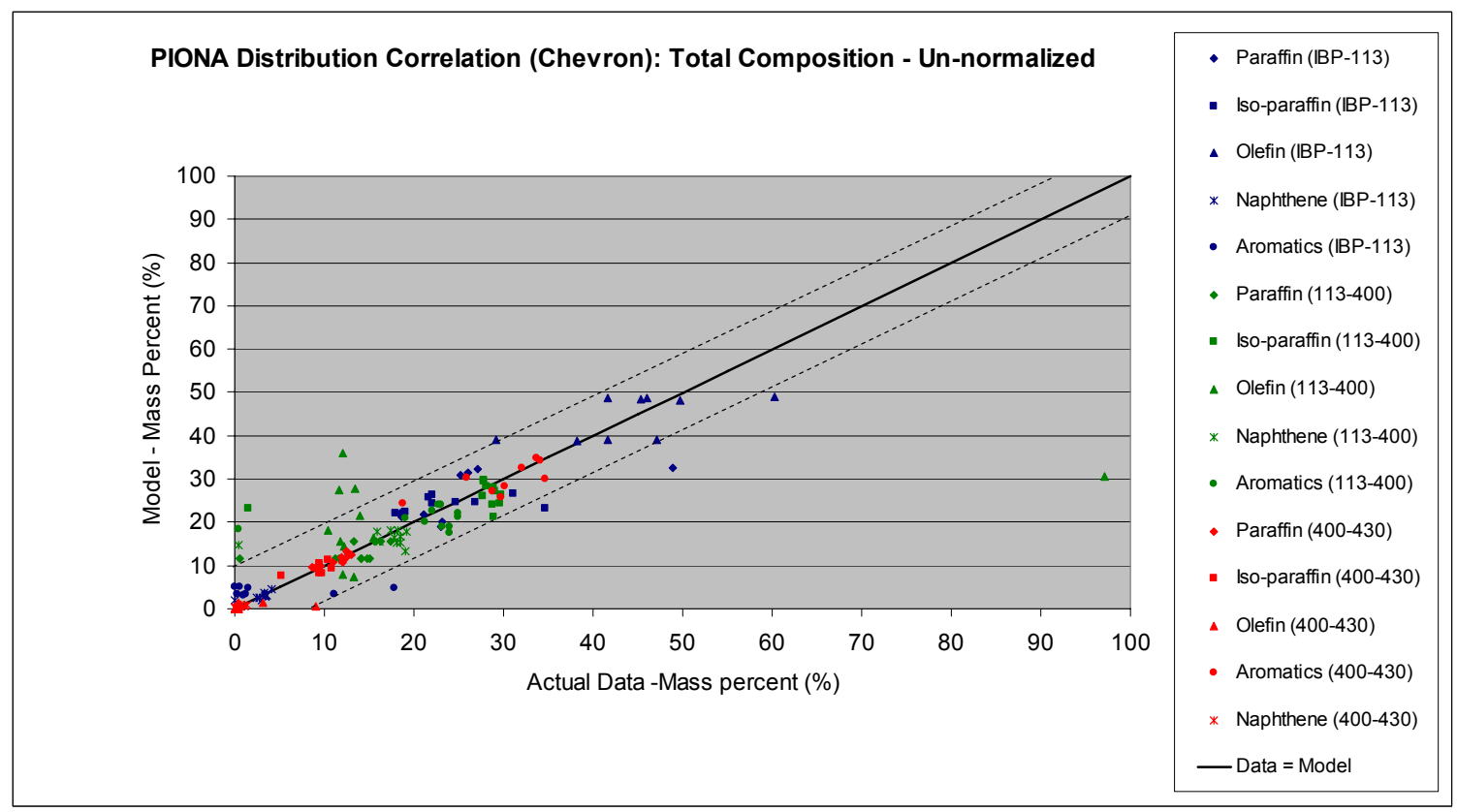

Figure 282 - Chevron PIONA Distribution Correlation (Un-normalized) 


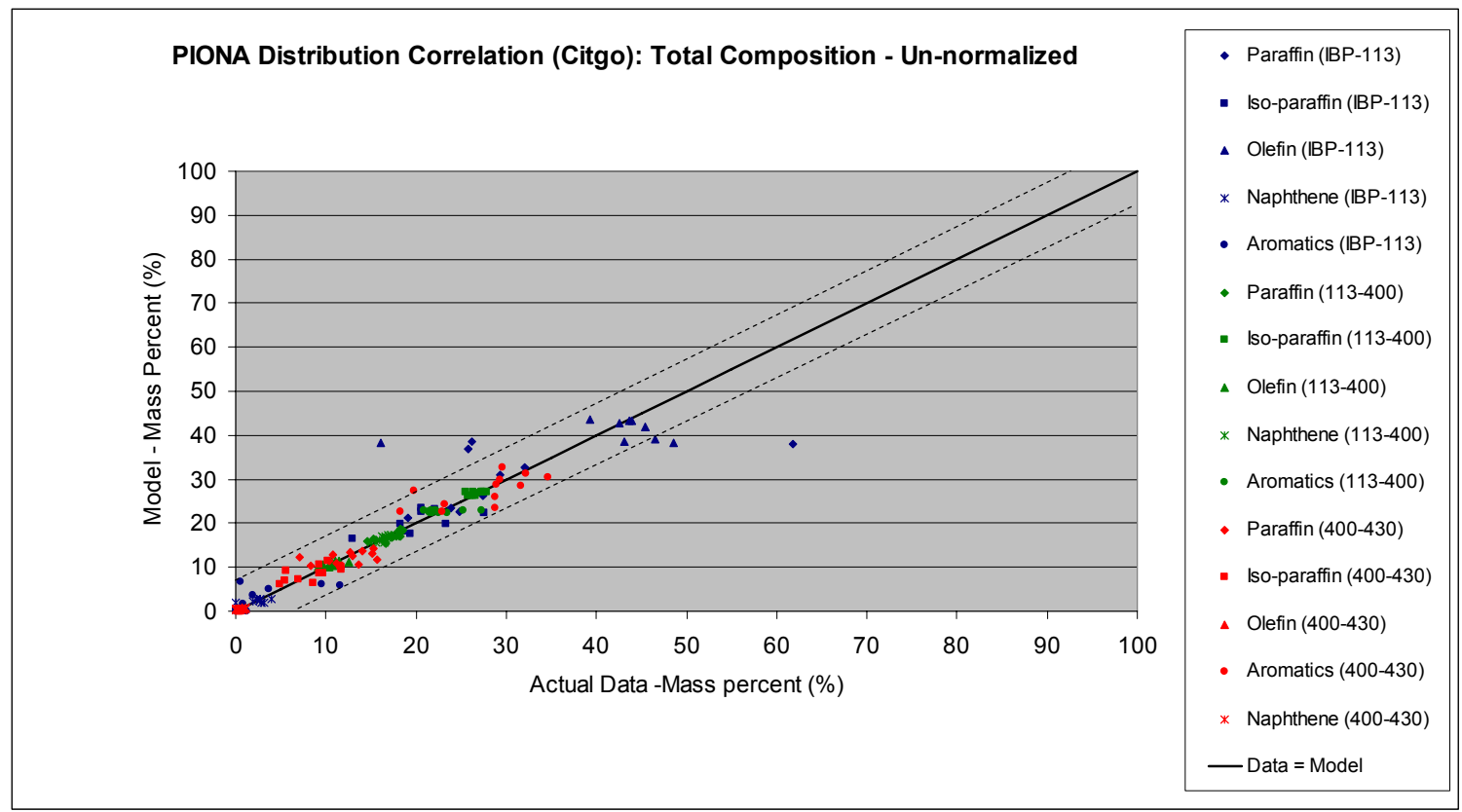

Figure 283 - Citgo PIONA Distribution Correlation (Un-normalized)

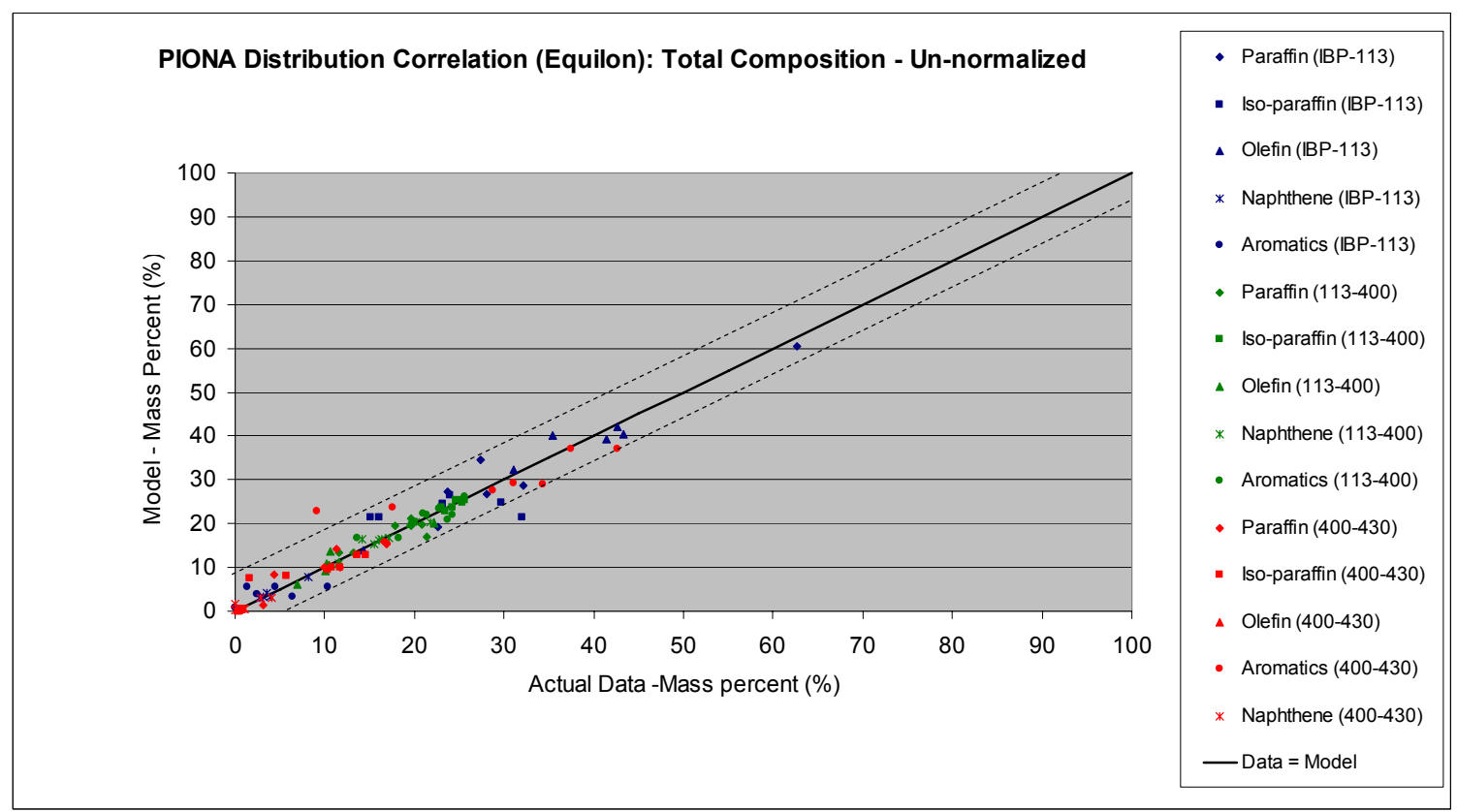

\section{Figure 284 - Equilon PIONA Distribution Correlation (Un-normalized)}

Several points are worth noting concerning the feedstock effect on the PIONA. First, the effect of feedstock and of temperature and pressure were clearly discernable. Generally, the paraffins and aromatics increase and the iso-paraffins, olefins, and naphthenes decrease as pressure is raised. On the other hand, the paraffins and aromatics generally decrease with increasing temperature, while the olefins and naphthenes generally increase. 
Second, the feedstock characteristic (paraffinic, naphthenic, or aromatic) is sometimes, but not always, an indicator of the characteristics of the liquid products. For example, the Marathon resid is a paraffinic feeedstock, having the highest NMR saturate to aromatic ratio (2.7) of all the feedstocks, and it makes the highest percentage of paraffins of all the feeds. Likewise, the Chevron resid, which is characterized as a naphthenic feed, consistently has the highest percentage of naphthenes in the liquid products. However, the Citgo resid, which is characterized as an aromatic resid and has the lowest NMR saturate to aromatic ratio (1.9) of all the feedstocks, does not make the most aromatic liquid products.

\section{3. $R O N$ analysis}

Research octane number (RON) for the light liquids, were determined by DHA. The results show the highest RON with the least variation with resid for the IBP- $113^{\circ} \mathrm{F}$ cut, and the lowest RON with the greatest variation for the $400-430^{\circ} \mathrm{F}$ cut.

A good correlation between RON numbers and the PIONA results was found.

\section{Sulfur analysis}

Sulfur analyses on the hydrocarbon liquid sub-fractions, carried out on the HP6890a chromatograph, showed variations when different dilution factors were used. This indicated that the dilution factor used was insufficient to prevent the column from being saturated, thus leading to potentially false readings. Samples are being re-run and the proper dilution factor is being determined.

\section{Silicon partitioning}

Partitioning of the silicon from antifoam addition was correlated against total silicon added. It was assumed that any feed silicon present was in the form of sand, which would remain in the coke. In general, most of the Silicon partitioned in the HC.

\section{Density CoRRELATION FOR COKE}

Density of coke made is quite important in the coking process. If the density of coke can be improved, a larger amount of resid can be processed in a given coking cycle. It was noted earlier that the density of the coke varied with temperature, pressure and feedrate. In this section an attempt has been made to correlate both bulk density and gamma densities using these operating variables. Values for temperature and pressure have been directly taken from the test run data. But feedrate is converted into mass accumulation by multiplying feedrate with the $\%$ of coke formed for a given test run.

\section{Sponge coke correlation}


For resids that made pure sponge coke (Petrobras and Marathon), the three variables, temperature, pressure and mass accumulation provided a good correlation. Table 88 gives the correlation coefficients of predicted Bulk and gamma densities for Petrobras and Marathon resids which made pure sponge coke irrespective of the operating conditions.

Table 88 - Correlation coefficients of Predicted Bulk and Gamma densities for Petrobras and Marathon resids

\begin{tabular}{|l|c|c|c|c|c|}
\hline & Adjusted $R^{2}$ & Temperature & Pressure & Mass Accumulation & Intercept \\
\hline & Coefficient & A & B & C & D \\
\hline Petrobras Bulk & 0.95 & $3.59 \mathrm{E}-03$ & $3.01 \mathrm{E}-03$ & $-1.82 \mathrm{E}-04$ & -2.52 \\
\hline Petrobras Gamma & 0.72 & $4.73 \mathrm{E}-03$ & $2.41 \mathrm{E}-03$ & $-1.65 \mathrm{E}-04$ & -3.69 \\
\hline & & & & & \\
\hline Marathon Bulk & 0.76 & & $4.84 \mathrm{E}-03$ & $-6.23 \mathrm{E}-05$ & 0.63 \\
\hline Marathon Gamma & 0.80 & $2.19 \mathrm{E}-03$ & $3.38 \mathrm{E}-03$ & $-1.47 \mathrm{E}-04$ & -1.45 \\
\hline
\end{tabular}

Equation 1 Density correlation equation for sponge coke.

Density $=A^{*}$ Temperature $+B^{*}$ Pressure $+C *$ Mass Accumulation $+D$.

Positive coefficients for temperature and pressure indicate that an increase in these operating variables increases the density of coke formed while the negative coefficient for mass accumulation (factor of feedrate) indicates a decrease in coke density with an increase in feedrate. For Marathon resid bulk density prediction using temperature has a coefficient less than standard error so for this case bulk density is predicted only with pressure and mass accumulation.

Considering the overall effects of operating conditions on sponge coke densities, it is observed that an increase of temperature and pressure results in an increase in coke density. Feedrate increase decreased coke density.

\section{Shot coke correlation}

Similar analysis was done for the resids that made shot coke (Equilon and Suncor).

Table 89 gives the correlation coefficients of predicted Bulk and Gamma densities.

Table 89 - Correlation coefficients of Predicted Bulk and Gamma densities

\begin{tabular}{|l|c|c|c|c|c|}
\hline & Adjusted $R^{2}$ & Intercept & Temperature & Pressure & Mass Accumulation \\
\hline & Coefficient & D & A & B & C \\
\hline Equilon Bulk & 0.31 & 1.65 & $-9.81 \mathrm{E}-04$ & $4.71 \mathrm{E}-03$ & $-3.40 \mathrm{E}-05$ \\
\hline Equilon Gamma & 0.62 & -6.90 & $7.97 \mathrm{E}-03$ & $4.10 \mathrm{E}-03$ & $1.04 \mathrm{E}-04$ \\
\hline & & & & & \\
\hline Suncor Bulk & 0.10 & -0.35 & $8.48 \mathrm{E}-04$ & $5.39 \mathrm{E}-03$ & $3.11 \mathrm{E}-04$ \\
\hline Suncor Gamma & 0.14 & -0.54 & $1.07 \mathrm{E}-03$ & $4.99 \mathrm{E}-03$ & $1.32 \mathrm{E}-04$ \\
\hline
\end{tabular}


Since these resids made agglomerated shot coke which has variable densities, the adjusted $\mathrm{R}^{2}$ values are poor. The correlations could be improved by including a factor for agglomeration of shot coke.

BB shot:

The Suncor resid made BB's at some locations in the drum depending on the test run. The locations where it made BB's were identified and the densities picked from the gamma traces. A correlation for the resids that made shot coke was predicted using temperature, pressure and mass accumulation as variables.

Table 90 gives the correlation coefficients of predicted BB's density.

Table 90 - Correlation coefficients of Predicted BB density for Suncor resid

\begin{tabular}{|l|c|c|c|c|c|}
\hline & Adjusted $\mathrm{R}^{2}$ & Temperature & Pressure & Mass Accumulation & Intercept \\
\hline & Coefficient & A & B & C & D \\
\hline Suncor BB density & 0.97 & $3.00 \mathrm{E}-03$ & $-1.74 \mathrm{E}-03$ & $-9.70 \mathrm{E}-04$ & -1.33 \\
\hline
\end{tabular}

From the above table it can be observed that positive coefficient for temperature indicates that an increase in temperature increases shot coke density where as negative coefficients in pressure and feedrate (mass accumulation) decreases shot coke density. This is due to the fact that an increase in temperature makes more BB's which are dense spheres, where as an increase in pressure and feedrate reduces shot coke formation which in turn decreases density of shot coke formed.

\section{Sponge $\mathrm{v} / \mathrm{s}$ shot}

Chevron and Citgo resids made both sponge and shot coke at different locations in the drum at different operating conditions. A similar analysis was done for the resids that made variable morphology in the drum (Chevron and Citgo). Table 91 gives the correlation coefficients of predicted Bulk and Gamma densities.

Table 91 - Correlation coefficients of Predicted Bulk and Gamma densities

\begin{tabular}{|l|c|c|c|c|c|}
\hline & Adjusted $R^{2}$ & Intercept & Temperature & Pressure & Mass Accumulation \\
\hline & Coefficient & D & A & B & C \\
\hline Chevron Bulk & -0.14 & -1.41 & $2.34 \mathrm{E}-03$ & $1.39 \mathrm{E}-03$ & $-5.41 \mathrm{E}-05$ \\
\hline Chevron Gamma & 0.44 & -2.53 & $3.52 \mathrm{E}-03$ & $1.26 \mathrm{E}-03$ & $-1.52 \mathrm{E}-04$ \\
\hline & & & & & \\
\hline Citgo Bulk & 0.17 & -2.47 & $3.04 \mathrm{E}-03$ & $1.07 \mathrm{E}-03$ & $3.79 \mathrm{E}-04$ \\
\hline Citgo Gamma & 0.11 & -2.23 & $2.98 \mathrm{E}-03$ & $2.38 \mathrm{E}-03$ & $-2.61 \mathrm{E}-05$ \\
\hline
\end{tabular}

Since these resids made variable morphology in the drum with variable densities, the adjusted $R^{2}$ values are poor. The correlations could be improved by including a factor for this variable morphology.

\section{Comparison of sponge and shot correlations}

Table 92 gives the coefficients for shot coke made by the Suncor resid and overall sponge coke gamma density (Petrobras and Marathon resids). The values are fairly comparable. 
Table 92 - Correlation coefficients of Predicted Gamma densities for overall sponge and shot coke

\begin{tabular}{|l|c|c|c|c|c|}
\hline & Adjusted $R^{2}$ & Temperature & Pressure & Mass Accumulation & Intercept \\
\hline & Coefficient & A & B & C & D \\
\hline Suncor BB density & 0.97 & $3.00 \mathrm{E}-03$ & $-1.74 \mathrm{E}-03$ & $-9.70 \mathrm{E}-04$ & -1.33 \\
\hline & & & & & \\
\hline Sponge coke Gamma density & 0.63 & $3.45 \mathrm{E}-03$ & $3.31 \mathrm{E}-03$ & $-1.38 \mathrm{E}-04$ & -2.59 \\
\hline
\end{tabular}

\section{J. FuRNACE COIL MODEL}

Work has begun on developing a comprehensive model for the furnace tube, based on reaction kinetics, two-phase flow patterns, and vapor-liquid equilibrium. Figure 285 shows the phase equilibrium calculation. Based on the feedstock properties and initial conditions in the furnace tube, calculations are made of the reaction rate and the vapor-liquid equilibrium. At each increment in the furnace tube, cracking products (gas, gasoline, diesel, gas oil, and coke) are calculated and a flash calculation is made to determine the vapor-liquid equilibrium. 


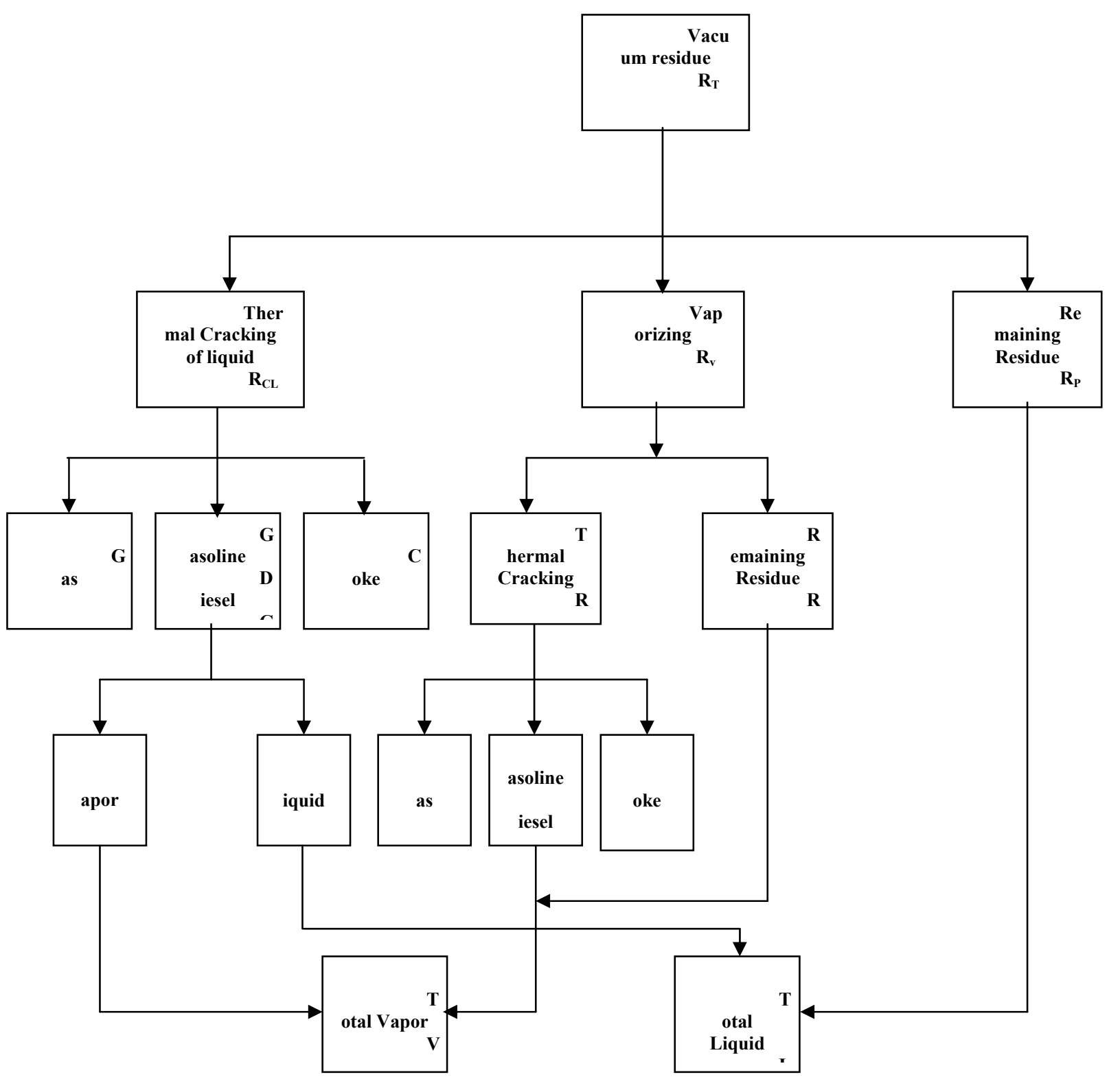

\section{Figure 285 - Process of phase equilibrium and thermal cracking in tube furnace}

Previous work (Jin Wang, 2001) has indicated that two-phase flow in the delayed coking furnace can exist either as slug flow or as annular flow, depending on resid properties, extent of vaporization, and flow rates. In order to establish a complete furnace tube model, the reaction kinetic/phase equilibrium calculations must be combined with a fluid mechanic description of the flow.

Figure 286 describes schematically how these are related for slug flow. The slug unit consists of two regions, a liquid slug body of length $L_{S}$, and a film zone of length $L_{F}$. The slug body contains small bubbles, the liquid velocity is $V_{L S}$ and the bubble velocity is $V_{G s}$, for the horizontal furnace tube the gas and liquid moves at same velocity $v_{S}$. the slug front velocity is $v_{T B}$ which represents the translational velocity of the slug. The liquid holdup in the slug body is $H_{L S}$, and the 
void is $H_{G S}$. The slug length $L_{s}$ will be decayed due to the thermal cracking and vaporizing. The slug front will pick up liquid from the film which moves at velocity $V_{T B E}$. This velocity is smaller than the velocity of the slug body. The scooped liquid is accelerated from $v_{T B e}$ to $v_{S}$ and forms a mixing zone of length $L_{m}$. The pickup rate is $x_{p}$. The liquid in the tail of the slug also will be shaded into the film. The shedding rate is $x_{s} . x_{p}$ and $x_{s}$ is not same for the slug flow in the tube furnace, $x_{p}<x_{s}$. This is another reason for the decrease of the slug length. In the film zone, the liquid holdup $H_{L T B}$ varies along the stratified region. The velocity of the liquid $V_{L T B}$ and gas velocity $V_{G T B}$ also vary due to the variation of the film thickness $h_{F}(z)$ behind the liquid slug. Some small bubbles will move in the velocity of the film and some others will come into the gas pocket and accelerated from the velocity $V_{L T B}$ to $V_{\text {GTB }}$. These bubbles are produced by the thermal cracking and vaporizing. The vapor in the gas pocket also will be cracked into gas and light oil vapor. This is another reason for the variation of the velocities of the liquid and gas in the film region. 
The University of Tulsa

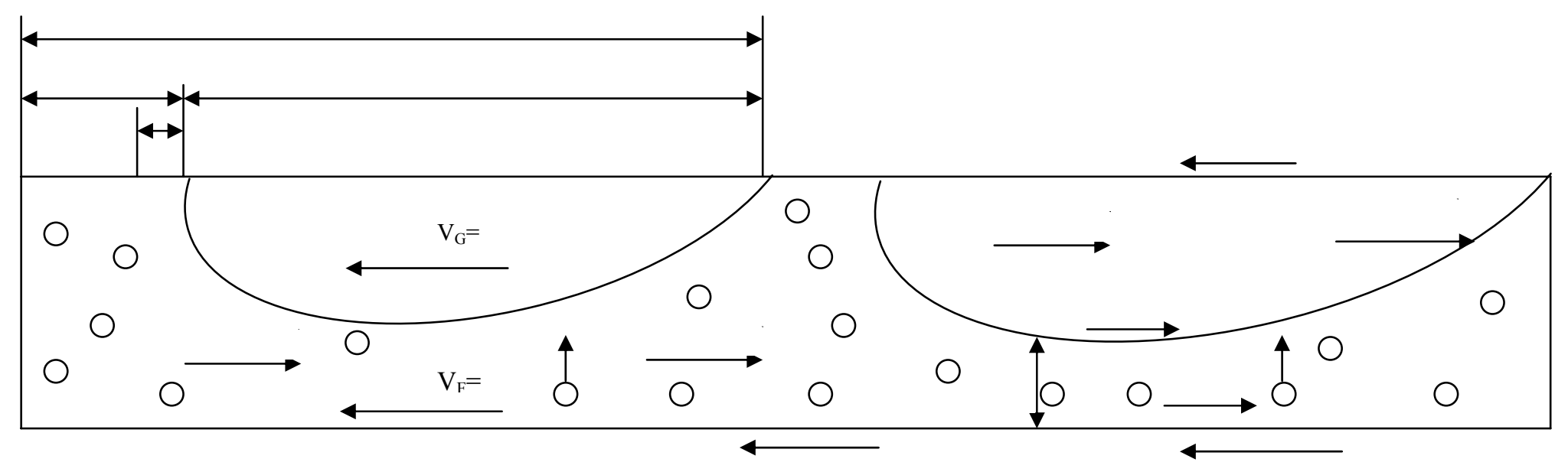

Figure $\mathbf{2 8 6}$ - Physical model for slug flow 
Figure 287 shows the calculation algorithm for slug flow in the furnace. The procedure is as follows:

1. Specify the input parameters: (pressure, temperature, fluid properties, tube diameter)

2. Calculate the slug frequency $v_{s}$ from the closure correlation. Determine the slug period $t_{u}$ and the total number of slugs from the run length $t_{\text {r }}$.

3. Calculate the vaporized and cracked liquid total volume $V_{L C V}$ and the vapor and gas mixture total volume $V_{G C V}$, vaporized and cracked liquid volume $V_{L C V i}$ and the vapor and gas mixture volume $V_{G C V i}$ in each slug unit and in the slug region $V_{L C V S i}$ and stratified region $V_{L C V F i}$.

4. Calculate the mass $w_{L i}$ and $w_{G i}$ and volumetric flow rates $q_{L i}$ and $q_{G i}$ for each slug unit.

5. Calculate the physical properties $\rho, \mu, \sigma$ for both liquid phase and the gas mixture phase.

6. Calculate the variables from the closure correlations, $v_{T B i}, H_{L S i}$.

7. Calculate the slug velocity $v_{S i}$ (mixture velocity).

8. Guess a film thickness $h_{F i}$, determine $A_{F i}, H_{L T B i}, \underline{A_{G}}, S_{F}, S_{G}, S_{l}$ and $d_{h F}$ from the geometrical relationships.

9. Determine $v_{L T B i}$ and $v_{G T B i}$.

10. Check for convergence; if convergence has not been reached, give another film thickness $h_{F i}$, repeat the calculation.

11. Calculate $L s, L u$.

12. Calculate the pressure drop. 


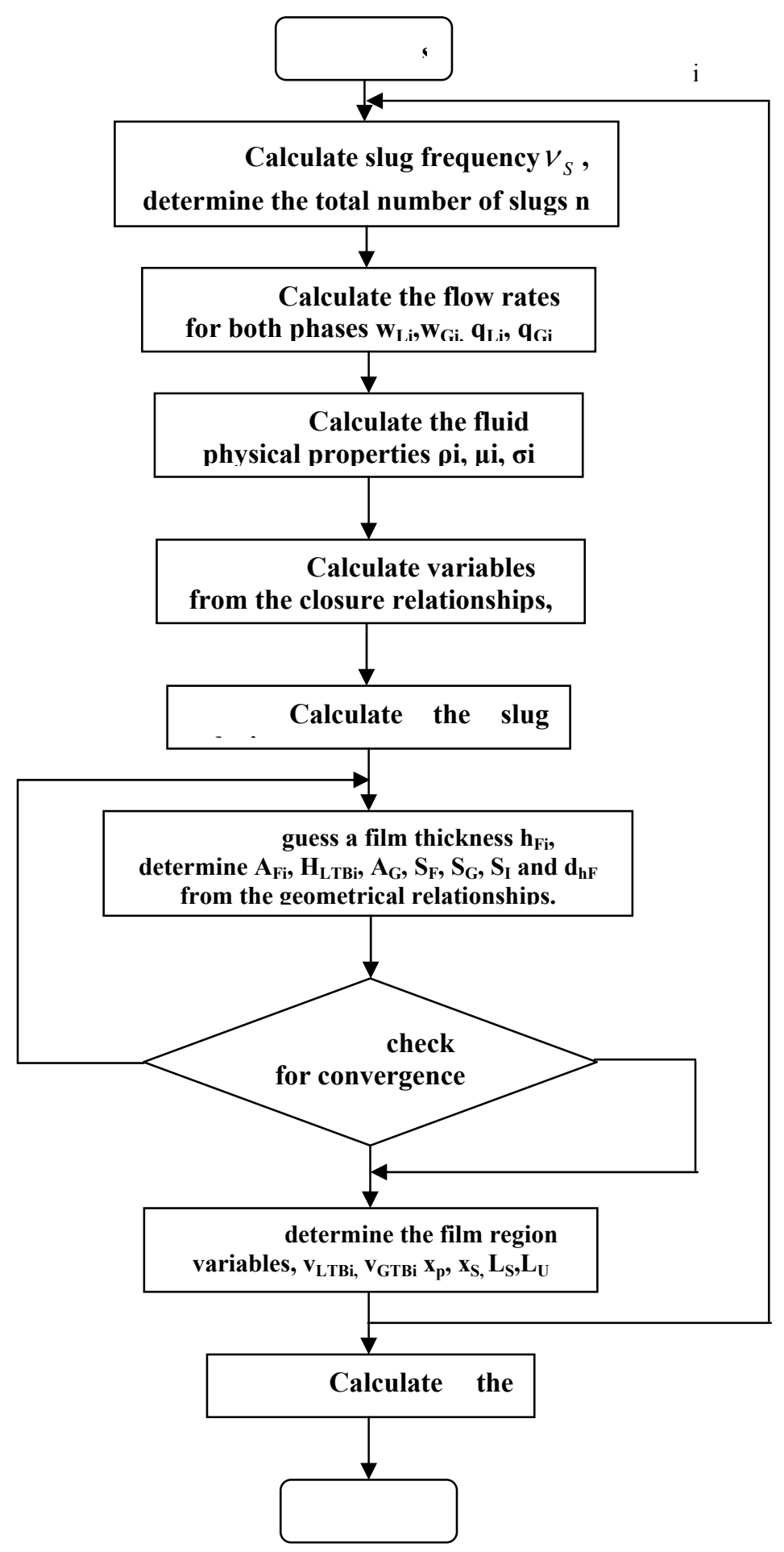

Figure $\mathbf{2 8 7}$-Flow chart of slug flow model for the tube furnace

A similar algorithm is currently being developed for the annular flow calculation scheme. 


\section{K. MORPHOLOGY StUdIES}

Twenty eight samples were analyzed for gas and liquid permeability. When choosing the samples for analysis, the methodology was to cover all the possible coke morphology classifications. The majority of the samples used were sponge; however, to get some of them in right cylinders they had to be filled with wax. Dust, sedimentation and volatile matter trapped in the pore bodies can alter the measured permeabilities. Pressures in the range $1-28$ [psig] were used to get measurable flows for liquid permeability. Pressures in the range $0.01-0.03$ [psig] were used to get measurable air flows for gas permeability.

There is a great variation of permeability values, even for samples taken next to each other. Three samples (MARA-16-PUAFV 0-7-sponge-4) were taken from the same location having the same morphology, however the gas and liquid permeability values were close in two of them, but the third sample showed a large discrepancy in gas and liquid permeability values.

\section{Permeability}

The ability, or measurement of a material's ability, to transmit fluids, is typically measured in Darcies or millidarcies. Materials that transmit fluids readily, are described as permeable and tend to have many large, well-connected pores. Impermeable materials tend to be finer grained or of a mixed grain size, with smaller, fewer, or less interconnected pores.

Darcy empirically defined fluid flow in the porous media as being proportional to the differential pressure per unit length. The relationship was derived from data collected during a series of experiments on the vertical flow of water through gravel packs. Subsequent work has proved the validity for Darcy's law in all directions and confirmed the experimental observations by derivations from the basic laws of physics.

$$
Q=\frac{k A\left(P_{1}-P_{2}\right)}{\mu L} \quad \text { Darcy's Law. }
$$

Where:

k Permeability [Darcy]

$\mu \quad$ Viscosity [cp]

Q Flow rate $[\mathrm{cc} / \mathrm{sec}]$

$\mathrm{L} \quad$ Length of flow [cm]

A Cross-sectional area of flow [cm²]

$\mathrm{P}_{1} \quad$ Upstream pressure [atmosphere]

$\mathrm{P}_{2} \quad$ Downstream pressure [atmosphere]

This formula works for both air and water permeability measurements, but gas permeability at high flow rates differ to that observed in liquid permeability.

It is observed during the gas flow in porous media as gases become rarefied (molecules separated by large distances), there is slippage of the gas molecules at the pipe walls, i.e., the velocity no longer remains zero at the wall as that of the liquid flow. This is called Klinkenberg effect. The absolute permeability computed experimentally by flowing gas through a porous medium and applying Darcy's Law gives erroneously high values of absolute permeability and must be corrected. The relationship between gas permeability $\mathrm{k}_{\mathrm{g}}$ (computed from Darcy's Law) and true absolute (liquid) permeability $\mathrm{k}_{\mathrm{l}}$ is given by 


$$
k_{g}=k_{l}\left[1+\frac{b}{P_{m}}\right]
$$

Where:

$\mathrm{k}_{\mathrm{g}} \quad$ Permeability [md].

$\mathrm{k}_{\mathrm{l}} \quad$ True absolute liquid permeability or permeability at infinite mean free pressure, [md].

b Klinkenberg factor, [atm].

$\mathrm{P}_{\mathrm{m}} \quad\left(\mathrm{P}_{1}+\mathrm{P}_{2}\right) / 2 \quad$ mean pressure [atm].

A way to minimize this effect is by keeping the flow rate at a low level so that the flow is in the laminar region.

Estimation of permeability from capillary pressure was accomplished, but to do so it was necessary to cover a wider range of pressure in order to get a wider range of pore throat radius distribution. The method treats the porous medium as a bundle of capillary tubes with the pore size distribution quantified by the mercury/air capillary pressure curve. The tortuosity is an empirical factor that brings the calculation into correspondence with measured permeability.

The average velocity in a capillary tube of radius $r$ is described by the Hagen-Poiseuille law.

$$
\langle v\rangle_{i}=\frac{r_{i}^{2} \Delta P}{8 \mu L}
$$

The capillary radius can be determined for the relationship of the capillary pressure to an equivalent pore radius.

$$
P c_{i}=\frac{2 \sigma \cos \theta}{r_{i}}, \quad r_{i}=\frac{2 \sigma \cos \theta}{P c_{i}}
$$

Thus the average velocity in a capillary tube can be expressed in terms of the capillary pressure at which that capillary is being entered be a nonwetting fluid.

$$
\langle v\rangle_{i}=\frac{(\sigma \cos \theta)^{2} \Delta P}{2 \mu L} \frac{1}{\left(P c_{i}\right)^{2}}
$$

By letting $S(P c)$ denote the fraction of the pore space that is occupied by the wetting phase when the capillary pressure is equal to $\mathrm{Pc}$, for water saturation $\mathrm{Sw}, \mathrm{S}(\mathrm{Pc})$ would be equal to 1-Sw and for mercury injection, the fraction of mercury injected. Then $d S$ is the incremental fraction of the pore space corresponding to $\mathrm{Pc}$ and $\mathrm{Pc}-\mathrm{dPc}$. The interstitial velocity is the integral over all pores.

$$
v=\int_{0}^{1}\langle v\rangle d S
$$

The superficial velocity $(q / A)$ is then as follows.

$$
u=\phi v=\frac{(\sigma \cos \theta)^{2} \Delta P \phi}{2 \mu L} \int_{0}^{1} \frac{d S}{\left(P c_{i}\right)^{2}}
$$

This equation can be compared with Darcy's law.

$$
u=\frac{k}{\mu} \frac{\Delta P}{L}
$$

By comparing the last two equations, an expression can be derived for the permeability. 


$$
k=\frac{(\sigma \cos \theta)^{2} \Delta P \phi}{2} \int_{0}^{1} \frac{d S}{P_{C}^{2}(S)}
$$

Tortuosity has not yet been considered to this point. Mercury porosimetry for measuring capillary pressure and calculation of permeability there from was introduced by Bob Purcell of Shell Oil Co. in 1949. Purcell introduced a factor, called the "lithology factor" to bring the calculated permeability into correspondence with the measured air permeability.

$$
\begin{aligned}
k & =\frac{(\sigma \cos \theta)^{2} \Delta P(F \phi)}{2} \int_{0}^{1} \frac{d S}{P_{C}^{2}(S)} \\
\tau & =F \phi
\end{aligned}
$$

$\mathrm{F}$ is the lithology factor introduced by Purcell, it encloses the concept of tortuosity. Tortuosity takes into account all the deviations of the real pore space network from the capillary tube bundle model. This difference is thought to be due to the sample surface roughness and/or the accessibility of pores to the external surfaces.

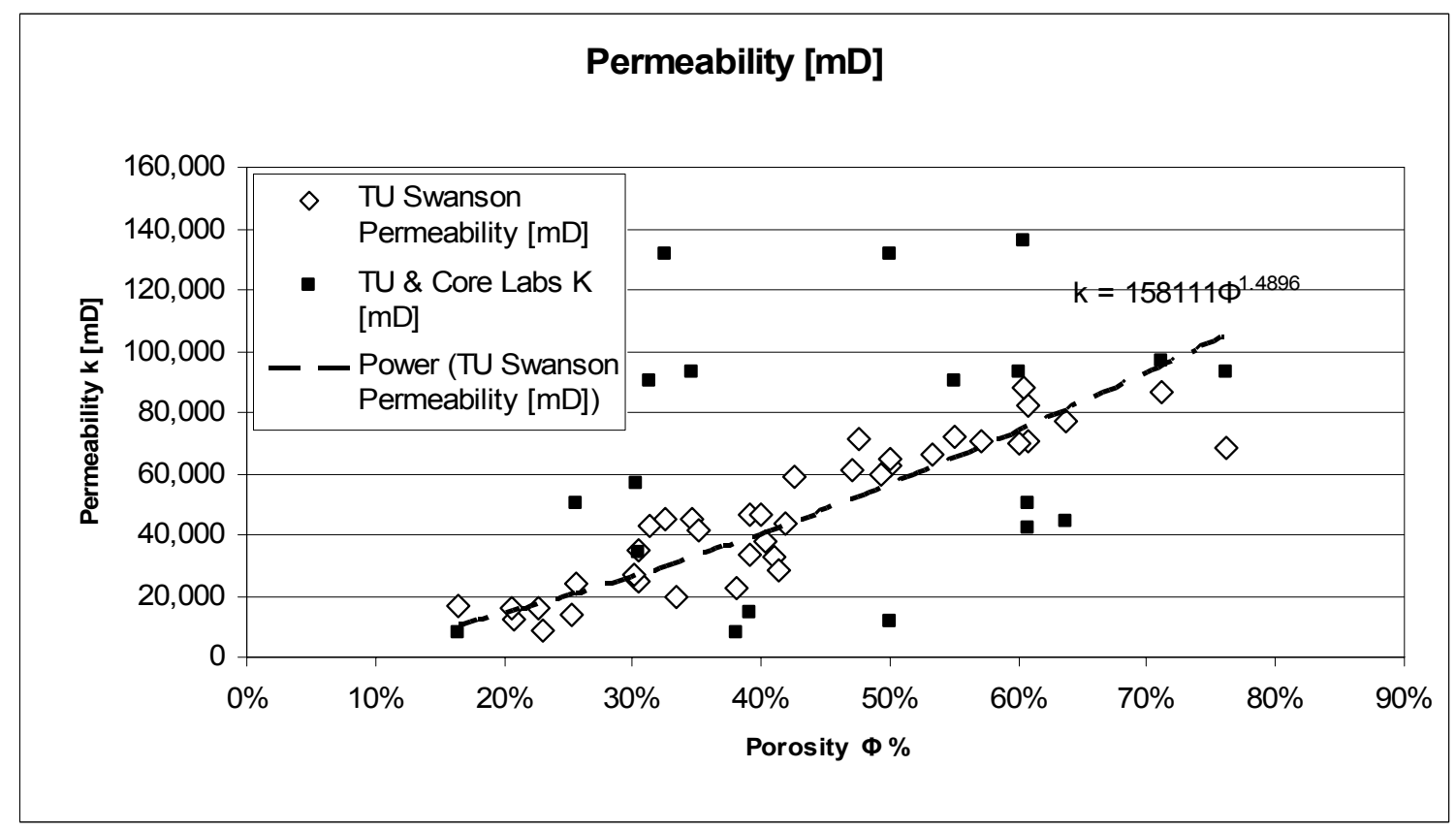

Figure 288 Permeability vs Porosity, calculated using different methods

Figure 288 shows a comparison for four different methods to estimate permeability. Swanson permeability was calculated by using the following formula, developed by Swanson and applied in carbonates and sandstones:

$$
k=355\left(\frac{S w}{P C}\right)_{\text {MAX }}^{2.005}
$$

Tulsa University and Core Lab permeabilities are the values measured in house and results from measurements performed by a core analysis laboratory. Based on these values and the Swanson parachor $(\mathrm{Sw} / \mathrm{Pc})_{\text {MAx }}$ a formula was developed by the least squares method, that resulted in the TU-Swanson permeability: 


$$
k=1338\left(\frac{S w}{P C}\right)_{\text {MAX }}^{0.9017}
$$

As can be seen the Swanson correlation estimates are much higher, nearly five times larger than the TU-Swanson permeabilities. These last estimations show a much more uniform permeability versus porosity values. Porosity for all cases was taken from the capillary pressure results; doing so, porosity is the effective porosity, that is the void space that contributes to fluid flow.

Figure 288 also shows Purcell permeabilities adjusted by using the lithology factors to fit the measured permeability values. All values estimated and measured lie between 0 and 150,000 [mD], except for those using Swanson estimation.

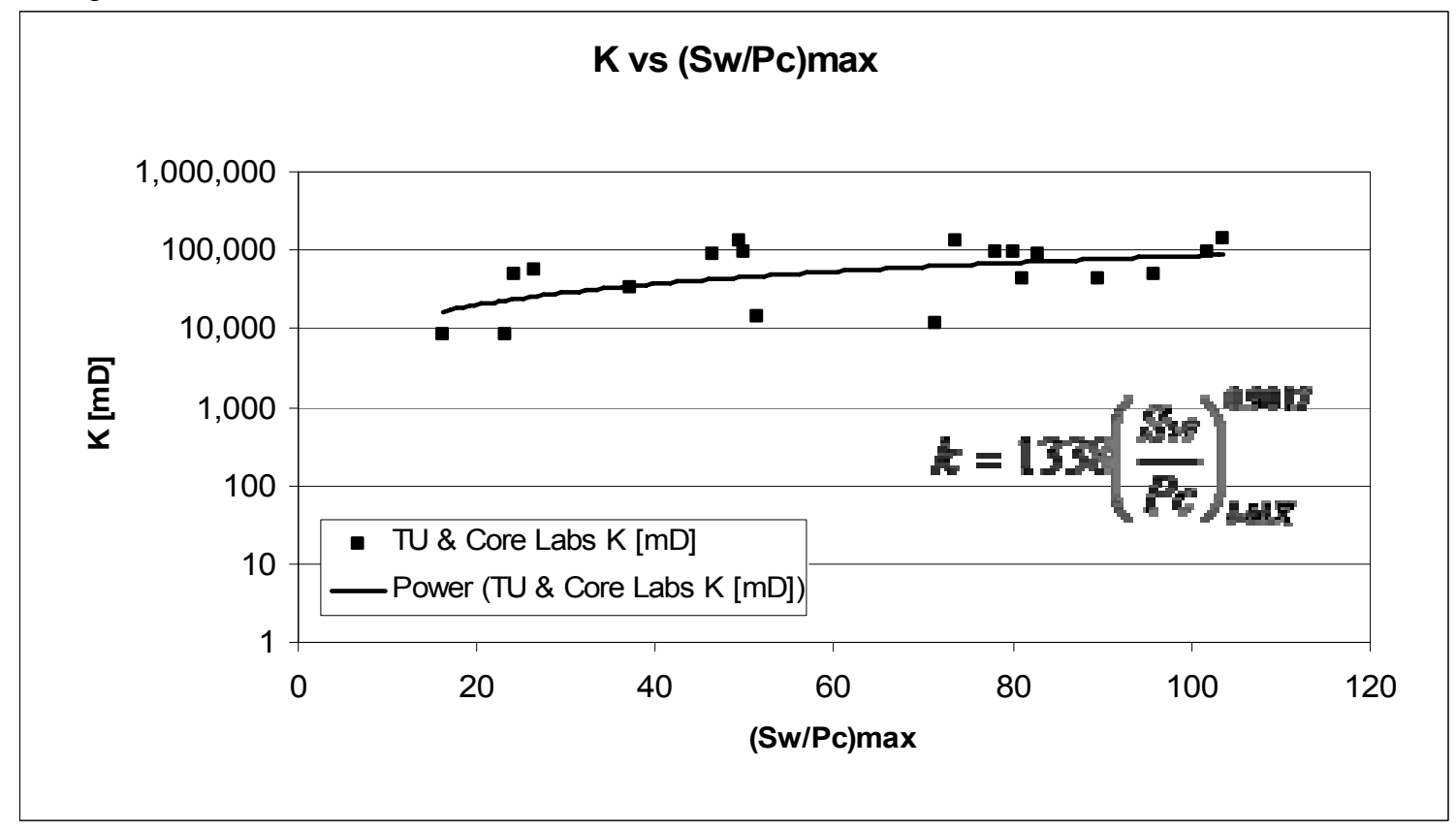

Figure 289 Estimation of permeability using the Swanson approach

Figure 289 shows the correlation developed using permeability measured values and capillary pressure information. 


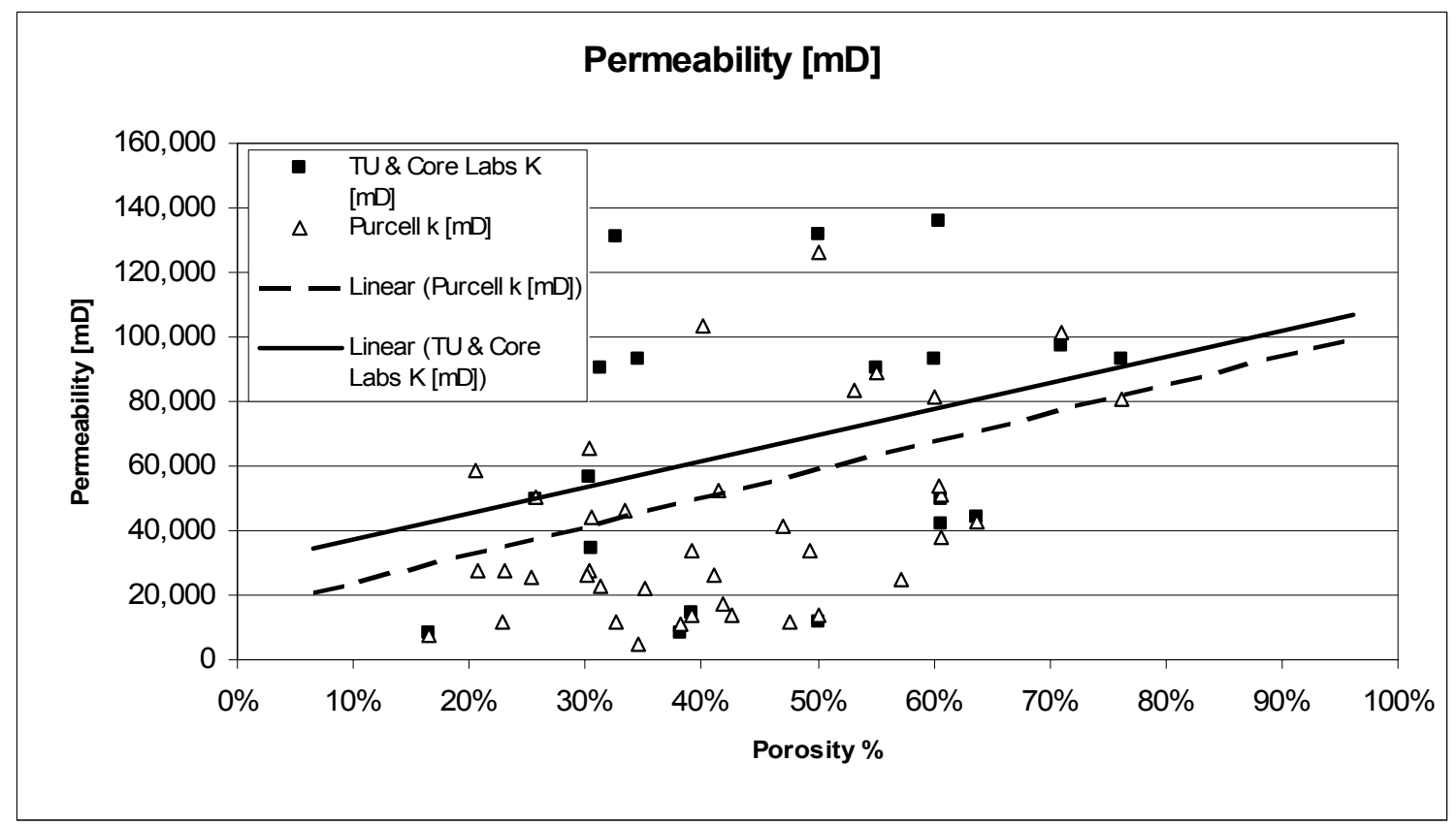

Figure 290 Permeability vs porosity, using TU Swanson approach.

Figure 290 shows how the correlation developed by using capillary pressure data and permeability measured values fit the values. Black points stand for the adjusted Purcell permeability model and white points stand for measured permeabilities. Agglomerated and transitional morphologies seem to have the lowest permeabilities; this finding is in accord with the observations using SEM. 


\section{Capillary Pressure Analyses on Transitional Coke Samples}

Thirteen transitional samples were sent to Core labs to better clarify their morphologies and confirm the close relationship between BB shot coke and Agglomerated shot coke.

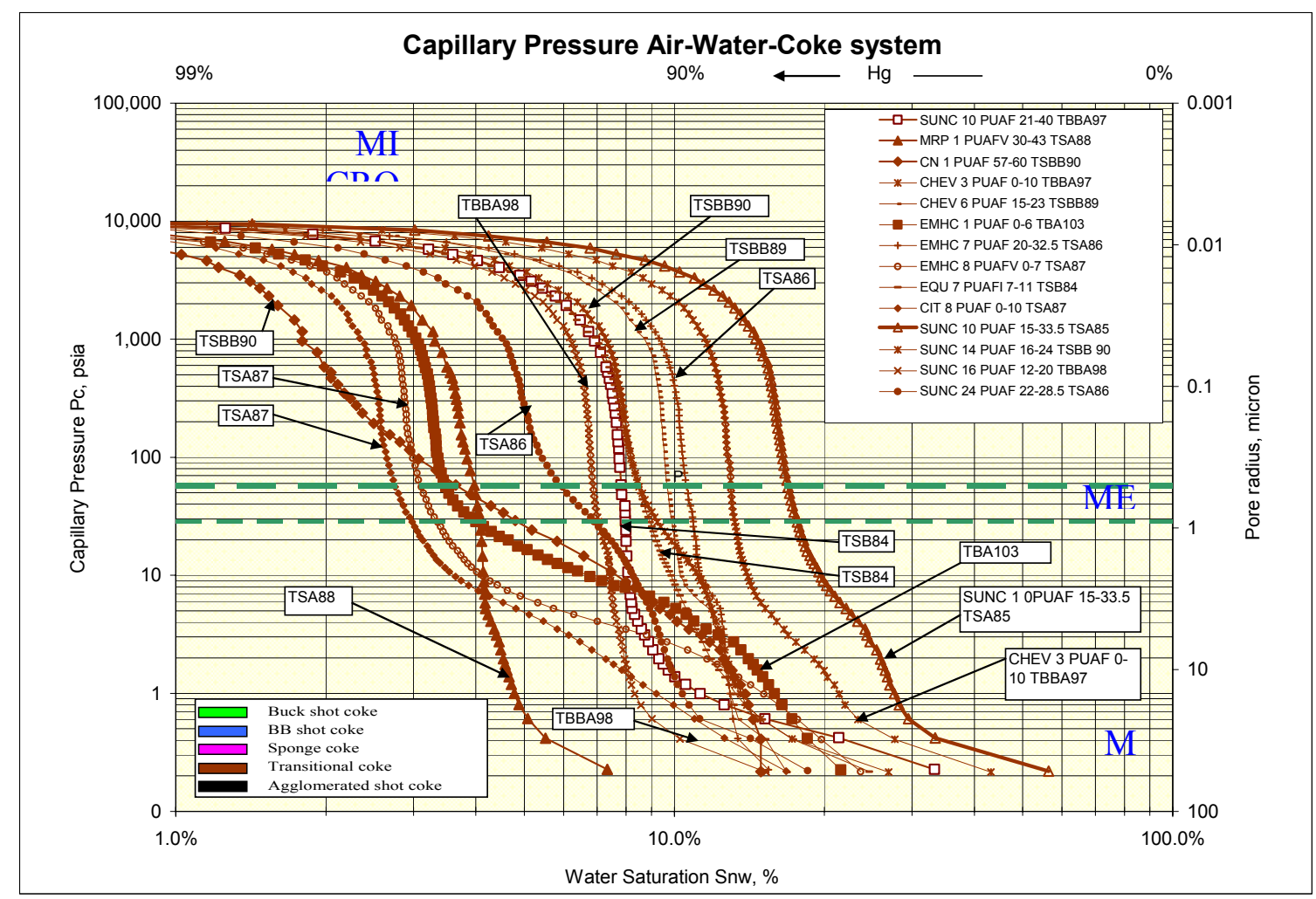

Figure 291 Capillary Pressure Air-Water-Coke system (Transitional coke)

Figure 291 shows the capillary pressure data for all the transitional samples. The transitional forms TSBB, TBA, and few TSA show the worst cooling properties, the more to the right the capillary pressure curve is observed the lower the cooling properties values. BB shot coke transitional forms are placed in the same place that BB shot coke would be expected to be; it shows that the BB shot coke structure lies at a micro level. The best cooling properties are shown by the Sponge-Agglomerated shot coke samples. This is due to the sponge micro structure that has a well connected pore network. Once again these capillary pressure curves show their usefulness. They serve as a tool to differentiate coke morphology when they are hard to classify by the naked eye. 


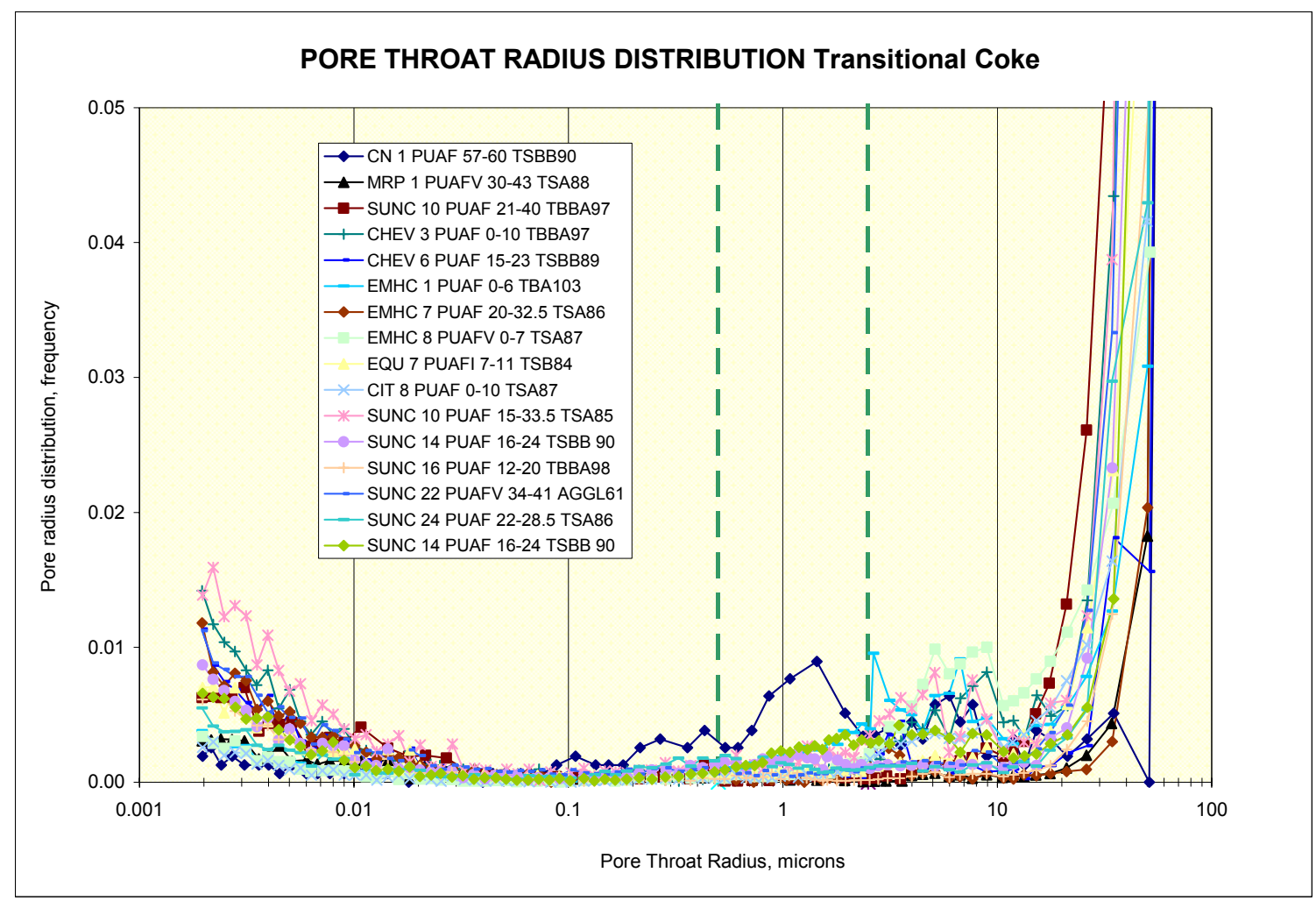

\section{Figure 292 Pore Size Distribution (Transitional coke)}

Figure 292 shows the pore radius distribution for 16 transitional coke samples. The majority of the samples show a common behavior regarding their pore size distribution. Pore throat openings are predominantly greater than 20 microns and a poor meso pore zone is observed except for the CN 1 PUAF sample. CN 1 PUAF shows a peak in the meso zone that might be caused by voids discussed in prior reports.

BB shot coke that is bonded by pitch material makes it appear as a solid surface as is seen in Figure 293 - C; however, the inter particle space inside the coke, between the BB spheres, creates a void space (white arrow in Figure 293 - D) through which mercury can spread filling the void without any significant pressure increase. 

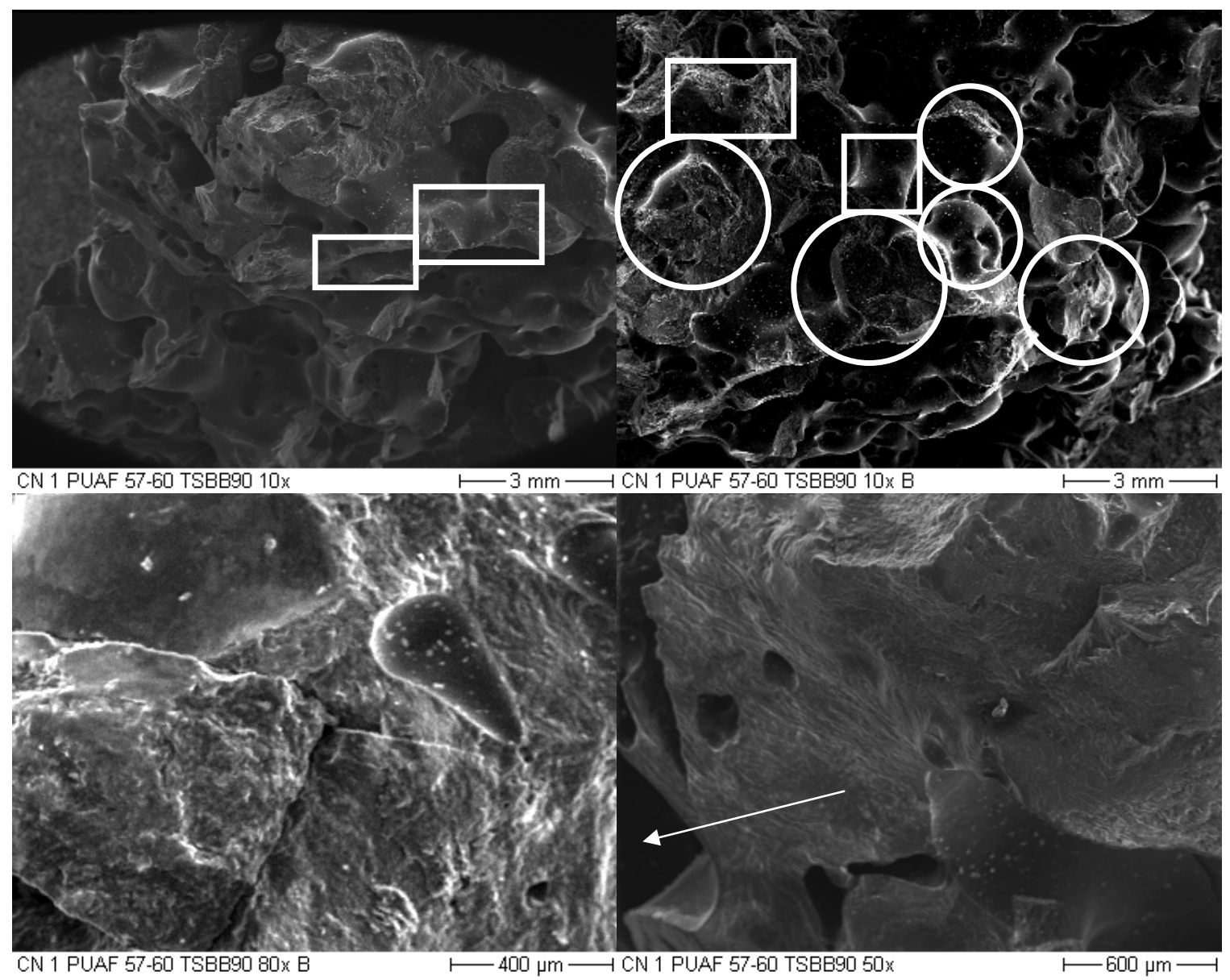

\section{Figure 293 SEM CN 1PUAF 57-60 TSBB90}

The white rectangles show the pitch material forming bridges among the tiny BB spheres, while the white circles show the BB shot coke particles. The majority of the transitional types of coke we identified are morphologies between BB shot coke and agglomerated shot coke; some of them even have a sponge look to them that will be discussed in the next section.

\section{SEM Analyses}

Figure 294 through Figure 296 are the latest SEM images that show that agglomerated shot coke was formed from BB shot coke, condensation and other mechanisms that clog the inter particle void space. 


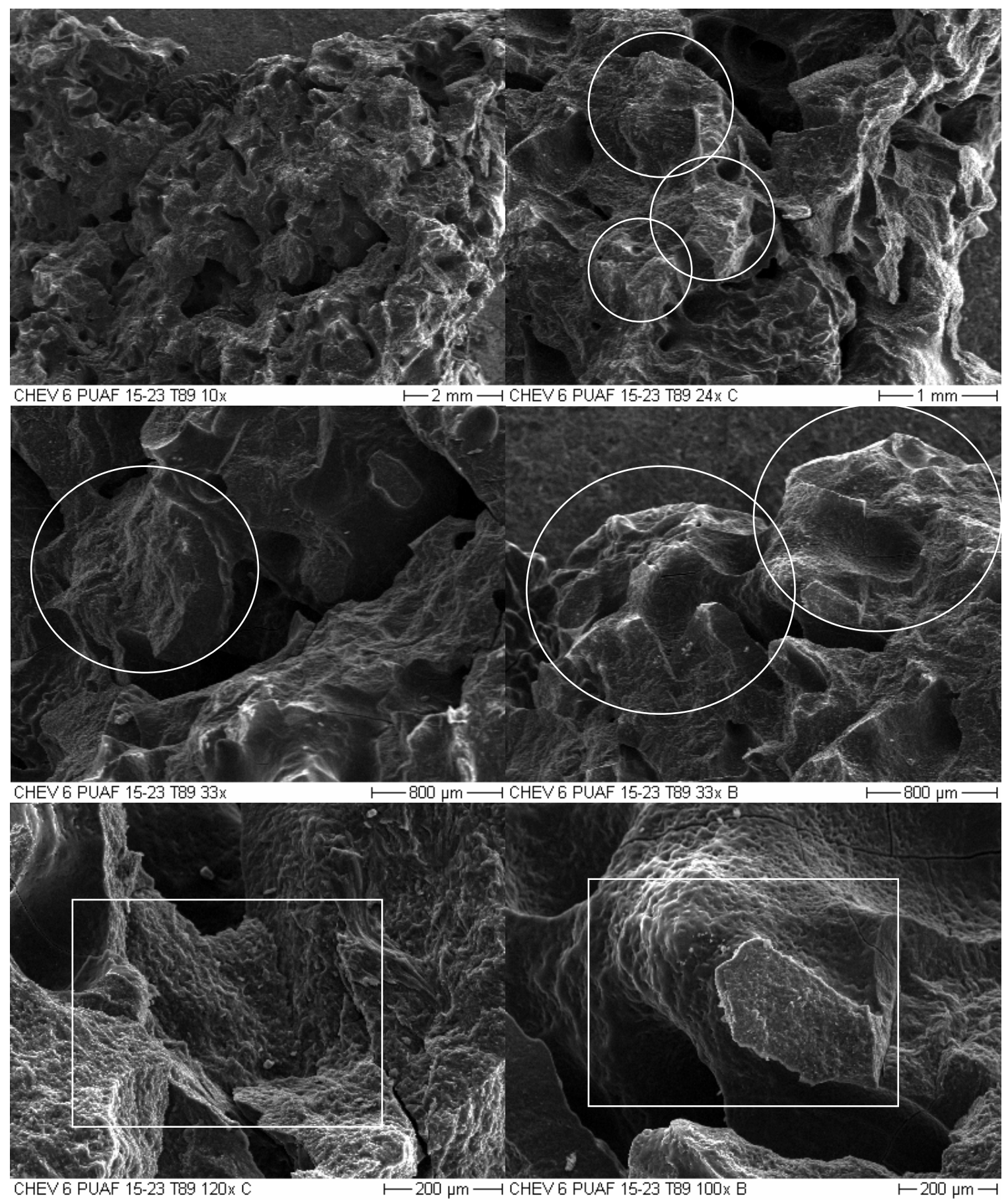

Figure 294 SEM CHEV 6 PUAF 15-23 T89 


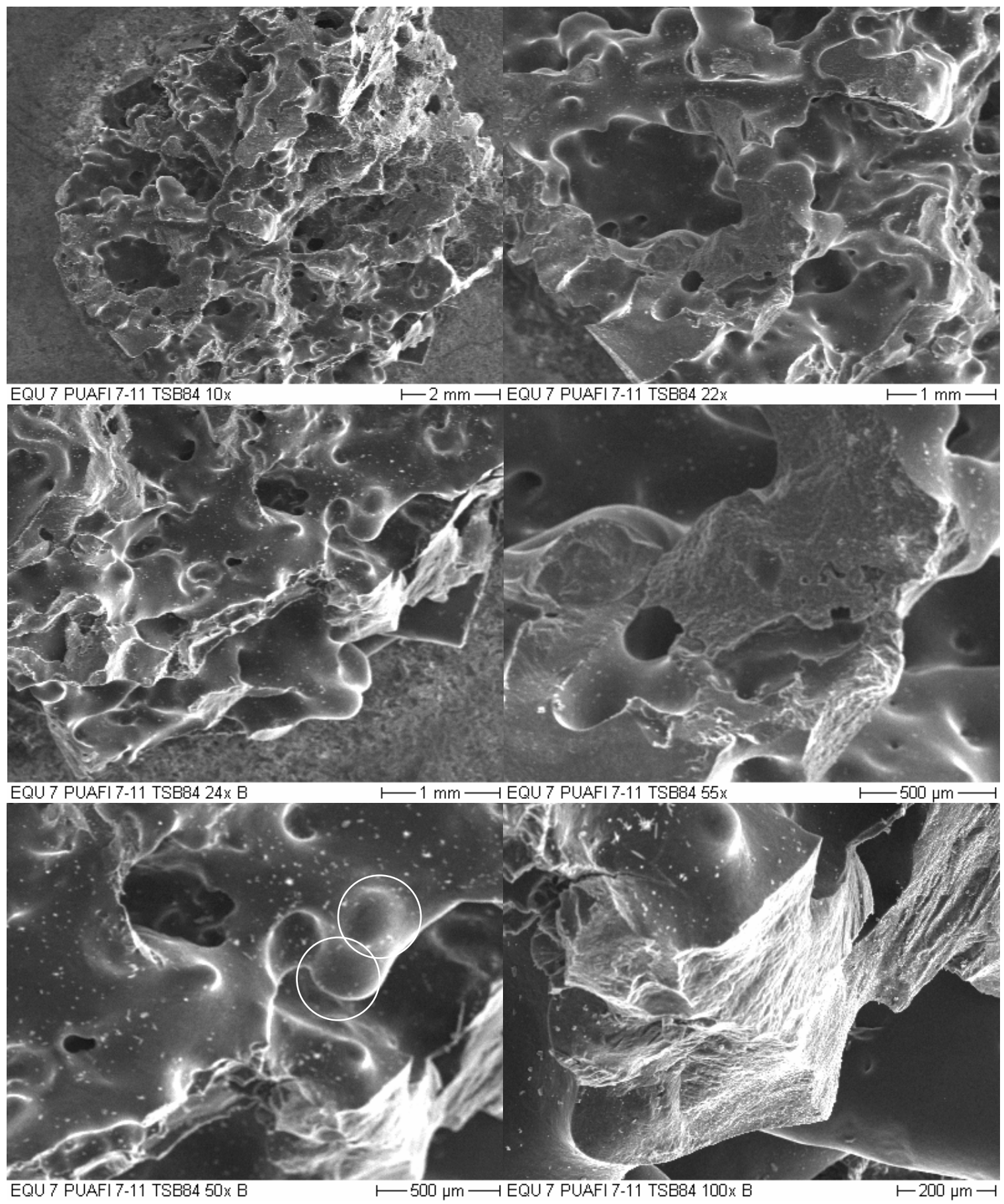

Figure 295 SEM EQU 7 PUAFI 7-11 TSB84

Figure 295 shows the nature of an Equilon sample. Some BB shot coke appears to be under a layer of material that covers them. 

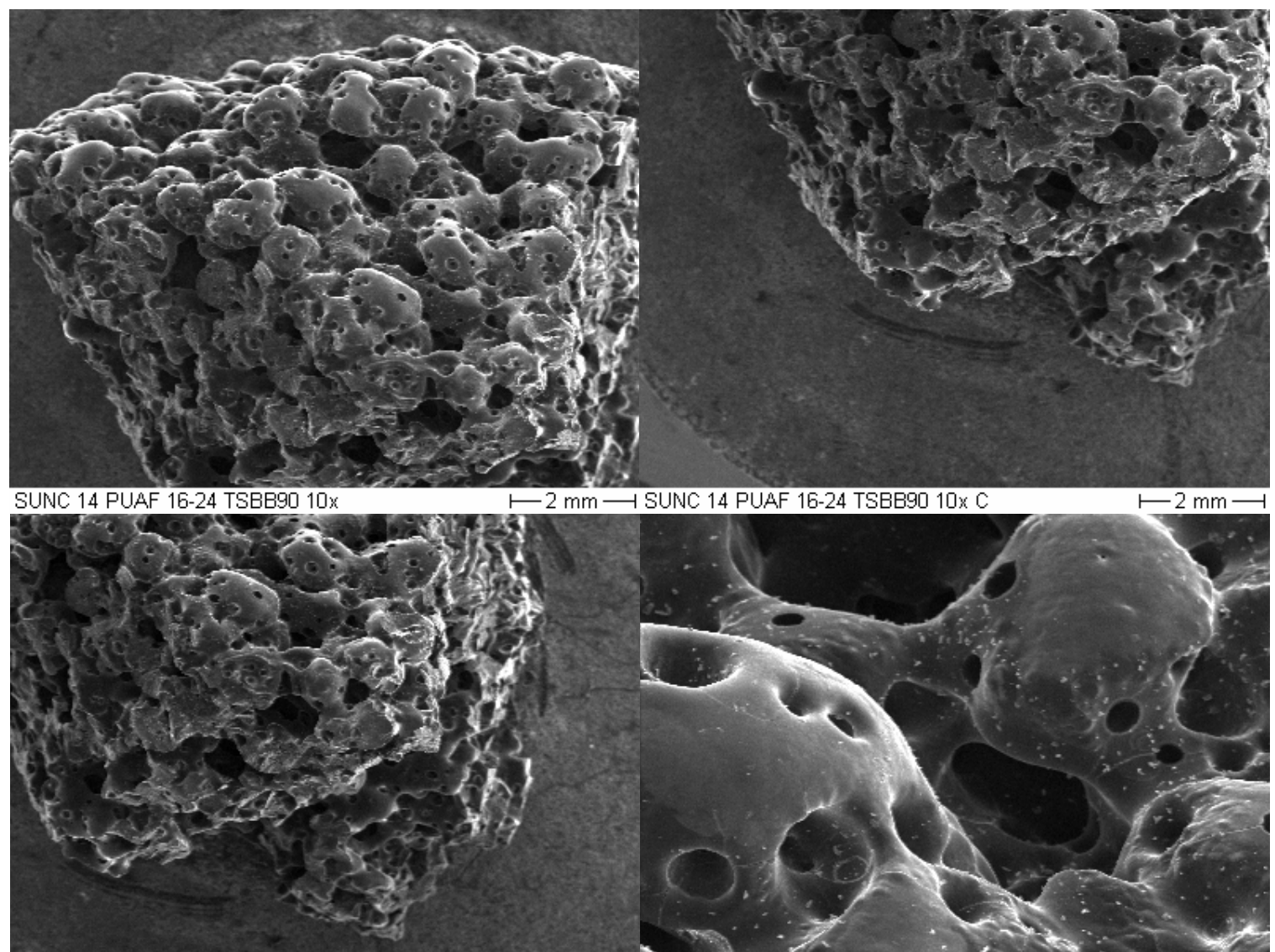

$-2 \mathrm{~mm} \longrightarrow \mathrm{SUNC} 14$ PUAF 16-24 TSBB90 10x C $-2 \mathrm{~mm} \longrightarrow$

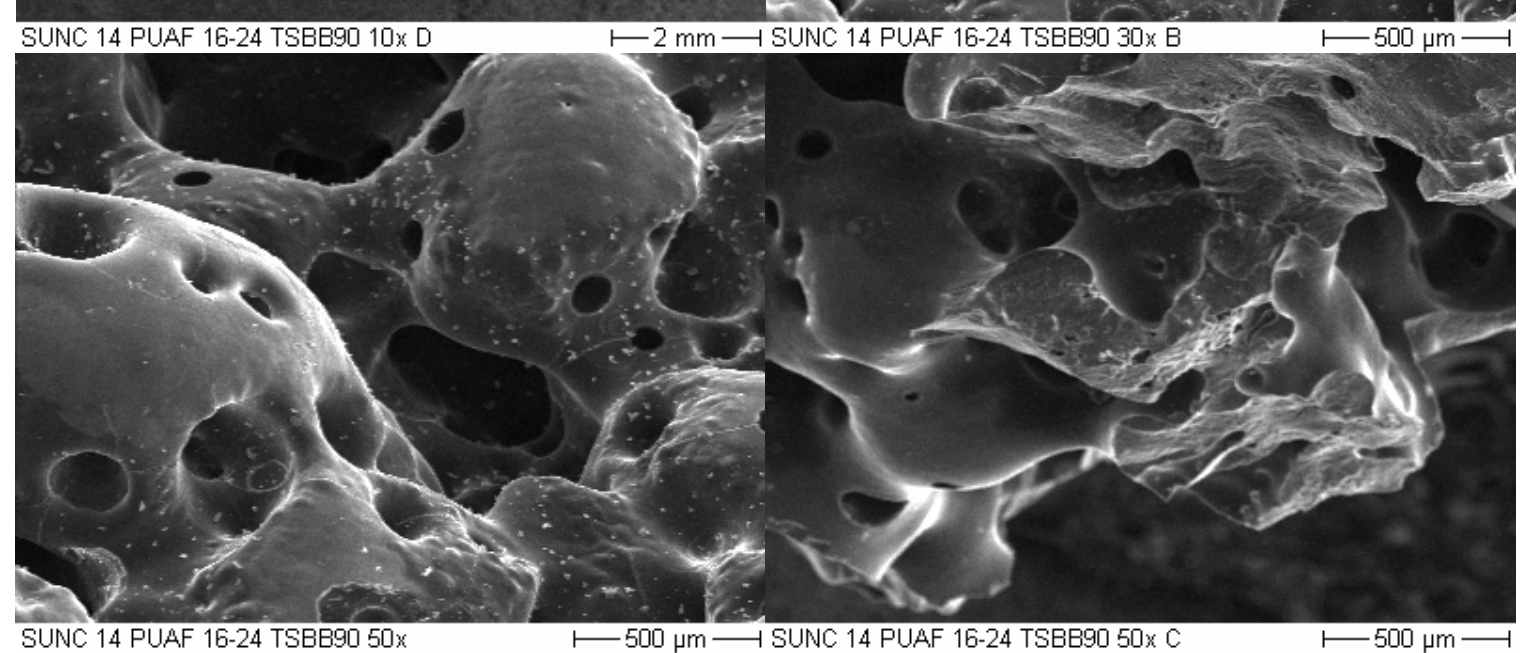

Figure 296 SEM SUNC 14 PUAF 16-24 TSBB90

Figure 296 shows a transitional sponge - BB shot coke sample. This sample clearly shows an early stage of the formation of agglomerated shot coke. Figure 296-A shows one face where BB shot coke is clearly identified, but in Figure 296-B the BB shot coke appearance is not quite clear. 


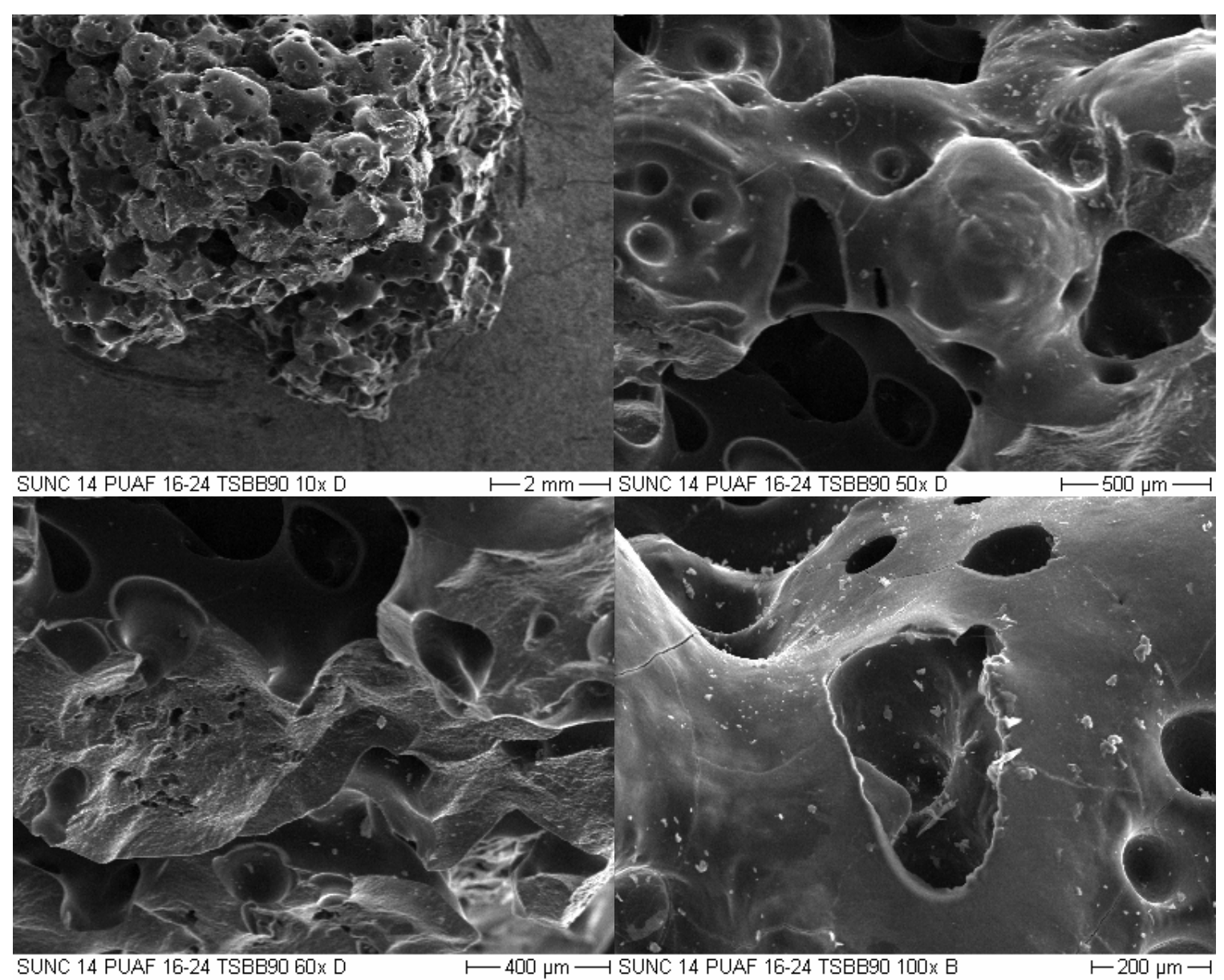

\section{Figure 297 SEM SUNC 14 PUAF 16-24 TSBB90}

Figure 297-A shows the agglomerated appearance of this Suncor sample. This sample clearly shows its BB shot coke nature micro structure as is shown in Figure 297-B and D.

\section{Conclusions}

Agglomerated and transitional morphologies have the lowest permeabilities; this fact is in accord with the observations using SEM. These last thirteen samples have provided more certainty about the morphology behind well defined forms such as sponge and BB shot coke.

The differences observed between the values calculated using the different methodologies (Swanson and Purcell), even when the same information (capillary pressure data) was used, are due to two main factors:

- Purcell relies on the capillary bundle theory, which assumes that pores are cylinder shaped. Purcell uses a lithology factor in order to adjust his model to the measured values, but even using this parameter the Purcell-based-predictive model for coke deviates much.

- The Swanson correlation was developed for carbonates and sandstones; which were originated in different depositional environments than coke, thereof the differences in permeability and porosity values. 
- The model developed using the Swanson methodology for coke relies on the assumption that there is a point in the capillary pressure curve which represents a barrier to fluid flow; based on this point $(\mathrm{Sw}, \mathrm{Pc})$ and a measured permeability for different samples holding different morphologies a correlation is set up.

Permeabilities calculated by using the Swanson method are five times greater than the measured values. The Purcell method fit the measured values well, but it fails with samples with permeabilities greater than $90,000 \mathrm{mD}$, as is shown in Figure 298.

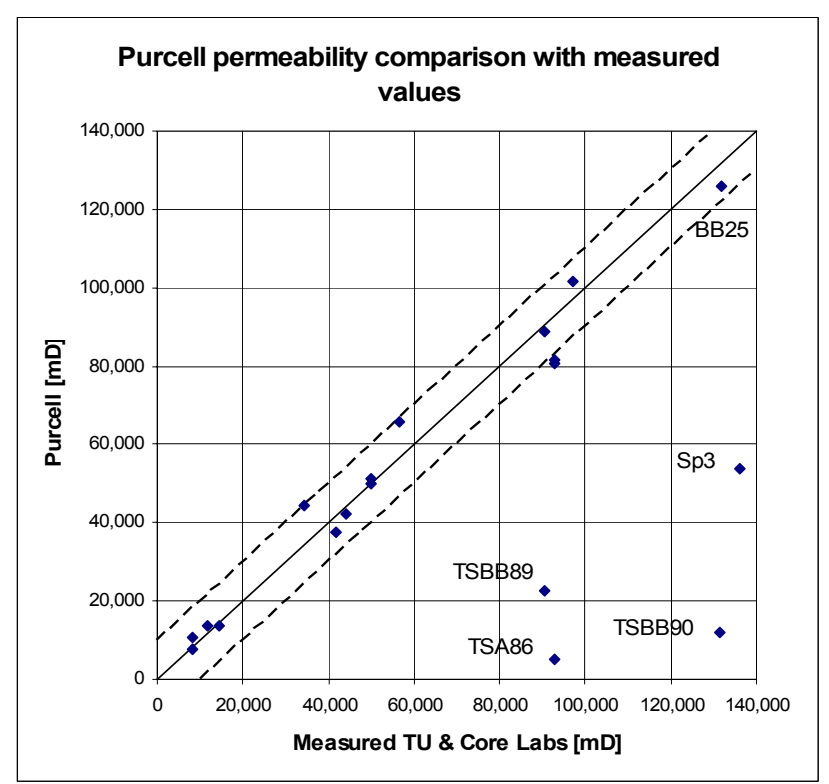

Figure 298 Purcell permeability comparison with measured values 


\section{Future Work}

More air and water permeability measurements will be performed on new samples in order to corroborate and enhance the correlation developed for coke using the Swanson methodology; in so doing a more robust model correlating morphology, permeability and porosity can be generated for the quench model. A different procedure will be utilized to measure permeability on hard-to-shape samples like BB and Buck shot coke and some agglomerated and transitional samples.

The Purcell method for estimating permeabilities collects all the contribution to fluid flow (permeability) for each pore throat diameter, makes full use of the capillary pressure data, but in order to fit this permeability value to permeability values obtained from measurements, it uses a lithology factor. More analyses will be conducted to quantify the lithology factor for all the morphologies under study. 